\title{
New Perspectives on the Chronostratigraphy and Magmatic Evolution of the Auckland Volcanic Field, New Zealand
}

\section{Jenni L. Hopkins}

A thesis submitted to Victoria University of Wellington

in fulfilment of the requirements for the degree of

Doctor of Philosophy (Geology)

Victoria University of Wellington, 2015 


\section{Abstract}

Understanding the eruptive history of a volcanically active region is critical in assessing the hazard and risk posed by future eruptions. In regions where surface deposits are poorly preserved, and ambiguously sourced, tephrostratigraphy is a powerful tool to assess the characteristics of past eruptions. The city of Auckland, New Zealand's largest urban centre and home to ca. 1.4 million people, is built on top of the active Auckland Volcanic Field (AVF). The AVF is an intraplate monogenetic basaltic volcanic field, with ca. 53 eruptive centres located in an area of ca. $360 \mathrm{~km}^{2}$. Little is known however, about the evolution of the field because the numerical and relative ages of the eruptions are only loosely constrained, and therefore the precise order of many eruptions is unknown. Here I apply tephrostratigraphic and geochemical techniques to investigate the chronology and magmatic evolution of the AVF eruptions.

First, I present an improved methodology for in-situ analysis of lacustrine maar cores from the AVF by employing magnetic susceptibility and X-ray density scanning on intact cores. These techniques are coupled with geochemical microanalysis of the tephra-derived glass shards to reveal details of reworking within the cores. These details not only allow assessment of the deposit relationships within cores (e.g. primary vs. reworked horizons), but also to correlate tephra horizons between cores. Through the correlation of tephra units across cores from a variety of locations across the field, an improved regional tephrostratigraphic framework for the AVF deposits has been established.

Following on from this, I detail the methods developed in this study to correlate tephra horizons within the maar cores back to their eruptive source. This technique uses geochemical fingerprinting to link the glass analyses from tephra samples to whole rock compositions. Such an approach has not been previously attempted due to the complications caused by fractional crystallisation, which affects concentrations of certain key elements in whole rock analyses. My method resolves these issues by using incompatible trace elements, which are preferentially retained in melt over crystals, and therefore retain comparable concentrations and concentration ratios between these two types of sample. Because of the primitive nature of the AVF magmas, their trace element signature is largely controlled by the 
involvement of several distinct mantle sources. This leads to significant variability between the volcanic centres that thus can be used for individually fingerprinting, and correlating tephra to whole rocks. Nevertheless, in some cases geochemistry cannot provide an unambiguous correlation, and a multifaceted approach is required to allow the correlation of the tephra horizons to source. The other criteria used to correlate tephra deposits to their source centre include, Ar-Ar ages of the centres, modelled and calculated ages of the tephra deposits, the scale of eruption, and the deposit locations and thicknesses.

The results of this research outline the methodology for assessing occurrence and characteristics of basaltic tephra horizons within lacustrine maar cores, and the methodology for correlating these horizons to their eruptive source. In doing this the relative eruption order of the AVF is accurately determined for the first time. Temporal trends suggest acceleration of eruption repose periods to 21 ka followed by deceleration to present. Although no spatial evolution is observed, coupling of some centres is seen when spatial and temporal evolution are combined. The geochemical signature of the magmas appears to evolve in a cyclic manner with time, incorporating increasing amount of a shallow source. This evolution is seen both during a single eruption sequence and throughout the lifespan of the AVF.

Finally, pre-eruptive processes are assessed as part of the study of the magmatic evolution of the AVF. The effects of contamination from the crust and lithosphere through which the magma ascends are evaluated using the Re-Os isotope system. The results show there are variable inputs from crustal sources, which have previously not been identified by traditional isotope systems (e.g. Pb-Sr$\mathrm{Nd}$ isotopes). Two sources of contamination are identified based on their Os systematics relating to two terranes beneath the AVF: the metasedimentary crust and the Dun Mountain Ophiolite Belt. The identification of this process suggests there is interaction of ascending melt with the crust, contrary to what previous studies have concluded. This body of research has provided a detailed reconstruction of the chronostratigraphy and magmatic evolution of the AVF to aid accurate and detailed risk assessment of the threat posed by a future eruption from the Auckland Volcanic Field. 


\section{Acknowledgements}

I would first like to thank my supervisors Prof. Colin Wilson, Dr. Graham Leonard, and Dr. Christian Timm for their support and guidance throughout this project. The last few years have been an absolute pleasure. I also owe a great deal of thanks to my advisor Marc-Alban Millet, thank you for continuing to offer essential advice and support to this research.

I am grateful to GNS and the DEVORA team for providing me with the funding and the scope for the project; and for the financial support from VUW submission scholarship and faculty strategic research grants, to allow continued research and travel.

This research would not have been completed without the technical assistance from various people in a number of institutions. At VUW my thanks go to Sabrina for always being ahead of the game in the geochem labs - you are a superstar; to Stewart for training and assistance in sample preparation; to Richard Wysoczanski for teaching me how to use the probe; to lan Schipper for continued probe assistance; and Monica Handler for ICP-MS assistance. Thanks also to Helen Neil and Alan Orphin (NIWA) for their assistance and discussions in relation to core analysis techniques; to Andrè Poirier (UQAM) for teaching me how to do complex isotope chemistry and analysis on Re and Os; to Michael Palin and Malcolm Reid (UoO) for their assistance with LA-ICP-MS techniques; to Phil Shane (UoA) for providing thought provoking discussion on AVF tephra deposits, and supplying some of the samples and data used in this thesis. I also thank Lucy McGee for also providing essential data, samples, and advice. Finally a huge thanks to Elaine Smid (UoA/DEVORA) - field assistant, colleague, and confidante, good luck for your PhD!

I would like to also thank the friends I have made throughout the PhD journey, VGP group students old and new, fifth floor/ARC representatives, and housemates old and new - you have to play hard to work hard! With a special mention to my PhD twin Chris 'Condor' Conway (you didn't have to break your collar bone just to keep up). To office mates past and present, Maria, Jess, Connie, and Denise, I couldn't have asked for a nicer environment to work in. To Loretta, the constant throughout my time at VUW, thank you for being a great wing(wo)man to ride the PhD rollercoaster with. Finally, to Becca, thank you for your support both here and over Skype, I couldn't ask for a better, more understanding best friend.

To my family, thank you for understanding and accepting my need to be at the other side of the world, I am sorry it has meant I have missed out on some important family moments. Your support and pride has kept me going.

Finally, Shaun, I was prepared for moving to New Zealand to be a life-changing adventure, I wasn't prepared for meeting you, my life changer. 


\section{Table of Contents}

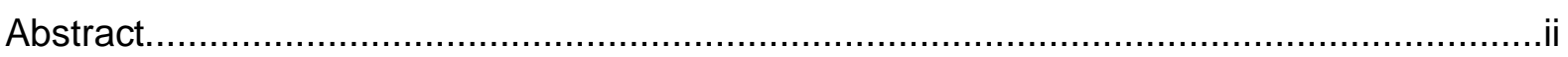

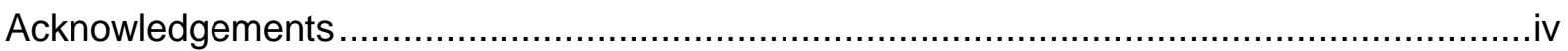

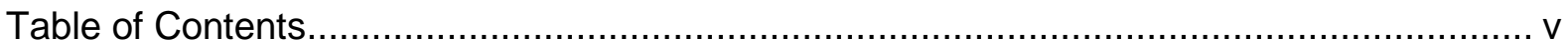

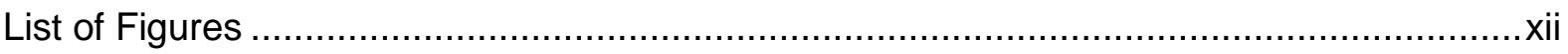

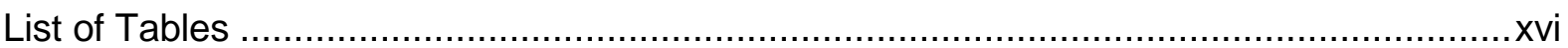

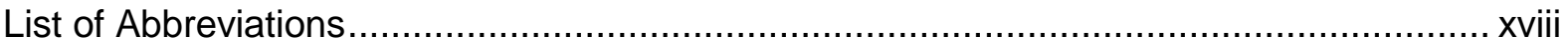

Chapter 1 - Monogenetic basaltic volcanism and the Auckland Volcanic Field................... 1

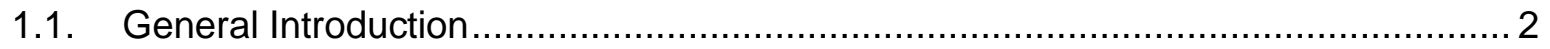

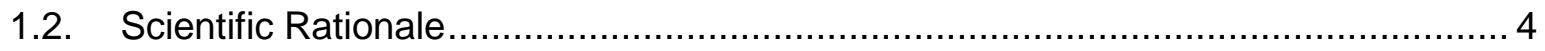

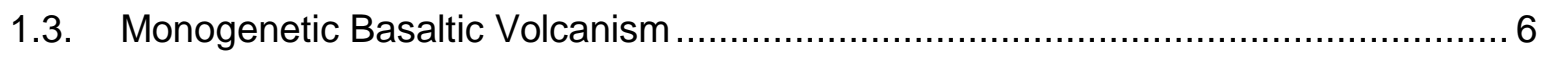

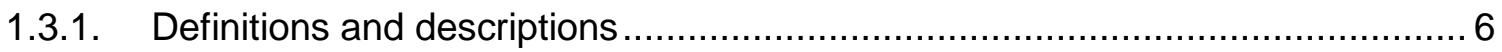

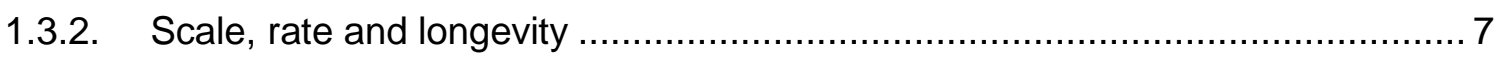

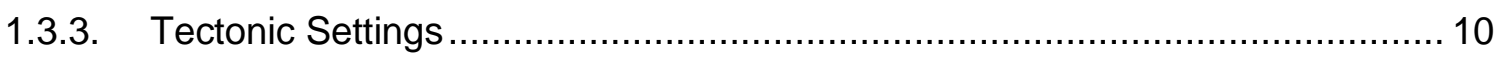

1.3.4. General petrology and geochemistry of monogenetic fields ........................ 10

1.3.5. Melting models for inception of eruptions............................................ 12

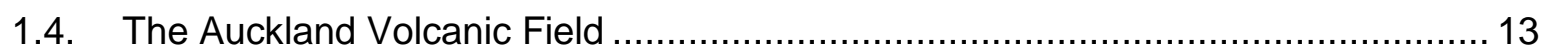

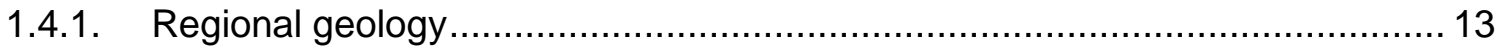

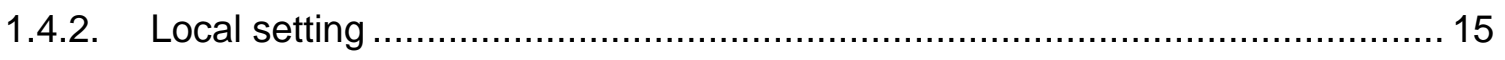

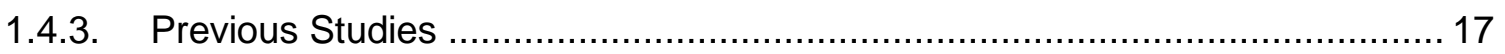

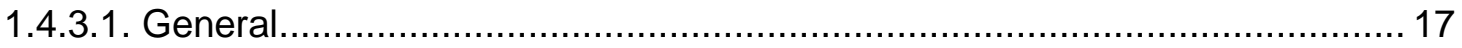

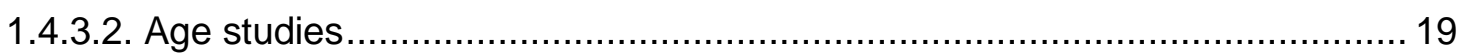

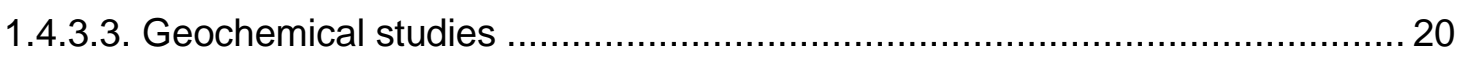

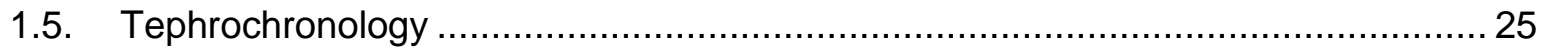

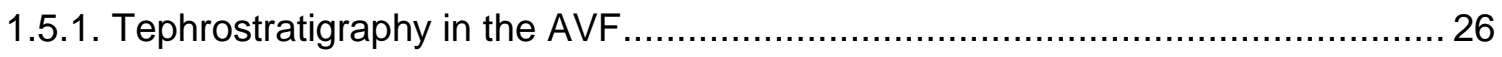

1.5.2. Previous correlations of the AVF tephra horizons .......................................... 27

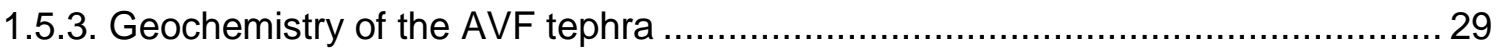




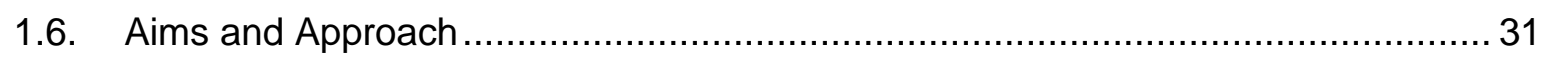

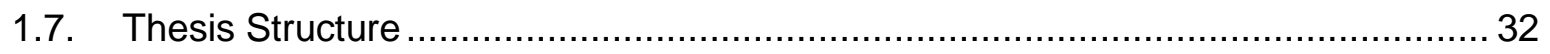

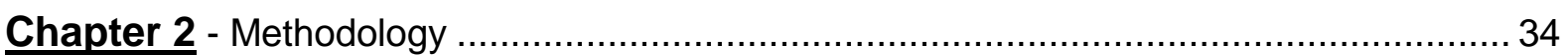

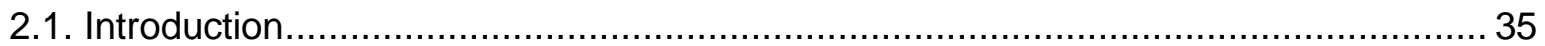

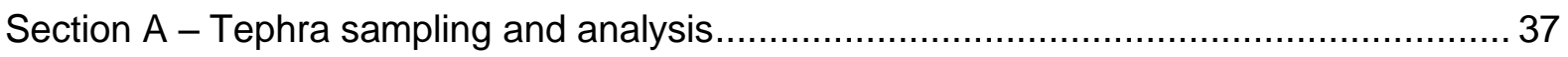

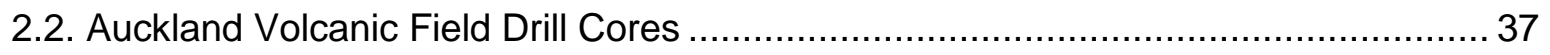

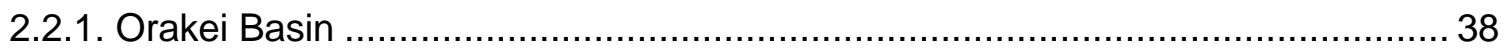

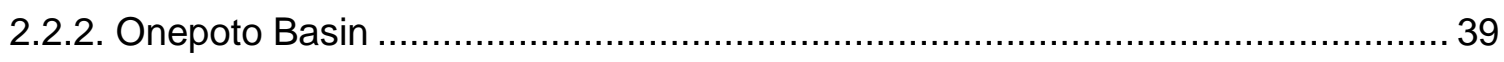

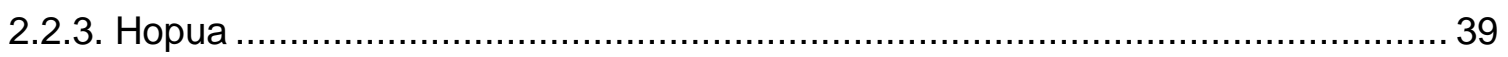

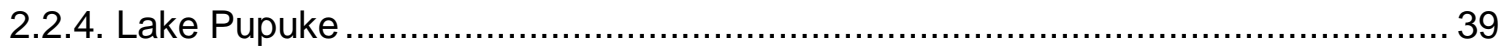

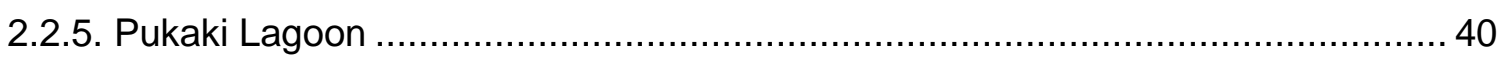

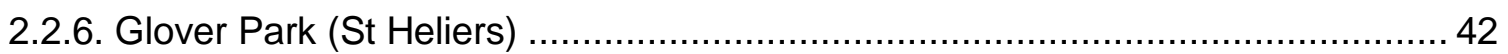

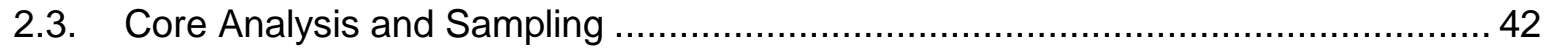

2.4. In-situ Major Element Analysis by EMPA ............................................... 44

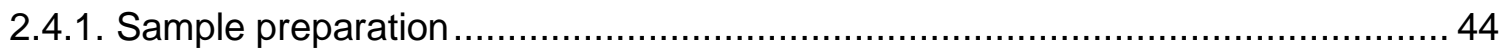

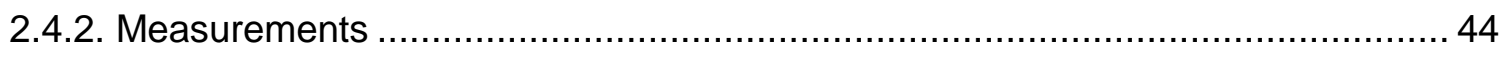

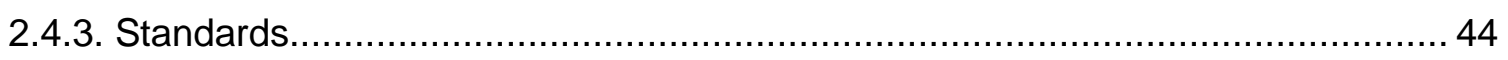

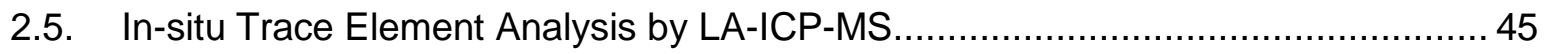

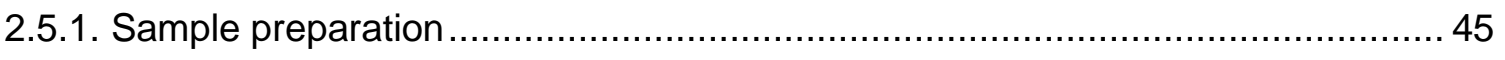

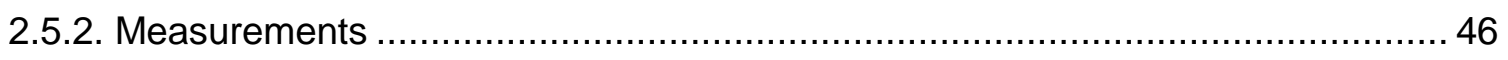

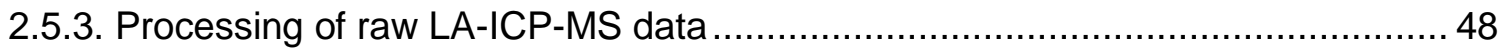

2.5.4. Accuracy and Precision of LA-ICP-MS .................................................... 50

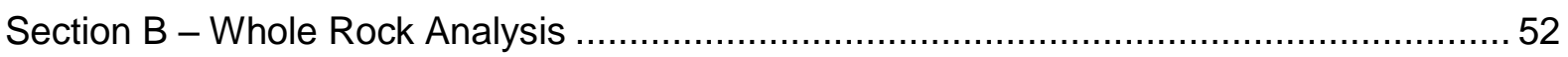

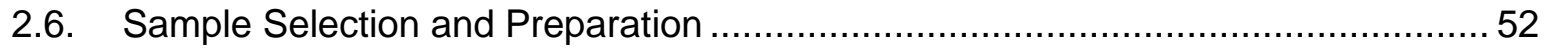

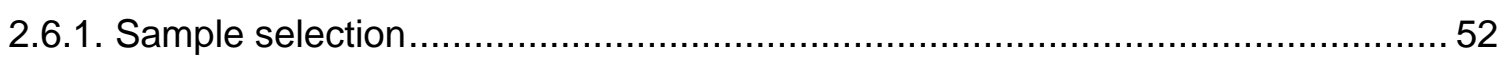

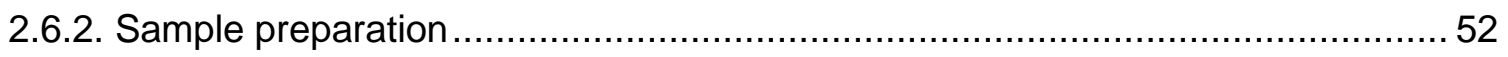

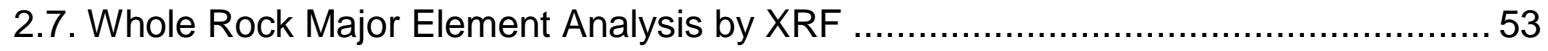

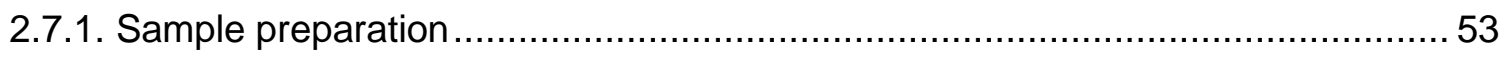




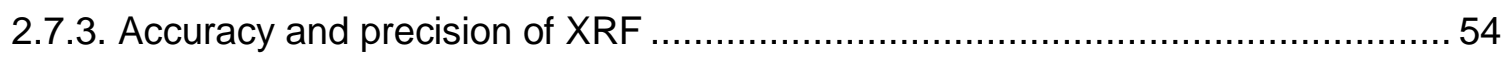

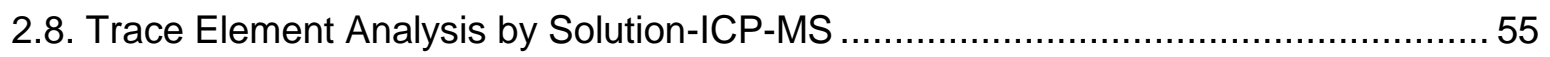

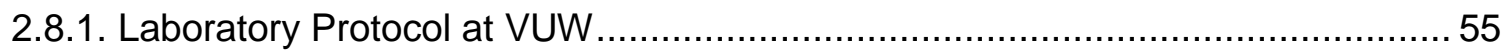

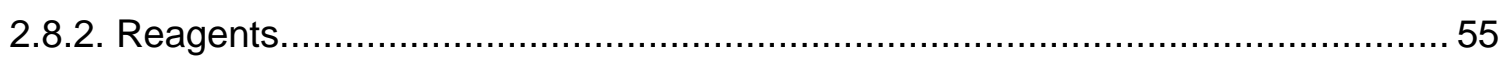

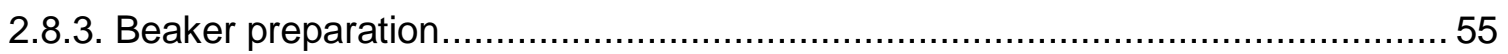

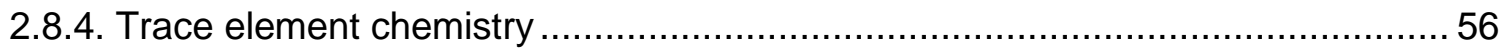

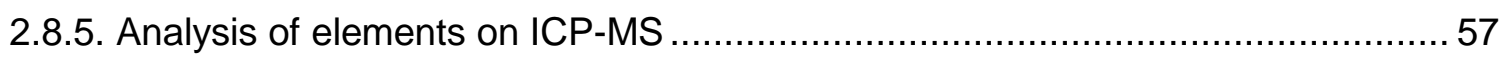

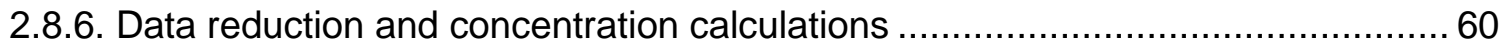

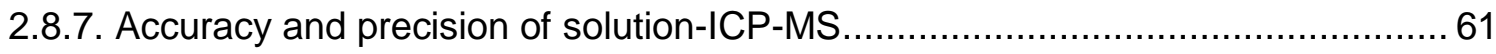

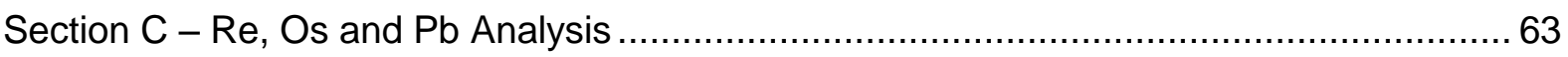

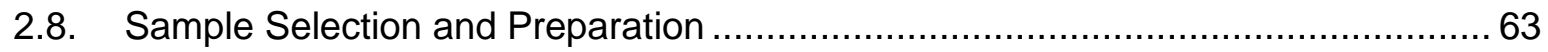

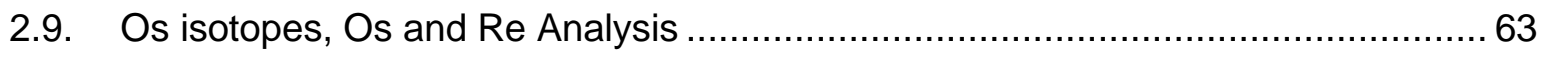

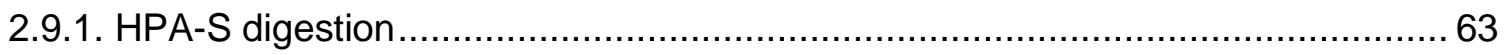

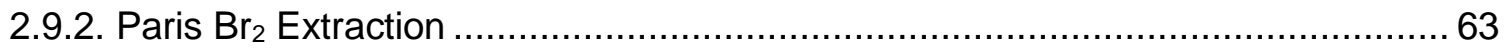

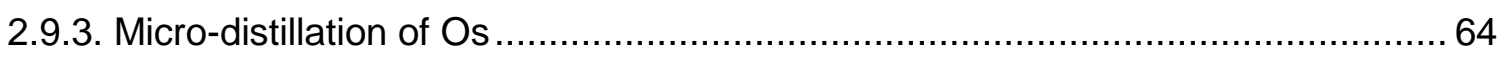

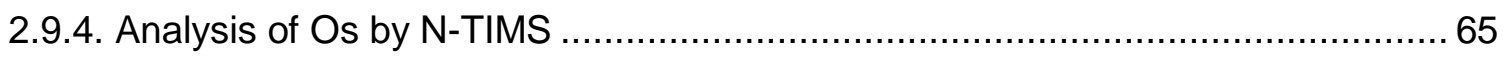

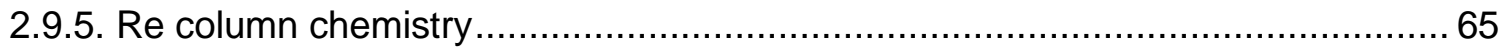

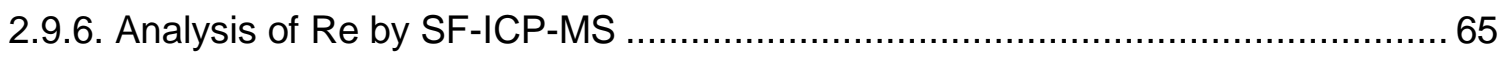

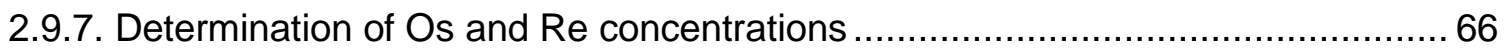

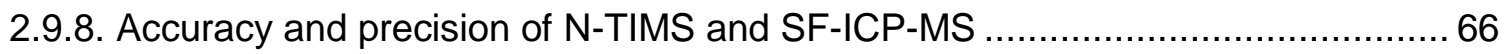

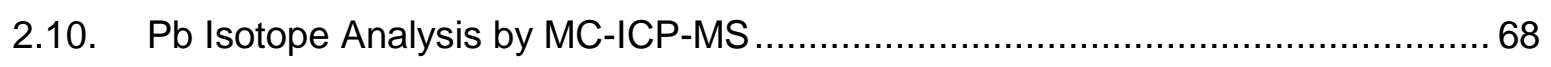

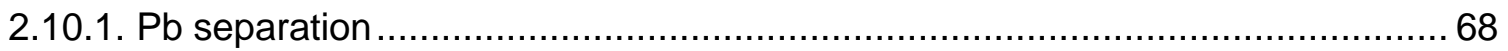

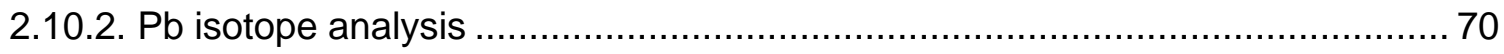

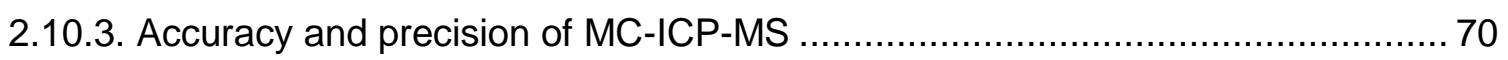

Section D - Review of Data Accuracy and Precision ................................................... 71

2.11. Review of in-situ analysis of tephra-derived glass shards ................................. 71

2.11.1. Major Element analysis comparison .................................................. 71

2.11.3. Comparability of EMPA analysis with LA-ICP-MS analysis ............................ 73 
Chapter 3.

Tools and techniques for developing tephra stratigraphies in lake cores: A case study from

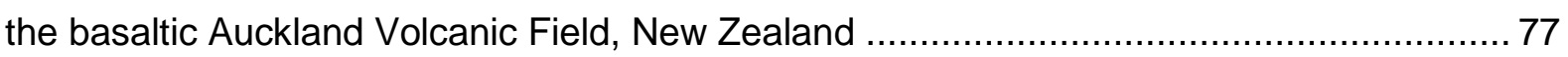

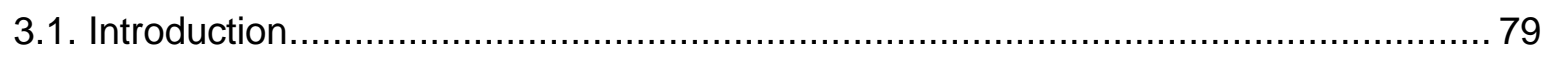

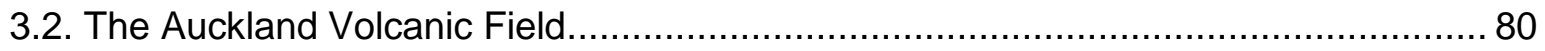

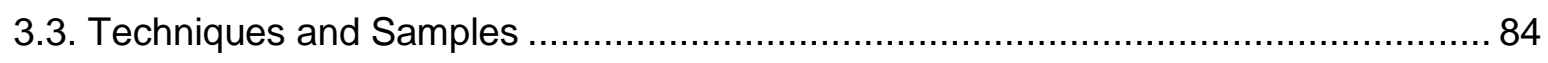

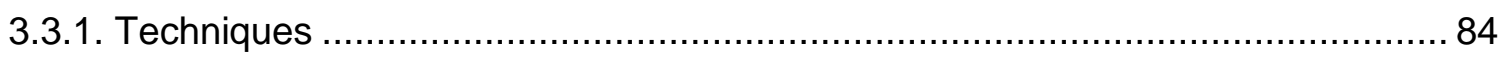

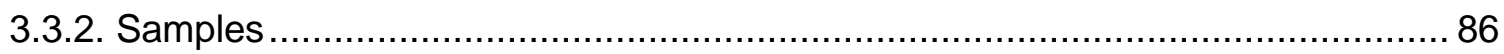

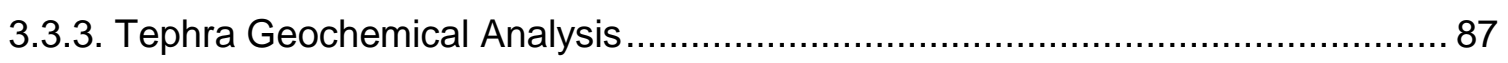

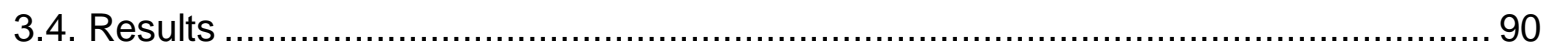

3.4.1. Tephra horizon identification and classification ............................................. 90

3.4.2. Tephra-derived glass shard Geochemistry ........................................... 91

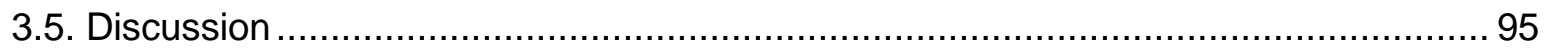

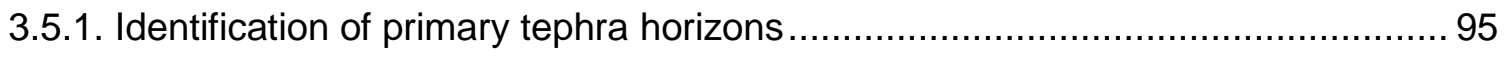

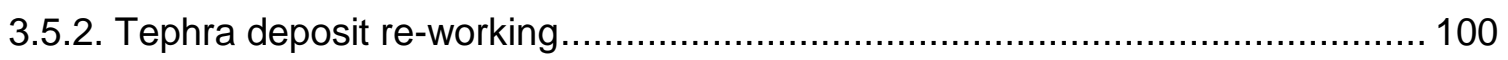

3.5.3. Geochemical variations within an individual tephra horizon ............................ 105

3.5.4. Cross-core correlation of individual tephra horizons .................................. 108

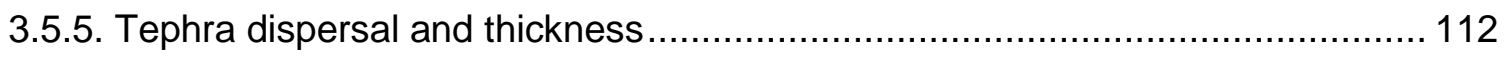

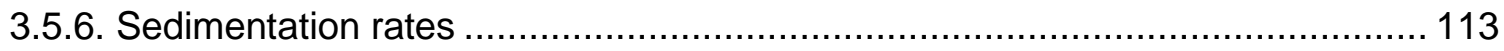

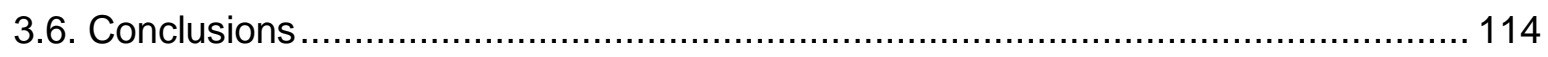

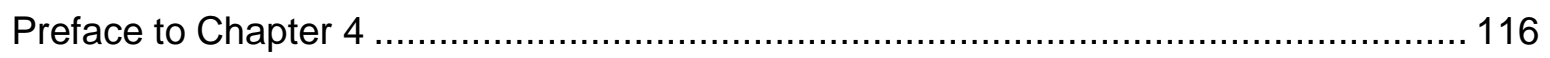

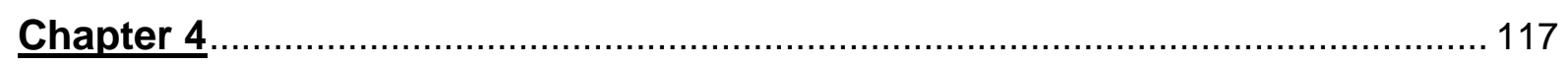

An overview of the geochemistry of the AVF from new and existing major and trace element, and isotope data; foundation for the tephra-whole rock correlation principles................... 117

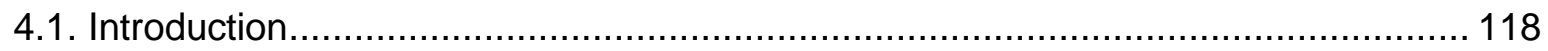


4.2. Methods.

4.2.1. Sample selection for geochemical analysis

4.2.2. Major element analysis

4.2.3. Trace element analysis

4.3. Results

4.3.1. Major Elements.

4.3.2. Trace Elements

4.4. Discussion 130

4.4.2. Geochemical variability intra-centre and field-wide 132

4.5. Conclusions 136

Preface to Chapter 5 137

\section{Chapter 5.}

The correlation of basaltic tephras to source volcanoes: Method development and implications for spatial, temporal and geochemical eruptive sequencing in the Auckland Volcanic Field, New Zealand

5.1. Introduction 139

5.1.1. Tephrochronology and provenance 139

5.1.2. Reconstructing eruptive history using tephra deposits. 139

5.1.3. Auckland Volcanic Field 140

5.2. Source correlation method and sequencing data 145

5.2.1. Tephrochronology 145

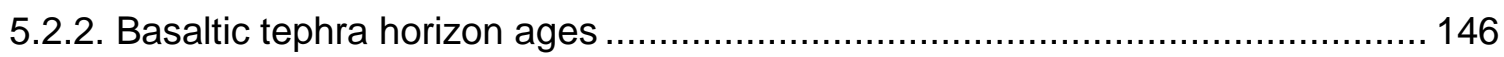

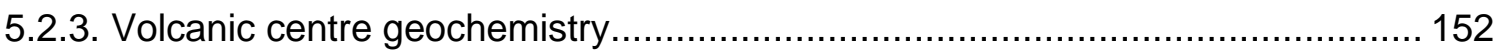

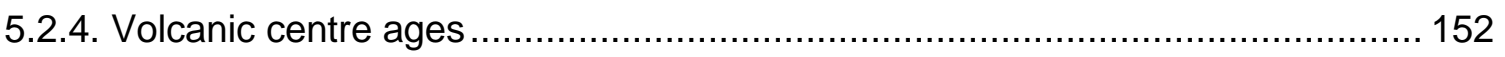

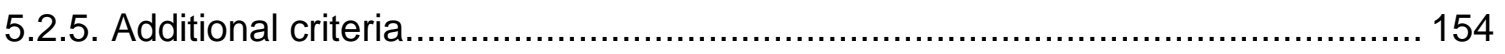

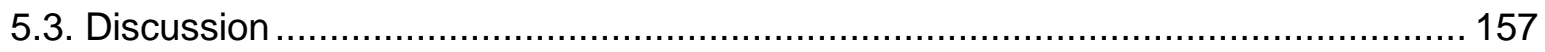

5.3.1. Geochemical compositions of whole rock and tephra-derived glass 157 
5.3.2. Correlation of tephra with interstitial glass in whole rock samples

5.3.3. Correlation of tephra with bulk whole rock samples ................................... 164

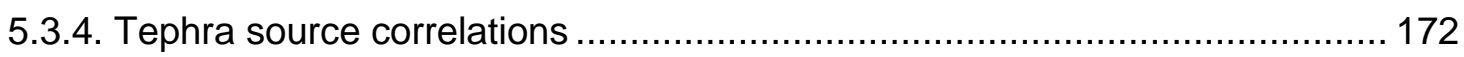

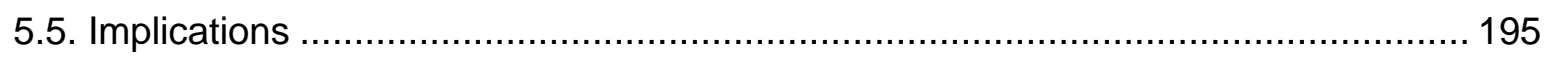

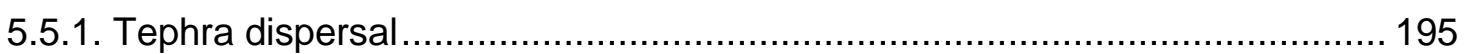

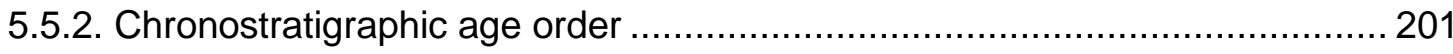

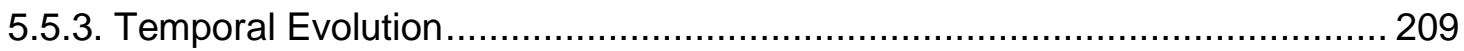

5.5.4. Spatial Evolution ............................................................................ 214

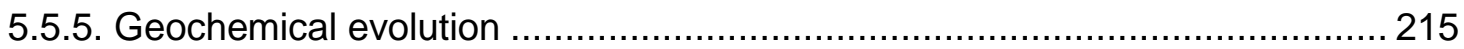

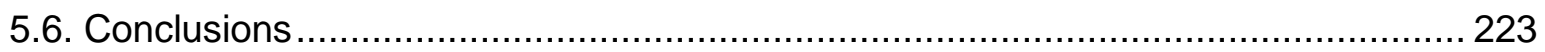

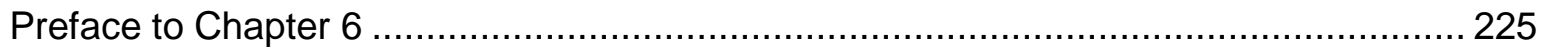

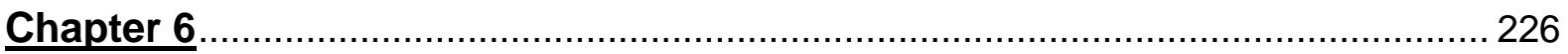

Os isotope constraints on crustal contamination in Auckland Volcanic Field basalts, New

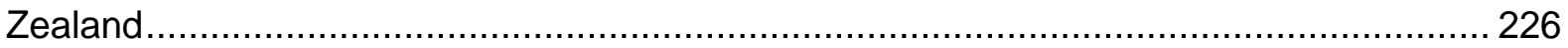

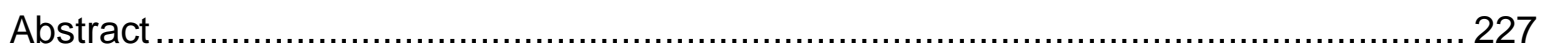

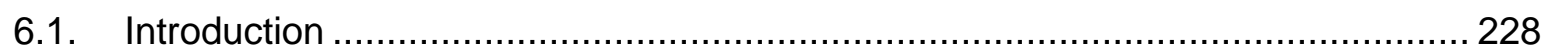

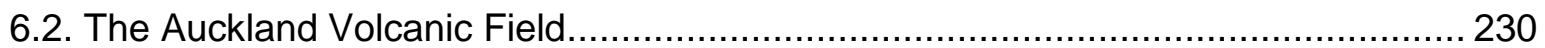

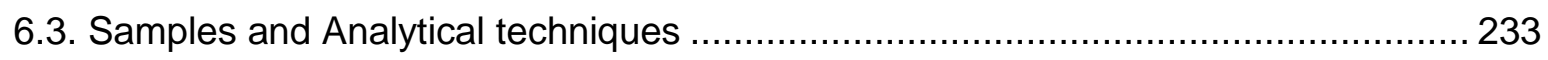

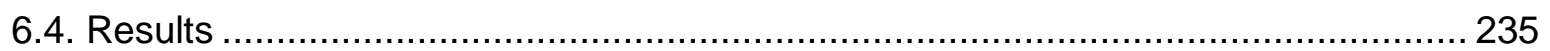

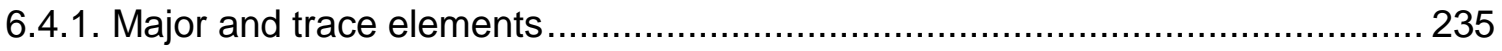

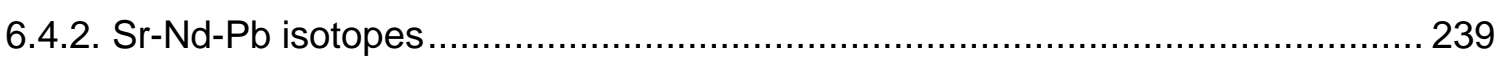

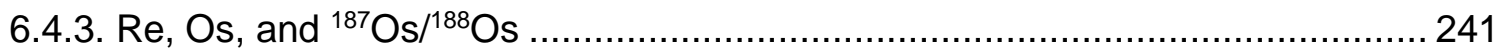

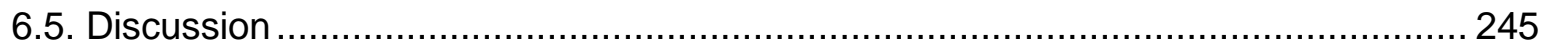

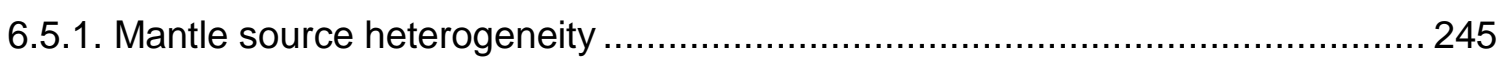

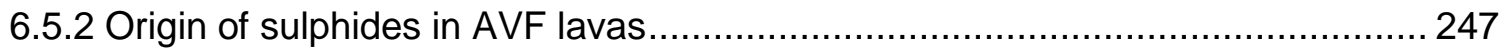

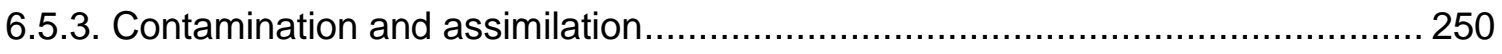

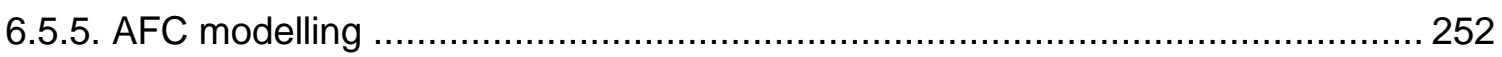


6.6. Conclusions

Chapter 7 - Synthesis and Conclusions 258

7.1. Introduction. 259

7.2. Original Scientific Contributions . 259

7.3. Research Questions 261

7.3.1. Can a more detailed basaltic tephra stratigraphy for the AVF be produced for the maar deposits using newly developing analysis methods? 261

7.3.2. Can individual horizons be linked to their source centre? 262

7.3.3. What is the spatial, temporal and geochemical evolution of the AVF? 263

7.3.4. What can the eruptive products of the AVF tell us about the pre-eruptive processes which act on the upwelling magma? 265

7.4. Further Research 266

7.4.1. Application of newly developed methods on other cores 266

7.4.2. Age refinement of tephra horizons and thus eruptive centres. 267

7.4.3. A further application of tephra horizon correlation 267

7.4.4. Centre and field geochemical evolution 268

References 269

\section{Appendices (electronic)}

Appendix A. Tephra and whole rock sample details. .1

Appendix B. Standard data for tephra and whole rock analyses........................... 74

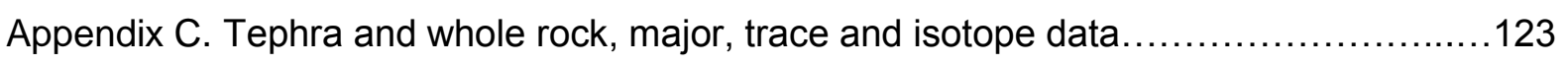

Appendix D. Manuscript overview, Leonard et al., in prep..............................215

Appendix E. Tephra horizons to whole rock geochemical correlations $\ldots \ldots \ldots \ldots \ldots \ldots \ldots \ldots . \ldots \ldots \ldots \ldots \ldots \ldots$ 


\section{List of Figures}

\section{Chapter 1}

Figure 1.1. Location map for global examples of basaltic monogenetic intraplate

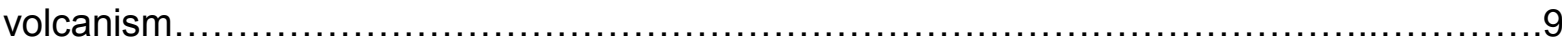

Figure 1.2. Regional setting and geology of the Auckland Volcanic Field (AVF) ............ 14

Figure 1.3. Examples of the landforms of the AVF ...................................

Figure 1.4. Total Alkali vs. $\mathrm{SiO}_{2}$ for AVF whole rock samples.....................................21

Figure 1.5. Primitive mantle normalised multi-element plots highlighting the signatures of

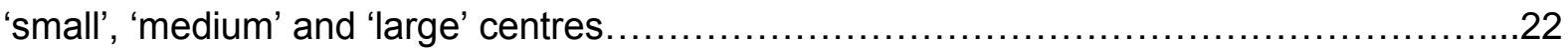

Figure 1.6. Pre-existing isotope data for 10 AVF centres..................................

\section{Chapter 2}

Figure 2.1. Schematic diagram of Pukaki core deposits .41

Figure 2.2. Mount set up for glass shard analysis at Victoria University of Wellington (VUW)

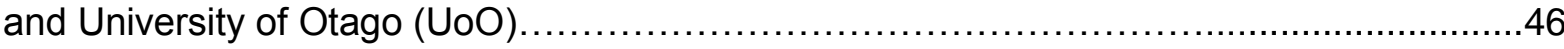

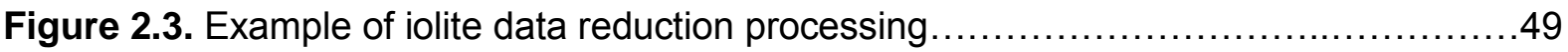

Figure 2.4. Schematic diagram for digestion process for solution chemistry and c-tube

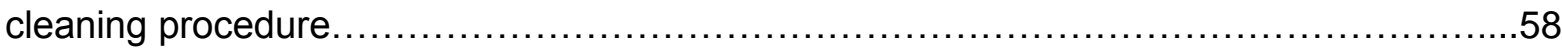

Figure 2.5. Schematic diagram for mirco-distillation techniques for removal of Re from Os

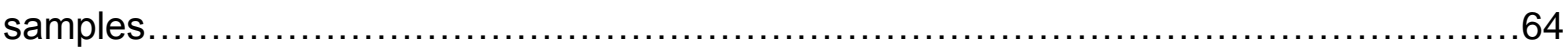

Figure 2.6. Schematic diagram for Re sample digestion and column chemistry............67

Figure 2.7. Schematic diagram for $\mathrm{Pb}$ sample digestion and column chemistry $\ldots \ldots \ldots \ldots \ldots 69$

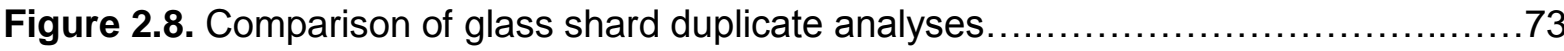

Figure 2.9. Comparison plots for major element analyses between EMPA and LA-ICP-MS

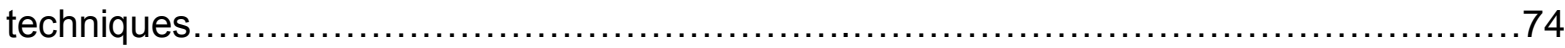




\section{Chapter 3}

Figure 3.1. Location map for AVF $\ldots \ldots \ldots \ldots \ldots \ldots \ldots \ldots \ldots \ldots \ldots \ldots \ldots \ldots \ldots \ldots \ldots \ldots \ldots \ldots \ldots 1$

Figure 3.2. Example for identification of basaltic tephra horizons in sediment cores.........85

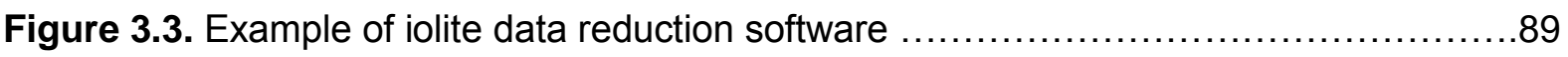

Figure 3.4. Major element variation diagram for tephra-derived glass shards within maar

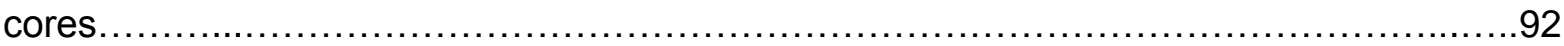

Figure 3.5. Major and trace element variability of individual horizons within the Orakei Basin

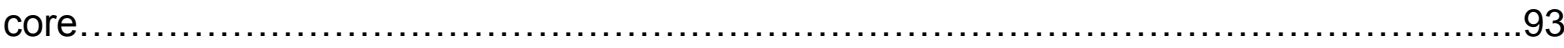

Figure 3.6. Trace element variation diagrams for tephra-derived glass within maar cores..94

Figure 3.7. Examples of features found within maar cores

Figure 3.8. Schematic diagram for basaltic tephra horizons in Orakei Basin, Onepoto and Glover Park cores. .99

Figure 3.9. Case study for re-working observed in the Orakei Basin Core. 104

Figure 3.10. Examples of trace element resolution for major element ambiguities 107

Figure 3.11. Schematic diagram for tephra horizon correlation for AVF maar cores Orakei Basin, Glover Park, Onepoto, Pukaki, Hopua and Pupuke. 110

\section{Chapter 4}

Figure 4.1. Location map for the AVF centres outlining the amount of geochemical data available for each centre 121

Figure 4.2. TAS diagram to show comparison of old and new major element data 125

Figure 4.3. Multi-element variation diagrams vs. $\mathrm{MgO}$ to show comparison old and new major element data 126

Figure 4.4. Multi-element variation diagrams vs. $\mathrm{MgO}$ to show comparison old and new trace element data. 128

Figure 4.5. Primitive mantle-normalised multi-element plots show comparison old and new trace element data. 129

Figure 4.6. Results of analysis for duplicate samples for existing and new data..... .131

Figure 4.7. Sr anomaly vs. elements indicative of source composition .135 


\section{Chapter 5}

Figure 5.1. Location map for the AVF highlighting all centres...........................141

Figure 5.2. Sedimentation rate plots for all cores....................................149

Figure 5.3. Discriminatory element plots for the AVF whole rock data...................158

Figure 5.4. Comparison plot for major and trace elements between whole rock and tephra-

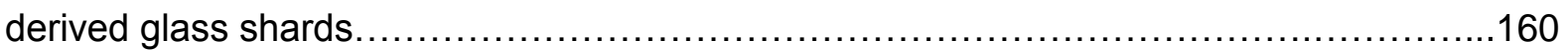

Figure 5.5. Comparison pictures for simulated glass and known glass..................162

Figure 5.6. Multi-element plots to show comparison between simulated glass shards and

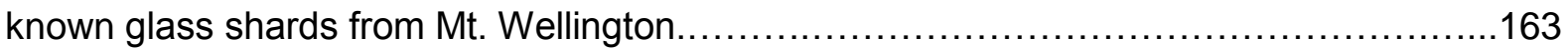

Figure 5.7. Selected element plots to show the effects of crystal removal on element

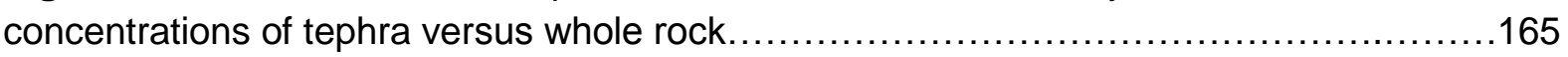

Figure 5.8. Selected element plots to show correlations between known glass, simulated glass, but lack of correlation with whole rock........................................166

Figure 5.9. Selected major element concentrations that correlated between whole rock and tephra-derived glass samples from Mt. Wellington.

Figure 5.10. Selected trace element combinations that correlate between whole rock and tephra-derived glass samples from Mt. Wellington.

Figure 5.11. Selected major and trace element variations through the eruption of Motukorea volcano.

Figure 5.12. Comparison of whole rock geochemical variation throughout an eruption to a distally correlated tephra deposit for Motukorea.

Figure 5.13. Flow chart outlining the process through which tephra horizons are cross correlated between cores and to their source centre.

Figure 5.14. Example of a geochemical correlation across cores and to source centre resulting in a level 1 confidence rating. .174

Figure 5.15. Relationship between distance from source and tephra deposit thickness and shard size.

Figure 5.16. Case study for level 1 confidence rated correlation, including shard size, deposit thickness, and isopach map. 199

Figure 5.17. Original age constraints on centres prior to this work. .202

Figure 5.18. Combined results from core correlation and centre correlation outlining the new age order for the AVF centres determined by this study. 203 
Figure 5.19. Comparison plot for relative vs. absolute age order for this study and the results from statistical modelling.

Figure 5.20. Age order of the field in map view to allow spatial and temporal evolution to be assessed.

Figure 5.21. Size vs. geochemistry plots for all AVF data, old and new. 218

Figure 5.22. Relative age order plotted with selected geochemical compositions to determine geochemical evolution of the AVF 221

\section{Chapter 6}

Figure 6.1. Location map for the AVF

Figure 6.2. Bivariate plots to show major element concentrations of selected samples used for this study section. 238

Figure 6.3. Primitive mantle normalised multi-element plot to show ranges of data for AVF centres .239

Figure 6.4. $\mathrm{Pb}$ isotope plots for selected samples used in this study 240

Figure 6.5. Bivariate plots for Os and Re concentrations vs selected major and trace elements. 243

Figure 6.6. Os Isotope vs. Os concentration for samples used in this study.... 244

Figure 6.7. Os isotope values vs. Pb isotope values for samples used in this study...... .245

Figure 6.8. Modelled contamination for causes of Os isotope signatures and Os content for selected AVF lava samples... .253

Figure 6.9. Schematic diagram to illustrate proposed magma ascent dynamics for AVF eruptions. 256 


\section{List of Tables}

\section{Chapter 1}

Table 1.1. Features of global monogenetic fields 8

Table 1.2. Limitations and resolutions for tephra correlation .28

\section{Chapter 2}

Table 2.1. Overview of AVF maar cores. .38

Table 2.2. Instrumental operating conditions for EMPA analysis. .45

Table 2.3. Instrumental operating conditions for LA-ICP-MS analysis. 47

Table 2.4. Over view of elements causing contamination in glass shards. 48

Table 2.5. Standard data summary for LA-ICP-MS analysis.............................51

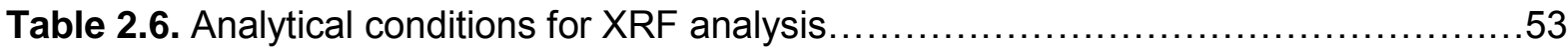

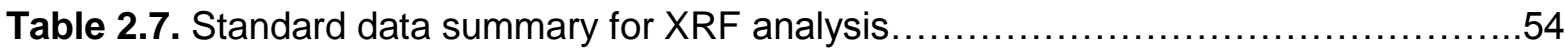

Table 2.8. Instrumental operating conditions for Solution ICP-MS analysis .................59

Table 2.9. Standard data summary for Solution ICP-MS analysis.........................62

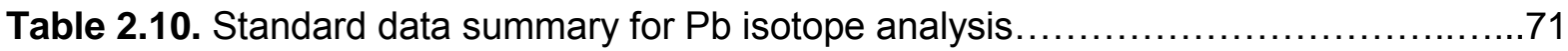

Table 2.11. Comparison of precision between WDS and EDS EMPA techniques.... .72

\section{Chapter 3}

Table 3.1. Overview of maar cores used in study. 87

Table 3.2. Overview of basaltic tephra horizons identified and correlated .111

\section{Chapter 4}

Table 4.1. Overview for pre-existing and new geochemical data for the individual AVF centres.

Table 4.2. Selected representative whole rock major and trace element analysis for new centres. 


\section{Chapter 5}

Table 5.1. Overview of AVF centres, eruption types, ages, eruptive scale, and the number of

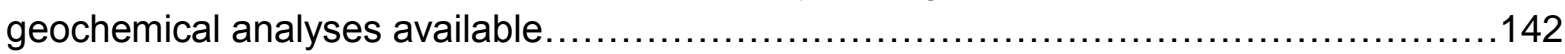

Table 5.2. Calculated sedimentation rates for all cores from the AVF maars...............148

Table 5.3. Overview of ages calculated for tephra horizons............................151

Table 5.4. Distribution coefficient values for selected elements in selected minerals including

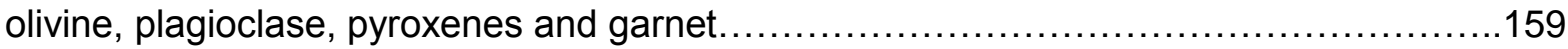

Table 5.5. Overview details for tephra to centre correlations............................192

Table 5.6. Overview details for tephra dispersal, thickness, and shard size for centres with a confidence level 1 or 2 correlation. 196

Table 5.7. Comparative global tephra dispersal and thickness values for monogenetic centres of a similar scale $\left(\mathrm{DRE}^{\text {tot }}\right)$ to the AVF centres.

Table 5.8. Relative age order for all AVF centres, time and distance relationships between the $\mathrm{n}^{\text {th }}$ and $\mathrm{n}^{\text {th }}+1$ centre

\section{Chapter 6}

Table 6.1. Results of $\mathrm{Os}$ and $\mathrm{Pb}$ isotope analysis 


\section{List of Abbreviations}

AFC - Assimilation Fractional

Crystallisation

AR - Analytical reagent

AVF - Auckland Volcanic Field

BMS - Base Metal Sulphides

ca. - from the Latin circa meaning

approximately

cal. yr BP - Calendar years before present

(taken as 1950)

CEVP - Central European Volcanic

Province

conc. - concentration

DEVORA - DEtermining VOlcanic Risk in

Auckland

DMM - Depleted MORB Mantle

DMOB - Dun Mountain Ophiolite Belt

DRE - Dense Rock Equivalent

DU - Durham University

EDS - Energy-dispersive spectrometry

EM - Enriched Mantle

GNS - Institute of Geological and Nuclear

Science

HIMU - high $\mu ; \mu={ }^{238} \mathrm{U} /{ }^{204} \mathrm{~Pb}$ isotope ratio

HREE - Heavy Rare Earth Elements ( $Y$,

$\mathrm{Tb}, \mathrm{Dy}, \mathrm{Ho}, \mathrm{Er}, \mathrm{Tm}, \mathrm{Yb}, \mathrm{Lu}$ )

JMA - Junction Magnetic Anomaly

ka - kiloannum, thousand years

Kk - Kawakawa (Oruanui) rhyolitic marker horizon

LA-ICP-MS - Laser Ablation-Inductively

Coupled Plasma - Mass Spectrometry

LGM - Last Glacial Maximum

LILE - Large Ion Lithophile Elements (K,

$\mathrm{Rb}, \mathrm{Cs}, \mathrm{Sr}, \mathrm{Ba}, \mathrm{Pb}^{2+}, \mathrm{Eu}^{2+}$ )

LOI - Loss-on-ignition

LREE - Light Rare Earth Elements

$\mathrm{Ma}$ - Megaannum, million years

MC-ICP-MS - Multi Collector - Inductively

Coupled Plasma - Mass Spectrometry'

$\mathrm{Mg \# -} \mathrm{Magnesium} \mathrm{number}=\left(\mathrm{Mg}^{2+} /\left(\mathrm{Mg}^{2+}\right.\right.$

$\left.\left.+\mathrm{Fe}^{2+}\right)\right) \times 100$

$\mathrm{MI}$ - Mayor Island volcano

$\mathrm{mL}$ - millilitre
MORB - Mid Ocean Ridge Basalt

$M Q$ - MilliQ water

MVF - Monogenetic Volcanic Field

NIWA - National Institute of Water and

Atmospheric Research

$\mathrm{nm}$ - nanometer

$\mathrm{NZ}$ - New Zealand

OB - Orakei Basin

OIB - Ocean Island Basalt

On - Onepoto

Ok - Okareka rhyolitic marker horizon

OVC - Okataina Volcanic Centre

PGEs - Platinum Group Elements

ppm - parts per million

$\mathrm{Re}$ - Rotoehu rhyolitic marker horizon

$\mathrm{Rk}$ - Rerewhakaaitu rhyolitic marker

horizon

$\mathrm{RMH}$ - Rhyolitic Marker Horizon

SAVF - South Auckland Volcanic Field

SB - Sub Boiled

SF-ICP-MS - Sector Field - Inductively Coupled Plasma - Mass Spectrometry

SMLM - Subduction Metasomatised

Lithospheric Mantle

SS - Sea Star

TgVC - Tongariro Volcanic Centre

Tk - Mt Taranaki volcano

TVZ - Taupo Volcanic Zone

UK - United Kingdon

$\mu \mathrm{L}$ - microliter

$\mu \mathrm{m}-$ micrometer (micron) $1 \times 10^{-6}$ of a

meter

UoA - University of Auckland

UoO - University of Otago

UQAM - L'Université du Québec à

Montréal

VEI - Volcanic Explosivity Index

VUW - Victoria University of Wellington

WDS - Wavelength Dispersive

Spectrometry

wt.\% - weight percent

$\mathrm{XRF}$ - X-ray Fluorescence 


\section{Chapter 1}

\section{Monogenetic basaltic volcanism and the Auckland Volcanic Field}

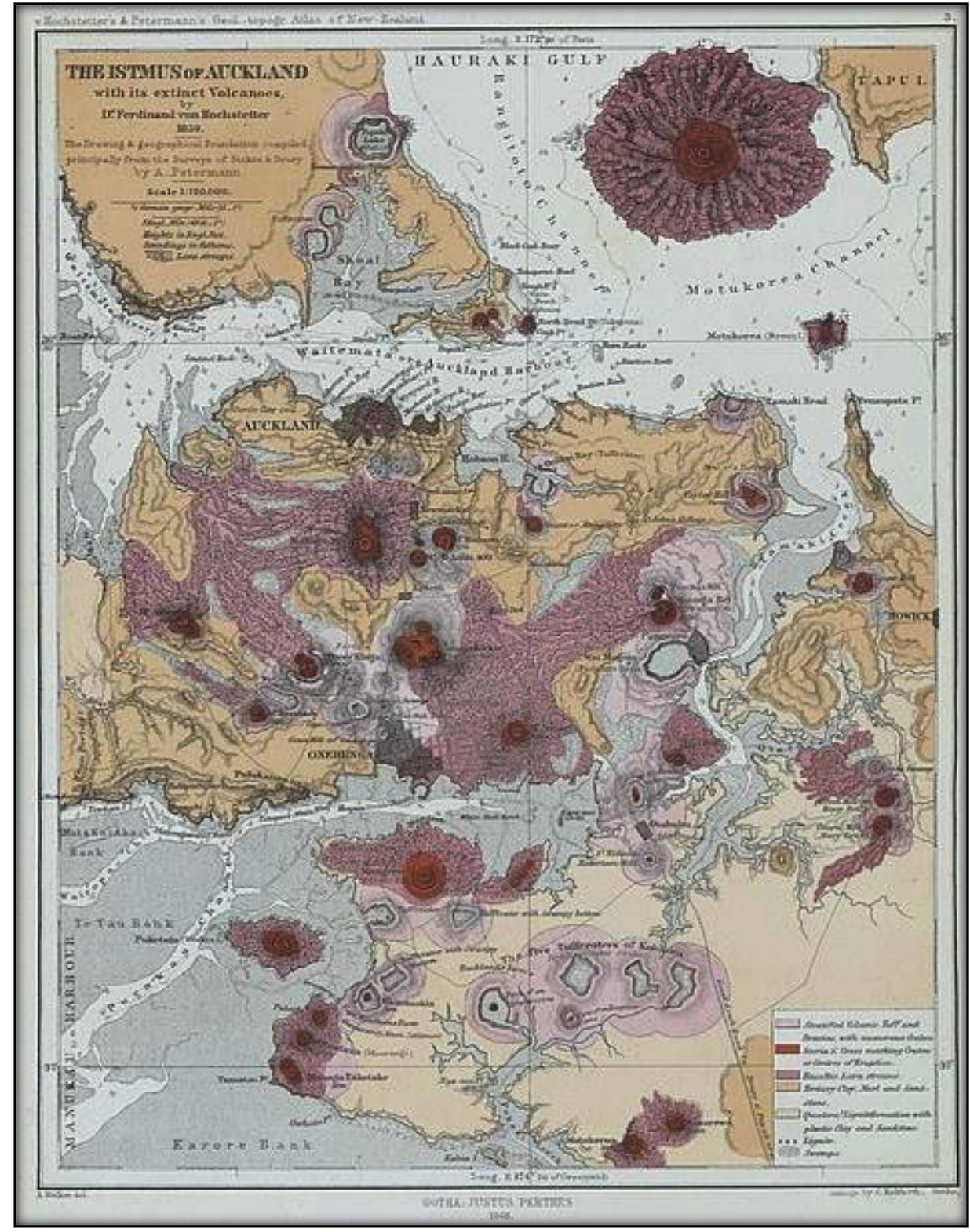

The isthmus of Auckland prior to urbanization with its extinct volcanoes

Ferdinand von Hochstetter, published by T. Delattre, Auckland, 1864. Sourced from the National Library of Australia.

A purely local set of happenings that produced a unique set of characteristics Professor E. J. Searle (1909-1996). 


\subsection{General Introduction}

Volcanism is one of many naturally occurring events that fall under the umbrella term of 'natural hazards'. Natural hazards are defined as naturally occurring elements of the physical environment, which have an adverse affect on people, infrastructure, and environment. The sub categories of which include, geological (e.g., volcanic eruption, earthquake, tsunami), meteorological (e.g., storms, drought, heat wave), and biological (e.g., disease, infestation) (Bryant, 2005). Amongst these natural hazards volcanism is often considered one of the most complex in affecting people, and causing costly damage to the urban and rural environments (Rymer, 2000). This is in part due to the association of active volcanism with a multitude of related hazards such as earthquakes, lahars, or ash fall. But in addition, due to the ever-increasing urbanisation in close proximity to active volcanic centres (Rymer, 2000).

Volcanic hazards are subdivided into two categories: primary hazards including lava flows, pyroclastic flows, lahars, and ash fall; and secondary hazards that occur as a result of the primary hazards, for example contamination of water supplies, or impact on aviation and those industries that rely on it (Rymer, 2000). Of the hazards associated with volcanic eruptions, ash fall has the potential to affect the largest areas, and often be the most frequent, disruptive, and costly (Miller and Casadevall, 2000). As well as the immediate effects of ash fall (from damage to buildings and transport links, to destruction of crops and livestock), man-made or natural remobilisation and re-suspension means that volcanic ash may continue to be a hazard for years to decades after an eruption (Horwell and Baxter, 2006).

The most costly impacts from volcanic ash are to the aviation industry (Miller and Casadevall, 2000), as the effects can become a global problem once ash is airborne, and reaches the stratosphere. The April-May 2010 eruption of Eyjafjallajökull, Iceland, sent ash hundreds of kilometres downwind covering much of the UK, Scandinavia, northern Europe, and western Russia. All European and north Atlantic airspace was closed, cancelling ca. 100,000 flights in 8 days (Oxford Economics, 2010). The resultant secondary global impacts on commerce and trade caused economic losses totalling ca. US \$5 billion (Oxford Economics, 
2010), made up of loss in the aviation sector, loss to revenue in the hospitality and tourism sectors, and losses in economical productivity. Similarly, in the southern hemisphere the eruption of Puyehue-Cordón Caulle volcano, Chile, in 2011 caused problems for New Zealand aviation, causing 7 days of disruption, with 60 flights cancelled and 7000 passengers stranded (New Zealand Transport Agency, 2011).

Although the impact on the economy is costly, one of the more researched topics in relation to ash fall hazards is the impact on respiratory health, both acute short-term effects (directly after eruptions), and more persistent long-term risks (as a result of long-term exposure). These health impacts are heavily dependent on particle size and ash composition. The highest toxic potential is attributed to shards of $<4 \mu \mathrm{m}$ that can travel into the alveoli in the lungs, and cause chronic diseases such as silicosis and pneumoconiosis, or larger particles (4-10 $\mu \mathrm{m})$ that, when trapped in the nasal cavities or airways, can cause laryngitis or bronchitis (Beckett, 2000). In comparison to natural dusts, fresh ash is a lot more toxic due to its unweathered surfaces that can carry condensed volatiles, trace metals and acids that add to irritations caused in the airways (Horwell et al., 2003). The toxicity and reactivity of the fresh surfaces of ash also has a exceptionally high leaching potential, and as well as the primary respiratory health issues, the secondary leaching of fresh ash into waterways can cause contamination of both drinking and irrigation water.

The superimposition of many urban areas on volcanically active regions, mean information is primarily required regarding future eruption potential and characteristics. Previous volcanic ash deposits are important in these instances for providing information about past eruption types, scale, composition, age and reoccurrence rates of an active volcanic regions. The information gathered is often crucial to assess the characteristics and evolution of a volcanic hazard through time, to allow predictions about potential future eruptions to be developed, and hazard and risk programmes to be implemented.

In 2008 the seven-year collaborative project 'DEVORA' (DEtermining VOlcanic Risk in Auckland) was set up between the University of Auckland (UoA) and GNS Science, with links to Victoria University of Wellington (VUW) and 
Massey University (Palmerston North). The project was developed with the aim of better understanding the monogenetic Auckland Volcanic Field in terms of the hazard and risk it poses to the people and infrastructure of Auckland city. Auckland is New Zealand's largest urban centre, housing over one third of the country's population, and is the main control point for the country's economic activity. Auckland's physical geographic setting between the Manukau and Waitemata harbours mean that major transport and infrastructure corridors are forced into very restricted areas. When all these aspects are coupled with its location on top of an active volcanic field, it was perceived that a better understanding of the potential volcanism was essential.

As with many geological studies uniformitarianism plays a key role in allowing reconstruction of the past to inform forecasts for the future. Where the eruptive history of a region is unknown, and there is a direct threat to a large population, tephrostratigraphic and geochemical reconstructions can provide critical insight into the magma source and evolution of an active volcanic area. Thereby providing accurate information that can be used to make hazard and risk predictions of future volcanic activity.

\subsection{Scientific Rationale}

Monogenetic volcanic fields by their nature often have very complex eruption histories. The deposition and preservation of the eruptive products from individual eruptions can allow a more informed reconstruction of the previous activity. In particular, distal pyroclastic deposits provide a time-resolvable record of activity. Therefore the examination and correlation of these deposits to their individual volcanoes gives the opportunity to build a precise picture of the temporal, spatial and geochemical evolution of the field.

Due to their primitive nature, analysis of basaltic eruptive products (e.g., lava, pyroclastic material) also permits investigation of the mantle processes that are occurring beneath the volcanic fields. Primitive melts are the product of initial melting of a rock with only minor amounts of differentiation or interaction with other 
rocks, and therefore the study of primitive basalts has the potential to give insights on the mantle source characteristics (Winter, 2010).

The over-arching goal of this thesis is to provide evidence for geological processes that are relevant to the development of hazard and risk management schemes for the city of Auckland. The composition of the mantle source, the eruption characteristics, and the absolute sequence of events in the field are all critical to understanding the hazards posed by a future eruption. All these aspects remained outstanding questions at the inception of this thesis (refer to section 1.6).

This introductory chapter provides the necessary background information for this research. It begins with a broad view of global monogenetic basaltic volcanism, the associated settings, the ranges of geochemistry, and the current models for the inception, and eruption, of these small-scale magmatic systems. The focus of this study, the monogenetic basaltic Auckland Volcanic Field (AVF), is then introduced including the regional tectonic setting, the local setting of the individual centres, and details of previous studies that have focused on the age and geochemistry of the field. The chapter then introduces tephrochronology, and focuses on previous tephra studies of the AVF. This introductory review from the larger picture of monogenetic volcanism, to the smaller-scale picture of the AVF characteristics, will highlight the reasoning and significance this study. Leading into the final section of Chapter 1, which describes the aims and key questions to be addressed, and finally outlines the structure of the research chapters in this thesis. 


\subsection{Monogenetic Basaltic Volcanism}

\subsubsection{Definitions and descriptions}

The term 'monogenetic' is applied to volcanoes that only erupt once, unlike 'polygenetic' volcanoes where eruptions occur repeatedly from one centre (Walker, 2000). Polygenetic and monogenetic systems are the end-member eruptive styles of volcanic behaviour, however natural systems often display a mixture of both style types. For the monogenetic end-member the volcanism is characterised by individual magma batches that are small $\left(0.0001\right.$ to $\left.4 \mathrm{~km}^{3}\right)$ (e.g., Guilbaud et al., 2012) and erupt infrequently (global average $\leq 0.0001$ eruption/yr.) (Connor and Conway, 2000). The pathway to the vent does not remain a favoured route for continuing activity, and therefore does not remain active for more than one episode of volcanism, which may last from only a few days to years (Connor and Conway, 2000). The magma batches generally erupt in close proximity to one another and therefore form clusters of volcanic structures creating fields of volcanism, suggesting their plumbing systems are more complex and dispersed compared to a polygenetic system (Francis and Oppenheimer, 2004). Compared to other volcanic systems which erupt basaltic magma (e.g., mid ocean ridges or larger intraplate volcanoes), monogenetic volcanic fields have the lowest output volume of eruptive products, on the order of tens of $\mathrm{km}^{3}$ in total (Connor and Conway, 2000). The eruption products that occur tend to vary widely with the degree to which there is water interaction with the upwelling magma. Magma interacting with sub-surface water results in explosive phreatomagmatic eruptions excavating maars and forming associated tuff rings. In comparison in 'dry' eruption the magma does not interact with water, and forms scoria cones and lava flows. Some centres erupt products of both 'dry' and 'wet' styles, showing that the eruption style can sometimes change over the course of an event. 


\subsubsection{Scale, rate and longevity}

Table 1.1 outlines examples and summarises the characteristics of monogenetic fields worldwide, and Figure 1.1 locates the currently active intraplate basaltic monogenetic fields. On a global scale the AVF is classed as relatively small with $<55$ centres spanning an area of $<1000 \mathrm{~km}^{2}$ (Connor and Conway, 2000). Larger fields are defined as having $>100$ centres over $>1000 \mathrm{~km}^{2}$; for example, the Michoacán-Guanajuato part of the Trans-Mexican volcanic belt, which contains over 1000 centres and covers an area of $>40,000 \mathrm{~km}^{2}$ (Connor, 1990).

In general, no apparent correlation exists on a global scale between the longevity of the field and the number of vents that are produced. For example, the Springerfield volcanic field (Arizona, USA) contains $>400$ vents that have been produced in the last 2 Myr (Condit and Connor, 1996) whereas the Cima volcanic field (California, USA) has only 70 vents formed over 4.5 Myr (Dohrenwend et al., 1986). The AVF has produced 53 vents in ca. 200 ka (Lindsay et al., 2011) making it comparatively quite active. However, within all given examples of fields, volcanic activity has waxed and waned over time, with periods of heightened activity and periods of quiescence, which is considered typical for basaltic volcanic fields (Connor and Conway, 2000).

A large majority of the volcanic fields identified in Figure 1.1 lie in close proximity to large urban centres (e.g., Michoacán-Guanajuato, Mexico City), and therefore most recent studies have focused on the hazard and risk implications as a result of the field's settings. Investigations have focused on finding patterns in vent distributions and considering eruptive reoccurrence rates (e.g., Conway et al., 1998), as well as understanding the processes that govern the magma supply and ascent (e.g., Berghuijs and Mattsson, 2013). Others, in order to predict future eruption styles, have recorded the detailed petrological evolution of the field through time (e.g., Blondes et al., 2008). Studies on volcanic fields have focused on both single centres (e.g., Udo, Jeju Island, Korea: Brenna et al., 2010), multiple centres (e.g., Mt. Gambier and Mt. Schank in the Newer Volcanics Province of eastern Australia: Demidjuk et al., 2007)) and whole fields (e.g., South Auckland Volcanic Field, New Zealand: Cook et al., 2005). 
Table 1.1. Features of major monogenetic volcanic fields world wide, with references; * McGee (2012); a Nicholls and Joyce (1989); b Condit and Connor (1996); c Conway et al. (1998); d Hwang et al. (2005); e Shaw (2004); f Delcamp et al. (2014); g Brenna et al. (2012); h Connor (1990); i Gutmann (2007); j Dohrenwend et al. (1986).

\begin{tabular}{|c|c|c|c|c|c|c|c|}
\hline Name & Location & $\begin{array}{c}\text { Primary } \\
\text { volcano type }\end{array}$ & $\begin{array}{c}\text { Composition of } \\
\text { eruptive } \\
\text { products }\end{array}$ & $\begin{array}{l}\text { Minimum } \\
\text { number of } \\
\text { centres }\end{array}$ & $\begin{array}{c}\text { Total area } \\
\left(\mathbf{k m}^{2}\right)\end{array}$ & $\begin{array}{l}\text { Last known } \\
\text { eruption }\end{array}$ & Reference \\
\hline $\begin{array}{l}\text { Auckland } \\
\text { Volcanic Field }\end{array}$ & $\begin{array}{l}\text { North Island, } \\
\text { New Zealand }\end{array}$ & $\begin{array}{c}\text { scoria cones, } \\
\text { maars }\end{array}$ & $\begin{array}{l}\text { nephelinite to } \\
\text { alkalic basalt }\end{array}$ & 53 & 360 & $\begin{array}{l}\text { Rangitoto ca. } \\
500 \text { yrs. BP }\end{array}$ & * \\
\hline $\begin{array}{l}\text { Newer Volcanics } \\
\text { Province }\end{array}$ & $\begin{array}{l}\text { Victoria, } \\
\text { Australia }\end{array}$ & $\begin{array}{l}\text { shields, scoria } \\
\text { cones, maars }\end{array}$ & $\begin{array}{c}\text { trachybasalt/ } \\
\text { tephrite basinite }\end{array}$ & 400 & 15000 & $\begin{array}{l}\text { Mt Gambier } \\
2900 \text { yrs. BP }\end{array}$ & a \\
\hline Springerville & Arizona, USA & scoria cones & $\begin{array}{l}\text { basaltic - } \\
\text { tholeiitic }\end{array}$ & 409 & 3000 & $0.3 \mathrm{Ma}$ & $\mathrm{b}$ \\
\hline San Francisco & Arizona, USA & $\begin{array}{l}\text { scoria cones, } \\
\text { lava domes }\end{array}$ & $\begin{array}{l}\text { basalt, rhyolite, } \\
\text { dacite }\end{array}$ & 606 & 5000 & $\begin{array}{l}\text { Sunset Crater } \\
950 \text { yrs. BP }\end{array}$ & c \\
\hline Wudalianchi & NE China & scoria cones & $\begin{array}{l}\text { trachybasalt/ } \\
\text { tephrite basanite }\end{array}$ & 14 & 800 & 1776 & d \\
\hline Eifel & $\begin{array}{l}\text { Rhineland, } \\
\text { Germany }\end{array}$ & $\begin{array}{l}\text { scoria cones, } \\
\text { maars \& tuff } \\
\text { rinas }\end{array}$ & foidite & 323 & 1000 & 8300 yrs. BP & e \\
\hline $\begin{array}{l}\text { Chaine des } \\
\text { Puys }\end{array}$ & $\begin{array}{l}\text { Central massif, } \\
\text { France }\end{array}$ & lava domes & $\begin{array}{l}\text { basalt/ picro } \\
\text { basalt }\end{array}$ & 100 & 50 & 4040 yrs. BP & f \\
\hline Jeju Island & South Korea & shield & $\begin{array}{l}\text { basaltic to } \\
\text { trachytic }\end{array}$ & 300 & 700 & 1007 yrs. BP & $\mathrm{g}$ \\
\hline $\begin{array}{l}\text { Michoacan- } \\
\text { Guanajuato }\end{array}$ & Mexico & cinder cones & $\begin{array}{c}\text { andesite / } \\
\text { basaltic andesite }\end{array}$ & 1000 & 40000 & Paricutin 1952 & h \\
\hline Pinacate & Mexico & $\begin{array}{l}\text { cinder cones, } \\
\text { maars \& tuff } \\
\text { rinas }\end{array}$ & $\begin{array}{l}\text { basalt / picro- } \\
\text { basalt }\end{array}$ & 408 & 1500 & unknown & $\mathrm{i}$ \\
\hline Cima & $\begin{array}{l}\text { California, } \\
\text { USA }\end{array}$ & cinder cones & $\begin{array}{l}\text { basalt to } \\
\text { basanite }\end{array}$ & 70 & 150 & $\begin{array}{c}\text { ca. } 10,000 \text { yrs. } \\
\text { BP }\end{array}$ & j \\
\hline
\end{tabular}




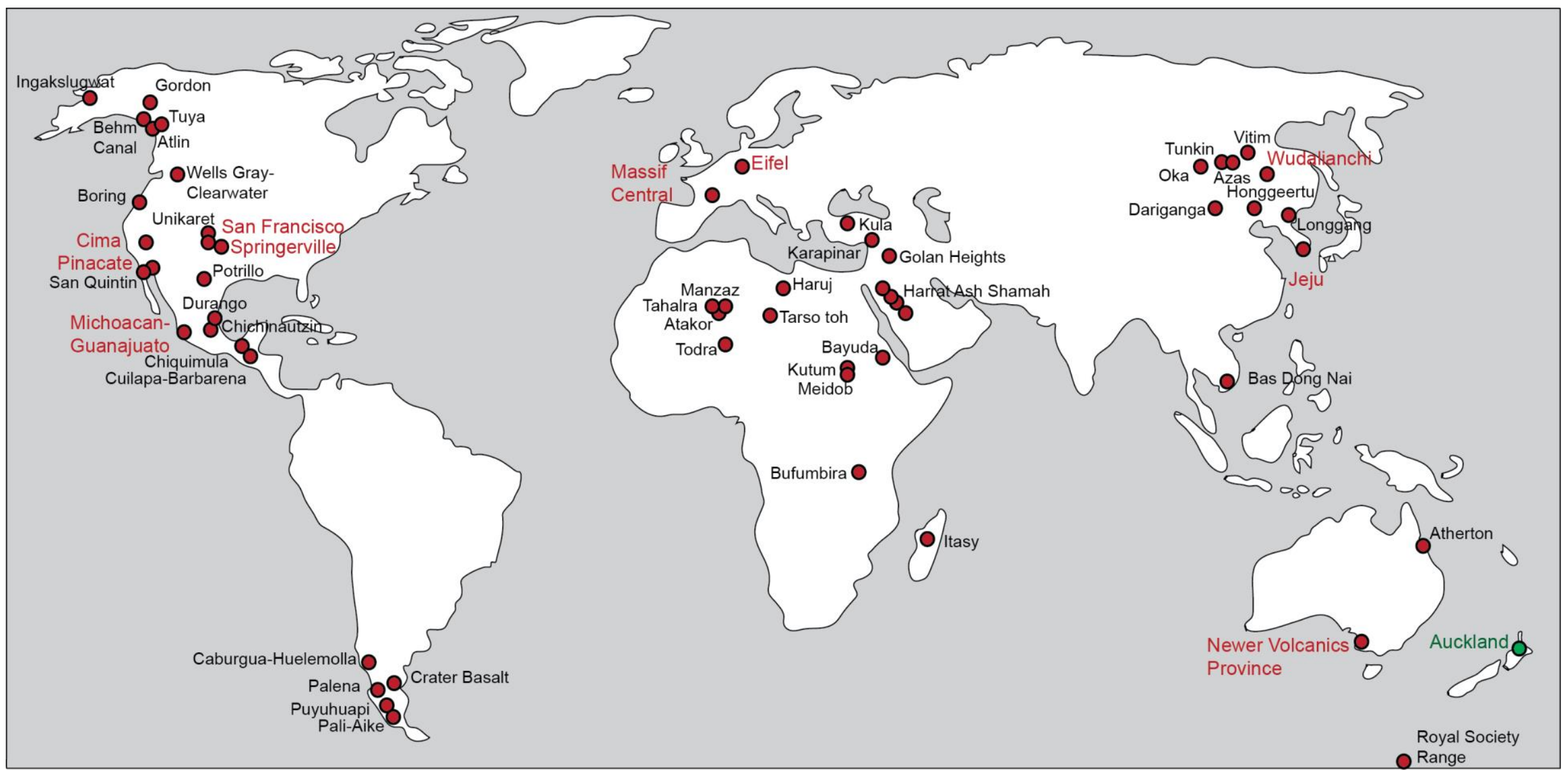

Figure 1.1. Location map for major, currently active, or dormant intraplate basaltic monogenetic volcanic fields globally. Highlighted in green is the Auckland Volcanic field, and in red are the major fields detailed in Table 1.1 


\subsubsection{Tectonic Settings}

The tectonic setting of monogenetic fields has traditionally been linked to regions of crustal extension coupled with low rates of magma production (Connor and Conway, 2000); however, increasing numbers of studies have found that monogenetic basaltic fields occur in a variety of tectonic environments. These environments vary, for example, from purely subduction related upwelling (e.g., the Michoacán-Guanajuato Field, Mexico, on the Cocos and Rivera plates; Ortega-Gutierrez et al., 2014), through to text-book examples of extensional intraplate settings, often associated with plume-like upwelling that results in rifting of the region (e.g., Eifel Volcanic Field, Germany; Shaw, 2004). Although the eruption of an individual monogenetic volcano can be short lived (days to years) and the total eruptive products are of low volume, a monogenetic field can have a long life span (e.g., 4.5 Ma, Cima volcanic field; Dohrenwend et al., 1986) and create a large cumulative volume of total eruptive products (Németh, 2010).

On a smaller scale, the geomorphologic analysis of fields worldwide has indicated that commonly a relationship is found between the structural environment and the spatial orientation of the centres (e.g., Timm et al., 2010; Le Corvec et al., 2013). For example, individual centres form along known fault traces (e.g., Springerville, Arizona, USA; Condit and Connor, 1996), or migrate relative to plate motion (e.g., San Francisco, Arizona, USA; Tanaka et al., 1986). Other examples include the formation of monogenetic fields on top of pre-existing polygenetic centres (e.g., Higashi-Izu, Japan; Hasebe et al., 2001), or the existence of both monogenetic and polygenetic centres erupting coevally in a single field (e.g., Wudalianchi, NE China; Hwang et al., 2005). These factors show the highly individual characteristics of the volcanic fields worldwide, and it is therefore considered that generic volcanic principles cannot always be applied to monogenetic fields (Connor and Conway, 2000; Németh, 2010).

\subsubsection{General petrology and geochemistry of monogenetic fields}

Volcanic products of monogenetic fields are dominated volumetrically by basaltic $\left(\mathrm{SiO}_{2} \leq 52\right.$ wt.\%) and basaltic-andesitic $\left(\mathrm{SiO}_{2} 52-56\right.$ wt.\%) compositions (Valentine and Gregg, 2008). Although minor siliceous andesitic to rhyolitic dome complexes occur (e.g., San Francisco volcanic field: Tanaka et al., 1986). In some 
cases entire fields can display unique chemical characteristics, for example the products of Wudalianchi volcanic field, China, all have high $\mathrm{K}$ compositions (Zou et al., 2008). Enrichment in incompatible elements (such as large ion lithophile elements (LILE) and light rare earth elements (LREE) relative to mid-ocean ridge basalts (MORB)) is also common, attributed by most studies to the small degrees of melting that generate the magma batches (e.g., South Auckland Volcanic Field (SAVF); Cook et al., 2005; Newer Volcanics Province; Vogel and Keays 1997). Other studies attribute incompatible element enrichment to alternative processes acting on the ascending magma, for example when mantle plume-related melts interact with the surrounding continental lithosphere and crust (e.g., Central European Volcanic Province (CEVP), Germany; Jung et al., 2011) or interaction of ascending melts with subduction-metasomatised lithosphere mantle (e.g., AVF; McGee et al., 2013). Studies of lava major and trace element and isotopic compositions globally (e.g., Sr-Nd-Pb) reveal that heterogeneous mantle sources and/or crustal assimilation (e.g., Harrat Al-Madinah volcanic field, Saudi Arabia; Moufti et al., 2012) are required to explain observed geochemistry at basaltic monogenetic fields, indicating that the mantle sources beneath monogenetic volcanic fields are rarely homogeneous (see Chapter $\mathbf{5}$ and $\mathbf{6}$ for more detail). These geochemical variations, both field-wide and for a single centre, have led a number of authors to question the term 'monogenetic' in favour of terms such as 'polymagmatic' (e.g., Brenna et al., 2010; McGee 2012).

Systematic changes in geochemical composition throughout a single eruption have also been identified, including: (1) gradual evolution through time to a more primitive composition, (2) a bimodal composition, where an initial evolved composition is followed by a primitive composition, and (3) an initial primitive composition followed by a more evolved composition (Smith et al., 2008). Three broad models are used to explain these changes; for (1) a single uninterrupted eruption (Smith et al., 2008), for (2) magma stalling at a rheological boundary or density barrier (e.g., brittle-ductile boundary between upper and lower crust) causing the more evolved magma to be pushed ahead by the upwelling of more primitive melt (Németh et al., 2003), and for (3) initial deep source eruption followed by stalling over months to years and a 'second' eruption of this more evolved magma over time (Johnson et al., 2008). 


\subsubsection{Melting models for inception of eruptions}

Initial models to explain the formation of volcanic fields linked crustal weaknesses (e.g., faults or fractures) to widespread, high degrees of partial melting and upwelling of the mantle (Connor and Conway, 2000). Studies of the petrogenesis of most volcanic fields question this model and instead suggest that melt production can occur at different levels within the mantle, and usually involves low degrees of partial melting undergoing limited fractional crystallisation (Erlund et al., 2010). The combination of these factors implies that volcanic fields do not develop large magma chambers and therefore their melts are relatively primitive in composition (e.g., Johnson et al., 2010).

Monogenetic fields can be separated into two overarching groups: (1) low eruptive volume flux predominately controlled by tectonism (e.g., south-western Nevada volcanic field; 0.5 km³/Myr; Valentine and Perry, 2007), (2) a high eruptive volume flux primarily controlled by magma volume (e.g., Eastern Snake River Plain field; 2.8 km³/kyr: Kuntz et al., 1986). Based on these characteristics Németh (2010) proposed that a close link exists between the output rates of the eruptive products, the local crustal thickness, the tectonic setting, the magma composition and melt generation rates.

Petrogenetic studies of monogenetic fields have aided the development of melting models aiming to describe the origin of the magma batches. The current understanding (e.g., Connor and Conway, 2000; Németh et al., 2003; Valentine and Perry, 2007; Smith et al., 2008; Erlund et al., 2010; McGee et al., 2011; McGee et al., 2013; McGee et al., 2015) links a consistent low level of partial melting and melt production from a number of levels within the asthenosphere, lithosphere or a mixture of the two. Most recently McGee et al. (2015) have highlighted evidence for a relationship between physical eruption properties (e.g., volume and explosivity) and chemistry of erupted products in monogenetic volcanic fields (e.g., AVF, Wudalianchi volcanic field, and selected Hawaiian examples). These more recent findings support the model proposed by McGee et al. (2015) outlined above. This is discussed in more detail in Chapter 4 and 5.

From this brief overview, we can see the complexities involved in understanding monogenetic volcanism, and the range of factors that must be 
considered when working towards an improved knowledge of the systems. It is fundamental to understand that volcanic fields are as much individual in their global context as they are within their contained system, and that the term 'monogenetic' has the potential to be misleading.

\subsection{The Auckland Volcanic Field}

\subsubsection{Regional geology}

The focus of this study is the basaltic monogenetic Auckland volcanic field (AVF), located in the north-west of North Island, New Zealand. Since late Pliocene times, the broader north-west region of North Island has hosted a series of basaltic volcanic fields migrating south to north: Ngatutura/Okete ca. 2.7-1.5 Ma (Briggs et al., 1994), South Auckland ca. 1.59-0.51 Ma (Cook et al., 2005), and Auckland ca. 200-0.5 ka (Lindsay et al., 2011). The Auckland Volcanic Field (AVF) is located ca. $250 \mathrm{~km}$ west of (behind) the current active arc - The Taupo Volcanic Zone (TVZ) - and ca. $400 \mathrm{~km}$ behind the active subduction margin of the Pacific Plate, which is migrating westward beneath the North Island of New Zealand along the Kermadec trench (Fig.1.2.A).

The regional basement is composed of two broadly coeval but contrasting Triassic to Jurassic shallow marine sedimentary terranes, the Waipapa and Murihiku groups, brought together as part of the Gondwana margin. The Permian ultramafic Dun Mountain ophiolite belt forms a suture between these two terranes, and runs continuously (apart from the $460 \mathrm{~km}$ offset of the Alpine Fault) throughout New Zealand. Although there is only one small outcrop of Dun Mountain ophiolite in the Auckland region, it appears as a series of prominent positive gravity anomalies, interpreted to be a series of eastward dipping serpentinised shear zones running northwest-southeast at $\geq 1.5 \mathrm{~km}$ beneath the Auckland Isthmus (Eccles et al., 2005; Fig.1.2.A). During the early Miocene the Auckland region was once again a marine basin, and deposited sands and muds form the now uplifted surface rocks of the region, the Waitemata Group (Kermode, 1992). Finally, atop this is the Quaternary monogenetic basaltic Auckland volcanic field. 


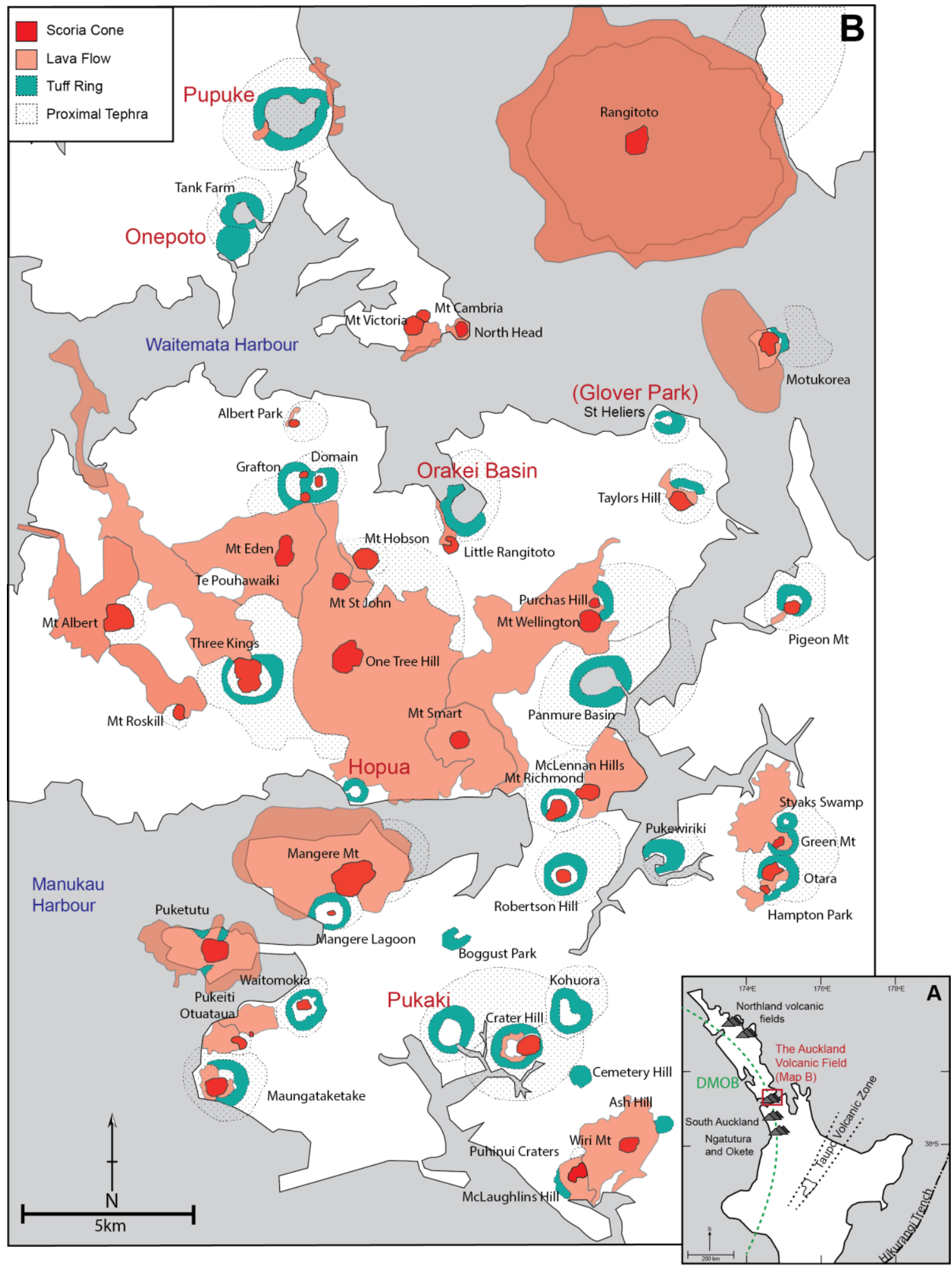

Figure 1.2. A) Regional setting of the AVF in the North Island, New Zealand, including the older volcanic fields, and the location of the Dun Mountain ophiolite belt (DMOB). B) Local setting map of the individual AVF centres, their associated volcanic products, and maars from which the cores were retrieved (red font). Figure modified from Hayward et al. (2011). 


\subsubsection{Local setting}

The term monogenetic is widely used in connection with the AVF, on the basis that each centre represents the rise and eruption of a single batch of magma that is confined in time. Each centre in the AVF is individual in terms of its physical characteristics and geochemical signatures, suggesting a complex interrelationship between source characteristics and transport mechanisms (Smith et al., 2008; Needham et al., 2011; McGee et al., 2011).

There are currently 53 identified centres in the AVF, including three newly discovered centres, Boggust Park, Cemetery Hill, and Puhinui Craters (Hayward pers. comm. 2014). Cemetery Hill and Puhinui Craters, however, have no data (age or geochemistry) associated with their eruptions. Of the 53 centres (identified on Fig.1.2.A), ten show purely phreatomagmatic eruption styles producing just maar craters and tuff rings. These centres are formed as a result of wet explosive eruptions where the ascending magma interacted with ground water (Ash Hill, Boggust Park, Hopua, Kohuora, Onepoto, Orakei Basin (pictured Fig. 1.3.A), Pukaki, St Heliers, Styaks Swamp, and Tank Farm). Twelve centres show evidence of only magmatic eruptions (with both effusive and explosive activity) with small scoria cones and some small lava flows. These centres generally have slightly larger volumes and form as a result of dry, fire fountaining eruptions (e.g., Mangere Mt, Mt. Eden (pictured Fig. 1.3.B), Mt. Victoria). The remaining twentynine include the largest centres and show evidence for both phreatomagmatic and magmatic styles (both effusive and explosive) of eruption. All, except one (Pupuke), show a general progression from phreatomagmatic to magmatic and effusive eruption styles. These centres often have poorly exposed tuff rings, usually buried by lava flows, and scoria cones built within the explosion craters (e.g., Motukorea; pictured Fig. 1.3.C). Two remain (Puhinui Craters and Cemetery Hill) yet to be fully investigated and classified (Hayward et al., 2011). 

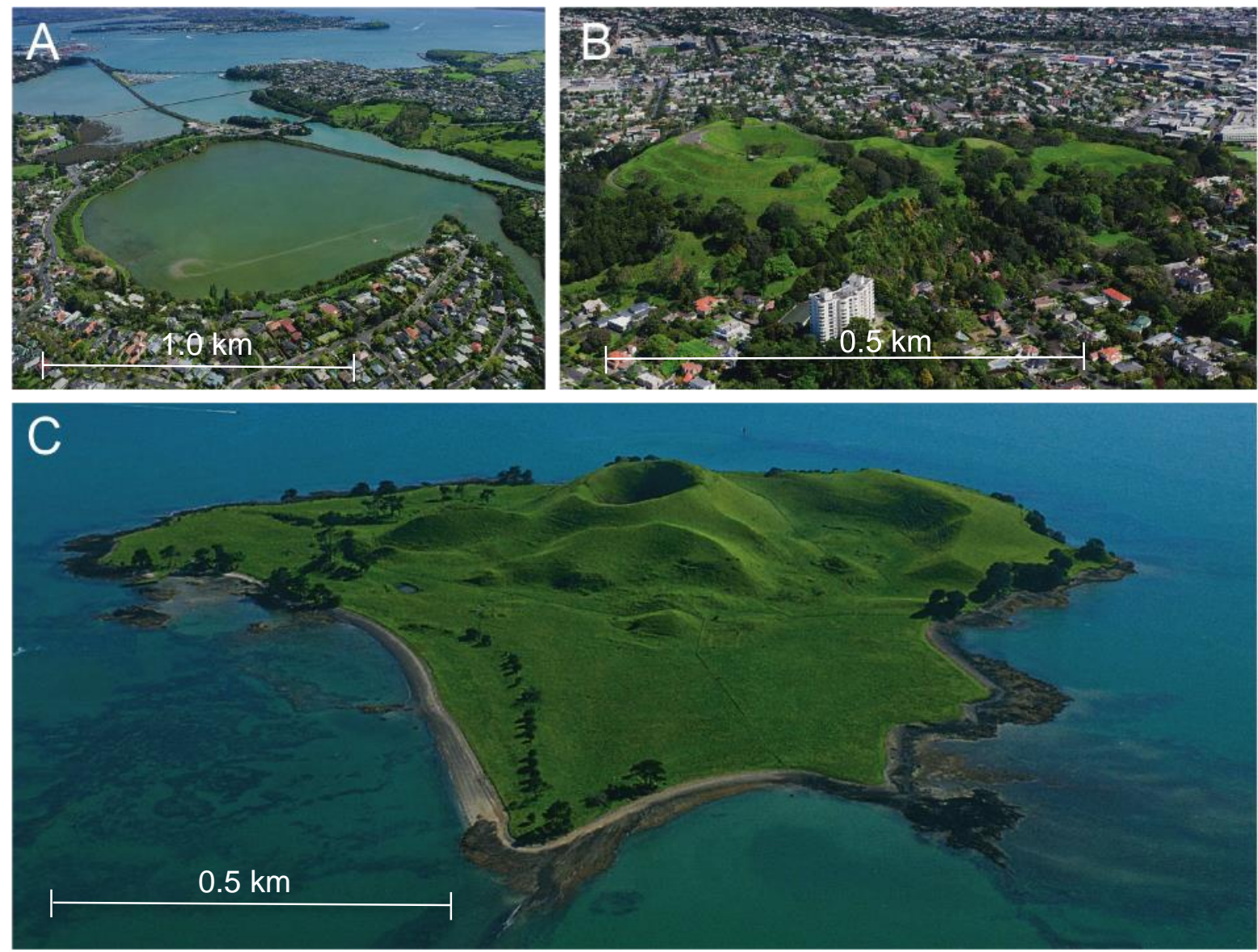

Figure 1.3. Pictures taken from Hayward et al. (2011), accredited to Alastair Jameson to show examples of the types of volcanic landforms associated with volcanoes of the AVF. Included are, A) Orakei Basin crater (maar) and the surrounding tuff ring formed through phreatomagmatic, wet, explosive eruptions. B) Mt Eden scoria cone and lava flows created through dry fire fountaining and magmatic effusive styles of eruption. $C$ ) Motukorea an example where all eruption types are identified within one centreremnants of the tuff ring can be seen in the top right of the picture, the scoria cone is very obvious in the middle of the picture, and lava flows extend out from the island. 
Current data, based on model simulations, suggest the AVF has a total eruptive output of $1.7 \mathrm{~km}^{3}$ dense rock equivalent (DRE) magma (Kereszturi et al., 2013) which is about half of the previous study's approximation of $3.4 \mathrm{~km}^{3}$ (Allen and Smith, 1994). In both these volume estimates the largest 5 centres include Rangitoto, One Tree Hill, Mt Eden, Mt Wellington and Three Kings, which make up ca. $69 \%$ of the field's eruptive products. Herein we used the more recently published values; for example Rangitoto, the largest Auckland volcanic centres, comprise ca. $41 \%$ (or $0.7 \mathrm{~km}^{3}$ ) of the total DRE. The majority of centres have eruptive material between $0.001-0.01 \mathrm{~km}^{3}$ (ca. 43 centres). For the cases of eruptions that exhibit both wet and dry eruptive styles the majority of the volume is made up from products of the dry eruption lava flows and scoria cones. The smallest centre (Kereszturi et al., 2013) is Ash Hill with total eruptive material of $0.000076 \mathrm{~km}^{3}$. All volume estimates are outlined and discussed in Chapter 5.

\subsubsection{Previous Studies}

\subsubsection{General}

Research on the AVF began with mapping by Charles Heaphy in 1857, followed shortly by a more in-depth geological survey by Ferdinand von Hochstetter resulting in the publication in 1864 of a full colour geologic map (shown on the title page of this chapter) (Hayward et al., 2011). This map shows 63 volcanoes with 27 explosion craters, a number of which have since been disproven. Hochstetter's memoirs remain useful today in giving information about sizes and locations of destroyed or hidden volcanoes of the field.

The next major phases of research on the AVF occurred nearly 100 years later with works from Ernie Searle in the 1950s and 60s (Searle, 1959a;,1959b; 1961a; 1961b; 1964; 1965), and Les Kermode in the 1960s-90s (Kermonde, 1975; 1992; Kermode et al., 1992). Searle undertook much of the initial petrographic work classifying the AVF rocks as basalts with phenocrysts of olivine and clinopyroxene. Heming and Barnet (1986) later confirmed these conclusions, with geochemical analysis identifying the rocks as predominantly alkali basalts.

Since the 1990s volcanological and geochemical research on the AVF has been predominantly based at the University of Auckland, with ever improving analytical techniques and methods allowing new aspects and details of the field to 
be investigated. Many studies have focused on geochemistry, and form a basis for the collation of geochemical data for this thesis (Chapter 4). These studies include MSc work from Bryner (1991), Miller (1996), Franklin (1999), Hookway (2000), Spargo (2007), Eade (2009) and Needham (2009). Most recently of note is the PhD work of McGee (2012) and associated papers (McGee et al., 2011; 2012; 2013; 2015), which significantly increased the set of geochemical data available and improved the understanding of the complexities both within centres and across the field. A summary of the geochemical database prior to this thesis research is shown and critically discussed in Chapter 4. Some studies have also primarily focused on the tephra and core deposits from the AVF, most notably Sandiford et al. (2001), Hoverd et al. (2005), Shane and Hoverd (2002), Molloy (2008), Molloy et al. (2009) and Zawalna-Geer (2012); this topic is discussed further in Section 1.5.

The purely monogenetic classification of the AVF has been brought into question by the work of Needham et al. (2011) and Spargo (2007) and more recently by Shane et al. (2013). Rangitoto is the youngest and the largest eruptive centre of the field. It is considered to reflect a change in eruption style at the AVF, and has therefore been the focus of many studies. The MSc thesis of Needham (2009) was the first to uncover evidence for two eruptions from Rangitoto, around 50 years apart $\left({ }^{14} \mathrm{C}\right.$ dates of $553 \pm 7$ and $504 \pm 5$ cal. yr. BP), with each eruption (Rangitoto1 and Rangitoto2) showing a different geochemical signature. Most recently tephrochronology on Rangitoto deposits from Shane et al. (2013) suggested that rather than two eruptions there is evidence within cryptotephra for multiple periodic eruptions over ca. 1000 years. However, this hypothesis is currently not supported by any other tephra work or physical volcanology on Rangitoto deposits, and thus remains uncertain. In either case, Rangitoto shows the simple 'monogenetic' nature of the AVF may be changing, or may be an oversimplification. For example, the older centres simply do not have the same chronological resolution as for Rangitoto. These observed changes in the characteristics of the field have made it necessary to conduct a more detailed and comprehensive study in order to better understand the evolutionary history of the field as a whole, and create better constraints to the hazards and risks posed on the city. 


\subsubsection{Age studies}

In order to assess volcanic hazards a critical first step is to determine eruption magnitude-frequency relationships (e.g., Lindsay et al., 2011 for a review in the specific case of the AVF). This analysis has been hampered in the AVF due to the lack of accurate age determinations (Magill et al., 2005).

${ }^{14} \mathrm{C}$ dating is of limited use, due to the age of many of the eruptions ( $>40$ ka) and the lack of carbonised material within the deposits. Early attempts at carbon dating (Fergusson and Rafter, 1959; Searle, 1961a) are helpful to some extent in ordering event timings but not necessarily allowing specific dates to be applied. Currently only 5 AVF centres are assigned ages through ${ }^{14} \mathrm{C}$ techniques (Rangitoto1 and 2, Mt Wellington, Purchas Hill, Three Kings, and Ash Hill). K-Ar techniques are also of limited value as excess radiogenic Ar within the samples commonly leads to false ages that are older than the inferred age derived by other means (Lindsay et al., 2011). Mochizuki et al. (2004) present further results from $\mathrm{K}-\mathrm{Ar}$ technique, however, more recently the developments in ${ }^{40} \mathrm{Ar} /{ }^{39} \mathrm{Ar}$ dating technology (Cassata et al., 2008) have opened a new chapter on the 'date-ability' of the AVF. This new ${ }^{40} \mathrm{Ar} /{ }^{39} \mathrm{Ar}$ dating technique has increased the number of reliable (to reasonably reliable) ages dates from 11 to 33 (Lindsay et al., 2011). For four centres the original Ar-Ar data from Cassata et al. (2008) are maintained (Wiri Mt., Puketutu, Crater Hill and Hampton Park). However, most recently an extensive campaign undertaken by Leonard et al (in prep. Appendix D) has added 24 Ar-Ar ages to the database (all AVF centre ages are outlined and discussed in Chapter 5).

Six centres remain totally undated (Mt Robertson, Otuataua, Pigeon Mt, Puhinui Crater, Cemetery Hill and Boggust Park), and the remaining 14 have their ages constrained by tephrostratigraphy $(n=6)$ or morphostratigraphy $(n=8)$. These constraints are discussed in detail in Chapter 5. Age estimates are therefore now available for ca. 46 of the centres (Chapter 5, Table 5.1) although, many of these centres are indistinguishable within uncertainty due to the errors associated with the analytical techniques, and thus have no definitive, relative eruption order. As a result we do not have the ability to assess the temporal and spatial evolution of the field as a whole. 


\subsubsection{Geochemical studies}

The geochemistry of the AVF is outlined and discussed in detail in Chapters 4 and 5, therefore this section just provides a brief overview of previously published work and key findings. Most of the bulk rocks of the AVF are classified as olivine-rich basalts and basinites (Fig.1.4.). They are mostly composed of olivine, clinopyroxene, feldspar, minor apatite, and Fe-Ti accessory oxides. The most common phenocrysts are olivine followed by clinopyroxene (Searle, 1961a; Heming and Barnet, 1986). The groundmass exhibited in bulk rocks shows a fine grained to glassy texture, with vesicularity observed in the upper parts of flow units. Groundmass crystals are plagioclase, clinopyroxene, olivine, and accessory Fe-Ti oxides (Searle, 1961a). Variations on this pattern include; nepheline found at the Domain tuff; amphibole (cummingtonite) found in Three Kings basalts (Searle, 1961a); biotite found in the groundmass of lavas at Mt Wellington and Pigeon Mt (Heming and Barnet, 1986); and subalkalic-tholeiitic products found in the second eruption of Rangitoto (Needham et al., 2011).

A number of centres have erupted xenolithic material, (reported in Jones, 2007; Spörli and Black, 2013; Spörli et al., 2015) including Glover Park and Taylors Hill. The xenoliths are thought to represent mid to lower crustal lithologies that have been linked to the Maitai terrain, a suture between greywacke basements (Jones, 2007). Xenocrystic olivines have also been found in eruptives from Lake Pupuke and Onepoto, they have a Cr-spinel composition that has suggested subduction related origins (Spargo, 2007).

The $\mathrm{SiO}_{2}$ content of the field is $<50$ wt.\%, and the total alkali $\left(\mathrm{Na}{ }_{2} \mathrm{O}+\mathrm{K}_{2} \mathrm{O}\right)$ contents generally range between 4-7 wt.\% (Fig.1.4.). The general relationship for total alkali vs. silica (TAS) shows a negative trend for these elements (Fig.1.4.). $\mathrm{MgO}$ content of the field is ca. 7.5-13.5 wt.\% with the corresponding Mg numbers (Mg\#) ranging from 52-70 (McGee et al., 2013). Varying trends are observed in the major elements between the centres, the majority showing variable negative trends for example $\mathrm{MgO}$ vs. $\mathrm{Al}_{2} \mathrm{O}_{3}$ (McGee et al., 2013). Major element trends and relationships are fully discussed and explored in Chapter $\mathbf{4}$ and $\mathbf{5 .}$ 


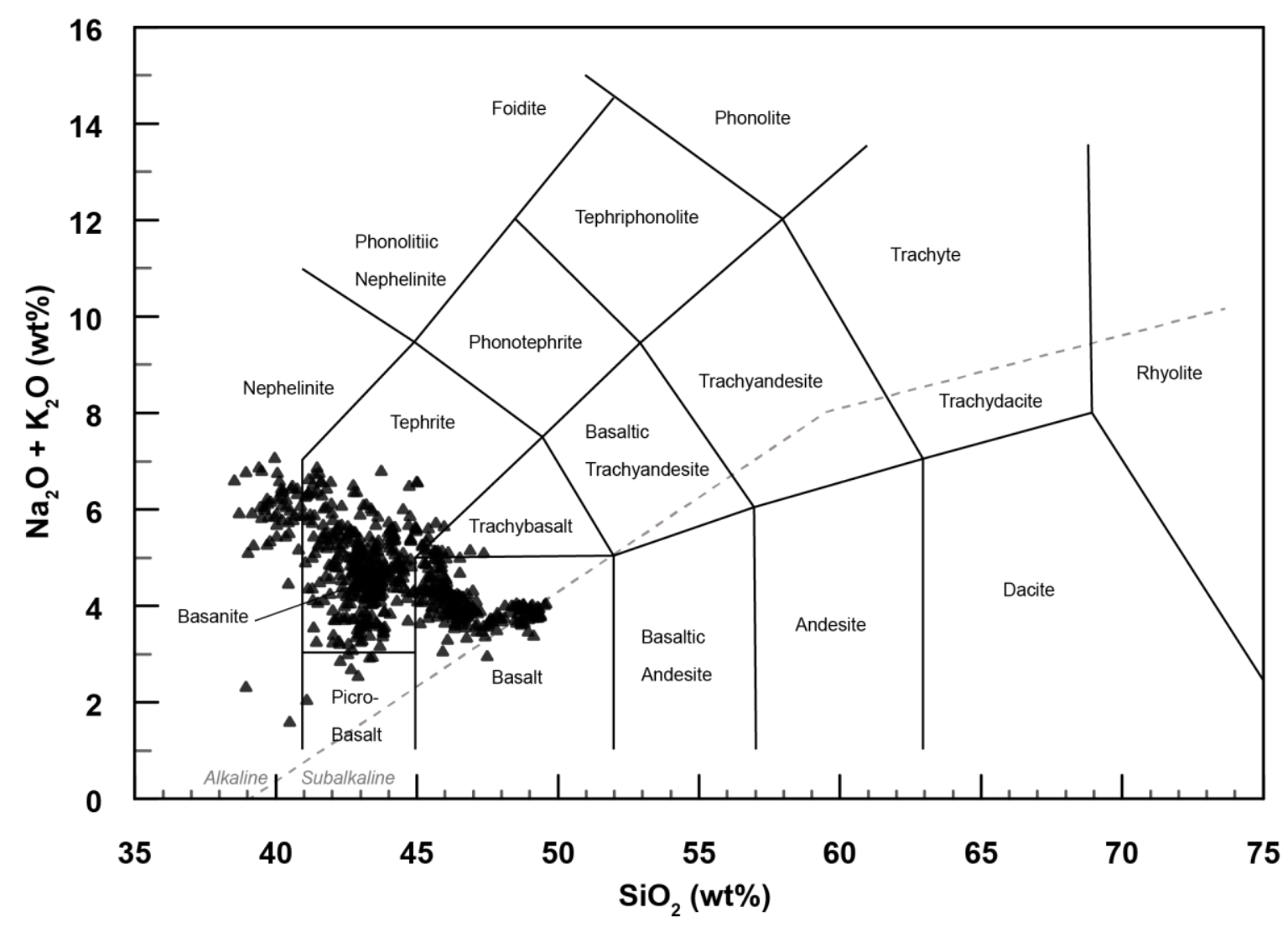

Figure 1.4. Total alkalis $\left(\mathrm{K}_{2} \mathrm{O}+\mathrm{Na}_{2} \mathrm{O}\right)$ vs. $\mathrm{SiO}_{2}$ for all whole rock analysis for all centres within the AVF prior to this research, database collated by McGee (2012).

In general the AVF lavas show trace element signatures that exhibit primitive-normalised multi-element trends similar to Ocean Island Basalts (OIB) (Fig.1.5.B). The range in trace element composition for the AVF as whole is large; for example La ranges from ca. 10-60 ppm, Ba from ca. 90-360 ppm, and $\mathrm{Nb}$ ca. 15-90 ppm, with the incompatible trace elements showing the largest range in variability across the centres. McGee et al. (2013) noted that in general there is enrichment in the heavy rare earth elements (HREE) in comparison to OIB values, with pronounced anomalies noted in $\mathrm{U}$ and $\mathrm{Pb}$ (Smith et al., 2009) and $\mathrm{K}$ and $\mathrm{Sr}$ (McGee et al., 2012; McGee et al., 2013; McGee et al., 2015) (Fig.1.5.). 


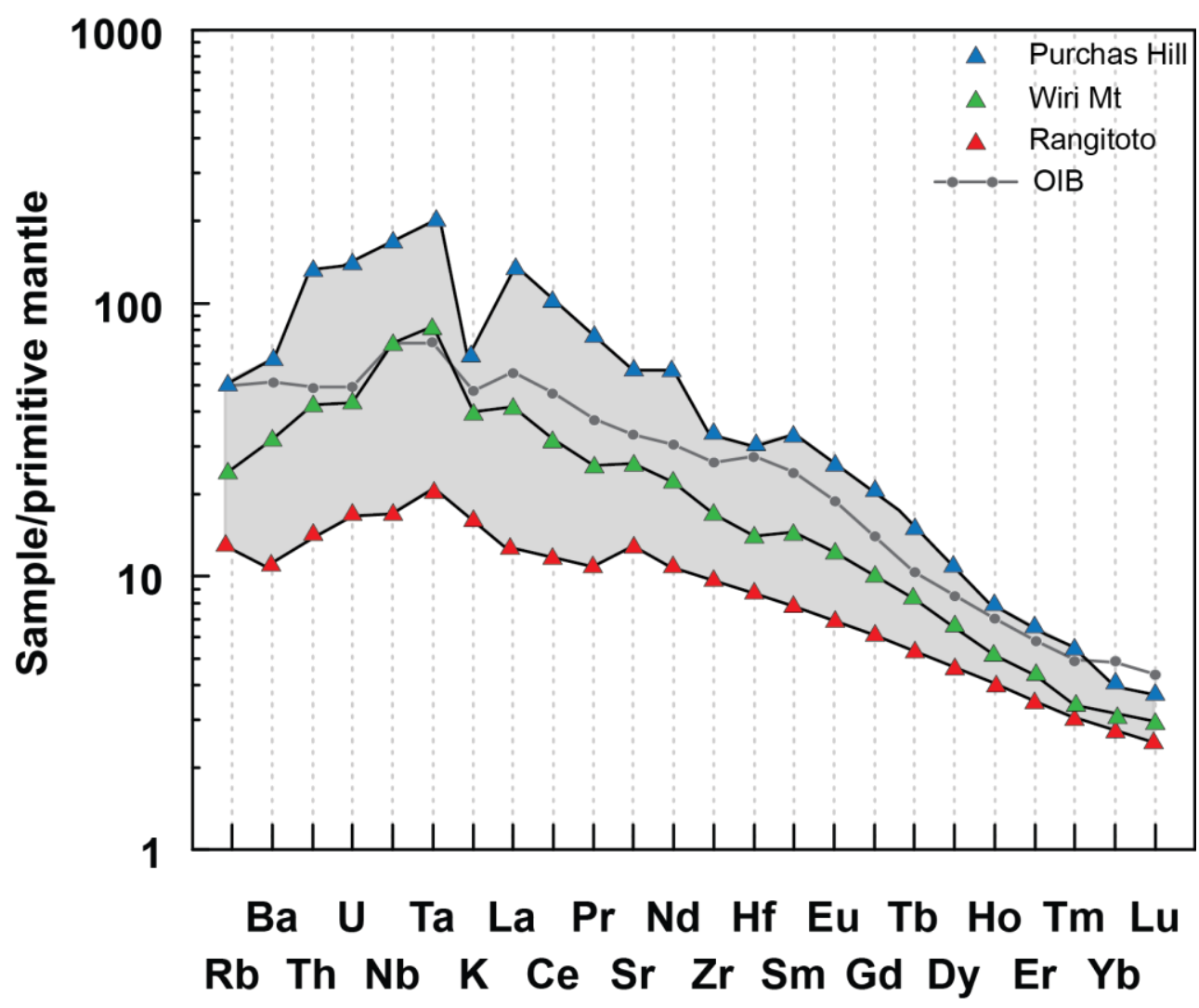

Figure 1.5. Primitive mantle-normalised multi-element plots for pre-existing whole rock samples from the AVF (data from McGee et al., 2013). Pale grey shows the entire range in the field, colour symbols indicate the three proposed compositional end members, (c.f. Fig 1.6.) for Rangitoto (red), Wiri Mt. (green), and Purchas Hill (blue). Normalisation and OIB values are from McDonough and Sun (1995).

Only a minor amount of isotopic data has been obtained for the AVF volcanic products (e.g., Huang et al., 1997; McGee et al., 2011; McGee et al., 2013). Studies have focused on the Sr-Nd-Pb (McGee et al., 2013) and U-Th-Ra (McGee et al., 2011; McGee et al., 2013) systems. The ${ }^{87} \mathrm{Sr} /{ }^{86} \mathrm{Sr}$ composition range from 0.702710 to 0.703125 , and the ${ }^{143} \mathrm{Nd} /{ }^{144} \mathrm{Nd}$ from 0.512931 to 0.512971 (Fig.1.6.). These two systems display only a minimal relationship (McGee et al., 2013), with the Rangitoto eruptions showing a broader range in ${ }^{87} \mathrm{Sr} /{ }^{86} \mathrm{Sr}$ than the other centres, and exhibiting a higher ${ }^{87} \mathrm{Sr} /{ }^{86} \mathrm{Sr}$ ratio at similar ${ }^{143} \mathrm{Nd} /{ }^{144} \mathrm{Nd}$ values. The $\mathrm{Pb}$ isotopes show ${ }^{206} \mathrm{~Pb} /{ }^{204} \mathrm{~Pb}$ range from 19.039 to $19.416,{ }^{207} \mathrm{~Pb} /{ }^{204} \mathrm{~Pb}$ from 15.574 to 15.617 and ${ }^{208} \mathrm{~Pb} /{ }^{204} \mathrm{~Pb}$ vary from 38.781 to 39.009 . When looked at in more detail the ${ }^{206} \mathrm{~Pb} /{ }^{204} \mathrm{~Pb}$ vs. ${ }^{207} \mathrm{~Pb} /{ }^{204} \mathrm{~Pb}$ plot in a mixing triangle (Fig.1.6.A), with Purchas Hill, Rangitoto, and Wiri/ Puketutu defining the end-members. A plot 
of ${ }^{206} \mathrm{~Pb} /{ }^{204} \mathrm{~Pb}$ vs. ${ }^{208} \mathrm{~Pb} /{ }^{204} \mathrm{~Pb}$ produces a linear trend with Rangitoto and Purchas Hill again defining the limits of this diagram (Fig.1.6.B). There is no relationship exhibited between ${ }^{143} \mathrm{Nd} /{ }^{144} \mathrm{Nd}$ and ${ }^{206} \mathrm{~Pb} /{ }^{204} \mathrm{~Pb}$, and a negative trend is seen when ${ }^{87} \mathrm{Sr} /{ }^{86} \mathrm{Sr}$ is plotted against ${ }^{206} \mathrm{~Pb} /{ }^{204} \mathrm{~Pb}$ (Fig.1.6.C\&D).

$\mathrm{U}$-Th-Ra isotope analysis was undertaken on the four most recent eruptions from the AVF; the two Rangitoto eruptions (McGee et al., 2011) followed by Purchas Hill and Mt Wellington (McGee et al., 2013). These analyses covered both the largest (Rangitoto 2) and one of the smallest (Purchas Hill) centres of the AVF. The results show that Purchas Hill displays the highest ${ }^{230} \mathrm{Th} /{ }^{232} \mathrm{Th}$ ratio of 1.380 and Rangitoto 2 the lowest at 1.140. The data show two clusters, one from Rangitoto 2 which has a high ${ }^{238} \mathrm{U} /{ }^{232} \mathrm{Th}$ ratio and a lower ${ }^{230} \mathrm{Th} /{ }^{232} \mathrm{Th}$ ratio, and the other encompassing Rangitoto1, Purchas Hill and Mt Wellington exhibiting a lower ${ }^{238} \mathrm{U} /{ }^{232} \mathrm{Th}$ and a more variable ${ }^{230} \mathrm{Th} /{ }^{232} \mathrm{Th}$. McGee et al. (2011) concluded this variability was created by two differing magmatic processes (discussed further in Chapter 5) causing the eruptions, and overall show that these measurements are some of the highest ${ }^{230} \mathrm{Th} /{ }^{232} \mathrm{Th}$ ratios measured for ocean island and continental intraplate volcanic field basalts.

Some centres show compositional variation throughout their eruptive products, with Crater Hill (Smith et al., 2008) and Motukorea (McGee et al., 2012) studied in detail. Those which have had their deposits sampled stratigraphically all show a similar evolution through time of low-Si, low-Mg, high-incompatible trace elements in the early eruptive phases, through to high-Si, high-Mg and low incompatible element contents towards the end of the eruptions (Smith et al., 2009). In general terms, the AVF centres show the broadest geochemical variation within the incompatible trace elements, and this variation is (most commonly) larger on a field-wide scale, than on an individual centre scale. 


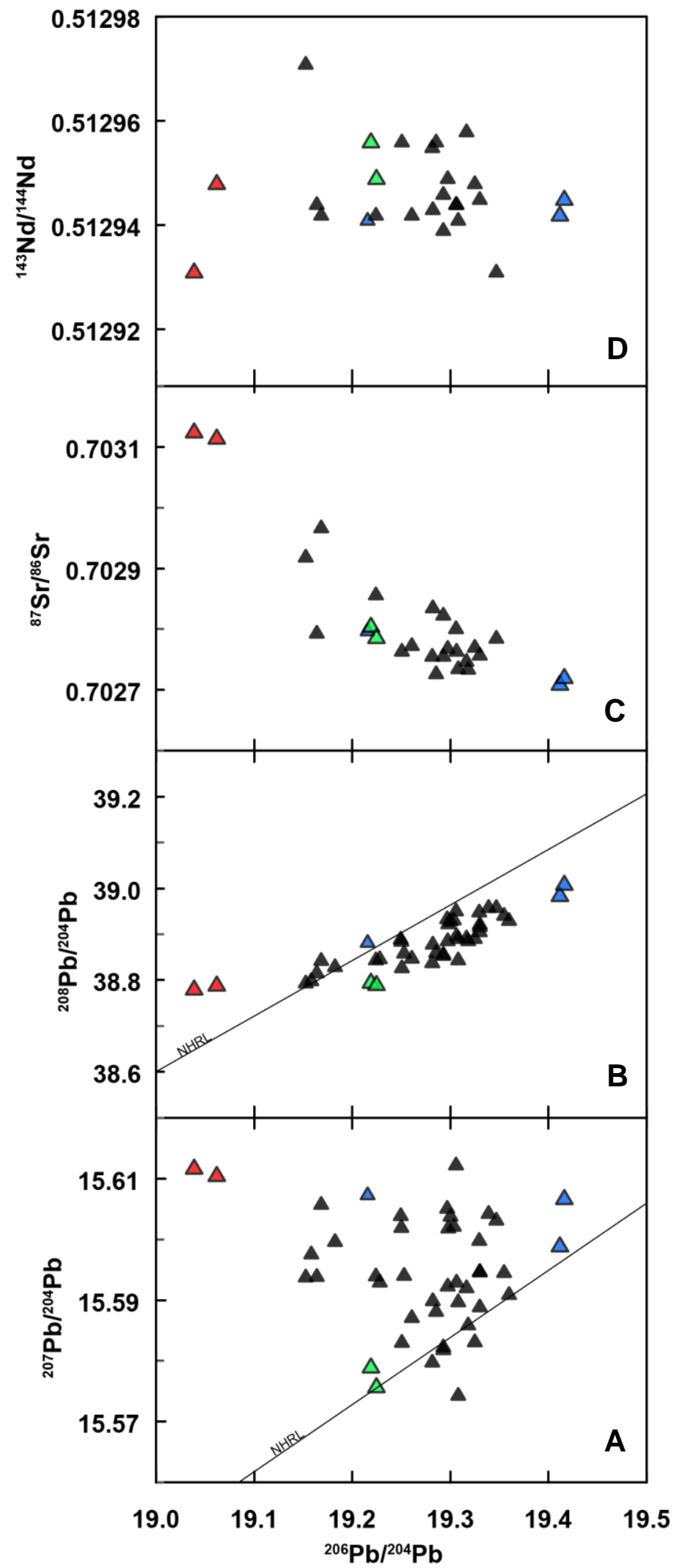

Figure 1.6. Isotope data from McGee et al., 2013, showing an overview of the field's characteristics. This data set includes samples from 10 centres. Highlighted in red are Rangitoto samples, blue Purchas Hill samples and, green Wiri Mt, proposed as the end members. Northern Hemisphere Reference Line (NHRL) is calculated after Hart (1984). 


\subsection{Tephrochronology}

Tephrochronology is a method of correlating and dating volcanic activity, and other geological events, using tephra deposits. It has been widely used both in New Zealand and around the world to study volcanic eruptions, and is a major source of data for eruption frequency, timing and geochemistry of volcanic events (Shane, 2000; Lowe, 2011). The term 'tephra' itself comes from the Greek word tephra meaning 'ashes'. It encompasses all unconsolidated explosively erupted pyroclastic material irrespective of size, shape, or composition, and includes ash (particles $<2 \mathrm{~mm}$ in diameter), lapilli $(2-64 \mathrm{~mm})$ and volcanic blocks and bombs (>64mm) (Lowe, 2011).

Where individual tephra deposits can be accurately correlated across an area, they can be used as isochronous marker horizons, allowing detailed and accurate stratigraphic frameworks to be constructed. The correlation and thus construction of a stratigraphic framework of deposits relies on the similarity of their lithologies, stratigraphic positions, and geochemistries (e.g., Shane, 2000; Alloway et al., 2004; Lowe et al., 2008; Lowe, 2011). The difficulties with correlations are two fold, they rely on the ability to link deposits by 1) dating the tephra using radiometric methods and/or 2) correlate tephra beds for example using lithology, geochemistry and/or petrology. In recent years, increasing emphasis has been placed on the latter of these two factors because the geochemical and petrological characteristics are likely to be more individual for a particular eruption, and thus more easily unambiguously correlated between individual deposits. In addition appropriate material for dating is often not present or difficult to find, for example a high enough quantity of specific minerals required for ${ }^{40} \mathrm{Ar} /{ }^{39} \mathrm{Ar}$ analysis, or organic material for ${ }^{14} \mathrm{C}$ analysis (Shane, 2000).

In the last decade, increasing improvements in single shard analysis techniques (e.g., Pearce et al., 2004; 2007; 2008) is allowing accurate measurements of both major and trace element concentrations of very small shards $(<30 \mu \mathrm{m})$. This allows tephra horizons to have their geochemical compositions individually fingerprinted to produce more reliable and robust tephrostratigraphic frameworks. The ability to cross correlate tephra deposits to create isochronous horizons not only allows constraints on the stratigraphic 
ordering of eruptions, but can also give details about tephra dispersal and deposit thicknesses, both of which are essential pieces of information for hazard and risk management planning.

\subsubsection{Tephrostratigraphy in the AVF}

In contrast to the extensive studies of rhyolitic (Allan et al., 2008; Lowe, 2011; Lowe et al., 2013; Vandergoes et al., 2013; and many previous studies summarised therein) and andesitic (Alloway et al., 1995; Shane, 2000; Shane, 2005; Turner et al., 2009) deposits of New Zealand, the proximal AVF basaltic deposits have received less attention (e.g., Molloy et al., 2009). This is due primarily to the scarcity of exposed tephra beds, coupled with the urbanisation of the region.

Shane and Smith (2000) studied a small number of proximal tephra compositions in relation to specific centres in the AVF as a potential tool for fingerprinting the centres. Previously this method has successfully been used to correlate distal tephra deposits with their source volcanoes in both New Zealand and worldwide (e.g., Westgate and Gorton, 1981; Shane, 2000; Lowe, 2011). However, Shane and Smith (2000) suggest limitations to the usability of subaerial AVF tephra deposits due to the rapid weathering of basaltic glass. They also note the limited presence of distal basaltic tephra due to poor preservation and low dispersal of small-scale eruptive events. It is for this reason that tephra from the AVF has mostly been studied from within sediment cores.

Most recently Molloy et al. (2009) studied andesitic, rhyolitic and basaltic tephra within the maar lake cores from Orakei, Pupuke, Onepoto and Hopua (highlighted on Fig 1.2.). Using visual observations they identified 24 basaltic tephra horizons that ranged from a few $\mathrm{mm}$ up $50 \mathrm{~cm}$ in thickness, and are composed of dark grey to black ash, lapilli and accidental ejecta. The individual horizons had sharp upper and basal contacts and exhibited normal and reverse graded beds. Two petrographic types were identified: one predominantly composed of glass shards (vesicular scoria-fluidal teardrops) and a small proportion of minerals (olivine plus plagioclase and clinopyroxene), the other consist of $30-60 \%$ accidental ejecta (quartz, glauconite, shell fragments and sedimentary lithics), the same mineral assemblage as for the first type and 
subordinate juvenile glass shards. The former was thought to have originated from magmatic or effusive activity whereas the latter was attributed to phreatomagmatic activity. As many of the deposits were not thick enough to have any internal structures related to them, the designation between fall and pyroclastic density current deposits was not defined. The distance over which some of the deposits occurred and the thicknesses observed for some deposits suggests the occurrence of prolonged eruption sequences and variable wind directions.

\subsubsection{Previous correlations of the AVF tephra horizons}

Correlation of the AVF tephra has been attempted both across cores, and in a few cases to the individual proximal source deposits. Most recently Green et al. (2014) used a statistical approach based on stochastic local optimization technique. This method input stratigraphic, mineralogical and geochemical data (obtained from previous studies on 5 cores (Onepoto (Shane and Hoverd, 2002), Pukaki (Sandiford et al., 2001), Orakei, Hopua, and Pupuke (Molloy et al., 2009)), in order to correlate and date the tephra deposits. The main basis of the basaltic tephra correlations was 'age dated tephra' which came from estimates on rhyolitic and andesitic deposits constrained by depositional rates, ${ }^{14} \mathrm{C}$ dates, and tephrochronology. The outcome assigned ages to basaltic horizons within the cores and then, using the ages it assigned, correlated across the cores the most closely matched ages. Potential correlations were then further constrained using major element glass chemistry (from Sandiford et al., 2001; Shane and Hoverd, 2002; and Molloy et al., 2009). The ages applied to the tephra horizons were then used to link the deposits to dated source centres (ages modelled by Bebbington and Cronin, 2011). Although, the errors associated with the age estimates for the sources mean that, especially with eruptions in the 35-24 ka range, a number of centres could be associated with each deposit. At the time of Green et al. (2014), the individual centres were not well dated (Bebbington and Cronin, 2011) and thus the justifications to pick which centres fitted within the correct age range were poorly constrained.

Attempts to correlate tephra to source have to date relied only upon poorly constrained ages of both the centres and the tephra horizons. Bebbington and Cronin (2011) noted the difficulty in correlation based on geochemistry due to the low variability in magma compositions in the AVF (Smith et al., 2008), and the 
limited appropriate proximal data set (Sandiford et al., 2001). This is true when based purely on major element chemistry, however, to date no study has looked into the potential of using trace elements as a geochemical fingerprinting tool for the AVF tephras. If the recent study of bulk rock trace element chemistry (McGee et al., 2013) is taken into account, it would seem that the potential variation in geochemistry could be broad enough across the field, but narrow enough for individual centres, to help better distinguish and correlate horizons across cores and to their specific centres of origin. Highlighted within past studies on the AVF tephra horizons (Shane and Smith, 2000; Sandiford et al., 2001; Smith et al., 2008; Smith et al., 2009; Molloy et al., 2009; Bebbington and Cronin, 2011) are some specific problems that will need to be addressed when correlating tephra. These are outlined in table $\mathbf{1 . 2}$ coupled with the ways in which this study aims to overcome these limitations.

Table 1.2. Limitations outlined from previous tephra studies within the AVF and how this study aims to overcome these limitations.

\begin{tabular}{|c|c|}
\hline $\begin{array}{l}\text { Potential limitations as } \\
\text { highlighted by previous studies: }\end{array}$ & How this study aims to overcome these limitations: \\
\hline $\begin{array}{l}\text { Geochemical variability within single } \\
\text { eruptions }\end{array}$ & $\begin{array}{l}\text { Limited by using incompatible trace element ratios and interpretation of multiple } \\
\text { analyses }\end{array}$ \\
\hline $\begin{array}{l}\text { Limited geochemical variability } \\
\text { across the field }\end{array}$ & Increased by using incompatible trace element ratios \\
\hline $\begin{array}{l}\text { Microcrystalline nature of glass } \\
\text { shards }\end{array}$ & $\begin{array}{l}\text { Careful analysis of shards and placement of probe/laser beam, geochemical } \\
\text { spikes from microcrysts are clearly visible in results and these analyses are } \\
\text { discarded. }\end{array}$ \\
\hline Limited dispersal of tephra & Coverage of multiple cores in a range of localities across the field \\
\hline $\begin{array}{l}\text { Deposition highly dependent on } \\
\text { wind direction which is variable }\end{array}$ & Taken into account where possible based on morphostratigraphy \\
\hline Preservation potential of tephra & Coverage of multiple cores in a range of localities across the field \\
\hline Contamination by accidental ejecta & $\begin{array}{l}\text { Analysis of distal deposits aims to limit their inclusion coupled with careful shard } \\
\text { selection process }\end{array}$ \\
\hline Limited proximal geochemical data & Increased by this study \\
\hline Limited reliable age data & Increased by Leonard et al. (in prep. Appendix D) \\
\hline
\end{tabular}




\subsubsection{Geochemistry of the AVF tephra}

Basaltic glass shards from the AVF often contain abundant microcrystalline phases (unlike rhyolitic glass that is predominantly microcryst free) including plagioclase, pyroxene, olivine, and a small proportion of Fe-Ti oxides. Microcrysts in the AVF tephra result from rapid elemental diffusion in high temperature, low viscosity, basaltic melts (Shane and Zawalna-Geer, 2011), allowing the rapid growth of small crystals during conduit ascent (Smith et al., 2008). Similar to fractional crystallisation in magma chambers, growth of microcrysts can affect the residual melt composition and thus could result in a large compositional spectrum in glasses quenched from a geochemically homogeneous magma. However, Shane and Zawalna-Geer (2011) showed from EDS microprobe analyses that, in the case of the Mt. Wellington centre, the major element variations were not significant $\left( \pm 1 \% \mathrm{SiO}_{2}\right)$ between different tephra samples from the same centre, and that with careful positioning of probe beam for analysis there is little detectable difference in the resulting chemistry between microcryst rich and poor glass shards (Shane and Smith 2000).

As previously discussed (sect. 1.4.3.4), a limited number of studies have analysed proximal (Shane and Smith, 2000) and distal (maar deposits, e.g., Sandiford et al., 2001; Hoverd et al., 2005) tephra-derived glass chemistry from the AVF. All studies measured major elements using in-situ EMPA methods (e.g., Molloy et al., 2009) with only Needham et al. (2011) also measuring a limited selection of trace elements on tephra-derived glass. All these studies show comparable results between AVF tephra deposits. Major element compositions range for $\mathrm{SiO}_{2} 42-53 \mathrm{wt} . \%, \mathrm{Al}_{2} \mathrm{O}_{3}$ 12-17 wt.\%, $\mathrm{FeO} 8-14$ wt.\%, $\mathrm{CaO} 8-12$ wt.\% and $\mathrm{Na}_{2} \mathrm{O}$ 4-7 wt.\% and $\mathrm{K}_{2} \mathrm{O}$ 1.5-3 wt.\%. The general relationship between elements shows increasing $\mathrm{Al}_{2} \mathrm{O}_{3}$ and $\mathrm{FeO}$ with $\mathrm{SiO}_{2}$ and decreasing $\mathrm{CaO}, \mathrm{Na}_{2} \mathrm{O}, \mathrm{K}_{2} \mathrm{O}$, and $\mathrm{P}_{2} \mathrm{O}_{5}$. MnO showed no consistent trend and, in some cases $\mathrm{MgO}$ show no trend (Shane and Smith, 2000) but in others it showed positive (Németh et al., 2012) or negative (Shane and Zawalna-Geer, 2011) trends with $\mathrm{SiO}_{2}$. For studies that analysed multiple deposits, often evidence for two geochemical populations was found (initially by Hoverd et al., 2005), for example: 
1) A low $\mathrm{SiO}_{2}$ group ( $<45$ wt.\%) with high $\mathrm{CaO}$ and $\mathrm{K}_{2} \mathrm{O}$, and

2) $\mathrm{A}$ high $\mathrm{SiO}_{2}$ group (>45 wt.\%) with lower $\mathrm{CaO}$ and $\mathrm{K}_{2} \mathrm{O}$.

The geochemical data presented by Needham et al. (2011) for Rangitoto show this bimodal geochemical grouping, however in all other studies this bimodality was identified over the whole data set of multiple centres (Hoverd et al., 2005, Shane et al., 2013), not just within a single centre's deposit.

Initial studies by Shane and Smith (2000) on proximal deposits suggested that tephra horizons are commonly geochemically homogeneous, demonstrated by little geochemical variation between individual tephra-derived glass shards (e.g., $\mathrm{SiO}_{2} \pm 0.5$ wt.\%). However, more recent studies (Shane and Hoverd, 2002; Shane, 2005; Hoverd et al., 2005; Molloy et al., 2009) have shown for more distal deposits (maar cores) the inter-shard major element composition in a single horizon can vary substantially (e.g., up to $\mathrm{SiO}_{2} \pm 5$ wt.\%) (6 wt.\% in Hoverd et al., 2005, but this was attributed to shard reworking). This variability has been interpreted to represent heterogeneity of magma composition and a rapid ascent rate resulting in little time for homogenisation (e.g., Molloy et al., 2009). Németh et al. (2012) further suggest that the variability in tephra geochemical composition seen within certain deposits could be related to some of the larger more complex eruptions, for example, Orakei (a small magma batch) showed minimal geochemical variation in all deposit types (lapilli/scoria/tephra). In comparison, Mt Eden (a volumetrically large centre) shows a very broad range in geochemical composition.

To date, very little is known about the trace element chemistry of the AVF tephra. Needham et al. (2011) published trace element contents from 4 Rangitoto tephras, which are the only tephra trace element data available from AVF. Their results showed the whole rock samples and tephra-derived glass samples had comparable trace element contents and ratios. The indication from the whole rock analysis, coupled with these results from Needham et al. (2011), show that there is a much wider range in variability of the trace elements concentrations (especially incompatible elements; McGee et al., 2013) in comparison to the major element concentrations for the AVF volcanic deposits. 


\subsection{Aims and Approach}

Literature reviews have highlighted the need to gain more detailed information about the potential hazard and risk posed to the city of Auckland by a future eruption from the monogenetic Auckland volcanic field. Reconstructing the chronology and magmatic evolution of the field as a whole is essential in order to forecast the characteristics of a future eruption. Specific gaps are found relating to the temporal eruption sequence, leading to an inability to resolve the spatial or geochemical evolution of the field. Recent methodological and technological advances in tephrochronology, including the accurate identification of basaltic tephra horizons within sediment cores, and geochemical fingerprinting of individual glass shards, have proven to be a very effective method for building reliable tephrostratigraphic framework for a region. If the cross-correlated horizons within this framework can be linked back to their individual source centre, we can build a more definitively sequenced eruption history of the AVF centres.

This project therefore has four key aims expressed as the following research questions:

1. Can a more detailed basaltic tephrostratigraphy for the Auckland Volcanic Field be produced from the maar deposits using newly improving tephraderived glass shard analysis methods? (Chapter $\mathbf{3}$ )

2. Can individual tephra horizons be linked to their source centre? (Chapters

\section{3,4 and 5 )}

3. What was the spatial, temporal, and geochemical evolution of Auckland Volcanic Field? (Chapter 5)

4. What can the eruptive products of the Auckland Volcanic Field tell us about the pre-eruptive processes which act on the magma? (Chapter 6) 


\subsection{Thesis Structure}

Chapter 1 details background information, and a summary of previous work, surrounding the research topic.

Chapter 2 outlines all the methods used in this study from insitu tephra-derived glass shard analysis for major and trace element compositions using electron microprobe analysis (EMPA) and laser ablation inductively coupled mass spectrometry (LA-ICP-MS), to whole rock analysis using X-ray fluorescence (XRF) for major element compositions and solution-ICP-MS for trace element compositions. It also outlines $\mathrm{Pb}$ column chemistry, and Re-Os extraction and measurement methods for isotope analysis. The final section of Chapter 2 reviews the analytical accuracy, precision, and consistency of the analyses run throughout this PhD project.

Chapter 3 gives details about the improved analytical procedures for core analysis and basaltic horizon detection. It also outlines the procedure for analysing tephraderived glass shards for major and trace elements, and the method by which the tephra-derived glass shards are geochemically fingerprinted and correlated across the cores. This cross correlation builds up a detailed tephrostratigraphic framework for the Auckland Volcanic Field eruptive history, and was a prerequisite for the accurate correlation of tephra deposits to their source centres.

Chapter 4 outlines the collation of pre-existing geochemical whole rock data from a number of sources including published and unpublished work, and MSc and PhD theses. It details new whole rock data collected and analysed by this thesis which are combined with the pre-existing data in order to produce the most holistic database for AVF whole rock geochemistry.

Chapter 5 uses the tephra horizon correlations and the tephra-derived glass shard geochemistry determined in Chapter 3 , coupled with pre-existing and additional complimentary geochemical data for whole rock analysis (collated in Chapter 4) to develop and detail the method to correlate the tephra horizons to their source centres, thereby creating a stratigraphically well-constrained chronology for the eruptions of the AVF. The results not only allow conclusions to be made in relation 
to tephra dispersal and deposition, but also provide the temporal, spatial, and geochemical evolution of the field.

Chapter 6 builds on conclusions made and highlighted by the previous chapters, which suggest that pre-eruptive processes and the geochemical evolution at the AVF remain poorly understood. This chapter aims to assess the interplay between crustal and mantle processes which produce the geochemical variability seen in the AVF.

Chapter 7 outlines and discusses the synthesis and conclusions as a result of the analyses undertaken by this research. It details how these address the aims outlined in the introduction, and the original contributions made by this work. Finally a number of potential future research avenues are discussed, highlighted by the findings of this research. 


\section{Chapter 2}

\section{Methodology}

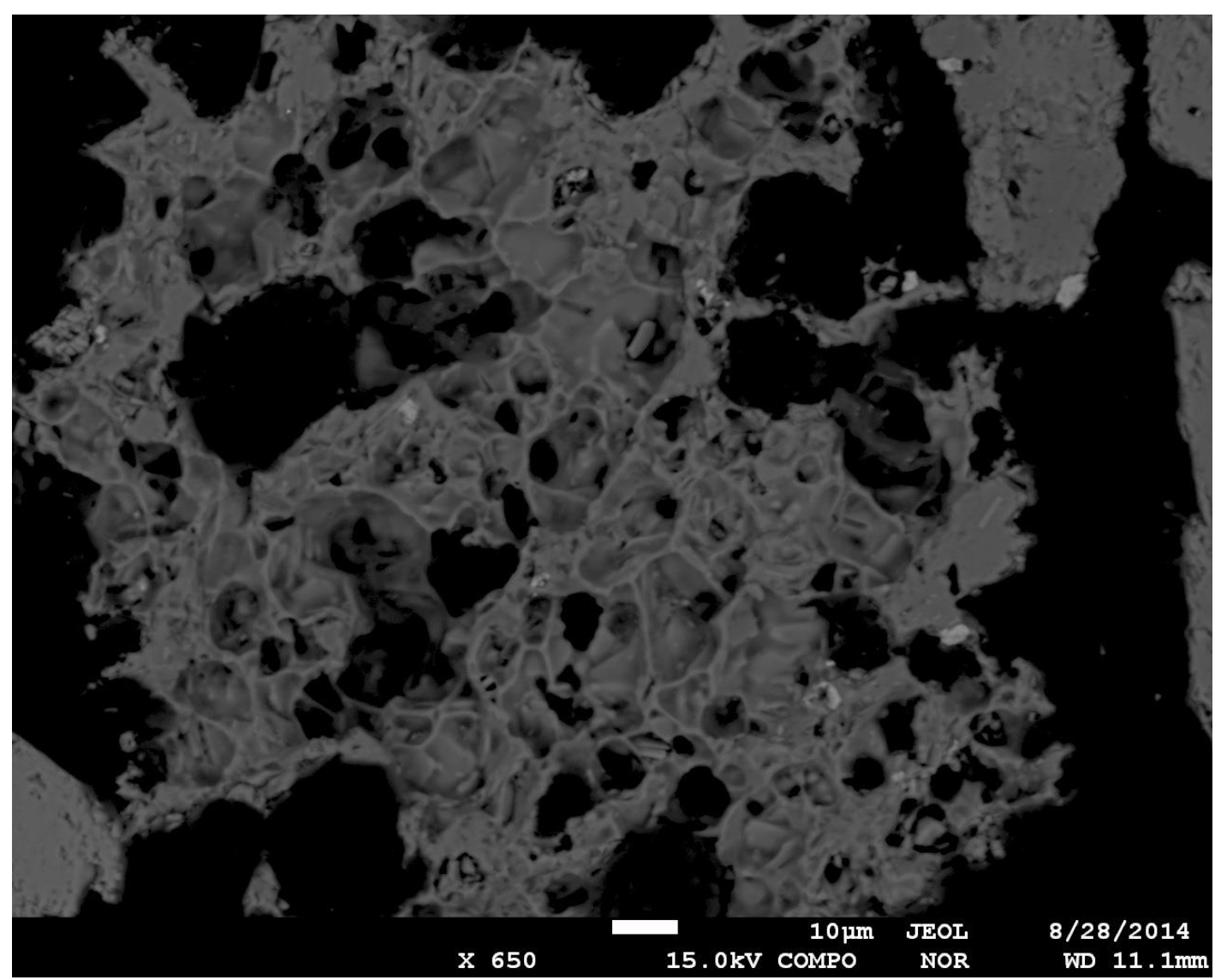

Glass shard from Glover Park core ca. 60 ka. yrs old, perfectly and intricately preserved (image by Hopkins, J.L.). 


\subsection{Introduction}

This chapter is separated into four parts (A-D). Section A details the sample selection, and method developed to analyse basaltic glass shards from within cores. Section B details the collection and analysis of whole rock samples for both major and trace elements. Section $\mathrm{C}$ details the analysis of rhenium, osmium and lead concentrations and isotopes from bulk rock data from a selection of centres in the $A V F$, and Section D presents and reviews the quality of the data obtained for this thesis. It also discusses specifically the ability to compare results measured by multiple types of machine at multiple institutes.

The data presented in this thesis were generated using various instruments in different laboratories:

- For the tephra, X-ray, core sampling and magnetic susceptibility on the Onepoto and Orakei cores was undertaken at the National Institute of Water and Atmospheric Science (NIWA), Wellington. Sampling of the Glover Park core was undertaken at GNS Science, Wellington. Tephra-derived glass sample preparation, mounting, polishing, and insitu major element analysis by electron microprobe (EMPA) were all undertaken at Victoria University (VUW). Trace element analysis by laser ablation (LA)-ICP-MS was undertaken partly at VUW and partly at the University of Otago (UoO), Dunedin. Cores were available for Orakei Basin (OB), Onepoto (On) and Glover Park (GP) and these were therefore analysed and sampled; for Hopua and Pupuke, cores were not available, but mounts made by Molloy (2008) were available, therefore these were analysed by EMPA and LA-ICP-MS; and for Pukaki core neither samples, nor core was available therefore data (major element only) was taken from Sandiford et al. (2001), and supplied by P. Shane pers. comm, (2014).

- For the whole rock analyses sample preparation, crushing and powdering was undertaken at VUW. 17 new centres were sampled (Boggust Park, Little Rangitoto, Mt Albert, Mt Cambria, Mt Hobson, Mt Roskill, Mt Smart, Onepoto, Otuataua, Pigeon Mt, Pukaki, Pukeiti, Pupuke, Robertson Hill, St Heliers, Taylors Hill and Te Pou Hawaiki) and analysed for both major and trace 
elements. For 7 centres (Green Mt, Hampton Park, Mangere Mt, McLaughlins Mt, Mclennan Hillls, Mt Victoria and Otara) samples had already been taken and major element concentrations reported in Miller (1996). The whole rock samples were re-crushed and analysed for both major and trace elements. Major elements were analysed by (XRF) at the Open University (OU), England, and trace elements were analysed by solution-ICP-MS at VUW. This study adds 99 individual whole rock major and trace element analyses to the existing AVF database.

- For the isotope work, the most primitive samples from Mt Wellington, Purchas Hill, Three Kings, Wiri Mt, Puketutu, Pupuke and Rangitoto were chosen for analysis. These centres were specifically chosen because they have previously published $\mathrm{Sr}-\mathrm{Nd}-\mathrm{Pb}$ isotope data available (McGee et al., 2013). Sample preparation, crushing, powdering, and trace element analysis by solution ICP-MS was undertaken at VUW and major element analysis was undertaken at the OU by XRF analysis. Re and Os chemistry and analysis of Os and Re concentrations and Os isotopes took place at the University of Quebec in Montreal (UQAM) in their geochemical and radiogenic isotope laboratory (GEOTOP). The $\mathrm{Pb}$ isotope analysis by multi-collector (MC)-ICPMS was undertaken at Durham University, UK (DU). 


\section{Section A - Tephra sampling and analysis}

\subsection{Auckland Volcanic Field Drill Cores}

The maar craters formed by wet style phreatomagmatic eruptions provide excellent depocentres for a well-preserved sediment record. In the AVF, maar craters have long been exploited for their tephra (rhyolitic, andesitic, and basaltic) deposits (e.g., Molloy et al., 2009). A collaborative group from GNS Science and the University of Auckland has created a collection of drill cores over the last 10 years. To date, there are 10 cores, 6 of which are suitable for analysis. These 6 cores include varying lengths from Hopua, Orakei Basin, Pupuke, Glover Park (St Heliers volcano), Pukaki, and Onepoto centres (highlighted in Fig.1.2.). The most recent core is from Onepoto, drilled in May 2011. The most extensive tephra record spanning depths of $16-80 \mathrm{~m}$ with a predicted age range of 7-83 $\mathrm{ka}$ is preserved in the Orakei Basin core (Molloy et al., 2009). Details of the cores are outlined in Table 2.1. Collectively the cores preserve an extensive tephra record; however, the degree of preservation is patchy and prior to this research correlation of basaltic tephra horizons across all cores remained speculative.

As outlined in Table 2.1 major element compositions of basaltic tephraderived glass from within the AVF were published in some previous studies: Orakei, Pupuke, Onepoto (old core), and Hopua - Molloy et al. (2009); Pukaki Core Sandiford et al. (2001); Onepoto (old core) - Shane and Hoverd (2002); Panmure, Hopua, Pukaki - Shane and Zawalna-Geer (2011). Andesitic to rhyolitic tephra from sources outside the AVF have also been analysed, including from the Taupo Volcanic Centre (TVC), Tongariro Volcanic Centre (TgVC), Okataina Volcanic Centre (OVC), Mount Tarankai (Tk) and Mayor Island (MI). These data have been used to infer a broad picture of the temporal evolution of $\mathrm{AVF}$ and central North Island volcanism. Molloy et al. (2009) correlated some AVF horizons between cores (outlined in Section 1.5.) using major element compositions and stratigraphic positions. However, no studies have looked into the trace element geochemistry. As a result, correlations of the tephra to their respective centres in the AVF remained less well constrained. 
Table 2.1. Overview of maar cores used in previous studies and this study, their location, the depth section of interest and the number of identified basaltic horizons, , the geochemical analyses obtained on the tephra and the references for the analyses. Note that all trace element data were analysed in this thesis, although for the Pupuke core, trace element data could not be obtained as samples were not available for re-analysis by this study. Ages are outlined as in previous studies where 'ca. 45.1' relates to the age of the Rotoehu tephra (see Sect. 3.3.2 for discussion), and the centre name indicates that the core reached the base of the maar, however the centre's age is poorly defined.

\begin{tabular}{|c|c|c|c|c|c|c|c|c|c|}
\hline \multirow[b]{2}{*}{$\begin{array}{l}\text { Core (centre) } \\
\text { Name }\end{array}$} & \multirow[b]{2}{*}{ Grid Reference } & \multirow[b]{2}{*}{$\begin{array}{c}\text { Section of } \\
\text { interest }(\mathrm{m})\end{array}$} & \multicolumn{4}{|c|}{ Previous Studies } & \multicolumn{3}{|c|}{ This Study } \\
\hline & & & $\begin{array}{c}\text { Proposed age } \\
\text { range (ka) prior } \\
\text { to this study } \\
\end{array}$ & $\begin{array}{r}\text { No. of } \\
\text { basaltic } \\
\text { horizons }\end{array}$ & $\begin{array}{l}\text { Geochemical } \\
\text { data }\end{array}$ & References & $\begin{array}{c}\begin{array}{c}\text { No. of } \\
\text { basaltic } \\
\text { horizons }\end{array} \\
\end{array}$ & $\begin{array}{l}\text { Status of core and } \\
\text { samples }\end{array}$ & $\begin{array}{l}\text { Geochemical data } \\
\text { obtained }\end{array}$ \\
\hline Pupuke & $\begin{array}{l}36^{\circ} 46^{\prime} 49.83^{\prime \prime S} \\
174^{\circ} 45^{\prime} 57.67^{\prime \prime E}\end{array}$ & 57 to 70 & 0.4 to 38 & 7 & Major & Molloy et al., (2009) & 7 & Mounts re-analysed & Major and trace \\
\hline Onepoto & $\begin{array}{l}36^{\circ} 48^{\prime} 27.09^{\prime \prime S} \\
174^{\circ} 45^{\prime} 0.39^{\prime \prime E}\end{array}$ & 38 to 69 & 25 to Onepoto & 6 & Major & Shane and Hoverd, (2002) & 9 & Core sampled & Major and trace \\
\hline $\begin{array}{l}\text { Glover Park } \\
\text { (St. Heliers) }\end{array}$ & $\begin{array}{l}36^{\circ} 50^{\prime} 49.68^{\prime \prime S} \\
174^{\circ} 52^{2} 2.60^{\prime \prime} \mathrm{E}\end{array}$ & 4 to 27 & $\begin{array}{l}\text { ca. } 45.1 \text { to St } \\
\text { Heliers }\end{array}$ & 13 & Major & Hoverd et al., (2005) & 4 & Core Sampled & Major and trace \\
\hline Orakei & $\begin{array}{l}36^{\circ} 52^{\prime} 4.14^{\prime \prime} \mathrm{S} \\
174^{\circ} 48^{\prime} 46.11^{\prime \prime E}\end{array}$ & 44 to 87 & 24 to 86 & 14 & Major & Molloy et al., (2009) & 16 & Core sampled & Major and trace \\
\hline Hopua & $\begin{array}{l}36^{\circ} 55^{\prime} 46.68^{\prime \prime S} \\
174^{\circ} 47^{\prime} 3.82^{\prime \prime E}\end{array}$ & 38 to 49 & 7 to Hopua & 5 & Major & Molloy et al., (2009) & 5 & Mounts re-analysed & Major and trace \\
\hline Pukaki & $\begin{array}{l}36^{\circ} 58^{\prime} 57.63^{\prime \prime S} \\
174^{\circ} 48^{\prime} 37.74^{\prime \prime E}\end{array}$ & 45 to 62 & 7 to ca. 45.1 & 12 & Major & $\begin{array}{l}\text { to } 52 \mathrm{~m} \text { Sandiford et al., (2001), } \\
52 \mathrm{~m} \text { to base Shane, (2005) }\end{array}$ & 12 & Core nor mounts avail & able for analysis \\
\hline
\end{tabular}

\subsubsection{Orakei Basin}

The Orakei Basin (or Rakeiora) is a $0.8 \mathrm{~km}$ diameter maar crater in the central north-eastern section of the AVF. Ejected ash built the tuff ring that surrounds three sides of the crater, with the north-eastern side composed mostly of unconsolidated ash. On filling with fresh water from rainfall the crater became a freshwater lake for $\sim 75,000$ years and more recently rising sea level following the Last Glacial Maximum (LGM) transformed it into a tidal basin. It now contains intertidal brackish salt flats whose nutrient intake is controlled by floodgates beneath the railway line, which borders the north-eastern bank. The oldest lake sediment recovered with the Orakei Basin core was calculated to be $85 \mathrm{ka}$ (81 m depth) (Molloy et al., 2009) based on tephrochronology and sedimentation rates. 


\subsubsection{Onepoto Basin}

Onepoto Basin (or Te Kopua o Matakerepo) is a $0.7 \mathrm{~km}$ diameter maar crater surrounded by a tuff ring formed from basaltic surge and fall deposits. This maar is located on the north-north western most part of the field. Similarly to the Orakei basin, Onepoto existed as a freshwater lake until 9000 years ago when the southeastern rim of the crater was breached as a result of sea level rise (Shane and Hoverd, 2002). The Onepoto core is ca. $69 \mathrm{~m}$ long, and the base of the core is characterised as a thick deposit of basaltic tephra and lapilli, which is considered to represent the crater floor (Shane and Sandiford, 2003).

\subsubsection{Hopua}

Te Hopua a Rangi (or Hopua, or Gloucester Park) is one of the smaller volcanic maars in the AVF at just $0.5 \mathrm{~km}$ in diameter. It is located in the centre of the AVF, but no longer has any outcrop. The eruption that formed the Hopua maar expelled a mixture of poorly sorted fine ash to lava bombs (Allen and Smith, 1994), and shows morphostratigraphic evidence of erupting through the lava of One Tree Hill (Searle, 1961b), showing it must be younger than One Tree Hill. The Hopua tuff ring was high sided to the north and low sided to the south, possibly as a consequence of the prevailing wind direction. After the LGM when sea levels rose the crater rim was breached and a tidal basin was created. The extracted Hopua core is $49 \mathrm{~m}$ long, of which the top $37.5 \mathrm{~m}$ were composed of estuarine sediments. The lower $11.5 \mathrm{~m}$ show lacustrine varves punctuated with tephra deposits of rhyolitic, andesitic, and basaltic composition. The core ended in a thick scoria unit proposed to represent the crater floor of the maar (G. Leonard pers. comm. 2015)

\subsubsection{Lake Pupuke}

Pupuke Moana (the 'over flowing lake') is one of the oldest volcanoes of the AVF, thought to have erupted around a similar time to Tank Farm and Onepoto (Lindsay et al., 2011). New Ar-Ar dating has yielded an age for Pupuke of ca. $190 \mathrm{ka}$ (Leonard et al., in prep. Appendix D), potentially younger than that proposed for Onepoto. The eruptions from Pupuke are thought to have occurred twice from two different vent sources, with eruptive products of slightly differing compositions 
(Spargo, 2007). The initial eruptions did not interact with ground water and were therefore 'dry', with lava flows from two different vents building up a low, thin shield. These initial eruptions were followed by large explosive wet eruptions from two vents forming the maar lakes that are seen today (Spargo, 2007). The tuff ring resulting from these eruptions created a natural barrier and the lake has remained fresh water since it was originally filled (Hayward et al., 2011). The core extracted from Lake Pupuke was $16.5 \mathrm{~m}$ long extending back to roughly $38 \mathrm{ka}$, and includes tephra from the eruptions of Rangitoto (Molloy et al., 2009).

\subsubsection{Pukaki Lagoon}

Pukaki lagoon is located in the south of the AVF and is considered one of the best-preserved explosion craters in the AVF. The crater was formed by multiple pulsating wet eruptions resulting from rising magma interacting with ground water (Sandiford et al., 2001). The current crater is $0.5 \mathrm{~km}$ across and $100 \mathrm{~m}$ deep with a 20-40 m high tuff ring that extends out, in places, a further $0.5 \mathrm{~km}$ (Hayward et al., 2011). The age of the crater is poorly defined with estimates based on sedimentation rates suggesting a minimum age of $52 \mathrm{ka}$ (Molloy et al., 2009). Multiple cores have been extracted from this centre, and can be used to show the complexity of deposition for this environment. For example, Figure 2.1 shows the published observations from cores retrieved in 2001 (Sandiford et al., 2001), 2002 (Shane 2005 and Shane pers. comm. 2013) and 2008 (Zawalna-Geer, 2012), comparing the basaltic tephra horizons that were found by these authors. In this figure the complexity in identifying the basaltic horizons through visual observations alone is shown by the disparity in the correlations. For this thesis I have chosen to use the published details, (including the name (AVF\#), thickness, position, and geochemical data; Sandiford et al., 2001 and Shane 2005), rather than the most recent details from Zawalna-Geer (2012), which are not published and do not have geochemical data available. 


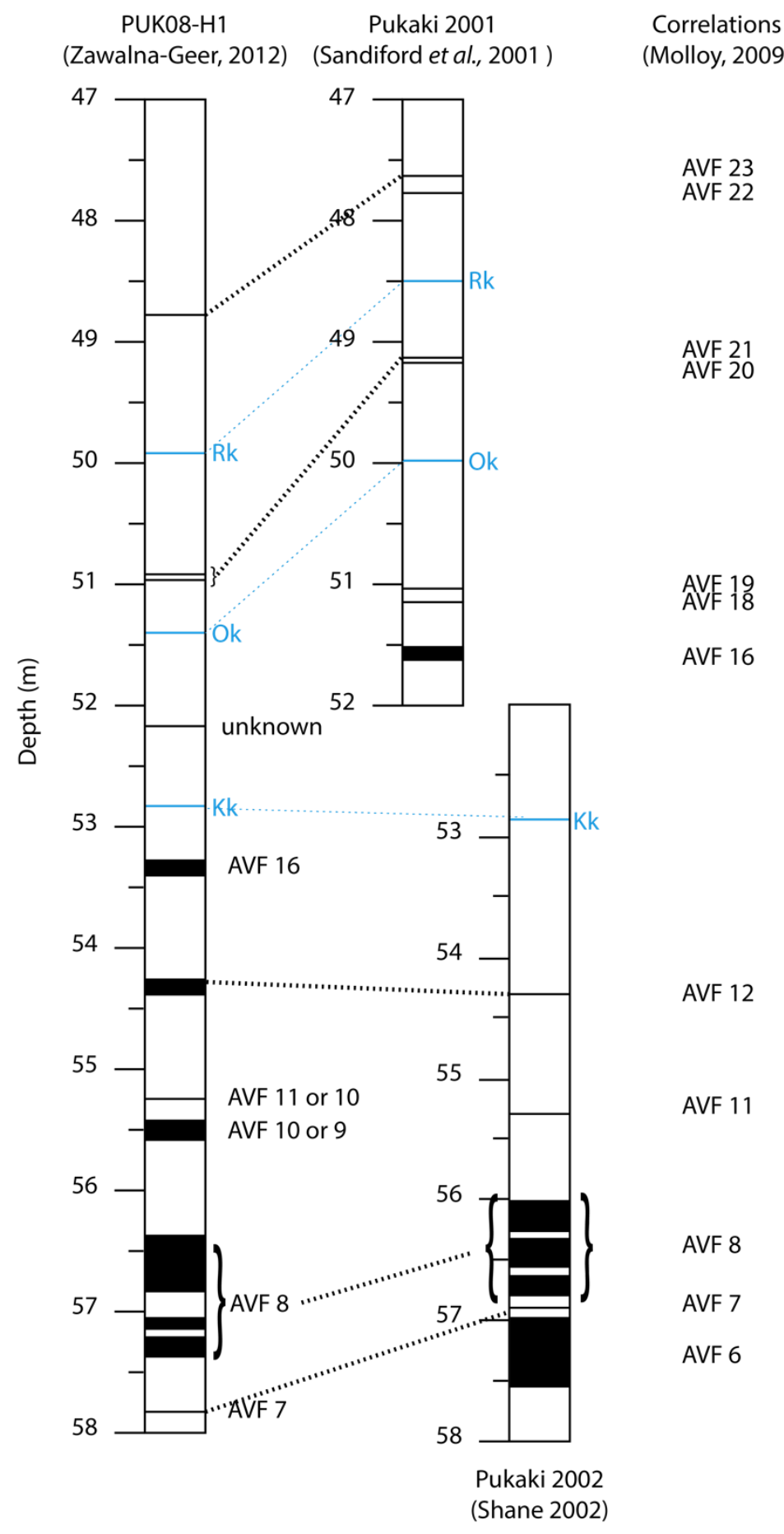

Figure 2.1. Schematic diagram to show correlation of Pukaki cores from 2001, 2002 and 2008. Sandiford et al. (2001) and Shane (2005) are used for this thesis as Zawalna-Geer (2012) remains unpublished and inconsistencies remain with the correlations proposed by Zawalna-Geer (back dashed lines). Also shown are the proposed AVF\# from Molloy et al. (2009) for the horizons in the 2001 and 2002 cores. Blue horizons are key rhyolitic deposits. Rk (Rerewhakaaitu), Ok (Okareka), Kk (Kawakawa). 


\subsubsection{Glover Park (St Heliers)}

St Heliers volcano is located beneath the modern day Glover Park. It was a classic phreatomagmatic eruptive centre forming a simple tuff ring structure. However, unlike most of the AVF maars, its base is $20 \mathrm{~m}$ above modern sea level and was therefore not breached by the post-LGM sea level rise. The crater was filled with fresh water that in geologically recent times had become in filled with sediment resulting in a swampy environment. Sixty years ago, the swamp was drained and turned into the Glover Park playing fields. In December 2004 two cores were drilled into the centre of Glover Park (GP1 and GP2), both of which terminated in hard vesicular basalt and consisted of ca. $2.7 \mathrm{~m}$ of backfilled topsoil, ca. $2.0 \mathrm{~m}$ of swamp deposits, ca. $11.4 \mathrm{~m}$ of fine grained massive, finely laminated freshwater sediments with interbedded tephra and finally below ca. $16.1 \mathrm{~m}$ intermittent coarse-grained horizons with distorted lacustrine sediments. This core is recorded in detail in Hoverd et al. (2005), with major element analyses on glass reported for 31 macroscopic tephra deposits including 8 rhyolitic horizons linked to Taupo Volcanic Zone (TVZ) and Mayor Island (MI), 10 trachytic-andesitic horizons linked to Mt. Taranaki (Tk) and Tongariro volcanic centre ( $\mathrm{TgVC}$ ), and 13 basaltic horizons linked to the AVF. These tephra horizons were re-sampled and re-analysed for this study.

\subsection{Core Analysis and Sampling}

All the cores used in this study were previously drilled, logged and analysed, but with the focus of research being palaeoclimate or silicic tephrochronology. In this study, Orakei was re-logged and sampled, and a new core from Onepoto was used from the same site as the old core. Samples from Hopua and Pupuke were reanalysed for trace elements using the same samples used by the Molloy et al. (2009), and Glover Park was totally resampled and analysed. Major element data from Pukaki used in this study are from published (Sandiford et al., 2001) and unpublished work (P. Shane, pers. comms, 2013).

Cores from Orakei Basin and Onepoto were scanned using an Ultra EPXF2800 portable veterinary radiological device (NIWA, Wellington, NZ). For the Onepoto core magnetic susceptibility analysis was undertaken using a BaringtonMS2 Magnetic susceptibility meter connected to a MS2F probe (data from UoA for 
the Orakei Core). Analysis was done every $2 \mathrm{~cm}$ down the centre of the core $(1 \mathrm{~cm}$ in regions of interest) and recorded in $10^{-5} \mathrm{SI}$ units with a sensitivity of $1.0 \times 10^{-5} \mathrm{SI}$. The X-ray images were compared to composite photographs of each section, and magnetic susceptibility data was combined to pin point the location of each tephra layer/layer. Sampling was undertaken in the core lab at NIWA and multiple samples were taken from tephra that were thick enough to permit sub-sampling of single horizons. Samples were also taken from Glover Park core, previously only major element analysis was undertaken (Hoverd et al. (2005), and the samples were no longer available for trace element analysis.

A small amount of deposit was removed from the core surface to expose a fresh surface from which to sample tephra. Sections of tephra from the centre of the core shaft were removed in order to reduce contamination potentially caused by core suck at the tubing edges. Three types of basaltic tephra deposit were identified from their morphostratigraphy including:

i) deposits which were a homogenous thickness and shape with distinct upper and lower boundaries,

ii) deposits which tended to be larger in thickness and have an obvious grading and sorting within them from large clasts at the base to finer clasts towards the top (multiple samples were taken from these to confirm all one event),

iii) and very obviously deformed deposits which had irregular, nonhorizontal boundaries, with some appearance of rafting events.

Approximately $2 / 3$ of the bulk horizon sample was retained for archive purposes and 1/3 was processed for analysis. Samples were individually washed with ultrapure Milli-Q water in an ultra sonic bath to remove organic debris. If the shards were $<30 \mu \mathrm{m}$, excess water was allowed to evaporate (oven overnight at $50^{\circ} \mathrm{C}$ ) and the sample was set aside. This is a bulk (B) sample, which includes both tephra shards and accidental ejecta (e.g. quartz, glauconite, shell fragments and sedimentary lithics). If the shards were larger than $30 \mu \mathrm{m}$, glass shards $(G)$ were removed and separated into a vial and juvenile crystals $(C)$ were also separated into a vial. Excess water was then evaporated from these to yield glass, crystal and bulk shard aliquots from each sample. 


\subsection{In-situ Major Element Analysis by EMPA}

\subsubsection{Sample preparation}

Deep epoxy mounts were created using a 4:1 ratio of resin to hardener. The mounts were cut into $7 \mathrm{~mm}$ depths using a bandsaw, and then 6 individual holes were drilled through the mounts at $3.5 \mathrm{~mm}$ diameters. The holes were then filled with sample, then epoxy, and left to set on the hot plate at $50-55^{\circ} \mathrm{C}$ overnight. The analysis face was polished using a sequence of silicon carbide papers starting with a coarseness of 400 , followed by 600,1000 and 2500, finally being finished using a diamond lap polisher at $3 \mu \mathrm{m}$ and $1 \mu \mathrm{m}$. This process exposed the sample faces and removed as much scratching from the surface as possible. Finally, a $25 \mathrm{~nm}$ carbon coat was applied to the mount prior to major element analysis.

\subsubsection{Measurements}

The major element or oxide proportions $\left(\mathrm{SiO}_{2}, \mathrm{TiO}_{2}, \mathrm{Al}_{2} \mathrm{O}_{3}, \mathrm{FeO}_{\mathrm{t}}, \mathrm{MnO}, \mathrm{MgO}\right.$, $\mathrm{CaO}, \mathrm{Na}_{2} \mathrm{O}, \mathrm{K}_{2} \mathrm{O}, \mathrm{Cl}, \mathrm{SO}_{3}$, and $\mathrm{P}_{2} \mathrm{O}_{5}$ ) were analysed using Wavelength Dispersive Spectrometry (WDS) on the JEOL JXA 8320 Superprobe at VUW. Table 2.2 shows the analytical conditions for EMPA. To produce the analyses, an accelerating voltage of $15 \mathrm{kV}$ under a static electron beam at $10 \mu \mathrm{m}$ and $8 \mathrm{nA}$ was used. 10-15 analyses were undertaken per sample on individual glass shards, with specific care taken not to hit any microcrysts or bubbles within the shards. $\mathrm{Na}_{2} \mathrm{O}$ and $\mathrm{K}_{2} \mathrm{O}$ were analysed first with shorter count times to reduce the loss of volatiles (Table 2.2.). Major element concentrations were determined using the ZAF correction method, and back-scattered electron images of each sample, and sample point, were taken to allow individual shard characterisation for later LA-ICP-MS analysis.

\subsubsection{Standards}

For quality control, the following standards were run along with our samples: 1) Basaltic Glass $\mathrm{A} 99$ (for $\mathrm{SiO}_{2}, \mathrm{TiO}_{2}, \mathrm{Al}_{2} \mathrm{O}_{3}, \mathrm{FeO}, \mathrm{MnO}, \mathrm{MgO}, \mathrm{CaO}$ ), 2) Rhyolitic Glass VG-568 (Na2O and $\mathrm{K}_{2} \mathrm{O}$ ), 3) Scapolite PSU63-1805 (for Cl), 4) Celestine (for $\mathrm{SO}_{3}$ ) and 5) Beesons Apatite (for $\mathrm{P}_{2} \mathrm{O}_{5}$ ). All standards were run at the beginning and end of each mount analysis, with A99 run 3 times between every 10-15 samples to monitor spectrometer drift. The data for all these standards can be found in Appendix B. 
Table 2.2. Instrumental operating conditions for electron microprobe analysis of in-situ major elements, analyser crystals are shortened to the acronyms, PETL/PETJ - pentaerythritol, $T A P$ - thallium acid pthalate, and LIF - lithium fluoride, these are varied during analysis to cover the entire $X$-ray spectrum.

\begin{tabular}{|c|c|c|c|}
\hline \multicolumn{4}{|l|}{ EMPA } \\
\hline \multicolumn{4}{|l|}{ Electron Microprobe Analysis } \\
\hline Instrument & \multicolumn{3}{|c|}{ JEOL JXA 8320 superprobe } \\
\hline Analysis mode & \multicolumn{3}{|c|}{ Wavelength dispersive spectrometry (WDS) } \\
\hline Accelerating voltage & \multicolumn{3}{|l|}{$15 \mathrm{kV}$} \\
\hline Spot size & \multicolumn{3}{|l|}{$10 \mu \mathrm{m}$} \\
\hline Probe current & \multicolumn{3}{|l|}{$8 \mathrm{nA}$} \\
\hline \multicolumn{4}{|l|}{ Standards } \\
\hline \multirow[t]{5}{*}{ Calibration standards } & \multicolumn{3}{|c|}{ Basaltic Glass $\mathrm{A} 99\left(\mathrm{SiO}_{2}, \mathrm{TiO}_{2}, \mathrm{Al}_{2} \mathrm{O}_{3}, \mathrm{FeO}, \mathrm{MgO}, \mathrm{CaO}\right)$} \\
\hline & \multicolumn{3}{|c|}{ Rhyolitic glass VG-568 $\left(\mathrm{Na}_{2} \mathrm{O}\right.$ and $\left.\mathrm{K}_{2} \mathrm{O}\right)$} \\
\hline & \multicolumn{3}{|c|}{ Scapolite PSU63-1805 (Cl) } \\
\hline & \multicolumn{3}{|l|}{ Celestine $\left(\mathrm{SO}_{3}\right)$} \\
\hline & \multicolumn{3}{|c|}{ Beesons Apatite $\left(\mathrm{P}_{2} \mathrm{O}_{5}\right)$} \\
\hline Secondary standard & \multicolumn{3}{|c|}{ Basaltic Glass A99 } \\
\hline \multicolumn{4}{|l|}{ Method Parameters } \\
\hline Channel 1 & Channel 3 & Channel 4 & Channel 5 \\
\hline $\mathrm{K}(20 \mathrm{sec})$ PETL $\mathrm{Na}(10 \mathrm{sec}) \mathrm{TAP}$ & $\mathrm{Si}(30 \mathrm{sec}) \mathrm{TAP}$ & Ca (30 sec) PETJ & P (30 sec) PETL \\
\hline $\mathrm{S}(30 \mathrm{sec})$ PETL $\mathrm{Mg}(50 \mathrm{sec}) \mathrm{TAP}$ & $\mathrm{Al}(30 \mathrm{sec}) \mathrm{TAP}$ & $\mathrm{Fe}(30 \mathrm{sec}) \mathrm{LIF}$ & $\mathrm{Cl}$ (30 sec) PETL \\
\hline Ti (30 sec) PETL & & Mn (30 sec) LIF & \\
\hline
\end{tabular}

\subsection{In-situ Trace Element Analysis by LA-ICP-MS}

\subsubsection{Sample preparation}

The carbon coat was removed from the pre-prepared mounts using AR grade methanol, and for VUW analyses the mounts were cut in half using a diamond edge saw and three samples on a $1 / 2$ mount were loaded along with the standard BHVO2G into the sample chamber for analysis (Fig. 2.2.A). For UoO analyses, mounts were kept whole and two mounts (12 samples) were loaded along with standard BHVO2G, BCR2G, NIST612, and NIST610 (Fig. 2.2.B). 


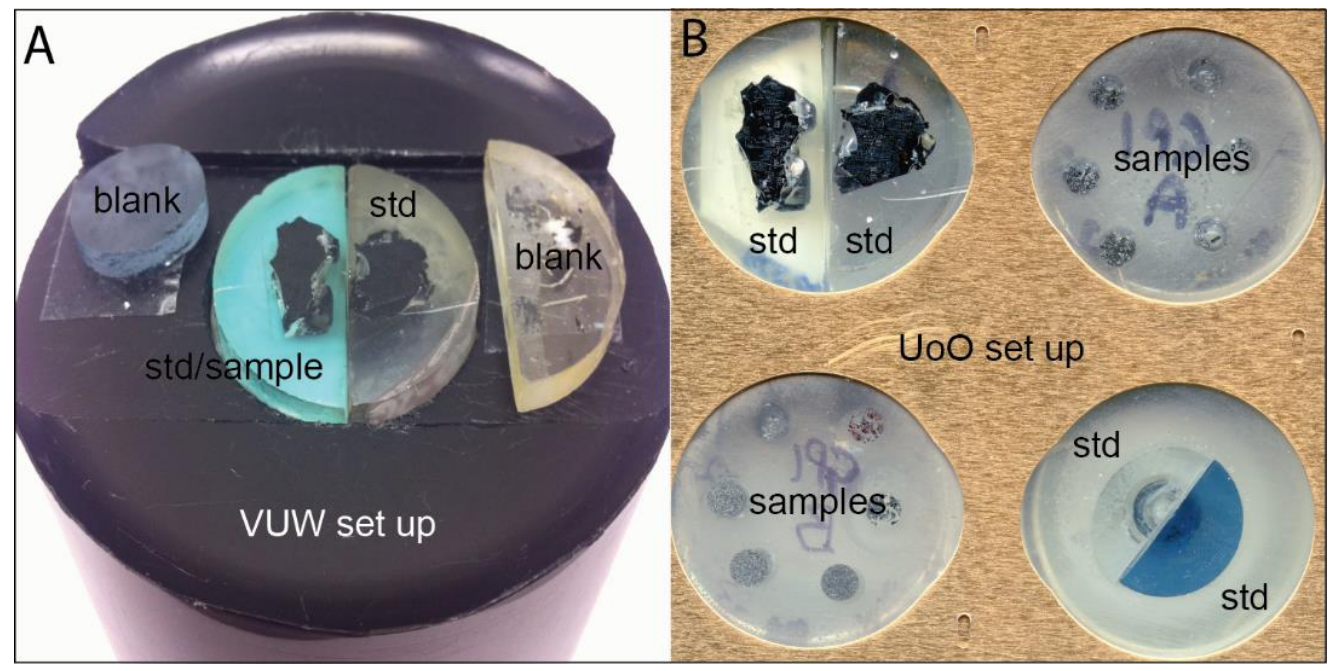

Figure 2.2. (A) Photograph to demonstrate mount set up (VUW) for laser ablation chamber. 'Blank' blocks have been shown (Allan et al., 2008) to increase signal stability. Photograph shows set up for standard (std) analysis, for sample analysis left hand half moon mount would be replaced with sample half moon for 3 individual sample analyses. (B) Mount set up for UoO analysis for laser ablation chamber. Samples from Glover Park core shown in situ for 12 individual analyses, all standards remain in position with sample mounts swapped for analysis.

\subsubsection{Measurements}

Trace element analysis was undertaken using an Agilent 7500cs Inductively Coupled Mass Spectrometer (ICP-MS) coupled with (at VUW) a New Wave UP 193nm Solid State laser, or (at UoO) a Resonetics RESOLution M-50-LR, using the methods developed by Allan et al. (2008). Analytical conditions for LA-ICP-MS analysis are detailed in Table 2.3. Prior to analysis the ICP-MS was tuned by rastering across BHVO-2G (or NIST612 at UoO) standard. The instrument conditions, predominantly the carrier gas $(\mathrm{Ar})$ or optional gas $(\mathrm{He})$ flow rates, were adjusted to optimise the machine sensitivity, but minimise the production of oxides. Oxide production was monitored using measured values of $\mathrm{ThO}^{+} / \mathrm{Th}^{+}$(masses $248 / 232$ ) and maintained to a value of $\leq 1.5 \%$. Pulse/Analogue (P/A) factors were measured on relevant elements (e.g. $\mathrm{Si}, \mathrm{Ca}, \mathrm{Mg}, \mathrm{V}, \mathrm{Zr}, \mathrm{Ti}, \mathrm{Cr}, \mathrm{Ni}, \mathrm{Sr}, \mathrm{Ba}, \mathrm{Ce}$ ) to 
allow the ICP-MS to perform the right correction when switching between pulse and analogue mode, which is required when the count rate is > 1million CPS. Multiple isotopes of selected elements were measured (e.g. ${ }^{90} \mathrm{Zr}$ and ${ }^{91} \mathrm{Zr}$ ) to assess the quality of the data, usually producing concentrations of $\pm 0.5 \%$ variability between the isotopes. 41 elements were analysed: $\mathrm{Si}, \mathrm{Li}, \mathrm{B}, \mathrm{Mg}, \mathrm{Ca}, \mathrm{Sc}, \mathrm{Ti}, \mathrm{V}, \mathrm{Cr}, \mathrm{Mn}, \mathrm{Ni}, \mathrm{Cu}$, Zn, Ga, Rb, Sr, Y, Zr, Nb, Cs, Ba, La, Ce, Pr, Nd, Sm, Eu, Gd, Tb, Dy, Ho, Er, Tm, $\mathrm{Yb}, \mathrm{Lu}, \mathrm{Hf}, \mathrm{Ta}, \mathrm{W}, \mathrm{Pb}, \mathrm{Th}$, and $\mathrm{U}$. All the data were acquired from static spot analysis with a spot size of $25-35 \mu \mathrm{m}$ pulsed at $5 \mathrm{~Hz}$.

Table 2.3. Instrumental operating conditions for LA-ICP-MS analysis of in-situ trace elements at both Victoria University of Wellington and University of Otago.

\begin{tabular}{|c|c|c|}
\hline \multicolumn{3}{|l|}{ LA-ICP-MS } \\
\hline Laser Ablation & \multicolumn{2}{|l|}{ VUW } \\
\hline Instrument & \multirow{2}{*}{$\begin{array}{l}\text { New wave } 193 \mathrm{~nm} \text { (deep UV) solid state } \\
\text { static spot analysis }\end{array}$} & New Wave UP $213 \mathrm{~nm}$ (deep UV) solid state \\
\hline Ablation mode & & static spot analysis \\
\hline Spot size & 25 or 35 um (predominantly 35 um) & 25 or $35 \mu \mathrm{m}$ (predominantly $35 \mu \mathrm{m}$ ) \\
\hline Repetition rate & $5 \mathrm{~Hz}$ & $5 \mathrm{~Hz}$ \\
\hline Laser power & $85-100 \%$ & $100 \%$ \\
\hline Instrument & Agilent 7500 CS octopole & Agilent $7500 C S$ octopole \\
\hline Aquisition mode & Peak hopping & Peak hopping \\
\hline Detection mode & Pulse and analogue counting (mostly pulse) & Pulse and analogue counting (mostly pulse) \\
\hline \multicolumn{3}{|l|}{ Standards } \\
\hline \multicolumn{3}{|c|}{ Method Parameters - same for both VUW and UoO } \\
\hline Background acquisition & \multicolumn{2}{|l|}{$20 \mathrm{~s}$} \\
\hline Standard aquisition & \multicolumn{2}{|l|}{$60 \mathrm{~s}$} \\
\hline Sample aquisition & \multicolumn{2}{|l|}{$60 \mathrm{~s}$} \\
\hline Measured isotopes and & \multirow{2}{*}{\multicolumn{2}{|c|}{$\begin{array}{ll}10 \mathrm{~ms}: & { }^{25} \mathrm{Mg},{ }^{29} \mathrm{Si},{ }^{43} \mathrm{Ca},{ }^{47} \mathrm{Ti},{ }^{53} \mathrm{Cr},{ }^{55} \mathrm{Mn} \\
20 \mathrm{~ms}: & { }^{7} \mathrm{Li},{ }^{45} \mathrm{Sc},{ }^{51} \mathrm{~V},{ }^{59} \mathrm{Co},{ }^{60} \mathrm{Ni},{ }^{63} \mathrm{Cu},{ }^{66} \mathrm{Zn},{ }^{71} \mathrm{Ga}, \\
& { }^{85} \mathrm{Rb},{ }^{86} \mathrm{Sr},{ }^{89} \mathrm{Y},{ }^{90} \mathrm{Zr},{ }^{91} \mathrm{Zr},{ }^{93} \mathrm{Nb},{ }^{95} \mathrm{Mo},{ }^{133} \mathrm{Cs},{ }^{138} \mathrm{Ba},{ }^{139} \mathrm{La} \\
& { }^{140} \mathrm{Ce},{ }^{141} \mathrm{Pr},{ }^{146} \mathrm{Nd},{ }^{147} \mathrm{Sm},{ }^{151} \mathrm{Eu}{ }^{153} \mathrm{Eu},{ }^{157} \mathrm{Gd},{ }^{159} \mathrm{~Tb},{ }^{163} \mathrm{Dy},{ }^{165} \mathrm{Ho},{ }^{166} \mathrm{Er}, \\
& { }^{169} \mathrm{Tm},{ }^{172} \mathrm{Yb},{ }^{175} \mathrm{Lu},{ }^{178} \mathrm{Hf},{ }^{181} \mathrm{Ta},{ }^{182} \mathrm{~W},{ }^{208} \mathrm{~Pb},{ }^{232} \mathrm{Th},{ }^{238} \mathrm{U},\end{array}$}} \\
\hline integration times & & \\
\hline Carrier Gas (Ar) & \multicolumn{2}{|l|}{$0.83-0.87 \mathrm{~L} / \mathrm{min}$} \\
\hline Ablation gas $(\mathrm{He})$ & \multicolumn{2}{|l|}{$80-90 \%$} \\
\hline RF power & \multicolumn{2}{|l|}{$1500 \mathrm{~W}$} \\
\hline RF matching & \multicolumn{2}{|l|}{$1.77 \mathrm{~V}$} \\
\hline Sample depth & \multicolumn{2}{|l|}{$4 \mathrm{~mm}$} \\
\hline Extract 1 ion lense & \multicolumn{2}{|l|}{$3.2-5 \mathrm{~V}$} \\
\hline Extract 2 ion lense & \multicolumn{2}{|l|}{-172 to $-117 \mathrm{~V}$} \\
\hline
\end{tabular}




\subsubsection{Processing of raw LA-ICP-MS data}

The raw data was reduced in the programme 'lolite' (Paton et al., 2011) using the $\mathrm{SiO}_{2}$ values measured by EMPA as an internal standard for specific sample spot sites. The $\mathrm{SiO}_{2}$ concentration for each site was converted into Si concentration and input as an internal calibration value for each shard. The .csv files output from the Agilent software was directly loaded in to iolite. The individual time-stamp for each analysis allowed multiple analyses to be loaded at once to allow calibration standard drift to be measured and corrected for over the course of a run ('Spline' process) (Fig. 2.3.A). During data processing care was taken to identify and remove any data that were compromised by accidental ablation of crystal inclusions (Fig. 2.3.B) or ablation through the glass shard itself (Fig. 2.3.C). This process is of critical importance to ensure the data for a given analysis are purely for the glass. Allan et al. (2008) detail some specific elements that show contamination by certain mineral phases, and these are detailed in Table 2.4. They were monitored during data reduction.

Table 2.4. Elements that cause contamination in glass shards (from Allan et al. 2008) and their related mineral phase.

\begin{tabular}{lcc}
\hline Contaminant & $\begin{array}{c}\text { Increased } \\
\text { concentration }\end{array}$ & $\begin{array}{c}\text { Decreased } \\
\text { concentration }\end{array}$ \\
\hline Olivine & $\mathrm{Mg}, \mathrm{Si}, \mathrm{Ni}, \mathrm{Co}$ & \\
Plagioclase & $\mathrm{Sr}, \mathrm{Al}, \mathrm{Ca}$ & \\
Orthopyroxene & $\mathrm{Mg}, \mathrm{Mn}, \mathrm{Zn}$ & \\
Magnetite & $\mathrm{Fe}, \mathrm{Ti}, \mathrm{Cr}$, & $\mathrm{Si}$ \\
\hline
\end{tabular}



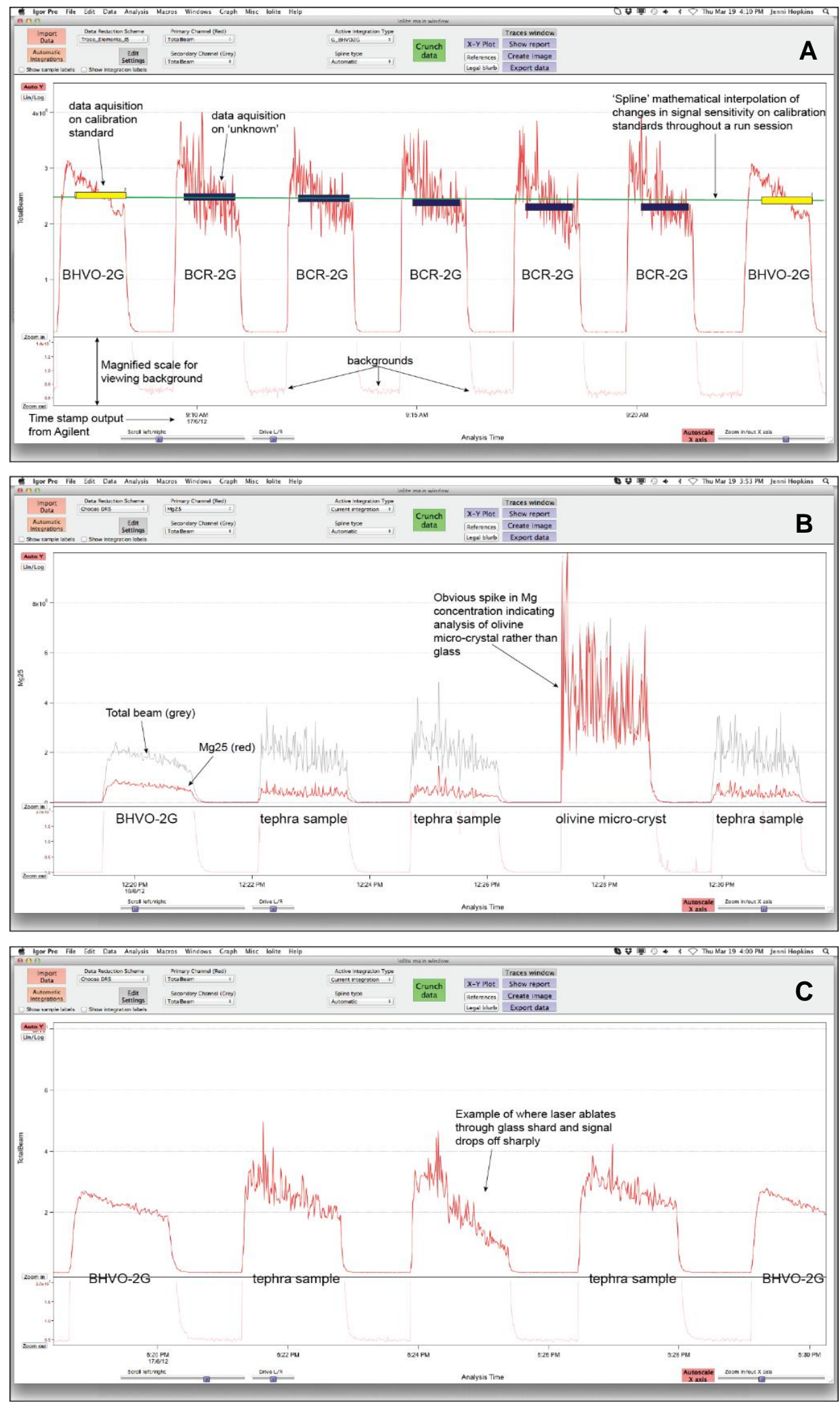

Figure 2.3. Annotated screen shot of iolite data reduction programme. (A) Set up for a standard data acquisition of calibration standards and 'unknowns'. (B) The identification of accidental ablation of a microcrystal shown by Mg concentrations plotted as secondary peak, (C) identification of accidental ablation through a glass shard. 


\subsubsection{Accuracy and Precision of LA-ICP-MS}

An initial standard test was run to check tuning using $\mathrm{BHVO}-2 \mathrm{G}$ as a bracketing standard and BCR-2G used as a secondary standard (e.g. run as an unknown but with known values for reference). The standard BHVO-2G was then run once every 5 samples for calibration. Values used for the reference materials were the preferred values from the GeoReM database (http://georem.mpchmainz.gwdg.de; Jochum et al. (2005), Table 2.5.). Comparisons of the precision and accuracy of the measurements for VUW vs. UoO are discussed in Section 2.11.4.

Table 2.5 shows a summary of the analyses made by LA-ICP-MS. External precision of analysis (measured as $2 \mathrm{sd} \%$ variability from the standard reference value) for BHVO-2G of elements at both $\mathrm{UoO}$ and VUW are poor for $\mathrm{Li}, \mathrm{Cr}, \mathrm{Cu}, \mathrm{Cs}$, $\mathrm{Pb}$, for VUW specifically Lu is poor, and for UoO specifically $\mathrm{Tm}$ and Eu are poor. For BCR-2G both VUW and UoO have consistently poor precision for $\mathrm{Li}, \mathrm{Cr}, \mathrm{Ni}, \mathrm{Cu}$ and $\mathrm{Cs}$, however, all other elements have a precision of $<3 \%$. For BHVO-2G the accuracy at VUW (17 elements were measured at $<1 \%$ offset (from the standard value), and 13 with $1-3 \%$ offset) is slightly better than at UoO (14 elements were measured at $<1 \%$ offset, and 15 with 1-3\% offset), including previously mentioned elements forming the outliers ( $>3 \%$ offset; $\mathrm{Li}, \mathrm{Cr}, \mathrm{Cu}, \mathrm{Cs}, \mathrm{Pb}, \mathrm{Eu}, \mathrm{Tm}, \mathrm{Lu}$ ). For BCR$2 \mathrm{G}$ the accuracy is better at $\mathrm{UoO}$ (9 elements were measured at $<1 \%$ offset, and 22 with $1-5 \%$ offset) in comparison to VUW (8 elements were measured at $<1 \%$ offset, and 17 with $1-5 \%$ offset), outliers (>5\% offset) here include Ti, Cr, Zr, Tm, Ta for $\mathrm{UoO}$, and $\mathrm{Li}, \mathrm{Cr}, \mathrm{Ni}, \mathrm{Cu}, \mathrm{Zn}, \mathrm{Y}, \mathrm{Zr}$, Cs, Hf, Ta for VUW. In many cases the analysis is very accurate, with a small \% offset from the reference value, but not very precise (e.g., VUW Ba on BCR-2G, \% offset $=0.5,2 \mathrm{sd} \%=7$ ), suggesting multiple analyses are necessary to gain accurate concentration values. 
Table 2.5. Summary of the standard data gained throughout the analysis sessions for 20112014 for standards BHVO-2G and BCR-2G analysed by LA-ICP-MS at VUW and UoO. All values are reported in ppm, accuracy of analyses shown by offset from reference values (GeoREM; Jochum et al., 2005) for $n=264$ number of analyses, for standard deviation of results see Appendix Bii. Elements are reported with their measured isotope numbers, and red highlights values discussed in the text as outliers.

\begin{tabular}{|c|c|c|c|c|c|}
\hline \multicolumn{2}{|c|}{ BHVO-2G values } & \multicolumn{2}{|c|}{ VUW } & \multicolumn{2}{|c|}{$\mathrm{UoO}$} \\
\hline Element & $\begin{array}{c}\text { Reference } \\
\text { value }\end{array}$ & Average & $\begin{array}{l}\% \text { offset } \\
\text { from std }\end{array}$ & Average & $\begin{array}{l}\% \text { offset } \\
\text { from std }\end{array}$ \\
\hline Li7 & 4.8 & 4.43 & -7.78 & 4.61 & -3.93 \\
\hline Sc45 & 32 & 32.9 & 2.69 & 32.3 & 0.90 \\
\hline Ti47 & 16300 & 16708 & 2.51 & 16709 & 2.51 \\
\hline V51 & 317 & 309 & 2.62 & 309 & 2.51 \\
\hline Cr53 & 280 & 294 & 5.14 & 315 & 12.6 \\
\hline Mn55 & 1317 & 1317 & 0.04 & 1311 & -0.44 \\
\hline $\mathrm{Ni60}$ & 119 & 116 & 2.57 & 120 & 1.15 \\
\hline Cu63 & 127 & 103 & -19.0 & 137 & 8.07 \\
\hline Zn66 & 103 & 102 & 1.13 & 101 & 2.28 \\
\hline Ga71 & 22 & 22.0 & 0.03 & 22.1 & 0.25 \\
\hline Rb85 & 9.08 & 9.33 & 2.78 & 9.19 & 1.26 \\
\hline Sr88 & 396 & 396 & 0.11 & 397 & 0.25 \\
\hline Y89 & 26 & 25.9 & 0.30 & 25.6 & 1.47 \\
\hline Zr9o & 172 & 169 & 1.53 & 168 & 2.10 \\
\hline $\mathrm{Nb93}$ & 18.1 & 18.3 & 0.88 & 18.1 & 0.08 \\
\hline Cs133 & 0.1 & 0.11 & 14.5 & -0.14 & -245 \\
\hline Ba137 & 131 & 133 & 1.52 & 131 & 0.13 \\
\hline La139 & 15.2 & 15.2 & 0.02 & 15.1 & 0.85 \\
\hline Ce140 & 37.5 & 37.6 & 0.32 & 37.5 & 0.10 \\
\hline Pr141 & 5.29 & 5.34 & 0.97 & 5.26 & 0.64 \\
\hline Nd146 & 24.5 & 24.5 & 0.01 & 24.4 & 0.21 \\
\hline Sm147 & 6.07 & 6.09 & 0.29 & 6.10 & 0.44 \\
\hline Eu153 & 2.07 & 2.07 & 0.03 & 2.17 & 4.66 \\
\hline Gd157 & 6.24 & 6.16 & 1.29 & 6.03 & 3.39 \\
\hline Tb159 & 0.936 & 0.92 & 1.98 & 0.91 & 2.93 \\
\hline Dy163 & 5.31 & 5.28 & 0.60 & 5.21 & 1.97 \\
\hline Ho165 & 0.972 & 0.98 & 0.93 & 0.99 & 1.72 \\
\hline Er166 & 2.54 & 2.56 & 0.82 & 2.46 & 3.17 \\
\hline Tm169 & 0.341 & 0.34 & 0.36 & 0.41 & 19.8 \\
\hline Yb172 & 2 & 2.02 & 0.77 & 2.01 & 0.55 \\
\hline Lu175 & 0.274 & 0.29 & 5.20 & 0.27 & 0.72 \\
\hline Hf178 & 4.36 & 4.31 & 1.25 & 4.23 & 2.98 \\
\hline Ta181 & 1.14 & 1.15 & 0.57 & 1.16 & 1.41 \\
\hline $\mathrm{Pb} 208$ & 1.6 & 1.80 & 12.6 & 1.81 & 13.1 \\
\hline Th232 & 1.22 & 1.23 & 1.22 & 1.20 & 1.79 \\
\hline U238 & 0.403 & 0.41 & 1.88 & 0.40 & 0.14 \\
\hline
\end{tabular}

\begin{tabular}{|c|c|c|c|c|c|}
\hline \multicolumn{2}{|c|}{ BCR-2G values } & \multicolumn{2}{|c|}{ VUW } & \multicolumn{2}{|c|}{ Uoo } \\
\hline Element & $\begin{array}{c}\text { Reference } \\
\text { value }\end{array}$ & Average & $\begin{array}{l}\text { \% offset } \\
\text { from std }\end{array}$ & Average & $\begin{array}{l}\% \text { offset } \\
\text { from std }\end{array}$ \\
\hline Li7 & 9 & 9.49 & 5.48 & 9.01 & 0.08 \\
\hline Sc45 & 33 & 33.8 & 2.52 & 34.1 & 3.38 \\
\hline Ti47 & 13500 & 14027 & 3.90 & 14291 & 5.86 \\
\hline V51 & 416 & 416 & -0.06 & 427 & 2.68 \\
\hline Cr53 & 13 & 15.7 & 20.8 & 17.1 & 31.2 \\
\hline Mn55 & 1550 & 1510 & -2.55 & 1571 & 1.35 \\
\hline Ni60 & 12 & 10.6 & -12.1 & 12.3 & 2.87 \\
\hline Cu63 & 21 & 5.69 & -72.9 & 20.0 & -4.94 \\
\hline Zn66 & 127 & 137 & 7.81 & 129 & 1.59 \\
\hline Ga71 & 23 & 23.7 & 2.95 & 23.0 & 0.14 \\
\hline Rb85 & 46.9 & 49.2 & 4.88 & 47.6 & 1.58 \\
\hline Sr88 & 340 & 346 & 1.75 & 345 & 1.56 \\
\hline Y89 & 37 & 34.7 & -6.19 & 36.0 & -2.84 \\
\hline Zr9o & 201 & 181 & -10.2 & 188 & -6.40 \\
\hline $\mathrm{Nb93}$ & 12.6 & 12.8 & 1.69 & 12.7 & 0.85 \\
\hline Cs133 & 1.1 & 1.23 & 12.1 & 1.11 & 1.30 \\
\hline Ba137 & 677 & 680 & 0.50 & 691 & 2.11 \\
\hline La139 & 24.9 & 24.5 & -1.70 & 25.3 & 1.74 \\
\hline Ce140 & 52.9 & 53.6 & 1.41 & 54.1 & 2.28 \\
\hline Pr141 & 6.7 & 6.72 & 0.36 & 6.83 & 1.88 \\
\hline Nd146 & 28.7 & 28.0 & -2.33 & 29.6 & 3.24 \\
\hline Sm147 & 6.58 & 6.42 & -2.49 & 6.57 & -0.09 \\
\hline Eu153 & 1.96 & 1.95 & -0.45 & 1.98 & 1.21 \\
\hline Gd157 & 6.75 & 6.58 & -2.55 & 6.68 & -0.97 \\
\hline Tb159 & 1.07 & 1.02 & -4.62 & 1.04 & -2.82 \\
\hline Dy163 & 6.41 & 6.24 & -2.58 & 6.57 & 2.51 \\
\hline Ho165 & 1.28 & 1.25 & -2.16 & 1.29 & 0.92 \\
\hline Er166 & 3.66 & 3.64 & -0.52 & 3.72 & 1.62 \\
\hline Tm169 & 0.54 & 0.52 & -4.05 & 0.50 & -7.10 \\
\hline Yb172 & 3.38 & 3.38 & -0.09 & 3.41 & 1.01 \\
\hline Lu175 & 0.503 & 0.51 & 0.89 & 0.51 & 1.00 \\
\hline Hf178 & 4.9 & 4.62 & -5.62 & 4.93 & 0.57 \\
\hline Ta181 & 0.74 & 0.78 & 5.59 & 0.81 & 8.86 \\
\hline $\mathrm{Pb} 208$ & 11 & 10.80 & -1.79 & 10.81 & -1.72 \\
\hline Th232 & 6.03 & 5.99 & -0.65 & 6.09 & 1.00 \\
\hline U238 & 1.69 & 1.71 & 1.40 & 1.71 & 1.07 \\
\hline
\end{tabular}




\section{Section B - Whole Rock Analysis}

\subsection{Sample Selection and Preparation}

\subsubsection{Sample selection}

In order to make the most informed correlations between tephra deposits and whole rock, it was necessary to obtain whole rock data from as many centres as possible. In this thesis (Chapter 4) we present a minimum of 5 analyses for all centres of the Auckland Volcanic Field (AVF), excluding those with no surface exposure, to test correlation potential. These data are obtained from literature values, and from new data presented in this thesis where gaps were found in the literature values.

Additional rock samples for centres with less than 5 analyses were collected from the field or pre-existing rock collections. For samples collected in a field campaign, sites were chosen to sample a range of deposits including lava flows, scoria deposits, and tuff ring deposits. For lava flows, samples were selected from a number of different sites; they were broken with a sledgehammer to obtain fresh surfaces with limited weathering or oxidation. Scoria samples were taken by hand or with a sledgehammer, with the large scoriaceous bombs being preferable. Welded and imbedded bombs were also the preferred material for sampling from the tuff rings. The samples were taken, where possible, from a variety of sites around an individual centre and samples were chosen for their unweathered and juvenile appearance.

\subsubsection{Sample preparation}

Fresh samples were then crushed using a Rocklabs Boyd crusher to chips $<15 \mathrm{~mm}$ in size. The crusher was cleaned with ethanol and dried using compressed air repeatedly between samples. The crushed material was then powdered using a TEMA tungsten-carbide swing mill at VUW. 


\subsection{Whole Rock Major Element Analysis by XRF}

\subsubsection{Sample preparation}

Samples were made into fused lithium metaborate glass discs and analysed for major oxide concentrations following methods of Ramsey et al. (1995). Approximately $0.7 \mathrm{~g}$ ( 1 part by weight) of powdered sample was dried at $110^{\circ} \mathrm{C}$ before being mixed with ca. $3.5 \mathrm{~g}$ ( 5 parts by weight) of dried lithium metaborate flux. This mix was then placed in $95 \% \mathrm{Pt}-5 \%$ Au crucibles and fused in a muffle furnace at $1100^{\circ} \mathrm{C}$ for 15 minutes. Loss-on-ignition (LOI) measurements were calculated by heating dried powdered samples in pre-ignited crucibles to $1000^{\circ} \mathrm{C}$ for $1 \mathrm{hr}$ and recording the weight loss.

\subsubsection{Measurements}

Glass discs were then measured for major elements $\left(\mathrm{SiO}_{2}, \mathrm{TiO}_{2}, \mathrm{Al}_{2} \mathrm{O}_{3}\right.$, $\mathrm{Fe}_{2} \mathrm{O}_{3}{ }^{\text {tot }}, \mathrm{MnO}, \mathrm{MgO}, \mathrm{CaO}, \mathrm{Na}_{2} \mathrm{O}, \mathrm{K}_{2} \mathrm{O}, \mathrm{P}_{2} \mathrm{O}_{5}$ ) on an $\mathrm{ARL} \circledast 8420+$ dual goniometer wavelength dispersive $\mathrm{X}$-ray fluorescence (XRF) spectrometer at the Open University. Analytical conditions are detailed in Table 2.6.

Table 2.6. Analytical conditions for XRF analysis of major elements at the Open University, UK; fpc flow portional counter, and $x$-ray tube operated at $40 \mathrm{kV} / 60 \mathrm{~mA}$, from Ramsey et al., 1995.

\begin{tabular}{ccccccc}
\hline \multicolumn{3}{c}{ Element Data } & \multicolumn{5}{c}{ Analytical Conditions } \\
\hline Element & X-ray line & Wavelength $(\AA)$ & Count time $(\mathbf{s})$ & Crystal & Detector & Collimator \\
\hline $\mathrm{Na}$ & $\mathrm{K}_{\alpha}$ & 11.910 & 40 & $\mathrm{AX06}$ & $\mathrm{fpc}$ & coarse \\
$\mathrm{Mg}$ & $\mathrm{K}_{\alpha}$ & 9.890 & 25 & $\mathrm{AX06}$ & $\mathrm{fpc}$ & coarse \\
$\mathrm{Al}$ & $\mathrm{K}_{\alpha}$ & 8.340 & 20 & $\mathrm{PET}$ & $\mathrm{fpc}$ & coarse \\
$\mathrm{Si}$ & $\mathrm{K}_{\alpha}$ & 7.126 & 30 & PET & $\mathrm{fpc}$ & coarse \\
$\mathrm{P}$ & $\mathrm{K}_{\alpha}$ & 6.158 & 30 & Ge111 & $\mathrm{fpc}$ & fine \\
$\mathrm{S}$ & $\mathrm{K}_{\alpha}$ & 5.373 & 20 & $\mathrm{Ge111}$ & $\mathrm{fpc}$ & fine \\
$\mathrm{K}$ & $\mathrm{K}_{\alpha}$ & 3.742 & 15 & LiF200 & $\mathrm{fpc}$ & fine \\
$\mathrm{Ca}$ & $\mathrm{K}_{\alpha}$ & 3.359 & 15 & LiF200 & $\mathrm{fpc}$ & fine \\
$\mathrm{Ti}$ & $\mathrm{K}_{\alpha}$ & 2.750 & 20 & LiF200 & $\mathrm{fpc}$ & fine \\
$\mathrm{Mn}$ & $\mathrm{K}_{\alpha}$ & 2.130 & 15 & LiF200 & $\mathrm{fpc}$ & fine \\
$\mathrm{Fe}$ & $\mathrm{K}_{\alpha}$ & 1.937 & 15 & LiF200 & $\mathrm{fpc}$ & fine \\
\hline
\end{tabular}




\subsubsection{Accuracy and precision of XRF}

A bivariate regression line of multiple reference materials was used as calibration standard (c.f. Ramsey et al., 1995) for XRF analysis. Secondary standards Whin Sill Dolerite (WS-E) and Nanhoron Microgranite (OU-3) were run at the beginning and end of each batch of samples to monitor accuracy and precision of results. Table 2.7 reports the average standard values over 4 batches, and Appendix B reports all the values measured for the standard analyses. For WS-E all elements agree closely with the reference value ( $<1 \%$ offset), except for $\mathrm{Na}_{2} \mathrm{O}$ ($2.37 \%$ ) and $\mathrm{P}_{2} \mathrm{O}_{5}(-1.59 \%)$, and exhibit precision of $<1.5 \%$ for all except $\mathrm{P}_{2} \mathrm{O}_{5}(2.7 \%)$. For OU-3 all elements show $<2 \%$ offset from the reference value, except $\mathrm{CaO}$ (3.08\%) and all exhibit a precision value of $<2 \%$, indicating that the XRF technique shows a high level of both precision and accuracy. Blind duplicate analyses were run for selected samples and for BHVO (reported in Appendix B) and show excellent reproducibility. With blind BHVO analyses all within $<2 \%$ offset of the reference value, and all with precision of $<3 \%$.

Table 2.7. Summary of the standard data gained through XRF analysis techniques for major element concentrations of whole rock. Reference values for WS-E from Govindaraju, 1994 with the exception of $\mathrm{SiO}_{2}, \mathrm{TiO}_{2}$, and $\mathrm{Fe}_{2} \mathrm{O}_{3}$ from Thompson et al., 2000 and for OU-3 reference values are accepted from long-term running averages from the Open University XRF lab.

\begin{tabular}{|c|c|c|c|c|c|c|c|c|}
\hline & \multicolumn{4}{|c|}{ Whin Sill Dolerite (WS-E) } & \multicolumn{4}{|c|}{ Nanhoron Microgranite (OU-3) } \\
\hline & $\begin{array}{c}\text { Reference } \\
\text { value }\end{array}$ & $\begin{array}{c}\text { average } \\
(w t \%)(n=8)\end{array}$ & $\begin{array}{l}\% \text { offset } \\
\text { from std }\end{array}$ & 2sd\% & $\begin{array}{c}\text { Reference } \\
\text { value }\end{array}$ & $\begin{array}{c}\text { average } \\
(w t \%)(n=8)\end{array}$ & $\begin{array}{l}\% \text { offset } \\
\text { from std }\end{array}$ & $2 s d \%$ \\
\hline $\mathrm{SiO}_{2}$ & 51.10 & 51.03 & 0.15 & 0.12 & 74.09 & 74.13 & 0.05 & 0.21 \\
\hline $\mathrm{TiO}_{2}$ & 2.43 & 2.43 & 0.33 & 0.35 & 0.22 & 0.22 & 0.11 & 2.50 \\
\hline $\mathrm{Al}_{2} \mathrm{O}_{3}$ & 13.78 & 13.89 & 0.80 & 0.24 & 11.11 & 11.08 & 0.28 & 0.47 \\
\hline $\mathrm{Fe}_{2} \mathrm{O}_{3}{ }^{\text {tot }}$ & 13.15 & 13.16 & 0.05 & 0.28 & 3.83 & 3.87 & 0.92 & 0.51 \\
\hline MnO & 0.17 & 0.17 & 0.50 & 1.14 & 0.09 & 0.09 & 1.78 & 1.35 \\
\hline MgO & 5.55 & 5.55 & 0.07 & 0.60 & - & 0.03 & - & - \\
\hline $\mathrm{CaO}$ & 8.95 & 8.94 & 0.14 & 0.32 & 0.20 & 0.21 & 3.08 & 1.82 \\
\hline $\mathrm{Na}_{2} \mathrm{O}$ & 2.47 & 2.41 & 2.37 & 0.72 & 3.68 & 3.71 & 0.68 & 0.99 \\
\hline $\mathrm{K}_{2} \mathrm{O}$ & 1.00 & 1.00 & 0.25 & 1.17 & 4.55 & 4.56 & 0.20 & 1.08 \\
\hline $\mathrm{P}_{2} \mathrm{O}_{5}$ & 0.30 & 0.30 & 1.59 & 2.70 & - & 0.02 & - & - \\
\hline LOI & 0.85 & 0.85 & 0.00 & 0.00 & 1.82 & 1.82 & 0.00 & 0.00 \\
\hline Total & 99.75 & 99.72 & 0.03 & 0.07 & 99.59 & 99.72 & 0.13 & 0.25 \\
\hline
\end{tabular}




\subsection{Trace Element Analysis by Solution-ICP-MS}

\subsubsection{Laboratory Protocol at VUW}

Sample preparation was undertaken in an ultraclean laboratory facility using Class 10 laminar flow workstations. The air within the laboratory is positively pressured and filtered to Class 100, in order to minimise the risk of sample contamination.

\subsubsection{Reagents}

All the water used for any lab work in this study was filtered Millipore $\mathrm{H}_{2} \mathrm{O}$ (MQ) with measured resistivity of $\sim 18.2 \mathrm{M} \Omega$. For sample preparation Seastar (SS) grade ultra-pure acids were used. For sample dissolution $\mathrm{SS}$ grade $\mathrm{HNO}_{3}$ and $\mathrm{HF}$ were used. For trace element analysis, analytical reagent (AR) grade $\mathrm{HNO}_{3}$ was distilled twice to produce a 2xsub-boiled (SB) acid. The acid dilutions were made with $\mathrm{MQ}$ water and their molarities checked using a density meter.

\subsubsection{Beaker preparation}

Prior to chemical procedures, $23 \mathrm{~mL}$ Savillex screw top beakers were cleaned to remove any potential contaminants. Dirty beakers were thoroughly rinsed with $\mathrm{MQ}$ and wiped down with methanol. The beakers were then soaked in $\mathrm{AR}$ grade $6 \mathrm{M} \mathrm{HCl}$ for a minimum of 24 hours on a hotplate at $120^{\circ} \mathrm{C}$. They were then removed and rinsed three times with $\mathrm{MQ}$ water. This process was then repeated but with $7 \mathrm{M}$ $\mathrm{HNO}_{3}$. Finally, the beakers were filled with 4-5 $\mathrm{mL}$ of $6-7 \mathrm{M} \mathrm{SB} \mathrm{HNO}_{3}$ sealed and refluxed for 24 hours. This acid was then removed and the beakers were rinsed three times with $M Q$ water. This process was then repeated with 4-5 $\mathrm{mL}$ of $6-7 \mathrm{M} \mathrm{SS}$ $\mathrm{HNO}_{3}$. Once rinsed with $\mathrm{MQ}$ beakers were then dried down and ready for use. For $\mathrm{Pb}$ isotopes this step is repeated with $6 \mathrm{M} \mathrm{SS} \mathrm{HCl}$, then rinsed and stored in $\mathrm{SB}$ $\mathrm{HNO}_{3}$ until ready for use. 


\subsubsection{Trace element chemistry}

For trace element analyses a split of the same sample powders previously used for XRF and isotope analysis from this and studies by McGee et al (2012 and 2013) was used. $50 \mathrm{mg}$ of rock powder was weighed on a high precision balance to $\pm 0.0001 \mathrm{~g}$ in a pre-cleaned (outlined above) $23 \mathrm{~mL}$ Savillex screw top beaker. Samples and international reference standards BHVO-2G and BCR-2 were digested using conventional methods (Fig. 2.4.); ca. $1 \mathrm{~mL}$ concentrated (conc.) hydrofluoric acid (29M SS HF) was combined with ca. $0.5 \mathrm{~mL}$ conc. nitric acid (16M SS $\mathrm{HNO}_{3}$ ), the beaker was sealed and this was refluxed at $120^{\circ} \mathrm{C}$ for $3-4$ days to ensure complete digestion. Once digested, the solution was dried to incipient dryness (to reduce sample loss by the production of insoluble fluoride), and taken up with ca. 2 $\mathrm{mL}$ conc. $\mathrm{HNO}_{3}$ and again dried to incipient dryness. This step is repeated to allow the removal of any fluorides that may have formed. Following this the samples were refluxed with $5 \mathrm{~mL} 6 \mathrm{M} \mathrm{HCl}(2 \times S B)$ overnight. After complete dissolution of sample the $\mathrm{HCl}$ was evaporated and then taken up with ca. $2 \mathrm{~mL}$ conc. $\mathrm{HNO}_{3}$. To allow the chlorides formed to turn back into nitrides the sample was then evaporated to incipient dryness, taken up again with $9 \mathrm{~mL} 1 \mathrm{M} \mathrm{HNO}_{3}$ (SS) and finally left to reflux for 2-3 days to form the analytical solution. Prior to analysis the samples were centrifuged at $2000 \mathrm{rpm}$ for 5 minutes. The final solutions were then transferred to pre-cleaned $10 \mathrm{~mL}$ centrifuge tubes (c-tubes), ensuring all drops were removed from the beakers, and weighed on a high precision balance $( \pm 0.0001 \mathrm{~g})$. To analyse the sample solutions dilutions of the stock solution are made by removing a $60 \mu \mathrm{L}$ aliquot into another c-tube, the aliquot was again precisely weighed and it then topped up with $5.94 \mathrm{~mL}$ of $1 \% \mathrm{HNO}_{3}$ and weighed again, this procedure ensures the final dilution of the sample could be accurately calculated. The process is outlined in Figure 2.4 using equations 2.8.6.1 and 2.8.6.2 for dilution calculations, where sample weight is recorded in grams $(g)$. 


\subsubsection{Analysis of elements on ICP-MS}

The sample dilutions prepared as described above were analysed on an Agilent 7500CS ICP-MS (the same instrument as used for the in situ tephra-derived glass analysis) at the VUW. Analysis conditions are shown in Table 2.8. Prior to analysis the ICP-MS was tuned using an Agilent $10 \mathrm{ppb}$ multi-element standard tuning solution diluted to $1 \mathrm{ppb}$. Instrumental conditions, torch conditions and gas flow rates, were optimised to maximise the machine sensitivity but minimise the production of oxides. This process was monitored using measured values of $\mathrm{CeO}^{+} / \mathrm{Ce}^{+}$(masses 156/140) and maintained to a value of $\leq 1.5 \%$. Pulse/Analogue (P/A) factors were measured on relevant elements (e.g., $\mathrm{Ca}, \mathrm{V}, \mathrm{Cr}, \mathrm{Ni}, \mathrm{Sr}, \mathrm{Ba}, \mathrm{Ce}$, Mo, and $\mathrm{Zr}$ ), and multiple isotopes of selected elements were measured, as detailed in Section 2.5.2. Samples were introduced into the ICP-MS using a wet spray chamber and peripump. The individual analysis of a sample is 120 seconds (s) in duration, preceded by a $30 \mathrm{~s}$ water wash, $180 \mathrm{~s} 1 \% \mathrm{HNO}_{3}$ wash out, $60 \mathrm{~s} 1 \% \mathrm{HNO}_{3}$ background analysis. Each analysis session included 3 bracketing standards, 7 samples, and one internal standard (BCR-2). 


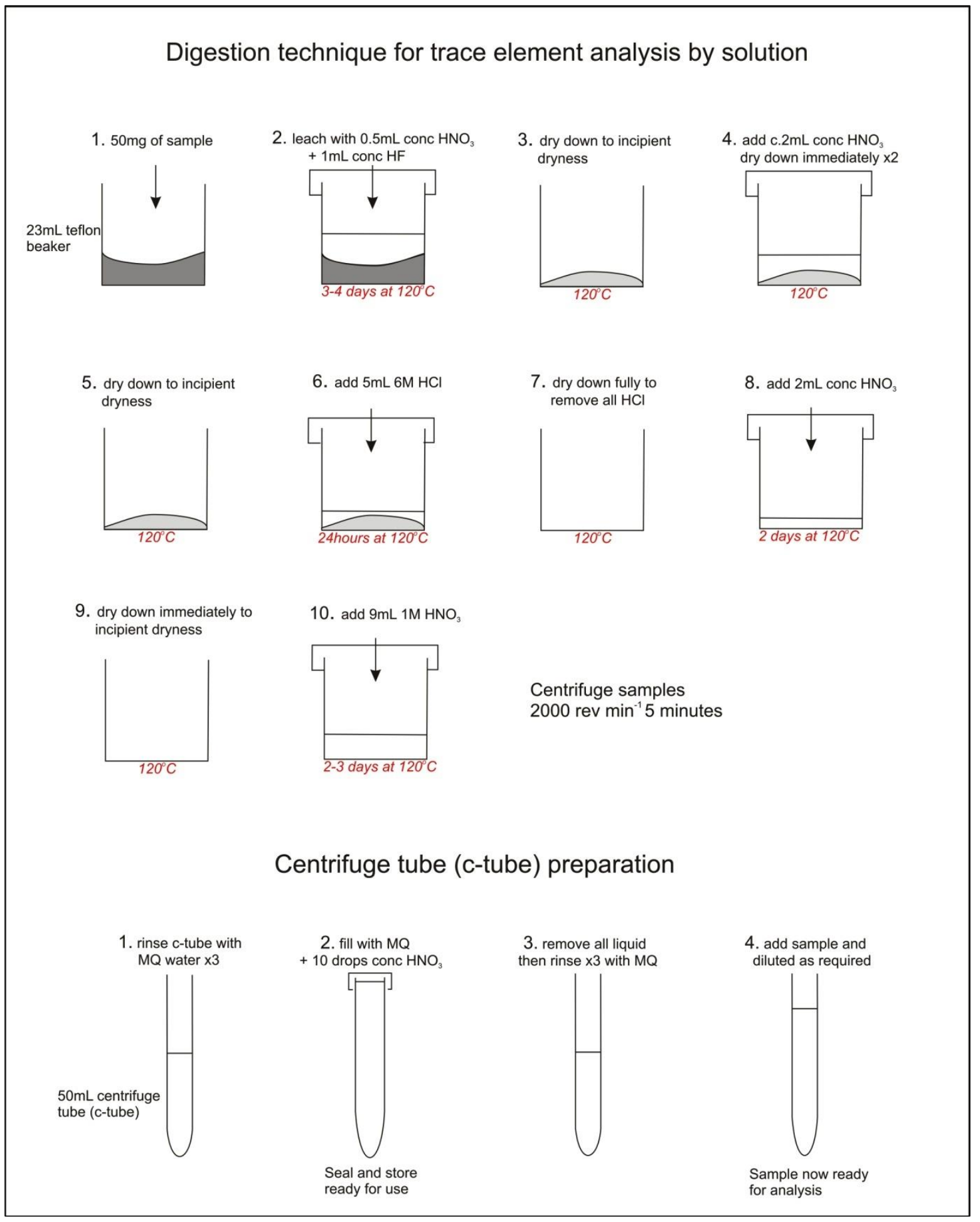

Figure 2.4. Schematic diagram of the procedure for trace element digestion prior to analysis by solution-ICP-MS and centrifuge tube preparation (after McGee et al., 2013). 
Table 2.8. Analysis conditions for solution ICP-MS analysis

\begin{tabular}{|c|c|}
\hline Solution-ICP-MS & \\
\hline Instrument & Agilent 7500 CS octopole \\
\hline Aquisition mode & Peak hopping \\
\hline Detection mode & Pulse and analogue counting (mostly pulse) \\
\hline \multicolumn{2}{|l|}{ Standards } \\
\hline Calibration standard & BHVO2 \\
\hline Secondary standard & BHVO2, BCR2 \\
\hline Blank standard & Procedural blank $\left(1 \% \mathrm{HNO}_{3}\right)$ \\
\hline Internal standard & ${ }^{43} \mathrm{Ca}$ \\
\hline \multicolumn{2}{|l|}{ Method Parameters } \\
\hline Background acquisition & $60 \mathrm{~s}$ \\
\hline Standard aquisition & $60 \mathrm{~s}$ \\
\hline Sample aquisition & $120 \mathrm{~s}$ \\
\hline Washout time & $125 \mathrm{~s}$ ( 5 secs water, 120 secs $1 \% \mathrm{HNO} 3)$ \\
\hline $\begin{array}{l}\text { Measured isotopes and } \\
\text { integration times }\end{array}$ & $\begin{array}{ll}10 \mathrm{~ms}: & { }^{7} \mathrm{Li},{ }^{25} \mathrm{Mg},{ }^{43} \mathrm{Ca},{ }^{45} \mathrm{Sc},{ }^{53} \mathrm{Cr},{ }^{51} \mathrm{~V},{ }^{60} \mathrm{Ni},{ }^{63} \mathrm{Cu},{ }^{66} \mathrm{Zn},{ }^{69} \mathrm{Ga}, \\
& { }^{71} \mathrm{Ga},{ }^{86} \mathrm{Sr},{ }^{89} \mathrm{Y},{ }^{90} \mathrm{Zr},{ }^{91} \mathrm{Zr},{ }^{93} \mathrm{Nb}^{137} \mathrm{Ba},{ }^{139} \mathrm{La},{ }^{140} \mathrm{Ce},{ }^{146} \mathrm{Nd}\end{array}$ \\
\hline & $20 \mathrm{~ms}: \quad{ }^{85} \mathrm{Rb},{ }^{141} \mathrm{Pr},{ }^{147} \mathrm{Sm},{ }^{157} \mathrm{Gd},{ }^{163} \mathrm{Dy}$ \\
\hline & $\begin{array}{ll}50 \mathrm{~ms}: & { }^{95} \mathrm{Mo},{ }^{133} \mathrm{Cs},{ }^{151} \mathrm{Eu},{ }^{153} \mathrm{Eu},{ }^{159} \mathrm{~Tb},{ }^{165} \mathrm{Ho},{ }^{166} \mathrm{Er},{ }^{169} \mathrm{Tm},{ }^{172} \mathrm{Yb}, \\
& { }^{175} \mathrm{Lu},{ }^{178} \mathrm{Hf},{ }^{181} \mathrm{Ta},{ }^{205} \mathrm{Tl},{ }^{208} \mathrm{~Pb},{ }^{232} \mathrm{Th},{ }^{238} \mathrm{U},\end{array}$ \\
\hline \multicolumn{2}{|r|}{ 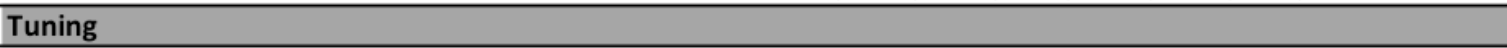 } \\
\hline Tuning standard & Agilent 1ppb solution (Li, Co, Y, Ce, Tl) \\
\hline Monitored isotopes during tuning & ${ }^{7} \mathrm{Li},{ }^{59} \mathrm{Co}{ }^{89} \mathrm{Y},{ }^{140} \mathrm{Ce},{ }^{205} \mathrm{TI}, \quad$ (RSD for each isotope $<2 \%$ ) \\
\hline Calibration standard & BHVO2 \\
\hline Monitored isotopes during tuning & ${ }^{7} \mathrm{Li},{ }^{59} \mathrm{Co},{ }^{88} \mathrm{Sr},{ }^{89} \mathrm{Y},{ }^{139} \mathrm{La},{ }^{140} \mathrm{Ce},{ }^{157} \mathrm{Gd},{ }^{172} \mathrm{Yb},{ }^{205} \mathrm{Tl}$, \\
\hline Oxides & $\mathrm{CeO}^{+} / \mathrm{Ce}^{+} 1 \mathrm{ppb}$ solution $<1.5 \%$ \\
\hline Isotope P/A factors calculated on & ${ }^{7} \mathrm{Li},{ }^{24} \mathrm{Mg},{ }^{27} \mathrm{Al},{ }^{59} \mathrm{Co},{ }^{88} \mathrm{Sr},{ }^{89} \mathrm{Y},{ }^{140} \mathrm{Ce},{ }^{205} \mathrm{TI},{ }^{238} \mathrm{U}$ \\
\hline BHVO-2 & \\
\hline Carrier Gas (Ar) & $0.89-0.97 \mathrm{~L} / \mathrm{min}$ \\
\hline Makeup gas (Ar) & $0.23-0.26 \mathrm{~L} / \mathrm{min}$ \\
\hline RF power & $1500 \mathrm{~W}$ \\
\hline RF matching & $1.77 \mathrm{~V}$ \\
\hline Sample depth & $7 \mathrm{~mm}$ \\
\hline Extract 1 ion lense & $5.9-6.0 \mathrm{~V}$ \\
\hline Extract 2 ion lense & -153.5 to $-143.5 \mathrm{~V}$ \\
\hline
\end{tabular}




\subsubsection{Data reduction and concentration calculations}

Trace element abundances were calculated relative to a matrix-matched bracketing standard (BHVO-2), which was run every 4 samples, three times within an analysis session, under identical conditions. ${ }^{43} \mathrm{Ca}$ was used as the internal standard for secondary data normalisation and this value was taken from the XRF results from the same samples.

The background count rates were measured for 60 s prior to analysis and the mean value was subtracted from the samples using the reduction programme lolite. Once this is removed the trace element concentrations were calculated using the following equations;

$$
C_{\text {sample }}^{\text {CaO,ICP-MS }}=C_{\text {std }}^{\text {CaO }} \times\left(\frac{C P S_{\text {sample }}^{C a}}{C P S_{\text {std }}^{C a}}\right)
$$

Where;

$C_{\text {sample }}^{\text {CaO,ICPS }}, C_{\text {sample }}^{\text {CaO,XRF }}=$ concentration of $\mathrm{CaO}$ measured by ICP-MS or XRF $C_{\text {std }}^{\mathrm{CaO}}=\mathrm{GeoREM} \mathrm{CaO}$ concentration for BHVO-2 standard $C P S_{\text {sample }}^{C a}, C P S_{\text {std }}^{C a}=$ counts per second obtained on ${ }^{43} \mathrm{Ca}$ during analysis of whole rock dilution (sample) or BHVO-2 (std)

$$
C_{\text {sample }}^{x, I C P-M S}=C_{\text {std }}^{x} \times\left(\frac{C_{\text {sample }}^{\text {CaO, } \mathrm{XRF}}}{C_{\text {sample }}^{\text {CaO,ICPS }}}\right) \times\left(\frac{C P S_{\text {sample }}^{x}}{C P S_{\text {std }}^{x}}\right)
$$

Where;

$C_{\text {sample }}^{x, I C P S}=$ concentration of element $\mathrm{x}$ determined by ICP-MS analysis

$C_{\text {sample }}^{\text {CaO,XRF }}=$ concentration of $\mathrm{CaO}$ measured by ICP-MS or XRF

$C_{\text {std }}^{x}=$ GeoREM concentration of element $\mathrm{x}$ in std BHVO-2

$C P S_{\text {sample }}^{x}$. CPS std $=$ counts per second obtained for element $\mathrm{x}$ during analysis of whole rock dilution (sample) or BHVO-2 (std) 


\subsubsection{Accuracy and precision of solution-ICP-MS}

Two secondary standards were run throughout an analysis session to monitor the accuracy and precision of the solution ICP-MS analysis. International rock standards BCR-2 and BHVO-2 were chosen based on their well-documented compositions recorded from a number of laboratories using modern analytical conditions, and their similarity to the composition of the samples used for this study. All the trace element data obtained by solution-ICP-MS for these standards is recorded in Appendix B. Table 2.9 records the average values of all the analyses and shows the accuracy (by \% offset) and precision (by 2sd\%) of the measurements made. Analytical precision based on 15 replicate analyses of BCR-2 is $<6.5 \%$ for most trace elements. The exceptions to this include $\mathrm{Cr} \pm 8.2 \%$, $\mathrm{Nb} \pm 16.5 \%$, Cs $\pm 6.8 \%, \mathrm{Ba} \pm 8 \%, \mathrm{Ta} \pm 19 \%$ and $\mathrm{Pb} \pm 21 \%$. For the majority of BCR-2 trace elements are accurate to $\leq 6 \%$ apart from $\mathrm{Li}, \mathrm{Cr}, \mathrm{Cu}, \mathrm{Nb}, \mathrm{Cs}$, Eu and Ta. For 11 replicates of BHVO-2 precision is $<5 \%$ for all trace elements except $\mathrm{Nb}(8.7 \%)$, Cs (6\%) and $\mathrm{Ta}$ $(8 \%)$, and all values are within $<1.5 \%$ of the reference value, except for Ta with an offset of $\pm 6.4 \%$. 
Table 2.9. Summary table of standard data gained whilst analysing whole rock for trace element concentrations using solution-ICP-MS. Reference values are taken from GeoREM preferred values; Jochum and Nerling, 2006. All values are reported in ppm, with meausred isotopes of elements detailed. Red highlights show those figures discussed in the text as outliers.

\begin{tabular}{|c|c|c|c|c|}
\hline \multicolumn{5}{|c|}{ BHVO values } \\
\hline Element & $\begin{array}{l}\text { Reference } \\
\text { value }\end{array}$ & $\begin{array}{c}\text { Average } \\
\text { (wt\%) }\end{array}$ & $\begin{array}{l}\% \text { offset } \\
\text { from std }\end{array}$ & $2 s d \%$ \\
\hline Ca43 & 11.4 & 11.4 & 0.00 & 0.00 \\
\hline Li7 & 4.8 & 4.77 & -0.71 & 2.69 \\
\hline Sc45 & 32.0 & 31.9 & -0.38 & 3.29 \\
\hline Ti47 & 16300 & 16248 & -0.32 & 3.40 \\
\hline Ti49 & 16300 & 16267 & -0.20 & 1.99 \\
\hline V51 & 317 & 318 & 0.17 & 3.15 \\
\hline Cr53 & 280 & 279 & -0.28 & 2.15 \\
\hline Mn55 & 0.2 & 0.17 & -0.62 & 3.16 \\
\hline Co59 & 45.0 & 44.7 & -0.65 & 2.01 \\
\hline $\mathrm{Ni} 60$ & 119 & 118 & -0.43 & 3.17 \\
\hline Cu63 & 127 & 127 & -0.15 & 2.99 \\
\hline Zn66 & 103 & 103 & -0.23 & 2.41 \\
\hline Ga71 & 22.0 & 22.0 & -0.22 & 2.68 \\
\hline Rb85 & 9.1 & 9.03 & -0.53 & 3.16 \\
\hline Sr88 & 396 & 394 & -0.43 & 1.76 \\
\hline Y89 & 26.0 & 25.9 & -0.30 & 2.98 \\
\hline Zr90 & 172 & 171 & -0.60 & 2.52 \\
\hline Zr91 & 172 & 171 & -0.62 & 2.79 \\
\hline Nb93 & 18.1 & 18.3 & 1.22 & 8.68 \\
\hline Cs133 & 0.1 & 0.10 & -0.95 & 6.00 \\
\hline Ba137 & 131 & 130 & -0.72 & 2.21 \\
\hline La139 & 15.2 & 15.1 & -0.48 & 2.53 \\
\hline Ce140 & 37.5 & 37.3 & -0.51 & 2.81 \\
\hline Pr141 & 5.3 & 5.25 & -0.84 & 2.38 \\
\hline Nd146 & 24.5 & 24.3 & -0.69 & 2.38 \\
\hline Sm147 & 6.1 & 6.01 & -0.95 & 3.41 \\
\hline Eu151 & 2.1 & 2.06 & -0.47 & 3.17 \\
\hline Eu153 & 2.1 & 2.06 & -0.46 & 2.26 \\
\hline Gd157 & 6.2 & 6.21 & -0.51 & 2.96 \\
\hline Tb159 & 0.9 & 0.93 & -1.04 & 2.67 \\
\hline Dy163 & 5.3 & 5.28 & -0.51 & 3.46 \\
\hline Ho165 & 1.0 & 0.97 & -0.16 & 2.80 \\
\hline Er166 & 2.5 & 2.53 & -0.53 & 3.72 \\
\hline Tm169 & 0.3 & 0.34 & -1.06 & 3.20 \\
\hline Yb172 & 2.0 & 1.98 & -1.19 & 1.89 \\
\hline Lu175 & 0.3 & 0.27 & -0.30 & 4.01 \\
\hline Hf178 & 4.4 & 4.34 & -0.35 & 2.26 \\
\hline Ta181 & 1.1 & 1.21 & 6.39 & 7.97 \\
\hline $\mathrm{Pb} 208$ & 1.6 & 1.60 & 0.04 & 4.56 \\
\hline Th232 & 1.2 & 1.21 & -1.18 & 1.89 \\
\hline U238 & 0.4 & 0.40 & -1.01 & 3.52 \\
\hline
\end{tabular}

\begin{tabular}{|c|c|c|c|c|}
\hline \multicolumn{5}{|c|}{ BCR2 (internal standard) values } \\
\hline Element & $\begin{array}{l}\text { Reference } \\
\text { value }\end{array}$ & $\begin{array}{c}\text { Average } \\
\text { (wt\%) }\end{array}$ & $\begin{array}{l}\% \text { offset } \\
\text { from std }\end{array}$ & $2 s d \%$ \\
\hline Ca43 & 7.1 & 7.12 & 0.00 & 0.03 \\
\hline Li7 & 9.0 & 10.2 & 13.01 & 5.59 \\
\hline Sc45 & 33.0 & 34.6 & 4.84 & 6.45 \\
\hline Ti47 & 13500 & 13847 & 2.57 & 4.87 \\
\hline Ti49 & 13500 & 13858 & 2.65 & 5.93 \\
\hline V51 & 416 & 429 & 3.10 & 4.98 \\
\hline Cr53 & 13.0 & 14.1 & 8.19 & 8.22 \\
\hline Mn55 & 0.2 & 0.20 & 2.30 & 4.99 \\
\hline $\operatorname{Co59}$ & 37.0 & 38.8 & 4.99 & 5.52 \\
\hline Ni60 & 12.0 & 12.6 & 5.12 & 6.93 \\
\hline Cu63 & 21.0 & 3.50 & -83.33 & 1983.15 \\
\hline Zn66 & 127 & 134 & 5.67 & 5.97 \\
\hline Ga71 & 23.0 & 23.6 & 2.71 & 6.00 \\
\hline Rb85 & 46.9 & 48.5 & 3.49 & 6.02 \\
\hline Sr88 & 340.0 & 352 & 3.58 & 6.05 \\
\hline Y89 & 37.0 & 37.2 & 0.62 & 6.08 \\
\hline Zr9o & 201 & 194 & -3.46 & 5.43 \\
\hline Zr91 & 201 & 194 & -3.38 & 6.01 \\
\hline Nb93 & 12.6 & 13.2 & 4.73 & 16.50 \\
\hline Cs133 & 1.1 & 1.24 & 12.49 & 6.79 \\
\hline Ba137 & 677 & 689 & 1.82 & 7.96 \\
\hline La139 & 24.9 & 25.9 & 4.16 & 6.19 \\
\hline Ce140 & 52.9 & 55.0 & 4.06 & 5.57 \\
\hline Pr141 & 6.7 & 7.03 & 4.92 & 5.64 \\
\hline Nd146 & 28.7 & 29.9 & 4.16 & 6.37 \\
\hline Sm147 & 6.6 & 6.80 & 3.35 & 6.35 \\
\hline Eu151 & 2.0 & 2.10 & 7.22 & 5.87 \\
\hline Eu153 & 2.0 & 2.15 & 9.59 & 6.18 \\
\hline Gd157 & 6.8 & 7.15 & 5.94 & 5.97 \\
\hline Tb159 & 1.1 & 1.10 & 2.45 & 5.84 \\
\hline Dy163 & 6.4 & 6.68 & 4.15 & 6.30 \\
\hline Ho165 & 1.3 & 1.33 & 4.17 & 5.71 \\
\hline Er166 & 3.7 & 3.79 & 3.60 & 5.81 \\
\hline $\operatorname{Tm} 169$ & 0.5 & 0.56 & 3.04 & 6.54 \\
\hline Yb172 & 3.4 & 3.51 & 3.96 & 6.00 \\
\hline Lu175 & 0.5 & 0.51 & 1.56 & 6.73 \\
\hline Hf178 & 4.9 & 5.03 & 2.55 & 6.10 \\
\hline Ta181 & 0.7 & 0.97 & 31.14 & 18.63 \\
\hline $\mathrm{Pb} 208$ & 11.0 & 10.9 & -0.96 & 20.52 \\
\hline Th232 & 6.0 & 6.18 & 2.52 & 5.19 \\
\hline U238 & 1.7 & 1.70 & 0.73 & 5.85 \\
\hline
\end{tabular}




\section{Section $\mathrm{C}-\mathrm{Re}$, Os and $\mathrm{Pb}$ Analysis}

\subsection{Sample Selection and Preparation}

Bulk rock samples were chosen to follow on from the work undertaken by McGee et al. (2013). Selected samples were chosen from the pre-existing sample set to satisfy two criteria

(1) be a primitive chemical composition (e.g., Mg\# >60) [caluculation $\left.\left.\mathrm{Mg} \#=([\mathrm{Mg}] /([\mathrm{Mg}]+[\mathrm{Fe}]))^{\star} 100\right)\right]$

(2) be representative for the range of $\mathrm{AVF}$ rock $\mathrm{Pb}$ isotopic composition.

By analysing this sample set it is possible to make a direct comparison with previous work and provide more robust conclusions as to the source characteristics below the AVF. 15 samples of both lava and scoria from Rangitoto, Mt. Wellington, Puketutu, Three Kings, Pupuke, Purchas Hill and Wiri were chosen. These samples were crushed using a Rocklabs Boyd crusher and powdered using an agate ring mill (to avoid contamination in $\mathrm{Re}$ ) at VUW. Re-Os chemistry and analysis was undertaken in the GEOTOP facilities at UQAM.

\subsection{Os isotopes, Os and Re Analysis}

\subsubsection{HPA-S digestion}

$1 \mathrm{~g}$ of sample powder was spiked with a known enriched tracer solution of ${ }^{190} \mathrm{Os} /{ }^{185} \mathrm{Re}$. This was then digested in Teflon sealed quartz tubes with $3 \mathrm{~mL} 6 \mathrm{M} \mathrm{HCl}$

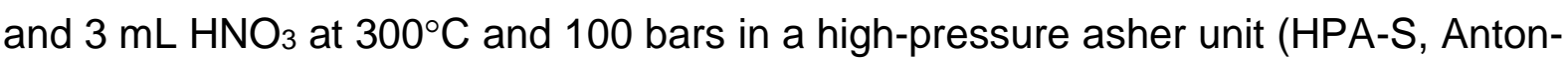
Parr-Perkin Elmer Instruments) for 12 hours (Meisel et al., 2003). This equilibrates the powdered sample and liquid spike by oxidation to $\mathrm{OsO}_{4}$ and acts to digest the sample.

\subsubsection{Paris $\mathrm{Br}_{2}$ Extraction}

After digestion Os was extracted using the Paris $\mathrm{Br}_{2}$ technique (after Birck et al., 1997). $2 \mathrm{~mL}$ chilled $\mathrm{Br}_{2}$ was added to sample and left on a hot plate at $90^{\circ} \mathrm{C}$ for 2 hours. This acts to scavenge the already oxidised Os from the aqueous solution into 
the liquid $\mathrm{Br}_{2}$, leaving $\mathrm{Re}$ and $\mathrm{PGEs}$ within the aqueous solution. Isolated liquid $\mathrm{Br}_{2}$ (inc Os) was then removed to a large Teflon beaker $(120 \mathrm{ml})$ and 20 drops of $\mathrm{HBr}$ was added to reduce the $\mathrm{Os}$ from volatile $\mathrm{Os}^{8+}\left(\mathrm{OsO}_{4}\right)$ to non-volatile $\mathrm{Os}^{4+}\left(\mathrm{OsBr}^{2-}\right)$. This was then left at $<90^{\circ} \mathrm{C}$ for $12 \mathrm{hrs}$ to allow the $\mathrm{Br}_{2}$ to evaporate leaving the Os within the $\mathrm{HBr}$. At this stage the Os is reasonably pure but requires a further microdistillation step to achieve sufficient sample purity for analysis.

\subsubsection{Micro-distillation of Os}

The Os and $\mathrm{HBr}$ was then transferred into the lid of the teflon beaker and left on the hot plate for $12 \mathrm{hrs}$ at $110^{\circ} \mathrm{C}$ to evaporate the $\mathrm{HBr}$. The Re and PGE's were left to one side in the large Teflon beaker. One drop of $\mathrm{Cr}_{2} \mathrm{O}_{3}$ in $\mathrm{H}_{2} \mathrm{SO}_{4}$ was then added to the remaining residue. $1 / 2$ drop of $\mathrm{HBr}$ was added to the tip of a conical tub, which was carefully inverted over the residue and secured tightly. This was then wrapped in Al-foil and left on a hot plate at $<90^{\circ} \mathrm{C}$ for no longer than $3 \mathrm{hrs}$. This process acts as a micro-distillation to remove any remaining Re from the sample (Fig. 2.5.). The $\mathrm{Cr}_{2} \mathrm{O}_{3}$ works to oxidise the osmium complex $\mathrm{OsBr}_{6}{ }^{2-}$ and thereby causes it to re-volatilise as $\mathrm{OsO}_{4}$. This then evaporates in its gas phase to the tip on the conical tub where it is reduced and stabilised by the $\mathrm{HBr}$ back to $\mathrm{OsBr}_{6}{ }^{2-}$ (Birck et al., 1997). The Al-foil was carefully removed, the tub is opened discarding the lid and the conical tub reverted to the correct way up. This was then left to dry down further to $0.5-1.5 \mu \mathrm{L}$ on a hot plate at $110^{\circ} \mathrm{C}$ for 20 minutes. The osmium is then ready for analysis by N-TIMS.
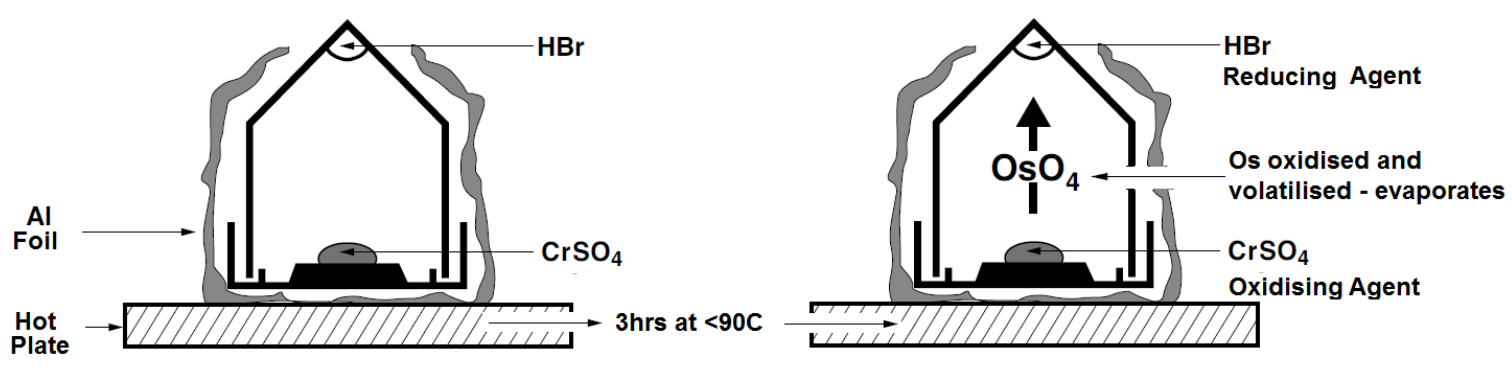

Figure 2.5. Schematic diagram to show micro-distillation technique after Birck et al. (1997) used to remove remaining $R e$ from sample. 


\subsubsection{Analysis of Os by N-TIMS}

Osmium isotopic measurements were carried out on a Triton TIMS in negative ion mode (Creaser et al., 1991). High purity Pt filaments were de-gassed in air to white hot temperatures for 2 minutes (Birck et al., 1997). Samples were then loaded onto the filaments in $\mathrm{HBr}$, as $\mathrm{OsBr}_{6}{ }^{2-}$, and coated with a saturated solution of $\mathrm{Ba}(\mathrm{OH})_{2}$ and $\mathrm{NaOH}$, to act as an electron emitter (Birck et al., 1997). The filaments were then quickly flash heated, to reduce the organic interference from masses 233235. Samples were loaded into the mass spec and $\mathrm{O}_{2}$ saturated with water vapour was leaked into the chamber (Walczyk et al., 1991). Filaments were then heated slowly to a temperature of $705^{\circ} \mathrm{C}$.

\subsubsection{Re column chemistry}

$3 \mathrm{~mL}$ conc. HF was added to the large Teflon beaker containing the Re and PGEs in aqueous solution, and left, sealed on a hot plate for $1 \mathrm{hr}$ at $110^{\circ} \mathrm{C}$. This was then uncapped and the HF evaporated off for $12 \mathrm{hrs}$ at $110^{\circ} \mathrm{C}$, to allow the removal of any remaining silicates. Pipette columns were prepared by the addition of ca. 0.6 $\mathrm{mL}$ AG1X8 200-400 resin. Whilst this was settling, $2 \mathrm{~mL} 0.8 \mathrm{M} \mathrm{HNO}_{3}$ was added to the dried down samples, the beakers were then sealed and placed in a sonic bath to allow the Re to be fully dissolved. The columns were then cleaned by three washes through of $5 \mathrm{~mL} 8 \mathrm{M} \mathrm{HNO}_{3}$, conditioned with $2 \mathrm{~mL} 0.8 \mathrm{M} \mathrm{HNO}_{3}$, and the sample is then introduced. Two lots of $5 \mathrm{~mL} 0.8 \mathrm{M} \mathrm{HNO}_{3}$ were added to wash out the unwanted elements, followed by collection of $\mathrm{Re}$ in $1 \mathrm{~mL} 8 \mathrm{M} \mathrm{HNO}$ and $4 \mathrm{~mL} 8 \mathrm{M} \mathrm{HNO}$. The solution was then dried down for $24 \mathrm{hrs}$ at $120^{\circ} \mathrm{C}$ and was then ready for analysis on Sector Field (SF) ICP-MS (Fig. 2.6.).

\subsubsection{Analysis of Re by SF-ICP-MS}

After evaporation, samples were taken back up in $1 \mathrm{~mL}$ of $2 \% \mathrm{HNO}_{3}$ and this solution was then transferred into $5 \mathrm{~mL}$ c-tubes, and centrifuged. Solutions were then transferred into miniature shot glasses $(3 \mathrm{~mL})$ ready for analysis. Analysis was undertaken on a NU instruments ATTO-M Sector Field (SF)-ICP-MS. Wash out with 
$\mathrm{MQ} \mathrm{H}_{2} \mathrm{O}, 4 \% \mathrm{HNO}_{3}$ and $2 \% \mathrm{HNO}_{3}$, was run between each sample and every two samples a blank (2\% $\left.\mathrm{HNO}_{3}\right)$ and the standard NIST SRM 3141 was run.

\subsubsection{Determination of Os and Re concentrations}

Os and Re concentrations were determined by isotope dilution techniques using ${ }^{185} \mathrm{Re}$ and ${ }^{190} \mathrm{Os}$ spiked samples. Blanks for the total procedure were $0.3 \mathrm{pg}$ for Os, and $7 \mathrm{pg}$ for Re. These values were subtracted from the sample totals in data processing, along with an oxygen interference and sample-spike unmixing correction (c.f. Luguent et al., 2000). Calculations for isotope dilution are after Albarède (1995).

\subsubsection{Accuracy and precision of N-TIMS and SF-ICP-MS}

Os isotope measurements were corrected for instrumental drift using the internal standard DROsS. Internal precisions (2 SE) for ${ }^{187} \mathrm{Os} /{ }^{188} \mathrm{Os}< \pm 0.00012$. All values are recorded in Appendix B. For Re, instrumental drift for SF-ICP-MS analysis was corrected for using the standard NIST SRM 3143 (values from Gramlich et al., 1973). Internal precision (2SE) for ${ }^{187} \mathrm{Re} /{ }^{185} \mathrm{Re}$ were $< \pm 0.05$, and all valuesare recorded in Appendix B. Unfortunately, no natural rock standards wih low enough concentrations are currently available to act as appropriate secondary standards for basaltic Os or Re analysis. Currently existing standards contain high levels (ppb) of Os and $\mathrm{Re}$, and their use would risk causing significant cross contamination. In addition, they also represent a poor matrix match to basaltic rocks and would not behave comparably to the samples during analysis. 


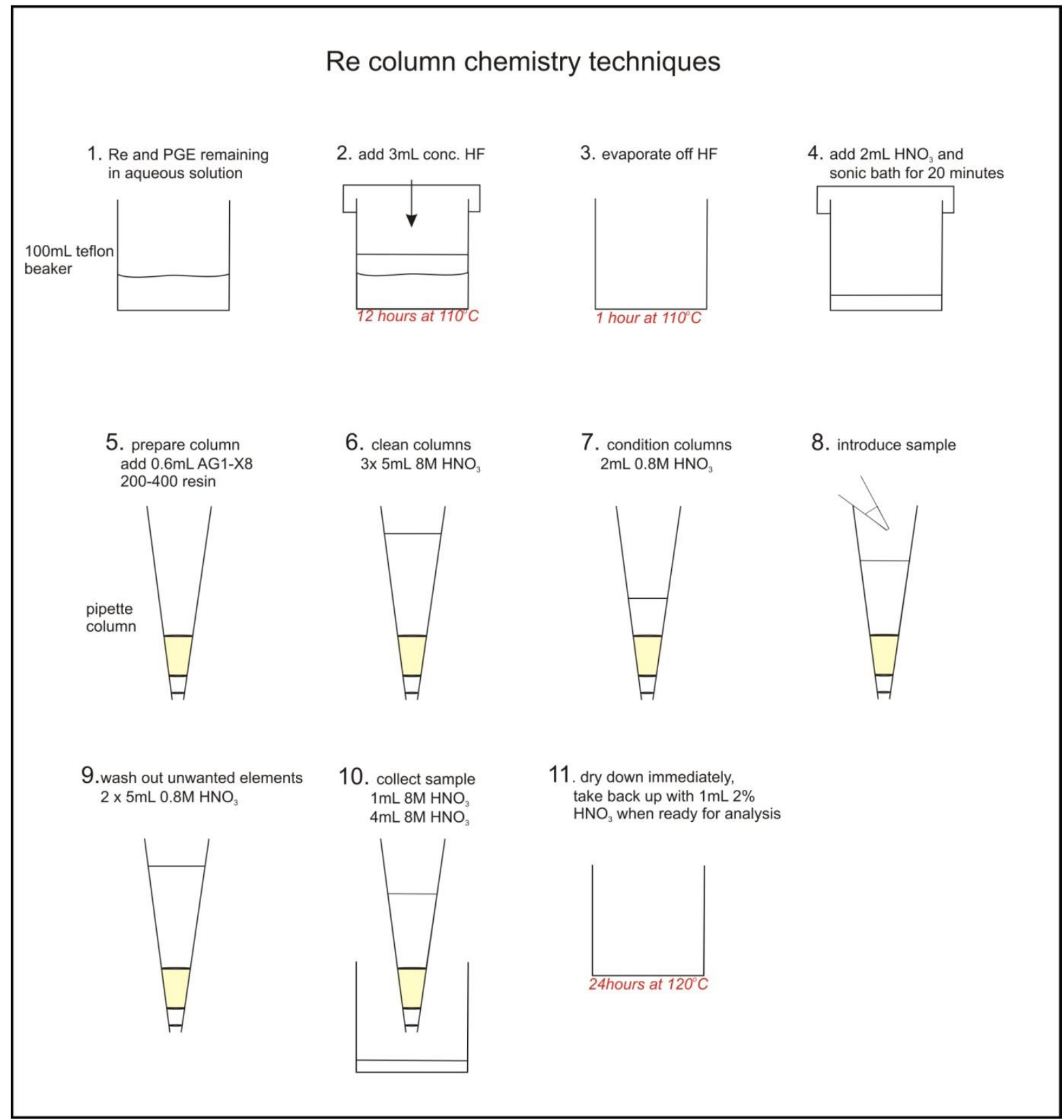

Figure 2.6. Schematic diagram of the procedure for sample digestion and extraction of Re and column chemistry. 


\subsection{0. $\mathrm{Pb}$ Isotope Analysis by MC-ICP-MS}

$\mathrm{Pb}$ isotope analysis was required for all samples that were run for Os-Re isotope work. Selected samples included those that were not analysed by McGee et al. (2013), and some duplicates of previously analysed samples. In total 9, whole rock samples were prepared and purified at VUW for analysis at Durham University, UK.

\subsubsection{Pb separation}

Figure 2.7 shows a schematic diagram of the digestion and separation procedure following after Baker et al. (2004). All beakers were pre-cleaned $23 \mathrm{~mL}$ Savillex beakers as outlined in 2.5.3.3, and Seastar (SS) grade acids ( $\mathrm{HNO}_{3}, \mathrm{HF}$, $\mathrm{HCl}$ and $\mathrm{HBr}$ ) were used throughout the procedure. The rock powder is the same used in all stages of chemistry and in some cases the same as that prepared for the McGee study. $200 \mathrm{mg}$ of rock powder (same as used for trace elements and in McGee et al., 2013) was weighed on a high precision balance to $\pm 0.0001 \mathrm{~g}$ and added to a pre-cleaned beaker. $4 \mathrm{~mL}$ of $6 \mathrm{M} \mathrm{HCL}$ was added, the beaker was sealed and allowed to boil for 1 hour at $120^{\circ} \mathrm{C}$. The supernatant formed was removed and the sample was rinsed 3 times with $M Q$ water. The sample was then digested using conventional methods; 30 drops of conc. HF and 15 drops of conc. $\mathrm{HNO}_{3}$ was allowed to reflux for 24 hours, followed by the sample being dried down to incipient dryness. 20 drops of conc. $\mathrm{HNO}_{3}$ was added and allowed to dry down fully. This process was repeated twice. Following this $1.5 \mathrm{~mL} 0.8 \mathrm{M} \mathrm{HBr}$ was added then evaporated immediately. $1.5 \mathrm{~mL} 0.8 \mathrm{M} \mathrm{HBr}$ was added again and left to reflux at $120^{\circ} \mathrm{C}$ with the beaker sealed for 3 hours. The solution was centrifuged for 8 minutes at 2000 rpm and was ready to pass through the separation columns.

The columns for $\mathrm{Pb}$ separation were made from $1 \mathrm{~mL}$ disposable pipette tips, their ends were cut off and frits, made out of polypropylene soaked for a minimum of 5 minutes in $6 \mathrm{M} \mathrm{HCL}$ (SS), were firmly inserted into the base of the column. Approximately $5 \mathrm{~mm}$ depth of Biorad anion exchange resin (AG1-X8) was inserted into the column within a small amount of $M Q$ water. It was critical to ensure no bubbles were formed during emplacement that would affect the rate of flow through the column. The column and resin were then washed three times using 1 vol. of $6 \mathrm{M}$ $\mathrm{HCl}$ followed by 1 vol. of $\mathrm{MQ}$. 


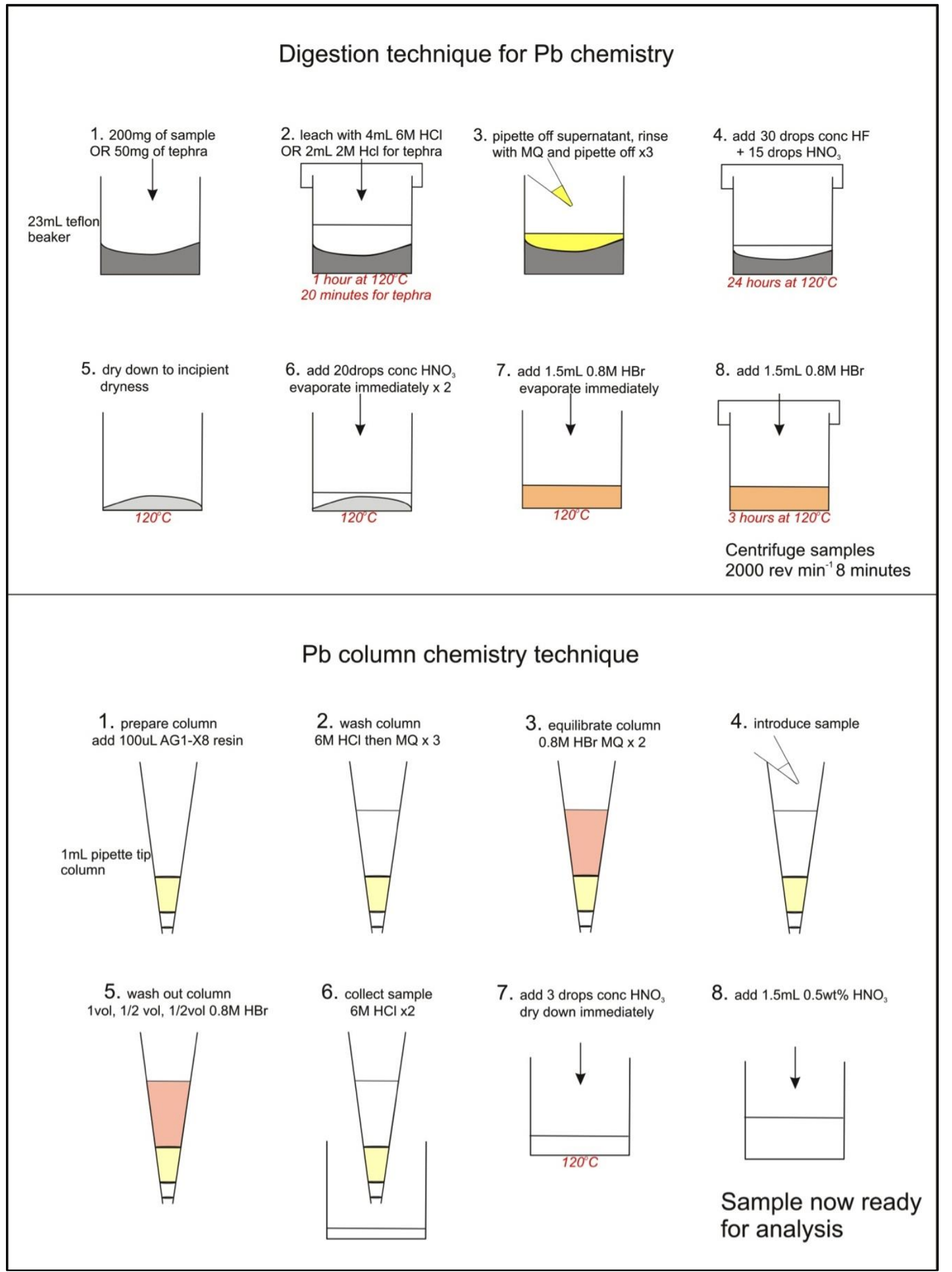

Figure 2.7. Schematic diagram of the procedure for sample digestion and extraction of $\mathrm{Pb}$ and column chemistry. 
The resin was then equilibrated using 2 vol. $0.8 \mathrm{M} \mathrm{HBr}$. The sample was introduced and unwanted elements were washed out using $1,0.5,0.5$ vol. of $0.8 \mathrm{M}$ $\mathrm{HBr}$. The $\mathrm{Pb}$ isotope cut was collected by passing 2vol. $6 \mathrm{M} \mathrm{HCl}$ through the column. This was immediately dried down and the column separation repeated. The process was repeated to ensure as pure as possible sample of $\mathrm{Pb}$. The final solution was dried down and three drops of conc. $\mathrm{HNO}_{3}$ was added and then dried down immediately. Samples were left in this dried down state until immediately before analysis where they were then taken up with $1.5 \mathrm{~mL} 0.5 \% \mathrm{HNO}_{3}$ (SS) and left on a hot plate at $120^{\circ} \mathrm{C}$ for at least 1 hour to ensure the full $\mathrm{Pb}$ cut goes into solution. The samples were then ready for analysis.

\subsection{2. $\mathrm{Pb}$ isotope analysis}

Samples were analysed for $\mathrm{Pb}$ isotope compositions using a Neptune MCICP-MS at Durham University, UK. Samples were introduced with the machine in wet plasma mode using a small volume cinnabar ${ }^{\mathrm{TM}}$ spray chamber. The machine was tuned using ca. $30 \mathrm{ppb}$ of Pb standard solution NBS-981. Adjustments were made to instrument conditions including torch position, nebuliser gas flow and voltage across each lens to optimise analytical sensitivity to ca. $8 \mathrm{~V}$ for ${ }^{208} \mathrm{~Pb}$. Samples were diluted to $8 \pm 2 \mathrm{~V}$ for ${ }^{208} \mathrm{~Pb}$ using $3 \mathrm{wt} . \% \mathrm{HNO}_{3}$ in pre-prepared acid-cleaned c-tubes. Isotope measurements were recorded for the samples in 5 s intervals over 50 integrations (2 blocks of 25). Background was recorded by deflecting the ion beam for 2 minutes and this value was automatically deducted from the sample measurements. Procedural blanks for this study were typically $<15$ pg and therefore insignificant.

\subsubsection{Accuracy and precision of MC-ICP-MS}

$\mathrm{Pb}$ isotope measurements were corrected for instrumental mass bias and drift by standard bracketing using NBS-981, internal precisions (2 SE) for this were for ${ }^{206} \mathrm{~Pb} /{ }^{204} \mathrm{~Pb}< \pm 0.0012,{ }^{207} \mathrm{~Pb} /{ }^{204} \mathrm{~Pb}< \pm 0.0013,{ }^{208} \mathrm{~Pb} /{ }^{204} \mathrm{~Pb}< \pm 0.0044$ all values are recorded in Appendix B. Secondary standard JB-2 was analysed repeatedly from multiple digestions, the average measured values are ${ }^{206} \mathrm{~Pb} /{ }^{204} \mathrm{~Pb} 18.3707 \pm 11$, for ${ }^{207} \mathrm{~Pb} /{ }^{204} \mathrm{~Pb} 15.5586 \pm 16$ and for ${ }^{208} \mathrm{~Pb} /{ }^{204} \mathrm{~Pb} 38.2784 \pm 34$ which are all within analytical error of the reference values from Baker et al. (2004), all values are reported in Table 2.10. 
Table 2.10. Internal standard values for JB-2 showing accuracy and precision for $P b$ isotope chemistry and analysis by MC-ICP-MS. Reference values for JB-2 from Baker et al. (2004).

\begin{tabular}{c|cccccc}
\hline \multicolumn{1}{c}{$\begin{array}{c}\text { Secondary Standard JB2 } \\
\text { Run\# }\end{array}$} & ${ }^{206} \mathbf{P b} /{ }^{204} \mathbf{P b}$ & 2SE & ${ }^{207} \mathbf{P b} /{ }^{204} \mathbf{P b}$ & 2SE & ${ }^{208} \mathbf{P b} /{ }^{204} \mathbf{P b}$ & 2SE \\
\hline B1 & 18.3422 & 0.00099 & 15.5628 & 0.00089 & 38.2754 & 0.00345 \\
B2 & 18.3451 & 0.00112 & 15.5629 & 0.00105 & 38.2771 & 0.00285 \\
\hline Ref values & 18.3435 & 0.00170 & 15.5619 & 0.00160 & 38.2784 & 0.00500 \\
average (n=2) & 18.3437 & 0.00106 & 15.5628 & 0.00097 & 38.2762 & 0.00315 \\
\hline
\end{tabular}

\section{Section D - Review of Data Accuracy and Precision}

\subsection{Review of in-situ analysis of tephra-derived glass shards}

For samples from Orakei Basin, Onepoto and Glover Park, new samples were taken from the cores, picked, mounted and analysed. Some of these horizons have already been previously sampled and analysed for major element concentrations and therefore values obtained can be compared to check for comparability of analyses. For shards from Hopua and Pupuke a more direct comparison can be made as the exact same shards and original mounts were re-analysed for this study.

\subsubsection{Major Element analysis comparison}

Previous analysis for all shards was run using EDS techniques on a Jeol JXA840 EMPA at the University of Auckland (UoA), however for our analysis we used WDS techniques at Victoria University of Wellington. The WDS technique is shown to produce a much smaller error for the major elements concentrations with typical errors associated with both methods shown in Table 2.11. The data for major element shard concentrations published by the UoA is normalised to $100 \%$ with the discrepancy attributed to loss of water on ignition of the sample (Shane 2005). To allow the comparison to previously published work we also apply this normalisation technique, however original and normalised values are both shown in Appendix $\mathbf{C}$.

The previously published data and the new data on the whole were shown to be comparable. Figure 2.8 shows two examples of comparisons. Example A shows re-analysis of the same samples within a pre-made mount, initially by Molloy (2008) and then repeated by this study. Example B shows two separate samples and 
analyses (Molloy (2008) and this study) for the same horizon (AVF 5 from the Orakei Basin core). Although the errors are much larger for the EDS analysis (Table 2.11.) these comparisons show that the data obtained by both methods are comparable and therefore confirms the ability to use a combination of both current and previously published data to correlate the tephra horizons. Tephra-derived glass shards from the AVF used for this study have not previously been analysed for trace element concentrations, and therefore the same principle of comparison cannot be applied to the trace element analyses made by this study.

Table 2.11. Comparison of average offset values for EDS vs. WDS analysis techniques.

\begin{tabular}{ccc}
\hline Element & $\begin{array}{c}\text { EDS analysis error }- \text { WDS analysis error - } \\
\text { average \% offset } \\
\text { (Molloy 2008) }\end{array}$ & $\begin{array}{c}\text { average \% offset } \\
\text { (This study) }\end{array}$ \\
\hline $\mathrm{SiO}_{2}$ & $< \pm 0.13$ & $< \pm 0.01$ \\
$\mathrm{Al}_{2} \mathrm{O}_{3}$ & $< \pm 0.75$ & $< \pm 0.43$ \\
$\mathrm{TiO}_{2}$ & $< \pm 10$ & $< \pm 0.24$ \\
$\mathrm{FeO}$ & $< \pm 2.5$ & $< \pm 0.16$ \\
$\mathrm{MnO}$ & $< \pm 25$ & $< \pm 11$ \\
$\mathrm{MgO}$ & $< \pm 10$ & $< \pm 1.25$ \\
$\mathrm{CaO}$ & $< \pm 2.5$ & $< \pm 1.5$ \\
$\mathrm{Na}_{2} \mathrm{O}$ & $< \pm 1.5$ & $< \pm 5.5$ \\
$\mathrm{~K}_{2} \mathrm{O}$ & $< \pm 2$ & $< \pm 0.64$ \\
$\mathrm{P}_{2} \mathrm{O}_{5}$ & $< \pm 10$ & $< \pm 1.8$ \\
\hline
\end{tabular}




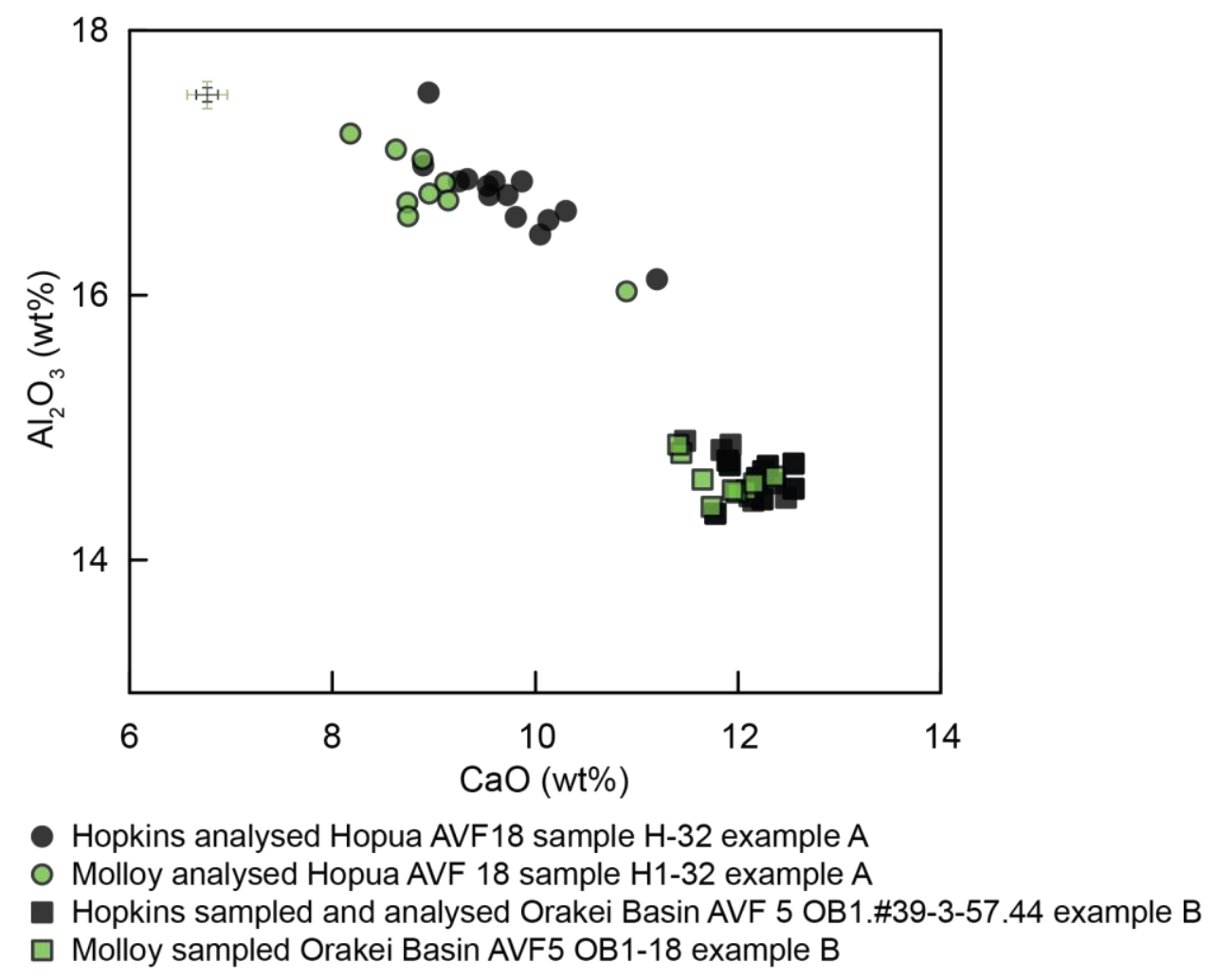

Figure 2.8. Comparison of duplicate data for mounted samples from Hopua and Orakei Basin core, between Molloy (2008) and this study. Error bars are plotted as typical \% offset outlined in Table 2.10, the green line indicates errors for Molloy (2008) and the black line for this study.

\subsubsection{Comparability of EMPA analysis with LA-ICP-MS analysis}

To monitor the comparability of the results from the two methods $\mathrm{MgO}, \mathrm{CaO}$ and $\mathrm{TiO}_{2}$, concentrations were obtained by both analysis techniques. Figure 2.9 shows the results obtained from a representative horizon with EMPA concentration (in wt.\%) on the x-axis and LA-ICP-MS concentration (calculated in wt.\%) on the yaxis. A 1:1 ratio line is also drawn to show where a perfect agreement between the two analyses would sit. For $\mathrm{CaO}$ and $\mathrm{TiO}_{2}$ the results are very similar with points plotting very close to the $1: 1$ line, in comparison $\mathrm{MgO}$ values are slightly more variable with the LA-ICP-MS generally plotting at higher concentrations than the EMPA analysis. This range in variation in the laser data in comparison to the probe data is attributed to the slightly larger spot size that is analysed by the laser. It is therefore concluded that the $\mathrm{CaO}$ and $\mathrm{TiO}_{2}$ analyses on the laser are more accurate and comparable to the probe data in comparison to $\mathrm{MgO}$. $\mathrm{CaO}$ is therefore chosen to act as an internal standard for data manipulation. 

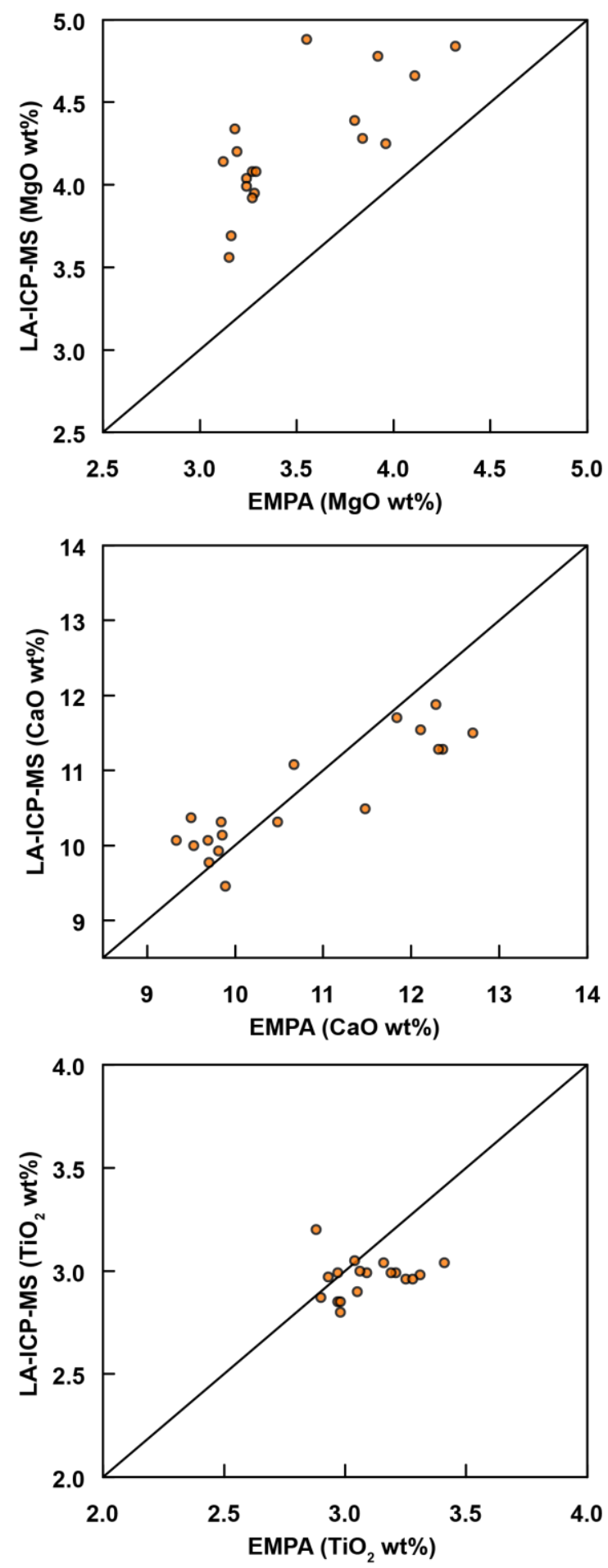

Figure 2.9. Bivariate plots of $\mathrm{MgO}, \mathrm{CaO}$ and $\mathrm{TiO}_{2}$ for comparison of data obtained on duplicate analyses from EMPA and LA-ICP-MS techniques. 


\subsubsection{LA-ICP-MS analysis at VUW vs. UoO}

The majority of samples were analysed at VUW, however, some samples where analysed at the University of Otago, Dunedin, NZ (UoO). The location of sample analysis is outlined in Appendix C, and methodologies and machines used are outlined in Section 2.5. The same standards used at VUW for BHVO-2G and BCR-2G were used at UoO, with BHVO-2G used as a bracketing standard and BCR$2 \mathrm{G}$ as an internal standard. All analyses can be found in Appendix B with average values, accuracy and precision outlined in Appendix B. Based on the average values for all the analyses done at both VUW and UoO on the internal standard BCR-2G (run as an unknown), both methods are equally as accurate with \% offset for the standard values variable with maximum errors on the same elements as outlined above. However, the UoO analyses are much more precise than the VUW values, with 2sd\% values for UoO between $3.14 \%(\mathrm{~V})$ to $32.06 \%(\mathrm{Cr})$ and for VUW between $5.69 \%(\mathrm{Ti})$ to $72.66 \%(\mathrm{Ni})$. 


\section{Preface to Chapter 3}

The study region for this thesis, the Auckland Volcanic Field (AVF), was introduced in Chapter 1, and the limits of the current understanding outlined. One of the key outstanding issues for the AVF is the lack of knowledge relating to the relative eruptive history of the field. Outlined in Chapter 1 are the benefits of tephrostratigraphy to build an eruptive history of a volcanically active region, and, due to the lack of sub-aerial tephra exposure in the AVF, tephrostratigraphy is considered the most appropriate way to reveal more details about the previous eruptions.

Extensive sediment cores have been retrieved out of the maar craters containing multiple basaltic tephra horizons sourced from the AVF centres, which can be used to over come the lack of surface exposures. In Chapter $\mathbf{3}$ I outline the improved tools and techniques used in assessing and sampling the maar lake cores, and the methods used to allow cross core correlation of the tephra horizons.

This chapter is in the form of a multi-author published paper; Hopkins, J.L., Millet, M.-A., Timm, C., Wilson, C.J.N., Leonard, G.S., Palin, J.M., Neil, H., 2015. Tools and techniques for developing tephra stratigraphies in lake cores: a case study from the basaltic Auckland Volcanic Field, New Zealand. Quaternary Science Reviews 123, 58-75. Authorship contributions include; Millet - facilitated research and manuscript development; Timm, Wilson, and Leonard - manuscript edits; Palin - training of Hopkins on LA-ICP-MS; Neil - training of Hopkins on x-ray and magnetic susceptibility scanners.

The study shows that the combination of X-ray and magnetic susceptibility analysis provides much more information about the maar cores (both sediments and basaltic tephra) in comparison to simple visual observations. Coupling these two new techniques allows accurate identification of the basaltic tephra in the cores including some new horizons previously not observed and more detail as to the characteristics of the previously identified deposits (i.e. primary vs. reworked). These identification methods are coupled with major and trace element analysis of individual basaltic tephra-derived glass shards. In combining these techniques the cross core correlation of the tephra deposits is improved, and results in the construction of a more accurate and precise eruptive history of the AVF to be constructed. 


\title{
Chapter 3
}

\section{Tools and techniques for developing tephra}

stratigraphies in lake cores: A case study from the

basaltic Auckland Volcanic Field, New Zealand

\author{
Jenni L. Hopkins*a \\ Marc-Alban Millet ${ }^{b}$, Christian Timm ${ }^{c}$, Colin J.N. Wilson ${ }^{a}$, Graham S. Leonard ${ }^{c}$, \\ J. Michael Palin ${ }^{d}$, Helen Neile.
}

aSchool of Geography, Environment and Earth Sciences, Victoria University, PO Box 600, Wellington, New Zealand

bDepartment of Earth Sciences, Durham University, Durham DH1 3LE, England

'GNS Science, PO Box 30368, Lower Hutt, Wellington, New Zealand

dDepartment of Geology, University of Otago, PO Box 56, Dunedin, New Zealand

eNational Institute of Water and Atmospheric Research, PO Box 14-911, Wellington, New Zealand

Keywords

Tephrostratigraphy; basalt; tephra; lake cores; magnetic susceptibility; X-ray density scanning; geochemistry; Auckland Volcanic Field; tephra reworking 


\section{Abstract}

Probabilistic hazard forecasting for a volcanic region relies on understanding and reconstructing the eruptive record (derived potentially from proximal as well as distal volcanoes). Tephrostratigraphy is commonly used as a reconstructive tool by cross-correlating tephra deposits to create a stratigraphic framework that can be used to assess magnitude-frequency relationships for eruptive histories. When applied to widespread rhyolitic deposits, tephra identifications and correlations have been successful; however, the identification and correlation of basaltic tephras are more problematic. Here, using tephras in drill cores from six maars in the Auckland Volcanic Field (AVF), New Zealand, we show how X-ray density scanning coupled with magnetic susceptibility analysis can be used to accurately and reliably identify basaltic glass shard-bearing horizons in lacustrine sediments and which, when combined with the major and trace element signatures of the tephras, can be used to distinguish primary from reworked layers. After reliably identifying primary vs. reworked basaltic horizons within the cores, we detail an improved method for cross-core correlation based on stratigraphy and geochemical fingerprinting. We present major and trace element data for individual glass shards from 57 separate basaltic horizons identified within the cores. Our results suggest that in cases where major element compositions $\left(\mathrm{SiO}_{2}, \mathrm{CaO}, \mathrm{Al}_{2} \mathrm{O}_{3}, \mathrm{FeO}, \mathrm{MgO}\right)$ do not provide unambiguous correlations, trace elements (e.g. $\mathrm{La}, \mathrm{Gd}, \mathrm{Yb}, \mathrm{Zr}, \mathrm{Nb}, \mathrm{Nd}$ ) and trace element ratios (e.g. $\left.[\mathrm{La} / \mathrm{Yb}]_{\mathrm{N}},[\mathrm{Gd} / \mathrm{Yb}]_{\mathrm{N}},[\mathrm{Zr} / \mathrm{Yb}]_{\mathrm{N}}\right)$ are successful in improving the compositional distinction between the AVF basaltic tephra horizons, thereby allowing an improved eruptive history of the AVF to be reconstructed. 


\subsection{Introduction}

Tephrostratigraphy is an important tool in many research disciplines because it has the ability to create chronostratigraphic horizons, by which other geological, palaeoenvironmental or archaeological events can be constrained (Lowe, 2011). When such chronostratigraphies are coupled with geochemical analysis of the tephra horizons, a detailed record of the evolution of a volcanic region can be established (e.g. Shane, 2005; Óladóttir et al., 2012; Kraus et al., 2013). A key aspect of tephrostratigraphy is the correlation of tephra deposits across localities (e.g. Shane, 2000; Alloway et al., 2004; Lowe et al., 2008; Lowe, 2011). Multiple problems can arise in cross correlation of tephra, most commonly where deposits are one or more of: (1) sparse or poorly preserved -for example where subsequent eruptions or urbanisation have occurred (e.g. Alloway et al., 1994; Dirksen et al., 2011; Engwell et al., 2014); (2) reworked (e.g. Payne and Gehrels, 2010; Bertrand et al., 2014; Sorrentino et al., 2014); or (3) where geochemical signatures are ambiguous, preventing unique characterisation of a deposit (e.g. Pearce et al., 2004; Brendryen et al., 2010; Bourne et al., 2013; Davies et al., 2014).

Preservation issues are often resolved by collecting samples in medial to distal environments rather than proximal locations (Lowe 2011). Tephra deposits in sediment cores are preferable, for example from lacustrine (e.g. Shane and Hoverd, 2002), peat lands (Payne and Gehrels, 2010) or marine environments (e.g. Allan et al., 2008), because they represent stratigraphically constrained deposits (Lowe et al., 2008; Lowe 2011). However, postdepositional reworking is sometimes observed in these environments (e.g. Payne and Gehrels, 2010), but a number of indicators can help identify areas where reworking has occurred. These include the geochemical signature of the shards (e.g. Allan et al., 2008), mineral assemblages within the deposits (e.g. de Klerk et al., 2008), palynostratigraphy (e.g. Newnham and Lowe, 1999), or the collection of multiple cores from a single area (e.g. Green and Lowe, 1985; Lowe, 1988a; Boygle, 1999). Where overlapping major element compositions preclude distinguishing between different eruptions (e.g. Icelandic tephra; Brendryen et al., 2010), trace element concentrations can be used to provide further fingerprinting because of their increased sensitivity to 
fractionation processes and mantle source heterogeneity (e.g. Westgate et al., 1994; Shane et al., 1998; Pearce et al., 2004; Alloway et al., 2004; Allan et al., 2008). Such techniques have permitted the distinction between tephra horizons that may otherwise be interpreted to be the same (e.g. Allan et al., 2008; Óladóttir et al., 2011).

In this study we introduce a protocol to identify more accurately, and effectively correlate the basaltic tephra record in cores extracted from maar crater lakes in the Auckland Volcanic Field (AVF), New Zealand. We first use a combination of $\mathrm{X}$-ray density and magnetic susceptibility scanning to reveal the detailed structure of tephra deposits and host sediments in order to provide new insights about reworking within the sediment cores. We then couple these results with in-situ major and trace element analysis of glass shards handpicked from tephra horizons to test the ability of major and trace elements as well as trace element ratios to distinguish and fingerprint horizons and thus aid cross-core correlations. Based on these correlations, the dispersal and frequency of the AVF eruptions can be developed to enable a more robust reconstruction of the eruptive history of the field.

\subsection{The Auckland Volcanic Field}

\subsubsection{Geological Setting}

New Zealand's largest city, Auckland, has a population of ca. 1.4 million and is superimposed on a collection of 53 Quaternary monogenetic basaltic centres, the Auckland Volcanic Field (AVF; Fig. 3.1.A). Individual centres typically show a range of eruption styles from explosive phreatomagmatic activity, caused by contact between upwelling magma and ground water, to magmatic activity coupled with synchronous or subsequent effusive activity after exhaustion or disconnection from local water sources (Allen and Smith, 1994; Németh et al., 2012). The initial phreatomagmatic activity results in the formation of maars and associated tuff rings, whereas the magmatic stages build scoria cones. Pyroclastic material (tephra) is associated with all eruption styles but is more important in terms of its 
dispersal in the initial phreatomagmatic phases that produce both tephra fall and surge deposits (Agustin-Flores et al., 2014). The close proximity of the maar craters to other eruptive centres (e.g. Lake Pukaki and Orakei Basin; Fig. 3.1.A) creates an environment that is favourable to preserve pyroclastic deposits from the other AVF eruptions.
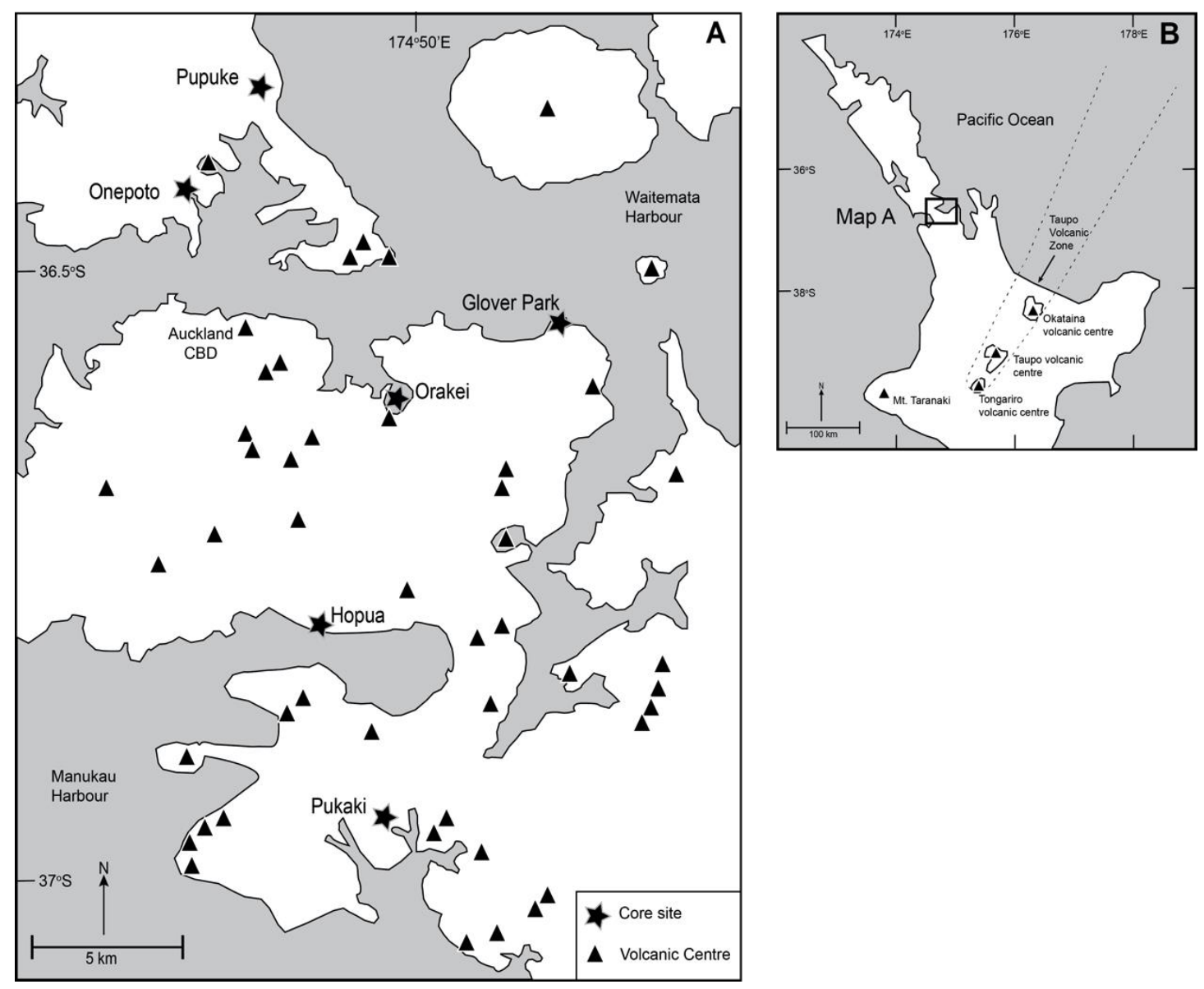

Figure 3.1. A) Extent of the Auckland Volcanic Field (AVF), with volcanic centres marked by triangles and core sites marked with a star and named, derived from Hayward et al., 2011. B) Location of the AVF within the North Island, New Zealand, and location of other volcanic centres, from which tephras have been recorded in the Auckland maar cores. 
Recent investigations of lacustrine tephra preservation elsewhere have discussed depositional complexities where deposits are affected by fluvial input from streams, run off, or lake currents, which lead to ambiguities in primary horizon identification (e.g. Bertrand et al., 2014; Shapley and Finney, 2015). The AVF maar craters are mostly closed systems; the surrounding tuff rings are outward dipping and composed of indurated, poorly sorted tuff, the surrounding topographic relief is very low, and the stream catchments that they intersect tend to be very small, resulting in minimal currents within the lakes (Striewski et al., 2013). During the Holocene sea-level maximum some of the maar craters were breached, but currently only Orakei Basin remains open to the marine environment. As a result the top ca. $25 \mathrm{~m}$ of the Orakei Basin core records marine muds rather than lacustrine sediments. The apparent pre-breach quiescence and consistency of the deposition in the maars is reflected in the finely laminated lacustrine sediments within core sequences (Hayward et al., 2008; Striewski et al., 2013). The maar lakes are therefore considered to provide a more accurate and complete tephra deposition history in comparison to open lacustrine systems, because they do not produce as many re-worked or over-thickened deposits (Molloy et al., 2009).

The superimposition of Auckland city, with its large population and complex infrastructure, over the area of the AVF, with the likelihood of future eruptive activity poses a significant volcanic hazard. Tephrochronology facilitates the reconstruction of the eruptive history of the area, in order to aid accurate hazard and risk forecasting (e.g. Shane and Zawalna-Geer 2011).

\subsubsection{Previous Tephrostratigraphic Studies}

To date, the highest resolution tephrostratigraphic study of the AVF maar lake cores have analysed shards from andesitic, rhyolitic (from distant sources) and basaltic (from the AVF) tephra horizons within multiple cores (Newnham et al., 1999; Molloy et al., 2009). The horizons were visually identified, which, although adequate for fine-grained, light-coloured silicic deposits, proved difficult for dark-coloured basaltic tephra deposits. This 
raises the possibility of errors in the identification of thin, very fine-grained basaltic tephra horizons or layers of a similar colour to the host lacustrine sediments. All glass shards in Molloy et al. (2009) were analysed for major element concentrations by electron microprobe analysis (EMPA), using energy dispersive X-ray spectroscopy (EDS) techniques, and sedimentation rates were estimated for each core based on reported ages of the rhyolitic tephras. These sedimentation rates were then used to estimate the age of the basaltic deposits, and thus constrain cross-core correlations.

In many cases where basaltic tephras were sparse and stratigraphically well constrained (by rhyolitic or andesitic marker horizons, and sedimentation rates), major element chemistries could uniquely fingerprint individual tephra horizons to allow correlations between cores (Molloy et al., 2009). However, when horizons were poorly constrained by stratigraphy, major element compositions for the basaltic tephras were not distinctive enough to distinguish and fingerprint individual horizons and crosscore correlations were ambiguous and unreliable. Some studies have identified the use of trace elements as a way to more uniquely fingerprint tephra horizons. For example, Alloway et al. (2004) measured Th, Nd and Y to distinguish tephras deposited in the Auckland region from rhyolitic and andesitic centres in the North Island, but these techniques have only been applied to local AVF basaltic tephras for Rangitoto by Needham et al. (2011). In addition, trace element ratios have the ability to outline smaller geochemical heterogeneities that provide additional fingerprinting criteria in correlations, however few studies have investigated the full use of these as a tool for correlation (Allan et al., 2008). Trace element ratios have the added advantage of being independent of the actual elemental concentrations and thus are also less affected by analytical issues (Pearce et al., 2007; Allan et al., 2008). They are therefore preferred where major and trace element compositions are largely indistinguishable or ambiguous for individual horizons. 


\subsection{Techniques and Samples}

\subsubsection{Techniques}

\subsubsection{Identification of tephra horizons}

Visual observations were coupled with non-destructive X-ray density scanning and magnetic susceptibility analysis to initially identify which sections of the core hosted basaltic glass shards. The density of basaltic tephra and its abundance of heavy X-ray absorbing elements (e.g. FeO content in basalts ca. 5-14 wt \% vs. rhyolites ca. 0-4 wt \%) makes the basaltic horizons appear bright on X-ray imagery, and the abundance of Fe-rich magnetic minerals is responsible for the peaks in magnetic susceptibility.

X-ray density scanning was undertaken at the National Institute of Water and Atmospheric Research (NIWA), Wellington, using an Ultra EPXF2800 portable veterinary radiological device. The voltage was optimized between $70-100 \mathrm{kV}$ with analysis duration of $25-5 \mathrm{mAs}$. This analysis was coupled with magnetic susceptibility scanning using a Bartington-MS2 magnetic susceptibility meter connected to a MS2F probe (also at NIWA). Magnetic susceptibilities are dimensionless and are reported according to the $10^{-5} \mathrm{SI}$ system with a sensitivity of $1.0 \times 10^{-5} \mathrm{SI}$. These values represent the ratio between the magnetization of the sample material (amps/metre $\left[\mathrm{Am}^{-1}\right]$ ) and the applied magnetic field strength $\left(\mathrm{Am}^{-1}\right)$. Data were obtained every 2 $\mathrm{cm}$ along the centre of the core and at $1 \mathrm{~cm}$ spacing across any regions of special interest. Together these analyses highlight the horizons of basaltic tephra within the lacustrine sediments (Fig. 3.2.): the horizons identified are then sampled for geochemical analysis. 


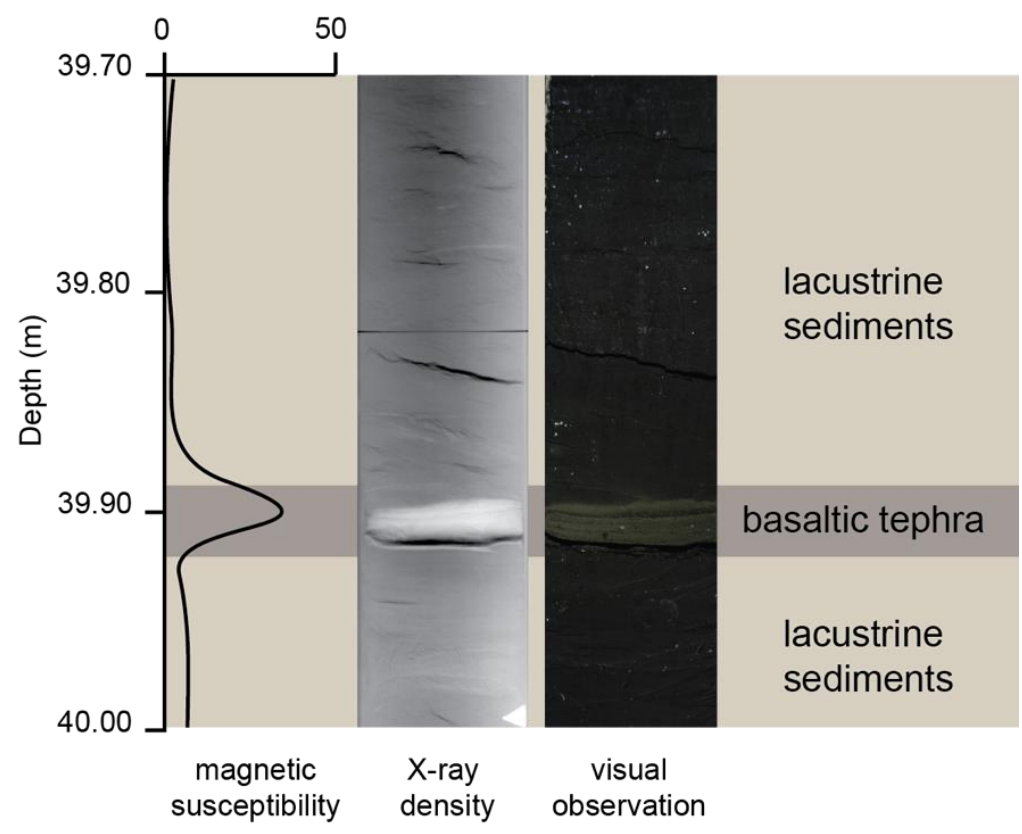

Figure 3.2. An example of a typical basaltic horizon identified from within the Orakei Basin core, showing sharp peak in magnetic susceptibility (S.I. units) and the bright contrast of the horizons on the X-ray density scan, in comparison to the 'background' lacustrine sediments.

\subsubsection{Distinction of primary and reworked tephra horizons}

To distinguish primary horizons we coupled results from the X-ray analysis and magnetic susceptibility scanning with the protocol outlined by Óladóttir et al. (2011), identifying (1) sharp contacts (including those in the Xray imagery) indicating an undisturbed deposit, (2) overall heterogeneous grain sizes and shapes, indicating a lack of erosion-related abrasion, and (3) shard grading as horizons deposited through water most commonly show normal grading if undisturbed. Most of the horizons were of sufficient thickness $(>10 \mathrm{~mm})$ to take multiple sub-samples to constrain geochemical variations across each horizon. All samples were taken from the centre of the sediment core in order to minimize shard contamination through 'core suck' (where removal of the core drags sediments up, or penetration of coring device drags sediments down at the edges of the casing). Exposed surfaces of the deposit were removed prior to sampling to avoid any sample contamination caused during core splitting. 


\subsubsection{Samples}

Amongst all the volcanic centres within the AVF, nine maar and tuffring formations have not been buried by subsequent eruptive phases. Six of these have core material available for analysis (see Fig. 3.1). The six maars are spread across the width of the AVF and provide an extensive record of the last ca. 200 ka (Lindsay et al., 2011). For this study the Orakei Basin and Onepoto cores were available for full analysis and were used to test and develop the techniques discussed above. The other cores were used for correlation purposes: for the Glover Park core (St Heliers volcano) tephra horizons were re-sampled and analysed; for Pupuke and Hopua cores original mounts from Molloy et al. (2009) were analysed for major and trace elements; and data from Pukaki core were taken from the literature (Sandiford et al., 2001) or from unpublished work (Phil Shane, pers. comms, 2015). The AVF tephra deposits are labelled with the prefix 'AVF' then a number from 1 at the base to 24 at the top. This nomenclature was based on the Orakei Basin core (Molloy et al., 2009) and extended throughout the cores, aiding clarity in cross-core correlation. Where possible this study maintains the nomenclature assigned by previous studies for the AVF basalts. Previous studies (e.g. Lowe 1988b) have outlined the complexity associated with post-depositional compaction of tephra horizons. Here we report deposit thicknesses as actually observed, and take them to be minimum thicknesses. Detailed core information can be found in Table 3.1.

Sections of the cores, where applicable, have been split into five age groups, based on the well-established ages of rhyolitic and andesitic tephras originating from the Taupo Volcanic Zone (TVZ) and Mt Taranaki (Eg). These serve as key stratigraphic marker horizons and for this study include, Rerewhakaaitu (Rk) 17,496 \pm 462 calendar (cal.) yr. BP; Okareka (Ok) 21,858 \pm 290 cal. yr. BP; Kawakawa/Oruanui (Kk) 25,358 \pm 162 cal. yr. BP (all ages from Lowe et al., 2013) and Rotoehu (Re), which currently has a less well defined age with estimates of between ca. 44.3 cal. ka (Shane and Sandiford, 2003 ) to ca. $61 \pm 1.4 \mathrm{ka}$ (Wilson et al., 2007). For the purpose of this study we use the most recently published age estimate $(45,100 \pm 3,300$ cal. yr BP; Danišík et al., 2014) to provide a minimum age constraint to basaltic tephras 
found below this horizon. The cores, where applicable, have been split into five age groups, based on the minimum and maximum errors (2 s.d.) associated with the published values to give the maximum age ranges for the groupings These groups are: older than $\operatorname{Re}(>41,800$ ka cal. yr. BP); Kk to $\operatorname{Re}$ (25,196 - 61,000 cal. yr. BP); Ok to Kk $(21,568-25,520$ cal. yr. BP); Rk to Ok $(17,034-22,148$ cal. yr BP) and younger than $R k(<17,958$ cal. yr. BP).

Table 3.1. Overview of drill cores, their locations, the section of the core that has been used for this study (in metres below the drill hole top), and the proposed age that the core section covers, based on the ages proposed for bracketing rhyolitic tephra. Also included are the number of basaltic horizons found within the cores by this study, and previous studies, and the geochemical data that are available for the glass shards.

\begin{tabular}{|c|c|c|c|c|c|c|c|c|c|}
\hline \multirow[b]{2}{*}{$\begin{array}{l}\text { Core (centre) } \\
\text { name }\end{array}$} & \multirow[b]{2}{*}{ Grid reference } & \multirow[b]{2}{*}{$\begin{array}{l}\text { Section of } \\
\text { interest (m) }\end{array}$} & \multirow[b]{2}{*}{$\begin{array}{l}\text { Proposed age } \\
\text { range (cal. ka) }\end{array}$} & \multicolumn{3}{|c|}{ Previous studies } & \multicolumn{3}{|c|}{ This study } \\
\hline & & & & $\begin{array}{c}\text { No. of } \\
\text { basaltic } \\
\text { horizons }\end{array}$ & $\begin{array}{l}\text { Geochemical } \\
\text { data }\end{array}$ & References & $\begin{array}{c}\text { No. of } \\
\text { basaltic } \\
\text { horizons }\end{array}$ & Status & Geochemical data \\
\hline Pupuke & $\begin{array}{l}36^{\circ} 46^{\prime} 49.83^{\prime \prime S} \\
174^{\circ} 45^{\prime} 57.67^{\prime \prime E}\end{array}$ & 57 to 70 & 0.4 to 38 & 7 & Major & Molloy et al., 2009 & 7 & Mounts re-analysed & Major and trace \\
\hline Onepoto & $\begin{array}{l}36^{\circ} 48^{\prime} 27.09^{\prime \prime S} \\
174^{\circ} 45^{\prime} 0.39^{\prime \prime E}\end{array}$ & 38 to 69 & 25 to $>150$ & 6 & Major & Shane and Hoverd 2002 & 9 & Core sampled & Major and trace \\
\hline $\begin{array}{l}\text { Glover Park } \\
\text { (St. Heliers) }\end{array}$ & $\begin{array}{l}36^{\circ} 50^{\prime} 49.68^{\prime \prime S}, \\
174^{\circ} 52^{2} 2.60^{\prime \prime} \mathrm{E}\end{array}$ & 4 to 27 & $\begin{array}{l}\text { Rotoehu to St } \\
\text { Heliers }\end{array}$ & 13 & Major & Hoverd et al., 2005 & 4 & Core Sampled & Major and trace \\
\hline Orakei & $\begin{array}{l}36^{\circ} 52^{\prime} 4.14^{\prime \prime} \mathrm{S} \\
174^{\circ} 48^{\prime} 46.11^{\prime E}\end{array}$ & 44 to 87 & 24 to 86 & 14 & Major & Molloy et al., 2009 & 16 & Core sampled & Major and trace \\
\hline Hopua & $\begin{array}{l}36^{\circ} 55^{\prime} 46.68^{\prime \prime S} \\
174^{\circ} 47^{\prime} 3.82^{\prime \prime} \mathrm{E}\end{array}$ & 38 to 49 & 7 to 31 & 5 & Major & Molloy et al., 2009 & 5 & Mounts re-analysed & Major and trace \\
\hline Pukaki & $\begin{array}{l}36^{\circ} 58^{\prime} 57.63^{\prime \prime S}, \\
174^{\circ} 48^{\prime} 37.74^{\prime \prime E}\end{array}$ & 45 to 62 & 7 to Rotoehu & 12 & Major & $\begin{array}{l}\text { to } 52 \mathrm{~m} \text { Sandiford et al., } 2001 \text {, } \\
52 \mathrm{~m} \text { to base Shane, } 2005\end{array}$ & 12 & Core nor mounts availe & able for analysis \\
\hline
\end{tabular}

\subsubsection{Tephra Geochemical Analysis}

The bulk tephra samples were washed and cleaned using an ultrasonic bath to remove organic debris. The glass shards were then mounted as bulk samples if shards were $<30 \mu \mathrm{m}$ across, and larger shards were hand-picked and mounted individually. Epoxy mounts $10 \mathrm{~mm}$ deep were created using a 4:1 ratio of resin to hardener. Once solidified, six holes were drilled through the mounts, the mounts were placed on adhesive tape and individual samples were then positioned into each hole, back-filled with epoxy, and left to harden. To expose the samples, mounts were polished using a sequence of $\mathrm{SiC}$ papers starting at 400 grade, followed by 600, 1000 and 2500, and finally finished using a diamond lap polisher at $3 \mu \mathrm{m}$ and $1 \mu \mathrm{m}$. 


\subsubsection{Major-Element Analysis}

In-situ major element analyses as oxides $\left(\mathrm{SiO}_{2}, \mathrm{TiO}_{2}, \mathrm{Al}_{2} \mathrm{O}_{3}, \mathrm{FeO}_{\mathrm{t}}\right.$, $\mathrm{MnO}, \mathrm{MgO}, \mathrm{CaO}, \mathrm{Na}_{2} \mathrm{O}, \mathrm{K}_{2} \mathrm{O}$ and $\mathrm{P}_{2} \mathrm{O}_{5}$ ) were undertaken on carbon coated sample mounts at Victoria University of Wellington (VUW) using WDS on a JEOL JXA 8230 Superprobe (EMPA) with a static beam at $10 \mu \mathrm{m}$ and $8 \mathrm{nA}$. For each horizon, back-scattered electron images of the shards were taken to locate the sampling spots for subsequent LA-ICP-MS analysis. Matrixmatched standard A99 basaltic glass was used as a bracketing standard and run three times every 10 samples to monitor instrument drift. Accuracy of the analyses was within $2 \%$ of the recommended values for the internal standards and analytical precision ( 2 s.d.) is $1 \%$ relative or better for all elements. Major element concentrations were determined using the ZAF correction method, and analytical totals for unknown glass were 97-100\% with deviations from $100 \%$ attributed to variable degrees of post-eruption hydration (Shane, 2000). To account for this secondary process, all major element data were normalised to $100 \%$.

\subsubsection{Trace element analysis}

After the carbon coat was removed, trace element concentrations were analysed by in-situ LA-ICP-MS using an Agilent 7500cs ICP-MS coupled with either a New Wave UP $193 \mathrm{~nm}$ solid state laser ablation system at VUW or a Resonetics RESOlution M-50-LR 193nm excimer laser ablation system at the University of Otago (UoO). Backscatter electron images obtained from probe analysis were used to allow re-location of individual analysis sites. All the data were acquired using static spot analysis with spot sizes of either 25 or $35 \mu \mathrm{m}$ with an ablation time of 60 seconds, with fluence varied between $2-4 \mathrm{~J} / \mathrm{cm}^{2}$. Ablated material was carried by He gas (0.75- 0.77 L/min [VUW], 0.65-0.75 $\mathrm{L} / \mathrm{min}$ [UoO]), and mixed with $\operatorname{Ar}$ (0.83-0.87 L/min [VUW], 0.65-0.750 L/min [UoO]). Gas flows were adjusted after each sample exchange to achieve maximum sensitivity and stability, and during analysis care was taken to avoid any visible microcrysts or thin bubble walls on the shards. BHVO-2G and NIST612 standards were run every 5 analyses and the beginning and end of each session, with BCR-2G run as an internal standard at the beginning of 
each session. All data were reduced off-line using the lolite software (Paton et al., 2011), using ${ }^{29} \mathrm{Si}$ analysis as the internal standard and BHVO-2G as the calibration standard. Analytical precision based on 15 replicate analyses of BCR-2 for both VUW and $\mathrm{UoO}$ is $<6.5 \%$. Exceptions to this include $\mathrm{Cr} \pm 10 \%$, $\mathrm{Nb} \pm 22 \%$, Cs $\pm 12 \%, \mathrm{Ba} \pm 11.8 \%, \mathrm{Ta} \pm 21 \%$ and $\mathrm{Pb} \pm 31 \%$, and the accuracy for all elements is $\leq 6 \%$ apart from $\mathrm{Li}, \mathrm{Cr}, \mathrm{Nb}, \mathrm{Cs}$, Eu and $\mathrm{Ta}$, with duplicate sample analyses yielding results within error between VUW and UoO.

When analysing the glass shards, every care was taken to analyse pure glass only, rather than any microcrystals (e.g. olivine, plagioclase or FeTi oxides; Fig. 3.3.B). On occasion, accidental ablation of microcrysts did occur and was identified by extreme spikes in major element concentration (e.g. Mg for olivine; Fig. 3.3.A). Such analyses were rejected from the data set.

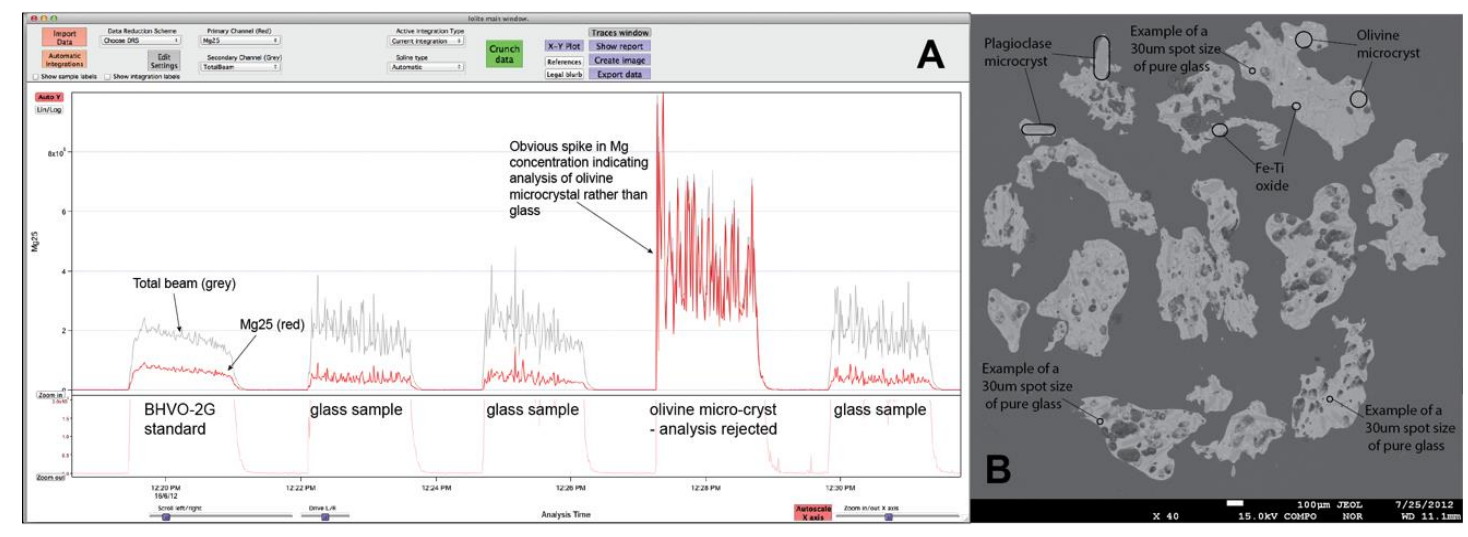

Figure 3.3. A) Example of identification of accidental microcryst analysis detected in Iolite data reduction software (Paton et al., 2011) with obvious concentration spike in $\mathrm{Mg}$ in comparison to pure glass analyses. B) Back Scatter Electron image from EMPA analysis, identifying clearly microcrystal types and locations, and examples of a $30 \mu \mathrm{m}$ spot size, where pure glass analyses could be taken. 


\subsection{Results}

\subsubsection{Tephra horizon identification and classification}

Visual observations show the basaltic tephra horizons are light grey to black in colour with shard size ranging from very fine ash $(<20 \mu \mathrm{m})$ to lapilli $(2$ $\mathrm{mm}$ to $2 \mathrm{~cm}$ ). Tephra horizons in the Orakei and Onepoto cores range from 1$2 \mathrm{~mm}$ to ca. $750 \mathrm{~mm}$ in thickness. Horizons $<20 \mathrm{~mm}$ thick show relatively small but well-defined magnetic peaks of $\geq 50\left(10^{-5} \mathrm{SI}\right)$ combined with bright appearance on X-ray scan. In comparison, $>20 \mathrm{~mm}$ thick horizons exhibit more complex $\mathrm{X}$-ray and magnetic susceptibility results. All horizons have sharp lower contacts, however, often only the thinner horizons $(<20 \mathrm{~mm})$ have well defined sharp upper contacts as well. The primary deposits are mostly (ca. $80 \%$ ) non-graded, or have normal grading. Some deposits contain visible minerals (commonly olivine or pyroxene) and/or a high proportion (30-60\%) of accidental ejecta (quartz crystals, shell fragments and sedimentary lithic fragments derived from the underlying Tertiary Waitemata beds). Thirty-eight tephra horizons are identified in the Orakei Basin, Onepoto and Glover Park cores collectively. These are combined with nineteen other horizons previously identified and sampled from within the Hopua, Pukaki and Pupuke cores.

The lacustrine sediments comprising most of the thickness in the maar cores show little to no increase in magnetic susceptibility from baseline values of 0 to a maximum of $10 \mathrm{~S}$.I. This lack of susceptibility change is coupled with homogeneous grey tones in the X-ray scans, punctuated with black lines. These black lines represent cavities within the cores that are most likely caused by the coring process, or drying out and contraction during storage (Fig. 3.2.). Rare small peaks ( $<10$ S.I.) were detected in magnetic susceptibility within the lacustrine sediments but no coincident glass shards were identified during subsequent X-ray scanning or sampling. These magnetic peaks are likely to represent variations of the magnetic properties in the lacustrine sediments. Conversely the deposits formed during marine incursions are more homogeneous than lacustrine deposits, showing no bedding, consistently low magnetic-susceptibility, and less frequent cavities in 
the core on the X-ray scan. Within the marine muds, the X-ray scans pick up small discontinuous spots of high-density reflecting the presence of small shells (Fig. 3.7.A).

\subsubsection{Tephra-derived glass shard Geochemistry}

We analysed 10-20 shards for major and trace elements from each of 57 basaltic tephra horizons from the six cores. In addition, where possible, subsamples of some of the thicker deposits were taken to monitor re-working or primary geochemical variation through an eruption sequence. For withincore tephra horizons, $\mathrm{MgO}$ content variations are minimal, and consistent, with all varying from 2.1 to 7.5 wt.\% (Fig. 3.4.). Compositional ranges in $\mathrm{CaO}$, $\mathrm{FeO}, \mathrm{K}_{2} \mathrm{O}$, and $\mathrm{TiO}_{2}$ are consistent throughout all cores, but the ranges for $\mathrm{Al}_{2} \mathrm{O}_{3}$ and $\mathrm{SiO}_{2}$ are less consistent between the cores. Onepoto and Orakei Basin core shards in general have consistently lower $\mathrm{Al}_{2} \mathrm{O}_{3}$ values for a given $\mathrm{MgO}$ value making the concentrations different to those of tephra in Pukaki, Glover Park, Hopua, or Pupuke cores. Onepoto core contains tephra with glass that has consistently higher $\mathrm{SiO}_{2}$ values at a given $\mathrm{MgO}$ value in comparison to the glass in the Hopua and Pukaki cores, but similar to values for glass shards from Pupuke, Orakei and Glover Park cores.

Most of the tephra horizons (50 out 57) show a unimodal signature with limited variability in major element concentrations with $\mathrm{MgO}, \mathrm{SiO}_{2}, \mathrm{FeO}$, and $\mathrm{TiO}_{2}$ all with a variation of $<1 \mathrm{wt} . \%$ and $\mathrm{CaO}, \mathrm{Al}_{2} \mathrm{O}_{3}, \mathrm{Na}_{2} \mathrm{O}$ and $\mathrm{K}_{2} \mathrm{O}$ with a variation of $<3$ wt.\%. Bivariate plots of a combination of $\mathrm{SiO}_{2}, \mathrm{MgO}, \mathrm{Al}_{2} \mathrm{O}_{3}$, $\mathrm{CaO}$ and $\mathrm{FeO}$ show the most distinction between the horizons (e.g. Fig. 3.5.A). Three of the 57 horizons show a bimodal distribution in major element/oxide concentrations. Differences between the two modes for $\mathrm{SiO}_{2}$, $\mathrm{Al}_{2} \mathrm{O}_{3}$ and $\mathrm{FeO}$ concentrations can be up to $5 \mathrm{wt} . \%$, but are $<2$ wt. \% for $\mathrm{MgO}$, $\mathrm{CaO}, \mathrm{TiO}_{2}$. For another small proportion of horizons $(\mathrm{n}=4)$, a systematic range is observed - for example, $\mathrm{SiO}_{2}$ ranges from 44-49 wt.\%, FeO from 12-14 wt. \% and $\mathrm{CaO}$ from 8-10 wt.\%. 

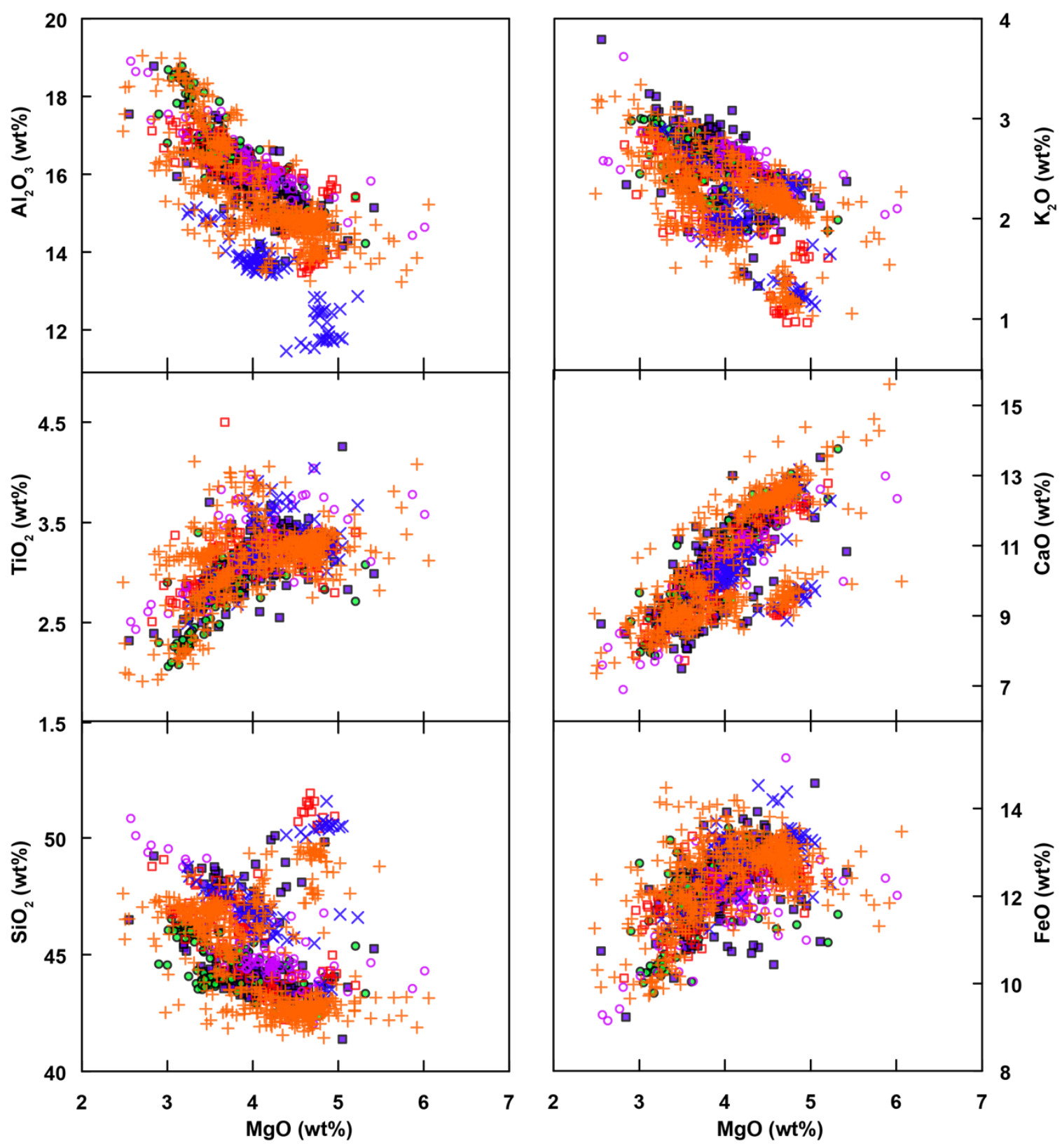

$\begin{array}{ll}\text { - Glover Park } & \circ \text { Pukaki } \\ \text { ○ Hopua } & \times \text { Onepoto } \\ \square \text { Pupuke } & + \text { Orakei Basin }\end{array}$

Figure 3.4. Selected major elements as oxides vs. MgO for all shards from all tephra horizons found within all six cores studied for this paper. 

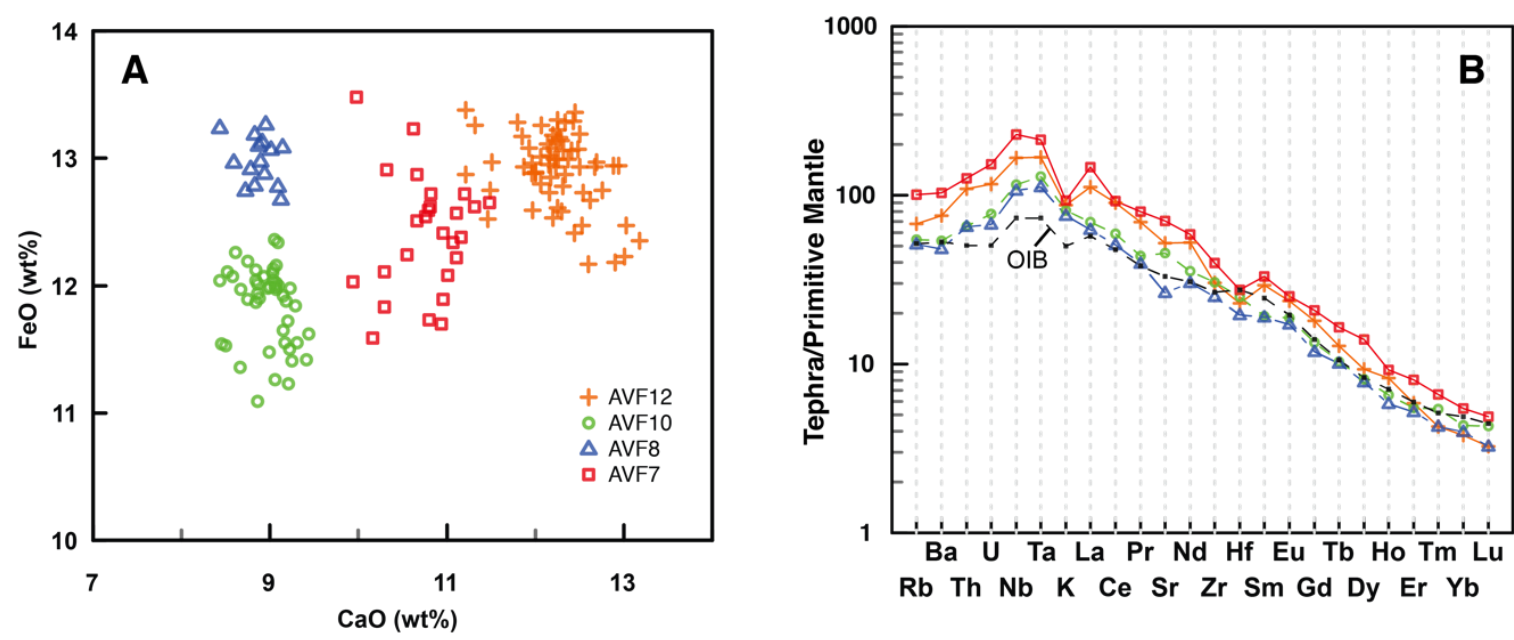

Figure 3.5. Data from selected successive horizons from Orakei Basin (AVF 12, 10, 8 , and 7) to show major and trace element variability from shards in tephras within a single core. (A) CaO vs. FeO (wt.\%). (B) Primitive mantle-normalized trace element patterns, with OIB values and normalisation values from Sun and McDonough (1989).

Forty-nine tephra horizons from five of the cores (Pukaki had no trace element data available) had shards large enough $(>30 \mu \mathrm{m})$ to be analysed for trace elements. Overall, all shards show a wide range in concentrations. For example La ranges from ca. 5 to $100 \mathrm{ppm}$, Nb from ca. 20 to $175 \mathrm{ppm}$, and $\mathrm{Rb}$ from ca. 5 to $75 \mathrm{ppm}$ (Fig. 3.6.). All glass samples show trace element distributions similar to those of ocean island basalts (OIB-type) on a primitive mantle-normalised multi-element plot (after Sun and McDonough, 1989). Pupuke and Onepoto samples have a much more limited range in variability in some trace elements in comparison to the ranges of glasses from the other cores. For example, in Pupuke and Glover Park cores, glass La values range between ca. 50-75 ppm. Glover Park glasses show a very high variation in trace elements that are coupled with high ( $>4 \mathrm{wt} . \%) \mathrm{MgO}$. This is not seen within the glasses in the tephras from the other cores. 

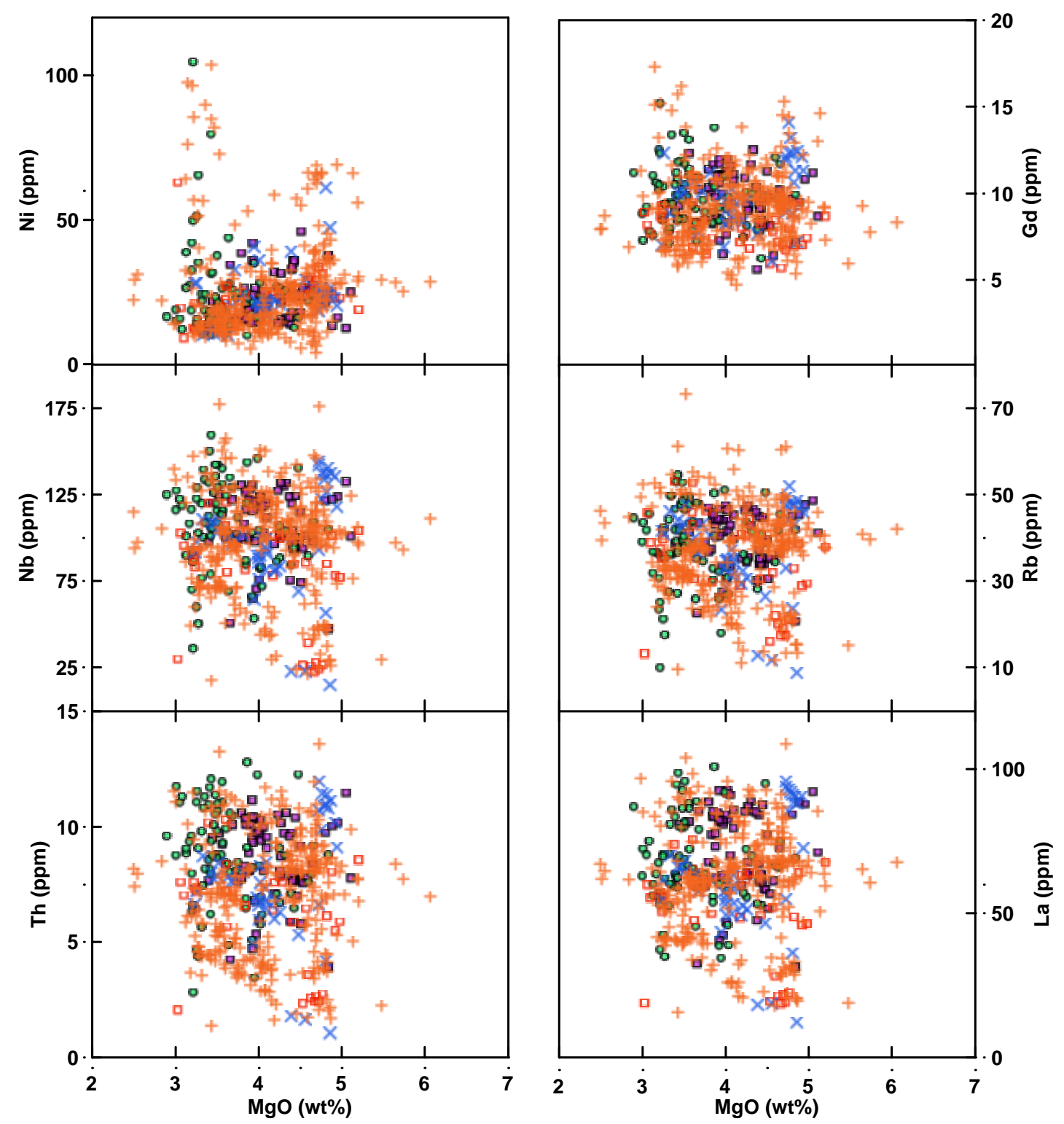

Figure 3.6. Concentrations of selected trace elements vs. MgO for shards from all tephra horizons from within five of the six cores (no trace element data available for Pukaki). Symbols are the same as Figure 3.4.

For Orakei Basin, Hopua, and to a lesser extent Glover Park, the trace element variations in the glass shards in the core are much greater, with $\mathrm{La}$ varying from ca. 5-100 ppm, 40-100 ppm and 35-95 ppm, respectively. For the individual horizons, the glass trace element variations are a lot less than those within all the tephra in the cores as whole. In general, the glass La values vary by ca. $<30 \mathrm{ppm}$, with $\mathrm{Nb}$ values a little more variable at ca. $<50$ $\mathrm{ppm}$ and $\mathrm{Rb}$ values a little less at $<10 \mathrm{ppm}$. 
Figure 3.5.B shows trace element values for glass of the Orakei Basin horizons AVF12, 10, 8, and 7 that indicate the average concentration for each horizon has a relatively distinct geochemical signature, and that this distinction is similar for all horizons. Although distinct, all analyses share the same general OIB-type pattern when normalised, with enrichment in LREE compared to HREE (e.g. $(\mathrm{La} / \mathrm{Yb})_{N}=21$ to 41$)$. Given that major and trace element concentration variations within glass pertaining to a single horizon are often small, and in most cases within error, the observed range in geochemistry of glass shards within, and between cores, is attributed to differences between individual horizons.

\subsection{Discussion}

\subsubsection{Identification of primary tephra horizons}

Observations (visual, magnetic susceptibility and X-ray) and geochemical composition are important for the identification and definition of primary tephra horizons. For the thin $(<20 \mathrm{~mm})$ deposits there is little ambiguity: the horizons are always constrained by sharp upper and lower contacts, seen by contrasting bright sections on the X-ray images and by a clear peak in magnetic susceptibility (Fig. 3.7.B). In some cases the thin deposits can be visually obscured because of their minimal thickness or similarity in colour to the lacustrine sediments. However, the X-ray imaging and magnetic susceptibility analyses overcome this difficulty. In comparison, thicker deposits (>20 mm) often appear more complex in both the X-ray images and magnetic susceptibility scans. Figure 3.7.C shows two contrasting thicker deposits. At the top of the core an apparently homogeneous deposit shows consistently high magnetic susceptibility and consistently bright X-ray imagery. In comparison the lower deposit shows an apparently heterogeneous horizon with changes in grain size displayed by variations in grey-scale of the X-ray images as well as multiple peaks in magnetic susceptibility. Both of these horizons are horizontally bedded, consistent with constant deposition, suggesting that they are both primary horizons. In addition, the similar geochemical composition of glasses from multiple tephra subsamples from each horizon supports the interpretation that 
both horizons are primary deposits. However, the slight variation in geochemical composition of glass from the lower horizon, coupled with the variation in shard size but lack of depositional hiatus, suggests this horizon has formed from multiple deposition events from one eruption episode.

A less clear example (Fig. 3.7.D) is evident where a section showing lower contrasting $X$-ray imagery and a gradual incline to an inconsistent peak in magnetic susceptibility follows the initial primary horizon. This subsequent section has blurred basal and upper contacts, with an X-ray transmissivity that is gradational, rather than sharply contrasting, from that shown by the lacustrine sediments. There are no obvious horizontal beds and some deformation can be picked out in the X-radiograph within the section. There is also a clear hiatus between the two sections shown by the magnetic susceptibility trough. If these features are combined with indistinguishable glass geochemistries from each section, then the deposits can be interpreted as being reworked.

We considered that re-mobilisation of a tephra horizon could also cause a sharp basal contact, here ascribed as a primary feature. However, it is likely that this feature would be coupled with 1) within-horizon deformation (e.g. overturning or convolute bedding), and 2) a mixture of sediment and glass shards, both of which would distinguish the deposit as reworked. Alternatively a diffuse contact, here taken as an indication of reworking, has the potential to form through density settling of a primary deposit (Manville and Wilson, 2004). However, if this were the case Stokes Law would dictate a fining upwards of the shards, which is not observed for those horizons classed as reworked. In addition, nearly all the AVF eruptions are volumetrically very small, and considered to only last for a number of weeks to months (Hayward et al., 2011). If the diffuse contacts observed within these cores were to be formed through gradual influx of material, sedimentation rates would suggest time periods of tens of years of constant eruption in most cases, which is wholly improbable for the AVF eruptions. Further clarification of these distinctions could be gained through the use of multiple cores to compare the individual deposit characteristics (e.g. Green and Lowe, 1985; Lowe, 1988a); however, multiple cores were not available for this study. 


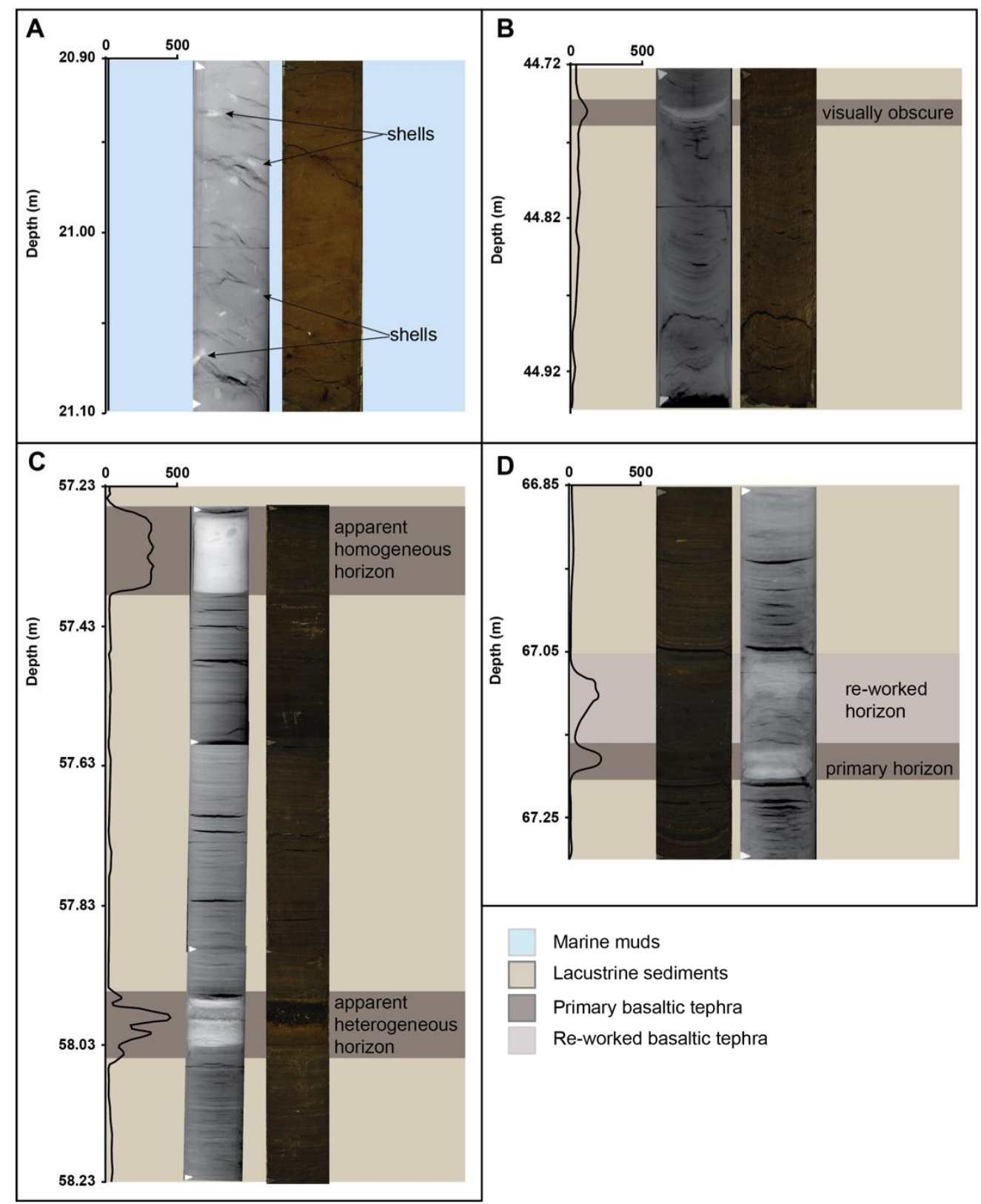

Figure 3.7. Examples of features seen within the Orakei Basin core. A) Intermittent bright signals on the $X$-ray image picking up shells within marine muds. B) $A$ thin basaltic deposit showing sharp upper and basal contacts in X-ray and magnetic susceptibility but ambiguity in visual observation. C) Two contrasting primary deposits. The upper deposit appears mostly homogeneous, as indicated by uniform $X$-ray contrast and corresponding magnetic susceptibility peak. In comparison, the lower deposit is more heterogeneous in shard size, as indicated by peaks and troughs in magnetic susceptibility and variable grey-tones in the $X$-ray imagery. D) Primary and re-worked deposit. The lower labelled band is a primary deposit with a sharp basal contact with a marked sharp contrast in grey scale on X-ray image and a sharp peak in magnetic susceptibility. The upper-labelled band has a blurred upper and basal contact, a lower contrast in grey scale on $X$-ray imagery, and more variable magnetic susceptibility levels. 
In summary, homogeneous glass-based trace element geochemistry, a sharp basal and upper contact between the tephra deposit and the lacustrine sediments, coupled with a sharp peak in magnetic susceptibility, and a highly contrasting section on the X-ray imagery are interpreted by us to indicate a primary deposit. A re-worked deposit is characterised typically by heterogeneous glass trace element geochemistry, blurred upper and lower contact boundaries, lower grey scale contrast in the X-ray imagery and sometimes upward grading of grey scale intensity (darker, lower density towards the top). A lack of horizontal bedding is usually observed, and deformation or a hiatus within the deposits can also be seen. The magnetic susceptibility is usually more variable in reworked deposits and often shows a more gradual peak in comparison to the sharp peak that is seen for a primary deposit.

It is important to note that the X-ray density scanning and magnetic susceptibility analysis rely on the contrasting characteristics of basaltic material versus and lacustrine sediments. As outlined in the methods, in comparison with lacustrine sediments, basaltic tephra has a higher proportion x-ray absorbing elements (e.g. FeO) coupled with a higher abundance of magnetic minerals. It is this contrast that allows the basaltic tephra to be identified by these methods. However, rhyolitic and to a lesser extent andesitic tephra have lower proportions of these elements and minerals implying that tephras of such composition may not be easily detected by these methods. Nevertheless, rhyolitic and andesitic tephra are usually light in colour, and (if sufficiently concentrated or thick enough) are thus more easily detected by careful visual observation.

Methods used in previous studies often may have led to inaccurate identification of primary vs. re-worked sections of deposits (Hoverd et al., 2005; Molloy et al., 2009) and left fine-grained and thin horizons unidentified, which led to misinterpretation of the thicknesses of some of the deposits. This misassociation has important implications for the establishment of sedimentation rates and past eruptive frequency (discussed in sect. 3.5.6.). Using our combined methodology, all basaltic tephra horizons from Orakei 


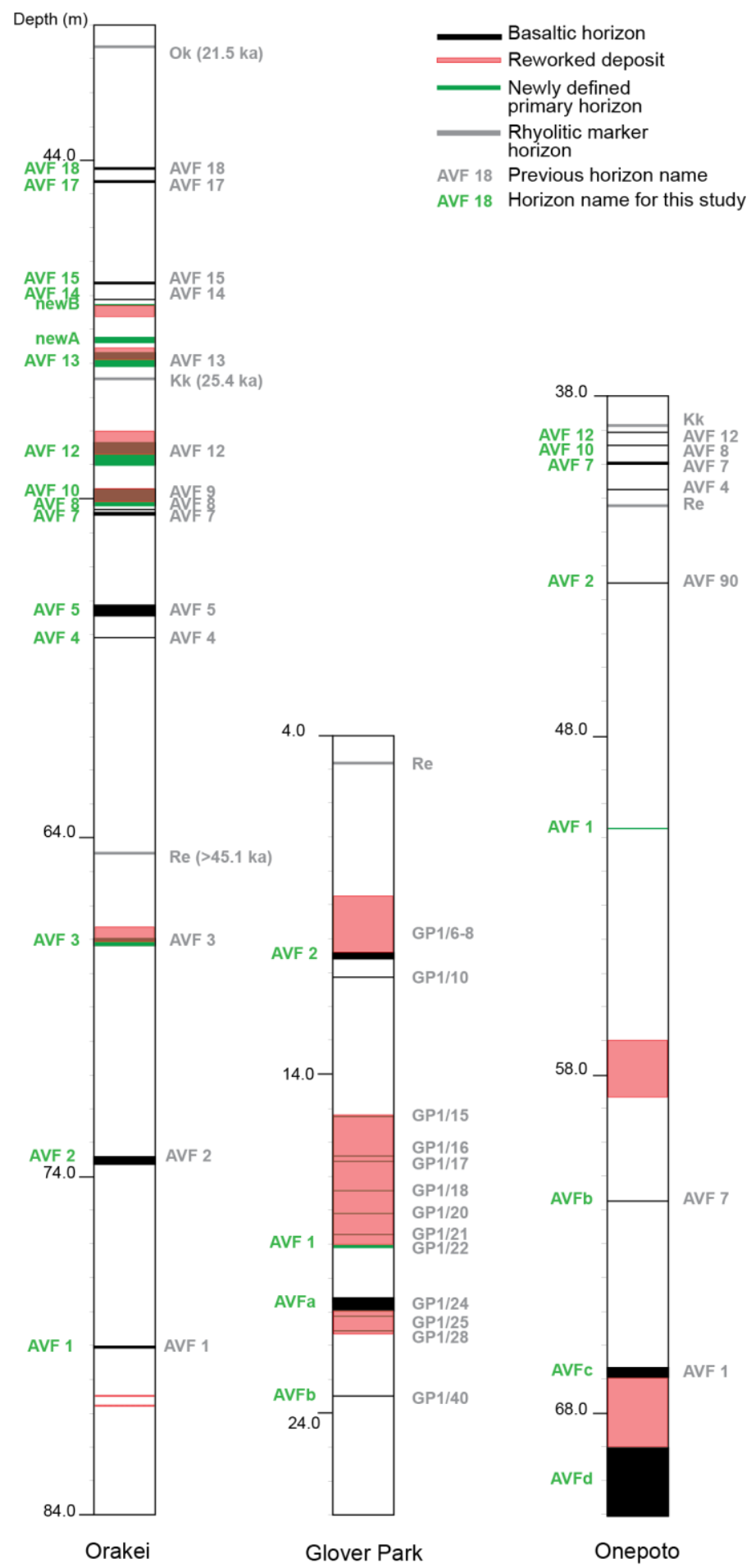

Figure 3.8. Schematic stratigraphic columns for the cores that were available for reassessment: Orakei Basin (Molloy et al., 2009), Glover Park (Hoverd et al., 2005), and Onepoto (Shane and Hoverd, 2002). Basaltic horizons are marked within the cores in black, sections identified as re-worked by this study are outlined in red dotted lines and green lines show the newly defined horizons. Grey text defines previous horizon name and green text shows previous and new names for all horizons given by this study. Key rhyolitic marker horizons are shown by grey lines (Ok - Okareka; Kk - Kawakawa/Oruanui; Re - Rotoehu). 
Basin, Onepoto and Glover Park were re-assessed as being primary or reworked deposits.

Figure 3.8 shows all individual horizons found within these cores. We have identified eight new horizons and redefined seven as reworked, these previously being considered as primary. Thin horizons $(<20 \mathrm{~mm}$ ) previously identified (Orakei Basin by Molloy et al., 2009; Onepoto by Shane and Hoverd, 2002; and Glover Park by Hoverd et al., 2005) were confirmed and, as previously discussed, their nomenclature maintained. Two of the horizons, AVF 4 in Onepoto, and GP1/10 in Glover Park, were not found by this study, potentially because of poor or discontinuous preservation. All relatively thick horizons (>100 mm) previously identified have been split using the techniques adopted in this study into 'primary' and 'reworked' categories, reducing the thickness of the primary deposit when compared to previous interpretations (Molloy et al., 2009). Examples of these (for the Orakei Basin core) include AVF14 with a combined thickness of $31 \mathrm{~mm}$ of intermittent primary deposits (previously $340 \mathrm{~mm}$ ), AVF13 with a primary deposit thickness of $160 \mathrm{~mm}$ (previously $740 \mathrm{~mm}$ ), and AVF3 with a primary thickness of $41 \mathrm{~mm}$ (previously $120 \mathrm{~mm}$ ). In summary, we identified two new tephra horizons within the Orakei Basin core (giving sixteen primary tephras in total) and one fewer than previously identified in the Onepoto core (giving nine in total). Finally, eight of the tephra horizons in the Glover Park core, previously interpreted as primary deposits, are now classified as re-worked, and one was not found, thereby reducing the number of primary horizons within the Glover Park core from thirteen to four.

\subsubsection{Tephra deposit re-working}

The geochemical signatures of tephras from each horizon are also essential to identify reworking relationships highlighted by the X-ray and magnetic susceptibility analyses. We classify the different types of reworked horizons observed into three groups (A-C) as discussed in the following sections. 


\subsubsection{Evidence for immediate re-working of deposits ('type-A')}

Type-A deposits show evidence of immediate re-working, with no evidence of a time break. This type encompasses horizons that have previously been interpreted as single thick primary deposits because of their apparent homogeneity in visual observations. Through coupling the X-ray imagery and magnetic susceptibility data, a more detailed stratigraphy is revealed (Fig. 3.9.A). Each basaltic horizon has a sharp basal contact with the laminated lacustrine deposits. These sharp contacts are clearly seen as magnetic susceptibility peaks and as bright sections within the X-ray images, contrasting with the grey background. The contacts are considered to be the base of a primary deposit from which the thickness of the deposit is measured.

Within some of the thick tephra deposits disturbances are identified in the form of cavities in the core, or angled or convolute bedding within the deposit. If these features coincide with dark patches on the X-ray image and low magnetic susceptibility (indicative of cavities within the core), or with grey scale-graded X-ray portions and declining magnetic susceptibility (indicative of a decreasing proportion of tephra in the lacustrine host sediment), the section is interpreted as reworked. Often in the case of immediate re-working, the top of the re-worked section is clearly seen by a very steep decline in magnetic susceptibility and a change to darker grey background colour in the X-ray images. In addition, a deposit is classified 'type- $A$ ' if the shards in a reworked material show the same geochemical composition (within error) as those of the primary tephra below, implying that the tephra is derived from a single geochemically homogeneous source. 'Type-A' reworking is considered to occur as a result of density flows from sub-lacustrine bank destabilisation due to loading from very thick tephra deposits (Bertrand et al., 2014). In these cases the primary deposit thickness is reduced in comparison to those reported in previous studies and is measured up to the point where reworking is first identified.

Figure 3.9.A shows a section from the Orakei Basin core that exemplifies a type-A reworked deposit. Here, our new results suggest that the primary deposit (AVF13) is only ca. $160 \mathrm{~mm}$ thick, compared to previous 
visual observations which classified the entire $710 \mathrm{~mm}$ thick deposit, from 50.19 to $49.48 \mathrm{~m}$ depth, as a single primary tephra horizon (Molloy et al., 2009).

\subsubsection{Evidence for periodic re-working ('type-B')}

Type-B deposits were found only within the Orakei Basin core, and are found in parts of the core that have multiple, closely spaced, visually similar horizons, interbedded with sections of laminated lacustrine deposits $(<10 \mathrm{~cm}$ thick) (Fig. 3.9.A). The tephra horizons have sharp basal contacts and are normally graded, similar to a primary horizon, and are therefore assumed to be representing individual depositional events. However, their upper contacts are blurred and show grey-tone grading on the X-ray imagery and a gradational decline in their magnetic susceptibility. These observations are interpreted to reflect upwards-decreasing shard concentrations, which we have earlier linked to re-working. We therefore propose that these repeated deposits are formed either as a result of episodic eruptions from a single centre, or periodic re-working of a single proximal deposit from a single eruption event.

Evidence for episodic eruptions exists for a number of AVF eruptive centres, including Rangitoto, and Motukorea. Needham et al. (2011) proposed two Rangitoto eruptions with a ca. 40-year period of quiescence based on ${ }^{14} \mathrm{C}$ dating of two individual tephra deposits (at $533 \pm 7$ and $504 \pm 5$ cal. yr. BP). The tephra horizons were separated by ca. $10-50 \mathrm{~cm}$ of peat, and have been shown to geochemically match the contrasting composition of lavas from two different eruption phases of Rangitoto. Studies of other AVF eruptions have also highlighted multiple explosive episodes from single centres (e.g. Crater Hill, Houghton et al., 1996; Motukorea, McGee et al., 2012). However, these other eruptive episodes, unlike Rangitoto, are defined from proximal pyroclastic successions, and are interpreted to reflect on-going eruptive activity as no hiatuses are reported. The changing styles of explosive volcanism are attributed to intermittent water-magma interaction, changes in magma supply rate and degassing, and shifting vent positions (Houghton et al., 1999). The aforementioned studies all monitored the geochemistry of the eruptive products and indicated that there were minor changes in 
geochemical composition throughout the eruption indicative of a gradational change between two source melts. Therefore if the 'type-B' deposits identified were related to episodic eruptions we would expect to see chemical evolution reflected in the tephra composition (e.g. Needham et al., 2011).

An example of the type-B reworked horizon is given here from the Orakei Basin core (Fig. 3.9.A). The section of interest includes three tephra units with their basal contacts at $49.14 \mathrm{~m}, 49.33 \mathrm{~m}$ and $49.46 \mathrm{~m}$. Based on calculated sedimentation rates (e.g. $1.96 \mathrm{~mm} / \mathrm{yr}$; Molloy, 2008, as discussed in the introduction), this section was proposed to span ca. 100 years, with ca. 50 years quiescence between each deposit. The glass geochemical signature of these horizons is different from that of the previous primary horizon, hence ruling out re-working of a previous deposit. However, the geochemical signatures of the three units are indistinguishable from one another (Fig. 3.9.B), and the lack of geochemical variation is taken to indicate that the three layers do not reflect episodic eruptions from one centre, but instead two periods of reworking, possible derived from influx from south eastern stream catchments, following deposition of the earliest, single primary deposit (Pickrill et al., 1991; Bertrand et al., 2014). 


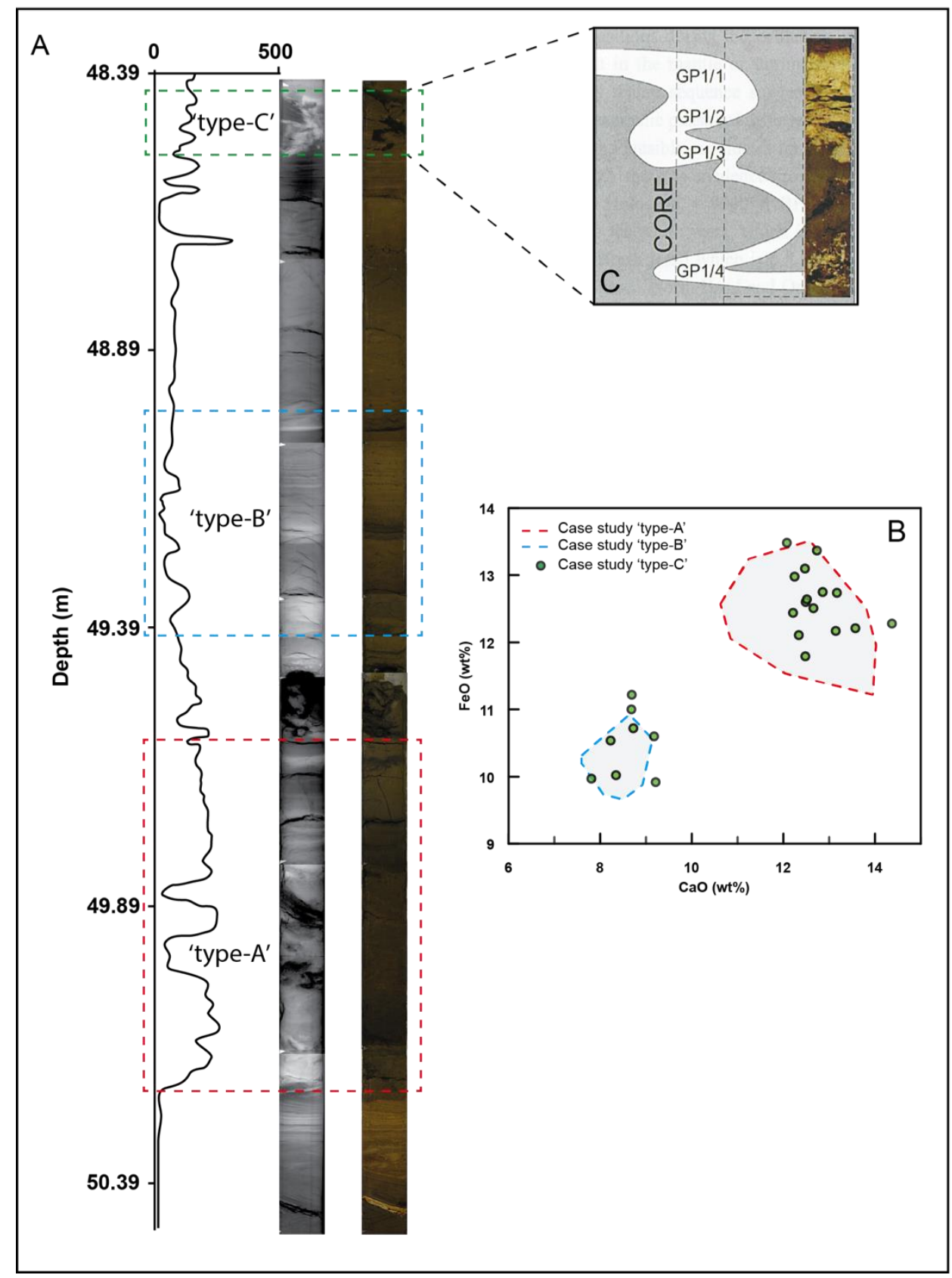

Figure 3.9. Case study from the Orakei Basin core from 50.39-48.39 m depth to show examples of re-working within the tephra sequence. (A) Magnetic susceptibility, $X$-ray image, and photograph of core section. From base to top immediate reworking of deposits ('type-A'); periodic re-working of deposits ('type-B'); delayed reworking of deposits ('type-C'). See text for descriptions. In addition a bivariate plot (B) of $\mathrm{CaO}$ $v s$. FeO measured in shards from each of the three units is given to show the geochemical variability of the horizons: 'Type-A' is shown by the dashed outline in red, 'type- $B$ ' by the dashed outline in blue, and 'type- $C$ ' by the green circles. (C) Shows the proposed slumping seen in a 'type-C' horizon, adapted from Hoverd et al. (2005) from the Glover Park core for the Rotoehu tephra deposit. 


\subsubsection{Evidence for slumped re-working of deposits ('type-C')}

Type- $C$ deposits occur infrequently (one deposit in the Orakei Basin core, one in the Onepoto core, four in the Glover Park core), but their identification is essential to avoid the misinterpretation of such deposits as representing multiple primary deposits. The termed 'slumped' (cf. Pickrill et al., 1991) is used here because the horizons are typically highly deformed with convolute bedding, and poorly sorted shard sizes. These characteristics show up as 'mottled' bright and dark colours in the X-ray scans and as an oscillatory result on the magnetic susceptibility analyses (Fig. 3.9.A). These results, together with a tephra geochemistry that is indistinguishable from the compositions of materials in the preceding (underlying) tephra(s) within the core, are here attributed to remobilisation of previously deposited tephra horizon(s).

Figure 3.9.A shows a typical 'type-C' deposit, where horizon disturbance is obvious, and magnetic susceptibility values are variable. The geochemistry for this horizon shows a mixture of shard compositions that match those of the two preceding deposits' signatures (Fig. 3.9.B), proposed to reflect sub-lacustrine mass flow re-working of both tephra layers together at some stage (centuries) after the eruptions (Pickrill et al., 1991). In contrast, Figure 3.9.C shows another example (Rotoehu rhyolitic tephra) of slumping, identified previously by Hoverd et al. (2005) within the Glover Park core that has formed a type $\mathrm{C}$ deposit. This deposit $(\mathrm{Re})$ was inferred to reflect post depositional deformation of a single tephra unit (Hoverd et al., 2005).

\subsubsection{Geochemical variations within an individual tephra horizon}

For individual primary tephra horizons, major element concentrations may show three patterns: 1) unimodal, 2) bimodal, and 3) gradational variations. Because of the improved identification of primary tephra horizons (outlined in sect. 3.5.1), any variability in tephra geochemical composition represents a natural variation in the sample itself, and is not considered to be a result of reworking. Samples of glass from 50 primary horizons show a unimodal distribution of major element contents (e.g., Fig. 3.10.B), with 
variations of $<1 \mathrm{wt}$. \% attributed to natural variation within the glass shards or the EMPA process. Three horizons show a bimodal distribution of major element concentrations (e.g., Fig. 3.10.A), which had previously been attributed (Smith et al., 2008) to the rapid ascent of magma from two sources. Rapid magma ascent is likely to prevent homogenization resulting in the eruption of geochemically heterogeneous melt batches. Molloy et al. (2009) and Needham et al. (2011) also noted this bimodality within some tephra horizons, and McGee et al. (2012) further confirmed evidence of multiple magma sources based on whole rock analysis. Gradational variations, seen within four of the tephra horizons, are defined here from analyses of multiple shards in a single primary tephra horizon that lie on an increasing or decreasing trend for certain major element combination plots (e.g., Fig. 3.10.C). These variations are more indicative of the effects of microscopicscale fractional crystallisation of the tephra rather than the glass geochemical signature of the primary magma.

The major element (as oxide) concentrations of glass from some primary tephra horizons show considerable overlap and thus can yield ambiguities in fingerprinting and correlation. This limitation is overcome by the use of trace elements whose concentrations are much more strongly affected by processes pertaining to the genesis and evolution of magmas (partial melting, fractional crystallisation and magma mixing/mingling). Selected trace element combinations are therefore used to: 1) distinguish between two tephra horizons with similar major element geochemistry within a single core (Fig. 3.10.B), and 2) constrain better the geochemical composition of a tephra horizon (Fig. 3.10.A and C). Incompatible trace elements and trace element ratios (e.g. La, Gd, Nb, and La/Yb, Gd/Yb, Zr/Gd) are used here for two key reasons: 1) they are the least susceptible to the effects of fractional crystallisation; and 2) they are most sensitive to mantle source processes. Some elements, especially most major elements (e.g. Mg, Si, Al, Ca) are affected by fractional crystallisation, and therefore their concentrations are controlled by the growth of microcrysts, rather than the magma batch's residual melt. These elements are therefore not useful in fingerprinting individual tephra deposits and are avoided. 

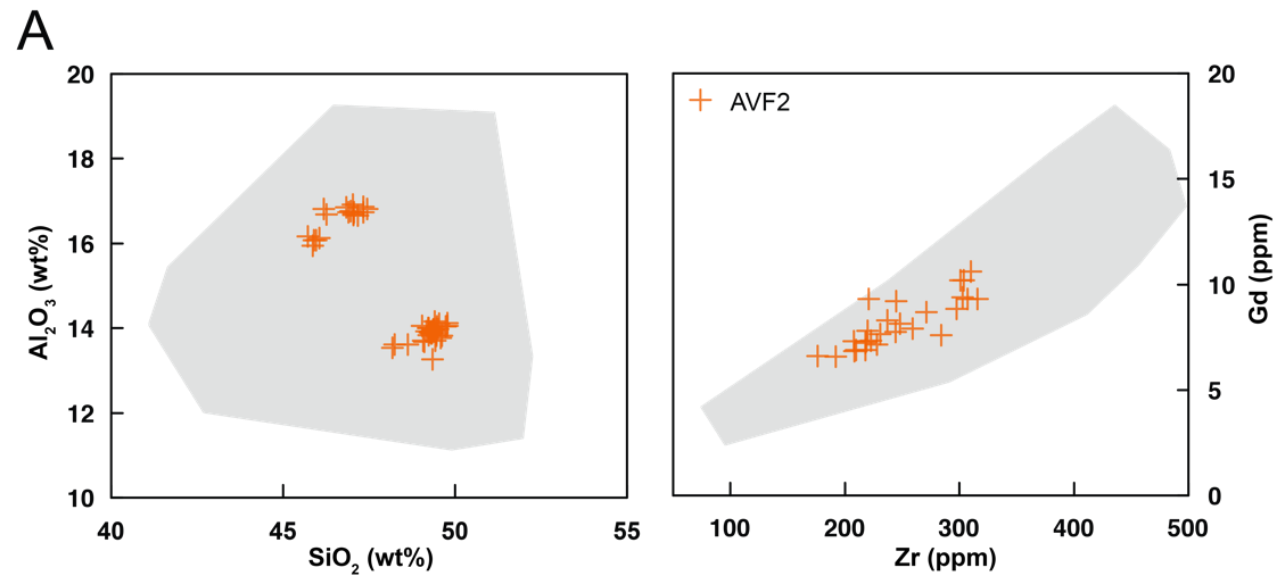

B
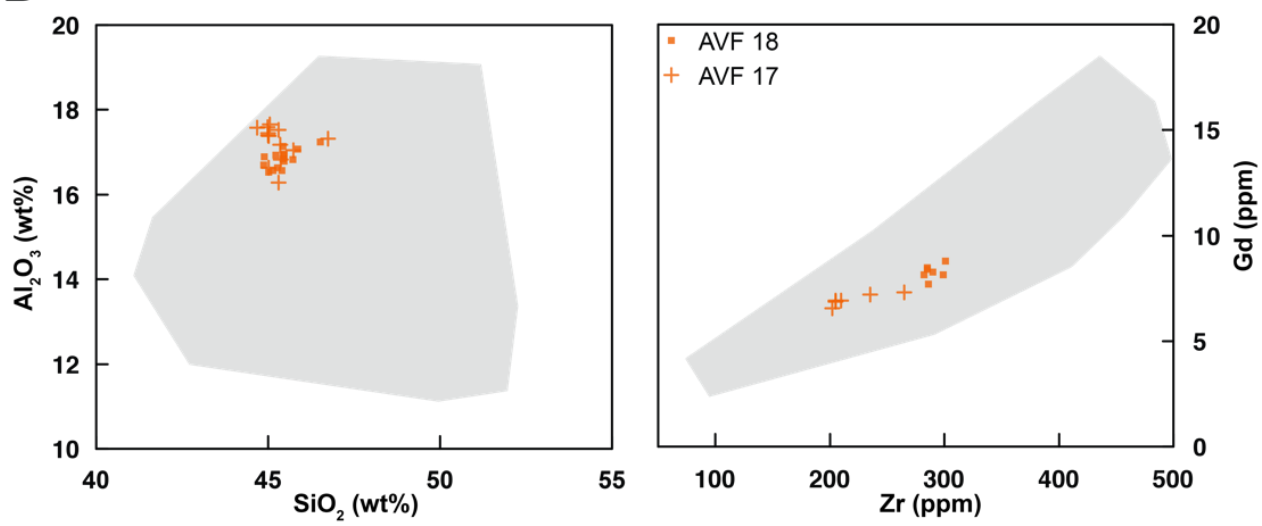

$\mathrm{C}$
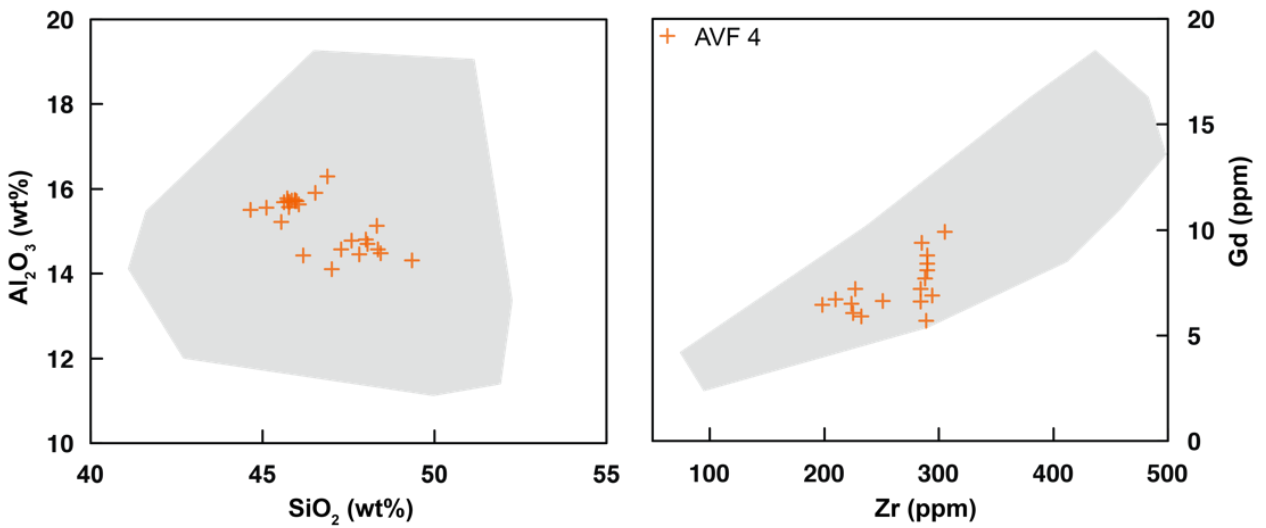

Figure 3.10. Examples of the resolution of some major element (as oxides) ambiguities using trace element concentrations in glass shards extracted from the AVF tephra horizons. The shaded region indicates the total ranges for $\mathrm{SiO}_{2} \mathrm{Vs} . \mathrm{Al}_{2} \mathrm{O}_{3}$ (wt. \%) and $\mathrm{Zr}$ vs. Gd (ppm) for shards from selected primary tephra horizons from the Orakei Basin core sequence. (A) A bimodal distribution in major element signature for a single horizon ( $A V F$ 2) narrows to a more homogeneous signature in trace element concentrations. B) Two contiguous primary tephra horizons (AVF 17 and 18) are indistinguishable on the basis of selected major elements (as oxides), but are distinguished by trace element concentrations. C) Gradational variation in major element signature for a single primary tephra horizon, attributed to effects of crystal removal, narrowed to a more homogeneous signature by trace elements. 
The trace elements chosen (e.g. $\mathrm{La}, \mathrm{Gd}, \mathrm{Nb}, \mathrm{Zr}, \mathrm{Nd}, \mathrm{Yb}$ ) are incompatible, and therefore will have similar concentrations in both pure glass and glass that includes microcrysts. In turn, ratios of these elements will be identical because any enrichment in the glass will be the same for both elements. These elements and ratios are also the most sensitive to mantle source processes and are therefore the most likely to be unique for individual magma batches and hence eruption centres. Figure 3.10 demonstrate that, for example, $\mathrm{Zr}$ vs. Gd better constrains the horizon's chemical fingerprint than do major element concentrations. This improved trace element fingerprinting is essential when attempting to correlate the horizons between cores to help ensure an accurate match. For example, Fig. 3.10.B, shows horizons AVF18 and AVF17, which are indistinguishable with major elements but can be distinguished by their trace element composition.

\subsubsection{Cross-core correlation of individual tephra horizons}

The basaltic tephra horizons found within the cores from across the AVF display a wide range of compositional diversity (sect. 3.4.2.), some of which show indistinguishable major element compositions. Here, trace elements are invaluable for providing a geochemically more distinct fingerprint for the individual horizons as noted above. Trace element compositions are not only useful to resolve both the relationship of complex deposits within the cores (e.g. primary vs. reworked deposits), but also provide the ability to more uniquely fingerprint individual horizons.

Cross-core correlations of AVF basaltic tephras for six cores are shown in Figure 3.11 and details are outlined in Table 3.2. For the first time, horizons from Pukaki, Onepoto, and Glover Park cores are inter-correlated with pre-existing 'AVF\#' classification originally proposed by Molloy et al. (2009) resulting in 14 well constrained cross correlated chronostratigraphic marker tephras, and another 15 tephras that were only found within one core. Previous correlations are enhanced and the ambiguity is reduced through trace element fingerprinting. For example, the newly assigned AVF10 in the Orakei Basin core was previously assigned to AVF9. The geochemistry (and 
location of the tephra) suggests it is more appropriately correlated to AVF10 within Onepoto and Pupuke cores. The addition of the Glover Park and Onepoto cores into the correlation suite extends the stratigraphy back from AVF1 (Molloy et al., 2009), with the new horizons here named AVFa, AVFb, and AVFc down core. Although much of the Glover Park core is affected by soft sediment deformation and reworking, our glass-based geochemical analyses have allowed recognition of these stratigraphic interrelationships, and helped to resolve of the complex relationships of the tephra deposits. Through our geochemical analysis AVF1 is now correlated from the Orakei Basin core into Onepoto and Glover Park cores as well: AVFa is only found in Glover Park, AVFb is correlated between Onepoto and Glover Park, and AVFc is only found in Onepoto. 


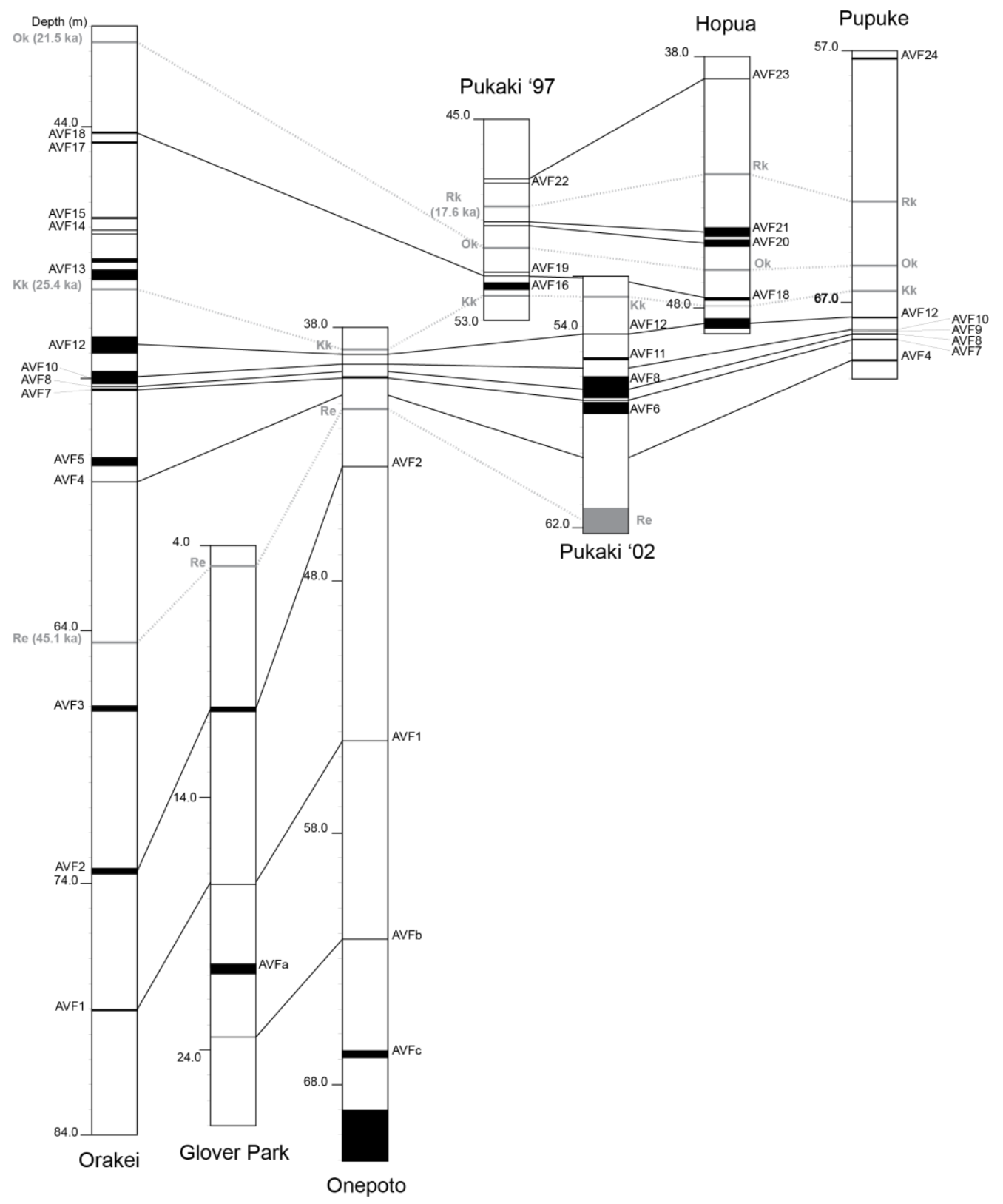

Figure 3.11. Stratigraphic columns depicting the new correlations of tephra horizons for the six maar cores. Basaltic tephras are in black and rhyolitic marker horizons shown in grey (Rk-Rerewhakaaitu, Ok-Okareka, Kk-Kawakawa/Oranui, Re-Rotoehu)

Table 3.2 (below). Summary of the tephra horizons identified and analysed, with newly defined primary tephra horizon thickness and new tephra horizon names. Also included are previous horizon names and references where applicable. Samples from Orakei Basin, Glover Park, and Onepoto were collected for this study. For Pupuke and Hopua, the original samples mounted and picked by Molloy et al. (2009) were re-analysed with sample depth, thickness and sample name maintained, and for Pukaki, post-Rotoehu data were obtained from Sandiford et al. (2001), and preRotoehu data were obtained from P. Shane (pers. comms, 2014). Horizon depths stated in the table are reported to the nearest centimetre and define the base of the primary horizon. 


\begin{tabular}{|c|c|c|c|c|c|c|}
\hline Core & Sample name & New horizon\# & Depth (m) & Thickness (mm) & Previous horizon\# & Ref for previous horizon \# \\
\hline \multicolumn{7}{|c|}{ Post Rerewhakaaitu (<17.5 ka) } \\
\hline Pupuke & T21-1-48/58929 & 24 & 57.895 & 22 & 24 & Molloy et al., 2009 \\
\hline Hopua & T4-2-H1-2/58839 & 23 & 38.945 & 3 & 23 & Molloy et al., 2009 \\
\hline Pukaki & T14 47.72m & 22 & 47.72 & 1.0 & T14 & Sandiford et al., 2001 \\
\hline \multicolumn{7}{|c|}{ Rerewhakaaitu to Okareka (17.5-21.5 ka) } \\
\hline Pukaki & AT209 49.15m & 21 & 49.15 & 3.0 & AT209 & Sandiford et al., 2001 \\
\hline Hopua & T5-2-H1-18/58855(-58856) & 21 & 45.17 & 290 & 20 & Molloy et al., 2009 \\
\hline Pukaki & AT210 49.17m & 20 & 49.17 & 2.0 & AT210 & Sandiford et al., 2001 \\
\hline Hopua & T6-5-H1-20/58857(-58858) & 20 & 45.505 & 235 & 21 & Molloy et al., 2009 \\
\hline \multicolumn{7}{|c|}{ Okareka to Kawakawa/Oruanui (21.5-25.4 ka) } \\
\hline Pukaki & T43 51.05 & 19 & 51.05 & 1.0 & T43 & Sandiford et al., 2001 \\
\hline Orakei Basin & OB1.\#30-4-44.22 & 18 & 44.22 & 8 & 18 & Molloy et al., 2009 \\
\hline Hopua & T5-6-H1-32-58869 & 18 & 47.81 & 40 & 18 & Molloy et al., 2009 \\
\hline Pukaki & T45 51.19 & 18 & 51.19 & 0.5 & T45 & Sandiford et al., 2001 \\
\hline Orakei Basin & OB1.\#30-6-44.652(-44.654) & 17 & 44.654 & 5 & 17 & Molloy et al., 2009 \\
\hline Pukaki & $\mathrm{T} 42 / 4551.52$ & 16 & 51.52 & 50.0 & $\mathrm{~T} 42$ & Sandiford et al., 2001 \\
\hline Orakei Basin & OB1.\#30-6-47.715 & 15 & 47.715 & 12 & 15 & Molloy et al., 2009 \\
\hline Orakei Basin & OB1.\#33-2-48.12(-48.128) & 14 & 48.128 & 12 & 14 & Molloy et al., 2009 \\
\hline Orakei Basin & OB1.\#33-2-48.19(-48.276) & newB & 48.276 & 10 & - & \\
\hline Orakei Basin & OB1.\#33-4-49.14(-49.46) & newA & 49.46 & 45 & - & \\
\hline Orakei Basin & OB1.\#34-3-50.089(-49.554) & 13 & 50.089 & 160 & 13 & Molloy et al., 2009 \\
\hline \multicolumn{7}{|c|}{ Oruanui to Rotoehu (25.4-45.1 ka) } \\
\hline Orakei Basin & OB1.\#36-2-52.817(-53.029) & 12 & 53.029 & 410 & 12 & Molloy et al., 2009 \\
\hline Onepoto & On2.\#4-39.06 & 12 & 36.1 & 12 & 121 & Shane and Hoverd 2002 \\
\hline Pukaki & $54.355 \mathrm{~m}$ & 12 & 54.355 & - & 12 & Shane Unpublished \\
\hline Pupuke & P23/58947 & 12 & 67.59 & 7 & 12 & Molloy et al., 2009 \\
\hline Hopua & T6-3-H1-39/58876 & 12 & 48.8 & 460 & 12 & Molloy et al., 2009 \\
\hline Pukaki & c. $55.355 \mathrm{~m}$ & 11 & 55.335 & $\cdot$ & 11 & Shane Unpublished \\
\hline Orakei Basin & OB1.\#37-2-54.119(-54.213) & 10 & 54.213 & 407 & 9 & Molloy et al., 2009 \\
\hline Onepoto & On2.\#4-39.47 & 10 & 39.5 & 15 & $116 / 115$ & Shane and Hoverd 2002 \\
\hline Pupuke & T18-7-P26/58951 & 10 & 68.09 & 3 & 10 & Molloy et al., 2009 \\
\hline Pupuke & P27/58952 & 9 & 68.15 & 6 & 9 & Molloy et al., 2009 \\
\hline Orakei Basin & OB1.\#37-2-54.27 & 8 & 54.27 & 45 & 8 & Molloy et al., 2009 \\
\hline Pupuke & P28/58953 & 8 & 68.24 & 20 & 8 & Molloy et al., 2009 \\
\hline Pukaki & ca. 56.87 & 8 & 56.4 & ca. 720 & 8 & Shane Unpublished \\
\hline Orakei Basin & OB1.\#37-2-54.324 (AVF7) & 7 & 54.34 & 20 & 7 & Molloy et al., 2009 \\
\hline Onepoto & On2.\#4-39.905(-39.914) & 7 & 39.9 & 20 & 114 & Shane and Hoverd 2002 \\
\hline Pukaki & c. 56.8 & 7 & 56.9 & - & 7 & Shane Unpublished \\
\hline Pupuke & T19-3-P29/58954 & 7 & 68.485 & 2 & 7 & Molloy et al., 2009 \\
\hline Pukaki & c.57.0 & 6 & 57.1 & c.a. 500 & 6 & Shane Unpublished \\
\hline Orakei Basin & OB1.\#39-3-57.342(-57.44) & 5 & 57.342 & 110 & 5 & Molloy et al., 2009 \\
\hline Orakei Basin & OB1.\#39-5-58.11(-58.07) & 4 & 58.11 & 41 & 4 & Molloy et al., 2009 \\
\hline Pupuke & P33/58960 & 4 & 69.315 & 15 & 4 & Molloy et al., 2009 \\
\hline \multicolumn{7}{|c|}{ Pre Rotoehu $45.1 \mathrm{ka}$} \\
\hline Orakei Basin & OB1.\#45-5-67.039(-61.17) & 3 & 67.039 & 41 & 3 & Molloy et al., 2009 \\
\hline Orakei Basin & OB1.\#50-2-73.555 & 2 & 73.555 & 510 & 2 & Molloy et al., 2009 \\
\hline Glover Park & GP6-8-10.38(-10.6) & 2 & 10.6 & 60 & GP1/6-8 & Hoverd et al., 2005 \\
\hline Onepoto & On2.\#6-2-43.66 & 2 & 43.7 & 4 & 90 & Shane and Hoverd 2002 \\
\hline Orakei Basin & OB1..\#54-3-80.047 & 1 & 80.047 & 100 & 1 & Molloy et al., 2009 \\
\hline Onepoto & AB1-On2-\#11-51.30 & 1 & 51.3 & 15 & - & Shane and Hoverd 2002 \\
\hline Glover Park & GP16-17.52(\&18.15) & 1 & 18.15 & 12 & GP1/20-18 & Hoverd et al., 2005 \\
\hline Glover Park & GP1/24 - 20.78-21.0 & a & 21.0 & 40 & GP1/24 & Hoverd et al., 2005 \\
\hline Onepoto & On2.\#18-62.36 & $b$ & 62.0 & 45 & 7 & Shane and Hoverd 2002 \\
\hline Glover Park & GP1/40 - 23.67 & b & 23.67 & 10 & GP1/40 & Hoverd et al., 2005 \\
\hline Onepoto & On2.\#21-66.68 & c & 66.7 & 270 & 1 & Shane and Hoverd 2002 \\
\hline
\end{tabular}




\subsubsection{Tephra dispersal and thickness}

As a result of correlations of the AVF tephra horizons between the maar cores, revised thicknesses and radii of tephra dispersions patterns can be inferred. Lacustrine tephra deposits will have a higher compaction rate than their on-land counterparts (e.g. on-land the tephra are a factor of about 1.75 thicker; Lowe, 1988a). Therefore the newly identified primary tephra horizon thicknesses represent minimum values (e.g. Óladóttir et al., 2012), which may be significant for on-land isopach mapping, or hazard assessment.

For correlated horizons, relative tephra thicknesses are variable. For example, tephra horizons found in the maar cores at the outer limits of the field (e.g. Onepoto, Pukaki and Pupuke) were consistently thinner than those found in the central cores (e.g. Orakei and Hopua). The thicker deposits (>100 $\mathrm{mm}$ ) are more common within the central cores, which likely reflects the higher density of eruptive centres in close proximity. However, thick deposits are not found exclusively in the central maars; for example, Pukaki core has multiple thick deposits (e.g. AVF6 ca. $500 \mathrm{~mm}$ thick) that are linked to eruptions from nearby sources (Sandiford et al., 2001).

The preservation potential of tephra horizons, and thus the completeness of the tephra record, can be assessed based on a number of factors, including the total number of individual tephra horizons found in relation to the number of eruptions within the time period covered by the maars, and the number of deposits found along a dispersal pathway. Although currently the age ranges of the maar cores are quite poorly chronologically constrained, they have been estimated to range from >150 ka (Onepoto; Lindsay et al., 2011) to present (Pupuke). Based on the modelled values from Bebbington and Cronin (2011) there is estimated to have been ca. 42 eruptions within this time period, with a "flare up" noted at 40-20 ka (Molloy et al., 2009; Bebbington and Cronin, 2011). The tephra deposits within the cores do reflect this period of increased activity, although the total number of individual horizons found within the cores only total 28 . One or more of the following factors can explain the absence of individual tephra horizons in some cores: (1) the eruption was not dispersed widely enough; (2) poor preservation at the specific maar site linked with smaller quantities of tephra; 
(3) dispersal direction of tephra did not coincide with a maar. Fifteen of the primary tephra deposits identified are only found in one core and very few $(n=5)$ of the correlated deposits appear in all of the cores studied, indicating that, for a single eruptive event, the pyroclastic material does not necessarily cover the entire field area. A number of correlations link tephra horizons to restricted areas of the field, and a number of field observations show tephra dispersal away from the directions of the maar sites (e.g. Green Mt; Hayward et al., 2011), suggesting field scale limits to the tephra dispersal. These limitations are attributed to the small eruptive volumes and eruption ash column heights, and the impact of wind direction of the AVF centres (e.g. Lowe, 1988a, b; Shane, 2005).

In some cases deposits are not necessarily found in all maars along a dispersal pathway. For example, two tephra horizons are linked to Orakei and Pupuke but are not found in Onepoto, which is located geographically between the two. These dispersal patterns are most likely indicative of either discontinuous preservation and/or complex diffuse distal fall out (Molloy et al., 2009). For more distal sites, where tephra thicknesses are minimal (1-2 mm), preservation potential through water columns is highly reduced, resulting in differential settling of tephra and thus in many cases discontinuous deposition (Beierle and Bond, 2002).

\subsubsection{Sedimentation rates}

As tephras are considered to represent instantaneous events (Shane, 2000), to calculate sedimentation rates their thicknesses are subtracted from the core thickness constrained by marker horizons with accurately documented ages. The thicknesses of the remaining lacustrine sediments, assumed to have accumulated at constant sedimentation rates between data points, are then divided by the number of years between the rhyolitic marker horizons to yield the sedimentation rate for the maar (e.g. in Orakei Basin, the sediment between Okareka and Kawakawa has a mean sedimentation rate of $1.96 \mathrm{~mm} / \mathrm{yr}$; Molloy et al., 2009). The reduction of thickness of primary deposits - now identified as being reworked - not only has implications for 
primary deposits, but also may affect calculated sedimentation rates and thus modelling for estimated eruption ages, frequency rates and source centre correlations. Bebbington and Cronin (2011) and Green et al. (2014) use previously published (Molloy et al., 2009) horizon thicknesses and correlations as inputs into horizon age, source centre modelling and thus source centre age estimates. Our study will allow more accurate data input into the models, with improved horizon correlation and horizon thickness estimates, thus supporting and improving future statistical modelling for the AVF eruption frequencies and centre ages. Future statistical analysis will also help to corroborate the tephra correlation and identification made in our study.

\subsection{Conclusions}

The use of multiple analytical techniques is critical to produce a highresolution correlation of basaltic tephras within sediment cores. X-ray density scanning not only reveals the areas of high-density material (e.g. basaltic shards) within a core, but also is sensitive enough to indicate inherent intrastratigraphic details that can be interpreted to reflect primary vs. re-worked deposits, grain shapes, grain sizes, and bedding features. Gradational grey scaling of the X-ray imagery is indicative of the proportions of shards within background sediment and in many cases shows the upward of basaltic shards that is also reflected in a decline in magnetic susceptibility. Provided that the background sediment is low in magnetic minerals, the magnetic susceptibility analysis is highly responsive to sub-millimetre scale basaltic tephra horizons, providing support to the inferences made from the X-ray imagery.

Reworking of tephra can occur through various means such as repetition of sedimentary processes or slumping of tephra-rich material. Evidence for this, shown by the X-ray and magnetic susceptibility analysis, is supported and enhanced by the complementary (for reworking) or contrasting (for primary deposition) glass-based geochemical signatures of the units. The combination of these methods allows a more detailed tephrostratigraphy to be constructed and resolution of ambiguities that arise from simple visual observations regarding the reworking and duplication of deposits. 
Complexities observed with re-working have important implications for sedimentation rate calculations and therefore the evaluation of eruption spacing.

For the AVF tephras, the major element (as oxides) relationships of $\mathrm{Al}_{2} \mathrm{O}_{3}$ vs. $\mathrm{SiO}_{2}, \mathrm{MgO}$ vs. $\mathrm{CaO}$, and $\mathrm{CaO}$ vs. $\mathrm{FeO}$ are useful for correlation purposes, because they are the least variable for individual horizons but most variable for the field as a whole. In the cases where major element signatures are inadequate, incompatible trace elements (mainly REE) and trace element ratios (e.g. REE/Yb) from glass analyses are valuable for providing more distinctive signatures that can allow individual tephras to be distinguished. It is important to note that for the ca. 53 centres in the AVF, geochemistry is not diverse enough to be used alone as a definitive correlation tool, and the use of stratigraphy and well dated marker horizons provides important additional constraints in cross core correlations. When using these methodological improvements, 52 individual basaltic tephra deposits were identified from six cores from the AVF maars. Of these, fourteen horizons have been crosscorrelated and another thirteen individual horizons identified, to provide a more robust tephrostratigraphic framework for the eruption evolution of the Auckland volcanic field.

\section{Acknowledgements from published paper}

$\mathrm{JH}$ is funded by the DEVORA (Determining VOlcanic Risk in Auckland) project, led by Jan Lindsay and Graham Leonard. We thank David Lowe and an anonymous reviewer for their constructive comments that helped to improve this manuscript. We also thank Richard Wysoczanski (NIWA) for helpful discussion on X-ray and probe analysis, Phil Shane for supplying unpublished tephra data from Pukaki core and helpful discussion, and University of Auckland Collections for supplying tephra mounts from Catherine Molloy's MSc thesis study. JH would also like to thank Elaine Smid and Shaun Eaves for aiding and assisting in transporting cores, Alan Orpin (NIWA) for discussion and assistance with core analysis and Malcolm Reid (UoO) for assistance with LA-ICP-MS analysis. 


\section{Preface to Chapter 4}

In Chapter 3 an eruptive history was constructed for the Auckland Volcanic Field by cross correlating tephra deposits between 6 lacustrine maar cores. Detailed geochemical analysis was undertaken on individual glass shards in order to fingerprint the chemical signature of individual horizons for correlation purposes. In building this tephrostratigraphic framework, the tephra dispersal and eruption frequency of the AVF was assessed. However, due to the high density of volcanic centres in the AVF, the source vent of each horizon remains unaddressed. Establishing a link between specific tephra horizons and their centre of origin is important as it allows consideration of the combined geochemical, spatial and temporal relationship within the AVF. It is therefore essential to develop a method that allows tracing tephra deposits back to their centre of origin.

Standard tephrostratigraphic protocols link distal tephra deposits to source using well-characterised proximal tephras (Lowe, 2011). However, due to the maritime climate and high urbanisation in the Auckland region, there are very few sub-aerial tephra deposits available that are exposed, and in fresh enough condition, for characterisation (c.f. Chapter 1; sect. 1.5.2.). In addition, the high spatial density of the centres in some cases prevents even proximal tephra deposits from being unambiguously matched to a given source centre.

It is potentially possible to use the geochemical signature of distal tephras to fingerprint their source centre. However, a prerequisite for this is to establish a comprehensive major- and trace-element tephra and whole rock database for all AVF centres. In order to allow comparisons and correlations to be made, in this chapter,I evaluate previous geochemical data for the Auckland centres, and present new major and trace element data for those centres that were un- or under-sampled prior to this research. 


\section{Chapter 4}

An overview of the geochemistry of the AVF from new and existing major and trace element, and isotope data;

foundation for the tephra-whole rock correlation principles

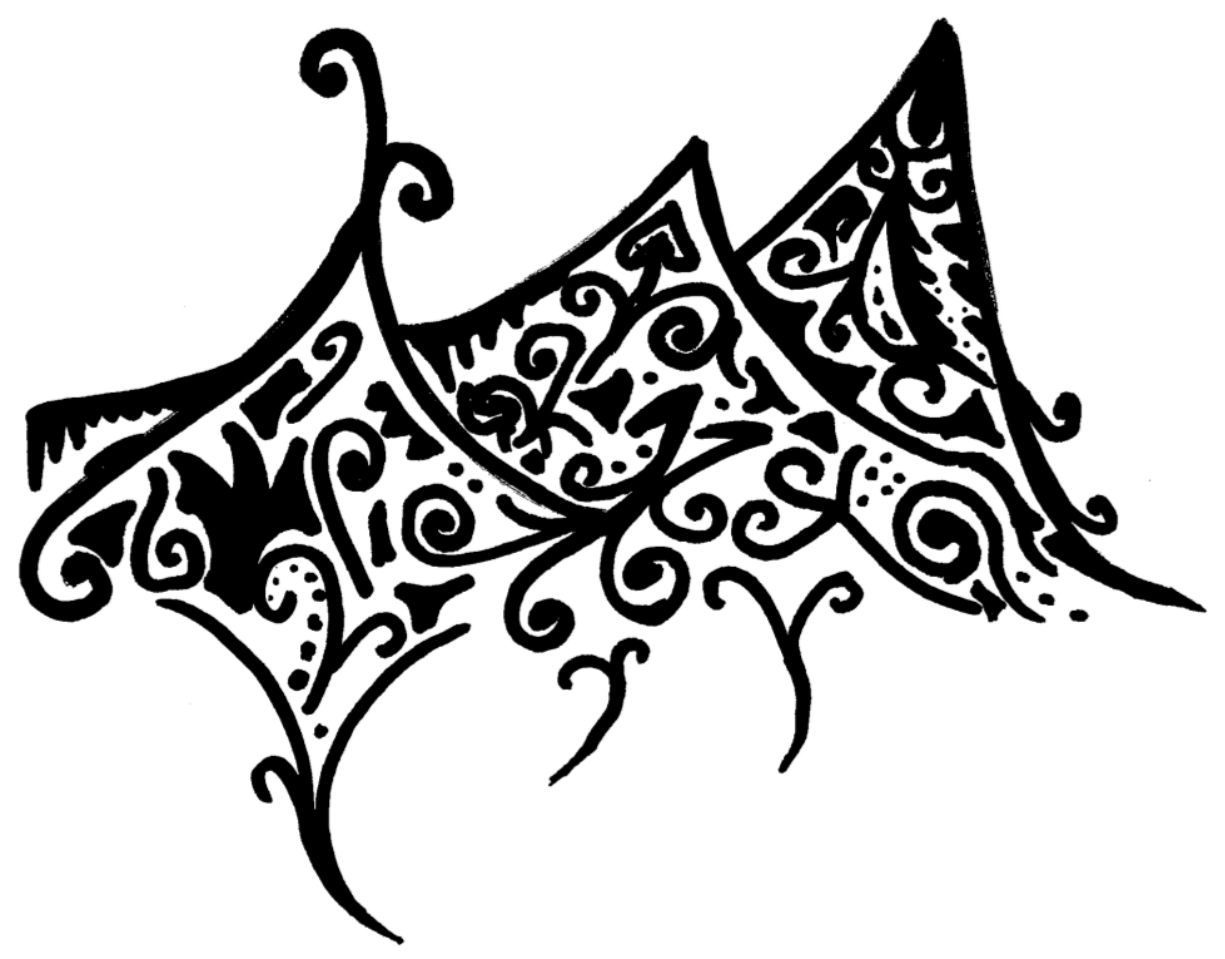

'Te Riri a Mataaho - Tāmaki Makaurau' 


\subsection{Introduction}

The Auckland Volcanic Field (AVF) is a world-renowned example of a smallscale basaltic monogenetic field, and as such the geochemistry has been extensively studied over the past thirty years. Previous studies have often focused on exploring the geochemical composition of a single centre, (e.g. Crater Hill; Smith et al., 2008, Motukorea; McGee et al., 2011, Rangitoto; Needham et al., 2011) (Table 4.1.) or a selection of centres (e.g., $\mathrm{n}=12$; McGee et al., 2013). To provide the most complete basis for tephra-source correlations (Chapter 5), a critical requirement is the existence of an extensive major and trace element database for all volcanic centres in the field, to which tephra-derived glass geochemical data can be compared. This chapter therefore present a major- and trace-element geochemical database including all existing whole-rock data from the AVF, complemented by new whole rock data from 24 centres which were previously un- (no analyses) or undersampled ( $<3$ trace element analyses).

Early studies by Heming and Barnet (1986) provided the first whole rock major element geochemical data. More recent studies have, however, provided more reliable and reproducible data, and therefore where possible the best quality data has been collated for this research. The most recent work of McGee (2012) significantly increased the amount of data in the geochemical database, through generating new major and trace element data for some previously under- or unsampled centres, including Albert Park, Motukorea, Mt Eden, Mt Richmond, Mt Roskill, Mt Smart, Mt Wellington, Otara, Puketutu, Purchas Hill, Taylor's Hill, Waitomokia, and Wiri Mt. In addition, I couple this existing data set with multiple unpublished data sets (see Bryner (1991), Miller (1996), Franklin (1999), Hookway (2000), Spargo (2007), and Eade (2009)), and unpublished data from lan Smith and co-workers (UoA and DEVORA). Table 4.1 outlines the existing geochemical database, and the additional 99 samples for 24 centres added in this study. Prior to this study, 28 centres had three or more pre-existing major and trace element analyses, 15 centres had less than three, and ten had no data at all. Now, 46 of the 53 centres have three or more major and trace element whole rock analyses available. 


\subsection{Methods}

\subsubsection{Sample selection for geochemical analysis}

Volcanic centres with less than three existing whole rock analyses were targeted for field sampling (field locations are listed in Appendix A). The seventeen new centres sampled for this study are Boggust Park, Little Rangitoto, Mt Albert, Mt Cambria, Mt Hobson, Mt Roskill, Mt Smart, Onepoto, Otuataua, Pigeon Mt, Pukaki, Pukeiti, Pupuke, Mt Robertson, St Heliers, Taylors Hill and Te Pou Hawaiki (highlighted orange on Fig. 4.1.). For an additional seven centres major element data exist (Miller, 1996), but no trace element data are reported. Thus, for these seven centres (highlighted yellow Fig. 4.1; Green Mt, Hampton Park, Mangere Mt, McLaughlins Mt, Mclennan Hills, Mt Victoria, and Otara) the samples collected by Miller (1996) were re-analysed for both major and trace elements. For six centres (Ash Hill, Kohuora, Mangere Lagoon, Styaks Swamp, Cemetery Hill, and Tank Farm; red on Fig. 4.1.) there are no longer exposures available (due to urbanisation and erosion) for sampling and therefore these centres have no available geochemical data.

\subsubsection{Major element analysis}

Whole rock samples were crushed to $<15 \mathrm{~mm}$ in a Rocklabs Boyd crusher, then powdered using a Rocklabs tungsten-carbide TEMA swing mill at Victoria University of Wellington, Wellington, NZ (VUW). Powders were made into fused lithium metaborate glass discs and analysed for major element oxide concentrations at the Open University, Milton Keynes, UK using X-ray Fluorescence (XRF) analysis following the methods of Ramsey et al. (1995). Internal standards WS-E (Whin Sill Dolerite) and OU-3 (Nanhoron microgranite) were analysed to monitor precision and accuracy. Major element oxides were accurate to within $2.0 \%$ of the recommended values for the internal standards and analytical precision $(2 \sigma)$ was $1.5 \%$ or better for all elements (Appendix B). 
Table 4.1. Summary of geochemical data (pre-existing and additions from this study) ordered by the number of analyses, including those centres without any current data; of 50 centres 3 or more data points were achieved for 44 volcanoes.

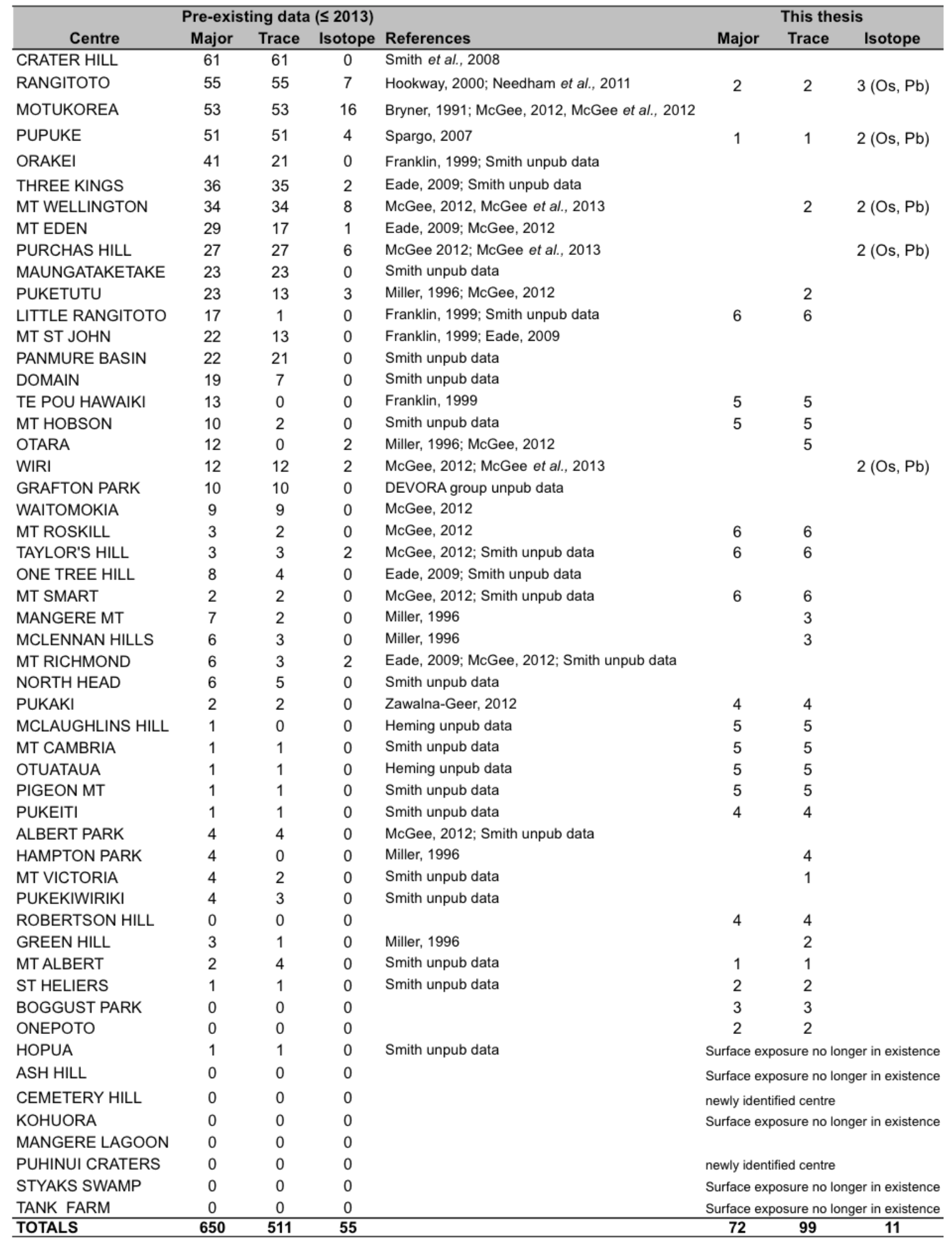




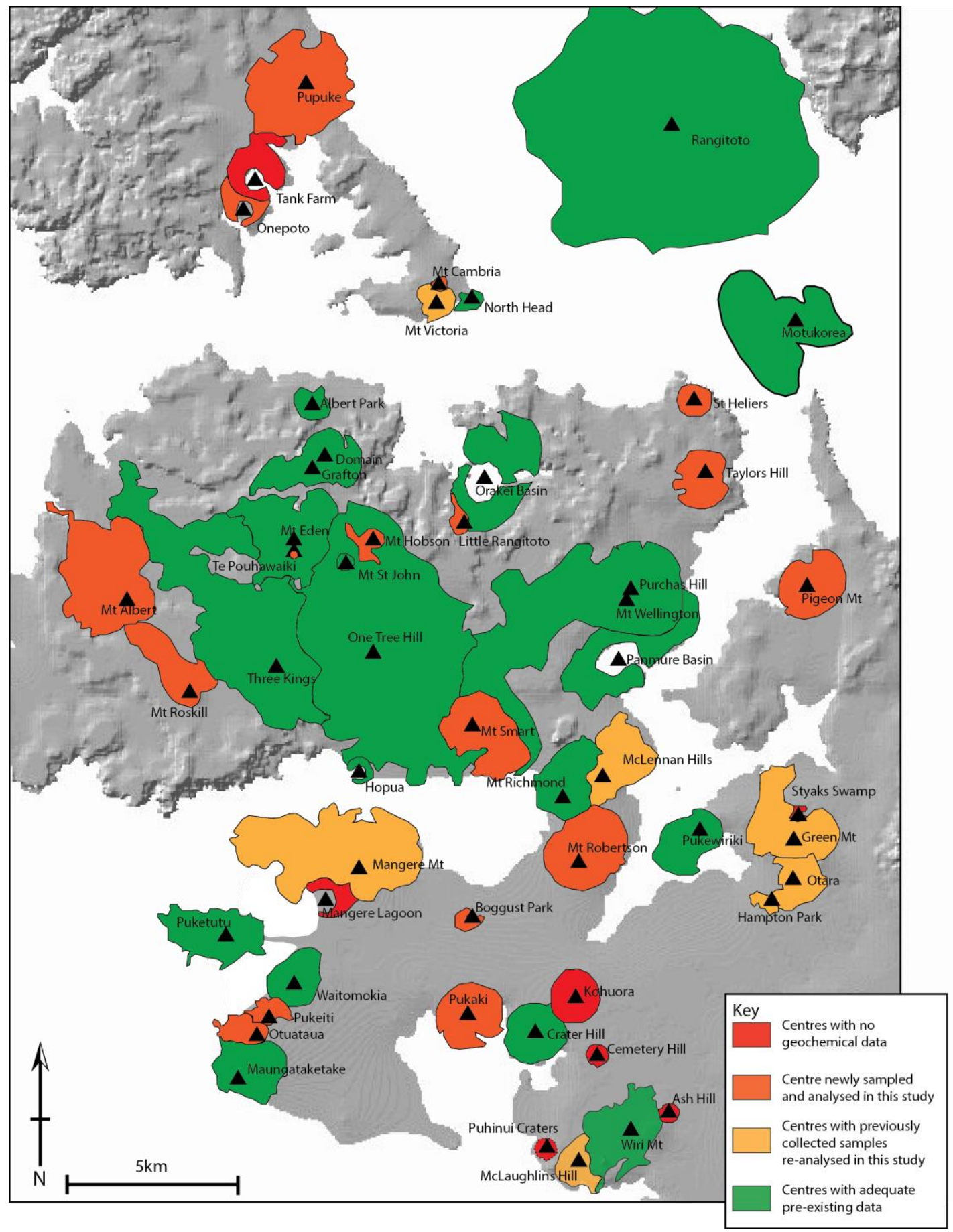

Figure 4.1. Location map for the centres of the AVF outlining the amount of geochemical data available for each centre. Prior to this study those in green $(n=23)$ had an adequate number (>3) analyses. Those in orange did not have an adequate number of analyses and so were analysed for major and trace element by this study; the dark orange show centres sampled in the field by this study ( $n=17$, field sites detailed in Appendix $\boldsymbol{A})$, the light orange show centres with existing whole rocks with only major element analysis ( $n=7$, Miller, 1996) that were re-analysed for major and trace elements for this study. Those in red ( $n=6)$, have no available data and currently no exposure available to sample, Puhinui Craters has a dashed outline because the extent of this centre is currently undefined (B. Hayward pers. comm. 2014). 


\subsubsection{Trace element analysis}

For trace element analysis, 50mg of whole rock powder was treated using conventional methods (details in Chapter 2) of $\mathrm{HF}-\mathrm{HNO}_{3}$ digestion and analysed on an Agilent 7500CS ICP-MS (VUW) in solution mode. Trace element abundances were calculated using the reduction program lolite (Paton et al., 2011), using BHVO2 as a bracketing standard, and BCR-2 as a normalisation standard. ${ }^{43} \mathrm{Ca}$ was used as an internal standard using $\mathrm{CaO}$ contents measured by XRF. Trace element analyses were accurate to within $<6 \%$ of the recommended values for the secondary standard (BCR-2) and precision ( $2 \sigma$ ) was $<6.5 \%$ with the exceptions of $\mathrm{Cr} \pm 10.4 \%$, $\mathrm{Nb} \pm 22 \%$, Cs $\pm 12.2 \%$, Ba $\pm 11.8 \%$, Ta $\pm 20.9 \%$ and $\mathrm{Pb} \pm 31 \%$ (Appendix $\mathrm{B}$ ).

\subsection{Results}

This study adds 99 individual whole rock major and trace element analyses for 24 centres (previously under or un-sample) to the AVF database, increasing the number of centres with major and trace element data available from 28 to 46 out of 53. Representative values for each of the new centres are shown in Table 4.2, with all new data given in Appendix $\mathbf{C}$.

\subsubsection{Major Elements}

All analysed samples range from basanitic/nephelenitic to basaltic in composition (based on the rock classification of LeMaitre, 2002) with $\mathrm{SiO}_{2}$ values ranging from 39 - 49 wt.\% and MgO contents ranging from 6 - 16 wt.\% (Mg\# = 5072) (Fig. 4.2.).

Overall, the new data show a positive relationship between $\mathrm{MgO}$ vs. $\mathrm{CaO}$, and a negative relationship between $\mathrm{MgO}$ vs. $\mathrm{Al}_{2} \mathrm{O}_{3}$. There are less distinct, but generally negative trends, for $\mathrm{MgO}$ vs. $\mathrm{SiO}_{2}, \mathrm{TiO}_{2}, \mathrm{Fe}_{2} \mathrm{O}_{3}{ }^{\text {tot }}$, and $\mathrm{P}_{2} \mathrm{O}_{5}$, and for these elements, a higher range in compositional variation is recorded within a single centre's data, than observed for $\mathrm{MgO}$ vs. $\mathrm{CaO}$ and $\mathrm{Al}_{2} \mathrm{O}_{3}$. For example for $\mathrm{MgO}$ vs. $\mathrm{TiO}_{2}$, the Taylors Hill data show a flat trend where $\mathrm{MgO}$ variations but no $\mathrm{TiO}_{2}$ variation, but in comparison the Pukaki samples show minimal variation in $\mathrm{MgO}$ content but have a larger variation in $\mathrm{TiO}_{2}$. In general, data plotted from individual centres (Fig. 4.3.) show clustered signatures that mimic the general trend but often show their own 
specific, separate trend lines, consistent with the findings of McGee et al. (2013). Representative values from this study for the newley sampled centres, and extreme values representing the AVF endmember compositions from McGee et al. (2013) (Rangitoto, Purchas Hill, and Motukorea) are outlined in Table 4.2, for comparison all pre-existing values are also plotted on all figures.

Table 4.2. Selected representative results for new whole rock data suite. Major elements are reported as oxides in wt.\%, trace elements in ppm. Additional representative data for the AVF geochemical endmembers, Rangitoto, Purchas Hill and Motukorea are taken from McGee et al. (2013) for comparison.

\begin{tabular}{|c|c|c|c|c|c|c|c|c|c|}
\hline $\begin{array}{l}\text { Centre name } \\
\text { Field Number }\end{array}$ & $\begin{array}{l}\text { Boggust } \\
\text { Park } \\
\text { BgPk003 }\end{array}$ & $\begin{array}{c}\text { Little } \\
\text { Rangitoto } \\
\text { LilRa002 }\end{array}$ & $\begin{array}{l}\text { McLaughlins } \\
\text { Hill } \\
\text { McLaH003 }\end{array}$ & $\begin{array}{l}\text { Mt Cambria } \\
\text { MtCam004 }\end{array}$ & $\begin{array}{r}\text { Mt Hobson } \\
\text { MtHob001 }\end{array}$ & $\begin{array}{l}\text { Mt Roskill } \\
\text { MtRos006 }\end{array}$ & $\begin{array}{l}\text { Mt Smart } \\
\text { MtSm001 }\end{array}$ & $\begin{array}{c}\text { Onepoto } \\
\text { On002 }\end{array}$ & $\begin{array}{c}\text { Otuataua } \\
\text { Otua002 } \\
\end{array}$ \\
\hline $\mathrm{SiO}_{2}$ & 47.63 & 44.03 & 42.26 & 41.48 & 41.14 & 43.23 & 43.65 & 44.10 & 45.98 \\
\hline $\mathrm{TiO}_{2}$ & 3.06 & 2.78 & 2.86 & 2.78 & 2.80 & 2.72 & 2.69 & 2.44 & 2.34 \\
\hline $\mathrm{Al}_{2} \mathrm{O}_{3}$ & 13.57 & 13.42 & 12.98 & 12.07 & 12.10 & 12.46 & 12.65 & 11.51 & 13.74 \\
\hline $\mathrm{Fe}_{2} \mathrm{O}_{3 \text { (total) }}$ & 13.83 & 14.39 & 14.56 & 14.75 & 14.71 & 13.92 & 14.08 & 13.60 & 13.22 \\
\hline MnO & 0.15 & 0.19 & 0.19 & 0.21 & 0.20 & 0.19 & 0.19 & 0.19 & 0.18 \\
\hline MgO & 6.36 & 9.43 & 11.64 & 11.28 & 12.20 & 11.99 & 11.62 & 15.82 & 10.15 \\
\hline $\mathrm{CaO}$ & 7.95 & 8.73 & 9.56 & 10.25 & 10.64 & 10.18 & 10.39 & 8.55 & 10.60 \\
\hline $\mathrm{Na}_{2} \mathrm{O}$ & 2.52 & 3.60 & 2.42 & 3.81 & 2.38 & 2.50 & 3.30 & 3.06 & 2.88 \\
\hline $\mathrm{K}_{2} \mathrm{O}$ & 1.13 & 1.67 & 0.99 & 1.32 & 0.67 & 1.25 & 1.34 & 1.12 & 0.89 \\
\hline $\mathrm{P}_{2} \mathrm{O}_{5}$ & 0.79 & 0.69 & 0.61 & 0.88 & 0.71 & 0.56 & 0.63 & 0.52 & 0.37 \\
\hline LOI & 2.97 & 0.72 & 1.55 & 0.95 & 2.08 & 0.67 & -0.17 & -0.39 & -0.10 \\
\hline Total & 99.95 & 99.67 & 99.63 & 99.79 & 99.62 & 99.66 & 100.38 & 100.50 & 100.25 \\
\hline Sc & 13.9 & 17.2 & 20.9 & 19.1 & 21.5 & 21.5 & 21.0 & 23.3 & 25.2 \\
\hline v & 195 & 190 & 237 & 223 & 218 & 256 & 231 & 198 & 243 \\
\hline $\mathrm{Cr}$ & 151 & 236 & 307 & 273 & 338 & 398 & 336 & 466 & 356 \\
\hline $\mathrm{Ni}$ & 100 & 186 & 263 & 237 & 267 & 272 & 239 & 545 & 191 \\
\hline $\mathbf{R b}$ & 18.5 & 23.3 & 28.9 & 27.5 & 18.2 & 17.0 & 20.8 & 16.8 & 12.2 \\
\hline $\mathrm{Sr}$ & 766 & 740 & 609 & 831 & 663 & 611 & 638 & 510 & 433 \\
\hline $\mathbf{Y}$ & 21.5 & 21.7 & 20.4 & 25.1 & 22.7 & 20.0 & 21.3 & 20.8 & 20.2 \\
\hline $\mathrm{Zr}$ & 322 & 274 & 214 & 269 & 236 & 212 & 206 & 184 & 145 \\
\hline $\mathrm{Nb}$ & 69.7 & 60.9 & 44.9 & 65.5 & 56.9 & 44.5 & 53.3 & 35.3 & 33.4 \\
\hline Cs & 0.38 & 0.22 & 1.03 & 0.48 & 0.69 & 0.24 & 0.33 & 0.23 & 0.25 \\
\hline $\mathrm{Ba}$ & 422 & 273 & 267 & 378 & 357 & 233 & 274 & 216 & 170 \\
\hline La & 45.5 & 38.8 & 35.1 & 59.7 & 49.3 & 33.7 & 37.2 & 29.1 & 21.0 \\
\hline $\mathrm{Ce}$ & 99.0 & 81.9 & 69.4 & 114 & 93.9 & 68.1 & 73.6 & 57.0 & 43.4 \\
\hline $\mathrm{Pr}$ & 11.2 & 9.29 & 8.38 & 12.6 & 10.64 & 8.10 & 8.59 & 6.73 & 5.29 \\
\hline Nd & 44.2 & 37.1 & 33.8 & 49.5 & 41.9 & 32.4 & 34.4 & 27.2 & 22.7 \\
\hline Sm & 8.59 & 7.34 & 6.83 & 9.47 & 8.15 & 6.61 & 6.99 & 5.55 & 5.09 \\
\hline Eu & 2.76 & 2.42 & 2.27 & 3.04 & 2.63 & 2.16 & 2.26 & 1.86 & 1.74 \\
\hline Gd & 7.97 & 7.02 & 6.62 & 8.89 & 7.72 & 6.46 & 6.82 & 5.61 & 5.13 \\
\hline Tb & 0.98 & 0.92 & 0.87 & 1.13 & 0.99 & 0.85 & 0.89 & 0.77 & 0.75 \\
\hline Dy & 4.92 & 4.68 & 4.47 & 5.56 & 5.03 & 4.47 & 4.68 & 4.15 & 4.19 \\
\hline Ho & 0.81 & 0.79 & 0.76 & 0.93 & 0.83 & 0.77 & 0.81 & 0.77 & 0.75 \\
\hline $\mathrm{Er}$ & 1.99 & 1.99 & 1.89 & 2.29 & 2.09 & 1.87 & 2.02 & 2.00 & 1.96 \\
\hline $\mathrm{Tm}$ & 0.26 & 0.26 & 0.24 & 0.27 & 0.25 & 0.24 & 0.25 & 0.27 & 0.26 \\
\hline $\mathrm{Yb}$ & 1.37 & 1.50 & 1.34 & 1.55 & 1.48 & 1.32 & 1.41 & 1.57 & 1.54 \\
\hline Lu & 0.18 & 0.20 & 0.17 & 0.20 & 0.19 & 0.18 & 0.19 & 0.23 & 0.21 \\
\hline $\mathrm{Hf}$ & 6.97 & 5.81 & 4.60 & 5.69 & 5.18 & 4.74 & 4.66 & 4.07 & 3.45 \\
\hline $\mathrm{Ta}$ & 4.50 & 3.50 & 2.34 & 3.51 & 3.14 & 2.62 & 3.01 & 1.96 & 2.03 \\
\hline $\mathrm{Pb}$ & 3.58 & 3.32 & 1.44 & 1.26 & 2.00 & 2.33 & 3.24 & 1.97 & 1.37 \\
\hline Th & 5.42 & 4.14 & 3.98 & 6.97 & 5.46 & 3.77 & 4.41 & 3.39 & 2.52 \\
\hline U & 1.23 & 1.37 & 1.20 & 1.94 & 1.45 & 1.10 & 1.28 & 1.00 & 0.69 \\
\hline
\end{tabular}


Table 4.2 continued.

\begin{tabular}{|c|c|c|c|c|c|c|c|c|c|}
\hline $\begin{array}{l}\text { Centre name } \\
\text { Field Number }\end{array}$ & $\begin{array}{c}\text { Pigeon Mt } \\
\text { PgMt004 }\end{array}$ & $\begin{array}{l}\text { Pukeiti } \\
\text { Pkit004 }\end{array}$ & $\begin{array}{c}\text { Robertson } \\
\text { Hill } \\
\text { RoHI003 }\end{array}$ & $\begin{array}{l}\text { St Heliers } \\
\text { StHel003 }\end{array}$ & $\begin{array}{c}\text { Taylors Hill } \\
\text { TaHi001 }\end{array}$ & $\begin{array}{l}\text { Te Pou } \\
\text { Hawaiki } \\
\text { TePou005 }\end{array}$ & $\begin{array}{l}\text { Rangitoto } \\
\text { Ra-AN-79 }\end{array}$ & $\begin{array}{l}\text { Purchas Hill } \\
\text { AVF-917 }\end{array}$ & $\begin{array}{c}\text { Motukorea } \\
\text { AVF-560 }\end{array}$ \\
\hline $\mathrm{SiO}_{2}$ & 42.30 & 44.56 & 42.98 & 43.81 & 44.76 & 47.38 & 48.97 & 40.06 & 43.41 \\
\hline $\mathrm{TiO}_{2}$ & 2.75 & 2.44 & 3.08 & 2.58 & 2.69 & 1.91 & 1.86 & 3.00 & 2.71 \\
\hline $\mathrm{Al}_{2} \mathrm{O}_{3}$ & 12.25 & 13.55 & 13.08 & 12.78 & 14.05 & 13.68 & 14.06 & 11.46 & 12.48 \\
\hline $\mathrm{Fe}_{2} \mathrm{O}_{3 \text { (total) }}$ & 14.01 & 13.52 & 15.40 & 14.10 & 14.14 & 12.54 & 12.22 & 16.38 & 14.01 \\
\hline MnO & 0.19 & 0.19 & 0.20 & 0.20 & 0.18 & 0.17 & 0.17 & 0.24 & 0.22 \\
\hline MgO & 12.08 & 10.63 & 9.25 & 11.09 & 9.11 & 10.54 & 9.68 & 9.60 & 11.63 \\
\hline $\mathrm{CaO}$ & 10.37 & 10.77 & 9.85 & 10.74 & 9.39 & 9.48 & 9.31 & 11.38 & 11.33 \\
\hline $\mathrm{Na}_{2} \mathrm{O}$ & 3.27 & 2.60 & 3.61 & 3.41 & 2.75 & 2.96 & 3.10 & 4.87 & 3.15 \\
\hline $\mathrm{K}_{2} \mathrm{O}$ & 1.41 & 0.79 & 1.63 & 1.32 & 1.04 & 0.73 & 0.62 & 1.88 & 1.50 \\
\hline $\mathrm{P}_{2} \mathrm{O}_{5}$ & 0.60 & 0.49 & 0.89 & 0.75 & 0.76 & 0.31 & 0.24 & 1.34 & 0.75 \\
\hline LOI & -0.18 & 0.56 & 0.51 & -0.04 & 1.23 & 0.15 & -0.42 & 0.10 & 0.97 \\
\hline Total & 99.04 & 100.09 & 100.47 & 100.74 & 100.11 & 99.84 & 99.91 & 99.88 & 102.16 \\
\hline Sc & 21.5 & 25.3 & 17.9 & 22.9 & 20.6 & 24.3 & 27.6 & 20.0 & 25.7 \\
\hline v & 253 & 252 & 223 & 247 & 211 & 202 & 208 & 217 & 271 \\
\hline $\mathrm{Cr}$ & 345 & 398 & 211 & 299 & 260 & 378 & 319 & 202 & 469 \\
\hline $\mathrm{Ni}$ & 275 & 204 & 165 & 233 & 170 & 243 & 225 & 195 & 248 \\
\hline $\mathbf{R b}$ & 22.0 & 11.3 & 27.0 & 22.2 & 13.9 & 10.7 & 10.2 & 32.6 & 24.3 \\
\hline $\mathrm{Sr}$ & 630 & 468 & 870 & 721 & 555 & 371 & 322 & 1213 & 784 \\
\hline$Y$ & 21.0 & 21.0 & 24.5 & 24.5 & 20.1 & 18.7 & 19.8 & 34.8 & 24.7 \\
\hline $\mathrm{Zr}$ & 201 & 152 & 304 & 218 & 208 & 130 & 123 & 371 & 246 \\
\hline $\mathrm{Nb}$ & 55.7 & 33.3 & 73.5 & 60.5 & 44.1 & 21.9 & 13.2 & 114 & 77.2 \\
\hline Cs & 0.28 & 0.17 & 0.41 & 0.32 & 0.20 & 0.26 & 0.34 & 0.43 & 0.37 \\
\hline $\mathrm{Ba}$ & 277 & 190 & 340 & 300 & 235 & 125 & 101 & 431 & 356 \\
\hline La & 36.0 & 23.7 & 51.5 & 44.3 & 27.9 & 14.6 & 12.5 & 90 & 54.5 \\
\hline $\mathrm{Ce}$ & 71.9 & 48.6 & 107 & 87.4 & 56.5 & 31.9 & 26.5 & 166 & 101 \\
\hline $\mathrm{Pr}$ & 8.46 & 5.87 & 12.0 & 10.3 & 6.85 & 4.07 & 3.52 & 19.4 & 11.7 \\
\hline Nd & 34.1 & 24.7 & 47.3 & 41.0 & 27.9 & 17.7 & 16.9 & 76.2 & 46.5 \\
\hline Sm & 6.81 & 5.60 & 9.30 & 8.10 & 6.06 & 4.18 & 4.18 & 14.0 & 8.90 \\
\hline Eu & 2.22 & 1.87 & 2.99 & 2.64 & 2.03 & 1.48 & 1.45 & 4.14 & 2.66 \\
\hline Gd & 6.51 & 5.48 & 8.61 & 7.74 & 5.84 & 4.50 & 4.49 & 11.76 & 7.55 \\
\hline Tb & 0.88 & 0.79 & 1.11 & 1.01 & 0.82 & 0.67 & 0.66 & 1.48 & 1.07 \\
\hline Dy & 4.58 & 4.31 & 5.58 & 5.29 & 4.35 & 3.77 & 4.26 & 7.88 & 5.54 \\
\hline Ho & 0.79 & 0.78 & 0.91 & 0.91 & 0.76 & 0.69 & 0.78 & 1.27 & 0.97 \\
\hline $\mathrm{Er}$ & 1.91 & 1.99 & 2.17 & 2.22 & 1.90 & 1.83 & 2.09 & 2.87 & 2.45 \\
\hline $\mathrm{Tm}$ & 0.24 & 0.26 & 0.28 & 0.29 & 0.25 & 0.25 & 0.31 & 0.35 & 0.30 \\
\hline $\mathrm{Yb}$ & 1.36 & 1.55 & 1.45 & 1.63 & 1.42 & 1.50 & 1.87 & 1.91 & 1.82 \\
\hline Lu & 0.18 & 0.21 & 0.19 & 0.22 & 0.18 & 0.21 & 0.26 & 0.23 & 0.24 \\
\hline $\mathrm{Hf}$ & 4.57 & 3.61 & 6.42 & 4.83 & 4.62 & 3.11 & 3.18 & 8.5 & 5.13 \\
\hline $\mathrm{Ta}$ & 3.08 & 1.96 & 3.98 & 3.17 & 2.49 & 1.30 & 0.94 & 7.63 & 5.40 \\
\hline $\mathrm{Pb}$ & 2.02 & 1.56 & 3.69 & 3.16 & 2.07 & 1.78 & 2.40 & 5.95 & 6.23 \\
\hline Th & 4.18 & 2.85 & 5.94 & 5.01 & 3.26 & 1.63 & 1.62 & 10.6 & 6.84 \\
\hline U & 1.22 & 0.81 & 1.84 & 1.43 & 0.95 & 0.48 & 0.42 & 2.84 & 1.76 \\
\hline
\end{tabular}




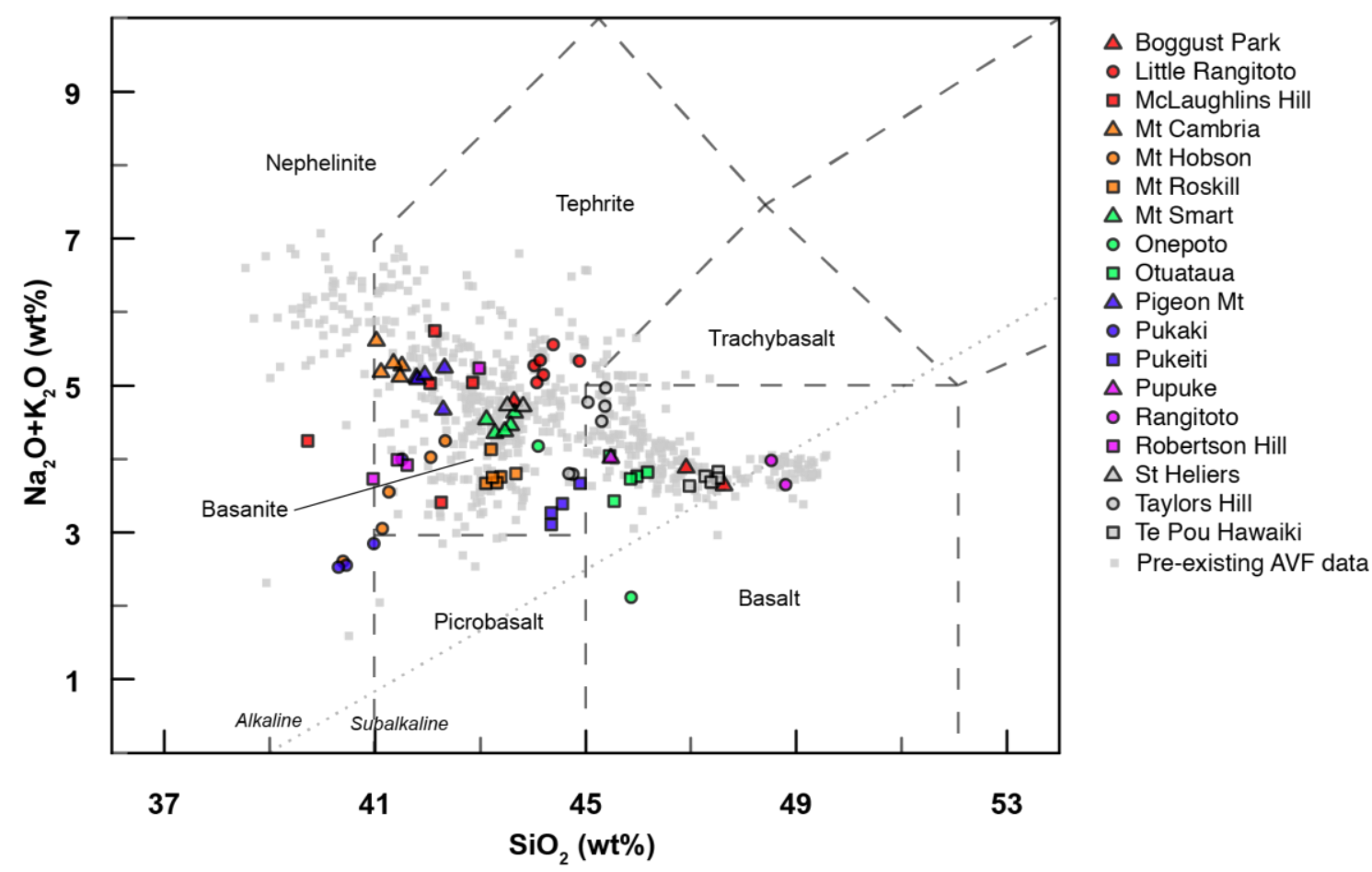

Figure 4.2.Total-alkali vs. silica (TAS) diagram (after LeMaitre, 2002) to show the comparison between the existing database and the samples added by this study. Previous data plotted as grey outline (see references in text sect. 4.1.); new values plotted by colour for each centre (full data in Appendix C).

For most major element concentrations the new data plot within the limits previously documented by McGee et al. (2013). However, a number of samples, from Boggust Park, Onepoto, and Pupuke, plot outside of the main field of AVF major element data (Fig. 4.3.). Samples from Onepoto and Pupuke have higher $\mathrm{MgO}$ (>14 wt.\%), and lower $\mathrm{CaO}$ (<8 wt.\%) and $\mathrm{Al}_{2} \mathrm{O}_{3}$ (<10 wt.\%) contents compared to samples from other AVF centres. For the Boggust park samples, the element signatures are different to Onepoto and Pupuke, with low $\mathrm{CaO}$ concentrations $(<8 \%)$, but coupled with very low $\mathrm{MgO}$ content (<8\%) (Fig. 4.3.). 

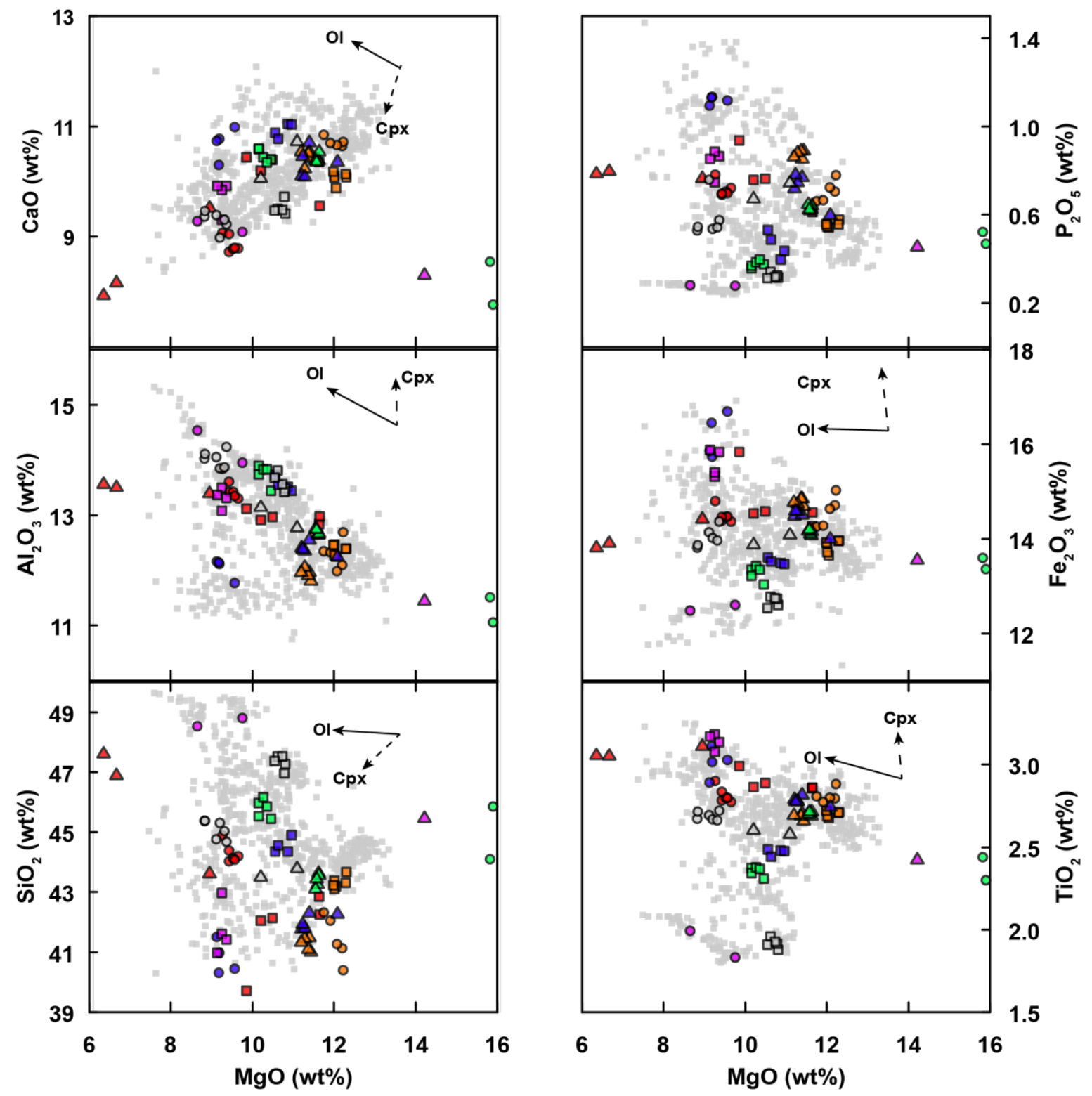

Figure 4.3. Multi-element variation diagrams (wt.\%) for AVF volcanic rocks. New data plotted as coloured symbols and existing data plotted as grey symbols, see Figure 4.2 for key. Trajectory values from Needham et al., 2010 from individual mineral analysis on Rangitoto samples. 


\subsubsection{Trace Elements}

The new analytical data in general exhibit large ranges for trace element concentrations, for example, La 10-90 ppm, Nb 10-80 ppm and Sr 300-1000 ppm. Similar to the major element relationships, the trace elements again show general trends for the field overall, as well as trends specific to each centre. There is a strong positive trend for $\mathrm{MgO}$ vs. $\mathrm{Cr}$, and $\mathrm{Sc}$, and for $\mathrm{MgO}$ vs. $\mathrm{Th}, \mathrm{Nb}, \mathrm{Sr}$, and $\mathrm{La}$ there is a general negative trend of variable slope. Again no new extremes are observed, with all the new data sitting within the pre-existing data fields (Fig. 4.4.).

Primitive mantle-normalized trace element patterns are plotted for each centre (Fig. 4.5.), with all showing broadly similar patterns characterized by a peak at $\mathrm{Nb}$ and a negative slope to less incompatible elements, similar to Ocean Island Basalt (OIB). Some centres are less enriched in trace elements, and are characterised by a shallower REE pattern gradient. In contrast, other samples from more trace element-enriched centres have a relatively steep REE pattern gradient, and show a small trough at $\mathrm{Zr}-\mathrm{Hf}$. A positive $\mathrm{Sr}$ anomaly ( $>1$; calculated as $\left(\operatorname{Sr}_{N} / \sqrt{ }\left(\operatorname{Pr}_{N}{ }^{*} N d_{N}\right)\right)$, where elements are normalised $(\mathrm{N})$ to primitive mantle values after McDonough and Sun, 1995) is present in centres that are less enriched in trace elements, but absent in those that are more enriched (0.94-1.27). There is no significant Eu anomaly (calculated in the same manner as the $\mathrm{Sr}$ anomaly, in this case using Sm and Gd) for any centres (1.0-1.05), and for those centres without an $\mathrm{Sr}$ anomaly typically there is a negative $\mathrm{K}$ anomaly (0.93-0.19; calculated as previously outlined for $\mathrm{Sr}$ and Eu anomaly, but using $\mathrm{Ta}$ and $\mathrm{La}$ ). There is a strong negative correlation exhibited between $\mathrm{Sr}$ anomaly vs. $(\mathrm{La} / \mathrm{Sm})_{\mathrm{N}}$ and $\mathrm{Th} / \mathrm{Yb}$, with values for $(\mathrm{La} / \mathrm{Sm})_{\mathrm{N}}$ ranging from 1.86 to 4.16 and $\mathrm{Th} / \mathrm{Yb}$ values ranging from 0.87 to 5.61 (Fig. 4.7.). 

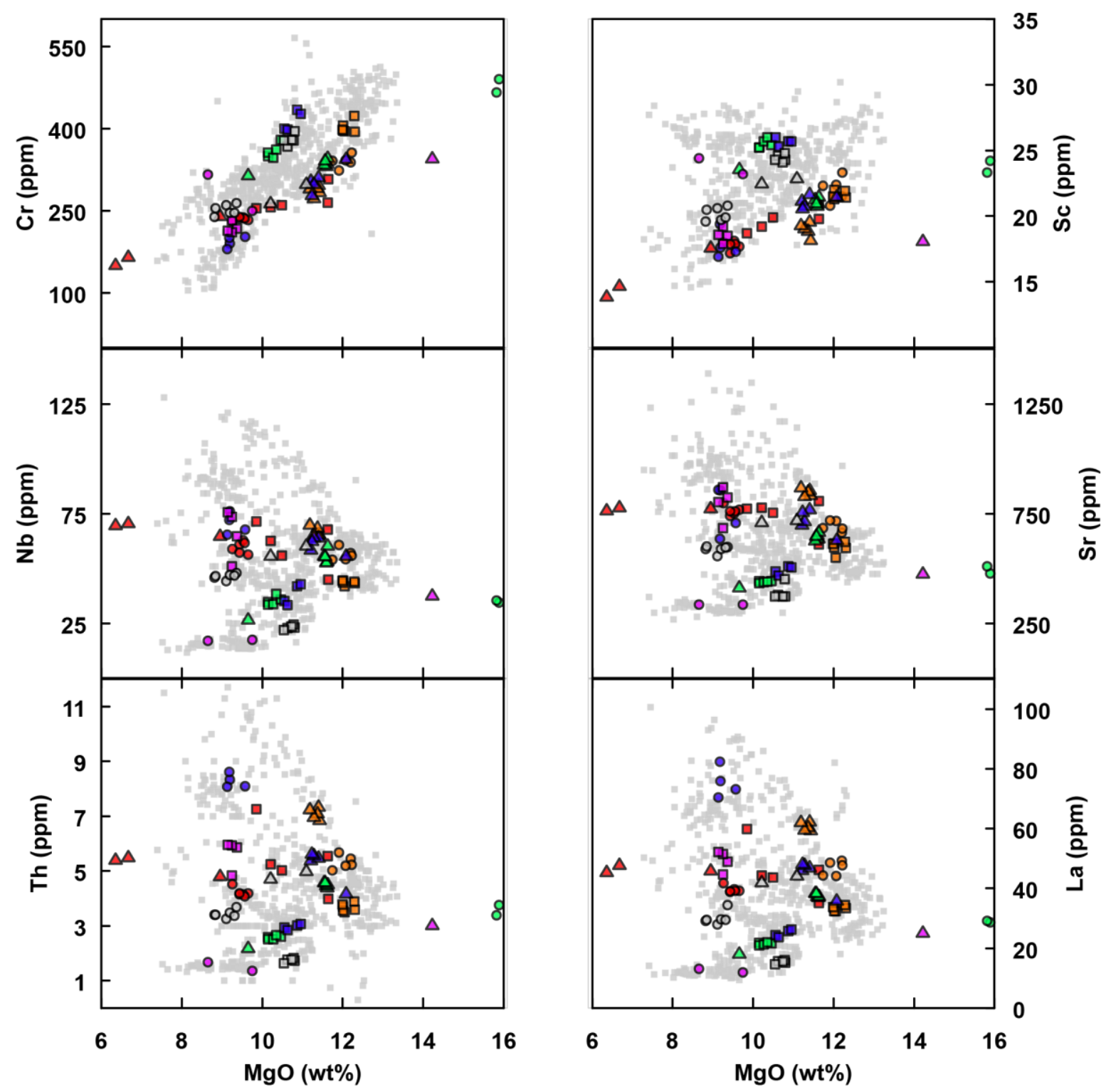

Figure 4.4. Trace element multi-variation diagrams for AVF volcanic rocks. New data plotted as coloured symbols, outlined in the key for Figure 4.2. Existing data is plotted as grey symbols. 

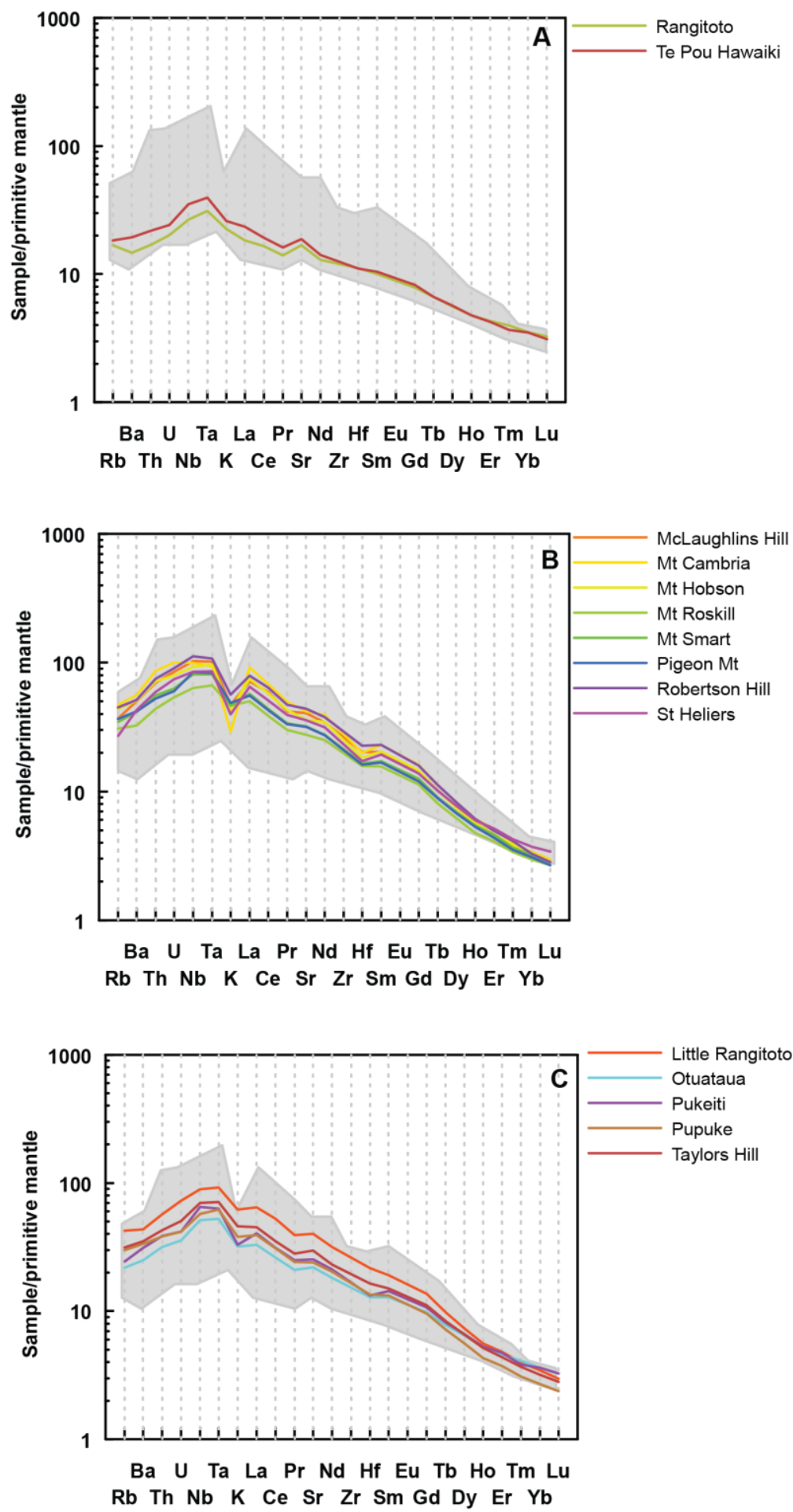

Figure 4.5. Primitive mantle-normalised multi-element plots for newly analysed samples from the AVF. Pale grey field shows the total AVF database range with pre-existing Purchas Hill sample defining the upper limit, and Rangitoto sample defining the lower limit (from McGee et al., 2013). Normalisation values are from McDonough and Sun (1995). (A) Samples that exhibit a large Sr anomaly coupled with no K anomaly and a shallow REE pattern gradient. (B) Samples that exhibit no Sr anomaly, a large $K$ anomaly, and a steep REE pattern gradient. (C) Samples with a small K anomaly and a small Sr anomaly. 


\subsection{Discussion}

\subsubsection{Evaluation and comparison to previously obtained analyses}

The database constructed for whole rock analysis contains data from multiple sources (McGee, 2012; Bryner, 1991; Miller, 1996; Franklin, 1999; Hookway, 2000; Spargo, 2007; Eade, 2009; Needham, 2009) and unpublished data from lan Smith and co-workers (UoA and DEVORA)). All the previous major element analyses were run at University of Auckland using XRF analysis, and most trace elements were analysed by LA-ICP-MS at the Australian National University (ANU) using the mounts prepared for XRF analysis. Analyses of some trace elements from McGee et al. (2013) were run at Victoria University of Wellington using the same digestion methods and instruments that were used by this study (section 4.2.3). The only samples that have been discounted are those analysed by Heming and Barnet in the 1980s because they show a systematic offset in all elements suggesting an incompatibility of the data sets. In addition, the vast majority of these samples now have superseding analyses with much higher precision and accuracy (based on analyses of appropriate standards). A number of individual analyses (in Hookway, 2000; Spargo, 2007; and I.E.M. Smith unpub.) are obvious outliers affected by fractional crystallisation or olivine accumulation. This modification is also observed in the new samples: the signature of the Boggust Park samples ( $\mathrm{CaO}$ and $\mathrm{MgO}<8$ wt.\%) is indicative of fractional crystallisation of olivine. However, this cannot explain the low $\mathrm{CaO}$ content seen in the Pupuke and Onepoto samples, which is here ascribed to olivine accumulation causing a dilution effect on the $\mathrm{CaO}$ content. The concentrations of these samples, and therefore the signatures that they give the centres, are not reflecting mantle source, but ascent processes, therefore these samples will not be used in the correlation process.

To maintain consistency with the previous data GEOReM values were used as reference values (Appendix B), and primitive mantle values from (McDonough and Sun 1995) were used for normalisation. To identify potential differences between the existing and our new datasets, ten samples from different centres previously analysed by McGee et al. (2013) and Eade (2009) were compared to new analyses of the same samples. Figure 4.6 shows a representative selection of trace element comparisons for these data where previous analyses are plotted against the 
corresponding samples analysed by this study. For most elements there is very little discrepancy between the two data sets. Concentration variations between the two data sets are observed in $\mathrm{Cr}, \mathrm{Ni}$, and $\mathrm{Cs}$, and also for some of the HREE with very low concentrations $\mathrm{Er}, \mathrm{Tm}, \mathrm{Yb}$ and $\mathrm{Lu}$. These differences are not significant (they overlap at 2 sd\% error) and confirm that the new data are comparable with the previously obtained analyses.
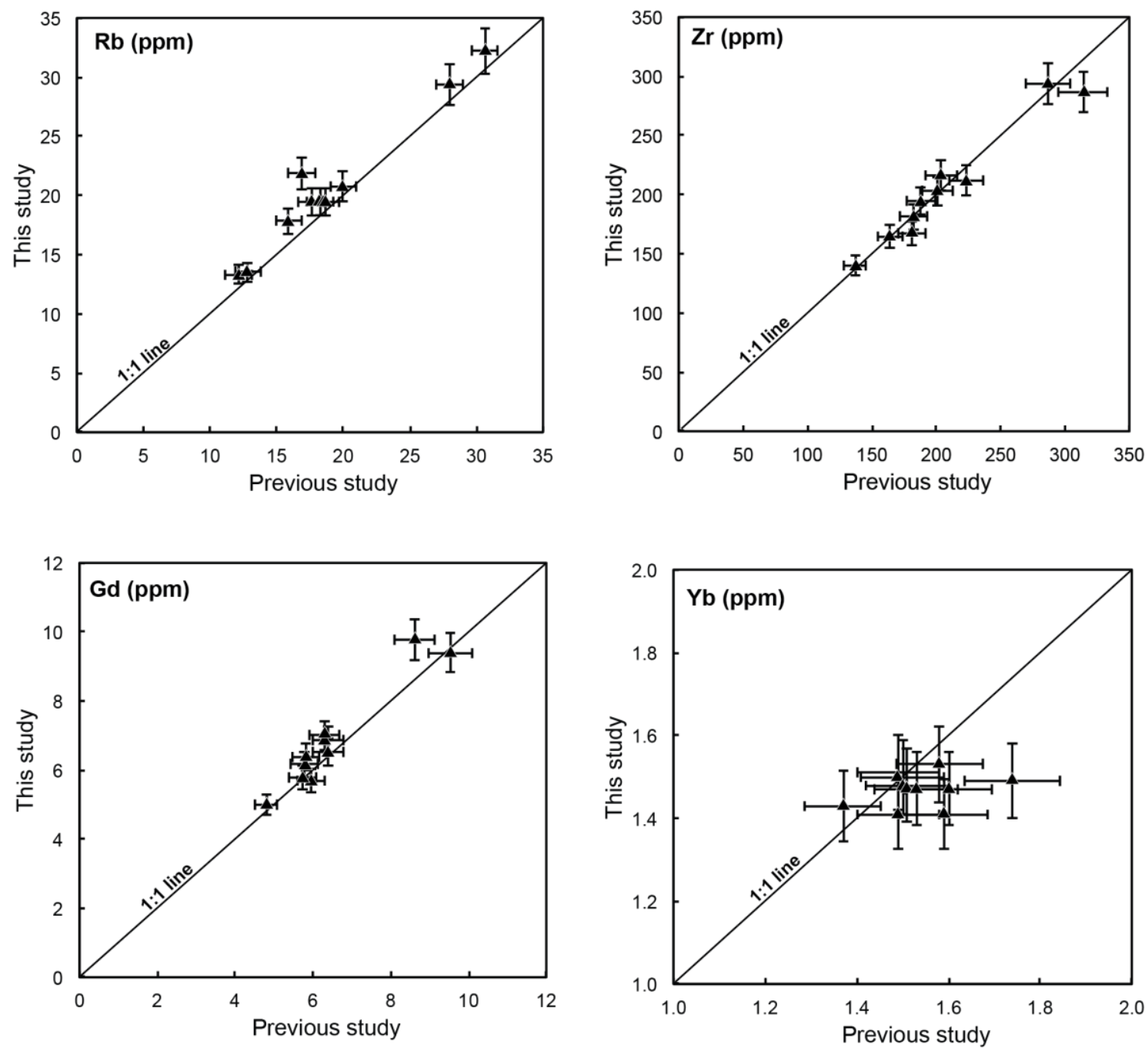

Figure 4.6. Selected trace element duplicate analyses to compare whole rock sample analyses from this study to those presented in previous studies. The 1:1 relationship line is shown with most samples overlapping this line within 2 sd\% error. 


\subsubsection{Geochemical variability intra-centre and field-wide}

For the new data gathered, the intra-centre variability in geochemical signatures is much smaller than the field-wide variability. For example intra-centre variation for $\mathrm{SiO}_{2}$ is $<3 \mathrm{wt} . \%$, for $\mathrm{MgO}<2 \mathrm{wt} . \%$, and for all other major elements $\left(\mathrm{TiO}_{2}, \mathrm{Al}_{2} \mathrm{O}_{3}, \mathrm{Fe}_{2} \mathrm{O}_{3}\right.$ tot, $\mathrm{P}_{2} \mathrm{O}_{5}$, and $\left.\mathrm{CaO}\right)<1.5$ wt.\%. In comparison the range for the field for $\mathrm{SiO}_{2}$ is $\leq 10 \mathrm{wt} . \%$, for $\mathrm{MgO}<8 \mathrm{wt} . \%$, for $\mathrm{Al}_{2} \mathrm{O}_{3}, \mathrm{Fe}_{2} \mathrm{O}_{3}{ }^{\text {tot }}<5 \mathrm{wt} . \%$, for $\mathrm{CaO}<4$ wt.\% and for $\mathrm{TiO}_{2}$ and $\mathrm{P}_{2} \mathrm{O}_{5}<2$ wt.\% (e.g. Fig. 4.3.). A number of intra-centre geochemical trends are noted: 1) minimal variation (e.g. $<0.5$ wt.\%) across multiple samples, 2) $\leq 2$ data points and therefore no trends can be identified and, 3) minor systematic variations in composition, which can be explained by fractional crystallisation.

Figure 4.3 shows the trajectories for fractional crystallisation of olivine (ol), clinopyroxene (cpx), and high-pressure clinopyroxene (cpx ${ }^{\text {hiP }}$ ) (c.f. Deer et al., 1992). Influences from Ti-augite and amphibole were discounted as their crystallisation trajectories fail to recreate any of the trends observed in the data. Although plagioclase is known to occur in very small proportions in the groundmass phases of the AVF lavas (e.g., Needham et al., 2011), the general lack of an Eu anomaly or any large plagioclase phenocrysts, and the inability of plagioclase trajectories to recreate any of the trends observed, suggest that plagioclase does not play a major role (McGee et al., 2013). Previous authors (Smith et al., 2008; McGee et al., 2013) have also suggested that high-pressure clinopyroxene can be used to explain a decreasing $\mathrm{Al}_{2} \mathrm{O}_{3}$ with decreasing $\mathrm{MgO}$ trend seen in other centres (e.g., Crater Hill, Mt Eden, Mt Wellington). This trend however, is not observed in the new data presented here (Fig. 4.3.).

The trends in geochemical data (Fig. 4.3.) exhibited for Little Rangitoto, Otuataua, Pigeon Mt, Mt Cambria, and Te Pou Hawaiki, can be explained by varying fractional crystallisation of olivine, with decreasing $\mathrm{MgO}$ and $\mathrm{Fe}_{2} \mathrm{O}_{3}{ }^{\text {tot }}$ coupled with increasing $\mathrm{SiO}_{2}, \mathrm{Al}_{2} \mathrm{O}_{3}$, and $\mathrm{TiO}_{2}$. For McLaughlins Hill, these trends are also seen, but require minor amounts of clinopyroxene crystallisation also to form the decreasing $\mathrm{SiO}_{2}$ and increasing $\mathrm{Fe}_{2} \mathrm{O}_{3}{ }^{\text {tot }}$ with $\mathrm{MgO}$. The trends in erupted material from Mt Hobson can be explained by clinopyroxene crystallisation, showing increasing $\mathrm{Al}_{2} \mathrm{O}_{3}$ and $\mathrm{Fe}_{2} \mathrm{O}_{3}{ }^{\text {tot }}$ at consistent $\mathrm{MgO}$ content. This is also seen at Pukaki, coupled with a minor decrease in $\mathrm{MgO}$ suggesting that a minor amount of olivine 
crystallisation is also present. Fractional crystallisation is not needed to explain the variations in centres that have tightly clustered data. These results are consistent with the conclusions in Smith et al. (2008) and McGee et al. (2013).

The within-field geochemical variability is much greater than the within-centre variability, and is responsible for the individual geochemical signatures associated with each centre. The within-field variation cannot be explained simply by modification of the magma from a single source by fractional crystallisation or crystal accumulation, and therefore multiple sources are inferred to be present.

The primitive mantle-normalised multi-element plots for the new data show that the new AVF samples have a range of trends between two end-members. At one end-member (e.g., Mt Cambria; Fig. 4.5.B.) there is a steep HREE trend showing a trough at $\mathrm{Zr}-\mathrm{Hf}$, and large negative $\mathrm{K}$ anomaly which becomes increasingly less pronounced to the other end-member, which exhibits a positive $\mathrm{Sr}$ anomaly, no $\mathrm{K}$ anomaly, a shallower HREE trend and no trough at $\mathrm{Zr}$-Hf (e.g., Rangitoto; Fig.4.5.A).

Most centres show a relatively flat relationship between $\mathrm{Sr}$ anomaly and $\mathrm{Zr} / \mathrm{Nb}$, with a larger range in $\mathrm{Sr}$ anomaly values (0.47 to 1.15$)$ in comparison to $\mathrm{Zr} / \mathrm{Nb}$ (5 to 8) (Fig. 4.7.).Interestingly, Rangitoto and Te Pou Hawaiki show highly variable $\mathrm{Zr} / \mathrm{Nb}$ values (5 to 8) for more restricted $\mathrm{Sr}$ anomaly values (1.22-1.28) in comparison to all other centres. $\mathrm{Zr} / \mathrm{Nb}$ and $(\mathrm{La} / \mathrm{Sm})_{\mathrm{N}}$ ratios can be used to show depleted or enriched mantle sources (e.g., Haase and Devey, 1996; Kamber and Collerson, 2000), the signatures of these ratios are here attributed to mixing of melts generated from mantle sources that have seen variable amounts of melt extraction. Depleted sources show higher $\mathrm{Zr} / \mathrm{Nb}$, and higher positive $\mathrm{Sr}$ anomaly, and lower $(\mathrm{La} / \mathrm{Sm})_{\mathrm{N}}$ than fertile sources (Haase and Devey, 1996; Kamber and Collerson, 2000), indicating that samples that show a positive Sr anomaly originate from a mantle source with a history of previous melt depletion. In addition, the relationship between the $\mathrm{Sr}$ anomaly and ${ }^{207} \mathrm{~Pb} /{ }^{204} \mathrm{~Pb}$ and ${ }^{87} \mathrm{Sr} /{ }^{86} \mathrm{Sr}$ in the AVF rocks (c.f. McGee et al., 2013) is consistent with a relationship between Sr anomaly and mantle source, rather than it being due to crystal fractionation or crustal contamination (McGee et al., 2013). 
The negative $\mathrm{K}$ anomaly observed in most samples is typical of OlB-type basalts (e.g., Sun and McDonough, 1989). The negative $\mathrm{K}$ anomaly and positive $\mathrm{Sr}$ anomaly have a positive correlation (Fig. 4.7.). A negative $K$ anomaly $(<1)$ is seen in a higher proportion of the samples than a positive $\mathrm{Sr}$ anomaly $(>1)$. These anomalies are only mutually exclusive in the end-member samples, with most samples exhibiting evidence of both signatures (Fig. 4.5.). This is indicative of variable mixing between multiple mantle sources, with the dominant input from the source of the negative $\mathrm{K}$ anomaly. As previously outlined, the samples with a negative $\mathrm{K}$ anomaly also exhibit steeper HREE trend and lower $\mathrm{Zr}$-Hf contents. The HREE and $\mathrm{Zr}-\mathrm{Hf}$ are more compatible in garnet in comparison to the LREE and therefore they are preferentially retained in a garnet-bearing source, creating a relative depletion in these elements in melts that have garnet in their source.

The samples with a high positive $\mathrm{Sr}$ anomaly (and a small or no negative $\mathrm{K}$ anomaly) show a trough at $\mathrm{Zr}-\mathrm{Hf}$ and have a shallower HREE trend, indicating their signature is not depleted in HREE or $\mathrm{Zr}-\mathrm{Hf}$, and therefore come from a source that does not contain garnet. Due to the stability of garnet in peridotite at depths of $\geq 80$ km (e.g., McKenzie and O'Nions, 1991), it is possible to conclude that the geochemical variations exhibited by the AVF melts are linked to the source depth of the melt and the presence or absence of garnet. Based on the stability field of garnet, a garnet-bearing mantle must be found at depths of $\geq 80 \mathrm{~km}$, and spinel bearing mantle found $\leq 80 \mathrm{~km}$ depth (McKenzie and O'Nions, 1991). McGee et al. (2013) split these zones into deeper garnet bearing 'asthenosphere' and overlying spinel-bearing 'lithosphere'.

These data are further and more extensively discussed in Chapter 5 section 5.5.5, with regards to the geochemical evolution of the field and source, and the relationship between chemistry and eruptive centre characteristics. 


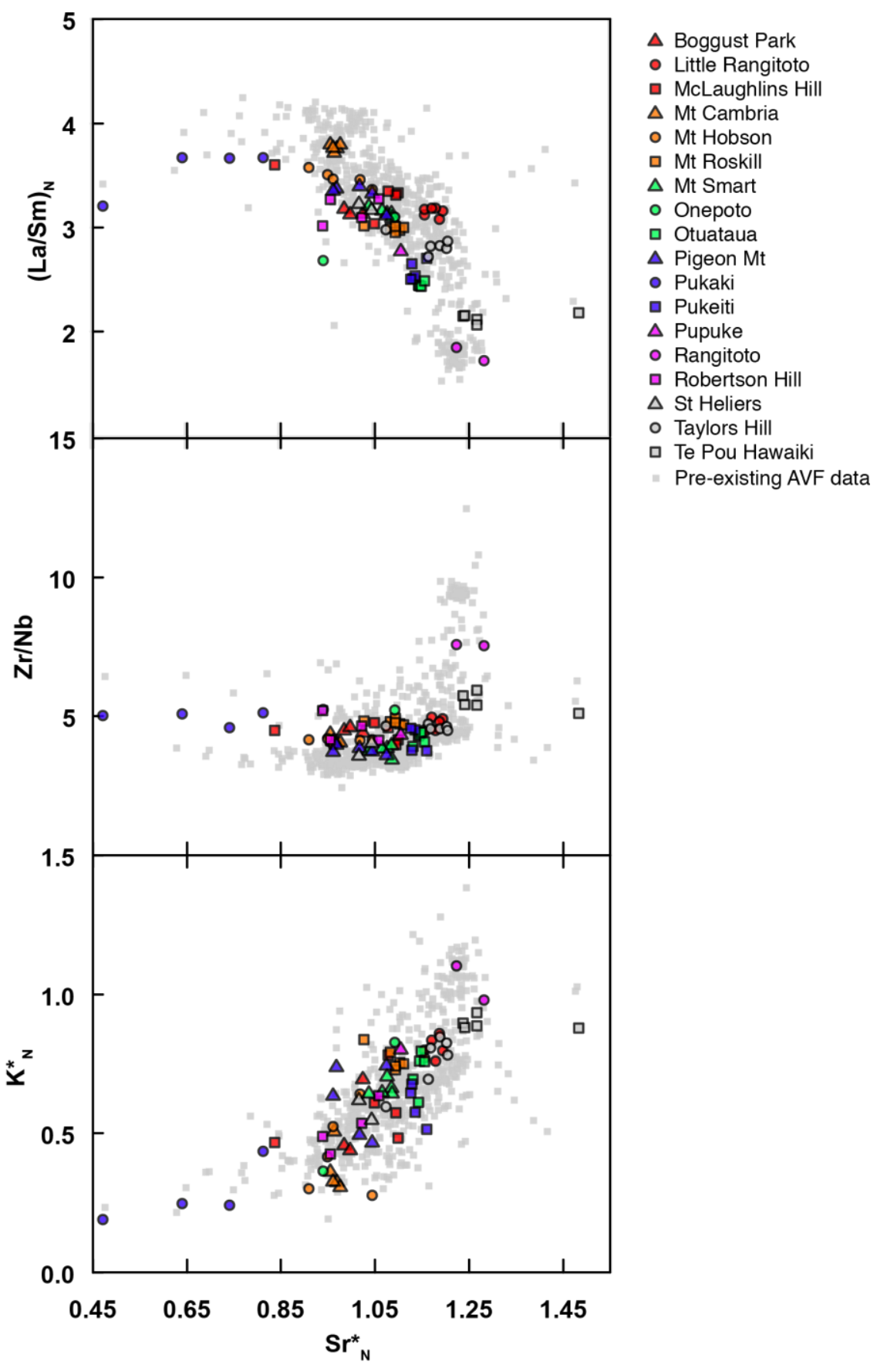

Figure 4.7. $\mathrm{Sr}$ anomaly $\left(S r^{*}{ }_{N}\right)$ vs. elements suggestive of varying source fertility and composition. The $S r$ anomaly is calculated as $\operatorname{Sr}_{N} V\left(\operatorname{Pr}_{N}{ }^{*} N d_{N}\right), K$ anomaly is calculated as $K_{N} \sqrt{ }\left(\operatorname{Ta}_{N}{ }^{*} L a_{N}\right)$, where ${ }_{N}$ indicates normalisation to primitive mantle values after McDonough and Sun (1995). 


\subsection{Conclusions}

This study provides 99 new whole rock major and trace element analyses to the AVF database for previously un- or under-sampled centres (Appendix $\mathbf{C}$ ). In doing this, the study gains more detailed insight into the whole rock signatures of the AVF as a whole. The results of this study support conclusions made by previous studies (McGee et al., 2011; McGee et al., 2012; McGee et al., 2013; McGee et al., 2015); minor intra-centre geochemical variability is related to the fractional crystallisation of olivine, coupled with minor amounts of clinopyroxene and potentially some high pressure clinopyroxene; the major intra-field geochemical variability relates to the mixing of three mantle sources, in varying proportions for each magma batch, to produce unique geochemical signatures for each centre. The individuality of each magma batch, coupled with the minor fractional crystallisation, facilitates the ability to geochemically fingerprint each centre. Thus further highlighting the potential to fingerprint each centre's products, and therefore correlate distal deposits back to source. 


\section{Preface to Chapter 5}

Chapter 5 presents new methods developed to correlate distal tephra deposits to their source volcano. In order to achieve these correlations, the tephraderived glass geochemistry and cross-core horizon correlations from Chapter $\mathbf{3}$ are compared with previous and newly obtained whole rock geochemistry for the entire field (Chapter 4). These data are analysed to ascertain which geochemical signatures can be used to correlate between tephra and whole rock.

The results suggest that incompatible trace element ratios are the most variable in volcanic rocks from the Auckland Volcanic Field. These ratios are also the least affected by fractional crystallisation, and crystal removal, and are therefore considered to be the most appropriate tools for correlation. However, the volcanic rocks from all individual centres do not have a unique geochemistry in the field as a whole, to be successfully correlated purely based on these signatures. I therefore combine a number of criteria to further constrain the source centres for the horizons, resulting in proposed sourced centres for most of the tephra horizons identified.

Once the tephra horizons are correlated to their proposed source, and therefore stratigraphically constrained, I combine this tephrostratigraphic framework with Ar-Ar dated centres, and calculated sedimentation rate ages for the tephra horizons, to resolve the chronostratigraphy for 45 of the 53 centres in the field. I then use this newly constructed age order to comment on the spatial, temporal, and geochemical evolution of the AVF. 


\section{Chapter 5}

The correlation of basaltic tephras to source volcanoes:

Method development and implications for spatial, temporal and geochemical eruptive sequencing in the Auckland Volcanic Field, New Zealand

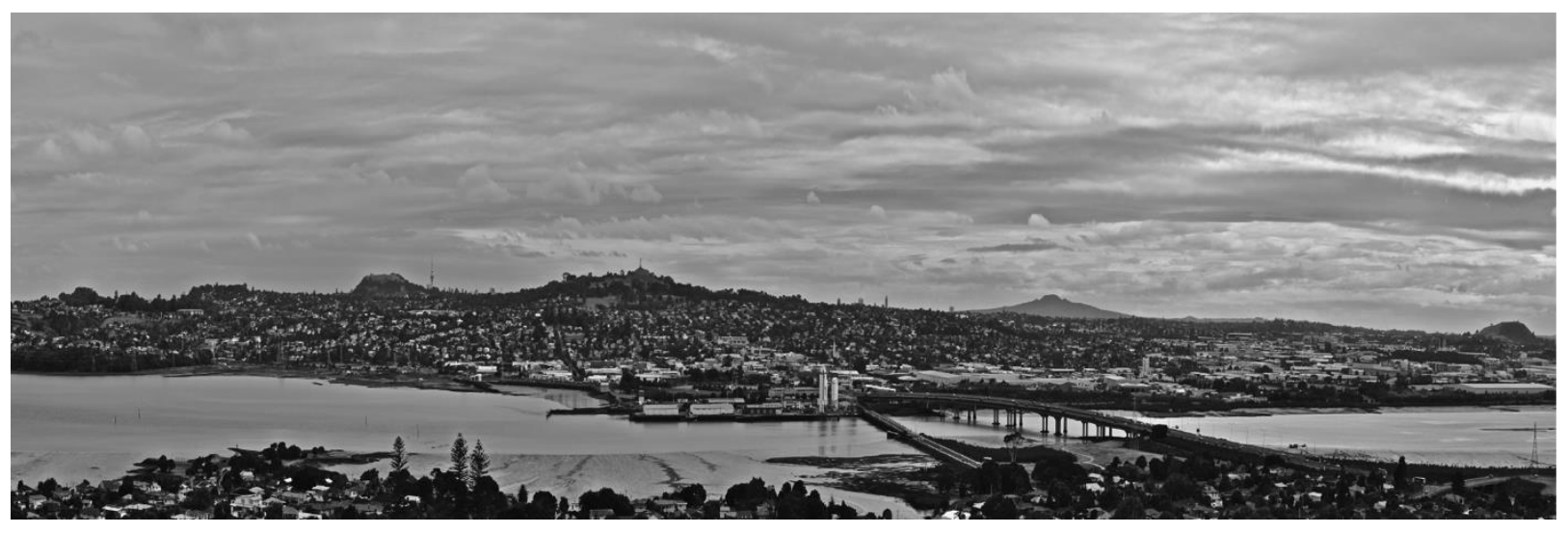

'Auckland - A city on volcanoes'

View from Mangere Mt to the north across the city, with volcanic scoria cones from left; $M$ t. Roskill, Three Kings, Mt. Eden, (Sky Tower), One Tree Hill, Rangitoto, Mt. Wellington, Hopua maar is located at the northern end of the bridge, and Mangere lava flows can be identified in the foreground to the left (image by Hopkins, J.L.). 


\subsection{Introduction}

\subsubsection{Tephrochronology and provenance}

Tephrochronology is the process of linking, dating, and synchronizing a sequence of geological, palaeoenvironmental or archaeological events using tephra deposits (Lowe, 2011). Tephra correlation is used on a number of levels from simply correlating tephra deposit across cores or outcrops, defining stratigraphic marker horizons (e.g. Molloy et al., 2009), or matching horizons to volcanic source or provenance to yield information about the eruptive history of a region (e.g. Alloway et al., 2004; Allan et al., 2008). Linking tephra horizons (or deposits) back to their source volcanic centre can be a relatively simple exercise when potential sources are limited, the eruptive episodes (and horizons) are precisely dated, stratigraphic succession is established in proximal tephra layering, and/or the volcanic products have highly distinctive geochemical signatures (Lowe, 2011). However, where these criteria are not met, difficulties arise in accurately linking the tephra deposit to their source. In cases of multiple potential sources, with multiple poorly characterised proximal eruption products, there currently is no established method to resolve the origin of distal tephra horizons.

\subsubsection{Reconstructing eruptive history using tephra deposits}

The eruptive history of a region can often be reconstructed by dating of lava and scoria deposits. In monogenetic fields however, often the errors associated with the age dating are greater than the eruption spacing, and thus do not allow a definitive stratigraphic age order of the centres to be created (e.g., Leonard et al., in prep. Appendix D). Similarly, due to the restricted distribution of scoria and lavas from small monogenetic centres, stratigraphic relationships and laws of superposition often cannot be relied on alone to resolve the ambiguities that arise from the dating techniques. In these circumstances distal fall deposits can often be more successful at resolving the chronological uncertainties due to their higher preservation potential, and often stratigraphically restricted relationships. 
Fortunately maar craters that form in monogenetic fields from phreatomagmatic eruption styles can provide ideal, within-field, depocentres for any subsequent eruptions. Meteoric water retained by the tuff ring often creates a lacustrine environment for capturing and preserving the palaeoenvironmental history of the surrounding region. Tephra deposits within cores retrieved from these maar lakes, therefore have the potential to accurately preserve the stratigraphic sequence of eruptions from the field that is otherwise lost through surface erosion and weathering (Chapter 3). If these distal deposits can be linked to their source centre the chronology of a region can be resolved.

\subsubsection{Auckland Volcanic Field}

The AVF is one such case where climate and urbanization has resulted in a loss, or obscuration, of proximal tephra deposit outcrops. The spatial density of centres (53 centres distributed over $360 \mathrm{~km}^{2}$ ) adds further complexity; if a proximal tephra deposit is found, often it has the potential to have come from one of a number of possible centres. In addition, because of the rapid thinning of basaltic tephra away from each source, evidence of stratigraphic succession is often limited in subaerial outcrops. Proximal lava and scoria deposits in the AVF have a higher preservation potential, and their sources are more easily defined. Therefore it is necessary to develop a methodology to reliably correlate distal tephra to their source centre, allowing us establish the provenance of the tephra. With its several maars (Fig.5.1.) the AVF is an ideal location to develop and test this methodology. Although previous studies have undertaken a significant effort to date a number of the centres using a range of techniques (e.g. Lindsay et al., 2011; Leonard et al., in prep. Appendix D), the complete eruption sequence of the AVF remains unknown. Consequently the spatial and geochemical evolution of the field also remains uncertain. Here we combine new developments in tephrochronology (Chapter 3), with geochemical analysis of whole rock samples (Chapter 4), to develop a new tephra correlation method. 


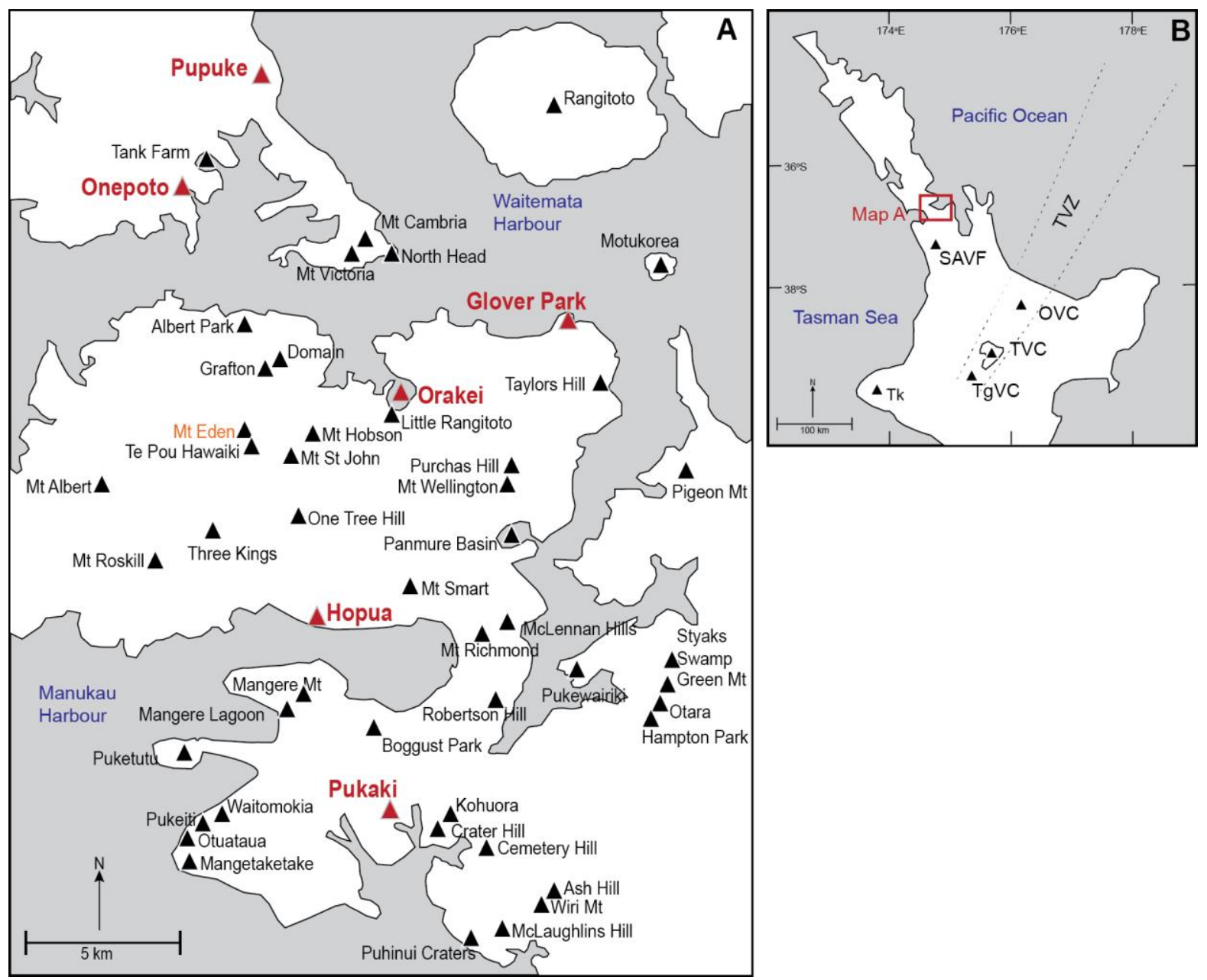

Figure 5.1. (A) Map of the Auckland Volcanic Field and its eruptive centres (from Hayward et al., 2011). The locations of maar craters from which cores documented in this chapter were collected are highlighted by red symbols and red font: Pupuke, Onepoto, Glover Park, Orakei, Hopua and Pukaki. Although the Glover Park core is from St Heliers Volcano, to avoid confusion within this chapter the core location will continue to be called Glover Park. (B) General location of the AVF within the North Island, New Zealand. Highlighted are other key volcanic centres including the South Auckland Volcanic Field, and the key rhyolitic (Taupo Volcanic Centre (TVC), Okataina Volcanic Centre (OVC)) and andesitic (Tongariro Volcanic Centre (TgVC), Mt. Taranaki (Tk)) sources of tephra found in Auckland maar cores. 
Table 5.1. Details of all 53 centres in the AVF, their eruption type; relative age relationships where known including, current age estimates and the methods by which they are calculated and the morphological features which give age constraints ( ${ }^{*}$ Hayward et al., 2011; å Allen and Smith 1992; $\Omega$ Affleck et al., 2001); the estimated eruptive size of the centres (Kereszturi et al., 2013); the geochemical data available for each centre including data added by this study (Chapter 4). For the eruption types, A) phreatomagmatic wet explosive eruption which produces maar craters and tuff rings, B) dry magmatic eruptions including fire fountaining creating scoria cones, and C) effusive eruptions resulting in lava flows, and shield building ( ${ }^{*}$ details from Hayward et al., 2011).

\begin{tabular}{|c|c|c|c|c|c|c|c|c|c|c|c|c|}
\hline \multirow[b]{2}{*}{ Centre name } & \multirow{2}{*}{$\begin{array}{c}\text { Eruption } \\
\text { types* }\end{array}$} & \multicolumn{3}{|c|}{ Age estimate (ka) 2sd } & \multirow[b]{2}{*}{ Method and reference } & \multirow{2}{*}{$\begin{array}{l}\text { Relative ages and relationships } \\
\text { based on morphology }\end{array}$} & \multicolumn{2}{|c|}{ Minimum total DRE $\mathrm{km}^{3}$} & \multicolumn{3}{|c|}{ Geochemical analyses (2013) } & \multirow[b]{2}{*}{ Geochemical reference } \\
\hline & & $\min 2 s d$ & mean & $\max 2$ sd & & & $\begin{array}{l}\text { Kereszturi et al., } \\
2013\end{array}$ & $\begin{array}{l}\text { Allen and Smith, } \\
1992\end{array}$ & major & trace & isotope & \\
\hline ALBERT PARK & $A, B, C$ & 138.8 & 144.4 & 150.0 & Ar-Ar; Leonard et al., Appendix D & & 0.028 & 0.002 & 4 & 4 & 0 & $\begin{array}{l}\text { Smith unpub data; McGee, 2012, PhD } \\
\text { thesis }\end{array}$ \\
\hline ASH HILL & A & 31.6 & 31.8 & 32.0 & 14C; Lindsay et al., 2001 & older than Wiri Mt ${ }^{\hat{A}}$ & 0.000076 & 0.00008 & 0 & 0 & 0 & \\
\hline BOGGUST PARK & $A ?$ (new) & & & & & & 0.00032 & & 3 & 3 & 0 & This thesis \\
\hline CEMETERY HILL & (new) & & & & & & 0.00024 & & 0 & 0 & 0 & \\
\hline CRATER HILL & $A, B, C$ & 26.7 & 32.1 & 37.5 & Ar-Ar; Cassata et al., 2008 & $\begin{array}{l}\text { paleomag excursion }(32.4 \pm 0.3 \mathrm{ka}) \text {, } \\
\text { younger than Kohuora* }\end{array}$ & 0.024 & 0.01 & 61 & 61 & 0 & Smith et al., 2008 \\
\hline DOMAIN & $A, B$ & 45.0 & & & Rotoehu Tephra in drill core & younger than Grafton Park* & 0.011 & 0.01 & 19 & 7 & 0 & Smith unpub data \\
\hline GRAFTON PARK & $A, B$ & 45.0 & & & morphostratigrpahy -> & older than Domain* & 0.011 & & 10 & 10 & 0 & DEVORA \\
\hline GREEN MT & $A, B, C$ & 12.7 & 19.1 & 25.5 & Ar-Ar; Leonard et al., Appendix D & older than Styaks Swamp* & 0.012 & 0.02 & 3 & 3 & 0 & Miller, 1996; This thesis \\
\hline HAMPTON PARK & $A, B, C$ & 19.0 & 27.0 & 35.0 & Ar-Ar; Cassata et al., 2008 & just older than Otara* & 0.0024 & 0.002 & 4 & 4 & 0 & Miller, 1996; This thesis \\
\hline HOPUA & A & 44.4 & 50.4 & 56.4 & Ar-Ar; Leonard et al., Appendix D & younger than One Tree Hill* & 0.00086 & 0.004 & 1 & 1 & 0 & Smith unpub data \\
\hline KOHUORA & A & 30.0 & 31.0 & 32.0 & Ar-Ar; Leonard et al., Appendix D & older than Crater Hill** & 0.0072 & 0.001 & 0 & 0 & 0 & \\
\hline LITTLE RANGITOTO & $B, C$ & 15.9 & 20.3 & 24.7 & Ar-Ar; Leonard et al., Appendix D & younger than Orakei* & 0.0017 & 0.0003 & 23 & 7 & 0 & $\begin{array}{l}\text { Franklin, 1999; Smith unpub data: } \\
\text { This thesis }\end{array}$ \\
\hline MANGERE LAGOON & $A, B$ & & & & morphostratigrpahy -> & older than Mangere Mt* & 0.0020 & 0.002 & 0 & 0 & 0 & \\
\hline MANGERE MT & $B, C$ & 64.7 & 71.7 & 78.7 & Ar-Ar; Leonard et al., Appendix D & & 0.046 & 0.2 & 7 & 5 & 0 & Miller, 1996; This thesis \\
\hline MAUNGATAKETAKE & $A, B, C$ & 82.6 & 87.4 & 92.2 & Ar-Ar; Leonard et al., Appendix D & & 0.034 & 0.008 & 23 & 23 & 0 & Smith unpub data \\
\hline MCLAUGHLINS HILL & $A, B, C$ & 41.7 & 48.3 & 54.9 & Ar-Ar; Leonard et al., Appendix D & & 0.0076 & 0.007 & 6 & 5 & 0 & Heming and Barnet, 1986; This thesis \\
\hline MCLENNAN HILLS & $A, B, C$ & 29.3 & 34.1 & 38.9 & Ar-Ar; Leonard et al., Appendix D & $\begin{array}{l}\text { paleomag excursion }(40.4 \pm 1.1 \mathrm{ka}) \text {, } \\
\text { older than Mt Richmond* }\end{array}$ & 0.022 & 0.01 & 6 & 6 & 0 & Miller, 1996; This thesis \\
\hline MOTUKOREA & $A, B, C$ & 3.3 & 14.3 & 25.3 & Ar-Ar; Leonard et al., Appendix D & & 0.0046 & 0.02 & 53 & 53 & 16 & Bryner, 1991; McGee, 2012, \\
\hline
\end{tabular}


Table 5.1. continued.

\begin{tabular}{|c|c|c|c|c|c|c|c|c|c|c|c|c|}
\hline \multirow[b]{2}{*}{ Centre name } & \multirow{2}{*}{$\begin{array}{l}\text { Eruption } \\
\text { types* }\end{array}$} & \multicolumn{3}{|c|}{ Age estimate (ka) 2sd } & \multirow[b]{2}{*}{ Method and reference } & \multirow{2}{*}{$\begin{array}{l}\text { Relative ages and relationships } \\
\text { based on morphology }\end{array}$} & \multicolumn{2}{|c|}{ Minimum total DRE $\mathrm{km}^{3}$} & \multicolumn{3}{|c|}{ Geochemical analyses (2013) } & \multirow[b]{2}{*}{ Geochemical reference } \\
\hline & & $\min 2 s d$ & mean & $\max 2 s d$ & & & $\begin{array}{l}\text { Kereszturi et al., } \\
2013 \\
\end{array}$ & $\begin{array}{l}\text { Allen and Smith, } \\
1992\end{array}$ & major & trace & isotope & \\
\hline MT ALBERT & $A, B, C$ & 112.4 & 117.6 & 122.8 & Ar-Ar; Leonard et al., Appendix D & older than Mt Eden and Mt Roskill* & 0.023 & 0.03 & 4 & 5 & 0 & Smith unpub data; This thesis \\
\hline MT CAMBRIA & $B, C$ & 23.9 & 44.5 & 65.1 & Ar-Ar; Leonard et al., Appendix D & & 0.00029 & 0.0002 & 6 & 6 & 0 & Smith unpub data; This thesis \\
\hline MT EDEN & $B, C$ & 13.3 & 19.3 & 25.3 & Ar-Ar; Leonard et al., Appendix D & $\begin{array}{l}\text { much younger than Mt St John, } \\
\text { younger than Three Kings** }\end{array}$ & 0.090 & 0.2 & 29 & 17 & 1 & Eade, 2009; DEVORA; McGee, 2012 \\
\hline MT HOBSON & $B, C$ & 44.9 & 55.9 & 66.9 & Ar-Ar; Leonard et al., Appendix D & older than Three Kings* & 0.0067 & 0.005 & 15 & 7 & 0 & Smith unpub data; This thesis \\
\hline MT RICHMOND & $A, B$ & 18.4 & 23.8 & 29.2 & Ar-Ar; Leonard et al., Appendix D & $\begin{array}{l}\text { paleomag excursion ( } 32.4 \pm 0.3 \mathrm{ka}) \text {, } \\
\text { younger than McLennan Hills** }\end{array}$ & 0.0057 & 0.004 & 6 & 3 & 2 & $\begin{array}{l}\text { Eade, 2009; Smith unpub data; } \\
\text { DEVORA; McGee, } 2012\end{array}$ \\
\hline MT ROBERTSON & $A, B$ & & & & & & 0.0027 & 0.002 & 4 & 4 & 0 & This thesis \\
\hline MT ROSKILL & $A, B, C$ & 98.6 & 104.8 & 111.0 & Ar-Ar; Leonard et al., Appendix D & younger than Mt Albert* & 0.014 & 0.007 & 9 & 8 & 0 & McGee, 2012; This thesis \\
\hline MT SMART & $A, B, C$ & 11.9 & 16.1 & 20.3 & Ar-Ar; Leonard et al., Appendix D & younger than One Tree Hill** & 0.013 & 0.09 & 8 & 8 & 0 & $\begin{array}{l}\text { Smith unpub data; McGee, 2012; This } \\
\text { thesis }\end{array}$ \\
\hline MT ST JOHN & $B, C$ & 71.1 & 74.3 & 77.5 & Ar-Ar; Leonard et al., Appendix D & $\begin{array}{l}\text { much older than Mt Eden and Three } \\
\text { Kings* }\end{array}$ & 0.028 & 0.003 & 22 & 13 & 0 & Franklin, 1999; Eade, 2009 \\
\hline MT VICTORIA & $B, C$ & 46.1 & 54.5 & 62.9 & Ar-Ar; Leonard et al., Appendix D & & 0.0048 & 0.002 & 4 & 3 & 0 & Smith unpub data; This thesis \\
\hline MT WELLINGTON & $B, C$ & 10.0 & 10.5 & 11.0 & 14C; Lindsay et al., 2001 & just younger than Purchas Hill** & 0.082 & 0.2 & 34 & 36 & 10 & DEVORA; McGee, 2012; This thesis \\
\hline NORTH HEAD & $A, B$ & 70.8 & 86.0 & 101.2 & Ar-Ar; Leonard et al., Appendix D & & 0.0026 & 0.003 & 6 & 5 & 0 & Smith unpub data \\
\hline ONE TREE HILL & $B, C$ & 44.3 & 51.9 & 59.5 & Ar-Ar; Leonard et al., Appendix D & $\begin{array}{l}\text { older than Hopua, Mt Hobson, Mt } \\
\text { Eden, Mt Smart, Three Kings* }\end{array}$ & 0.26 & 0.3 & 8 & 4 & 0 & Eade, 2009; Smith unpub data \\
\hline ONEPOTO & A & 45.0 & & & Rotoehu Tephra in drill core & younger than Pupuke* & 0.0026 & 0.004 & 2 & 2 & 0 & This thesis \\
\hline ORAKEI & A & 85.0 & & 130.0 & $\begin{array}{l}\text { sed. rate ages of tephra horizons; } \\
\text { Molloy et al., } 2009\end{array}$ & $\begin{array}{l}\text { not breached in last interglacial, } \\
\text { older than Little Rangitoto* }\end{array}$ & 0.0067 & 0.010 & 41 & 21 & 0 & Smith unpub data; Franklin, 1999 \\
\hline OTARA & $A, B, C$ & 0.0 & & 35.0 & morphostratigrpahy -> & just younger than Hampton Park* & 0.0023 & 0.008 & 12 & 5 & 2 & $\begin{array}{l}\text { Miller, 1996; McGee, 2012; This } \\
\text { thesis }\end{array}$ \\
\hline OTUATAUA & $A, B, C$ & & & & & & 0.0063 & 0.004 & 6 & 6 & 0 & Heming unpub data; This thesis \\
\hline PANMURE BASIN & $A, B$ & 17.5 & & & Rerewhakaaitu tephra in drill core & & 0.0074 & 0.009 & 22 & 21 & 0 & Smith unpub data \\
\hline PIGEON MT & $A, B, C$ & & & & & & 0.0033 & 0.003 & 6 & 6 & 0 & Smith unpub data; This thesis \\
\hline PUHINUI CRATERS & (new) & & & & & & & & 0 & 0 & 0 & \\
\hline
\end{tabular}


Table 5.1. continued.

\begin{tabular}{|c|c|c|c|c|c|c|c|c|c|c|c|c|}
\hline \multirow[b]{2}{*}{ Centre name } & \multirow{2}{*}{$\begin{array}{l}\text { Eruption } \\
\text { types* }\end{array}$} & \multicolumn{3}{|c|}{ Age estimate (ka) 2sd } & \multirow[b]{2}{*}{ Method and reference } & \multirow{2}{*}{$\begin{array}{l}\text { Relative ages and relationships } \\
\text { based on morphology }\end{array}$} & \multicolumn{2}{|c|}{ Minimum total DRE $\mathrm{km}^{3}$} & \multicolumn{3}{|c|}{ Geochemical analyses (2013) } & \multirow[b]{2}{*}{ Geochemical reference } \\
\hline & & $\min 2 s d$ & mean & $\max 2 s d$ & & & $\begin{array}{l}\text { Kereszturi et al., } \\
2013 \\
\end{array}$ & $\begin{array}{l}\text { Allen and Smith, } \\
1992\end{array}$ & major & trace & isotope & \\
\hline PUKAKI & A & 52.0 & & & Core extent & & 0.0092 & 0.006 & 6 & 6 & 0 & Zawalna-Greer, 2012; This thesis \\
\hline PUKEITI & $\mathrm{B}, \mathrm{C}$ & 3.2 & 10.6 & 18.0 & Ar-Ar; Leonard et al., Appendix D & & 0.0037 & 0.004 & 5 & 5 & 0 & Smith unpub data; This thesis \\
\hline PUKEWAIRIKI & $A, C$ & 130.0 & & & morphostratigrpahy -> & $\begin{array}{l}\text { sea cut platform from last } \\
\text { interglacial* }\end{array}$ & 0.011 & 0.005 & 4 & 3 & 0 & Smith unpub data \\
\hline PUKETUTU & $B, C$ & 29.8 & 33.6 & 37.4 & Ar-Ar; Cassata et al., 2008 & 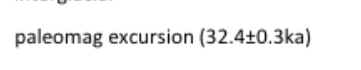 & 0.018 & 0.03 & 23 & 15 & 3 & $\begin{array}{l}\text { Miller, 1996; McGee, 2012; This } \\
\text { thesis }\end{array}$ \\
\hline PUPUKE & $\mathrm{C}, \mathrm{B}, \mathrm{A}$ & 184.7 & 190.3 & 195.9 & Ar-Ar; Leonard et al., Appendix D & Older than Tank Farm and Onepoto* & 0.047 & 0.05 & 52 & 52 & 6 & Spargo, 2007; This thesis \\
\hline PURCHAS HILL & $A, B$ & 11.0 & 11.0 & 11.0 & 14C; Lindsay et al., 2001 & just older than Mt Wellington* & 0.0017 & 0.000 & 27 & 27 & 6 & McGee, 2012 \\
\hline RANGITOTO & $A, B, C$ & 0.5 & 0.6 & 0.6 & 14C; Lindsay et al., 2001 & youngest in the field* & 0.70 & 2.0 & 57 & 57 & 10 & $\begin{array}{l}\text { Hookway, 2000; Needham et al., } \\
\text { 2011; McGee 2012; This thesis }\end{array}$ \\
\hline ST HELIERS & A, & 45.0 & & & Rotoehu Tephra in drill core & & 0.0022 & 0.002 & 3 & 3 & 0 & Smith unpub data; This thesis \\
\hline STYAKS SWAMP & $\mathrm{A}$ & 0.0 & & 25.5 & morphostratigrpahy -> & younger than Green Mt* & 0.00037 & 0.0004 & 0 & 0 & 0 & \\
\hline TANK FARM & A & 45.0 & & & morphostratigrpahy -> & younger than Onepoto* & 0.0059 & 0.003 & 0 & 0 & 0 & \\
\hline TAYLORS HILL & $A, B, C$ & 23.8 & 26.8 & 29.8 & Ar-Ar; Leonard et al., Appendix D & palaeomag excursion (32.4 $\pm 0.3 \mathrm{ka})$ & 0.0051 & 0.003 & 9 & 9 & 2 & $\begin{array}{l}\text { Smith unpub data; McGee, 2012; This } \\
\text { thesis }\end{array}$ \\
\hline TE POU HAWAIKI & B & 13.3 & & & morphostratigrpahy -> & older than Mt Eden ${ }^{\circ}$ & 0.028 & 0.0003 & 18 & 5 & 0 & Franklin, 1999; This thesis \\
\hline THREE KINGS & $A, B, C$ & 28.4 & 28.6 & 28.8 & 14C; Lindsay et al., 2001 & $\begin{array}{l}\text { younger than OTH, Mt St John, Mt } \\
\text { Hobson, older than Mt Eden* }\end{array}$ & 0.069 & 0.1 & 36 & 35 & 2 & Eade, 2009; Smith unpub data \\
\hline WAITOMOKIA & $A, B$ & 18.0 & & & morphostratigrpahy -> & older than Pukeiti* & 0.0098 & 0.003 & 9 & 9 & 0 & McGee, 2012 \\
\hline WIRI & $A, B, C$ & 25.7 & 30.1 & 34.5 & Ar-Ar; Cassata et al., 2008 & $\begin{array}{l}\text { paleomag excursion }(32.4 \pm 0.3 \mathrm{ka}) \text {, } \\
\text { younger than Ash Hill }\end{array}$ & 0.016 & 0.03 & 12 & 12 & 4 & DEVORA; McGee, 2012; This thesis \\
\hline
\end{tabular}




\subsection{Source correlation method and sequencing data}

The key aspects of this method are to accurately link the cross-core correlated tephra horizons to their source centre. In order to test a method by which tephra can be correlated to the whole rock composition of a candidate source, detailed information about each individual centre, and distal tephra deposit has been collated. An assessment of all the current data, including tephrochronology and tephra horizon ages (Chapter 3), source volcano geochemistries and ages (Chapter 4), and a number of other additional criteria, is discussed below. This selection process was used to determine the input data for the development of the tephra-tosource correlation method.

\subsubsection{Tephrochronology}

Tephrochronology has been applied to, and utilized extensively, for the deposits from the AVF maar cores. Relevant studies used the correlation of multiple distally derived rhyolitic and andesitic tephras for different reasons, from volcanology (Shane, 2000) to archaeology (Lowe and Newham 2004). Multiple well-dated rhyolitic marker horizons found across the Auckland region, in multiple lacustrine maar cores, have helped to establish the construction of a well-constrained chronostratigraphic history. The basaltic horizons within the cores have been crosscorrelated by a number of different techniques, most recently through geochemistry and stratigraphy (see Chapter 3), and through statistical modelling (Green et al., 2014). Green et al. (2014) used basaltic horizon details (geochemistry, stratigraphy, mineralogy) from Molloy et al. (2009), together with age data from statistical models (Bebbington and Cronin 2011), to produce the cross core correlations. All the input data used by Green et al. (2014) have now been superseded, and therefore here I used the geochemistry, AVF nomenclature, correlations, and tephra horizon thicknesses from Chapter 3 (Figure 3.11 and Table 3.2). 


\subsubsection{Basaltic tephra horizon ages}

The most recently published ages of key rhyolitic marker horizons (RMHs) are used as a comparative framework to constrain the basaltic horizons with age ranges across the cores. The cores are constrained by four chosen key horizons, which denote five age brackets (see Chapter 3):

(1) Younger than the Rerewhakaaitu ( $<17.5 \mathrm{ka})$ including tephra numbers AVF 24 to 22 ;

(2) Rerewhakaaitu to the Okareka (17.5 to $21.5 \mathrm{ka}$ ) including AVF 21 and 22;

(3) Okareka to Kawakawa/Oruanui (21.5 to $25.4 \mathrm{ka}$ ) including AVF 19 to 13;

(4) Kawakawa/Oruanui to Rotoehu (25.4 to $\leq 45.1 \mathrm{ka}$ ) including AVF 12 to 4;

(5) Older than the Rotoehu (>45.1ka) including AVF 3 to 1 (and AVF a-c)

The ages for Rerewhakaaitu (Rk), Okareka (Ok), and Kawakawa/Oruanui (Kk) RMHs are reviewed in Lowe et al. (2013). The age of the Rotoehu RMH is, however, relatively controversial. Regardless, this tephra is found in four of the six cores studied, and is thus a useful horizon to correlate older core sections. Therefore here the Rotoehu RMH is used for correlation purposes, in contrast to some previous AVF tephra studies (e.g., Shane and Hoverd, 2002; Molloy et al., 2009). For the purpose of this study we use the most recently published age estimate of 45.1 ka (Danišík et al., 2014) to provide a minimum age constraint to basaltic tephras found beneath this horizon.

The numerical ages of the basaltic tephra horizons within all the cores have previously been estimated using two methods: 1) through sedimentation rates relative to the rhyolitic marker horizons (Molloy, 2008) and 2) through statistical modelling (Green et al., 2014). However, both these studies used sources that have been recently superseded for both rhyolitic horizon ages, and basaltic tephra deposit thicknesses. For the purpose of this study, the sedimentation rates, and ages have therefore been recalculated using the more recent data for basaltic horizon thicknesses in Orakei and Glover Park cores (Chapter 3) and RMH ages (Lowe et al., 2013; Danišík et al., 2014). 
The new basaltic tephra horizon thicknesses for the Onepoto core were not used here, as these data comes from a new core in which the rhyolite and andesite marker horizons have not been assessed yet. For the Onepoto core all tephra thicknesses and depths were adapted from Shane and Hoverd (2002). Marker rhyolite and andesite tephra thicknesses in Orakei Basin, Hopua, Pupuke and lower Pukaki cores (below the Kk) are from Molloy (2008) and from Sandiford et al. (2001) in upper Pukaki core (above Kk). Tephra deposits preserve effectively instantaneous events (Shane, 2005), and therefore are removed from the total sediment thickness for a section bound by key rhyolitic marker horizons. The total sediment thickness is then divided by the age range for the given section, calculated from the mean ages for the rhyolitic horizons (Table 5.2).

The sedimentation rate recorded in the Onepoto core was consistent from the top to the Rotoehu tephra horizon (Fig. 5.2.). Therefore the overall sedimentation rate value was taken from the best-fit line $\left(r^{2}=0.99\right)$ as $0.136 \mathrm{~mm} / \mathrm{yr}$ (Fig. 5.2.). For the sedimentation rate between the Rotoehu and the base of the core, the basaltic deposit AVFd (c.f Chapter 3), was used as a lower constraint. AVFd, although not a tephra fall deposit (nor a rhyolitic marker horizon), was labelled thus in Chapter 3 to allow for unambiguous identification. This deposit comprises of lava and scoriaceous blocks interpreted to represent the Onepoto maar crater floor (Shane and Hoverd, 2002). Although no age dates exists from the Onepoto eruption, morphostratigraphy shows that it is younger than Pupuke, and we therefore use the mean age measured for Pupuke (190.3 \pm 5.6 ka; Ar-Ar dating Leonard et al., in prep. Appendix D) as a maximum age for Onepoto. The respective calculated sedimentation rate of 0.19 $\mathrm{mm} / \mathrm{yr}$ is comparable to those recorded previously $(0.18 \mathrm{~mm} / \mathrm{yr}$; Shane and Hoverd, 2002). In addition, the calculated ages are comparable to those calculated for the correlated horizons AVF2 and AVF1 in the Orakei Basin core (Table 5.3.), suggesting that these assumptions are realistic.

The thickness estimates for the basaltic and rhyolitic horizons below the Kawakawa/Oruanui marker horizon in the Pukaki core are ambiguous (andesite horizon details are outlined in Shane, 2005). Therefore the sedimentation rates for these sections (Kawakawa/Oruanui (Kk) to Okaia (O), and Okaia to Maketu (Mk)), are also calculated from best-fit lines (Fig. 5.2.). 
Table 5.2. Calculated sedimentation rates for all cores assessed from the Auckland Volcanic Field maars. The rhyolitic marker horizons used to constrain sections include Rotoma (Ro), Opepe (Op), Waiohau (Wh), Rotorua (Rr), Rerewhakaaitu (Rk), Okareka (Ok), Te Rere (Tr), Kawakawa/Oruanui (Kk), Okaia (O), Maketu (Mk), and Rotoehu (Re). * Indicates sedimentation rates calculated from best-fit line equations as discussed in the text. ${ }^{* *}$ See discussion in the text for calculation of this rate. ${ }^{1}$ Indicates where sedimentation rates are assumed constant below the Rotoehu, and ${ }^{2}$ indicates where Glover Park sedimentation rate is calculated from the ages of the correlated basaltic horizons found in Onepoto core.

\begin{tabular}{|c|c|c|c|c|c|c|c|}
\hline & $\begin{array}{c}\text { Total rhyolite } \\
\text { thickness } \\
\text { (mm) }\end{array}$ & $\begin{array}{c}\text { Total basalt } \\
\text { thickness } \\
(\mathrm{mm})\end{array}$ & $\begin{array}{l}\text { Total andesite } \\
\text { thickness } \\
\text { (mm) }\end{array}$ & $\begin{array}{l}\text { Total tephra } \\
\text { thickness } \\
(\mathrm{mm})\end{array}$ & $\begin{array}{l}\text { Sediment } \\
\text { thickness } \\
(\mathrm{mm})\end{array}$ & $\begin{array}{l}\text { Age range of } \\
\text { section } \\
\text { (ka) }\end{array}$ & $\begin{array}{c}\text { Sedimentation } \\
\text { rate } \\
(\mathrm{mm} / \mathrm{yr})\end{array}$ \\
\hline \multicolumn{8}{|c|}{ ORAKEI BASIN } \\
\hline Ok to $\mathrm{KK}$ & 10 & 197 & 17 & 224 & 9876 & 3.5 & 2.81 \\
\hline $\mathrm{KK}$ to $\mathrm{Mk}$ & 45 & 626 & 10 & 681 & 7859 & 11.0 & 0.72 \\
\hline Mk to $\operatorname{Re}^{1}$ & 75 & 0 & 3.5 & 78.5 & 5432 & 8.8 & 0.62 \\
\hline \multicolumn{8}{|l|}{ ONEPOTO } \\
\hline Ro to $\mathrm{Re}^{1}$ & & & & & & & $0.14^{*}$ \\
\hline Re to base $e^{\star *}$ & - & 217 & - & 217 & 27580 & 145.2 & 0.19 \\
\hline \multicolumn{8}{|l|}{ GLOVER PARK } \\
\hline AVF1 to $A V F b^{2}$ & - & 50 & - & 50 & 5520 & 82.9 & 0.07 \\
\hline \multicolumn{8}{|l|}{ HOPUA } \\
\hline Ro to Op & 2 & 3 & 0 & 5 & 120 & 0.6 & 0.21 \\
\hline $\mathrm{Rk}$ to Ok & 23 & 525 & 9 & 557 & 2793 & 4.4 & 0.64 \\
\hline Ok to $\mathrm{Kk}$ & 61 & 40 & 5 & 106 & 1679 & 3.5 & 0.48 \\
\hline \multicolumn{8}{|l|}{ PUKAKI } \\
\hline Wh to Ro & 20 & 1 & 0 & 21 & 229 & 1.6 & 0.14 \\
\hline $\mathrm{Rk}$ to Ok & 4 & 2 & 9 & 15 & 1755 & 4.4 & 0.40 \\
\hline Ok to $\mathrm{Tr}$ & 0.5 & 2 & 4 & 6.5 & 1363.5 & 3.3 & 0.41 \\
\hline $\operatorname{Tr}$ to $\mathrm{Kk}$ & 22 & 50 & 1 & 73 & 137 & 0.2 & 0.72 \\
\hline $\mathrm{Kk}$ to $\mathrm{O}$ & & & & & & & $0.93^{*}$ \\
\hline $\mathrm{O}$ to $\mathrm{Mk}$ & & & & & & & $0.55^{\star}$ \\
\hline \multicolumn{8}{|l|}{ PUPUKE } \\
\hline $\mathrm{Kk}$ to $\mathrm{O}$ & 7.5 & 7 & 4 & 18.5 & 486.5 & 3.3 & 0.15 \\
\hline $\mathrm{O}$ to $\mathrm{Mk}$ & 73 & 46 & 6.5 & 125.5 & 2190 & 7.7 & 0.28 \\
\hline
\end{tabular}

In the Glover Park core, only the Rotoehu $\mathrm{RMH}$ has been identified but no other well-dated deposits are found below precluding the calculation of a sedimentation rate. Therefore, for the horizons correlated to other cores (AVF2 and AVF1) the ages are assigned from an average of the values calculated from these cores. For horizon AVFa, which is only found within Glover Park, an age estimate was obtained through calculating the sedimentation rate between the bounding basaltic horizons, AVF1 and AVFb. The ages for these horizons were assigned based on the ages calculated for these deposits in Orakei Basin (AVF1) and Onepoto cores (AVF1 and AVFb). 

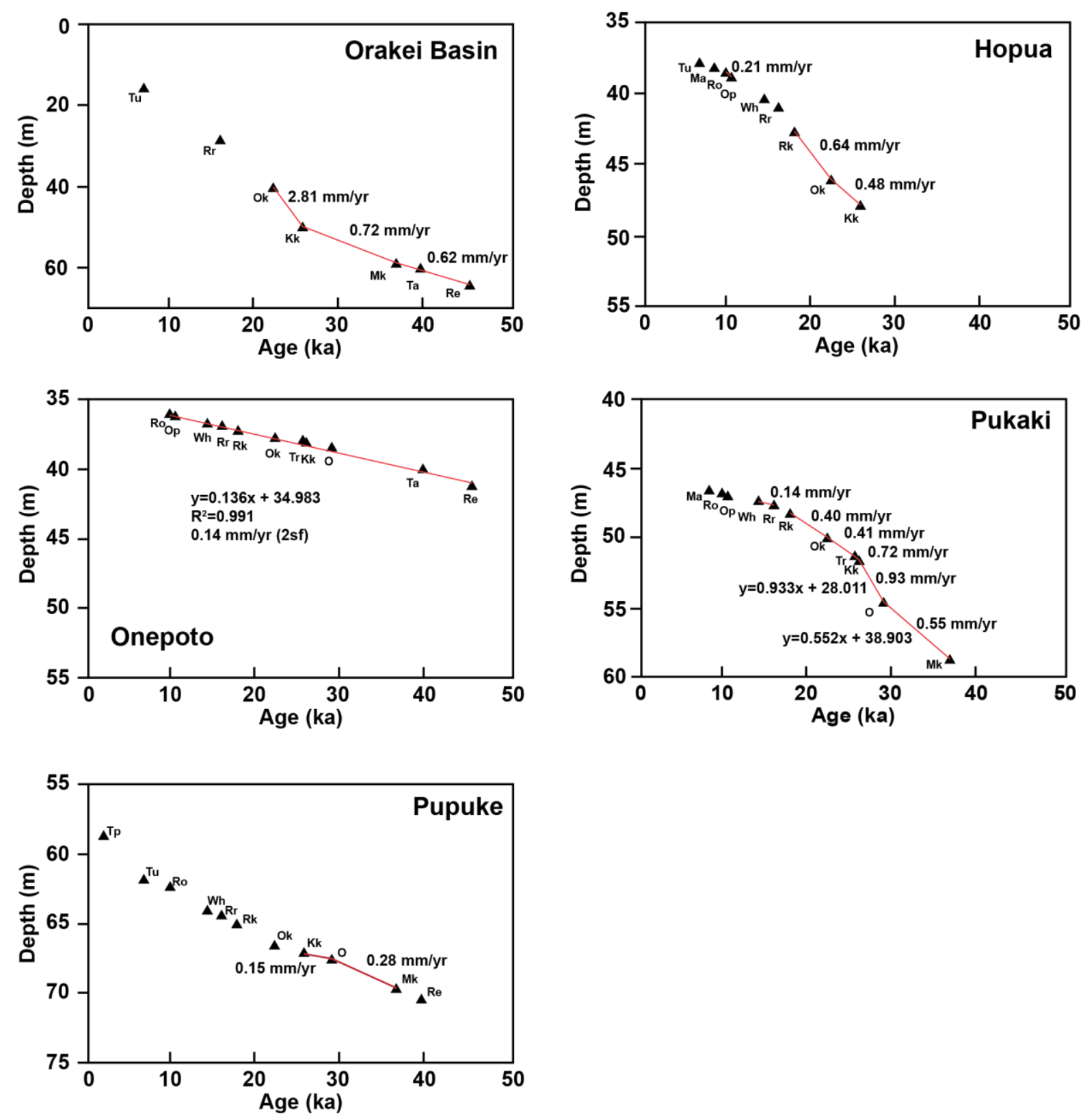

Figure 5.2. Sedimentation rate plots for all cores with multiple rhyolitic marker horizons. Abbreviations are defined in Table 5.2. Lines in red define sections where basaltic horizons have had their ages estimated with the corresponding sedimentation rates shown (in $\mathrm{mm} / \mathrm{yr}$.). Where sedimentation rates have been taken from best-fit lines (discussed in the text), the equation of the line is also shown. 
These results produce an up-to-date estimation for the ages of all the tephra horizons used in this study. Overall the ages produced show a good agreement where multiple deposits are correlated across core (for all horizons post $\mathrm{Re}$, a maximum error of $\pm 1.7 \mathrm{ka}$ from the calculated mean value for deposits in horizon AVF7, and a maximum error of \pm 15.2 ka for deposits in AVF1 horizon pre Rotoehu). There are however two discrepancies (highlighted in Table 5.3.): 1) The calculated age for AVF 17 (Orakei Basin core) is too young for the horizon order, and 2) the calculated age of AVF16 is older than the nomenclature order dictates.

The age for AVF 17 (23.4 ka) within only the Orakei Basin core is not out of place (AVF18 is $23.2 \mathrm{ka}$ and AVF15 is $24.5 \mathrm{ka}$ ). However, the average age for AVF18 is calculated from a range of ages (Hopua 25.2 ka, Pukaki 24.6 ka and Orakei) that are slightly older than the Orakei Basin core estimates. Therefore the average age for this horizon is calculated to be higher than that of the preceding horizon, which is only found in Orakei Basin.

AVF 16 (Pukaki core only) has also been repositioned within the overall core sequence. Not only does the age estimate imply it is older than suggested by the original position in the AVF nomenclature sequence, but also there are limited constraints on this horizon's relationship with the other deposits from other cores. The Te Rere and the Kawakawa/Oruanui rhyolitic horizons stratigraphically constrain horizon AVF16, but there are no other basaltic tephra restricted to this (Te Rere tephra is not found in the Orakei Basin core). Therefore based on the age estimates and the flexibility of the positioning, AVF16 is repositioned between AVF14 and AVF13 (Table 5.3.).

For this study, the numerical ages of the rhyolitic marker horizons are taken as boundaries and the calculated sedimentation rate ages taken as guide to estimate the basaltic tephra ages. A caveat is that there are still errors $( \pm 5-5000$ yrs.) associated with the ages of these rhyolitic markers, and although smaller than those associated with the Ar-Ar age dates for the AVF centres, they still need to be taken into account (see discussion in Sect. 5.3.4.). 
Table 5.3. The ages calculated for each basaltic horizon (in ka) using the sedimentation rates from Table 5.2. References: a. Needham et al. (2011), b. Lowe et al. (2013), c. Molloy (2008), d. Danišík et al. (2014), and e. Leonard et al. (in prep.). AVF24 is split into Rangitoto1 and 2 identified and dated $\left({ }^{14} \mathrm{C}\right.$ in cal. yr. BP) by Needham et al. (2011), the upper and basal units nomenclature from *Molloy et al. (2009), see text for details. The ages for the rhyolitic marker horizons (grey text) are outlined in cal. yr. BP. The age of AVF17 is highlighted as an outlier as discussed in the text, and the position of AVF16 is highlighted as out of sequence, also discussed in the text. The age of deposit AVFd in the base of the Onepoto core is taken from the minimum Ar-Ar age estimation for Pupuke centre, see text for details. All errors are reported as 1 sd.

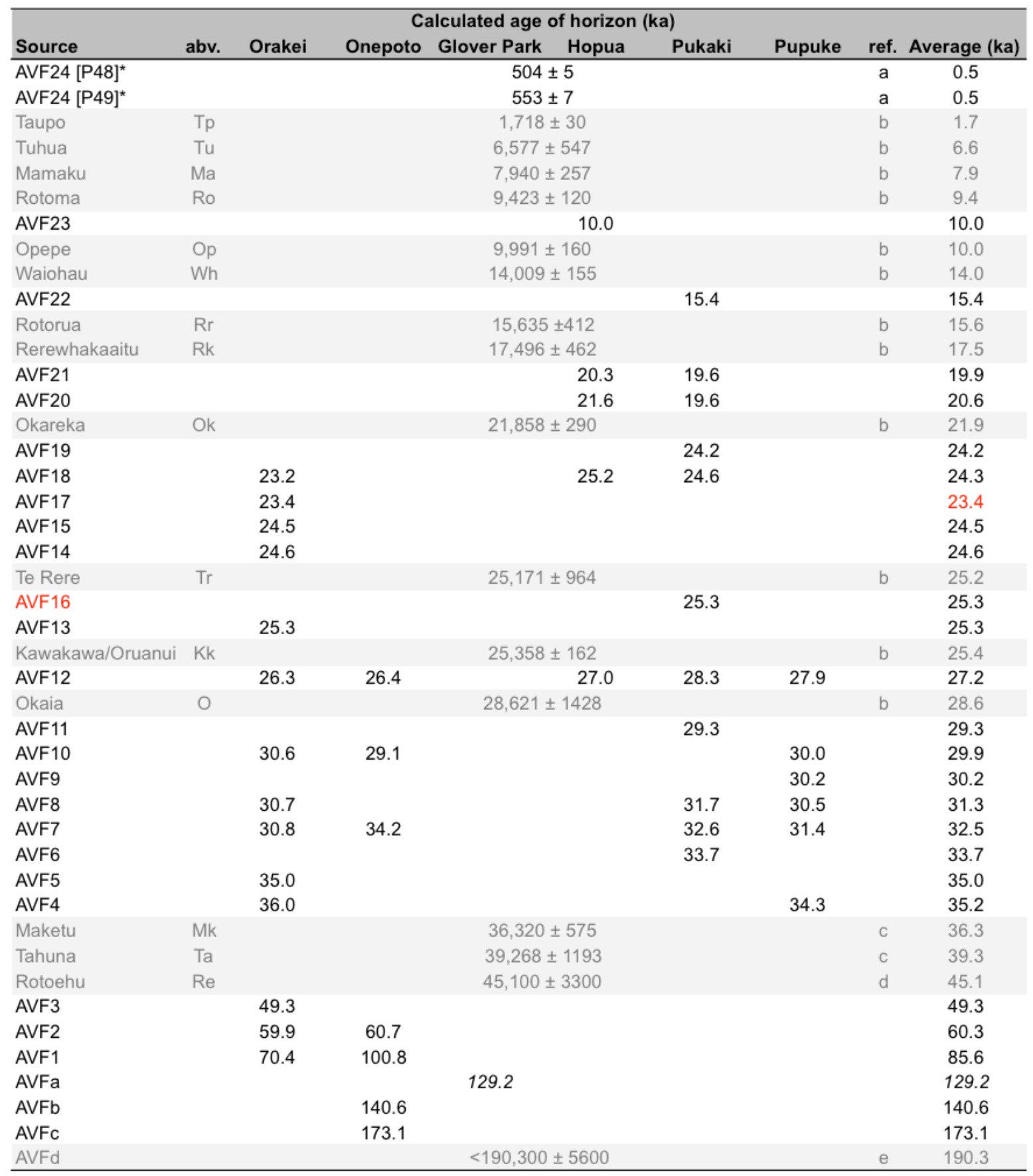




\subsubsection{Volcanic centre geochemistry}

In order to develop a method to geochemically correlate tephra horizons to source centres it was imperative to create a comprehensive source centre geochemical database to maintained a thorough and holistic approach. The whole rock database as collated in Chapter 4 (Appendix C) is the most complete compilation of geochemical data from the AVF centres. I report that 46 of 53 centres now have $>3$ major and trace element analyses available (Appendix $\mathbf{C}$ ). For the newly discovered centres Puhinui Craters and Cemetery Hill (Hayward pers. comms, 2012), no geochemical or age data exist and therefore these centres are not included in this study. Furthermore, due to evidence of extreme fractional crystallisation or olivine accumulation (common in Pupuke samples) as Chapter 4 details, measurements made by Heming and Barnet (1986) are all excluded, as are a number of single data points from previous authors (Hookway, 2000; Spargo, 2007; and Smith unpublished).

\subsubsection{Volcanic centre ages}

To maximise the data available for the ages of the individual eruptive centres, data from three methods have been collated. These methods include morphostratigraphic evidence (e.g. Hayward et al., 2011), ${ }^{40} \mathrm{Ar} /{ }^{39} \mathrm{Ar}$ dating of groundmass (Leonard et al., in prep, Appendix D; Cassata et al., 2008), and ${ }^{14} \mathrm{C}$ dating of organic debris (compiled in Lindsay et al., 2011). The centre ages, and their sources are outlined in Table 5.1.

Modelled ages for the AVF centres given by Bebbington and Cronin (2011) are excluded from this study, as they are considered to form a circular argument with our proposed method:

(1) Tephra horizons details (from Molloy et al., 2009) were input into the model to get the age outputs.

(2) The tephra horizons details are now superseded by work presented in Chapter 3. 
Morphostratigraphy is here defined as the interrelationships exhibited by the surface landforms (see examples below). Due to the proximity of the centres to one another within the field, 35 of 53 centres have morphostratigraphic constraints associated with them. Based on the laws of superposition a number of examples can be identified:

(1) Tephra or lava deposits that are found on top of other deposits must be from a younger eruption: e.g., Mt. Eden tephra on top of Three Kings lava flows.

(2) Lava that has flowed around or into another centre must be from a younger source: e.g., Little Rangitoto lava flowing around Orakei Basin tuff ring.

(3) A volcano that has erupted through an older lava flow must be younger than the lava's source: e.g., Hopua through One Tree Hill lava.

(4) Erosional features from sea level changes provide additional constraints: e.g., Pukewiriki has a wave cut platform, arguably from the last interglacial, and is therefore > ca. $130 \mathrm{ka}$ yrs old.

(5) For three of the centres (Domain, St Heliers and Onepoto) the morphostratigraphic constraint is based on tephrochronology, with the presence of the Rotoehu tephra within crater drill cores showing a minimum age for the centre of $45.1 \mathrm{ka}$.

These morphostratigraphic constraints give optimum relative ages, which need to be combined with the numerical ages derived from Ar-Ar dating. In all cases the Ar-Ar age ranges are consistent with the morphostratigraphic constraints.

The Ar-Ar ages presented in Leonard et al. (in prep. Appendix D) are stated through the following text as age ranges with a 2sd error (the mean ages are reported in Table 5.1.), although any age within the range is considered appropriate with no extra emphasis given to the mean ages. The Ar-Ar data suite produced by Leonard et al. (in prep. Appendix D) triples the number of centres with measured age dates from 11 to 33 (Lindsay et al., 2011). From the remaining twenty centres with no $\mathrm{Ar}-\mathrm{Ar}$ or ${ }^{14} \mathrm{C}$ ages, relative ages of fourteen centres were derived by morphostratigraphy (or tephrochronology; see Table 5.1.). With the age of six 
(Otuataua, Pigeon Mt., Robertson Hill, Boggust Park, Cemetery Hill, and the Puhinui Craters) from the 53 AVF centres remaining unknown. As previously mentioned Cemetery Hill and Puhinui Craters are not considered for this study, and therefore the centres Otuataua, Pigeon Mt., Robertson Hill, and Boggust Park will be included as possible correlatives for any dated horizon during the correlation process.

\subsubsection{Additional criteria}

To complement the geochemical and age data, a number of other assumptions are made to constrain the correlations further. These include the scale and style of eruptions, the location of the relevant centre(s), and locality(ies) of the relevant core(s). These criteria are discussed below.

The volcanoes of the AVF erupt with a range of styles and scales that need to be considered when approaching the problem of tephra correlation. Strombolian and Hawaiian styles produce only minor ash plumes that deposit tephra to only a few kilometres from source and are thus less likely to deposit large quantities of distal tephra (Valentine and Gregg, 2008). To form cm-thick tephra deposits a few kilometers from the vent, eruptions must either be 'violent-Strombolian' or phreatomagmatic in style (Houghton et al., 1999). However, for the AVF the designation between Hawaiian, Strombolian, and violent-Strombolian styles are not defined (Kerezturi et al., 2014; Allen and Smith, 1994) and therefore for correlation purposes the differences between phreatomagmatic vs. magmatic styles are considered. It is assumed that during a phreatomagmatic eruption the potential of a centre to disperse more tephra to greater distances is higher, in comparison to a similar sized centre with only magmatic (explosive or effusive) eruption phases.

For this study, the total erupted volume (total dense rock equivalent, DRE ${ }^{\text {tot}}$; Kereszturi et al., 2013, Table 5.1.) is assumed to be equivalent to the scale of an eruption, which correlates to dispersal distance. Here we take the most recently published DRE tot values from Kereszturi et al. (2013) rather than the original estimates from Allen and Smith (1994) (both of which are reported in Table 5.1.). The values from Kereszturi et al. (2013) are preferred as they take into account multiple additional factors (e.g., diatreme volume, crater infil volume) that were not 
considered by Allen and Smith (1994), and also include all the currently identified volcanoes.

In addition tephra deposits are assumed to thin away from source (Pyle, 1989; Lowe, 2011). Therefore an eruption that produces a large DRE ${ }^{\text {tot }}$ volume will be assumed to produce a volumetrically large tephra output and hence, a thick proximal deposit, and a thin, but greater dispersed distal deposit. For thick tephra deposits $(>100 \mathrm{~mm}$ ) in a core, the source centre is therefore constrained to either 1) being close to the deposition site ( $\leq$ few kilometres, Brand et al., 2014), and/or 2) having a predominantly phreatomagmatic eruption style.

Due to the relatively volumetrically small size of the AVF volcanoes, the tephra dispersal area from single eruptions usually does not cover the entire field (Kermonde, 1992). Therefore the distribution and thickness of the tephra deposits in cores can be indicative of the source centre. For example, tephra deposits that are only found in the northern maar sites (Onepoto, Pupuke, Orakei and Glover Park) are assumed to indicate sources in the north or central AVF (based on the dominant wind direction, discussed below). Conversely a deposit only found in the southern maar site (Pukaki) is suggestive of sources in the south of the field. Tephra deposits found in both northern and southern maar sites are likely derived from the central part of the field, and/or reflect a large enough eruption widely dispersing tephra over the AVF area.

Wind direction is also a factor taken into consideration when making source correlations due to its controlling influence on volcanic plume direction and tephra dispersal. For the Auckland region evidence of prevailing past wind directions can be inferred from the morphology of the volcanic centres. Two examples include:

(1) The build up of a higher tuff ring on Motukorea's north-eastern side (McGee et al., 2012) and One Tree Hill's asymmetrical scoria cone built up on the north-eastern side of the vent (Hayward et al., 2011).

(2) Some of the eastern centres, e.g. Green Mt., Otara Hill, Styaks Swamp and Hampton Park, show evidence for a dominant westerly wind, creating high tuff rings to the east of the vents (Hayward et al., 2011). 
These historic wind patterns in the Auckland region are still the dominant patterns for today (Houghton et al., 2006), resulting in more common tephra deposition to the northeast and east of the field (confirmed by the high number of deposits found within the Orakei Basin core, situated north-east of most centres; Fig. 5.1.). Tephra deposits are therefore more readily traced back to sources to the west and southwest. Accordingly centres found to the east or north east of the maar sites (e.g. Pigeon Mt., Hampton Park, Otara, Green Mt., and Styaks Swamp; Fig. 5.1.) are less likely to be represented in the maar tephra record.

When the correlation technique is applied, each horizon is taken as an individual case, and all potential sources are accounted for and discussed. In some cases potential sources will have been correlated to an alternative horizon, however, because each correlation is not definitive, correlated sources are not discounted for other tephra horizons. In these instances, those centres correlated to a horizon are identified in italic font, with their correlated horizon detailed. They do however, become a less likely potential source for another horizon if they are already a best fit for an alternative deposit.

The factors discussed here are all taken into account when making correlations, and a 'confidence value' is assigned for each correlation based on the number of criteria that are satisfied. In general, if all four criteria (geochemistry, age, scale, location) are satisfied a confidence level of 1 is given, when three are satisfied a confidence level of 2 is give, and if only two are satisfied a confidence level of 3 is given. Each of these criteria is variably weighted in importance with age $\geq$ geochemistry >> locality $\geq$ scale and style, and therefore in some cases the confidence values are skewed to show this. For example if geochemistry, locality and scale are all appropriate, but age is not, the confidence value will be 3 rather than 2 because age is a more important and restricting factor.

By collating the maximum amount of information about the tephrostratigraphic framework, and the known eruptive scales, styles, ages and geochemistries, this study presents the method developed to correlate of AVF tephra horizons to their source centre. I initially discuss the method developed to correlate tephra to whole rock samples, followed by detailing the correlations made, and the resultant implications of the outcomes. 


\subsection{Discussion}

\subsubsection{Geochemical compositions of whole rock and tephra-derived glass}

\subsubsection{Discriminating elements}

The (generally) monogenetic nature of the AVF results in the potential for each centre to have a discrete geochemical signature. Previous studies on the petrogenesis of the AVF eruptives (Huang et al., 1997; McGee et al., 2013) have shown that each batch of magma is generated by differing degrees of partial melting of multiple mantle sources located at different depths within the mantle. This includes a deep source $(\geq 80 \mathrm{~km}$, more $c p x+$ more garnet) and a shallower source $(\leq 80 \mathrm{~km}$, less cpx + less garnet) (McGee et al., 2012). The involvement of multiple mantle sources is the cause of the large trace element variability observed in the AVF lavas (discussed in Chapter 4).

The geochemical results show that although there is overlap for many elements for the field, some specific element concentrations and their trends can be more discriminatory for individual centres (Fig. 5.3.). Combinations of major $\left(\mathrm{SiO}_{2}\right.$, $\left.\mathrm{MgO}, \mathrm{CaO}, \mathrm{FeO}, \mathrm{P}_{2} \mathrm{O}_{5}\right)$ and trace ( $\mathrm{Zr}, \mathrm{Gd}, \mathrm{La}, \mathrm{Sm}, \mathrm{Nd}, \mathrm{Nb}, \mathrm{Ce}$ ) elements, and trace element ratios (e.g., $\mathrm{La} / \mathrm{Yb}$ or $\mathrm{La} / \mathrm{Y}$ ) are particularly useful for this purpose. The selected elements not only show the widest range in concentrations in eruptive products from the AVF, but are most representative in eruptive products from individual centres.

The rare earth elements (REEs) are especially useful as they can be used to discriminate between melts from a deep or shallow source. (e.g., McKenzie and O'Nions, 1991; Robinson and Wood, 1998; Table 5.4.). The light REE (LREE) are incompatible in garnet (e.g. $\mathrm{K}_{\mathrm{D}}[\mathrm{La}]=0.001$; Winter, 2010) compared to the heavy REE (HREE) which are compatible in garnet (e.g. $\mathrm{K}_{\mathrm{D}}[\mathrm{Yb}]=3.1$; Winter 2010). As a result melts from a deep garnet-bearing mantle source have lower LREE/HREE ratios. $\mathrm{Y}$ and $\mathrm{Yb}$ are used here as the HREE denominators. If a sample has a high LREE/Y or LREE/Yb ratio it is indicative of a deeper, more garnet rich source, in comparison to a low LREE/Y or LREE/Yb ratio, which will be indicative of more of an input from a shallower source. In addition, during low pressure differentiation, for example fractional crystallisation of magmas on ascent, the effects on these ratios is 
minor in comparison to the effects of partial melting in the source in the presence of garnet or spinel stability fields. Therefore there is very minor alteration of these source signatures on ascent.
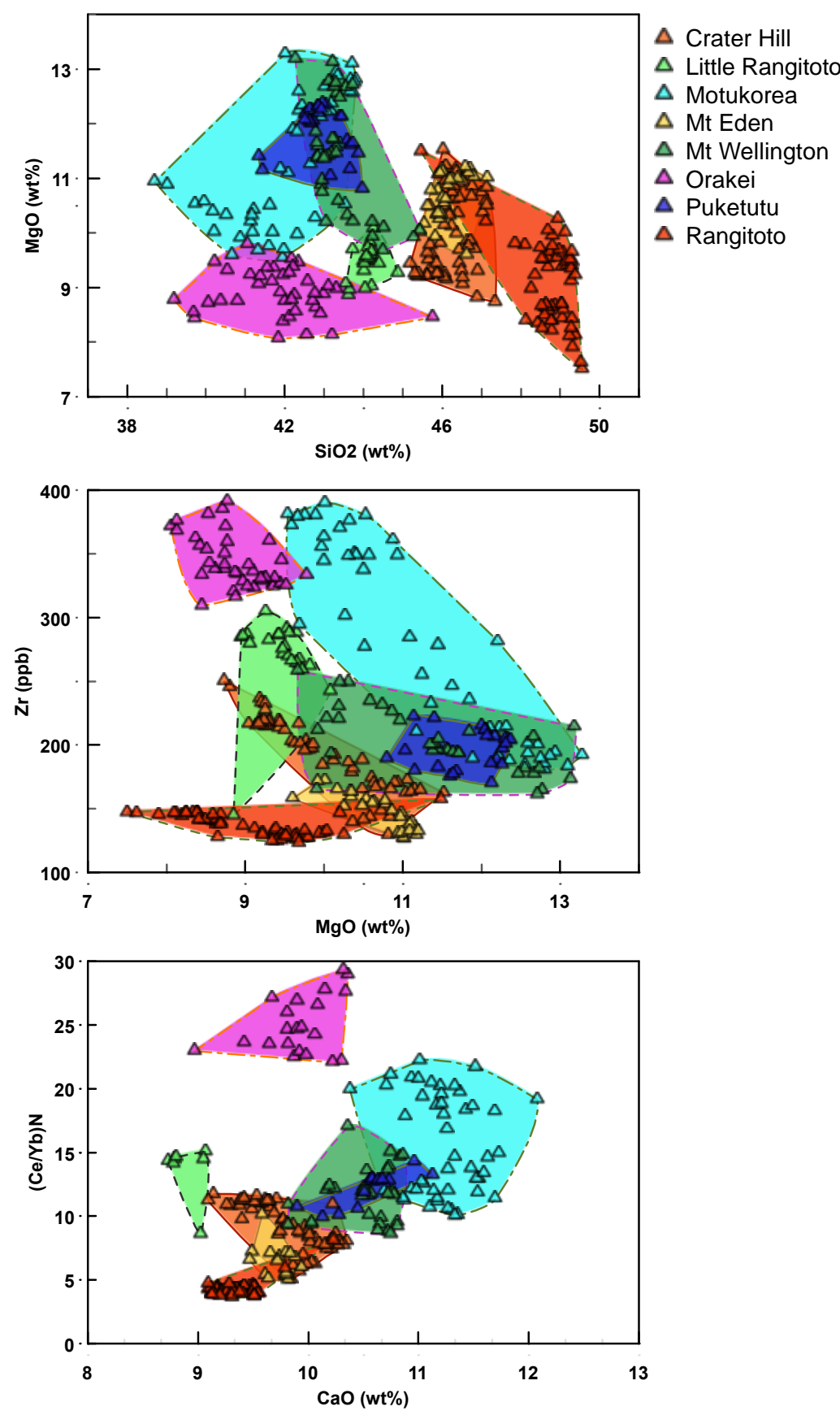

Figure 5.3. Collection of whole rock element/oxide plots (data in Appendix C) to show an example of a selection of those elements that are discriminatory for the AVF. I include examples of elements that have the widest range in the field and the least overlap for each centre, and are therefore the most individual for each centre. $(N=$ normalised to primitive mantle values after McDonough and Sun, 1995). 
Table 5.4. Distribution co-efficient values for selected trace elements into selected minerals. Of note are the compatibility $\left(K_{D}>1\right)$ of $Y b$ and $Y$ in garnet, and the incompatibility $\left(K_{D}<<1\right)$ of all REE into olivine. From Winter (2010, $p$ 165, and references therein.)

\begin{tabular}{lccccc}
\hline Element & Olivine & \multicolumn{4}{c}{ Distribution Co-efficients $\left(\mathbf{K}_{\mathbf{D}}\right)$} \\
Opx & Cpx & Plag & Garnet \\
\hline $\mathbf{N i}$ & 14 & 5 & 7 & 0.01 & 0.955 \\
$\mathbf{C r}$ & 0.7 & 10 & 34 & 0.01 & 1.345 \\
$\mathbf{~ a a}$ & 0.007 & 0.030 & 0.056 & 0.148 & 0.001 \\
$\mathbf{C e}$ & 0.006 & 0.020 & 0.092 & 0.082 & 0.007 \\
$\mathbf{N d}$ & 0.006 & 0.030 & 0.230 & 0.055 & 0.026 \\
$\mathbf{N b}$ & 0.004 & 0.004 & 0.006 & 0.024 & 0.010 \\
$\mathbf{Z r}$ & 0.003 & 0.030 & 0.130 & 0.090 & 0.900 \\
$\mathbf{G d}$ & 0.004 & 0.034 & 0.400 & 0.040 & 0.500 \\
$\mathbf{Y b}$ & 0.049 & 0.340 & 0.542 & 0.023 & 5.500 \\
$\mathbf{Y}$ & 0.007 & 0.300 & 0.410 & 0.010 & 3.100 \\
\hline
\end{tabular}

\subsubsection{Comparison of whole rock to tephra-derived glass geochemistry}

In general, when the entire whole rock and tephra-derived glass data suites are compared $\mathrm{MgO}, \mathrm{Cr}$, and $\mathrm{Ni}$ whole rocks all show distinctly higher concentrations than in the glasses (e.g. MgO in glass ca. 2-6 wt.\%; in whole rock ca. 6-16 wt.\%) (Fig. 5.4.A). Compared to whole rock analyses, all glasses have higher (but slightly overlapping) $\mathrm{SiO}_{2}, \mathrm{Al}_{2} \mathrm{O}_{3}, \mathrm{Na}_{2} \mathrm{O}$, and $\mathrm{K}_{2} \mathrm{O}$ contents (e.g. $\mathrm{SiO}_{2}$ in tephra ca. 42-52 wt.\%; whole rock ca. 38-50 wt.\%). $\mathrm{CaO}, \mathrm{Fe}_{2} \mathrm{O}_{3}$ tot, $\mathrm{TiO}_{2}$, and $\mathrm{P}_{2} \mathrm{O}_{5}$ are comparable range between whole rock and glass, as are the trace elements, including REEs. The REEs in general do show a slightly wider range in the glass than the whole rock, although, this discrepancy is removed by the use of trace element ratios. For example $\mathrm{Mg}, \mathrm{Cr}$ and $\mathrm{Ni}$ are highly compatible with olivine, pyroxene (cpx) and oxides, and are strongly partitioned and enriched in these minerals. Consequently, these elements are not useful for trying to correlate tephra to whole rock. The REE are generally incompatible with the major silicate mineral phases, and are therefore not preferentially enriched in crystals. They therefore have comparable REE contents and ratios in tephra-derived glass and whole rock (e.g. Fig. 5.4.B). The discrepancies seen between the tephra and whole rock compositions are therefore inferred to reflect the difference between whole rock, which includes both melt and crystals components, in comparison to tephra, which just reflects the melt. 

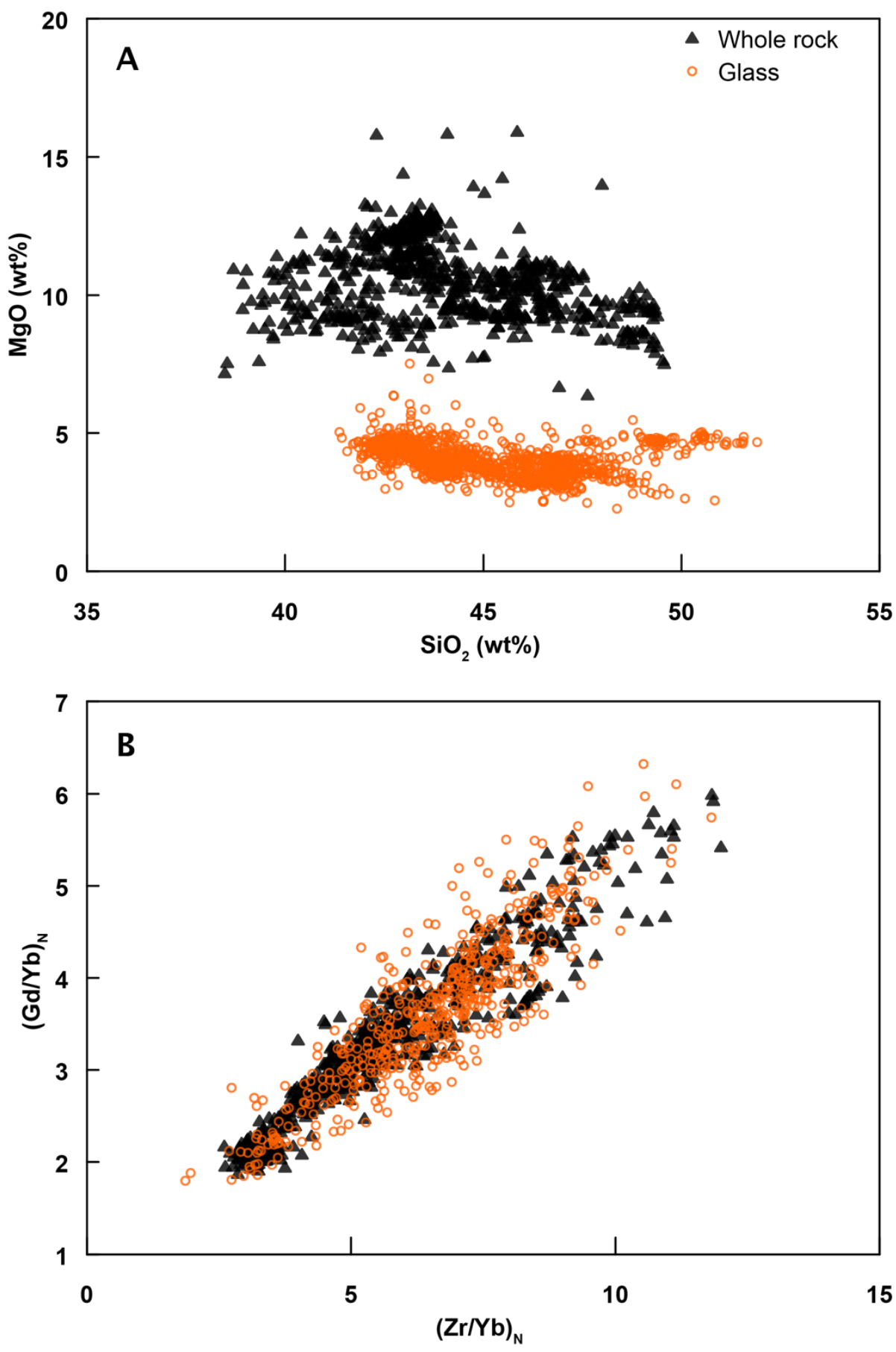

Figure 5.4. Comparison plot for concentrations of major and trace elements for whole rock and glass for full sample suite (all data in Appendix C). (A) $\mathrm{MgO}$ vs. $\mathrm{SiO}_{2}$ indicating an example of elements that do not correlate, and $(B)(Z r / Y b)_{N} v s .(G d / Y b)_{N}$ indicating an example of trace element ratios that do correlate. 


\subsubsection{Correlation of tephra with interstitial glass in whole rock samples}

Due to the discrepancies in the element concentrations between glass in tephra and crystal-bearing whole rock, it is hypothesised that interstitial glass contained in the whole rock samples will provide a more comparable signature to the tephra (Fig.5.5. A and B). To test this hypothesis, a sample from Mt. Wellington (AU62394) was chosen as a 'test sample' for two reasons, 1) it was a glassy whole rock sample (glass ground mass with phenocrysts) and, 2) because distal tephra from Mt. Wellington has been unambiguously identified within the Hopua core based on age, scale and stratigraphy (Molloy et al., 2009; Fig. 5.5.). The whole rock sample (AU62394) was processed in two ways, first as a whole rock sample (as outlined in Chapter 4) and second as a 'simulated (tephra) glass' sample. This process involved roughly crushing the whole rock, and then picking shards of interstitial glass that were of comparable size $(30-100 \mu \mathrm{m})$ to the glass shards in the cores. These simulated whole rock-derived-glass shards were then treated as tephra derivedglass shards and analysed by the methods outlined in Chapter 3 (Fig.5.5. C and D).

Figure 5.6 shows the results of multi-element comparison of the simulated glass with the known glass samples (from Hopua core). A wide range of both major and trace element compositions (including, $\mathrm{MgO}$ vs. full major element suite plus trace elements $\mathrm{Rb}, \mathrm{Zr}, \mathrm{Cs}, \mathrm{Ni}, \mathrm{Cr}, \mathrm{Y}$, and $\mathrm{Er} ; \mathrm{SiO}_{2}$ vs. $\mathrm{Al}_{2} \mathrm{O}_{3}, \mathrm{Na}_{2} \mathrm{O}, \mathrm{K} 2 \mathrm{O}$, and $\mathrm{CaO}$ vs. $\mathrm{Al}_{2} \mathrm{O}_{3}, \mathrm{Na}_{2} \mathrm{O}$ ) are comparable in these two sample types. Limited variability exists between trace elements (e.g., $\mathrm{Rb}, \mathrm{Zr}, \mathrm{Ni}, \mathrm{Cr}$ and $\mathrm{Y}$, and the $\mathrm{REE}$ ) when plotted against each other, or against $\mathrm{Al}_{2} \mathrm{O}_{3}$ or $\mathrm{MgO}$. Regardless, these elements show a good overall agreement between the two glass types.

Some elements (Figure 5.6.) in the tephra derived-glass show a larger spread compared to the simulated glass, which we attribute to two potential reasons: 1) simulated glass was made from a single whole rock sample therefore there would be limited variability in element content, and 2) a natural tephra-derived glass sample will show some minor variability due to the effects of crystal removal and source heterogeneity in different tephra-derived shards. Because both the simulated whole rock-derived glass and known tephra-derived glass exclude the phenocrystic material, they can best be correlated using elements which are highly compatible and which are preferentially incorporated in key crystallising minerals within the 
whole rock (e.g. olivine). These elements are therefore strongly partitioned into the crystal phases, and result in comparable glass chemistries. We therefore propose that interstitial glass of whole rock samples can be used, with caveats, for correlation purposes. This method, however, relies on the ability to sample and extract interstitial glass from whole rock samples, which is often not possible. For this reason we aimed to further develop the tephra-whole rock correlation method to correlate tephra deposits to their corresponding whole rock (if devitrified), and thus their centre of origin.

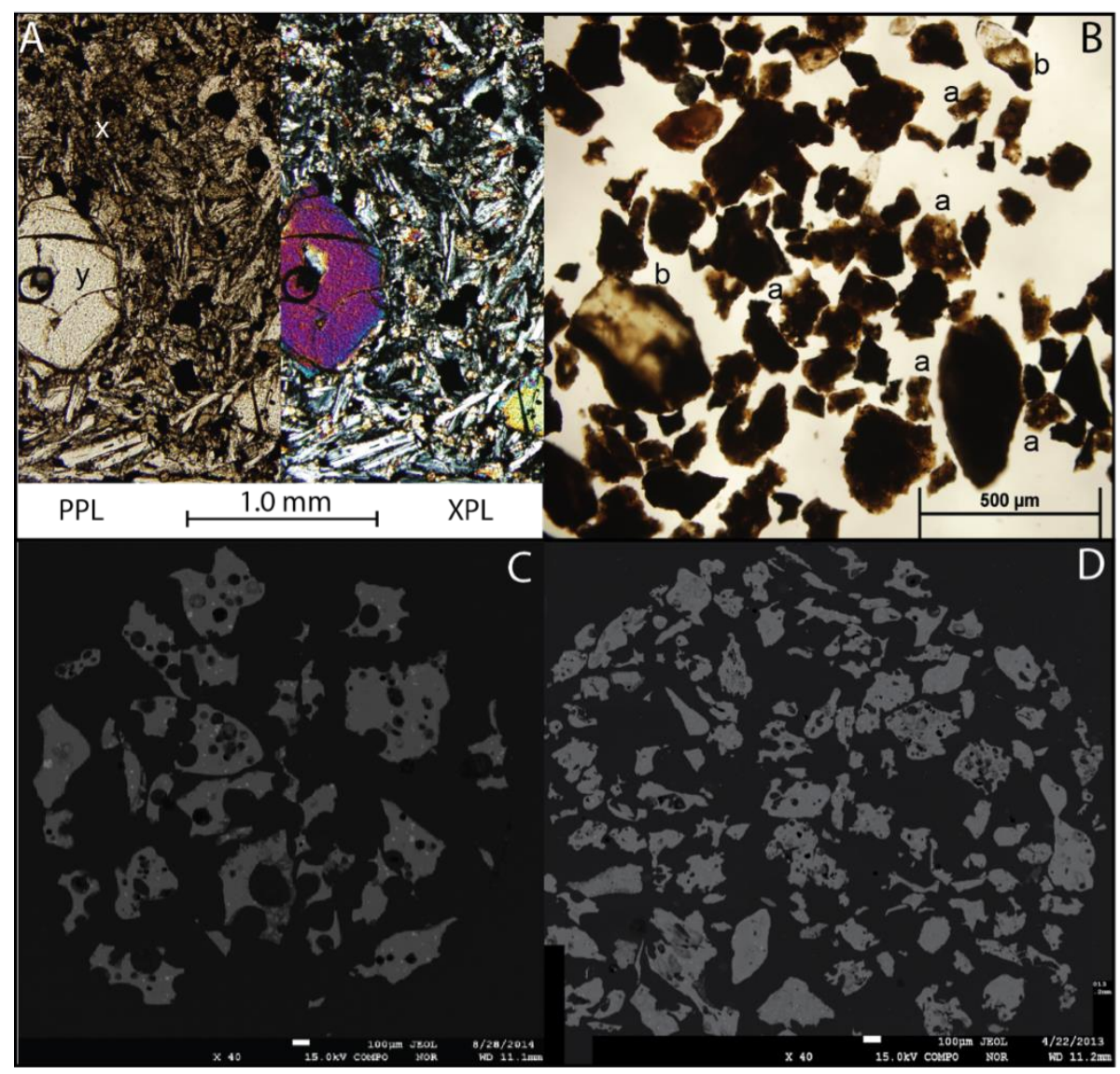

Figure 5.5. Pictures to show simulated tephra created by crushing a glassy whole rock sample and separation of the interstitial glass component. (A) Shows a microscope image of a thin section of the whole rock sample AU62394 in plain polarised light (ppl) on the left and cross polarised light (xpl) on the right. Glassy groundmass $(x)$ can be identified with a few large phenocrysts of predominantly olivine (y). (B) Crushed whole rock sample AU62394 including glass shards (a) that were hand picked and mounted for analysis and comparison, and phenocrysts (b) specifically large olivine crystals that were not analysed. (C) SEM backscattered electron image of handpicked, mounted, polished, 'simulated whole rock derived-glass' shards created from interstitial glass and, (D) a distal deposit of Mt. Wellington tephra from within Hopua maar core. Scales for images in panels $C$ and $D$ are the same. 

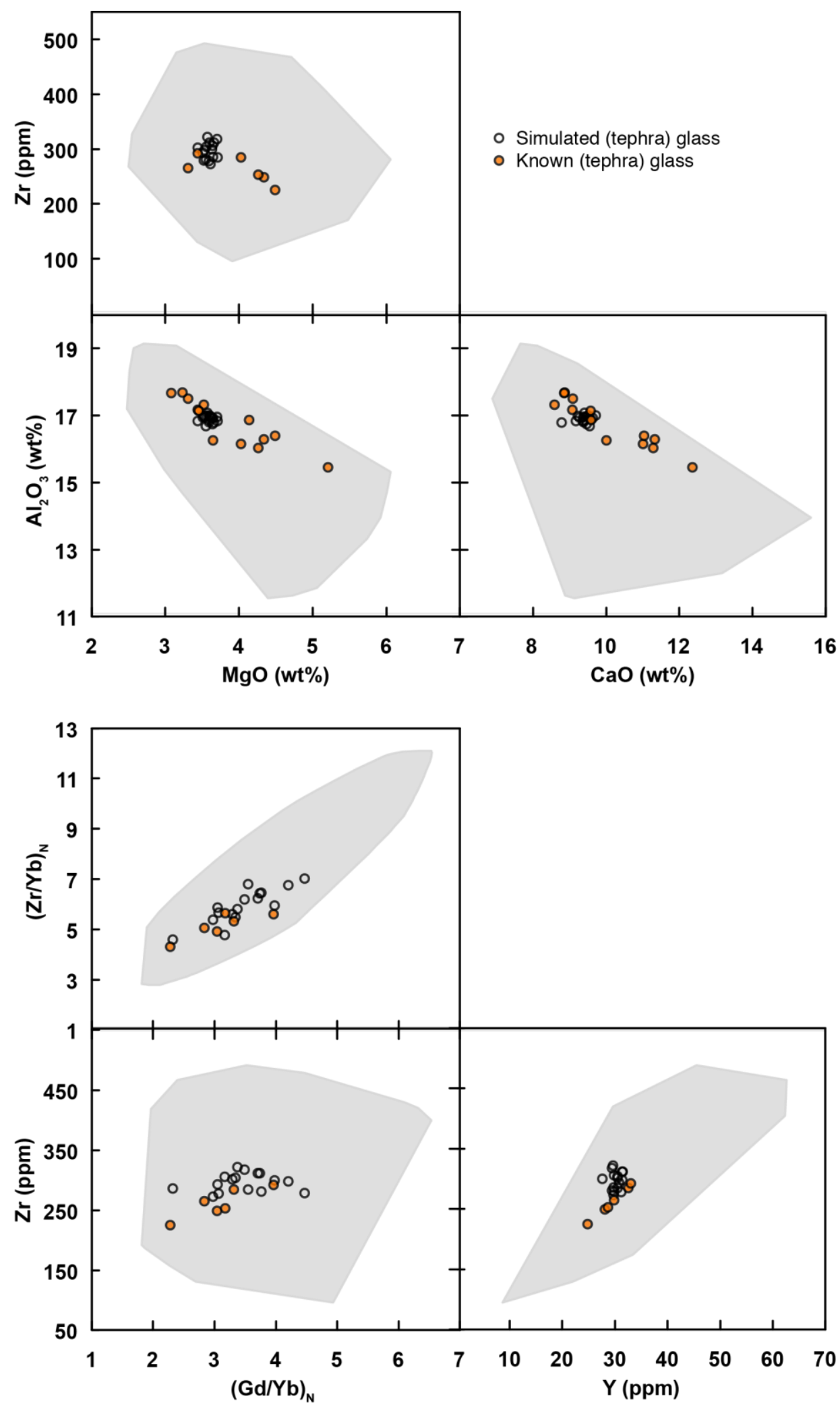

Figure 5.6. Multi-element plot for comparison of a known Mt. Wellington tephra deposit from the Hopua maar core with simulated tephra (interstitial glass) made from Mt. Wellington whole rock sample AU62394. Grey areas show the range of values (for glass analysis) for the entire field. 


\subsubsection{Correlation of tephra with bulk whole rock samples}

\subsubsection{Geochemical constraints}

Correlating major element concentrations from whole rock to tephra (glass) samples has proved difficult due to the effect fractional crystallization has on the concentrations of some elements. Plotting element concentrations (for a whole rock from a single centre or tephra shard analyses from one horizon) against other elements that are compatible with certain crystals, (e.g. $\mathrm{MgO}$ for olivine, $\mathrm{CaO}$ and $\mathrm{Al}_{2} \mathrm{O}_{3}$ for pyroxene or plagioclase), can monitor the effect of crystal removal on these elements. If an element shows a positive or negative correlation with these key compatible major elements $\left(r^{2} \geq 0.6\right.$, where no single point is responsible for the trend), then it is significantly affected by crystal removal and therefore will not be useful for correlation purposes. Most major elements are affected, as are certain more compatible trace elements (e.g. $\mathrm{Ni}, \mathrm{Cr}, \mathrm{Sc}$ ) with high partition coefficients for olivine and pyroxene (Table 5.4.). Figure 5.7 shows that for $\mathrm{MgO}$ vs. $\mathrm{Ni}$, whole rock $\left(r^{2}=0.75\right)$ and tephra-derived glass $\left(r^{2}=0.61\right)$ and, vs. La $\left(r^{2}=0.02\right.$ for tephra, $r^{2}=$ 0.11 for whole rock). This exercise was repeated for all tephra horizons and all centres using $\mathrm{MgO}, \mathrm{CaO}, \mathrm{Al}_{2} \mathrm{O}_{3}, \mathrm{Ni}, \mathrm{Mn}$ and $\mathrm{Sr}$ on the $\mathrm{x}$-axis, and results suggested that the incompatible $\mathrm{REE}$ (and $\mathrm{Nb}, \mathrm{Zr}$ ) were the least affected by crystal removal.

The incompatible trace elements (such as La, Gd, $\mathrm{Zr}$ ) are therefore well suited for geochemical fingerprinting because they have similar concentrations in whole rock and tephra, and are not affected by crystal removal. Incompatible trace element ratios of both $\mathrm{Y}$ and $\mathrm{Yb}$ were also tested. The results showed in a number of cases ratios with $\mathrm{Y}$ had minor correlations with $\mathrm{MgO}$ and $\mathrm{Ni}$, suggesting a preferential enrichment in olivine. Conversely, the ratios with $\mathrm{Yb}$ showed no correlation with any of the $\mathrm{x}$-axis elements. Therefore, in the AVF samples $\mathrm{La} / \mathrm{Yb}, \mathrm{Gd} / \mathrm{Yb}, \mathrm{Zr} / \mathrm{Yb}, \mathrm{Ce} / \mathrm{Yb}$, $\mathrm{Nb} / \mathrm{Yb}$ and $\mathrm{Nd} / \mathrm{Yb}$ are distinguished as the best ratios for correlation. Showing a broad range in the field as a whole, but relatively restricted ranges in samples from the same centre, and no relationship with fractional crystallisation. 

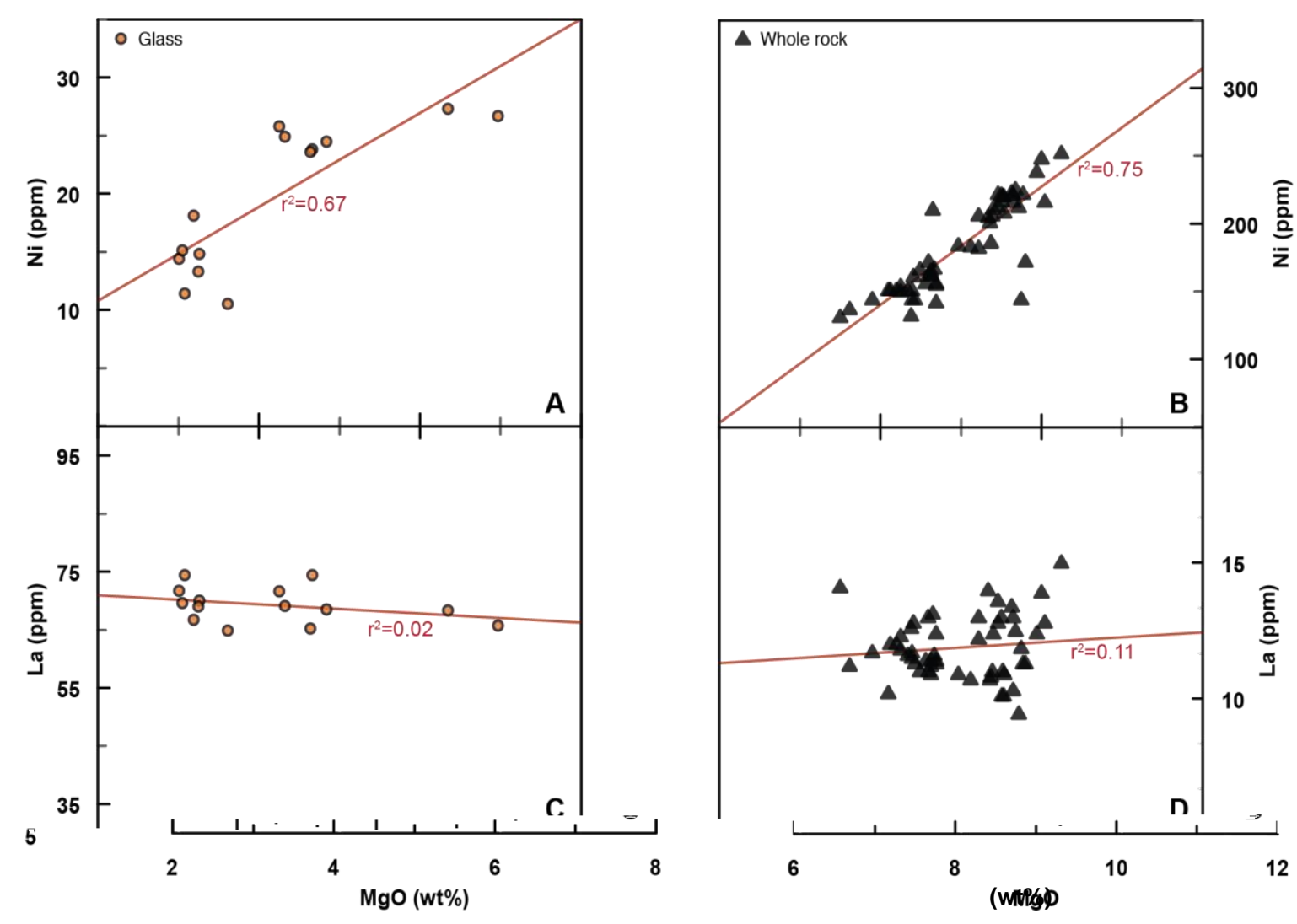

Figure 5.7. Selected whole rock and tephra sample concentrations from Rangitoto, to show the effects of crystal removal. (A) MgO vs. Ni for tephra-derived glass and, (B) whole rock. Both show a high $r^{2}$ value suggesting a statistically significant relationship between the two elements. In comparison (C) MgO vs. La for glass and, (D) for whole rock. Both show $r^{2}$ values near zero, indicating no statistically significant relationships between the elements.

\subsubsection{Method testing using Mt. Wellington samples}

The previous sections have highlighted some specific combinations of major, trace, and trace element ratios that are suitable for correlation between whole rock and tephra, and can therefore be tested. To test for this, we used Mt. Wellington simulated tephra from whole rock sample AU62394, and Mt Wellington derived tephra from the Hopua core. 

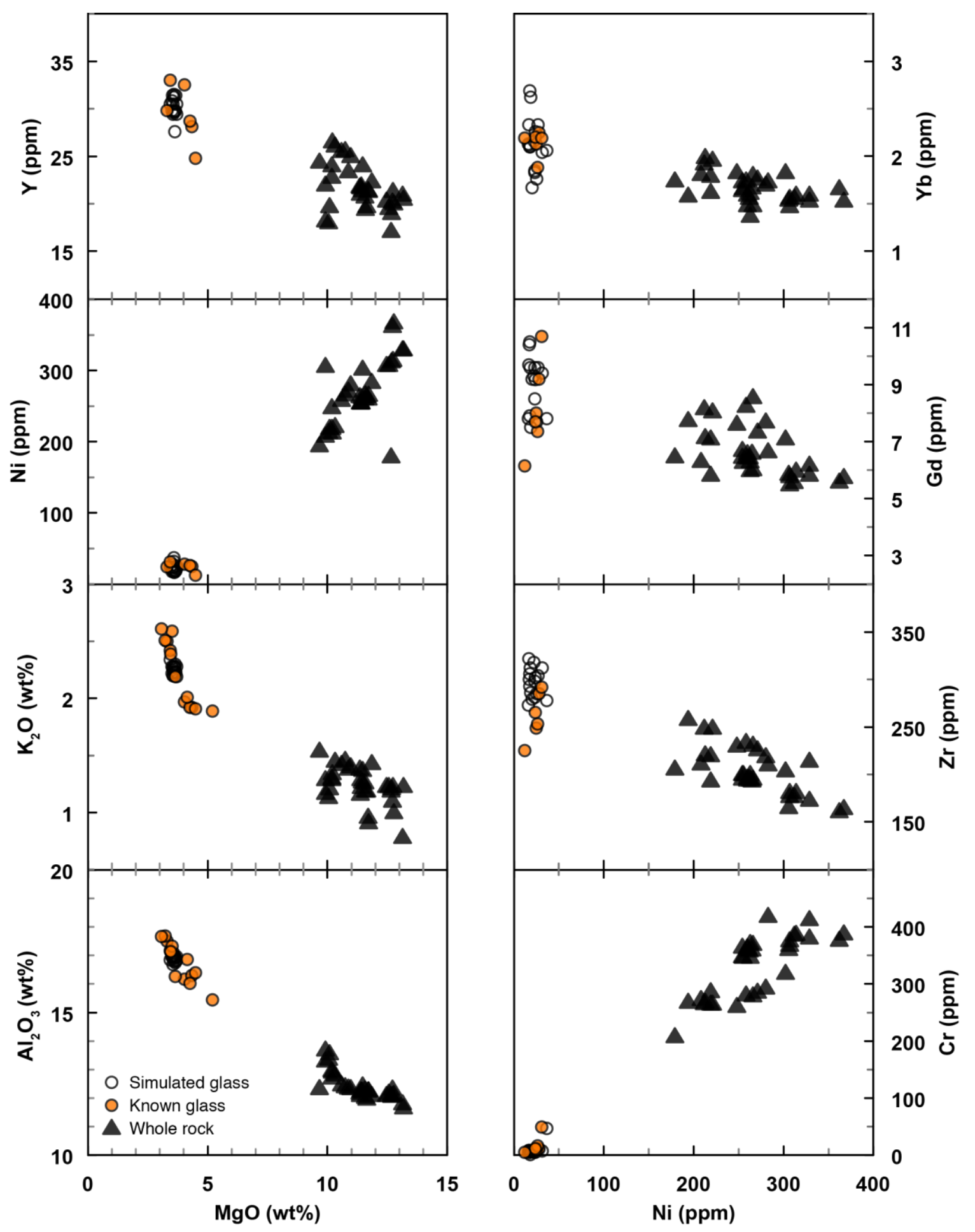

Figure 5.8. Selected major and trace element combinations for Mt. Wellington that were shown to correlate tephra ('known glass') to interstitial glass ('simulated glass'), but do not correlate tephra (both types) to whole rock. See text for discussion. 
Figure 5.8 shows selected element combinations of $\mathrm{MgO}$ vs. $\mathrm{Al}_{2} \mathrm{O}_{3}, \mathrm{~K}_{2} \mathrm{O}, \mathrm{Ni}$, $\mathrm{Cr}$, and the REE that work for glass-glass correlations but do not work for glasswhole rock correlations. Contrary to this, some major element combinations do appear to correlate the bulk whole rock with the tephra-derived glass (including $\mathrm{SiO}_{2}$ vs. $\mathrm{TiO}_{2}$ and $\mathrm{FeO}$, and $\mathrm{CaO}$ vs. $\mathrm{TiO}_{2}, \mathrm{FeO}$ and $\mathrm{Al}_{2} \mathrm{O}_{3}$; Fig. 5.9.). However, this is mainly due to the small variability observed in these Mt Wellington samples, and may not be applicable for the field as a whole. Figure $\mathbf{5 . 1 0}$ shows some of the selected trace element and trace element ratio combinations that are sufficiently distinctive to allow independent correlation to be made between the field wide suite of whole rock and tephra-derived glass data. It is therefore concluded that from incompatible ratios LREE/HREE (La/Yb, Gd/Yb, Zr/Yb, Ce/Yb, $\mathrm{Nd} / \mathrm{Yb}$ and $\mathrm{Nb} / \mathrm{Yb})$, correlation between tephra and whole rock is possible.

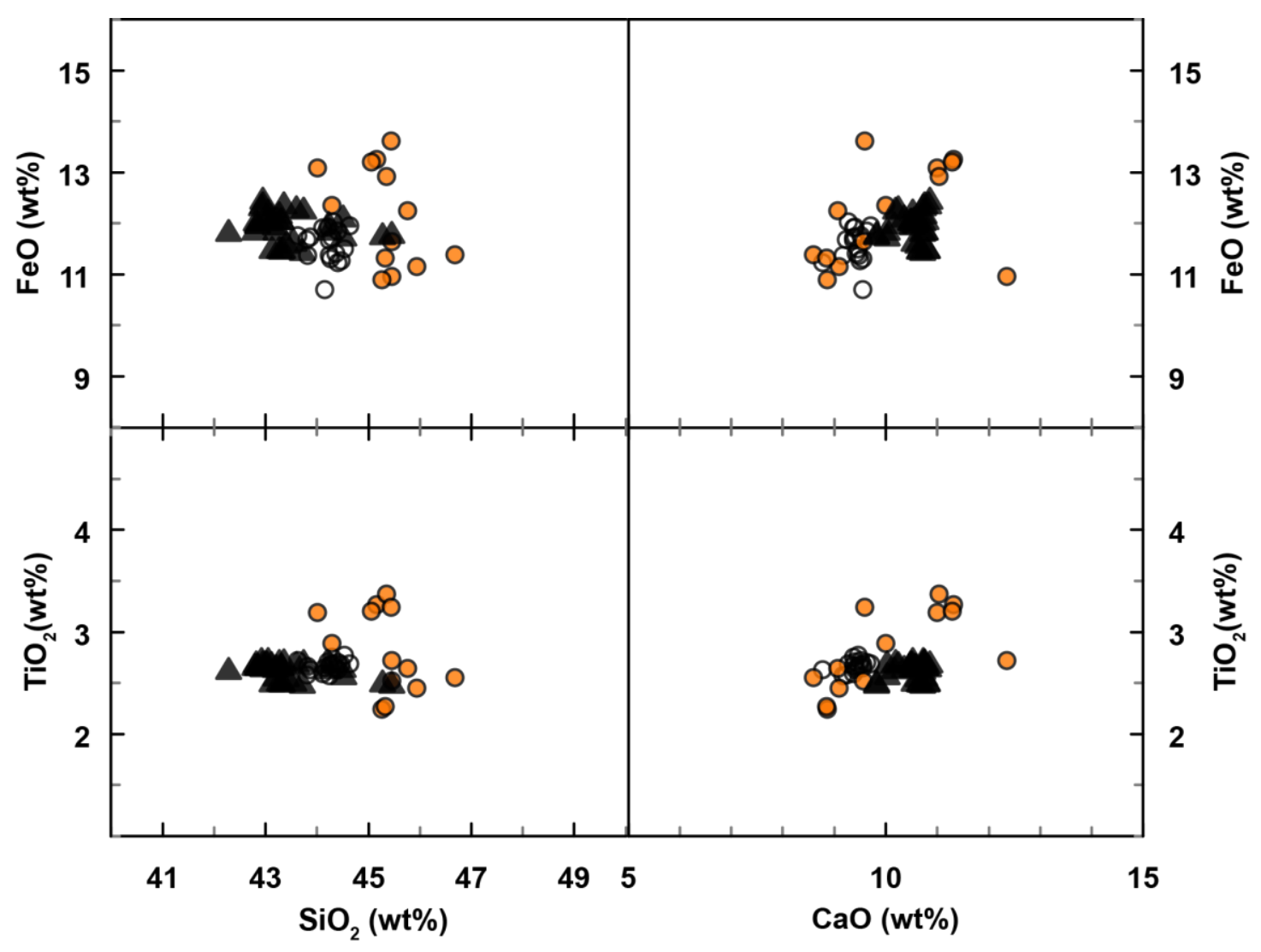

Figure 5.9. Selected major element combinations for Mt. Wellington that were shown to be comparable for tephra-derived glass and interstitial glass, and are also comparable for whole rock vs. glass. Symbols as in Figure $\mathbf{5 . 8 .}$ 

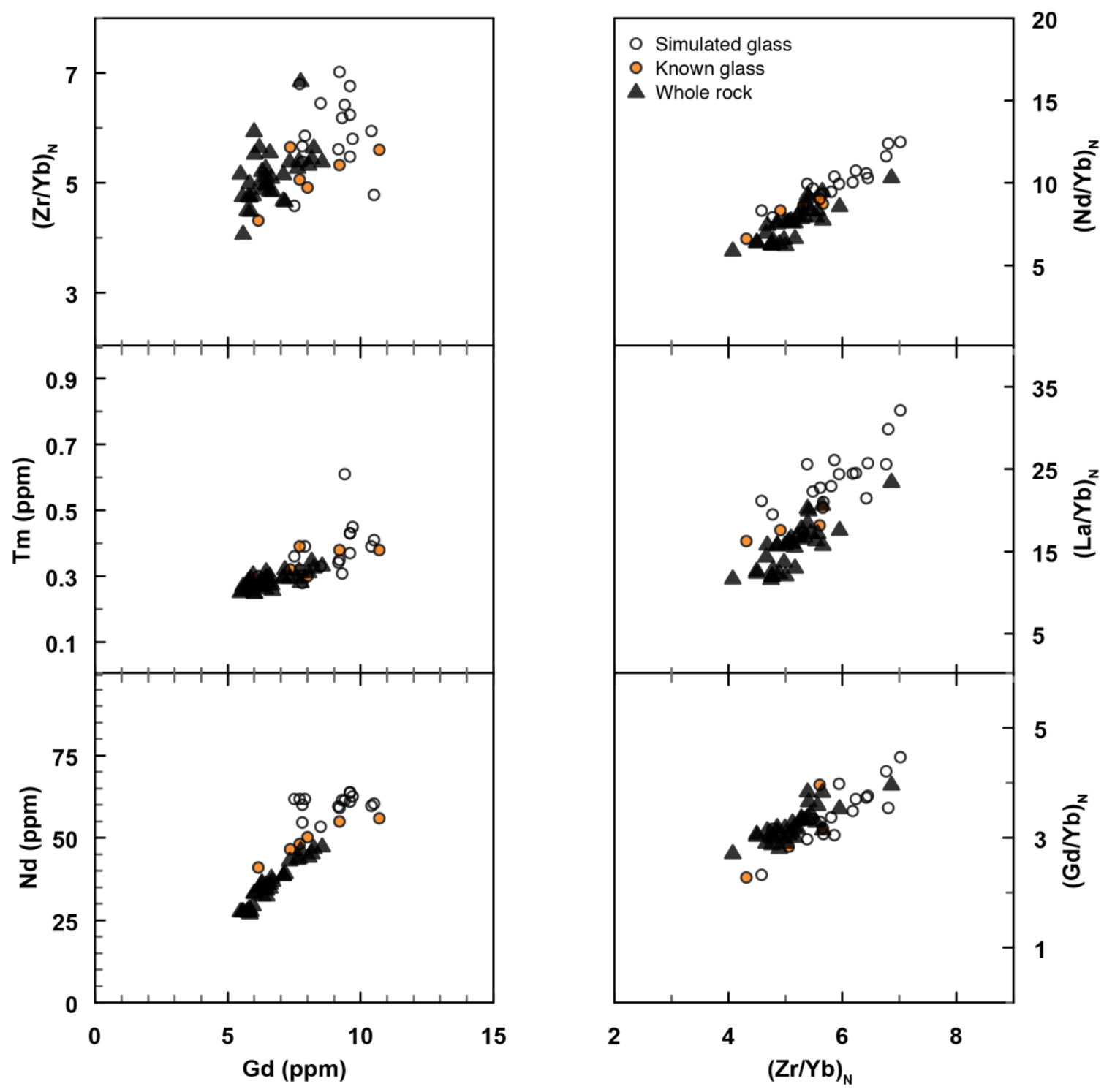

Figure 5.10. Selected trace element combinations for Mt. Wellington that are comparable for tephra-derived glass and interstitial glass, and are also comparable for whole rock vs. glass. Symbols as in Figure 5.9. 


\subsubsection{Geochemical variations in single eruptions}

Previous studies have shown a variation in the geochemistry throughout an eruption in samples from some of the AVF centres (e.g. Crater Hill; Smith et al., 2008, and Motukorea; McGee et al., 2012), primarily evolving in eruption style from phreatomagmatic to magmatic (Table 5.1.). These centres consistently show, for example, initially low $\mathrm{SiO}_{2}$ and $\mathrm{Mg} / \mathrm{Fe}$ ratios (Smith et al., 2008) and higher incompatible elements that evolve to final products with higher $\mathrm{SiO}_{2}, \mathrm{Mg} / \mathrm{Fe}$ ratios and lower incompatible elements (Fig. 5.11. and Fig. 5.12.). It was therefore considered important to test whether the geochemical signature of the widely dispersed tephra reflects only one specific part of the eruption sequence.

Figure 5.12 shows the geochemical progression throughout the eruption of Motukorea (data from McGee et al., 2012), compared with the correlated Motukorea tephra horizon found within the Orakei Basin Core for $\mathrm{SiO}_{2} \mathrm{vs.} \mathrm{Zr}$, and normalised (to primitive mantle values: McDonough and Sun, 1995) trace element ratios for $(\mathrm{Zr} / \mathrm{Yb})_{\mathrm{N}}$ vs. $(\mathrm{Gd} / \mathrm{Yb})_{\mathrm{N}}$ (similar relationships are also seen for $(\mathrm{La} / \mathrm{Yb})_{\mathrm{N}},(\mathrm{Ce} / \mathrm{Yb})_{\mathrm{N}}$, $(\mathrm{Nb} / \mathrm{Yb})_{\mathrm{N}}$, and $\left.(\mathrm{Nd} / \mathrm{Yb})_{\mathrm{N}}\right)$. The tephra-derived glass shards appear to show slightly higher $\mathrm{SiO}_{2}$ concentrations for the same $\mathrm{Zr}$ concentrations (as previously discussed due to fractional crystallisation) but show the signatures of the full evolutionary trend for the entire eruption. For the trace element ratios the glass shards appear to be geochemically comparable and again have signatures that are the same as all phases of the eruption including tuff, lava and scoria.

However, it is considered that for some of the eruptions where there are both explosive and effusive phases, distal tephra deposits may only preserve evidence for the explosive phases of the eruption. This is because the explosive phases are generally more violent, and produce more pyroclastic material, which is distributed further (discussed sect. 5.2.5.). For the AVF centres, most of the primary eruptive phases are explosive (Table 5.1.), and therefore, if all centres show a geochemical evolution throughout an eruption (e.g. Motukorea and Crater Hill), there is the potential for tephra deposits (from early phreatomagmatic phases) to have higher trace element ratios than their subsequent lava or scoria deposits (from later magmatic phases). This deposition bias may hinder the potential for some tephras to be matched to their source centre. 


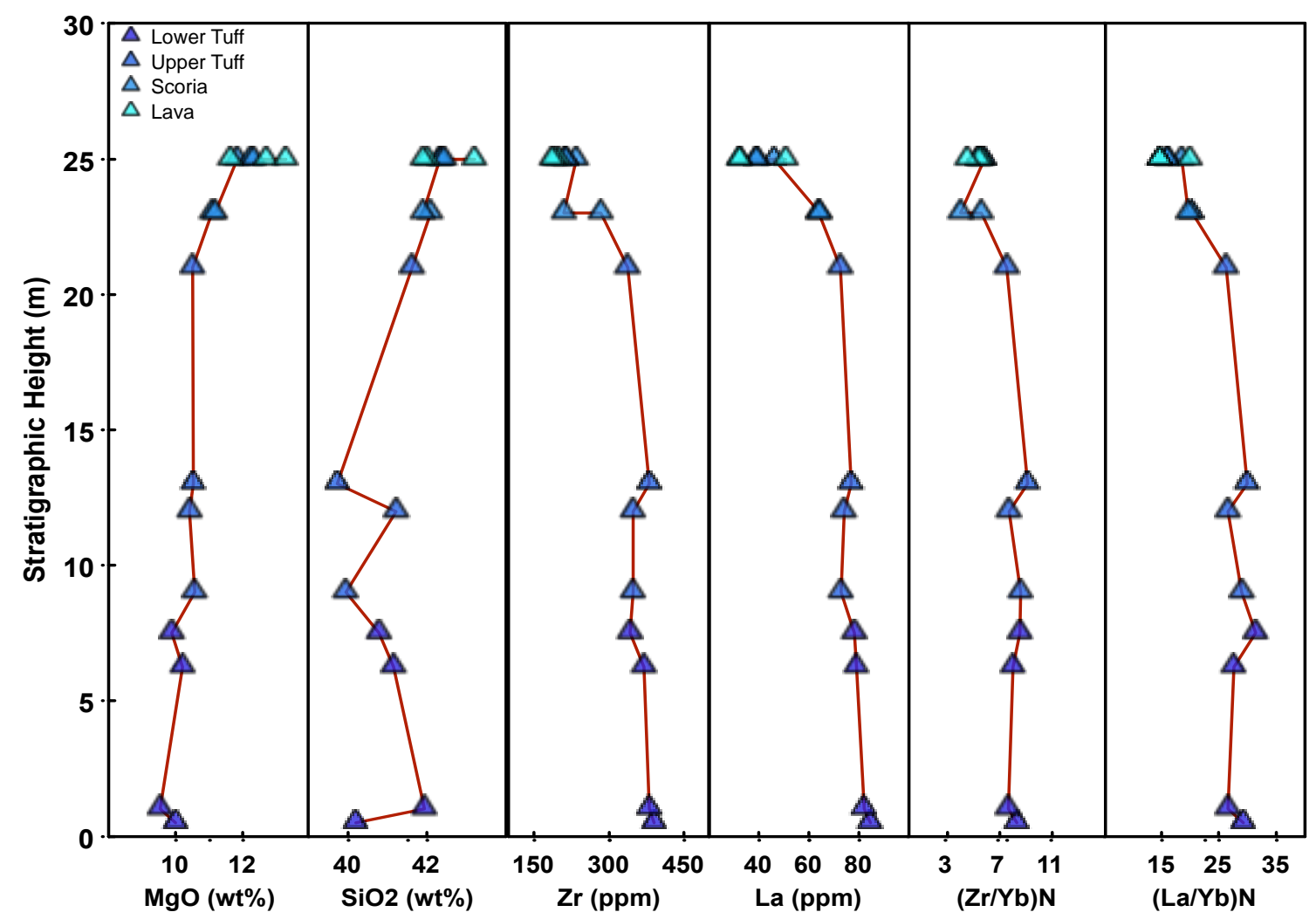

Figure 5.11. Variations seen in selected elements for the Motukorea eruption products. Data and figure adapted from McGee et al. (2012). 

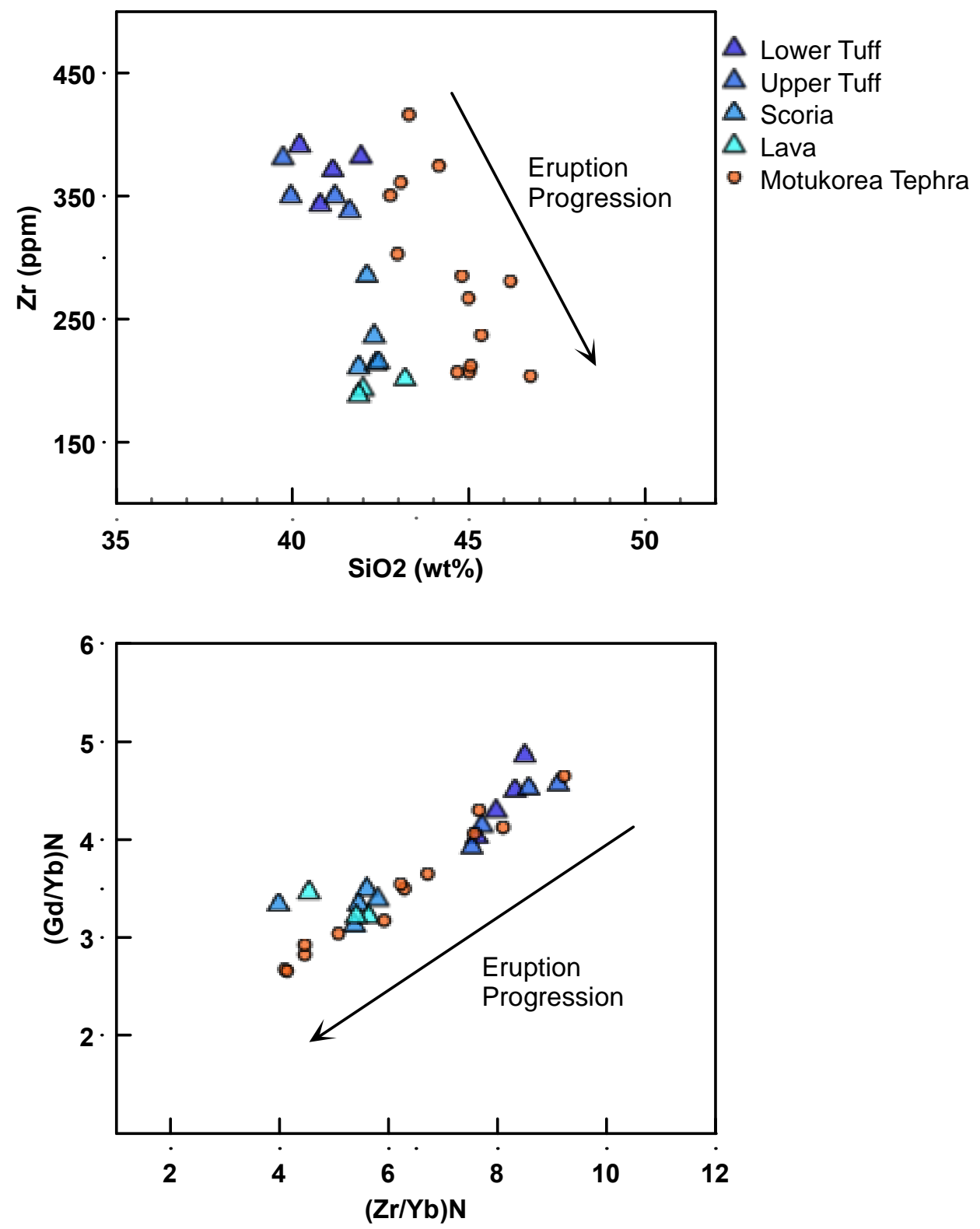

Figure 5.12. Graphs showing the geochemical variations and comparability of the geochemical signatures observed through the eruptive products of Motukorea volcano (from McGee et al., 2012), and the distal tephra erupted from this volcano found within the Orakei Basin core (data from Appendix C). 


\subsubsection{Limiting factors with geochemical correlation}

Although the ability to correlate tephra to whole rock has been confirmed, there are a number of limiting factors. In addition to the previously outlined complexity of geochemical variability in some centres (sect. 5.3.3.3.), the geochemical composition of most lava from individual AVF volcanic centres overlap. Thus there are not 53 individual signatures that can be used to directly correlate the geochemical composition of the distal tephra deposits and whole rock samples. In the instances where the geochemical composition alone cannot unambiguously fingerprint the centre, this is due to either the large number of centres with relatively similar geochemical compositions, and/or due to a general lack of geochemical data (either whole rock or tephra). It is therefore necessary to introduce other criteria to allow the most confident correlations to be made. These criteria were discussed in Section 5.2.5, and are outlined where appropriate in relation to each of the correlations discussed below.

\subsubsection{Tephra source correlations}

Chapter 3 outlines the methodology of cross core tephra correlations. It details twenty-nine tephra horizons, twelve of which are cross-correlated linking two or more deposits, and seventeen of which are single deposits found within one core. Below I discuss each horizon in turn, and detail the process by which the source centre has been assigned. For twenty-nine horizons the proposed source centres are given in Table 5.5 along with the alternatives that were considered. Each tephra to source correlation is given a confidence rating as discussed in Section 5.2.5, based on the criteria which are satisfied (cf. Figure 5.13). Of the twenty-nine horizons, eight have been given a correlation with confidence rating of 1 , twelve have been given a confidence rating of 2 , and seven have been given a confidence rating of 3 , with two horizons remaining uncorrelated. An example of the geochemical signatures for a level 1 confidence rated correlation is given in Figure 5.14, all other geochemical correlation plots can be found in Appendix E. 


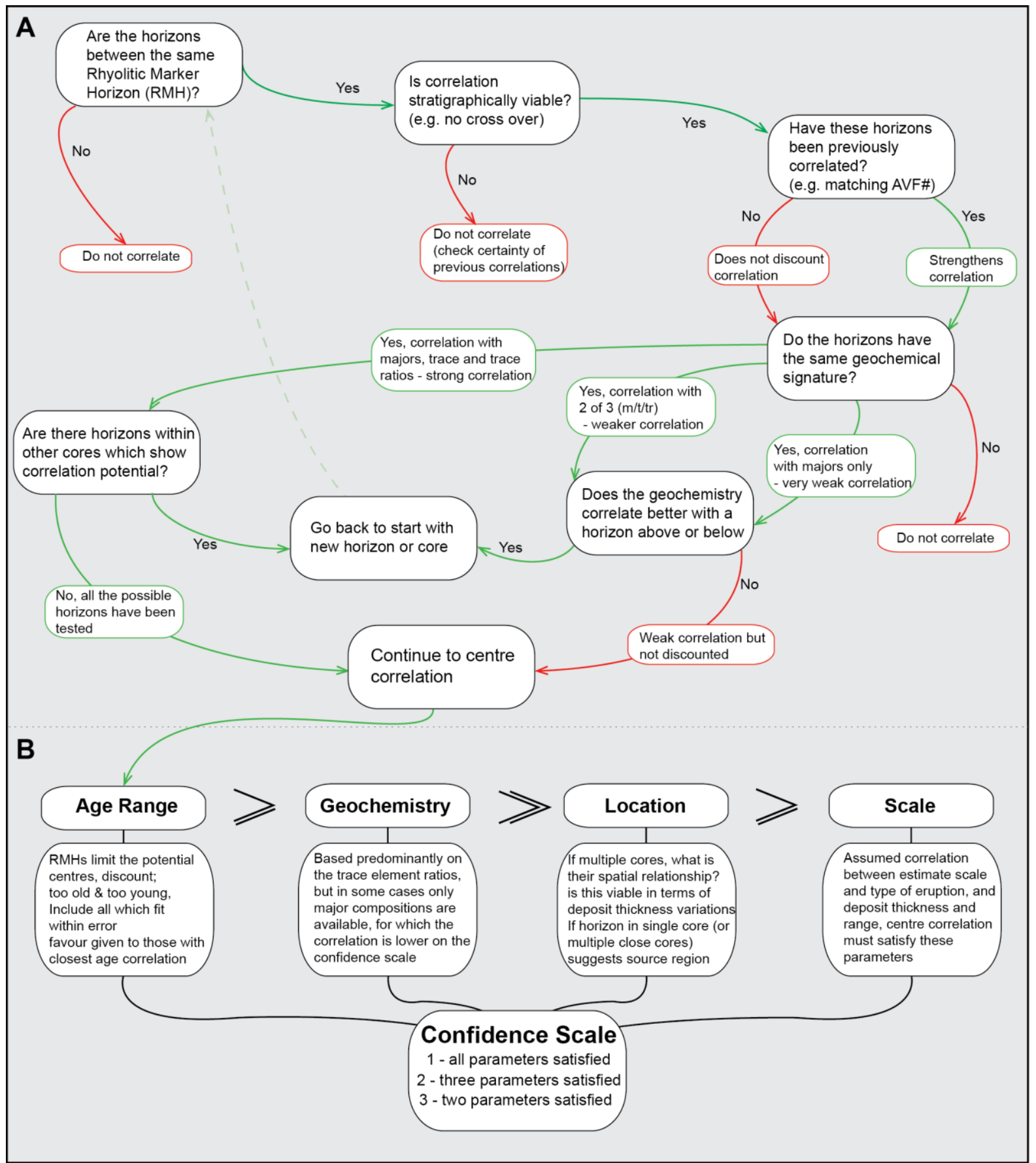

Figure 5.13. (A) Flow chart outlining the step-by-step process in determining the correlation of tephra horizons across cores (used for Chapter 3). It is important to note that major elements alone are not enough to accurately determine a horizon match or not, and in all cases a multi-parameter approach is used to obtain the result with highest confidence value, ' $m / t / t r$ ' - major/trace/trace ratio. (B) Steps in determining the source centre for the previously linked horizons and the confidence scale as a result of satisfying the outlined parameters. Highlighted is a hierarchy of importance for the parameters. 

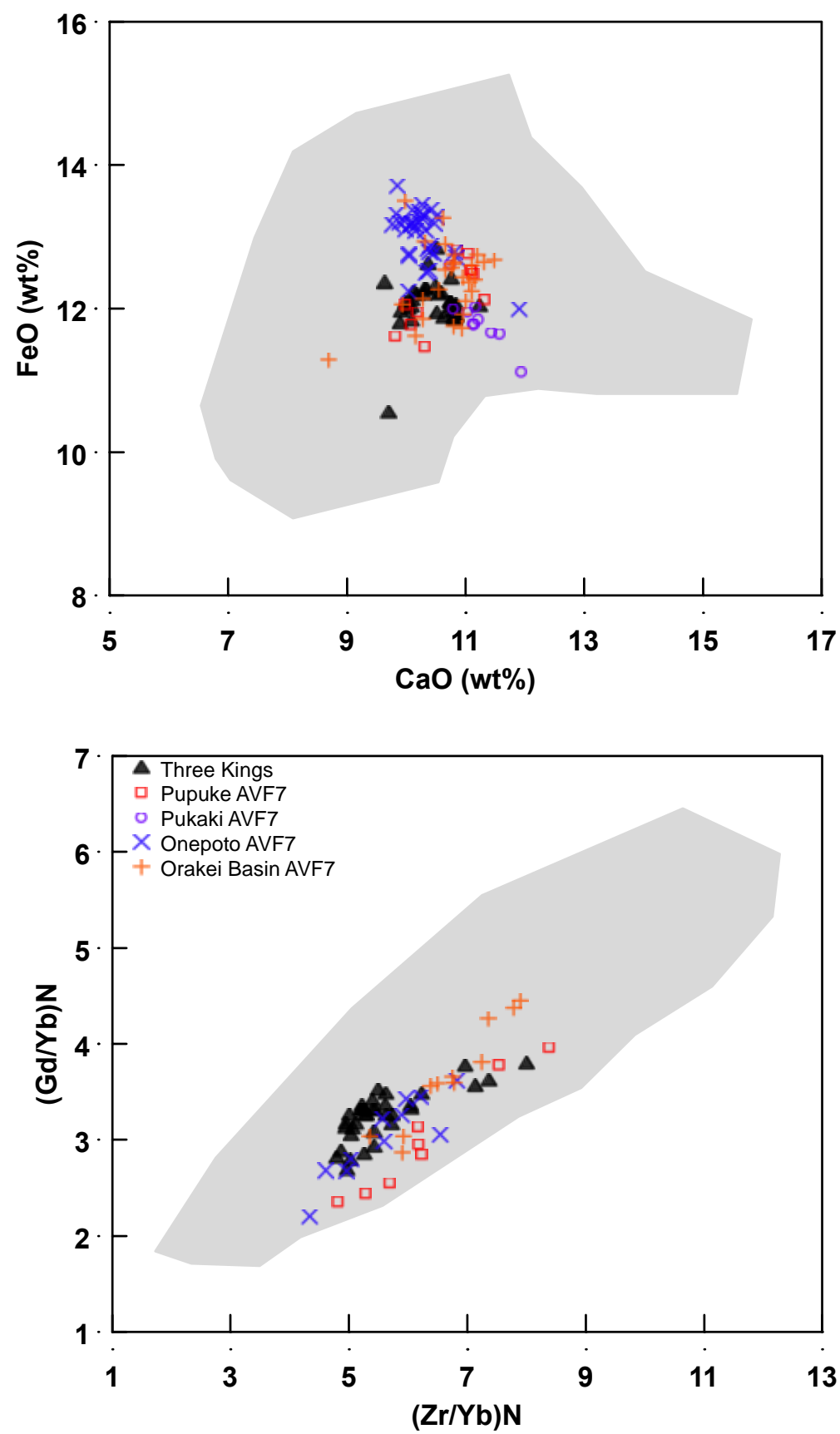

Figure 5.14. Example of a confidence level 1 correlation for the Three Kings centre with tephra layer AVF7, showing selected major element and normalised trace element ratios (all data is outlined in Appendix C). Tephra shown in coloured symbols indicating each core, whole rock shown by black triangles, while the grey field shows the spread for the entire AVF. Age constraints are also well matched, as are centre location, tephra dispersal area and eruption scale 
Previously assigned AVF numbers by Molloy et al. (2009) have been maintained to ensure a consistent tephra horizon nomenclature in the literature. However, if the geochemical composition of tephras in some deposits were inconsistent with previously proposed correlations (e.g., AVF9 and AVF10, Chapter 3) new correlations across cores were established. For more detail the reader is referred to Chapter 3, where the respective horizons were re-assigned AVF numbers based on the new data from this study (Table 3.2). In Chapter 3 horizon thickness is also discussed and re-evaluated in relation to primary vs. reworked horizons. For many of the thicker horizons new primary thicknesses are outlined (Table 3.2.), and these new values are used within this thesis chapter. The ages of tephra horizons were recalculated in this study and can be found in Table 5.3. Groundmass feldspar Ar-Ar ages from the AVF centres (quoted as ranges with a 2sd error) are adapted from Leonard et al. (in prep; Appendix D; for mean ages refer to Table 5.1). Eruptive scales used in this study are taken from Kereszturi et al. (2013) (discussion in Sect. 5.2.5. Table 5.1.), and relevant tephra-whole rock geochemical plots can be found in Appendix E.

Within each paragraph the AVF number of the horizon in discussion is in bold, and once the corresponding centre is assigned, its name is also bold. Each tephra horizon is assessed as an individual, and therefore all potential centres are discussed, even if they have been correlated to an alternative horizon (discussion in Sect. 5.2.5.). Correlations of tephra horizon to source centre are discussed below in order from youngest to oldest horizon:

AVF24 from the Pupuke core (samples P48 and P49, "separated by $15 \mathrm{~mm}$ of slumpy unlaminated sediments"; Molloy, 2008) and AVF23 (Hopua core) have previously been assigned centres with a high level of confidence due to their stratigraphy and major element geochemistry (Molloy et al., 2009; Needham et al., 2011; Shane and Zawalna-Geer, 2011). The addition of the trace element geochemistry from this study supports these correlations, with AVF24 (upper [P48] and basal [P49]; Molloy, 2008) assigned to Rangitoto 2 and 1 respectively and AVF23 to Mt. Wellington, all with confidence level 1. 
AVF22 is a fine (1mm thick) deposit at a depth of $47.72 \mathrm{~m}$ within the Pukaki core. The calculated age for this horizon is 15.4 cal. ka BP (Table 5.3.). Data from Sandiford et al. (2001) consists of one major element analysis and therefore correlation of this horizon based on geochemical composition is problematic. There is only one centre, however, which is appropriate in age, scale and location and that is Pukeiti, (DRE ${ }^{\text {tot }} 0.0037 \mathrm{~km}^{3}$ ) in the south of the field (ca. $5 \mathrm{~km}$ from Pukaki) with Ar-Ar age range of $3.2-18.0 \mathrm{ka}$. It is therefore given a confidence level 2 correlation, taking into account the sparse geochemical information.

AVF21 and $\mathbf{2 0}$ are both similar deposits. They display similar geochemical signatures, are both thick within the Hopua core (290 mm and $235 \mathrm{~mm}$, respectively) and much thinner within the Pukaki core $(3 \mathrm{~mm}$ and $2 \mathrm{~mm}$, respectively). The estimated ages for the horizons are $19.9 \mathrm{ka}$ and $20.6 \mathrm{ka}$, respectively (Table 5.3.). The deposit thicknesses and distributions point to source centres within close proximity of Hopua core in the central-south of the field. Tephras from both horizons have similar geochemical compositions, leading to difficulty in assigning specific source centres. Potential source options for these tephra horizons, that fit the age and location criteria, therefore include Pukeiti, Mt. Richmond, Mt. Smart, Panmure Basin, Mt. Robertson, and Waitomokia. Mt. Robertson can be excluded as the geochemistry does not match and the age is not constrained. Pukeiti could also be included as the geochemistry is relatively well correlated; however, its small eruptive volume and the distance (ca. $6.5 \mathrm{~km}$ ) from Hopua and Pukaki make Pukeiti an unlikely candidate. Waitomokia can also potentially be ruled out, because the centre is larger than Pukeiti, was predominantly a phreatomagmatic eruption, and therefore, the expected tephra deposit should be much thicker within the Pukaki core. This, together with a poorly constrained age, and lack of geochemical data makes it less likely than the alternatives. Panmure Basin, Mt. Richmond and Mt. Smart all have similar whole rock geochemical signatures (Appendix E) which match that of tephra horizons AVF20 and AVF21. Panmure Basin is, however, less likely due to its greater distance to the Hopua core than Mt. Smart and Mt. Richmond. In addition the Panmure Basin centre is located closer to the Orakei Basin core which shows no evidence of a $\sim 20$ ka old tephra deposit. Mt. Smart and Mt. Richmond are therefore the most likely source centres for AVF21 and AVF20. The Ar-Ar ages of 11.9-20.3 ka (Mt Smart) and 21.1-30.7 ka (Mt Richmond) suggest that Mt. Smart is slightly 
younger than Mt. Richmond and thus AVF21 is assigned to Mt. Smart and AVF20 to Mt. Richmond. However due to the ambiguity in age and inconclusive geochemistry, these correlations are given a confidence rating of 3 .

AVF 19 is only found as a very thin deposit $(1 \mathrm{~mm})$ within the Pukaki core with only one published major element point (Sandiford et al., 2001), precluding any conclusive correlation based on geochemistry. Potential source centres however need to satisfy the following criteria, a small-medium size eruption in the south of the field (as no deposits of this age span are present in any other cores), most likely less than $10 \mathrm{~km}$ away from Pukaki, with an age of 24.2 cal. ka BP (Table 5.3.). Centres with these characteristics include Green Mt. (12.7-25.5 ka), Hampton Park (11.065.0 ka), Otara (5.5-70.5 ka), Otuataua (no Ar-Ar age) and Wiri Mt. (22.0-38.0 ka). Of these, Green Mt., Hampton Park and Otara are the furthest away, all $>8 \mathrm{~km}$ from Pukaki and are therefore considered as less likely eruption source. Wiri Mt. and Otuataua are both just over $5 \mathrm{~km}$ for Pukaki, and have DRE ${ }^{\text {tot }}$ volumes of $0.016 \mathrm{~km}^{3}$ and $0.006 \mathrm{~km}^{3}$ respectively. Therefore, due to the thinness of the deposit in the Pukaki core and its limited dispersal, a small eruption from Otuataua is considered as a more likely source than Wiri Mt. Due to the lack of geochemical data and age constraints on Otuataua centre the correlation is given a confidence rating of 3 .

AVF 19 is separated from AVF 18 within the Pukaki core by an andesitic deposit (Eg36) from the Taranaki Volcanic Centre (Molloy et al., 2009), which therefore acts as a secondary constraint on the cross core correlation for the AVF18 deposit. AVF 18 occurs as an $8 \mathrm{~mm}$ deposit in the Orakei Basin core, a $40 \mathrm{~mm}$ deposit in the Hopua core, and a $0.5 \mathrm{~mm}$ deposit in the Pukaki core. This dispersal is indicative of a medium sized eruption from the central-southern part of the field, which must have occurred between 23.2 and 25.3 cal. ka BP (cf. Table 5.3.). Centres that satisfy these criteria include Mt. Richmond (AVF20), Otuataua (AVF19), Panmure Basin, Puketutu (slightly too old), and Waitomokia (undated). Panmure Basin and Otuataua are ruled out, as the geochemistry does not correlate (Appendix E). In comparison, Waitomokia, Puketutu, and Mt. Richmond all show good geochemical correlation (although there are minimal data for Mt. Richmond; Appendix E). The localities and scales of eruption for Puketutu ( $5 \mathrm{~km}$ to Hopua, and large $\mathrm{DRE}^{\mathrm{tot}}=0.018 \mathrm{~km}^{3}$ ) and Mt. Richmond ( $5 \mathrm{~km}$ to Hopua and $\mathrm{DRE}^{\mathrm{tot}}=0.0057 \mathrm{~km}^{3}$ ) 
reduce their likelihood to be the source centre for AVF 18. Waitomokia is undated by Ar-Ar techniques, however, morphostratigraphy makes it older than Pukeiti and the other factors all correlate well. Therefore Waitomokia is given a correlation confidence level of 2 for horizon AVF18.

AVF17 is only found in Orakei Basin core with a thickness of $5 \mathrm{~mm}$ at a depth of $44.65 \mathrm{~m}$. Based on sedimentation rates an age of $23.4 \mathrm{cal}$. ka BP was calculated for this horizon (see discussion in section. 5.2, and Table 5.3.). Potential sources therefore are most likely to be a small-medium sized eruption from within $<10 \mathrm{~km}$ of Orakei Basin. As AVF17 was not identified in the Pupuke and Onepoto cores, the source eruption is more likely to be in the north or north-east of the field. Possible eruption sources therefore include Little Rangitoto, Motukorea, Mt. Cambria, Mt. Richmond (AVF20), Panmure Basin, Pigeon Mt., and Taylors Hill. Because geochemical composition of samples from Mt. Cambria, Mt. Richmond, Panmure Basin, and Taylors Hill are different to the AVF17 tephra these centres are initially discounted (Appendix E). Due to its very close proximity to Orakei Basin, an eruption from Little Rangitoto would have formed a thicker deposit with much larger shard sizes. Pigeon Mt. and Motukorea are both ca. $8 \mathrm{~km}$ from Orakei, and Motukorea is slightly larger (DRE ${ }^{\text {tot }} 0.0046 \mathrm{~km}^{3}$ ) than Pigeon Mt. (DRE ${ }^{\text {tot }} 0.0033 \mathrm{~km}^{3}$ ). Both have similar geochemical compositions (although Pigeon Mt. has less data) and Motukorea is dated (although with large error) to 3.3-25.3 ka (Ar-Ar, Leonard et al., in prep, Appendix D). Although difficult to split with similar geochemistry, based on the scale of the eruption coupled with the deposit thickness, AVF17 is assigned to Pigeon Mt. with a confidence level 3.

AVF 16 is a relatively thick deposit $(50 \mathrm{~mm})$ only identified within the Pukaki core at a depth of $51.52 \mathrm{~m}$, suggesting a source in the south of the field. It is located just slightly above the Kawakawa/Oruanui (Kk) rhyolitic marker horizon, and therefore has an age estimate of 25.3 cal. ka BP (Table 5.3.). There is limited geochemical data for this deposit (2 major element analyses) and therefore geochemical constraints are limited, and correlations are therefore based primarily on alternative criteria. Potential source centres that satisfy the age and locality criteria include Puketutu (29.8-37.4 ka), Otuataua (AVF19, undated), Crater Hill (26.7-37.5 ka), Kohuora (30.0-32.0 ka), Wiri Mt. (25.7-34.5 ka), Ash Hill (31.6-32.0 
ka), Mt. Robertson (undated), or Mt. Richmond (AVF20, 18.4-29.2 ka). Crater Hill is immediately eliminated as the Kawakawa/Oruanui $\mathrm{RMH}$ has been identified overlying the centre in the field (Hayward et al., 2011). Because Kohuora represents a relatively large eruption (DRE $\left.{ }^{\text {tot }} 0.0076 \mathrm{~km}^{3}\right)$ and is located nearby $(<3 \mathrm{~km})$, this centre is likely to have produced a much thicker tephra deposit (also true for Crater Hill) and is therefore also discounted as the source. Ash Hill (no geochemical data) is also discounted, as the eruption was very small (DRE tot $0.000076 \mathrm{~km}^{3}$ ) and the centre is located ca. $6 \mathrm{~km}$ away, to the south-east of Pukaki, making it very unlikely to be the source. This leaves Puketutu, Otuataua, Wiri Mt., and Mt. Richmond: all of these are appropriately located, and only Puketutu is slightly too old. The larger volumes of Wiri Mt. (DRE tot $0.016 \mathrm{~km}^{3}$ ), Otuataua (DRE ${ }^{\text {tot }} 0.006 \mathrm{~km}^{3}$ ), and Mt. Richmond (DRE ${ }^{\text {tot }} 0.0057 \mathrm{~km}^{3}$ ), all of which are located $5-6 \mathrm{~km}$ away, make them an unlikely source to produce a $50 \mathrm{~mm}$ deposit in Pukaki. However the geochemistry for Wiri Mt. matches well with geochemistry of the tephra deposit (unlike for Otuataua and Mt. Richmond) (Appendix E). The geochemical composition of Puketutu samples is similar to the geochemical composition of the deposit and the centre is slightly larger (DRE ${ }^{\text {tot }} 0.017 \mathrm{~km}^{3}$ ) than Wiri Mt. In addition Puketutu is located $\sim 6 \mathrm{~km}$ to the west of Pukaki, which is a more favourable position based on the predominant south-westerly winds. Although the Ar-Ar age for Puketutu is slightly older than the stratigraphic position of the deposit, AVF 16 is correlated to Puketutu with a confidence level 2.

AVF15 is only found within Orakei Basin with a thickness of $12 \mathrm{~mm}$ at a depth of $47.715 \mathrm{~m}$. This deposit has an age estimate of $24.5 \mathrm{cal}$. ka BP (Table 5.3.). Many centres are an appropriate source within this age range, but the occurrence of this thin deposit only in the Orakei Basin core is indicative of an origin in the north or central-north of the field from a relatively small eruption. This narrows the potential source centres down to Motukorea (3.3-25.3 ka), Mt. Cambria (23.9-65.1 ka), or Pigeon Mt. (undated). The geochemistry of this deposit is similar to both Motukorea and Pigeon Mt., but not to Mt. Cambria, and therefore could be assigned to either Motokurea or Pigeon Mt. Motukorea was a slightly larger eruption (DRE ${ }^{\text {tot }} 0.0046$ $\mathrm{km}^{3}$ ) located ca. $8.5 \mathrm{~km}$ away, in comparison to Pigeon Mt. which was a slightly smaller eruption (DRE ${ }^{\text {tot }} 0.0033 \mathrm{~km}^{3}$ ) but located a similar distance away. Therefore 
based on the deposit thickness, AVF15 is assigned to Motukorea. A confidence level of 2 is given although the age remains poorly constrained.

At depth of ca. 50-48 m the Orakei Basin core becomes extremely complex containing multiple deposits and a number of reworked sections. Details of this complex core sequence are given in Chapter 3 (and Appendix A). In Chapter 3 I confirmed AVF13 (50.089-49.554 m, including ca. $70 \mathrm{~cm}$ of reworking, Chapter 3) and below I correlate this deposit to its source centre. I also:

(1) define a new horizon 'newA' which is represented by three layers at 49.14 $\mathrm{m}, 49.33 \mathrm{~m}$ and $49.46 \mathrm{~m}$;

(2) discredit original AVF14 (cf. Molloy, 2008) as representing the reworking of the two underlying units (AVF13 and newA), and redefine to a continuous deposit with samples taken at $48.128 \mathrm{~m}$ and $48.120 \mathrm{~m}$;

(3) define a new horizon 'newB' which is represented by two layers at $48.19 \mathrm{~m}$ and $48.27 \mathrm{~m}$.

Due to the limited age range for these new deposits (ca. 24.6-25.3 ka; sedimentation rates from this study, Table 5.3.), they all have a similar range of possibilities for centre correlations. These include (with $\mathrm{Ar}-\mathrm{Ar}$ age ranges reported), Little Rangitoto (15.9-24.7 ka), Motukorea (AVF15, 3.3-25.3 ka), Mt. Cambria (23.965.1 ka), Panmure Basin (15.6-33.6 ka), Taylors Hill (23.8-29.8 ka), and McLennan Hills $(23.9-65.1 \mathrm{ka})$. For horizons newA and newB the geochemistry does not correlate specifically well to any of these centres in particular and is therefore not a discerning feature. As a result these horizons cannot be confidently correlated and therefore are left as unknowns. 
AVF14, although only a thin deposit only found in the Orakei Basin core, has very large shard sizes $(>150 \mu \mathrm{m})$, suggesting the source is in close proximity to Orakei, but a small-scale eruption. The calculated age of this deposit is $24.6 \mathrm{cal}$. ka BP (Table 5.3.). The geochemical composition of this deposit matches the geochemical composition of Little Rangitoto (Appendix E), and therefore this correlation is given a confidence rating of 1 , because all parameters (geochemistry, age, scale, location) are satisfied.

AVF13 is only found within the Orakei Core at a depth of $50.089 \mathrm{~m}$ (although reworked up to $49.554 \mathrm{~m}$ ) with a primary deposit thickness of ca. $160 \mathrm{~mm}$ (Chapter 3), and an estimated age of $25.3 \mathrm{cal}$. ka BP (Table 5.3.). Due to the thickness of the deposits in Orakei, the source centre is proposed to be a relatively large eruption from nearto Orakei. Potential options which satisfy age, locality and scale for this include; Mt. Eden, Little Rangitoto (AVF14), Panmure Basin, Mt. Richmond (AVF20), and Taylors Hill. Of these centres only Panmure Basin has a matching geochemical composition (Appendix E) and because the correlation satisfies all the criteria, this is given a confidence rating of 1 .

AVF12 is found in all analysed AVF cores of appropriate age (Pupuke, Onepoto, Orakei, Hopua, and Pukaki), the scale, distribution, and thickness of the tephra deposits suggest a very large eruption in the centre of the field just prior to the Kawakawa/Oruanui. The horizon has an estimated average age of 27.2 cal. ka BP, but a range throughout the cores of 26.3-28.3 ca. ka BP (Table 5.3.). The only centre that satisfies these criteria is Mt Eden, however the geochemical signature of horizon AVF12 is complex, and highly variable (Appendix E). The top two subsections of tephra within the Hopua core show very different geochemical composition to the basal section. This could be indicative of a separate eruption occurring at the same time with a different geochemical signature. There is, however, no mixing of shard signatures within the deposit (which would be expected from coeval deposition from two separate eruptions), or break in the deposition of the horizon. The horizon could therefore be interpreted in two ways, 1) to represent one continuous eruption, with the tephra showing a geochemical evolution from more- to less REE-rich, or 2) to represent two immediately successive eruptions, with products from the first eruption having higher REE contents and the second having 
lower REE contents. Of note is that the centre Te Pou Hawaiki, is morphostratigraphically constrained to just older than Mt Eden, it is therefore conceivable that these two eruptions were successive, and would have produced tephra deposits without a hiatus. However, the geochemical signatures of Mt Eden and Te Pou Hawaiiki are indistinguishable, both of which correlate to the upper horizon in the Hopua core. As this geochemical complexity is unresolvable, AVF12 is assigned here to Mt Eden with a confidence level 1, with Te Pou Hawaiki remaining slightly older in age. AVF12 also marks the base of the Hopua core, thus providing a minimum age constraint on the eruption of this centre.

AVF11 is a relatively thin unit (ca. $<10 \mathrm{~mm}$; $P$. Shane pers. comms, 2014), only found within the Pukaki core at a depth of ca. $55.35 \mathrm{~m}$ and with an estimated age of 29.3 cal. ka BP (Table 5.3.). The thickness and restricted dispersal of this layer indicates a relatively small eruption source in the south of the field, most likely within 5-10 km of Pukaki. Centres that satisfy these criteria include, Kohuora, Otuataua (AVF19), Mt. Robertson, Puketutu (AVF16,) and Wiri Mt. Although Otuataua and Mt. Robertson are appropriate in locality and scale, samples from these centres have somewhat different geochemical compositions to the AVF11 tephras and their ages are unknown. Kohuora has no geochemical data but is of similar age, although its scale and locality should have formed a much thicker deposit (>100 mm) in the Pukaki core. Puketutu has similar (major element) geochemistry to the horizon and is of similar age and well located as source centre. However, Puketutu has been assigned as source centre for AVF16. Wiri Mt. also satisfies all the criteria, including matching major element composition, but is given a confidence level of 2 as a source centre because only major element data are available and the difficulty in resolving the correlation between Wiri Mt. and Puketutu.

Within the Pupuke core Molloy (2008) recorded deposits labelled as AVF10, AVF9 and AVF8, with each one classified as an individual eruption. Shard sizes within AVF9 and AVF8 were too small $(<25 \mu \mathrm{m})$ for trace element analysis for this study. However, AVF10 included large shards $(>100 \mu \mathrm{m})$ which have a similar size and chemistry to shards found in a horizon at $39.47 \mathrm{~m}$ within the Onepoto core. Although previously unclassified in the Onepoto core, this horizon is geochemically, stratigraphically and locationally appropriate to be correlated with AVF10 within the 
Pupuke core. Thicknesses within the cores for Onepoto and Pupuke are $15 \mathrm{~mm}$ and $3 \mathrm{~mm}$ respectively, with both deposits containing large $(>100 \mu \mathrm{m})$ shards. Horizon AVF 9 was previously correlated with deposits in Orakei Basin $(407 \mathrm{~mm}$ thick, Chapter 3) and Pupuke (6 mm thick). The major elements AVF9 and AVF10 are indistinguishable and because no trace element chemistry has been analysed for AVF 9, the cross core correlation remains ambiguous. However, based on the scale of the deposits and the shard sizes the deposit within the Orakei core it is more appropriately correlated to AVF10 (Onepoto and Pupuke). Therefore, I here consider the AVF10 horizon to consist of deposits in Orakei Basin (depth of $54.213 \mathrm{~m}$ ), Onepoto $(39.47 \mathrm{~m})$ and the original AVF10 deposit from Pupuke at $68.09 \mathrm{~m}$ depth, and AVF9 remains as a single horizon found within in Pupuke core.

The thickness of AVF10 in the Orakei core, and the presence of large shards of this deposit in the Onepoto and Pupuke cores require a source centre near Orakei with an age of ca. $29.9 \mathrm{cal}$. ka BP (Table 5.3.). Based on its proximity to Orakei and scale of eruption (DRE ${ }^{\text {tot }} 0.0067 \mathrm{~km}^{3}$ ) Mt. Hobson was initially considered. However, the Ar-Ar age is 44.9-66.9 ka (Leonard et al., in prep, Appendix D), and morphostratigraphically it has to be older than Three Kings eruption (due to Three Kings tephra found mantling Mt Hobson; Hayward et al., 2011). In addition the geochemical composition of this horizon does not match with those from Mt Hobson ruling out this possibility. Little Rangitoto (AVF14) is too young (Ar-Ar age range of 15.9 - $24.7 \mathrm{ka}$ ) and the geochemistry is poorly correlated. The remaining possible source centres that are relatively close and in the correct age range are Taylors Hill (23.8-29.8 ka) and Panmure Basin (AVF13, >17.5 ka). Panmure Basin was a slightly larger eruption (DRE ${ }^{\text {tot }} 0.0074 \mathrm{~km}^{3}$ ) than Taylors Hill (DRE ${ }^{\text {tot }} 0.0051 \mathrm{~km}^{3}$; Kereszturi et al., 2013), with Panmure Basin ca. 14-16 km away from Pupuke and Onepoto, in comparison to Taylors Hill, which is ca. $12-13 \mathrm{~km}$ away. The geochemistry correlates better for Taylors Hill than Panmure Basin (Appendix E), and therefore all criteria considered, AVF 10 is correlated to Taylors Hill with a confidence level of 2.

AVF9 consists of a $6 \mathrm{~mm}$ deposit in the Pupuke core at $68.15 \mathrm{~m}$, with a sedimentation rate age estimate of $30.2 \mathrm{cal}$. ka BP (Table 5.3.). Due to the thickness of the deposit and its absence in other cores and thus limited dispersal the source is likely in the north of the field (close to Pupuke). The only eruption that fits these 
criteria and age is Mt. Cambria (Ar-Ar age range of 23.9-65.1 ka, Leonard et al., in prep, Appendix D), however, the geochemistry (majors only) does not correlate (Appendix E). If the potential source area is widened (to the middle of the field), McLennan Hills (Ar-Ar age range 29.3-38.9 ka) is the only other centre with a similar age, however the geochemistry also does not correlate. With a $\mathrm{DRE}^{\text {tot }}=0.022 \mathrm{~km}^{3}$ and the location of the McLennan Hills $18 \mathrm{~km}$ to the south-east this centre is a less likely match than Mt. Cambria. Another potential alternative source centre is the $\sim 10$ ka older centre Hopua (44.4-56.4 ka; Leonard et al., in prep, Appendix D). The Hopua maar core, contains the Kawakawa/Oruanui rhyolitic tephra (at ca. $48 \mathrm{~m}$ ), followed by AVF12 (Molloy et al., 2009), followed by thick scoria, assumed to represent the maar floor of Hopua (Leonard pers. comms, 2015). If Kawakawa/Oruanui has an age of $25.4 \mathrm{ka}$, and AVF 12 has an estimated age of 27.2 $\mathrm{ka}$, the deposit relating to the Hopua eruption has a similar age to AVF9 and does not seem impossible as the source centre. However Hopua is one of the smallest AVF centres $\left(0.00086 \mathrm{~km}^{3}\right)$ located $17 \mathrm{~km}$ away from Pupuke. In addition the geochemical composition of AVF9 tephra is similar to the geochemical composition of Hopua samples although only based on a single set of major element whole rock data from Hopua. Although it is surprising that no deposit is found in Orakei Basin linked with this eruption, this deposit tentatively assigned to Hopua, but with a confidence level of 3 due to the insufficient geochemical evidence and the poor age constraint.

AVF 8 is correlated across the Pukaki, Orakei Basin and Pupuke cores (Chapter 3), with thicknesses of 720, 45 and $20 \mathrm{~mm}$, respectively, and an average age of 31.3 cal. ka BP (Table 5.3.). The thick deposit in the Pukaki core, its widespread dispersal and thinning to the north suggests a large eruption in the (central) south of the field, taking into account potential impacts from wind. The shard sizes within the Pupuke deposit are not large enough to analyse for trace elements and therefore both cross-core correlation and centre correlation are of lower confidence levels. To produce such a thick deposit in Pukaki the source centre is considered to be very close in proximity, such as Kohuora and Crater Hill. Both centres have similar Ar-Ar ages to the AVF8 tephra horizon (22.0-42.0 ka for Crater Hill and 28.0-36.0 ka for Kohuora). There are no whole rock data available for Kohuora, and only limited major element data from the Pukaki core, therefore only 
limited conclusions can be drawn based on geochemistry. In addition, Kohuora represents a small volume eruption $\left(\mathrm{DRE}^{\text {tot }} 0.0076 \mathrm{~km}^{3}\right.$ ), whereas Crater Hill, with DRE $^{\text {tot }} 0.024 \mathrm{~km}^{3}$ is one of the larger eruptions in the field (Kereszturi et al., 2013). In addition morphostratigraphy shows Kohuora to be older than Crater Hill. Therefore, based primarily on the thickness of the deposit in the maar and the morphological constraints, AVF8 is correlated to Crater Hill with a confidence of only 2 due to the minimal geochemical data from the Pukaki core tephra deposit.

AVF7 is a field-wide dispersed tephra found in Orakei Basin (20 mm), Pupuke (2 mm), Onepoto (12 mm), and Pukaki ( $\leq 10 \mathrm{~mm}$; P. Shane pers. comms, 2014). Rather than concentrated in one core (like AVF8) the thickness of AVF7 is more homogeneous across the field, suggesting a potentially large eruption within the central field (e.g. not specifically close to any of the depocentres). One option is the centre Three Kings, which is located in the central part of the field, and represents one of the largest eruptions in the AVF $\left(D R E^{\text {tot }}=0.069 \mathrm{~km}^{3}\right)$. There is a slight discrepancy with the ages; AVF7 has a modelled age of 32.5 cal. ka BP (Table 5.3.), however, the ${ }^{14} \mathrm{C}$ age measured for Three Kings centre is $28.6 \pm 0.4 \mathrm{ka}$ cal. yrs. BP (Lindsay et al., 2011). In addition the geochemical signatures of the Three Kings whole rock and the tephra horizons are very similar (Fig. 5.14) and so, this horizon is correlated with a level 1 confidence to Three Kings volcano.

AVF6 is found only in the Pukaki core at a depth of ca. $57 \mathrm{~m}$. There is only major element data available for this horizon, thereby precluding any conclusive correlation based on geochemistry. The deposit is $500 \mathrm{~mm}$ thick and is given a modelled age of $33.7 \mathrm{cal}$. ka BP (Table 5.3.). The source centre is therefore most likely to be in the south of the field very close to Pukaki. Crater Hill (AVF8), Kohuora, Puketutu (AVF16), Mt. Robertson, and Wiri Mt. (AVF11) all satisfy these criteria. For Wiri Mt. and Mt. Robertson, although only major elements are compared, the geochemistry does not show a convincing correlation (Appendix E). Crater Hill and Puketutu both show well-correlated geochemistry (Appendix E) and are within the correct age range, but both these centres have quite large eruptive scales (DRE ${ }^{\text {tot }}$ $0.024 \mathrm{~km}^{3}$ and $0.018 \mathrm{~km}^{3}$ respectively, Kereszturi et al., 2013) and would therefore be assumed to produce distal tephra units. Kohuora eruption however is proposed to only have total DRE $0.0076 \mathrm{~km}^{3}$ and is within $<3 \mathrm{~km}$ of Pukaki centre. Ar-Ar dating 
for Kohuora yields an age estimate of 28.0-36.0 ka (Leonard et al., in prep, Appendix D), which is supported by morphostratigraphy (Kohuora is older than Crater Hill), and previous ${ }^{14} \mathrm{C}$ dating for a Kohuora core putting it at ca. $33 \mathrm{ka}$ (c.f. Newnham et al., 2007). Therefore, although there is no whole rock geochemical data for Kohuora to allow full confirmation the other criteria are all satisfied and the correlation is given a confidence rating level 2 .

AVF5 is a thick $(110 \mathrm{~mm})$ homogeneous deposit found only in the Orakei Basin core at a depth of ca. $57.44 \mathrm{~m}$, with coarse shard sizes and abundant detritus included in the bulk sample. The source must therefore be relatively close to Orakei Basin in the north of the field. Sedimentation rates imply an age of 35.0 cal. ka BP for the horizon (Table 5.3.). Only Mt. Cambria (AVF9) has the appropriate age, however due to the thickness of the deposit and shard size, Mt Cambria is unlikely to be the source. It is one of the smallest centres in the field (DRE ${ }^{\text {tot }} 0.00029 \mathrm{~km}^{3}$ ) and is located ca. $5 \mathrm{~km}$ away therefore it is highly improbable that this would have produced a $110 \mathrm{~mm}$ thick tephra deposit within Orakei Basin. Many other centres have appropriate locations but are older than $35 \mathrm{ka}$ (Ar-Ar ages from Leonard et al., in prep, Appendix D): Mt. Hobson (44.9-66.9 ka), Mt. St John (71.1-77.5 ka), Mt. Victoria (46.1-62.9 ka), and North Head (70.8-101.2 ka), and conversely Little Rangitoto (AVF14) (15.9-24.7 ka), Taylors Hill (AVF10) (23.8-29.8 ka), and Panmure Basin (AVF13) (15.6-33.6 ka) are younger than required. Of these centres only Mt. Victoria and Mt. Hobson have a similar (but indiscriminate) geochemical signature to the tephras within the AVF5 horizon (Appendix E). Mt. Victoria has a DRE ${ }^{\text {tot }}=0.0048$ $\mathrm{km}^{3}$ and is located ca. $4.7 \mathrm{~km}$ to the northwest of Orakei. In comparison Mt. Hobson has a $D_{R E}^{\text {tot }}=0.0067 \mathrm{~km}^{3}$ and is ca. $2.5 \mathrm{~km}$ down wind to the south west of Orakei basin. Based on this, Mt. Hobson is more likely than Mt. Victoria to have produced a thick deposit with large shard sizes. The Ar-Ar age for Mt. Hobson (44.9-66.9 ka) is older than the modelled horizon age (35.0 cal. ka BP), however, the only morphostratigraphic constraint is that Mt. Hobson is older than Three Kings (which this correlation does satisfy). As this correlation is predominantly based on the locality and scale of eruption, coupled with locality and scale of the deposit, with inconclusive geochemistry and age, it is given a confidence rating of 3 . 
AVF4 is found cross-correlated (Chapter 3) within Orakei Basin and Pupuke cores with thicknesses of $41 \mathrm{~mm}$ and $15 \mathrm{~mm}$, respectively, and has an average estimated age of $35.2 \mathrm{cal}$. ka BP (Table 5.3.). The deposit in the Orakei Basin core is relatively coarse with small-medium lapilli coupled with medium-fine ash, and medium to fine ash within the Pupuke core. Due to the dispersal of the tephra and the coarseness of the deposit at Orakei Basin, this deposit must have been sourced proximal to Orakei, from an eruption large enough in scale to deposit tephra within the Pupuke core as well. As previously discussed for AVF5 only Mt. Cambria (AVF9) (23.9-65.1 ka) is appropriate in location and age (however, with a large error). However, the scale of the eruption, in relation to the dispersal and grain size of the deposit makes this correlation unlikely. The tephra horizons have a large scatter in major element data and only the Orakei Basin tephra deposit has associated trace element data. Some centres have appropriate locations but not necessarily the correct age, including, Mt. Victoria, North Head, Mt. Hobson (AVF5), Mt. St John, Little Rangitoto (AVF14) and Taylors Hill (AVF10). Mt. Victoria, Taylors Hill, Mt. Hobson and Little Rangitoto all have matching geochemical signatures, although only proposed by the spread in major element data coupled with the minimal trace element data for some centres. Scale and location of eruptions, and deposits, therefore become the qualifying criteria for correlation. The correlated horizon in Pupuke is important here as it suggests a location that has to be relatively close to Pupuke and Orakei, thus ruling out Little Rangitoto (when coupled with scale of eruption) and Taylors Hill. Mt. Victoria and Mt. Hobson are therefore both potential candidates for this deposit (and AVF5) however, based primarily on the presence of AVF4 in Pupuke, it is considered more likely to have come from Mt. Victoria rather than Mt. Hobson (based on location). In addition, due to the proximity of Mt. Hobson to Orakei, a slightly thicker deposit would potentially be expected in Orakei Basin core. Therefore AVF4 is correlated to Mt. Victoria, with a confidence level 3 due to the inconclusive geochemistry and age.

AVF3 is the first deposit found below the Rotoehu rhyolitic marker horizon. It is only found within the Orakei Basin core, it has a thickness of $41 \mathrm{~mm}$ with coarse tephra shards $(>100 \mu \mathrm{m})$, and an estimated age of 49.3 cal. ka BP (Table 5.3.). Based on the thickness of the deposit and its occurrence only in Orakei core, volcanoes from the centre and north of the field are considered. Potential centres 
that have appropriate ages and locations therefore include Hopua (AVF9) (44.4-56.4 ka), Mt. Cambria (23.9-65.1 ka), Mt. Hobson (AVF5) (44.9-66.9 ka), and Mt. Victoria (AVF4) (46.1-62.9 ka), all of which have matching trace element compositions. Based on the scale of the eruption (inferred by deposit thickness) Mt. Victoria is considered less likely as it would be more likely have deposited material in Pupuke or Onepoto maars. Mt. Hobson is the closest to and largest centre near Orakei, which would potentially result in thicker tephra deposit as outlined for AVF5. Hopua is one of the smallest eruptions in the field with a $D R E^{\text {tot }}=0.00086 \mathrm{~km}^{3}$, is located ca. $7.5 \mathrm{~km}$ away from Orakei, and would most likely for a thin deposit in the Orakei Basin. Although Mt. Cambria is even smaller than Hopua $\left(\mathrm{DRE}^{\text {tot }}=0.00029 \mathrm{~km}^{3}\right.$ ) the centre is located closer (5 km) from Orakei Basin. Therefore, (although geochemistry is inconclusive) based on locality, age, and scale of eruption, AVF3 is assigned to Mt. Cambria, with a confidence rating of 3 .

AVF2 is found in the Orakei Basin, Glover Park, and Onepoto cores with thicknesses of 510,60 , and $4 \mathrm{~mm}$ respectively. The estimated average age for this horizon is 60.3 cal. ka BP (Table 5.3.). The widespread dispersal of AVF2, and the thick deposit in the Orakei Basin core, suggests a large eruption near Orakei Basin. The geochemical composition of AVF2 tephras correlate well to One Tree Hill and the scale and location of the eruption is appropriate for the tephra dispersal and thickness. The proposed horizon age is only slightly higher than the Ar-Ar age range for One Tree Hill at 44.3-59.5 ka (Leonard et al., in prep, Appendix D). This deposit is therefore correlated with a level 1 confidence to the One Tree Hill eruption.

AVF1 is the oldest tephra horizon recorded in the Orakei core at a depth of $80.047 \mathrm{~m}$, with a thickness of $100 \mathrm{~mm}$. It has also been correlated to a $15 \mathrm{~mm}$ horizon within the Onepoto core at a depth of $51.3 \mathrm{~m}$ (however, shards within this deposit were too small to analyse for trace elements), and as a section of highly disturbed and reworked units within the Glover Park core between $16.5 \mathrm{~m}$ and 19.8 $\mathrm{m}$. The three horizons are geochemically indistinguishable (with major elements) and were therefore cross-correlated in Chapter 3. The average age of these deposits is estimated at $85.6 \mathrm{cal}$. ka BP (Table 5.3.), although as previously discussed these pre-Rotoehu age estimates might be slightly too high (c.f. sect. 5.2.2), therefore respective source centres that are younger than the horizon age are also 
considered. The source is thus either a medium eruption in the north of the field, or a large eruption in the central field. Potential source centres that satisfy these age and location criteria therefore include Domain and/or Grafton ( $\mathrm{Ar}-\mathrm{Ar}$ age range of 77.5$122.5 \mathrm{ka}$ ), Mt. St John (Ar-Ar age range of 71.5-77.6 ka), and North Head (Ar-Ar age range of 70.8-101.2 ka; Leonard et al., in prep, Appendix D). Although the major element compositions in samples from all these centres are indistinguishable, the trace element compositions from the Domain/Grafton and Mt. St John are more closely correlated in comparison to North Head (Appendix E). Domain and/or Grafton and North Head were smaller eruptions with $\mathrm{DRE}^{\text {tot }}=0.011$ and $0.0026 \mathrm{~km}^{3}$ respectively, compared to $D R E^{\text {tot }}=0.028 \mathrm{~km}^{3}$ of Mt. St John. Although Mt. St John is located furthest away ( $<3.5 \mathrm{~km}$ ) from Glover park and Onepoto, it is the largest of the three potential source centres and thus the most likely have produced a $100 \mathrm{~mm}$ thick deposit in Orakei Basin and thinner deposits at Onepoto and Glover Park. Therefore, AVF1 is correlated to Mt. St John, however, because of the inclusive geochemical composition, this correlation is given a confidence rating of 3 .

AVF1 marks the oldest tephra horizon in the Orakei Basin core. Assuming the previous correlations are accurate, the Glover Park and Onepoto cores extend back further and contain two and three more horizons respectively. These are: in the Glover Park core at $20.78 \mathrm{~m}$ (GP1/24, now AVFa) with a thickness of $40 \mathrm{~mm}$, and at $23.67 \mathrm{~m}$ (GP1/40, now AVFb) with a thickness of $<10 \mathrm{~mm}$; and in Onepoto core at $62.36 \mathrm{~m}$ (now AVFb) with a thickness of $8 \mathrm{~mm}$, at $66.94 \mathrm{~m}$ with a thickness of 190 mm (now AVFc), finally, the Onepoto core ends in large clasts of scoria and lava (not a distal tephra deposit; Shane and Hoverd, 2002) at ca. 69 m (AVFd).

AVFa in the Glover Park core contains numerous small (25 $\mu \mathrm{m}-100 \mu \mathrm{m})$ shards that have a large spread in trace element geochemistry. This heterogeneity makes it difficult to define a source centre based on the geochemistry and correlations are therefore primarily based on locality, scale, and age, with a commensurately low confidence level. Based on extrapolation of the sedimentation rates between AVF 1 and AVFb in the Onepoto cores (discussed in Sect. 5.2.) a rough age of 129.2 cal. ka BP is assigned (Table 5.3.). The scale of the deposit is indicative of a smallmedium sized eruption in the northern part of the field, or alternatively a large eruption in the centre of the field. Based on these factors the possible candidates for 
tephra source include, Domain/Grafton (morphostratigraphic age $>45.1 \mathrm{ka}$ ), Mt. Albert (Ar-Ar age range of 112.4-122.8 ka), Mt. Roskill (Ar-Ar age range of 96.6$111.0 \mathrm{ka}$ ), North Head (Ar-Ar age range of 70.8-101.2 ka), and Orakei (morphostratigraphic age range 85.0-130.0 ka). Mt. Albert and Mt. Roskill have quite large $\mathrm{DRE}^{\text {tot }}$ volume estimates $\left(0.023 \mathrm{~km}^{3}\right.$ and $0.014 \mathrm{~km}^{3}$, respectively) but are considered less likely due to their distal location (ca. 13-14 km). North Head (5.4 km distance) and Orakei Basin (5.4 km distance) are potential candidates, with smaller DRE $^{\text {tot }}$ volumes calculated $0.0026 \mathrm{~km}^{3}$ and $0.0067 \mathrm{~km}^{3}$ respectively, however the geochemistry for both these centres is poorly correlated to the tephra horizon (Appendix E). Although the age for Domain/Grafton is poorly constrained, the scale $\left(\mathrm{DRE}^{\text {tot }}=0.011 \mathrm{~km}^{3}\right.$ ) and location ( $8 \mathrm{~km}$ distance from Glover Park core site) seems appropriate with the shard size and horizon thickness. These criteria coupled with closely correlating major and trace element geochemistry means that AVFa is correlated to Domain/Grafton with a confidence level 2, due to the poorly constrained age of both deposit and centre(s).

AVFb is found within both the Glover Park core at $23.67 \mathrm{~m}$ with a thickness of $<10 \mathrm{~mm}$, and the Onepoto core at $62.3 \mathrm{~m}$ with a thickness of $8 \mathrm{~mm}$. This horizon has a calculated average sedimentation rate age (by this study) of $140.4 \mathrm{ka}$. The deposit thicknesses suggest a relatively large/medium eruption mid way between Onepoto and Glover Park in the north or central field. Centres that satisfy these criteria include Albert Park, and Domain/Grafton. The morphostratigraphic constraint for the Domain/Grafton (>45.0 ka) is minimal, however, the locality and geochemistry are well correlated for this centre. Albert Park however, is a better candidate satisfying all the criteria required for this deposit; the Ar-Ar age range for Albert Park is 138.8150 ka (Leonard et al., in prep, Appendix D); it was quite a volumetrically large eruption with a total $\mathrm{DRE}^{\text {tot }} 0.028 \mathrm{~km}^{3}$, and is centred ca. $5 \mathrm{~km}$ from Onepoto and ca. $9 \mathrm{~km}$ from Glover Park; the geochemistry is well correlated to the tephra deposits in both cores. For these reasons AVFb is assigned to Albert Park with a confidence level of 2 (not 1 , due to the inability to confidently determine the age of the core deposits).

AVFc is the final distal basaltic tephra horizon within the Onepoto core, however it did not yield any appropriate shards for geochemical analysis. The 
deposit comprises of poorly sorted large clasts ( $\mathrm{cm}$ scale) of microcrystalline lava and scoria, with no obvious bedding structures. Due to the thickness of the deposit and the clast sizes it must have originated very close to Onepoto, with the only potential candidates being Pupuke and Tank Farm. Morphostratigraphy shows that Pupuke is older than both Tank Farm and Onepoto, and Tank Farm is only just younger than Onepoto (Hayward et al., 2011). Therefore this deposit must correlate to the eruption of Tank Farm, with confidence level of 1, and an age estimate of 173.1 ka.

The final deposit within the Onepoto core is found at its base where the core terminates in thick scoria and lava $2 \mathrm{~m}$ below the AVFc horizon. This deposit is thought to represent the base of the maar crater and therefore record the Onepoto eruption itself (Shane and Hoverd, 2002). 
Table 5.5. Outline of correlations for individual tephra horizons to their source centre. Average ages are calculated by this study by sedimentation rates (Table 5.3.). Proposed centre is given in bold with certainty value, outlined in the text and in Figure 5.14. Ticks indicate where correlation satisfies the criteria of age (within error of Ar-Ar), chemistry, scale, and location. Alternative possible centres are outlined with their certainty value and criteria. Final identifications are outlined in the text, see text also for ambiguities in the table in relation to rating given.

\begin{tabular}{|c|c|c|c|c|c|c|c|c|c|c|c|c|c|c|c|c|c|}
\hline \multirow{2}{*}{ Core } & \multirow{2}{*}{ Sample name } & \multirow{2}{*}{ New Horizon\# } & \multirow{2}{*}{ Depth (m) } & \multirow{2}{*}{ Thickness (mm) } & \multirow{2}{*}{$\begin{array}{c}\text { Average age } \\
\text { (ka) }\end{array}$} & \multirow{2}{*}{$\begin{array}{l}\text { Proposed } \\
\text { Centre(s) }\end{array}$} & \multirow{2}{*}{$\begin{array}{c}\text { Certainty } \\
\text { Value }\end{array}$} & \multicolumn{4}{|c|}{ Confidence rating } & \multirow{2}{*}{ Alternative(s) } & \multirow{2}{*}{$\begin{array}{c}\text { Certainty } \\
\text { Value }\end{array}$} & \multicolumn{4}{|c|}{ Confidence rating } \\
\hline & & & & & & & & Age & Chem & Scale & Location & & & Age & Chem & Scale & Location \\
\hline \multicolumn{18}{|c|}{ Post Rerewhakaitu (<17.5ka) } \\
\hline Pupuke & T21-1-48/58929 & 24 & 57.90 & 22 & 0.6 & Rangitoto & 1 & 2 & 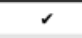 & 2 & 2 & - & - & & & & \\
\hline Hopua & T4-2-H1-2/58839 & 23 & 38.95 & 3 & 10 & Mt Wellington & 1 & r & r & r & v & & & & & & \\
\hline Pukaki & T14 47.72m & 22 & 47.72 & 1.0 & 15.4 & Pukeiti & 2 & 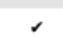 & & r & o & - & - & & & & \\
\hline \multicolumn{18}{|c|}{ Rerewhakaitu to Okareka (17.5 - 21.5ka) } \\
\hline Pukaki & AT209 49.15m & 21 & 49.15 & 3.0 & \multirow{2}{*}{19.9} & \multirow{2}{*}{ Mt Smart } & \multirow{2}{*}{3} & \multirow{2}{*}{ r } & \multirow{2}{*}{\multicolumn{2}{|c|}{ - }} & \multirow[b]{2}{*}{ r } & Panmure Basin & 3 & \multirow[t]{3}{*}{ r } & 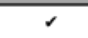 & & \multirow{5}{*}{$\dot{s}$} \\
\hline Hopua & T5-2-H1-18/58855(-58856) & 21 & 45.17 & 290 & & & & & & & & Pukeiti & 3 & & 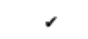 & & \\
\hline & & & & & & & & & & & & Mt Robertson & 3 & & & 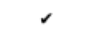 & \\
\hline Pukaki & AT210 49.17m & 20 & 49.17 & 2.0 & \multirow[b]{2}{*}{20.6} & \multirow{2}{*}{ Mt Richmond } & & & & & & Waitemokia & 3 & & r & r & \\
\hline Hopua & T6-5-H1-20/58857(-58858) & 20 & 45.51 & 235 & & & 3 & 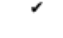 & & $v$ & ' & Green Mt & 3 & r & & & \\
\hline Okareka & Oruanui (21.5- 25.4ka) & & & & & & & & & & & & & & & & \\
\hline Pukaki & T43 51.05 & 19 & 51.05 & 1.0 & 24.2 & Otutaua & 3 & & & $\sigma$ & $\sigma$ & Green Mt & 3 & 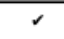 & & 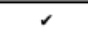 & \\
\hline & & & & & & & & & & & & Hampton Park & 3 & 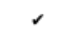 & & 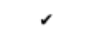 & \\
\hline & & & & & & & & & & & & Otara & 3 & 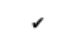 & & & \\
\hline & & & & & & & & & & & & Wiri Mt & 3 & $\checkmark$ & & & 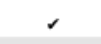 \\
\hline Orakei Ba & n OB1.\#30-4-44.22 & 18 & 44.22 & 8 & 24.3 & Waitemokia & 2 & & r & r & 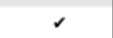 & Mt Richmond & 3 & $r$ & & & r \\
\hline Hopua & T5-6-H1-32-58869 & 18 & 47.81 & 40 & & & & & & & & Puketutu & 2 & & - & & 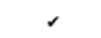 \\
\hline Pukaki & T45 51.19 & 18 & 51.19 & 0.5 & & & & & & & & Panmure Basin & 3 & r & & & 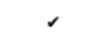 \\
\hline & & & & & & & & & & & & Otuataua & 2 & $\checkmark$ & & $r$ & 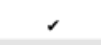 \\
\hline Orakei Ba & n OB1.\#30-6-44.652(-44.654) & 17 & 44.65 & 5 & 23.4 & Pigeon Mt & 3 & & 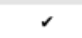 & 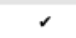 & 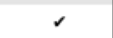 & Little Rangitoto & 3 & 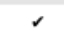 & r & & \\
\hline & & & & & & & & & & & & Motukorea & 2 & 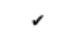 & r & 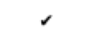 & r \\
\hline & & & & & & & & & & & & Mt Cambria & 3 & 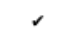 & & & r \\
\hline & & & & & & & & & & & & Mt Richmond & 3 & 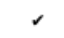 & & r & \\
\hline & & & & & & & & & & & & Panmure Basin & 3 & r & & & \\
\hline & & & & & & & & & & & & Taylors Hill & 3 & r & & & s \\
\hline Pukaki & T42/45 51.52 & 16 & 51.52 & 50.0 & 25.3 & Puketutu & 2 & & 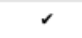 & 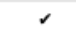 & 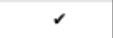 & Otuataua & 2 & r & & & - \\
\hline & & & & & & & & & & & & Mt Robertson & 2 & 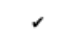 & & 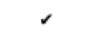 & 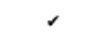 \\
\hline & & & & & & & & & & & & Wiri Mt & 2 & r & s & & 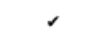 \\
\hline Orakei Ba & n OB1.\#30-6-47.715 & 15 & 47.72 & 12 & 24.5 & Motukorea & 2 & 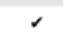 & r & r & 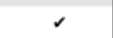 & Pigeon Mt & 3 & & 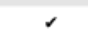 & $r$ & 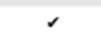 \\
\hline & & & & & & & & & & & & Mt Cambria & 3 & 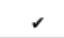 & & & 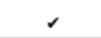 \\
\hline
\end{tabular}


Table 5.5. continued.

\begin{tabular}{|c|c|c|c|c|c|c|c|c|c|c|c|c|c|c|c|c|c|}
\hline \multirow{2}{*}{ Core } & \multirow{2}{*}{ Sample name } & \multirow{2}{*}{ New Horizon\# } & \multirow{2}{*}{ Depth (m) } & \multirow{2}{*}{ Thickness (mm) } & \multirow{2}{*}{$\begin{array}{c}\text { Average age } \\
\text { (ka) }\end{array}$} & \multirow{2}{*}{$\begin{array}{l}\text { Proposed } \\
\text { Centre(s) }\end{array}$} & \multirow{2}{*}{$\begin{array}{l}\text { Certainty } \\
\text { Value }\end{array}$} & \multicolumn{4}{|c|}{ Confidence rating } & \multirow{2}{*}{ Alternative(s) } & \multirow{2}{*}{$\begin{array}{c}\text { Certainty } \\
\text { Value }\end{array}$} & \multicolumn{4}{|c|}{ Confidence rating } \\
\hline & & & & & & & & Age & Chem & Scale & Location & & & Age & Chem & Scale & Location \\
\hline \multicolumn{2}{|c|}{ Orakei Basin OB1.\#33-2-48.12(-48.128) } & 14 & 48.13 & 12 & 24.6 & Little Rangitoto & 1 & $\sigma$ & $v$ & 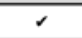 & 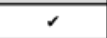 & - & - & & & & \\
\hline \multicolumn{2}{|c|}{ Orakei Basin OB1.\#33-2-48.19(-48.276) } & newB & 48.28 & 10 & & & & & & & & & & & & & \\
\hline \multicolumn{2}{|c|}{ Orakei Basin OB1.\#33-4-49.14(-49.46) } & newA & 49.46 & 45 & & & & & & & & & & & & & \\
\hline \multirow{4}{*}{\multicolumn{2}{|c|}{ Orakei Basin OB1.\#34-3-50.089(-49.554) }} & 13 & 50.09 & 160 & 25.3 & Panmure Basin & 1 & - & r & r & s & Mt Eden & 2 & r & & & - \\
\hline & & & & & & & & & & & & Little Rangitoto & 2 & 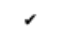 & & & - \\
\hline & & & & & & & & & & & & Mt Richmond & 2 & r & & & r \\
\hline & & & & & & & & & & & & Taylors Hill & 2 & 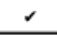 & & & \\
\hline \multicolumn{18}{|c|}{ Oruanui to Rotoehu (25.4 - $45.1 \mathrm{ka})$} \\
\hline \multicolumn{2}{|c|}{ Orakei Basin OB1.\#36-2-52.817(-53.029) } & 12 & 53.03 & 410 & \multirow{5}{*}{27.2} & \multirow{5}{*}{ Mt Eden } & \multirow{5}{*}{1} & \multirow{5}{*}{ - } & \multirow{5}{*}{ r } & & & & & & & & \\
\hline Onepoto & On2.\#4-39.06 & 12 & 36.09 & 12 & & & & & & & & & & & & & \\
\hline Pukaki & $54.355 \mathrm{~m}$ & 12 & 54.36 & & & & & & & 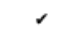 & - & - & - & & & & \\
\hline Pupuke & P23/58947 & 12 & 67.59 & 7 & & & & & & & & & & & & & \\
\hline Hopua & T6-3-H1-39/58876 & 12 & 48.80 & 460 & & & & & & & & & & & & & \\
\hline Pukaki & c. $55.355 \mathrm{~m}$ & 11 & 55.34 & & 29.3 & Wiri Mt & 2 & r & & r & r & Kohuroa & 3 & 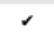 & & & r \\
\hline & & & & & & & & & & & & Otuataua & 3 & & & - & 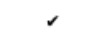 \\
\hline & & & & & & & & & & & & Mt Robertson & 3 & & & 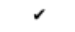 & - \\
\hline & & & & & & & & & & & & Puketutu & 2 & r & $\sigma$ & & - \\
\hline Orakei Basi & OB1.\#37-2-54.119(-54.213) & 10 & 54.21 & 407 & & & & & & & & Panmure Basin & 3 & r & r & & \\
\hline Onepoto & On2.\#4-39.47 & 10 & 39.47 & 15 & 29.9 & Taylor's Hill & 2 & 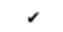 & r & & s & Mt Hobson & 3 & & & 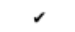 & 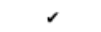 \\
\hline Pupuke & T18-7-P26/58951 & 10 & 68.09 & 3 & & & & & & & & Little Rangitoto & 3 & r & & & r \\
\hline Pupuke & P27/58952 & 9 & 68.15 & 6 & 30.2 & Hopua & 3 & & 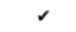 & $\sigma$ & 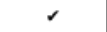 & Mt Cambria & 3 & 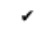 & & 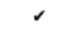 & 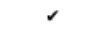 \\
\hline & & & & & & & & & & & & McLennan Hills & 3 & r & & 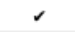 & \\
\hline Orakei Basi & OB1.\#37-2-54.27 & 8 & 54.27 & 45 & & & & & & & & Kohuora & 2 & $r$ & & 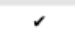 & 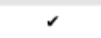 \\
\hline Pupuke & P28/58953 & 8 & 68.24 & 20 & 31.3 & Crater Hill & 2 & 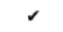 & 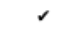 & & 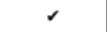 & & & & & & \\
\hline Pukaki & c. $56.4 \mathrm{~m}$ & 8 & 56.40 & ca. 720 & & & & & & & & & & & & & \\
\hline Orakei Basi & OB1.\#37-2-54.324 (AVF7) & 7 & 54.34 & 20 & & & & & & & & & & & & & \\
\hline Onepoto & On2.\#4-39.905(-39.914) & 7 & 39.90 & 20 & 325 & Three Kinas & 1 & 1 & $x$ & 1 & 1 & $-5+2$ & $\therefore$ & & & & \\
\hline Pukaki & c. 56.8 & 7 & 56.90 & & 20.0 & 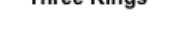 & 1 & ( & ( & ( & ( & & & & & & \\
\hline Pupuke & T19-3-P29/58954 & 7 & 68.49 & 2 & & & & & & & & & & & & & \\
\hline Pukaki & c.57.0 & 6 & 57.10 & ca. 500 & 33.7 & Kohuroa & 2 & r & & 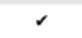 & 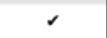 & Crater Hill & 2 & $r$ & r & & 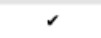 \\
\hline & & & & & & & & & & & & Puketutu & 2 & $r$ & $r$ & & 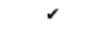 \\
\hline & & & & & & & & & & & & Wiri Mt & 3 & r & & & $r$ \\
\hline & & & & & & & & & & & & Mt Robertson & 3 & & & 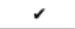 & $s$ \\
\hline
\end{tabular}


Table 5.5. continued.

\begin{tabular}{|c|c|c|c|c|c|c|c|c|c|c|c|c|c|c|c|c|c|}
\hline \multirow{2}{*}{ Core } & \multirow{2}{*}{ Sample name } & \multirow{2}{*}{ New Horizon\# } & \multirow{2}{*}{ Depth $(m)$} & \multirow{2}{*}{ Thickness (mm) } & \multirow{2}{*}{$\begin{array}{l}\text { Average age } \\
\text { (ka) }\end{array}$} & \multirow{2}{*}{$\begin{array}{l}\text { Proposed } \\
\text { Centre(s) }\end{array}$} & \multirow{2}{*}{$\begin{array}{c}\text { Certainty } \\
\text { Value }\end{array}$} & \multicolumn{4}{|c|}{ Confidence rating } & \multirow{2}{*}{ Alternative(s) } & \multirow{2}{*}{$\begin{array}{c}\text { Certainty } \\
\text { Value }\end{array}$} & \multicolumn{4}{|c|}{ Confidence rating } \\
\hline & & & & & & & & Age & Chem & Scale & Location & & & Age & Chem & Scale & Location \\
\hline \multirow{6}{*}{\multicolumn{2}{|c|}{ Orakei Basin OB1.\#39-3-57.342(-57.44) }} & 5 & 57.34 & 110 & 35 & Mt Hobson & 3 & & & r & $\bar{\sigma}$ & Little Rangitoto & 3 & & & r & r \\
\hline & & & & & & & & & & & & Mt Cambria & 3 & r & & & 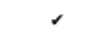 \\
\hline & & & & & & & & & & & & Mt St John & 3 & & & 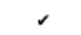 & 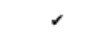 \\
\hline & & & & & & & & & & & & Mt Victoria & 3 & & & r & 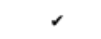 \\
\hline & & & & & & & & & & & & North Head & 3 & & & r & r \\
\hline & & & & & & & & & & & & Taylors Hill & 3 & & & - & 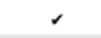 \\
\hline \multirow{6}{*}{$\begin{array}{l}\text { Orakei Basin } \\
\text { Pupuke }\end{array}$} & OB1.\#39-5-58.11(-58.07) & 4 & 58.11 & 41 & $35 ?$ & Mt Yintoria & 3 & & 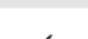 & 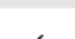 & 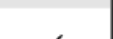 & Little Rangitoto & 3 & r & & r & s \\
\hline & P33/58960 & 4 & 69.32 & 15 & 30.2 & Mit victoria & 3 & & ( & r & 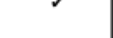 & Mt Cambria & 3 & r & & & 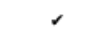 \\
\hline & & & & & & & & & & & & Mt Hobson & 3 & r & & & 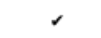 \\
\hline & & & & & & & & & & & & Mt St John & 3 & & & & 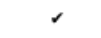 \\
\hline & & & & & & & & & & & & North Head & 3 & & & 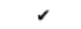 & s \\
\hline & & & & & & & & & & & & Taylors Hill & 3 & 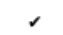 & & & r \\
\hline \multicolumn{18}{|c|}{ Pre Rotoehu $>45.1 \mathrm{ka}$} \\
\hline \multirow{2}{*}{\multicolumn{2}{|c|}{ Orakei Basin OB1.\#45-5-67.039(-61.17) }} & 3 & 67.04 & 41 & 49.3 & Mt Cambria & 3 & 2 & & & 2 & Mt Hobson & 3 & 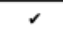 & & & 2 \\
\hline & & & & & & & & & & & & Mt Victoria & 3 & $\checkmark$ & & & s \\
\hline \multicolumn{2}{|c|}{ Orakei Basin OB1.\#50-2-73.555 } & 2 & 73.56 & 510 & & & & & & & & & & & & & \\
\hline Glover Park & GP6-8-10.38(-10.6) & 2 & 10.60 & 60 & 60.3 & One Tree Hill & 1 & r & 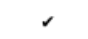 & r & 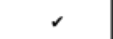 & - & - & & & & \\
\hline Onepoto & On2.\#6-2-43.66 & 2 & 43.66 & 4 & & & & & & & & & & & & & \\
\hline \multicolumn{2}{|c|}{ Orakei Basin OB1.\#54-3-80.047 } & 1 & 80.05 & 100 & & & & & & & & Domain/Grafton & 3 & $\checkmark$ & & & r \\
\hline Onepoto & AB1-On2-\#11-51.30 & 1 & 54.30 & 15 & 85.6 & Mt St John & 3 & & & r & s & North Head & 3 & - & & & - \\
\hline Glover Park & GP16-17.52(\&18.15) & 1 & 18.15 & 12 & & & & & & & & & & & & & \\
\hline \multirow[t]{4}{*}{ Glover Park } & GP1/24 - 20.78-21.0 & AVFa & 21.00 & 40 & 129.2 & Domain/Grafton & 2 & s & - & r & r & Orakei Basin & 3 & s & & s & s \\
\hline & & & & & & & & & & & & Mt Albert & 3 & s & & 2 & \\
\hline & & & & & & & & & & & & Mt Roskill & 3 & r & & r & \\
\hline & & & & & & & & & & & & North Head & 2 & s & & - & s \\
\hline Onepoto & On2.\#18-62.36 & AVFb & 62.00 & 45 & & & & & & & & Domain/Grafton & 2 & 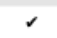 & r & & 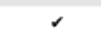 \\
\hline Glover Park & GP1/40 - 23.67 & AVFb & 23.67 & 10 & 140.6 & Albert Park & 2 & 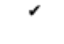 & r & r & r & & & & & & \\
\hline Onepoto & On2.\#21-66.68 & AVFc & 66.68 & 270 & 173.1 & Tank Farm & 1 & 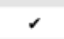 & & $\checkmark$ & $\checkmark$ & Pupuke & 3 & & & 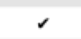 & 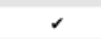 \\
\hline
\end{tabular}




\subsection{Implications}

\subsubsection{Tephra dispersal}

As a result of tephra horizons being correlated to their source centres, and between core locations, inferences can be made about the tephra dispersal distances (defined as the minimum distance from source which the tephra has travelled, in $\mathrm{km}$ ) and thickness of the deposits from the AVF eruptions. Table 5.6 outlines the distance, thickness and (where applicable) the estimated shard sizes for all of the centres that have been assigned a correlation with confidence level 1 or 2 .

The recorded thicknesses are here considered to be minima values due to potential post-depositional compaction and erosion (Óladóttir et al., 2012). The amount of compaction in the lacustrine deposits is unquantifiable, due to the lack of subaerial deposits in Auckland (discussed in Chapter 3). For the confidence level 1 correlations, the maximum dispersal distance is $13.5 \mathrm{~km}$ for Three Kings eruption recorded in Pupuke maar, with a thickness of $2 \mathrm{~mm}$ and a shard size of ca. 50-100 $\mu \mathrm{m}$. The thickest deposits $(\geq 100 \mathrm{~mm}$ ) are all found within $\leq 6 \mathrm{~km}$ from the source, with a sharp decrease in deposit thickness (all $<80 \mathrm{~mm}$ ) at distances $>6 \mathrm{~km}$ (Fig. 5.15.A). This observation correlates well to previously published estimates (Brand et al., 2014) for pyroclastic density current deposits, which are modelled for the AVF to reach a maximum dispersal of $6 \mathrm{~km}$. The maximum thickness recorded in the cores is $510 \mathrm{~mm}$ from One Tree Hill eruption in Orakei Basin, suggesting that for a volumetrically large eruption, tephra deposits can be $>500 \mathrm{~mm}$ thick at distances ca. $6 \mathrm{~km}$, however, this is in a more unusual and extreme case. Shard size also decreases with distance from source (Fig. 5.15.B), with $70 \%$ of deposits' $<5 \mathrm{~km}$ from source found to have shards sizes $>200 \mu \mathrm{m}$, which reduces to $40 \%$ of deposit $5-10$ $\mathrm{km}$ away and $0 \%>10 \mathrm{~km}$ away from source. These findings are particularly applicable as inputs for tephra dispersal simulations, evacuation, and 'clean up' forecasting, planning, and management, all of which are current projects that are running within the DEVORA group (e.g., Tomsen et al., 2014; Wilson et al., 2014). 
Table 5.6. For those deposits with a correlation certainty of 1 or 2 , the distance to the deposition site (core) (km), thickness of the deposit within the core $(\mathrm{mm})$ and the average shard size of the tephra $(\mu \mathrm{m})$ are shown. '?' shows where deposit thickness is unknown, $P$. Shane pers. comm.

\begin{tabular}{|c|c|c|c|c|c|c|c|c|c|c|c|c|c|c|c|c|c|c|c|c|}
\hline \multirow[b]{2}{*}{$\begin{array}{c}\text { Centre } \\
\text { (eruption) }\end{array}$} & \multirow[b]{2}{*}{ AVF\# } & \multirow[b]{2}{*}{$\begin{array}{c}\text { Confidence } \\
\text { level }\end{array}$} & \multirow[b]{2}{*}{ DRE $\mathrm{km}^{3}$} & \multicolumn{3}{|c|}{ Orakei Basin } & \multicolumn{3}{|c|}{ Glover Park } & \multicolumn{3}{|c|}{ Onepoto } & \multicolumn{2}{|c|}{ Pukaki } & \multicolumn{3}{|c|}{ Hopua } & \multicolumn{3}{|c|}{ Pupuke } \\
\hline & & & & $\begin{array}{l}\text { Distance } \\
\text { to }(\mathrm{km})\end{array}$ & $\begin{array}{c}\text { Horizon } \\
\text { thickness } \\
(\mathrm{mm})\end{array}$ & $\begin{array}{c}\text { shard } \\
\text { size }(\mu \mathrm{m})\end{array}$ & \begin{tabular}{|l} 
Distance \\
to $(\mathrm{km})$
\end{tabular} & $\begin{array}{c}\text { Horizon } \\
\text { thickness } \\
(\mathrm{mm})\end{array}$ & $\begin{array}{c}\text { shard } \\
\text { size }(\mu \mathrm{m})\end{array}$ & \begin{tabular}{|c} 
Distance \\
to $(\mathbf{k m})$
\end{tabular} & $\begin{array}{c}\text { Horizon } \\
\text { thickness } \\
(\mathrm{mm})\end{array}$ & $\begin{array}{c}\text { shard } \\
\text { size }(\mu \mathrm{m})\end{array}$ & \begin{tabular}{|c} 
Distance \\
to $(\mathrm{km})$
\end{tabular} & $\begin{array}{c}\begin{array}{c}\text { Horizon } \\
\text { thickness } \\
(\mathrm{mm})\end{array} \\
\text {. }\end{array}$ & \begin{tabular}{|c} 
Distance \\
to $(\mathbf{k m})$
\end{tabular} & $\begin{array}{c}\text { Horizon } \\
\text { thickness } \\
(\mathrm{mm})\end{array}$ & $\begin{array}{c}\text { shard } \\
\text { size }(\mu \mathrm{m})\end{array}$ & $\begin{array}{l}\text { Distance } \\
\text { to }(\mathbf{k m})\end{array}$ & $\begin{array}{c}\text { Horizon } \\
\text { thickness } \\
(\mathrm{mm})\end{array}$ & $\begin{array}{c}\text { shard } \\
\text { size }(\mu \mathrm{m})\end{array}$ \\
\hline Rangitoto & AVF24 & 1 & 0.6989 & \multicolumn{3}{|c|}{ core too old } & \multicolumn{3}{|c|}{ core too old } & & core too old & & \multicolumn{2}{|c|}{-} & \multicolumn{3}{|c|}{-} & 8.38 & 22 & $>200$ \\
\hline Mt Wellington & AVF23 & 1 & 0.0823 & \multicolumn{3}{|c|}{ core too old } & \multicolumn{3}{|c|}{ core too old } & \multicolumn{3}{|c|}{ core too old } & 10.44 & 1 & 6.96 & 3 & $>200$ & \multicolumn{3}{|c|}{$\cdot$} \\
\hline Little Rangitoto & AVF14 & 1 & 0.0017 & 0.9 & 12 & $>200$ & \multicolumn{3}{|c|}{ core too old } & \multicolumn{3}{|c|}{ - } & \multicolumn{2}{|r|}{ - } & \multicolumn{3}{|c|}{ - } & \multicolumn{3}{|c|}{ - } \\
\hline Panmure Basin & AVF13 & 1 & 0.0074 & 5.2 & 160 & $100-200$ & \multicolumn{3}{|c|}{ core too old } & & - & & \multicolumn{2}{|c|}{ - } & \multicolumn{3}{|c|}{ - } & \multicolumn{3}{|c|}{ - } \\
\hline Mt Eden & AVF12 & 1 & 0.0898 & 4.4 & 410 & $>200$ & & core too old & & 7.9 & 12 & $100-200$ & 12.3 & 3 & 6 & 460 & $>200$ & 10.7 & 7 & $50-100$ \\
\hline Three Kings & AVF7 & 1 & 0.0693 & 6.5 & 20 & $100-200$ & & core too old & & 10.6 & 12 & $50-100$ & 10.1 & 2 & & core too youns & & 13.5 & 2 & $50-100$ \\
\hline One Tree Hill & AVF2 & 1 & 0.2604 & 4.6 & 510 & $>200$ & 9.6 & 60 & $>200$ & 10.8 & 4 & $100-200$ & core to & o young & & core too young & & & core too young & \\
\hline Tank Farm & AVFc & 1 & 0.0059 & \multicolumn{3}{|c|}{ core too young } & & core too young & & 0.6 & 270 & $>200$ & core to & o young & & core too youns & & & core too young & \\
\hline Pukeiti & AVF22 & 2 & 0.0037 & & core too old & & & core too old & & & core too old & & 4.7 & 1 & & - & & & - & \\
\hline Mt Smart & AVF21 & 2 & 0.013 & & core too old & & & core too old & & & core too old & & 7.0 & 3 & 2.7 & 290 & $>200$ & & - & \\
\hline Mt Richmond & AVF20 & 2 & 0.0057 & & core too old & & & core too old & & & core too old & & 6.1 & 2 & 5 & 235 & $100-200$ & & - & \\
\hline Waitemokia & AVF18 & 2 & 0.0098 & 12.8 & 8 & $50-100$ & & core too old & & & core too old & & 3.7 & 0.5 & 5.6 & 40 & $>200$ & & - & \\
\hline Puketutu & AVF16 & 2 & 0.018 & & - & & & core too old & & & core too old & & 6 & 50 & & - & & & - & \\
\hline Motukorea & AVF15 & 2 & 0.0046 & 8.4 & 12 & $50-100$ & & core too old & & & core too old & & & - & & - & & & - & \\
\hline Wiri Mt & AVF11 & 2 & 0.016 & & - & & & core too old & & & - & & 5.1 & $?$ & & core too young & & & - & \\
\hline Taylors Hill & AVF10 & 2 & 0.0051 & 5.1 & 407 & $>200$ & & core too old & & 12.4 & 15 & $100-200$ & & - & & core too youn & & 13.2 & 3 & $100-200$ \\
\hline Crater Hill & AVF8 & 2 & 0.024 & 13.2 & 45 & $100-200$ & & core too old & & & - & & 1.5 & 720 & & core too youn & & 23.5 & 20 & $<50$ \\
\hline Kohuora & AVF6 & 2 & 0.0072 & & - & & & core too old & & & - & & 2.9 & 500 & & core too young & & & - & \\
\hline Hopua & AVF3 & 2 & 0.00086 & 7.3 & 41 & $50-100$ & & core too old & & & - & & core to & o young & & core too youns & & & core too young & \\
\hline Albert Park & AVFb & 2 & 0.028 & & core too young & & 8.8 & 10 & $50-100$ & 5 & 45 & $100-200$ & core to & o young & & core too young & & & core too young & \\
\hline
\end{tabular}



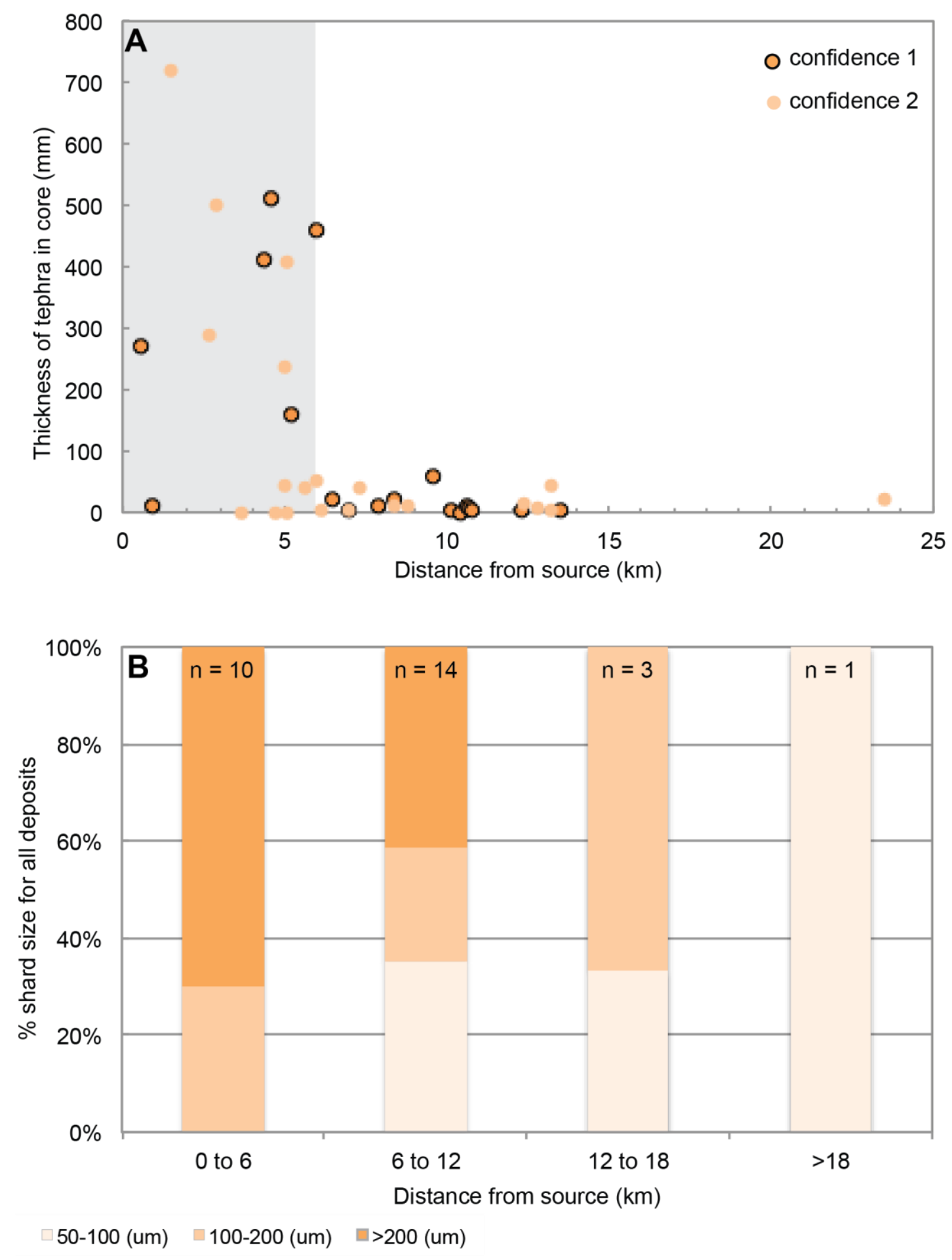

Figure 5.15. For all correlations with a confidence rating of 1or 2, data detailed in Table 5.6.; (A) Horizon thickness vs. distance from source, showing the thinning of deposits increases away from source. Grey shaded area marks $<6 \mathrm{~km}$, within which all the deposits $>100 \mathrm{~mm}$ thick are found. (B) \% shard size for all deposits vs. distance from source, indicating the fining of shard size away from source. 
Tephra horizon AVF12, correlated to Mt. Eden (highlighted on Fig. 5.1.), is one of the most widely dispersed tephra horizons: $>10 \mathrm{~mm}$ thick in both Pupuke and Pukaki cores, which are $11 \mathrm{~km}$ and $12 \mathrm{~km}$ from source, respectively. The Mount Eden event is also linked to some of the thickest tephra deposits in the cores with $410 \mathrm{~mm}$ in Orakei $(4.5 \mathrm{~km}$ ), and $460 \mathrm{~mm}$ in Hopua (6 km from source). Figure 5.16.A shows the decrease in tephra thickness away from source, coupled with the reduction in tephra shard size. Mt. Eden is also used here as example to show how the core-to-core and core-to-centre correlations can build isopach maps Figure 5.16.B for the dispersal pattern of the eruption. The impact of the prevailing westerly wind (Hayward et al., 2011) is taken into account and produces an elliptical tephra dispersal pattern, and with a calculated total DRE of $0.0898 \mathrm{~km}^{3}$ the eruption of Mt. Eden was one of the largest in the Auckland Volcanic Field. This example is therefore a more extreme tephra dispersal event from a larger scale eruption, which is not typical of the field.

Accordingly for smaller eruptions the tephra dispersal is restricted to smaller areas, but can form near-source tephra horizons with substantial thicknesses. For example AVF 10, now correlated to the eruption of Taylors Hill (DRE $0.0051 \mathrm{~km}^{3}$ ), is restricted to the north of the field with deposits found cross-correlated within Orakei Basin (407 mm at ca. $5 \mathrm{~km}$ away), Onepoto (15 mm at ca. $12 \mathrm{~km}$ away) and Pupuke ( $3 \mathrm{~mm}$ at ca. $13 \mathrm{~km}$ away). Additionally, 13 horizons are found only within a single core, suggesting that for some eruptions tephra would not be dispersed field wide.

Some deposits are not necessarily found in all maars along a dispersal pathway. For example AVF 4 is found in Orakei Basin (41 mm) and Pupuke (15 mm) but is absent in Onepoto, which lies directly between these two. These dispersal patterns are most likely indicative of either discontinuous preservation potential and/or complex distal fall out (Molloy et al., 2009). For more distal sites, the preservation potential of small tephra $(<1-2 \mathrm{~mm})$ is much lower, especially when settling through a water column. This can result in differential settling of tephra and thus in discontinuous deposition (Beierle and Bond, 2002). 


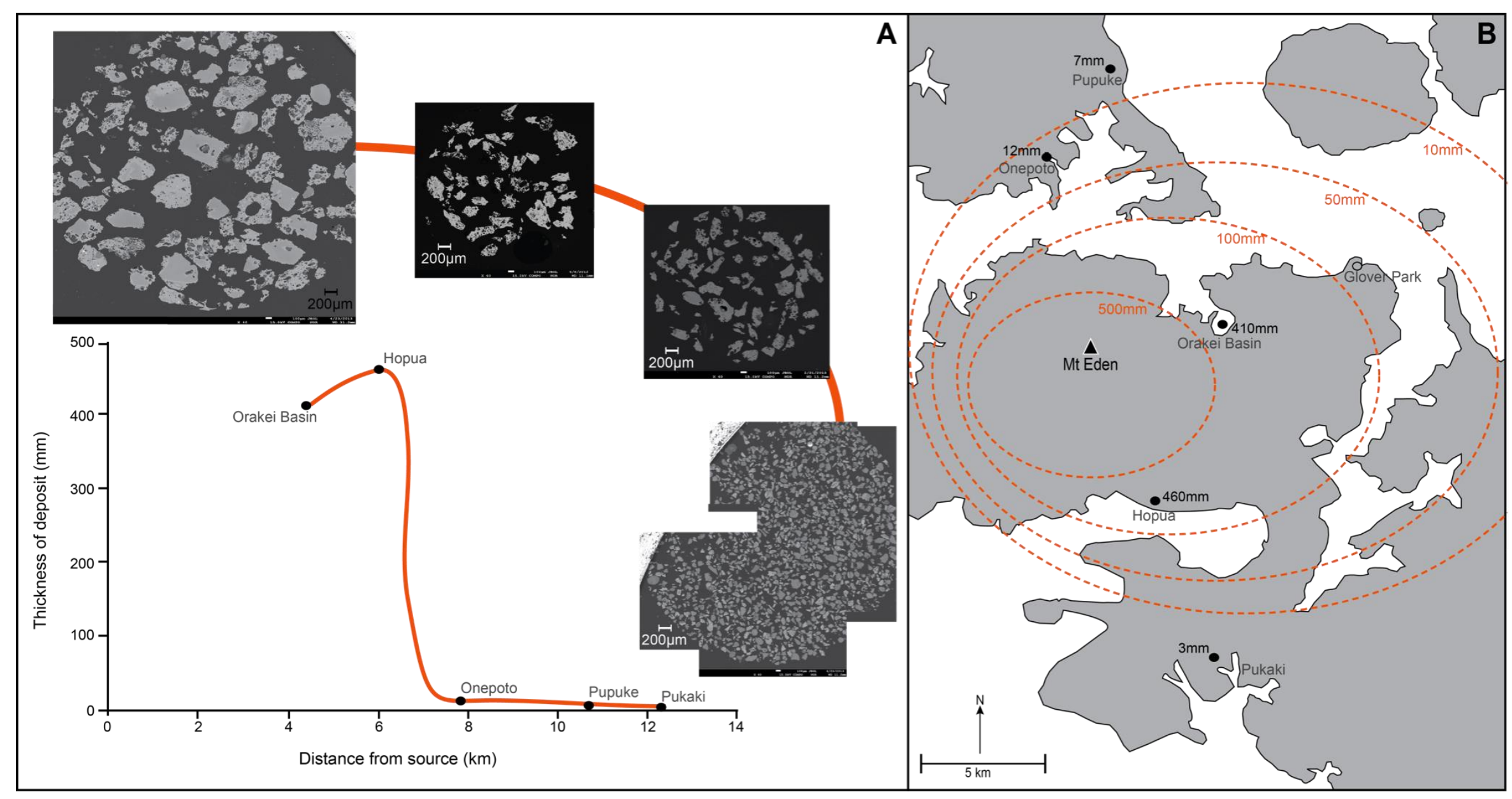

Figure 5.16. Example of the correlation of Mt. Eden eruption to tephra deposit AVF12. (A) Graph to show change in deposit thickness away from source, note the extreme decline in thickness after ca. $6 \mathrm{~km}$ distance. Also shown on $(A)$ are backscatter electron images of the shards from each core site taken on EMP. All pictures are at the same scale with the bar at the base of the images representing $200 \mu \mathrm{m}$. (B) inferred isopach map of the tephra dispersal from Mt. Eden based on the deposit thicknesses found in the cores. Dispersal is skewed to the east to reflect the westerly winds likely to have been present at the time of eruption (Hayward et al., 2011). 
Table 5.7 lists tephra dispersal characteristics from basaltic volcanic field worldwide together with those outlined for the AVF centres. Outlined are monogenetic basaltic eruptions that show comparable total eruptive volumes to the AVF centres. The larger (e.g. DRE ${ }^{\text {tot }}>0.1 \mathrm{~km}^{3}$ ) and medium size (e.g. DRE ${ }^{\text {tot }}>0.01$ $\mathrm{km}^{3}$ ) eruptions show similar dispersal distances and thicknesses to the AVF eruption deposits. For example Mt. Gambier in the Newer Volcanics province with an estimated $D^{2} E^{\text {tot }}=0.198 \mathrm{~km}^{3}$ (van Otterloo and Cas, 2013) has a measured tephra dispersal of $\leq 5 \mathrm{~cm}$ thick at 10-12 km distance (Lowe and Palmer, 2005). In comparison, One Tree Hill from the AVF has a $\mathrm{DRE}^{\text {tot }}=0.26 \mathrm{~km}^{3}$ and a measured tephra thickness and dispersal of $6 \mathrm{~cm}$ at $10 \mathrm{~km}$ away (Table 5.7.). Marcath Volcano in the Luna Crater volcanic field is a similar scale to the mid-range AVF volcanoes, with a $\mathrm{DRE}^{\text {tot }}=0.06 \mathrm{~km}^{3}$ (Johnson et al., 2014). It shows a $2 \mathrm{~cm}$ thickness at $7 \mathrm{~km}$ distance from vent, which is comparable to many similar scale eruptions in the AVF, e.g. Mt. Wellington and Three Kings (Table 5.7.). It is difficult to find comparisons for the smaller AVF eruptions. Some show equivalent values to the larger eruptions, for example, Mt. Richmond, with a $D R E^{\text {tot }}=0.0057 \mathrm{~km}^{3}$ depositing tephra a thickness of $0.2 \mathrm{~cm}$ at $7 \mathrm{~km}$ from vent. However, a number of AVF centres show larger tephra dispersal distances and thicknesses in comparison to the larger eruptions. For example, based on the results of this study, Crater Hill, with a DRE ${ }^{\text {tot }}=0.0024 \mathrm{~km}^{3}$ has dispersed tephra $2 \mathrm{~cm}$ thick up to $23 \mathrm{~km}$ away, and Hopua, with a DRE ${ }^{\text {tot }}=$ $0.00086 \mathrm{~km}^{3}$, is correlated (this study) to a $4 \mathrm{~cm}$ thick, $7 \mathrm{~km}$ away.

A number of factors could contribute to the apparent wider dispersal of AVF tephras including,

(1) The occurrence of more explosive phreatomagmatic eruptions leading to wider tephra dispersal e.g., Taylors Hill is calculated at c. $78 \%$ volume related to phreatomagmatic phases (Kereszturi et al., 2013),

(2) More favourable wind direction leading to more efficient ash dispersal to the north and north-west of the field e.g., Crater Hill in Orakei or,

(3) Better preservation within the maar deposit sites in comparison to aerial deposits e.g., Orakei Basin maar. 
Table 5.7. Comparative global values for tephra dispersal and thickness for monogenetic basaltic volcanoes. * Cerro Negro is a polygenetic scoria cone, but it has a comparable total volume estimate for the 1995 basaltic eruption, and is therefore deemed applicable for comparison. In bold are examples from this study to allow a direct comparison, note that Three Kings is the $5^{\text {th }}$ largest eruptive centre in the AVF, and Mt. Richmond is the $29^{\text {th }}$ largest.

\begin{tabular}{|c|c|c|c|c|c|}
\hline Centre Name & Region & $\begin{array}{l}\text { Total DRE } \\
\quad\left(\mathrm{km}^{3}\right)\end{array}$ & $\begin{array}{c}\text { Tephra } \\
\text { thickness } \\
(\mathbf{c m})\end{array}$ & $\begin{array}{l}\text { Dispersal } \\
\text { distance } \\
(\mathbf{k m})\end{array}$ & Reference \\
\hline Paricutin & $\begin{array}{l}\text { Michoacán-Guanajuanto } \\
\text { volcanic field, Mexico }\end{array}$ & 2.5 & 25 & 7 & Ort et al., 2008 \\
\hline Sunset Crater & $\begin{array}{l}\text { San Francisco volcanic } \\
\text { field, Arizona }\end{array}$ & 0.58 & 10 & 20 & Ort et al., 2008 \\
\hline One Tree Hill & $\begin{array}{l}\text { Auckland volcanic field, } \\
\text { New Zealand }\end{array}$ & 0.26 & 6 & 10 & This study \\
\hline Mt Gambier & $\begin{array}{l}\text { Newer Volcanics province, } \\
\text { south-eastern Australia }\end{array}$ & 0.198 & $\leq 5$ & 10 to 12 & $\begin{array}{l}\text { Lowe and Palmer, 2005; } \\
\text { van Otterloo and Cas, } 2013\end{array}$ \\
\hline Lanthrop Wells & $\begin{array}{l}\text { Southwestern Nevada } \\
\text { volcanic field }\end{array}$ & 0.12 & 1 & 10 & Valentine et al., 2008 \\
\hline Cerro Negro* & Nicaragua & 0.16 & 0.5 & 16 & Hill et al., 1998 \\
\hline Three Kings & $\begin{array}{l}\text { Auckland volcanic field, } \\
\text { New Zealand }\end{array}$ & 0.069 & 2 & 6.5 & This study \\
\hline Marcath Volcano & $\begin{array}{l}\text { Lunar Crater volcanic field, } \\
\text { Central Nevada }\end{array}$ & 0.06 & 2 & 7 & Johnson et al., 2014 \\
\hline Mt Richmond & $\begin{array}{l}\text { Auckland volcanic vield, } \\
\text { New Zealand }\end{array}$ & 0.0057 & 0.2 & 7 & This study \\
\hline
\end{tabular}

\subsubsection{Chronostratigraphic age order}

As previously outlined, although the recent Ar-Ar dating (Leonard et al., in prep, Appendix D) has provided a significant improvement on the absolute age constraints for the AVF centres, the associated errors from this method mean that an exact age order for the AVF centres could not be constrained from these data alone. For example, in Figure $\mathbf{5 . 1 7}$ the centres are presented in order based on their mean Ar-Ar ages, but there then is a large number of centres with overlapping ages that could easily be rearranged in a different order. The correlation of deposits, coupled with Ar-Ar ages and morphostratigraphy enabled us to construction a relative age order for 45 of the 53 centres, thus allowing us to re-assess the numerical ages for all centres. For example, of six previously un-dated centres, the tephra correlation 
method can be used to assign ages to the centres Otuataua and Pigeon Mt. But for Boggust Park and Mt. Robertson (Cemetery Hill and Puhinui Craters) no further constraint could be put on their ages. For Mangere Lagoon, Pukaki, and Pukewairiki numerical and relative ages are also not defined by this study, however these have morphostratigraphic constraints. Presented below is a discussion on the relative and numerical age orders proposed, from the youngest to oldest centre.

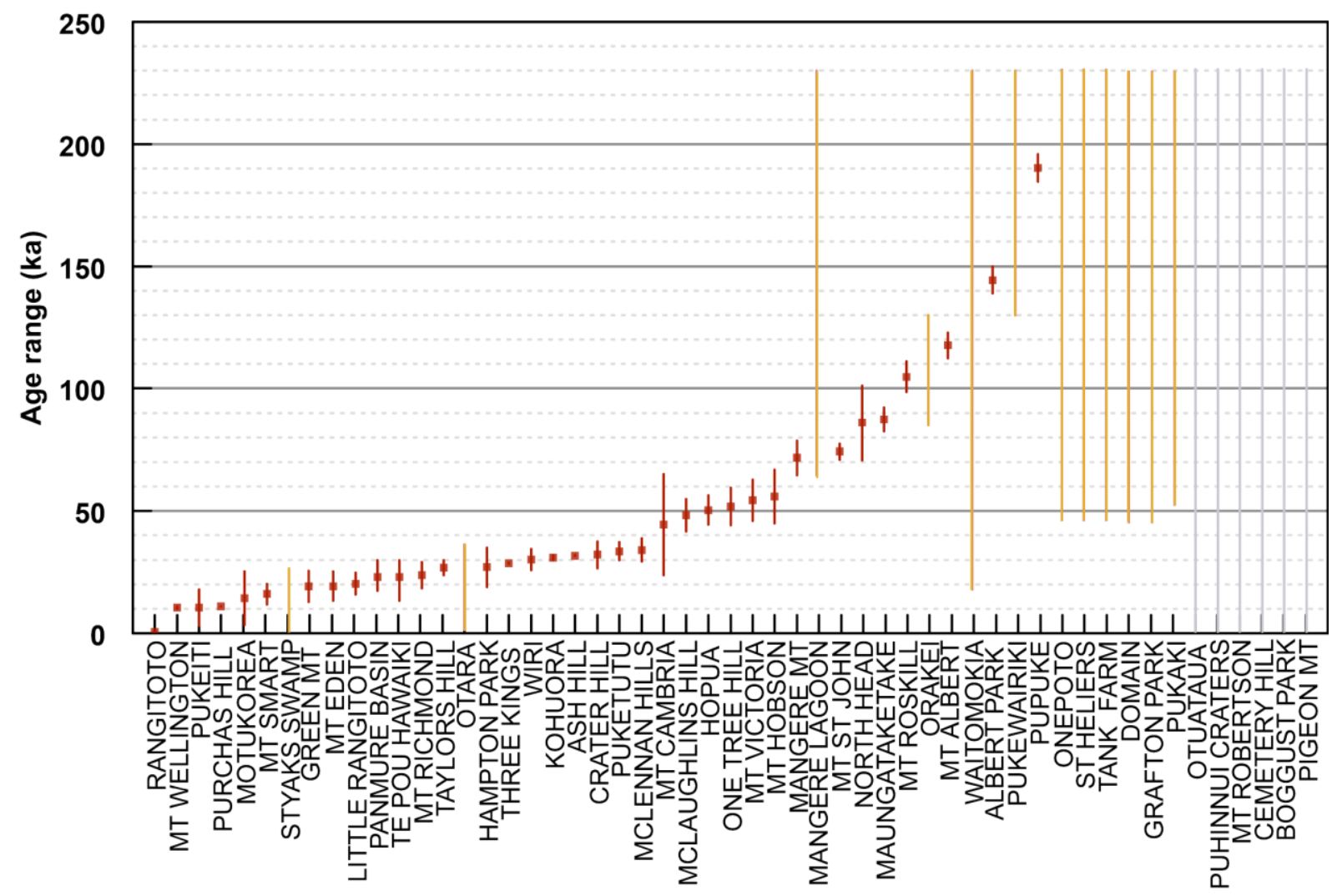

Figure 5.17. Age range chart for all centres (data from Table 5.1). Those in red are Ar-Ar (2 sd error) or ${ }^{14} \mathrm{C}$ ages (from Cassata et al., 2008; Leonard et al., in prep., (Ar-Ar); and Lindsay et al., $2011\left({ }^{14} \mathrm{C}\right)$ ). Markers show the mean ages measured by these techniques. Those in orange have their ages based only on morphostratigraphy, and those in grey have no ages associated with them. Of note is the number of centres which, based on errors, could have erupted at a given time. For example at 50 ka there are 18 potential centres (Mt. Cambria, McLaughlins Hill, Hopua, One Tree Hill, Mt. Victoria, Mt. Hobson, Waitomokia, Onepoto, St Heliers, Tank Farm, Domain, Grafton, Otuataua, Puhinui Craters, Mt. Robertson, Cemetery Hill, Boggust Park, and Pigeon Mt.) whose age ranges include $50 \mathrm{ka}$. 


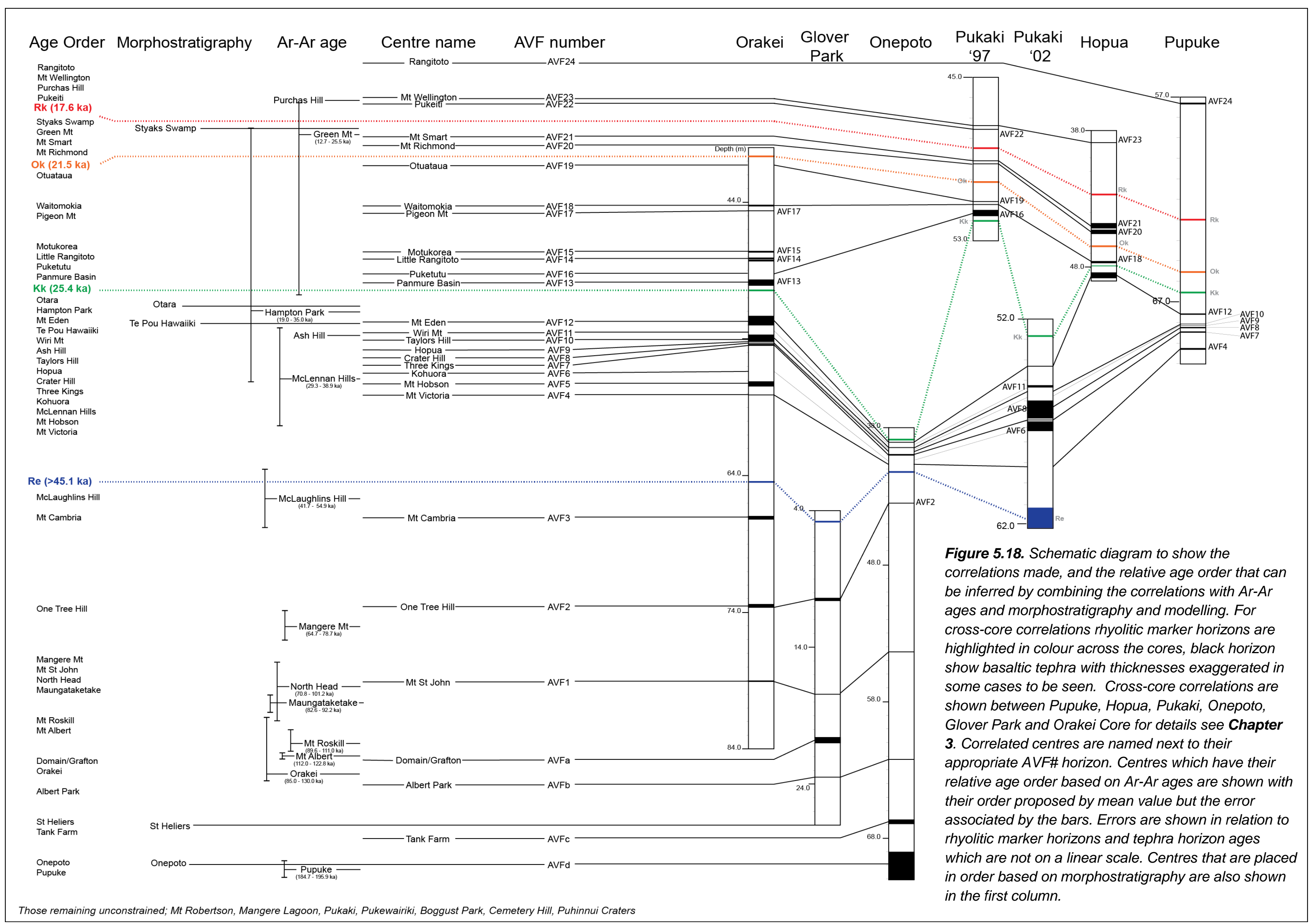


Rangitoto volcano is known to be the youngest centre within the Auckland Volcanic Field, with two resolvable eruptive episodes $\left({ }^{14} \mathrm{C}\right.$ dates of $553 \pm 7$ and $504 \pm$ 5 cal. yrs. BP; Needham et al., 2011). However, recent geochemical and tephrochronological studies have outlined two conflicting views of the eruption characteristics. Initial research by Needham et al. (2011) suggested evidence for two main eruptive events, identifying a bimodal geochemical signal from both whole rock and tephra deposits (Needham et al., 2011), as well identifying an apparent hiatus between the two. Later research from McGee et al. (2011) supports this observed geochemical bimodality and hiatus, and showed evidence for multiple magma sources through geochemical and isotopic analysis (Pb-Sr-Nd and U-Th-Ra). McGee et al. (2011) termed the eruptions Rangitoto 1 and Rangitoto 2 supporting the polymagmatic conclusions of Needham et al. (2011). More recently, Shane et al. (2013) proposed from cryptotephra analysis, that the activity from Rangitoto was constantly intermittent for a much longer time period, $1498 \pm 140$ to $504 \pm 6$ cal. yrs. $\mathrm{BP}$, rather than two punctuated events. This debate is currently on-going, but for the purpose of this study the polymagmatic conclusions from Needham et al. (2011) are assumed as the most reliable.

Three more eruptions are identified post-dating the Rerewhakaaitu marker horizon (17.5 $\pm 0.46 \mathrm{ka}$; Lowe et al., 2013). The eruptions of Mt. Wellington and Purchas Hill are well documented and dated as the next youngest eruptions in the AVF. Although there is no evidence in the maar crater tephra layers for the Purchas Hill eruption, which we attribute to its small scale, the morphostratigraphy of Mt. Wellington lavas flowing into the Purchas Hill crater coupled with a ${ }^{14} \mathrm{C}$ date of $11 \pm$ 0.14 ka (Lindsay et al., 2011) confirm that Purchas Hill is ca. 0.5 ka older than Mt. Wellington. Tephra horizon AVF23 is correlated to Mt. Wellington and horizon AVF22 is correlated here to Pukeiti, the $4^{\text {th }}$ youngest eruption in the field.

The Rerewhakaaitu and Okareka (21.5 \pm 0.29 ka; Lowe et al., 2013) rhyolitic tephra horizons bracket the next group of samples. Styaks Swamp and Green Mountain (Mt.) are the next eruptions, based on the mean Ar-Ar age for Green Mt. $(19.1 \pm 3.1 \mathrm{ka})$ and morphostratigraphic constraint for Styaks Swamp (its tephra directly mantles the Green Mt. lava flows (Hayward et al., 2011). Green Mt. records evidence for a dominantly south-westerly wind in the increased tuff build up to the north and east of the crater. The lack of tephra deposits associated with these 
eruptions found within the maar cores is attributed to this dominant wind direction. Only two basaltic horizons are found in this time interval and they are correlated with Mt. Smart (AVF21) and Mt. Richmond (AVF20), and given sedimentation rate ages of 19.9 and $20.6 \mathrm{ka}$, respectively.

The next set of deposits is constrained by the Okareka and Kawakawa/Oruanui rhyolitic marker horizons (25.4 \pm 0.16 ka; Lowe et al., 2013). Seven basaltic tephras are found within this time window, correlated to Otuataua (AVF19), Waitomokia (AVF18), Pigeon Mt. (AVF17), Puketutu (AVF16), Motukorea (AVF15), Little Rangitoto (AVF14), and Panmure Basin (AVF13). For Otuataua, Waitomokia, and Pigeon Mt. the correlations provide constraints on the eruption ages, which previously had only been constrained by morphostratigraphy (Waitomokia) or not for all centres (Otuataua and Pigeon Mt.). For Little Rangitoto and Panmure Basin, the correlations are consistent with the Ar-Ar age ranges, but the correlations allow the relative eruptive order of these two centres to be put in place. For Puketutu the Ar-Ar age range is 29.8-37.4 ka (Leonard et al., in prep. Appendix D), however, the calculated tephra horizon age is slightly younger than that at $25.3 \mathrm{ka}$, suggesting a slight discrepancy between the dating techniques. This horizon is however constrained by the Kawakawa/Oruanui and therefore must be younger than $25.4 \pm 0.16 \mathrm{ka}$ (Lowe et al., 2013). It is of note that this age put AVF16 out of sync in terms of its nomenclature; this is noted in Figure $\mathbf{5 . 1 8}$ and discussed in Section 5.2.2. Finally, for Motukorea, the age for the tephra horizon ( $24.5 \mathrm{ka})$ fits within the Ar-Ar age range (3.3-25.3 ka), although within the older end of the range.

Between the Kawakawa/Oruanui and Rotoehu (45.1 \pm 3.3 ka; Danišík et al., 2014) rhyolitic marker horizons there are nine tephra deposits (AVF12 to AVF4). Based on Ar-Ar ages or morphostratigraphy seven other centres can also be added into this age window. Otara and Hampton Park are potentially the youngest in this age bracket based on the mean Ar-Ar age from Hampton Park (27 $\pm 8.0 \mathrm{ka}$; Cassata et al., 2008), and stratigraphic evidence with Otara lava flows directly overlying the Hampton Park tuff ring; Hayward et al., 2011). Again, due to the position of these centres to the east of the field coupled with the predominant westerly wind direction, it is likely that any significant tephra deposits from these centres would occur to the north and east of the centres, supported by the formation of asymmetric tuff rings at the eastern side of Hampton Park. This therefore potentially explains the lack of 
tephra deposits found associated with these eruptions, as all maar core sites are found to the west of these centres.

Mt. Eden is proposed to be the next preceding eruption based on the correlation to tephra horizon AVF12. The geochemical composition of all five tephra deposits and the whole rock samples correlate well. However, the position of AVF12 beneath the Kawakawa/Oruanui suggests an age of 27.2 ka that is slightly older than the Ar-Ar age from Mt Eden (13.3-25.3 ka). Because the Te Pou Hawaiki scoria cone and lava flows were identified directly beneath Mt. Eden lava flows (Bartrum, 1928; Kermode, 1975), the eruption Te Pou Hawaiki is positioned just prior to Mt. Eden.

With a horizon age of $29.3 \mathrm{ka}$, the tephra horizon AVF11 is correlated to Wiri Mt. with an Ar-Ar age range of 25.7-34.5 ka. Based on morphostratigraphy and a ${ }^{14} \mathrm{C}$ age (31.8 $\pm 0.2 \mathrm{ka}$; Lindsay et al., 2011), Ash Hill is suggested to be the next preceding eruption in the field. In similar fashion to the Mt. Eden/Te Pou Hawaiki relationship described above, Ash Hill has erupted just before Wiri Mountain, but due to its very small scale Ash Hill is unlikely to be present in the distal tephra record.

Based on the correlation to tephra horizon AVF10, Taylors Hill is proposed to be the next preceding eruption in the field with a horizon age of 29.9 ka. Erupting shortly after AVF9, correlated to Hopua (horizon age of $30.2 \mathrm{ka}$ ), and AVF8 correlated to the Crater Hill, (horizon age of $31.3 \mathrm{ka}$ ). All of these correlations support the Ar-Ar ages, but again allow us to reliably establish relative age order. This was not previously possible as the Ar-Ar age ranges from all these centres overlap.

AVF 7 is a very extensive deposit found within all the cores that also falls within this age range ( $\mathrm{Kk}$ to $\mathrm{Re}$ ). This tephra horizon is correlated to the eruption of Three Kings, although sedimentation rate calculations linked to the stratigraphic position of this horizon date it as older (32.5 ka) than the ${ }^{14} \mathrm{C}$ age (28.4-28.8 ka) suggests. The eruption of Kohuora centre is proposed to precede this, based on the correlation with tephra horizon AVF 6 which has a calculated age of $33.7 \mathrm{ka}$. The stratigraphic position for this tephra horizon fits well with the Ar-Ar age range (30-32 $\mathrm{ka}$ ), is consistent with the morphological restraints and previous radiocarbon and 
tephrostratigraphical dates (e.g., Newnham et al., 2007), and confirms, where the ArAr dating could not, that Kohuora is slightly older than Crater Hill.

Based on Ar-Ar dating McLennan Hills is proposed to be the next oldest centre with an age of 29.3-38.9 ka; however, tephra from this eruption was not found in any cores. The preceding eruption to McLennan Hills is Mt. Hobson, correlated to tephra horizon AVF5 (calculated age of $35.0 \mathrm{ka}$ ). Although the stratigraphic positioning of AVF5 would make this eruption younger than the Ar-Ar data suggest (44.9-66.9 ka) it agrees with the morphological constraint that it must be older than Three Kings (Table 5.1.). AVF 4, with a calculated horizon age of $35.2 \mathrm{ka}$, is correlated to the eruption of Mt. Victoria. Again, however, the correlation with this horizon would suggest the eruption is younger than the Ar-Ar age measured (46.1$62.9 \mathrm{ka})$.

The Rotoehu rhyolitic marker horizon marks the final tephra horizon constraint on the age order at older than $45.1 \pm 3.3 \mathrm{ka}$ (Danišík et al., 2014). The first preceding eruption has its position based on the Ar-Ar ages recorded, and this is McLaughlins Hill (41.7-54.9 ka). Following this is the deposit AVF 3 that is found only within the Orakei Basin core and is best correlated to Mt. Cambria, with an age of $49.3 \mathrm{ka}$ for the horizon. Prior to this, is the eruption of One Tree Hill, based on the correlation to tephra horizon AVF2. This horizon has an average calculated age of $60.0 \mathrm{ka}$, which is only slightly older than the Ar-Ar age (44.3-59.5 ka), and consistent with the morphological constraints (older than Mt. Hobson, Mt. Eden, Hopua, Mt. Smart and Three Kings all of which erupted through One Tree Hill lava flows; Hayward et al., 2011).

Based on $\mathrm{Ar}$-Ar age range of 64.6-78.7 ka, Mangere Mt. is the next older eruption, preceded by tephra horizon AVF1 $(84.5 \mathrm{ka})$ that is correlated to the eruption of Mt. St John. Based on the Ar-Ar age of 70.8-101.2 ka and 82.6-92.2 ka North Head and Maungetaketake, respectively are the next oldest eruptions in order. Due to the lack of tephra deposits or morphological constraints their relative eruption order remains unresolved. With $\mathrm{Ar}$ Ar ages of 98.6 - 111.0 and $112.0-$ $122.8 \mathrm{ka}$ and based on morphostratigraphy Mt. Roskill and Mt. Albert are the next oldest AVF centres. There is no overlap associated with the Ar-Ar ages therefore the relative order of these two centres seems accurate. 
A newly discovered 129.2 ka old tephra horizon within the Glover Park core (AVFa, Chapter 3) most likely records the eruption of Domain and/or Grafton. Prior to this is considered to be the eruption of Orakei Basin. This age sequence is based on sedimentation rates of the core, and morphostratigraphy. The Orakei Basin drill core is not considered to have reached the base of the maar ( $G$. Leonard pers. comm., 2015), and therefore the age estimate for the base of the core can only give a minimum age (of $85 \mathrm{ka}$ ). Morphostratigraphic constraints give a maximum estimate, based on the lack of evidence for erosion for the last interglacial high-stand (c.f. Pukewairiki; Table 5.1), of ca. 130 ka (Hayward et al., 2011).

The 140.6 ka old tephra horizon AVFb preserves the Albert Park eruption agreeing with the Ar-Ar age range of 138.8 -150.0 ka. This deposit (AVFb) is very close to the base of the Glover Park core. The base of the Glover Park core represents the maar crater floor and thus St Heliers (Glover Park) is proposed to be the next preceding eruption. Although there are no $\mathrm{Ar}-\mathrm{Ar}$ ages or morphostratigraphic evidence to test this conclusion, based on the sedimentation rates the base of the core at $27 \mathrm{~m}$ is calculated to be ca. $164 \mathrm{ka}$.

Only the Onepoto core records older tephra horizons below this stratigraphic level. Towards the base of the Onepoto core (at ca. $67 \mathrm{~m}$ ) the first (oldest) $173.1 \mathrm{ka}$ old tephra horizon of the AVF is correlated with the eruption of Tank Farm. Two metres deeper than the Tank Farm deposit the Onepoto core terminates in a thick lapilli and lava unit that is likely to represent products of the Onepoto eruption itself. As there is no deposit in the Onepoto core from Pupuke, the latter is considered to have erupted earlier, supported by morphological evidence and Ar-Ar dates which show an age for Pupuke as 184.7-195.9 ka. The Onepoto deposit is therefore assigned an age of $190.3 \mathrm{ka}$, as discussed previously in Section 5.2.2.

There remain 5 centres that have very limited age constraints, and therefore cannot be accurately included in this chronostratigraphy. These include Pukaki, Mangere Lagoon, which is morphostratigraphically constrained to be older than Mangere Mt., giving it an minimum age constraint of $64.7 \mathrm{ka}$, and Pukewairiki which has a minimum morphostratigraphic age constraint of $130 \mathrm{ka}$ (Table 5.1.). Boggust Park and Mt. Robertson as discussed previously remain undated. 


\subsubsection{Temporal Evolution}

To assess the temporal eruptive history, the mean ages from the Ar-Ar (Leonard et al., in prep. Appendix D, and Cassata et al., 2008; Table 5.1.) and ${ }^{14} \mathrm{C}$ (Lindsay et al., 2011 and Needham et al., 2011) determinations are taken for twelve of the centres. For twenty-eight centres their ages are assigned based on tephra horizons correlation, and the ages estimated by sedimentation rates for each tephra horizon (Table 5.2.). For five centres where morphostratigraphy controls the relative age, a value is assigned from the morphological and correlational constraints. For seven centres there remains not enough information to assign them absolute or relative ages, these are therefore not included in the following evaluations. The ages inferred by this study are outlined in Table 5.8, along with the calculated repose periods (time between eruption $n$ and $n+1$ ).

Bebbington and Cronin (2011) presented the only existing estimates for both relative and absolute age order based on a Monte Carlo simulation modelling. The input for this model simulation included deposit thickness and age estimation for basaltic tephra within maar cores (from Molloy et al., 2009), and age restrictions from distal tephras from the North Island rhyolitic and andesitic centres, and age estimations for the AVF centres. All of these inputs have now been superseded by more recent findings (e.g., Chapter 3; Ar-Ar ages from Leonard et al., in prep.). Figure 5.19 shows a comparison of the outputs from their model and our research. For relative age orders (Fig. 5.19. A), there is significant scatter around the 1 to 1 line, which indicates that the data sets are significantly different. In some cases the two data sets agree, with 8 centres put in the same relative positions. However, in their model 22 centres are in slightly older positions, and 14 in slightly younger positions in comparison to this study. There are only a few large (>20 positions) discrepancies between the two; Little Rangitoto, Motukorea, and Te Pou Hawaiki are all given much older positions $(42,35,43$ respectively) than for this study $(13,12$, 19), and McLaughlins Mt. and Mt. Mangere given much younger positions by Bebbington and Cronin (2011) (4 and 9 respectively) in comparison to this study (30 and 33 respectively).

For numerical age estimates (Fig. 5.19. B\&C), the variation between the data sets is much greater: nineteen centres show offsets of $<5$ ka between the modelled and our age estimates, with the remaining 26 showing much larger offsets between 
5.4 ka (Hampton Park) and 124 ka (Te Pou Hawaiki). The Bebbington and Cronin (2011) modelled numerical ages are clustered around $30 \mathrm{ka}$, whereas this study produces a much greater spread between 20 and $35 \mathrm{ka}$. The reason for this is that the Bebbington and Cronin model is linked predominantly to tephra deposits, of which most are found within close to $30 \mathrm{ka}$ age range, and thus imparts a bias on the age constraints of their model output. For all centres modelled by Bebbington and Cronin (2011) with ages between 45 and $75 \mathrm{ka}$, the ages appear to be lower in comparison to this study (e.g. One Tree Hill, Mt. Albert, and Tank Farm). Conversely, modelled centre ages >75 ka seem over estimates (e.g., Little Rangitoto, Orakei Basin and Onepoto). The conflicting results for both relative and absolute age estimates between the two studies (e.g., for Onepoto, Pupuke, and Tank Farm), is proposed to result from discrepancies between the data inputs. As our new method relies on current data, it is considered to have produced more realistic and precise results.

The relative and absolute age results of this study (Table 5.8.) suggest that 13 centres erupted in the first ca. $150 \mathrm{kyr}$ of the AVF history (ca. 190.3 - ca. $50 \mathrm{ka}$ ), with 31 erupting from ca. $50 \mathrm{ka}$ to $0.5 \mathrm{ka}$. By using the RMHs as age constraints the number of eruptions per 1000 years (erup/kyr) can be calculated: present to Rerewhakaaitu (Rk) (0 - $17.5 \mathrm{ka}$ ) eruption rate of 0.23 erup/kyr; Rerewhakaaitu to Okareka (Ok) (17.5 - $21.5 \mathrm{ka})$ eruption rate of 1.00 erup/kyr; Okareka to Kawakawa/Oruanui (Kk) (21.5 - $25.4 \mathrm{ka})$ eruption rate of 2.33 erup/kyr; Kawakawa/Oruanui to Rotoehu (Re) (25.4 - $45.1 \mathrm{ka}$ ) eruption rate of 0.71 erup/kyr and Rotoehu to inception (45.1 - $204 \mathrm{ka}$ ) eruption rate of 0.10 erup/kyr. These results suggest that in general there was an increase in the eruption frequency through time until ca. 21.5ka (Okareka $\mathrm{RMH}$ ), followed by a decrease over the last $21.5 \mathrm{ka}$. Repose periods show a wide range from $<0.1$ - $13 \mathrm{kyr}$ (Table 5.8.), with two outliers of 27.3 and 17.4 kyr, proposed between St Heliers and Albert Park, and Mt. Roskill and Maungetaketake, respectively. Twenty-four centres have repose periods of 1000 years or less, seventeen of which are 500 years or less. In general the longer repose periods were found at the beginning of the field's history, with all of the nine centres with repose periods of $>10,000$ years appearing in the first $160 \mathrm{kyr}$. Overall, the general trend for the temporal evolution of the field suggests repose periods of $<13$ $\mathrm{ka}$, but with an increase of this timing over the last ca. $21 \mathrm{ka}$. 

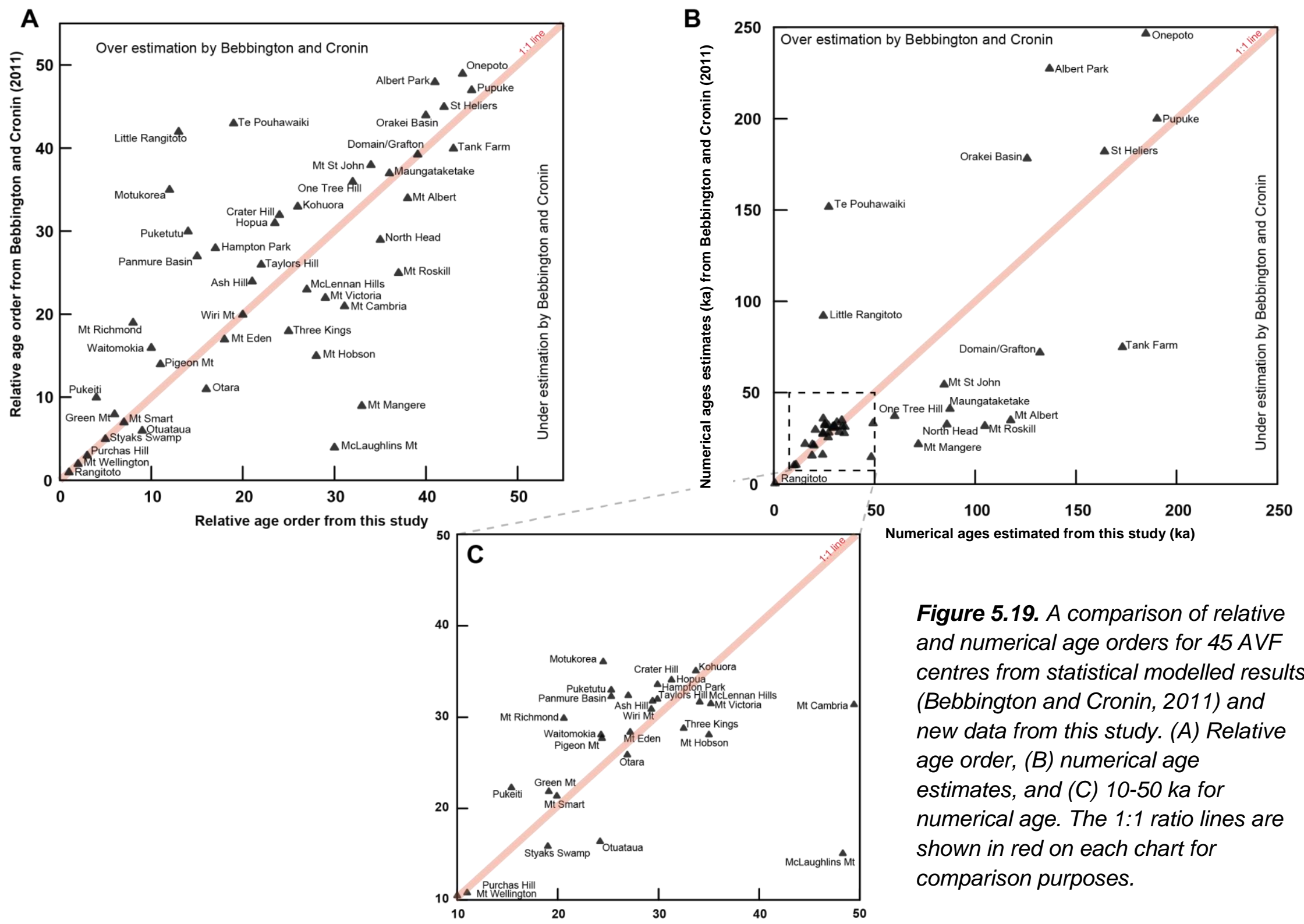

Figure 5.19. A comparison of relative and numerical age orders for 45 AVF centres from statistical modelled results (Bebbington and Cronin, 2011) and new data from this study. (A) Relative age order, $(B)$ numerical age estimates, and (C) 10-50 ka for numerical age. The 1:1 ratio lines are shown in red on each chart for comparison purposes. 
Table 5.8. Relative order of eruptions with calculated mean ages, time and distance relationship between the $n^{\text {th }}, n+1$ and $n+2$ centre. References a. sedimentation rates from this study, b. ${ }^{14} \mathrm{C}$ from Lindsay et al., 2011, c. Ar-Ar from Leonard et al., in prep. $d$. morphostratigraphic constraints (Table 5.1.) with numerical ages evaluated by this study.

\begin{tabular}{|c|c|c|c|c|c|c|c|c|}
\hline \multirow{2}{*}{$\begin{array}{c}\text { Relative } \\
\text { Order }\end{array}$} & \multirow{2}{*}{ Centre Name } & \multirow{2}{*}{$\begin{array}{c}\text { Mean age } \\
\text { (t) in ka }\end{array}$} & \multirow{2}{*}{$\begin{array}{l}\text { Error } \\
\text { (1sd) }\end{array}$} & \multirow[b]{2}{*}{ Ref. } & \multicolumn{2}{|c|}{ Time relationship } & \multicolumn{2}{|c|}{ Distance relationship } \\
\hline & & & & & $\mathrm{t}+1$ (ka) & $t+2(k a)$ & $\mathrm{d}+1(\mathrm{~km})$ & $\mathrm{d}+2 \quad(\mathrm{~km})$ \\
\hline & Rangitoto 2 & 0.5 & \pm 0.05 & $\mathrm{~b}$ & & & - & \\
\hline 1 & Rangitoto & 0.6 & \pm 0.07 & $b$ & 0.05 & & 0.1 & \\
\hline 2 & Mt Wellington & 10.0 & & a & 9.4 & 9.5 & 11.9 & 11.7 \\
\hline 3 & Purchas Hill & 11.0 & \pm 0.05 & $\mathrm{~b}$ & 1.0 & 10.4 & 0.6 & 11.1 \\
\hline 4 & Pukeiti & 15.4 & & a & 4.4 & 5.4 & 13.4 & 12.8 \\
\hline 5 & Styaks Swamp & 19.0 & & $d$ & 3.6 & 8.0 & 13.9 & 7.2 \\
\hline 6 & Green Mt & 19.1 & \pm 6.4 & c & 0.1 & 3.7 & 0.5 & 13.6 \\
\hline 7 & Mt Smart & 19.9 & & a & 0.8 & 0.9 & 8.1 & 8.2 \\
\hline 8 & Mt Richmond & 20.6 & & a & 0.7 & 1.5 & 3.0 & 5.3 \\
\hline 9 & Otuataua & 24.2 & & a & 3.6 & 4.3 & 9.7 & 9.2 \\
\hline 10 & Waitomokia & 24.3 & & a & 0.1 & 3.7 & 1.6 & 8.0 \\
\hline 11 & Pigeon Mt & 24.4 & & a & 0.1 & 0.2 & 15.3 & 17.1 \\
\hline 12 & Motukorea & 24.5 & & a & 0.1 & 0.2 & 6.6 & 19.9 \\
\hline 13 & Little Rangitoto & 24.6 & & a & 0.1 & 0.2 & 9.1 & 8.4 \\
\hline 14 & Puketutu & 25.3 & & a & 0.7 & 0.8 & 11.5 & 20.0 \\
\hline 15 & Panmure Basin & 25.3 & & a & 0.0 & 0.7 & 11.4 & 4.9 \\
\hline 16 & Otara & 26.9 & & $d$ & 1.6 & 1.6 & 6.4 & 13.4 \\
\hline 17 & Hampton Park & 27.0 & \pm 6.0 & c & 0.1 & 1.7 & 0.4 & 6.5 \\
\hline 18 & Mt Eden & 27.2 & & a & 0.2 & 0.3 & 14.3 & 14.1 \\
\hline 19 & Te Pou Hawaiiki & 27.3 & & $d$ & 0.1 & 0.3 & 0.7 & 13.6 \\
\hline 20 & Wiri Mt & 29.3 & & a & 2.0 & 2.1 & 16.1 & 16.7 \\
\hline 21 & Ash Hill & 29.4 & & a & 0.1 & 2.1 & 1.0 & 16.1 \\
\hline 22 & Taylors Hill & 29.9 & & a & 0.5 & 0.6 & 16.0 & 15.8 \\
\hline 23 & Hopua & 30.2 & & a & 0.3 & 0.8 & 10.5 & 11.4 \\
\hline 24 & Crater Hill & 31.3 & & a & 1.1 & 1.4 & 7.4 & 14.1 \\
\hline 25 & Three Kings & 32.5 & & a & 1.2 & 2.3 & 11.3 & 4.1 \\
\hline 26 & Kohuora & 33.7 & & a & 1.2 & 2.4 & 11.6 & 1.5 \\
\hline 27 & McLennan Hills & 34.1 & \pm 4.8 & c & 0.4 & 1.6 & 5.6 & 11.6 \\
\hline 28 & Mt Hobson & 35.0 & & a & 0.9 & 1.3 & 4.0 & 12.3 \\
\hline 29 & Mt Victoria & 35.2 & & a & 0.2 & 1.1 & 5.8 & 12.2 \\
\hline 30 & McLaughlins Hill & 48.3 & \pm 6.6 & $\mathrm{C}$ & 13.1 & 13.3 & 21.2 & 15.9 \\
\hline 31 & Mt Cambria & 49.3 & & a & 1.0 & 14.1 & 21.4 & 0.4 \\
\hline 32 & One Tree Hill & 60.3 & & a & 11.0 & 12.0 & 8.7 & 13.8 \\
\hline 33 & Mangere Mt & 71.7 & \pm 7.0 & $\mathrm{c}$ & 11.4 & 22.4 & 5.4 & 14.0 \\
\hline 34 & Mt St John & 85.6 & & a & 13.9 & 25.3 & 7.4 & 2.0 \\
\hline 35 & North Head & 86.0 & \pm 15.2 & c & 0.4 & 14.3 & 6.9 & 13.8 \\
\hline 36 & Maungetaketake & 87.4 & \pm 4.8 & c & 1.4 & 1.8 & 19.4 & 12.7 \\
\hline 37 & Mt Roskill & 104.8 & \pm 6.2 & $\mathrm{C}$ & 17.4 & 18.8 & 9.1 & 11.5 \\
\hline 38 & Mt Albert & 117.6 & \pm 5.2 & c & 12.8 & 30.2 & 2.9 & 11.8 \\
\hline 39 & Domain/ Grafton & 129.2 & & a & 11.6 & 24.4 & 6.0 & 6.6 \\
\hline 40 & Orakei & 130.0 & & $d$ & 0.8 & 12.4 & 3.5 & 8.6 \\
\hline 41 & Albert Park & 136.9 & & a & 6.9 & 7.7 & 4.4 & 1.3 \\
\hline 42 & St Heliers & 164.2 & & $d$ & 27.3 & 34.2 & 8.7 & 5.3 \\
\hline 43 & Tank Farm & 173.1 & & a & 8.9 & 36.2 & 11.4 & 5.6 \\
\hline 44 & Onepoto & 184.7 & & d & 11.6 & 20.5 & 0.7 & 11.3 \\
\hline \multirow[t]{8}{*}{45} & Pupuke & 190.3 & \pm 5.6 & c & 5.6 & 17.2 & 3.2 & 2.4 \\
\hline & Mangere Lagoon & $>64.7$ & & & & & & \\
\hline & Pukaki & $>52.0$ & & & & & & \\
\hline & Pukewairiki & $>130$ & & & & & & \\
\hline & Mt Robertson & - & & & & & & \\
\hline & Boggust Park & - & & & & & & \\
\hline & Cemetery Hill & - & & & & & & \\
\hline & Puhinui Craters & - & & & & & & \\
\hline
\end{tabular}




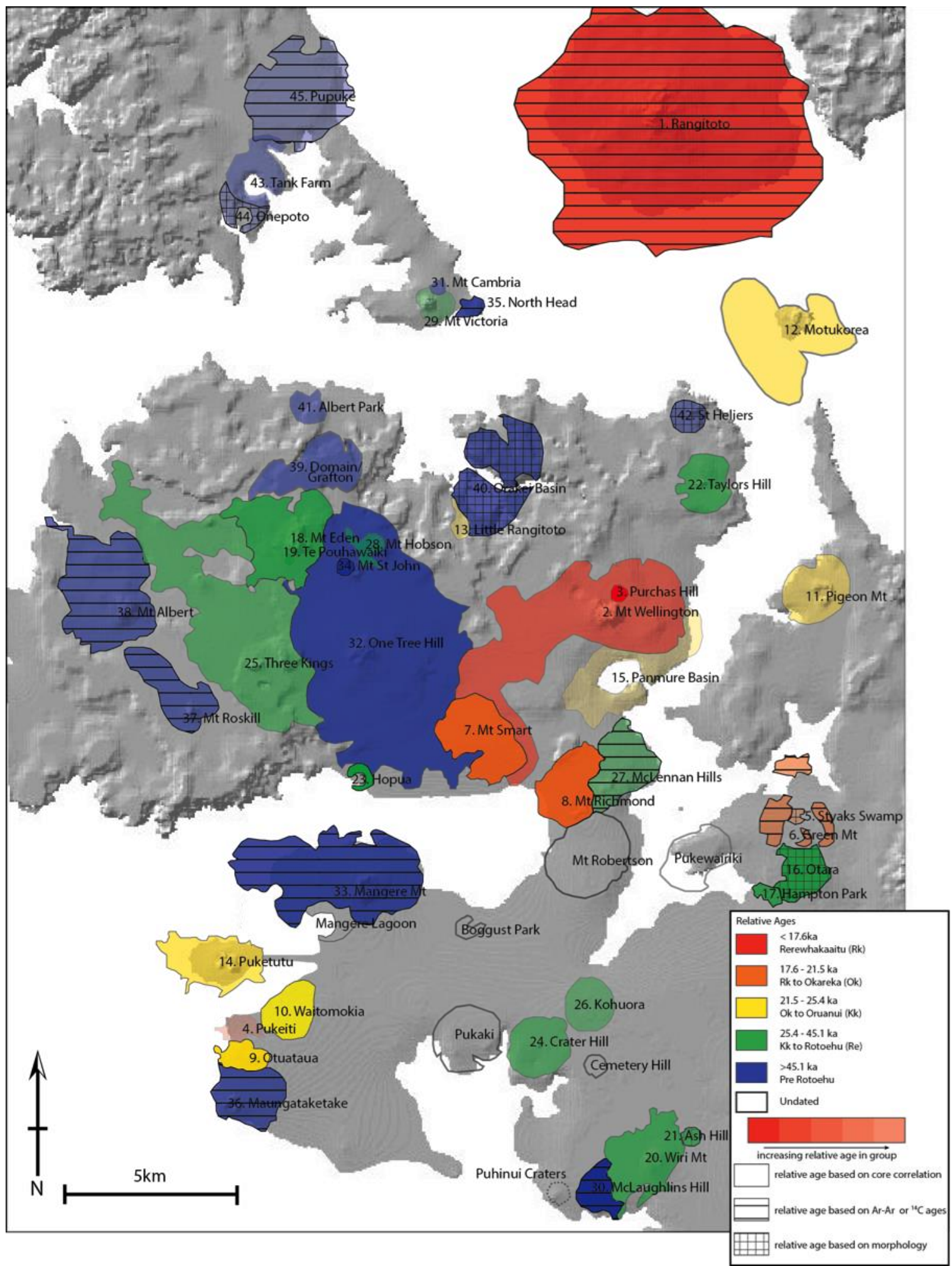

Figure 5.20. Location map of all the AVF centres in the field divided into colours representing the constraining time zones. The grades of colour represent the relative age within the group with darker colours younger in the group and lighter colours older in the group, and patterns on the colours outlining the way in which the age has been constrained, through core correlation, Ar-Ar dating, or morphostratigraphy. The ages of those without colour remain unconstrained, and the numbers show their relative age order from the oldest (45) to youngest (1). 


\subsubsection{Spatial Evolution}

Figure 5.20 shows the relative ages of the AVF centres in map view. The distances between successive eruption centres varies from $<0.5 \mathrm{~km}$ to $21 \mathrm{~km}$. There is alignment of some centres in specific areas (for example McLaughlins Hill - Wiri Mt. - Ash Hill) that have previously been attributed to pre-existing crustal fractures and faults (Magill et al., 2005; von Veh and Németh, 2009; Kereszturi et al., 2014). In general, however, there is no obvious spatial progression or patterns through time.

Previous studies (Le Corvec et al., 2013a; Bebbington, 2013) have suggested that the location of each centre is independent of that of the previous centre, and for the most part the results presented in this study support this suggestion. However, when linked with the temporal evolution, a number of 'coupled' centres appear to have erupted very closely in space and time. They are defined as having a repose period of less than 1000 years and vented $<1 \mathrm{~km}$ away from each other. For example, Mt. Wellington and Purchas Hill are very well dated to $10.5 \mathrm{ka}$ and $11 \mathrm{ka}$ respectively, and are located ca. $0.5 \mathrm{~km}$ apart. The other centres include Rangitoto 1 and 2, Styaks Swamp and Green Mt., Mt. Eden and Te Pou Hawaiki, Wiri Mt. and Ash Hill, and Otara and Hampton Park. It would also be possible to have Onepoto and Tank Farm, Mangere Mt. and Mangere Lagoon, and Domain and Grafton included, however the ages of one or both of these couples are poorly constrained and therefore their specific ages are unknown.

In other monogenetic volcanic fields 'clustered' eruptions have been attributed to the mechanism of magma production (Le Corvec et al., 2013b). Similarly, melt production at the AVF has, in some cases, been attributed to multiple sources (discussed below sect. 5.5.5.1.), which have differing methods of ascent (McGee et al., 2013), seen most often as zoned single eruptions (e.g. Motukorea; McGee et al., 2012). The first melt batch represents a smaller volume, lower flux melt, representing the initial 'path finder' to the surface, and the second batch represents a much larger higher flux melt, exploiting the pathway established by the first batch (e.g., Strong and Wolff, 2003). It is conceivable that if the magma flux of the initial melt is low that the ascent pathway does not remain open, the second batch will either not make it to the surface, or ascend via a slightly different route to the surface (e.g., Valentine and Krogh, 2006). McGee et al. (2011; 2015) discuss evidence that supports this second suggestion based on $U$ series data. Their study on coupled centres (e.g. Rangitoto 1 
and 2) found evidence for ascent through two methods, 1) Initial rapid ascent from depth through high porosity channels indicated by high ${ }^{230} \mathrm{Th} /{ }^{232} \mathrm{Th}$ but low ${ }^{226} \mathrm{Ra} /{ }^{230} \mathrm{Th}$, followed by 2) slower, more diffusive flow from shallower depths which developed lower ${ }^{230} \mathrm{Th} /{ }^{232} \mathrm{Th}$ but higher ${ }^{226} \mathrm{Ra} /{ }^{230} \mathrm{Th}$ (McGee et al., 2011). The evidence of a minimal time gap between two closely spaced eruptions would support this alternate ascent route. This characteristic is considered to be as a result of the small volumes of magma that are associated with monogenetic volcanoes (Le Corvec et al., 2013b). For this hypothesis to be correct the geochemistry of the two coupled centres would have to reflect the differing geochemistry of the two sources (McGee et al., 2012) (discussed below).

\subsubsection{Geochemical evolution}

\subsubsection{Mantle source geochemistry}

In Chapter 4 the geochemical variability of the AVF's eruptive products was discussed, with minor inter-centre variability attributed to the effects of fractional crystallisation on ascending magma (predominantly from olivine and clinopyroxene), and more major within-field variability attributed to the mixing of multiple magma sources. The three proposed sources include,

(1) Ambient MORB-like asthenosphere ( $\geq 80 \mathrm{~km}$ depth), containing

(2) Carbonated peridotite domains (McGee et al., 2015), which mix with

(3) A shallower $(\leq 80 \mathrm{~km})$ subduction metasomatised lithosphere

Evidence for these three mantle sources was primarily based on isotope analyses (McGee et al., 2013). The subduction metasomatised lithosphere was identified based on elevated ${ }^{87} \mathrm{Sr} /{ }^{86} \mathrm{Sr}$ (indicative of a weak subduction signature), and ${ }^{238} \mathrm{U} /{ }^{232} \mathrm{Th}$ (coupled with low ${ }^{230} \mathrm{Th} /{ }^{232} \mathrm{Th}$ ratios), the lowest ${ }^{206} \mathrm{~Pb} /{ }^{204} \mathrm{~Pb}(<19.1)$ and low ${ }^{208} \mathrm{~Pb} /{ }^{204} \mathrm{~Pb}$ (ca. 38.8) ratios indicating the involvement of a less radiogenic shallow source (e.g. Cook et al., 2005; Hoernle et al., 2006; Timm et al., 2010). In comparison, the carbonated peridotite source was characterised by high ${ }^{206} \mathrm{~Pb} /{ }^{204} \mathrm{~Pb}$ (>19.4) and ${ }^{208} \mathrm{~Pb} /{ }^{204} \mathrm{~Pb}$ (ca. 39) ratios coupled with high ${ }^{230} \mathrm{Th} /{ }^{232} \mathrm{Th}$ ratios indicative of an enriched garnet-bearing source. The ambient MORB like signature in the 
asthenospheric mantle is identified by intermediate ${ }^{206} \mathrm{~Pb} /{ }^{204} \mathrm{~Pb}$ ratios with relatively low ${ }^{207} \mathrm{~Pb} /{ }^{204} \mathrm{~Pb}$ ratios in comparison to the other sources (c.f. Fig. 1.6, Chapter 1). Isotopes have not however been measured for this study and therefore indicators from major and trace element compositions, and ratios, are more relevant here. Isotope signatures are further discussed and outlined in Chapter 6.

The major and trace element compositions that characterise the subduction metasomatised lithospheric source include a positive $\mathrm{Sr}$ anomaly and no negative $\mathrm{K}$ anomaly, and a decrease in trace element concentrations (McGee et al., 2013, discussed Chapter 4). For example high $\mathrm{Zr} / \mathrm{Nb}$ and $\mathrm{K} / \mathrm{La}$, and low (La/Sm) $\mathrm{N}$ ratios are attributed to a depleted source with high levels of previous melt extraction supported by low $\mathrm{CaO}$ and $\mathrm{MnO}$ concentrations (e.g. Timm et al., 2009). The shallow gradient in HREE is indicative of a garnet-poor source, as discussed in Chapter 4 section 4.4.2, attributed to a shallow lithospheric mantle.

The ambient MORB-like asthenosphere is proposed to be the main component in the AVF source (McGee et al., 2013), and it is primarily identified by the $\mathrm{Pb}$ isotope compositions as discussed previously. In addition, carbonated peridotite zones were identified within the ambient asthenospheric source (by McGee et al., 2015) based on the similarity of the Purchas Hill signatures to experimental derived values for carbonatites (c.f. Gerbode and Dasgupta, 2010; Beier et al., 2013; Scott et al., 2014). Key sample characteristics include high Siundersaturated, alkalic, nepheline-normative geochemistry, with elevated $\mathrm{CaO} / \mathrm{Al}_{2} \mathrm{O}_{3}$, low Mg\#, and negative correlations between $\mathrm{K} / \mathrm{La}$ or $\mathrm{Ti} / \mathrm{Eu}$ vs. La/Yb.

Those centres that exhibit a large negative $\mathrm{K}$ anomaly are interpreted to reflect a high proportion of carbonatite in their source (e.g., Purchas Hill is 100\% asthenospheric melt (ambient mantle + carbonatite domains); McGee et al., 2013). Conversely those that exhibit a large $\mathrm{Sr}$ anomaly are interpreted to reflect a larger proportion of lithospheric source melt (e.g., Rangitoto is ca. $80 \%$ lithospheric melt + 20\% asthenospheric melt (ambient mantle + carbonatite domains); McGee et al., 2013). Variable proportions of these three sources will produce the range in signatures across the field based on the associated mixing proportions, and thus variably coupled $\mathrm{Sr}$ and $\mathrm{K}$ anomalies. 
It is hypothesised (McGee et al., 2013, 2015) that initial melting occurs within carbonated peridotite domains in the asthenosphere due to the lower solidus of the material in comparison to the surrounding non-carbonated peridotite (Pertermann and Hirschmann, 2003; Herzberg et al., 2007). Once the domains of carbonated peridotite are exhausted, the melt source moves to the surrounding ambient mantle peridotite (e.g. McGee et al., 2012), and finally on ascent, the largest volumes of melt are generated through the incorporation of the shallow lithospheric source, which variably dilutes the initial deep-source signature. In order to retain the signature of the deeper source, the ascent of the smaller magma batches must be rapid, and efficient, adding further support to the ascent mechanisms modelled by McGee et al. (2011; 2015) (discussed in section 5.5.4).

\subsubsection{Centre geochemistry and scale relationship}

The primitive ( $\mathrm{MgO} \geq 8 \mathrm{wt} \%)$ AVF whole rock data show a correlation between the volume of the eruptive centre (Kereszturi et al., 2013), and geochemistry, specifically $\mathrm{SiO}_{2}, \mathrm{CaO} / \mathrm{Al}_{2} \mathrm{O}_{3}$, and ( $\left.\mathrm{La} / \mathrm{Yb}\right)_{\mathrm{N}}$ (Fig. 5.21; McGee et al., 2015). Contrary to comments by Brenna and Cronin (2015), in general, the smaller centres show the lowest $\mathrm{SiO}_{2}$, coupled with high $\mathrm{CaO} / \mathrm{Al}_{2} \mathrm{O}_{3}$, and high $(\mathrm{La} / \mathrm{Yb})_{\mathrm{N}}$ ratios, and the converse is true for the larger centres.

McGee et al. (2015) propose that the deeper mantle signature, identified by the high $(\mathrm{La} / \mathrm{Yb})_{\mathrm{N}}$, low $\mathrm{SiO}_{2}$ (wt.\%), and high $\mathrm{CaO} / \mathrm{Al}_{2} \mathrm{O}_{3}$ ratio, is produced from a higher proportion of carbonated source within the ambient mantle signature. This correlates with smaller magma batches, and thus smaller eruptions (indicated by $\left.D R E^{\text {tot }}\right)$. In comparison the shallower mantle signature, identified by the low $(\mathrm{La} / \mathrm{Yb})_{\mathrm{N}}$, higher $\mathrm{SiO}_{2}$ (wt\%) and lower $\mathrm{CaO} / \mathrm{Al}_{2} \mathrm{O}_{3}$ ratio, produced from the subduction metasomatised lithospheric source, is correlated to the larger eruptions. When combining the new data from this thesis with the pre-existing data used by McGee et al. (2015), Rangitoto remains the 'large' end-member, however, new data from Mt Cambria (and Boggust Park) are the new 'small' end-members, superseding previous 'small' end-member Purchas Hill (Fig. 5.21.). The values measured for $(\mathrm{La} / \mathrm{Yb})_{N}$ for Mt Cambria fit the trend, exhibiting higher ratio values than Purchas Hill. The geochemical signatures are not however fully comparable with the previously outlined criteria, for example the $\mathrm{SiO}_{2}$ values for $\mathrm{Mt}$ Cambria are higher and $\mathrm{CaO} / \mathrm{Al}_{2} \mathrm{O}_{3}$ values are lower than for those of Purchas Hill (Fig. 5.21). For $\mathrm{SiO}_{2}$ and 
$\mathrm{CaO} / \mathrm{Al}_{2} \mathrm{O}_{3}$ the correlation is clearly less well defined, attributed to the effects of minor amounts of fractional crystallisation on the major elements during magma ascent. The $(\mathrm{La} / \mathrm{Yb})_{N}$ ratio shows a strong correlation because these two elements are incompatible, and are therefore not affected by fractional crystallisation (as discussed in sect. 5.3.1.).
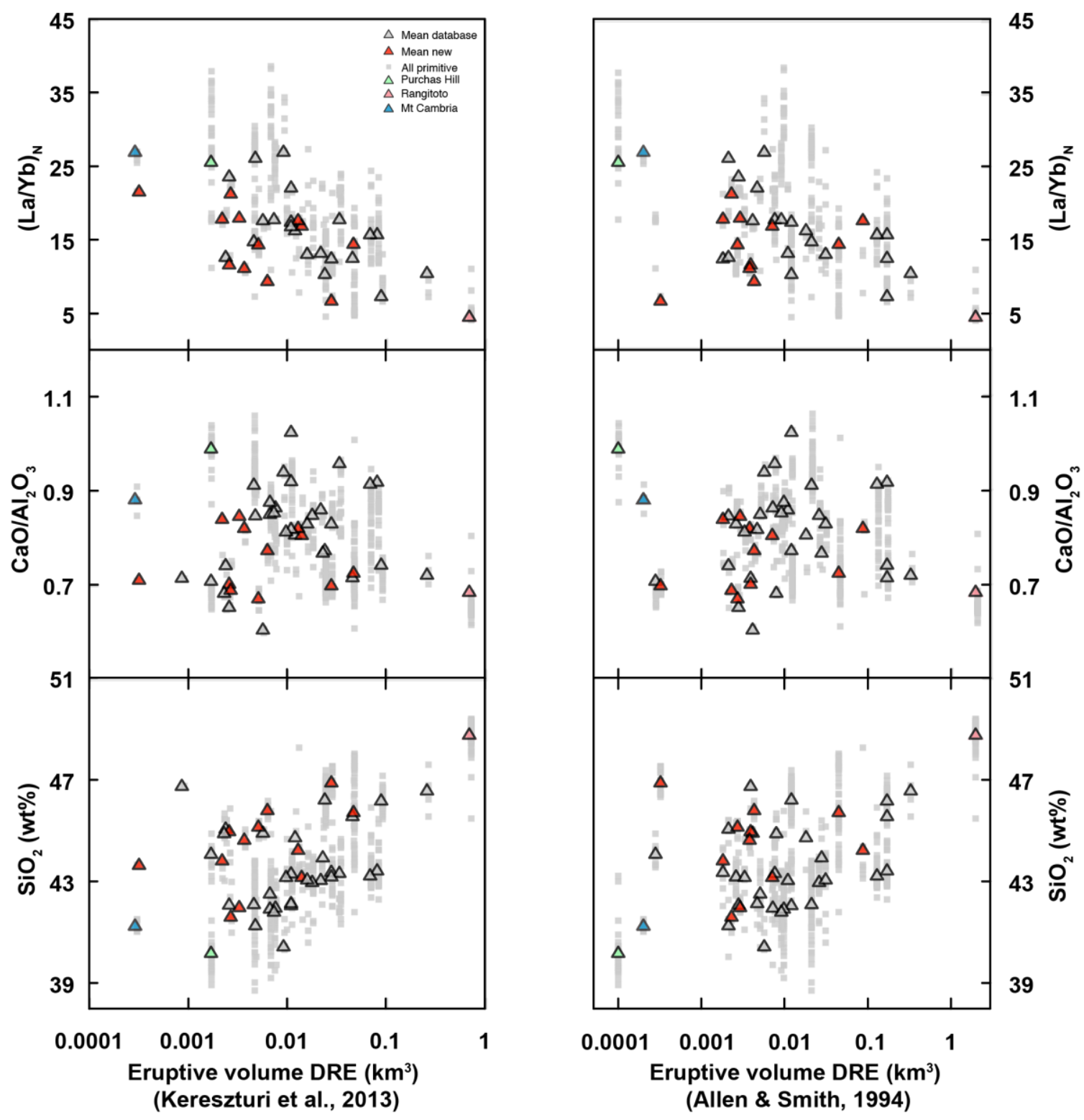

Figure 5.21. Comparison plots of geochemistry versus eruptive volume. Data are plotted versus both Kereszturi et al. (2013) and Allen and Smith (1994) estimates for DRE $E^{\text {tot }}$ (discussed in sect 5.2.5 and outlined in table 5.2.) Points show the average values for all primitive ( $>8 \mathrm{wt} \% \mathrm{MgO}$ ) samples for an individual centre: grey symbols showing existing database values, and red symbols show data added by this study, Rangitoto is highlighted in pink, Purchas Hill in green and Mt Cambria in orange. 
Previous studies (e.g. McGee et al., 2013) also indicated a more complex correlation for the centre size based on their multi-element primitive mantle normalised trace element plot trends. All the centres studied ( $n=10$; McGee et al., 2013) were split into three types: 'small' (e.g., Purchas Hill, with large negative K anomaly, no Sr anomaly, steep HREE trend), 'intermediate' (e.g., Wiri Mt, with both negative K and positive Sr anomaly), and 'large' (e.g., Rangitoto, with no negative K anomaly but a large positive Sr anomaly, and shallow HREE trend). For Mt Cambria again however, this geochemical-volume correlation appears to not be consistent with these previous size designations. Mt Cambria is one of the smallest centres in the field, and much smaller than Purchas Hill (DRE $0.00029 \mathrm{~km}^{3}$ versus $0.0017 \mathrm{~km}^{3}$, respectively: Kereszturi et al., 2013), but it does not show a much smaller $\mathrm{Sr}$ anomaly (0.96-0.98), a more extreme $\mathrm{Zr}-\mathrm{Hf}$ trough, or steeper REE element trend than Purchas Hill $\left(\mathrm{Sr}^{*} \mathrm{~N}=0.95-1.0\right.$; McGee et al., 2013). Conversely, new data from Little Rangitoto shows a small negative $\mathrm{K}$ anomaly, a large positive $\mathrm{Sr}$ anomaly (1.15-1.19), and a steep REE pattern, considered indicative of an 'intermediate' scale (McGee et al., 2013), but has an estimated DRE volume of $0.0017 \mathrm{~km}^{3}$, the same size as Purchas Hill. Te Pou Hawaiki, the only new centre to show a similar trend to Rangitoto (large positive Sr anomaly, no $\mathrm{K}$ anomaly and a shallow HREE slope), has a DRE of $0.028 \mathrm{~km}^{3}$, which is not one of the largest centres within the field (9th largest) (see Fig. 4.5.).

Assuming the correlation between scale and geochemistry is correct, a number of the new centres exhibit geochemical signatures indicative of larger magma batches than their total eruptive products suggest. Although distal tephra is not accounted for in the Kereszturi et al. (2013) model, this is not considered enough to balance the potential volume discrepancies. It is therefore conceivable to propose that, if the geochemical signatures of the erupted products are more representative of a larger centre than is calculated from the surface deposits, there is a loss in magma volume on ascent. There are two possible explanations for this, 1) some of the magma is simply not erupted and remains within the crust, or 2) some of the magma is lost through minor amounts of fractional crystallisation, coupled with the resultant omittance of crystals in the erupted lavas. This second possibility is supported by the slightly less defined correlations seen between $\mathrm{SiO}_{2}$ and $\mathrm{CaO} / \mathrm{Al}_{2} \mathrm{O}_{3}$ (Fig. 5.21.). However, because many of the AVF lavas have a primitive 
geochemical signature, there is only evidence of limited fractional crystallisation occurring (e.g., Smith et al., 2008), which may not be enough to account for the discrepancy between geochemical signature and eruptive scale. Therefore it is most likely that both retention and fractional crystallisation of ascending melts affect the final proportion of magma that is erupted. This assumption highlights a potentially complex relationship between ascending melt and crust.

\subsubsection{Time resolved geochemistry}

Figure $\mathbf{5 . 2 2}$ shows the centres in their proposed relative eruption order (Table 5.8.) versus the $\mathrm{SiO}_{2}$ and $(\mathrm{La} / \mathrm{Yb})_{\mathrm{N}}$ content, which, as outlined previously, are analogous with eruption size. This figure suggests that the erupted size over the history of the field is not random. There appears to be cyclicity in the eruption pattern that shows a large eruption (e.g. One Tree Hill) is followed by a small eruption (e.g. Mt. Cambria), which is followed by multiple medium eruptions that increase in scale up to another large eruption (e.g. Crater Hill). In general there is a shorter time period between the two extreme eruptions (e.g. 11 ka between One Tree Hill and Mt. Cambria), than the subsequent period of increasing scale (e.g. 18 ka between Mt. Cambria and Crater Hill). The timing of this periodicity is also concurrent with the repose periods, increasing in time until ca. $21.5 \mathrm{ka}$ then decreasing again to the most recent eruption.

As previously discussed, the eruptive scale and geochemical signatures are produced as a result of variably mixing the mantle source. The cyclicity that is observed over the history of the AVF therefore suggests that the mantle source is variably tapped through time. With a predominant deep source producing the small centre signature, followed by increasing input from a shallow source creating the multiple medium to large eruptions. 
- Mean values for centres with unambiguous relative ages

- Mean values for centres with ambiguous relative ages (confidence 3 correlations or Ar-Ar age placement)

All other primitive ( $\mathrm{MgO} \geq 8 \mathrm{wt} \%$ ) values

DRE $^{\text {tot }} \geq 0.0076 \mathrm{~km}^{3}$ largest $50 \%$ of centres

DRE $^{\text {tot }} \leq 0.0074 \mathrm{~km}^{3}$ smallest $50 \%$ of centres
Linking small centres Linking large centres

— Linking mean values

Error in relative age placement associated

with Ar-Ar age range estimates

$+\quad$ No primitive geochemical data

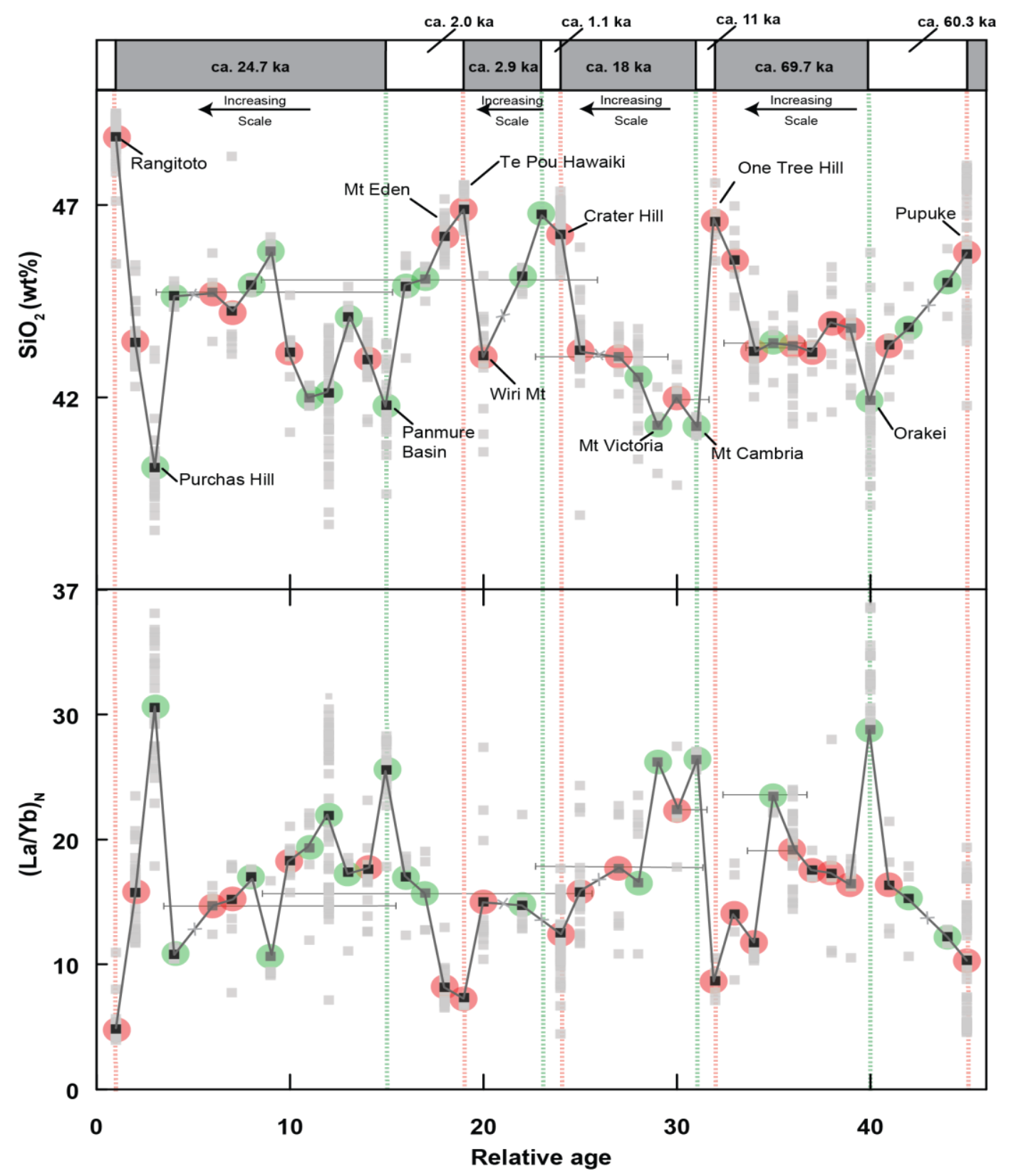

Figure 5.22. All primitive whole rock samples ( $M g O \geq 8 w t \%)$ from each centre plotted in their newly constrained relative age order (Table 5.7.) from 45 (Pupuke) as the oldest to 1 (Rangitoto) as the youngest. Black markers show the calculated mean concentrations for $(\mathrm{La} / \mathrm{Yb})_{\mathrm{N}}$ and $\mathrm{SiO}_{2}$ (wt\%). Those centres with slightly ambiguous ordering (e.g. an Ar-Ar age range which means they do not have a definitive position) are show in a lighter grey and have their error in relative age placement detailed. 
Centres that exhibit evidence for coupled eruptions, e.g. Rangitoto 1 and 2, and Mt. Wellington and Purchas Hill, show a systematic decrease in successive eruptions for $(\mathrm{La} / \mathrm{Yb})_{\mathrm{N}}$ vs. $(\mathrm{Gd} / \mathrm{Yb})_{\mathrm{N}}$, with the first centre having high values and the second centre having low values. This pattern is not however consistent for all the centres identified as 'coupled'. For Domain and Grafton, Otara and Hampton Park, Mt. Eden and Te Pou Hawaiki, both of the centres show geochemical signatures which span the full range of both high and low ratios. This therefore suggests that both source signatures are evident in a single centre, rather than occurring in the successive couplets. For some of the coupled centres there is limited geochemical data available, and therefore observation of the geochemical relationship cannot be made for Tank Farm and Onepoto, Green Mt. and Styaks Swamp, and Wiri Mt. and Ash Hill. Although inconclusive, due to the lack of data for some centres, these results suggest that although there is a temporal and spatial relationship between some of the centres, the hypothesised geochemical relationship for the coupled centres, from primary erupted small volume melts (e.g. low $\mathrm{SiO}_{2}$ and high $\left.(\mathrm{La} / \mathrm{Yb})_{\mathrm{N}}\right)$ to secondary erupted large volume melts (e.g. high $\mathrm{SiO}_{2}$ and low $(\mathrm{La} / \mathrm{Yb})_{\mathrm{N}}$ ) (sect. 5.5.4.) is not seen. This geochemical evolution is however observed within single eruptions (e.g., Motukorea and Crater Hill), suggesting that although geochemically linked couplets may be rare, systematic variation throughout an eruption sequence could also be prevalent in the AVF centres.

From these observations we can conclude that there is evidence for cyclicity relating to the scale of eruptions at the AVF, and that following a large eruption (e.g. Rangitoto) there is most likely to be a very small eruption. There is limited evidence for a systematic evolution in the geochemistry, indicating that the source signature is not evolving through time, rather that the field is variably tapping and mixing multiple magma sources. The geochemical signatures preserved in the eruptive products from the AVF centres provide evidence for the presence of a heterogeneous mantle (asthenospheric and lithospheric) source beneath the AVF. This heterogeneity is reflected as geochemical signature within single centres, coupled centres, and fieldwide. The apparent links between scale of eruption and geochemical signature (e.g. $\mathrm{SiO}_{2}$ and $\left.(\mathrm{La} / \mathrm{Yb})_{N}\right)$, imply that the ascent and eruption of the smaller batches must be highly rapid and efficient in order to preserve their signature. But for some centres 
there is also apparent evidence of magma volume loss through fractional crystallisation and/or retention of melt within the crust.

\subsection{Conclusions}

The collation of whole rock major and trace element data for the field has (with a few exceptions) facilitated the development and testing of a method to correlate the tephra deposits to their source volcanic centre. Correlation between tephra and the glassy matrix of whole rock deposits using geochemistry is proved to be reliable; it produces well-correlated results based on major element signatures, which is strengthened by the use of trace element signatures. Furthermore incompatible trace elements and their ratios (specifically $\mathrm{La} / \mathrm{Yb}, \mathrm{Ce} / \mathrm{Yb}, \mathrm{Gd} / \mathrm{Yb}$, $\mathrm{Zr} / \mathrm{Yb}, \mathrm{Nb} / \mathrm{Yb}$ and $\mathrm{Nd} / \mathrm{Yb}$ ) are representative for individual centres and can therefore be used to correlate basaltic tephra to whole rock samples. Specifically the ratios listed above are the most useful in assigning individual geochemical fingerprints because they are the more variable field wide, the least variable intra-centre, and the least affected by fractional crystallisation processes.

Although geochemistry has proven to be an effective tephra correlation tool, it is not always distinct enough to provide a definitive result. To efficiently correlate tephra layers to their source centres, a multi-faceted approach is required. This combined approach uses age (of both tephra deposit and whole rock deposit) and eruption characteristics (e.g. scale and locality), to assign the source centre to tephra deposits with the highest confidence. Of the twenty eight basaltic tephra horizons in the AVF maar cores, all but two (newA and newB) are correlated to a source; eight with a confidence rating of 1 , twelve with a confidence rating of 2 , and seven with a confidence rating of 3 .

As a result, the level 1 confidence correlations can be used to determine tephra dispersal and thickness from the AVF eruptions. The maximum tephra dispersal distance is $13.5 \mathrm{~km}$ with a deposit thickness of $2 \mathrm{~mm}$, and for all deposits with a thickness $>100 \mathrm{~mm}$ the source is $<6 \mathrm{~km}$ away. In a number of cases the deposits are restricted to local regions of the field, in close proximity to the source 
centre, suggesting that in the event of a future small-scale eruption, the entire Auckland area may not be affected.

The correlations also facilitate construction of a more definitive picture of the evolution of the AVF. Due to the stratigraphic relationships of the tephra horizons within the cores, and their association with the rhyolitic marker horizons, the absolute age order of the centres can be resolved. Because of the errors associated with dating techniques ( $\mathrm{Ar}-\mathrm{Ar}$ and ${ }^{14} \mathrm{C}$ ) a relative sequencing of the AVF centres was previously difficult. With our new method 45 centres have a high-confidence age estimate associated with their eruption leaving only seven centres with uncertain ages (Mangere Lagoon, Pukaki, Pukewairiki, Mt. Robertson, Boggust Park, Cemetery Hill and Puhinui Craters).

The temporal eruptive history suggests that the repose periods of the AVF are highly variable, from $<0.1$ to $13 \mathrm{kyr}$. In general, the field had a slow initial eruption frequency with 19 eruptions in the first $150 \mathrm{kyr}$, followed by an increase in eruption frequency until $21.5 \mathrm{ka}$, after which the eruption rate slowed. Successive eruptions are shown to be spatially highly variable with distances of ca. $0.5-21 \mathrm{~km}$ between vents. Some clustering of centres is observed, attributed to exploitation of preexisting crustal weaknesses or locally fractured crust, although no general spatial evolutionary trend could be determined for the AVF. Coupled eruptions in space and time are identified, however most are not geochemically related. Cyclicity in size and thus geochemistry is also highlighted showing that throughout the history of the AVF three mantle sources have been variably tapped to produce the erupted products of the field.

This study has outlined the method by which a distal basaltic tephra deposit can be correlated to its source signature using geochemical compositions of tephra and whole rock, coupled with a number of other criteria. This information is critical for the assessment and construction of future hazard and risk forecasting of the AVF, which poses a potentially significant threat to large population and complex infrastructure. 


\section{Preface to Chapter 6}

Chapter 5 outlined the geochemical evolution of the AVF based on the relative age order that was created as a result of the source centre correlation techniques. There is a perceived cyclicity in eruption scale, which is linked to the geochemical signature. Based on the conclusions of previous studies (Huang et al., 1997; McGee et al., 2013) these geochemical signatures were attributed to variations in source input, suggesting increasingly variable mixing proportions of the two sources through time. In general, the increasing input from a shallower, fluid enriched mantle source, was shown to result in volumetrically larger eruptions. This field wide general trend is also mirrored in some coupled eruptions (e.g. Rangitoto 1 and 2), and throughout some single eruptions. Chapter 5 also highlights evidence for loss of melt volume through fractional crystallisation and/or retention of melt in the crust, hinting at the complex nature of the pre-eruptive processes for the AVF volcanoes. Combined with the mantle processes, crustal processes (e.g. the interplay between ascending melt and crust) are suggested by some authors to be highly complex (e.g. Bryner, 1991; Spörli and Black, 2013; Spörli et al., 2015). However, the role for crustal processes has not been reported within the detailed mantle geochemical studies of Huang et al. (1997) or McGee et al. (2013).

To further investigate the geochemical evolution of the AVF, it was considered necessary to assess the complex pre-eruptive processes that have been indicated by the results from Chapter $\mathbf{5}$ and $\mathbf{4}$, and from previous studies. Until now only the Sr-Nd-Pb (e.g., Huang et al., 1997; McGee et al., 2013) and U-Ra-Th (McGee et al., 2011 ) isotope systems have been used to asses the AVF mantle processes. Here I use the Os-Re isotope system, which has been shown to be much more sensitive in tracing crustal (or recycled crustal) products within primitive lavas (e.g., McBride et al., 2001; Jung et al., 2011). Chapter 6 is presented in the form of a multi-author paper in preparation for submission to Chemical Geology. Authorship contributions include; Timm - development of discussion points and manuscript edits; Millet facilitated research and manuscript edits; Poirier - training of Hopkins on analytical methods, and some independant analysis of Os, Re, and Os isotopes; Wilson and Leonard - manuscript edits. 


\section{Chapter 6}

\section{Os isotope constraints on crustal contamination in Auckland Volcanic Field basalts, New Zealand}

Jenni L. Hopkins ${ }^{\star a}$

Christian Timm ${ }^{b}$, Marc-Alban Milletc, André Poirier ${ }^{d}$, Colin J.N. Wilson ${ }^{a}$, Graham S. Leonard ${ }^{b}$.

aSchool of Geography, Environment and Earth Sciences, Victoria University, PO Box 600, Wellington 6140, New Zealand

bGNS Science, PO Box 30368, Lower Hutt 5040, New Zealand

'Department of Earth Sciences, Durham University, Durham DH1 3LE, England

¿Geotop, Université du Québec à Montréal, Montréal, H3C 3P8, Canada

Keywords

Auckland Volcanic Field, Os isotope, crustal contamination, AFC modelling, Dun Mountain ophiolite belt 


\section{Abstract}

The Auckland Volcanic Field (AVF) represents the youngest and northernmost of three main intraplate volcanic fields on North Island, New Zealand. Previous studies suggested that AVF lava major and trace element, and Sr-, $\mathrm{Nd}$-, $\mathrm{Pb}$-isotope compositions primarily reflect their derivation from asthenospheric and lithospheric mantle sources. We present new $\mathrm{Os}$ and $\mathrm{Pb}$ isotope data, and Os and Re concentrations for 15 lava samples from 7 centres of the AVF, to further explore mantle and crustal processes. The samples include a selection of the most primitive lavas from the field (Mg\# 5969) and span a range of eruption sizes, ages, locations, and geochemical signatures. The new data show a large range in Os concentrations (6-579 ppt) and ${ }^{187} \mathrm{Os} /{ }^{188} \mathrm{Os}$ isotope ratios from mantle-like $(0.123)$ to highly radiogenic (0.547). Most samples exhibit highly radiogenic Os signatures together with relatively low Os contents suggesting that ascending melts experienced contamination primarily from metasedimentary crustal rocks with high ${ }^{187} \mathrm{Os} /{ }^{188} \mathrm{Os}$ (e.g., greywacke). Based on AFC modelling, $<1 \%$ crustal input into the ascending melt can produce the radiogenic Os isotope signatures. This low level of crustal contamination has no measurable impact on the AVF $\mathrm{Sr}-\mathrm{Nd}-\mathrm{Pb}$ isotope or trace element signatures. In addition, three samples have high Os (Os $=194-578$ ppt) contents at mantle-like Os isotope compositions $\left({ }^{187} \mathrm{Os} /{ }^{188} \mathrm{Os}=0.1283-0.1377\right)$ suggestive of contamination of the ascending melts with xenocrystic olivine-hosted mantle sulphides. An obvious source is the Permian-Triassic ultramafic Dun Mountain Belt, which traverses the crust beneath the Auckland Volcanic Field. We therefore interpret that the AVF Os isotopic composition and Os contents represent contamination events in a heterogeneous crust composed of Waipapa and Murihiku Terrane metasediments and ultramafic rocks of the Dun Mountain Ophiolite Belt. This demonstrates, contrary to previous models that primitive lavas from the Auckland Volcanic Field interacted variably with the crust. 


\subsection{Introduction}

Monogenetic volcanic fields (MVF) are the surface expression of smallscale magmatic systems found in a number of different tectonic settings, including extensional systems relating to active arcs (e.g., Cascades, USA; Borg et al., 2000), or subduction (e.g., Wudalianchi, China; Hwang et al., 2005), or intraplate settings relating to rifting or plume upwelling (e.g., Eifel, Germany; Shaw, 2004). Monogenetic volcanic centres are linked to individual, often small-volume, batches of magma $\left(<0.1 \mathrm{~km}^{3}\right)$ (e.g., Connor and Conway, 2000; Németh, 2010; Kereszturi et al., 2013), which erupt over short periods of time (e.g., Németh, 2010), eventually leading to the formation of fields encompassing tens to hundreds of individual centres (e.g., Condit and Connor, 1996; Conway et al., 1998; Connor and Conway, 2000; Valentine et al., 2005). These fields show a range of surface expressions, dependent on the eruption style and magma-water interaction, including tuff rings, maars, scoria cones, and lava flows (e.g., Allen and Smith, 1994; Németh, 2010; Kereszturi et al., 2014). In addition, a link between physical characteristics of monogenetic basaltic volcanism and mantle heterogeneity has recently been proposed (McGee et al., 2015) highlighting the importance to understand the characteristics of different sources contributing to magmas beneath volcanic fields.

Petrological and geochemical studies have shown that basaltic monogenetic fields are the most common petrology type (e.g., Connor and Conway, 2000), which are characterised by the eruption of silica undersaturated basinites, nephelenites and alkaline basalts that are akin to Ocean Island Basalt (OIB) (e.g., Huang et al., 1997; Cook et al., 2005; Valentine and Gregg, 2008;). Nevertheless, lavas can show considerable geochemical variations within volcanic fields (e.g., Valentine and Hirano, 2010; Timm et al., 2010; McGee et al., 2013), and within individual centres, the origins of which remain controversial (e.g., Bradshaw and Smith, 1994; Valentine and Gregg, 2008; Needham et al., 2011; Brenna et al., 2010, 2011; McGee et al., 2012). Several studies have attributed variations in geochemical and isotopic signatures, both for individual eruptions and on a field wide scale, to mantle heterogeneity (e.g., Huang et al., 1997; McBride et al., 2001; Cook et al., 
2005; McGee et al., 2013), or magma modification at various depths by wall rock assimilation and contamination or fractional crystallisation (e.g., Lassiter and Luhr, 2001; Alves et al., 2002; Chesley et al., 2002; Jamais et al., 2008; Timm et al., 2009). Any crustal assimilation and contamination may be facilitated by storage or ponding within the crust (e.g., Bohrson et al., 1997), however lava erupted in monogenetic volcanic fields are generally mafic (>8 wt.\% $\mathrm{MgO}$ ), suggesting that they have undergone little fractional crystallization and arguing against long magma storage in the crust. Variations mainly in the trace element, and $\mathrm{Sr}-$, $\mathrm{Nd}$-, and $\mathrm{Pb}$-isotopic composition of lavas from monogenetic volcanic fields are therefore proposed to primarily resemble the composition of the underlying lithospheric and asthenospheric mantle (e.g., Valentine and Perry, 2007; McGee et al., 2012, McGee et al., 2013; McGee et al., 2015).

Nevertheless, a prerequisite first step for the interpretation of geochemical data from continental intra-plate basalts is to distinguish between the geochemical signature of mantle heterogeneity and crustal contamination (e.g., Blondes et al., 2008; Jung et al., 2011). To understand the role of the crust and mantle petrogenesis beneath a continental monogenetic volcanic field we use the ${ }^{187} \mathrm{Re}^{187}$ Os decay system. This isotope system was chosen as it is highly sensitive to crustal contamination due to a significant difference in ${ }^{187} \mathrm{Os} /{ }^{188} \mathrm{Os}$ between continental crust and the mantle. It therefore provides a unique tool to study subtle signs of crustal influence (e.g. Central European Volcanic Province (CEVP), Jung et al., 2011; Newer Volcanics Province (NVP), McBride et al., 2001) and mantle heterogeneity in lavas. The significant differences of ${ }^{187} \mathrm{Os} /{ }^{188} \mathrm{Os}$ in the crust and mantle result from contrasting behaviour of $\mathrm{Re}$ and Os during partial melting. Because Os behaves compatibly in mantle sulphides it primarily remains in the mantle whereas $\mathrm{Re}$ is moderately incompatible, and it preferentially enters the melt. The difference in the behaviour of $\mathrm{Re}$ and Os therefore results in extreme fractionation (e.g. high Re/Os in melt and crust, and low Re/Os in the mantle). Radioactive decay of ${ }^{187} \mathrm{Re}$ to ${ }^{187} \mathrm{Os}$ generates highly radiogenic ${ }^{187} \mathrm{Os} /{ }^{188} \mathrm{Os}$ values in old crustal rocks (up to ${ }^{187} \mathrm{Os} /{ }^{188} \mathrm{Os}=5.0$; McBride et al., 2001) and unradiogenic ${ }^{187} \mathrm{Os} /{ }^{188} \mathrm{Os}$ in the mantle (ca. 0.12; McBride et al., 2001). Thus, 
the contamination of a melt through either crustal assimilation (or recycled crustal derived material in a heterogeneous mantle) will cause an unusually radiogenic Os isotope signature.

Here we present new Os and Re concentrations and ${ }^{187} \mathrm{Os} /{ }^{188} \mathrm{Os}$ and ${ }^{206} \mathrm{~Pb} /{ }^{204} \mathrm{~Pb},{ }^{207} \mathrm{~Pb} /{ }^{204} \mathrm{~Pb},{ }^{208} \mathrm{~Pb} /{ }^{204} \mathrm{~Pb}$ isotope data for 15 mafic lavas from the Auckland Volcanic Field. The collection of this new data is aimed at identifying the relative importance of mantle heterogeneity (including crustal recycling) and the role of crustal contamination into ascending melts to give new insights into dynamics of melt generation and ascent beneath the city of Auckland.

\subsection{The Auckland Volcanic Field}

This study focuses on the monogenetic basaltic Auckland Volcanic Field (AVF), North Island, New Zealand. The AVF is located $400 \mathrm{~km}$ to the west behind the currently active arc, the Hikurangi Margin (Seebeck et al., 2014). The arc is thought to have regressed and rotated clockwise during the Miocene towards the south-east (Kear, 2004), but since 16 Ma the arc front is proposed to have migrated parallel to the subducting plate as a result of slab rollback along the Tonga-Kermadec subduction system (Seebeck et al., 2014). The AVF is the northernmost of three intraplate monogenetic volcanic fields active in, and since, the Pliocene (Ngatutura and Alexandra ca. 2.7-1.5 Ma; Briggs et al., 1994, and South Auckland ca.1.59-0.51 Ma; Cook et al., 2005) (Fig. 6.1.A).

The AVF consists of ca. 53 individual centres (Fig. 6.1.C; Hayward et al., 2011) that are emplaced over an area of ca. $360 \mathrm{~km}^{2}$ (Figure 1; Allen and Smith, 1994). The centres comprise explosion craters, tuff rings (now maar lakes), scoria cones and lava flows. The edifices are interpreted to have formed through single eruptions of small magma batches (e.g., Allen and Smith, 1994), except for the youngest and largest volcano Rangitoto, where two eruption episodes were identified (Rangitoto 1 [553 \pm 7 cal. yrs. BP] and Rangitoto 2 [504 \pm 5 cal. yrs. BP]; Needham et al., 2011). The total volume of erupted material in the AVF field is estimated at $1.7 \mathrm{~km}^{3}$ total dense rock equivalent (DRE ${ }^{\text {tot }}$ ), ca. $41 \%$ of which $\left(0.7 \mathrm{~km}^{3}\right)$ formed Rangitoto (Kereszturi 
et al., 2013). Previous studies have shown that basaltic volcanism commenced ca. $190 \mathrm{ka}$ ago (Chapter 5) and shows some distinct changes in eruption frequency over time, with eruption rate increasing to ca. $21.5 \mathrm{ka}$ (Chapter 5) and then decreasing up to the Rangitoto eruption. In Chapter $\mathbf{5}$ it is also concluded that there is no obvious spatial evolution of the field through time.

The crust underlying the AVF is $20-30 \mathrm{~km}$ thick, composed of Waipapa and the Murihiku-Dun Mountain Maitai-Brook Street terranes (Fig. 6.1.B) (e.g., Kermode 1992; Eccles et al., 2005; Horspool et al., 2006), overlain by up to 1-2 km of Miocene Waitemata group sediments. The Waipapa and Murihiku terranes consist of ca. 227.5 to $148.5 \mathrm{Ma}$ old late Triassic to late Jurassic low-grade meta-sediments. The Dun Mountain terrane represents a Permian to late Cretaceous oceanic arc ophiolite obduction event at the eastern Gondwana margin (e.g., Kimbrough et al., 1992). The Dun Mountain terrane consists of ultramafic rocks and includes dunites, Iherzolites, harzburgites and werhlites (McCoy-West et al., 2013). The terrane forms a distinct positive magnetic lineament - the Junction Magnetic Anomaly (JMA). The JMA can be traced continuously through the North and South islands of New Zealand (Hatherton and Sibson, 1970) and crosses the Auckland Volcanic Field as a narrow (ca. 2-5 km), linear series of anomalies interpreted to be eastward-dipping serpentinised shear zones, extending to depths of 20$30 \mathrm{~km}$ (Eccles et al., 2005). Direct evidence of the Dun Mountain Ophiolite Belt (DMOB) beneath the AVF occurs in the form of serpentinite xenoliths within volcanic rocks in tuff rings from Pupuke, St. Heliers and Taylors Hill volcanoes (e.g., Searle, 1959a; Bryner, 1991; Jones, 2007; Spörli et al., 2015). The basement rocks that make up the region of the study area have been extensively investigated (e.g., Bryner, 1991; Kermode, 1992; Eccles et al., 2005; McCoy-West et al., 2013), allowing potential sources of crustal contamination to be well characterised. Although the Auckland Volcanic Field has been the focus of many geochemical and petrological studies (Smith et al., 2008; Needham et al., 2011; McGee et al., 2011, 2012, 2013), questions about the origin of the observed geochemical composition of the lavas remain. In order to understand the complexity of melt dynamics in the AVF it is 
important not only to understand where partial melting occurs in the mantle, but also how the geochemical composition of melts evolve and change during ascent.

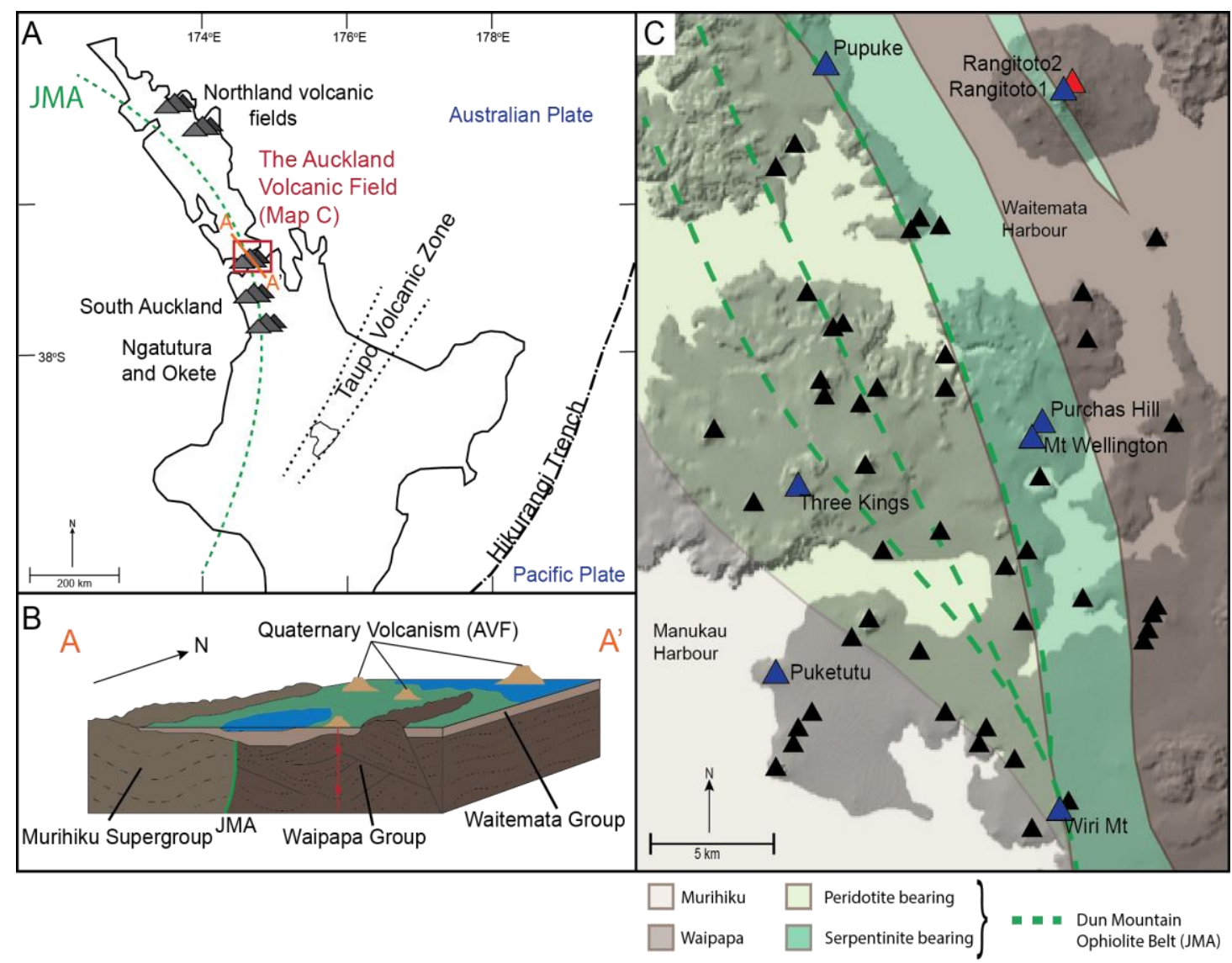

Figure 6.1. Schematic map of the Auckland Volcanic Field (AVF). (A) Location of the AVF within the North Island, New Zealand. The green dashed line indicates the Dun Mountain Ophiolite belt identified by the Junction Magnetic Anomaly (JMA) (Eccles et al., 2005), the Taupo Volcanic Field (TVZ) is shown with the dotted line, and the Hikurangi Trench between the Australian and Pacific plates is shown with a dash-dot line. The migrating monogenetic volcanic fields are also marked, Ngatutura and Okete ca.2.7-1.5 Ma (Briggs et al., 1994) and South Auckland ca.1.59-0.51 Ma (Cook et al., 2005). (B) Schematic diagram adapted from Kermode (1992) and Eccles et al. (2005) outlining the basement geology beneath the AVF: cross section A-A' is shown in diagram A. (C) DEM map of the AVF, black triangles indicate the sites of the volcanic centres. Those sampled for this study are highlighted by name, and the geochemical groups assigned denoted by blue - $\mathrm{Low}_{-} \mathrm{SiO}_{2}$ group, and red- High$\mathrm{SiO}_{2}$ group (outlined in section 6.4.1. in the text). Proposed terranes at $1.5 \mathrm{~km}$ depth are shown (from Eccles et al., 2005). 


\subsection{Samples and Analytical techniques}

The major- and trace-element chemistry and $\mathrm{Sr}-, \mathrm{Nd}-$, and $\mathrm{Pb}$ isotopic composition of selected volcanic centres from the Auckland Volcanic Field have previously been discussed (McGee et al., 2011, 2012, 2013, 2015). For the purpose of this study 15 samples from Mt Wellington, Purchas Hill, Three Kings, Wiri Mt, Puketutu, the oldest centre Pupuke (190 $\pm 5.6 \mathrm{ka}$; Leonard et al., in prep. Appendix C) and the youngest Rangitoto 2 (504 \pm 5.0 calendar (cal.) yrs BP; Needham et al., 2011) were chosen to complement existing $\mathrm{Pb}$ isotope data and generate new Os content and isotope analysis. The samples chosen are some of the most primitive of the AVF lavas (Mg\# = 59-69) from a range of eruption centres covering the field's areal extent, centre size, and age (Table 6.1.). Generally the selected samples contain minor olivine phenocrysts ( $\leq 3 \mathrm{~mm}$ across) in a plagioclase, pyroxene, olivine-bearing groundmass, except for samples from Pupuke, which contain abundant large olivines $\geq 5 \mathrm{~mm}$ across.

All new samples were prepared for chemical and isotopic analysis at Victoria University of Wellington, New Zealand (VUW). Fresh samples were chipped using a Rocklabs Boyd crusher to $<15 \mathrm{~mm}$ in size and then reduced to powder in an agate ring mill. Major elements were analysed by XRF analysis at the Open University, Milton Keynes, UK on an ARL® 8420+ dual goniometer spectrometer. Powdered samples were fused with lithium metaborate and subsequently analysed following methods of Ramsey et al. (1995). Whin sill dolerite (WS-E) was run as an internal standard with associated accuracy of $<1 \%$ except for $\mathrm{Na}_{2} \mathrm{O}$ (2.37\%) and $\mathrm{P}_{2} \mathrm{O}_{5}(1.59 \%)$ and precision of $<2 \%$. For trace element concentrations the powdered samples were digested in hot concentrated $\mathrm{HF}$ and $\mathrm{HNO}_{3}$ for 4 days, and then dried to incipient dryness and taken up in concentrated $\mathrm{HCl}$ to reduce sample loss through the production of insoluble fluorides. Following this, samples were converted back into $\mathrm{HNO}_{3}$ then left for 3 days in hot $1 \mathrm{M} \mathrm{HNO}_{3}$ to form the final analytical solution. Sample dilutions were measured on an Agilent 7500CS ICP-MS at Victoria University, Wellington, using BHVO-2 as a primary standard, and BCR-2 as a secondary standard. Precision on BCR-2 ( $n=15$ from five digestions) was $<6.5 \% 2$ sd\% except for $\mathrm{Nb}, \mathrm{Cs}$, and $\mathrm{Ba}$ (all $\leq 8 \%$ ), 
and $\mathrm{Ta}, \mathrm{Pb}$, and $\mathrm{Nb}(\leq 20.5 \%)$, and values were all within $<6 \%$ of the reference value, except for $\mathrm{Cu}, \mathrm{Cs}$, and $\mathrm{Ta}$. All standard values are reported in Appendix B.

$\mathrm{Pb}$ isotope samples were prepared and purified in an ultra-clean chemical separation laboratory at VUW. For $\mathrm{Pb}$ isotope analysis $200 \mathrm{mg}$ of powdered sample was leached in ultrapure $6 \mathrm{M} \mathrm{HCl}$ for 1 hour at $120^{\circ} \mathrm{C}$, rinsed with Millipore water, and digested in ultrapure conc. $\mathrm{HNO}_{3}$ coupled with ultrapure conc. $\mathrm{HF}$, then turned into solution with $0.8 \mathrm{M} \mathrm{HBr}$. The solution was then centrifuged and loaded onto $5 \mathrm{~mm}$ columns equipped with $A G 1-X 8$ resin and $\mathrm{Pb}$ was extracted in a double-pass using $6 \mathrm{M} \mathrm{HCl}$. $\mathrm{Pb}$ isotopic compositions were analysed using a Neptune MC-ICP-MS at Durham University, UK. International standard NBS-981 was used to monitor machine drift, with internal precisions (2SE) of ${ }^{206} \mathrm{~Pb} /{ }^{204} \mathrm{~Pb}< \pm 0.0012,{ }^{207} \mathrm{~Pb} /{ }^{204} \mathrm{~Pb}$ $< \pm 0.0013,{ }^{208} \mathrm{~Pb} /{ }^{204} \mathrm{~Pb}< \pm 0.0044$. All values of $\mathrm{NBS}-981$ are outlined in Appendix B, and measured data are reported in Table 6.1.

Os isotope compositions and Re and Os contents were determined at GEOTOP, Université du Québec à Montréal (UQÀM), Canada following the method of Meisel et al. (2003). For these analyses $0.8 \mathrm{~g}$ aliquots of whole rock powder were spiked with a known enriched tracer solution of ${ }^{190} \mathrm{Os}$ ${ }^{185} \mathrm{Re}$, and digested in Teflon-sealed quartz tubes with $3 \mathrm{ml} 6 \mathrm{M} \mathrm{HCl}$ and $3 \mathrm{ml}$ conc. $\mathrm{HNO}_{3}$ at $300^{\circ} \mathrm{C}$ and 100 bar in a high-pressure asher unit (HPA-S, Anton-Parr-Perkin Elmer Instruments). After digestion Os was extracted using the Paris $\mathrm{Br}_{2}$ technique. $2 \mathrm{ml}$ of chilled $\mathrm{Br}_{2}$ was added to sample and left on a hot plate at $90^{\circ} \mathrm{C}$ for 2 hours. This scavenges the oxidised $\mathrm{Os}\left(\mathrm{OsO}_{4}\right)$ from the aqueous solution into the liquid $\mathrm{Br}_{2}$, leaving $\mathrm{Re}$ (and $\mathrm{PGEs}$ ) within the aqueous solution. 20 drops of $\mathrm{HBr}$ was added to the isolated liquid $\mathrm{Br}_{2}$ (including Os) to reduce $\mathrm{Os}$ from volatile $\mathrm{Os}^{8+}\left(\mathrm{OsO}_{4}\right)$ to non-volatile $\mathrm{Os}^{4+}$ $\left(\mathrm{OsBr}_{6}{ }^{2-}\right)$, and evaporated down. A final step of micro-distillation using $\mathrm{Cr}^{\mathrm{VI}}$ containing $\mathrm{H}_{2} \mathrm{SO}_{4}$ was used to purify the Os, and make sure it was quantitatively separated from isobaric Re (after Birck et al., 1997). Samples were then measured using a Triton TIMS in negative-ion mode for Os (Creaser et al., 1991) and on a Sector Field (SF)-ICP-MS for Re. Os and Re concentrations were calculated by isotope dilution from known spike solution 
values. Os blanks for total procedure are $0.3 \mathrm{pg}$, and $7 \mathrm{pg}$ for $\mathrm{Re}$, this value is subtracted from the sample totals in data processing, along with oxygen interference correction and spike-sample unmixing. The widely used standard DROsS was also analysed, with an internal precision (2SE) for ${ }^{187} \mathrm{Os} /{ }^{188} \mathrm{Os}$ of average measurements of $< \pm 0.00012$. For Re, the standard NIST SRM 3143 was used, with an internal precision (2SE) for average ${ }^{187} \mathrm{Re} /{ }^{185} \mathrm{Re}$ measurements of $< \pm 0.05$. All values for DROsS and NIST SRM 3143 are outlined in Appendix B.

\subsection{Results}

\subsubsection{Major and trace elements}

Volcanic rocks from the AVF range in composition from sub-alkaline silica under-saturated basanites to alkaline basalts (e.g., $\mathrm{SiO}_{2}=39.8-48.8$ wt.\%) following the rock classification of LeMaitre (2002). Most AVF lavas form broad negative trends with $\mathrm{MgO}$ (wt.\%) vs. $\mathrm{SiO}_{2}$, and $\mathrm{Al}_{2} \mathrm{O}_{3}$ (wt.\%) and positive trends with $\mathrm{CaO} \mathrm{FeO}^{t}, \mathrm{TiO}_{2}$, and $\mathrm{P}_{2} \mathrm{O}_{5}$ (wt.\%) indicative of olivine and pyroxene fractionation (Fig. 6.2.). The only exception are lavas from Rangitoto (in particular Rangitoto 2 samples) having consistently lower wt. \% FeOt, $\mathrm{TiO}_{2}, \mathrm{CaO}$ and $\mathrm{P}_{2} \mathrm{O}_{5}$ and higher $\mathrm{SiO}_{2}$ and $\mathrm{Al}_{2} \mathrm{O}_{3}$ at given wt.\% $\mathrm{MgO}$. Here we therefore define two groups a high $\mathrm{SiO}_{2}$ group (Rangitoto 2 samples), and a low $\mathrm{SiO}_{2}$ group (all other samples). Cook et al. (2005) identify a similar variability in major element compositions in lavas from the South Auckland Volcanic Field.

All AVF samples show primitive mantle normalised trace element distributions similar to ocean island basalt (OIB) (normalisation values after McDonough and Sun, 1995), with typical positive $\mathrm{Nb}$ and negative $\mathrm{K}$ anomalies on multi-element diagrams (Fig. 6.3.). Compared to the high-SiO 2 group lavas, the low- $\mathrm{SiO}_{2}$ group lavas shows higher $\mathrm{Nb}$ and $\mathrm{Ta}$ (e.g., $\mathrm{Nb} / \mathrm{Ba} \geq$ 0.2 ) relative to the large ion lithophile elements (LILE; $\mathrm{Rb}, \mathrm{Ba}, \mathrm{K}$ ). The low $\mathrm{SiO}_{2}$ group lavas furthermore have higher light rare earth elements (LREE; $\mathrm{La}, \mathrm{Gd}, \mathrm{Nd}$ ) but low heavy rare earth elements (HREE; Yb) in comparison to 
the high $\mathrm{SiO}_{2}$ group lavas resulting in high LREE/HREE values (e.g., (La/Yb) N >20). In addition the low $\mathrm{SiO}_{2}$ group shows high ratios of more to less incompatible elements, for example Th/HREE (e.g., Th/Yb $\geq 2$ ), higher $\mathrm{Ce} / \mathrm{Pb}$ $(>10)$, lower $\mathrm{K} / \mathrm{Nb}(<300)$ and $\mathrm{Sr} / \mathrm{Nb}(<5)$. Conversely the high-SiO 2 group lavas show only minor enrichment in $\mathrm{Nb}$ and $\mathrm{Ta}$ relative to the LILE (e.g., $\mathrm{Nb} / \mathrm{Ba} \leq 0.2$ ), have lower LREE but similar to slightly higher HREE (e.g., $\left.(\mathrm{La} / \mathrm{Yb})_{N}<20\right)$. These lavas have higher Th relative to HREE (e.g. Th/Yb $\left.<1\right)$, lower $\mathrm{Ce} / \mathrm{Pb}(<10)$, yet higher $\mathrm{K} / \mathrm{Nb}(>300)$ and $\mathrm{Zr} / \mathrm{Nb}(>7)$. The distinct REE patterns and $\mathrm{Nb}$ and $\mathrm{Ta}$ contents are comparable to those outlined by Cook et al. (2005), who noted higher $\mathrm{Nb},(\mathrm{La} / \mathrm{Yb})_{\mathrm{N}}$ and Th/HREE values, for their Group $\mathrm{B}$ (equivalent to the low-SiO 2 group here) and low $\mathrm{Nb},(\mathrm{La} / \mathrm{Yb})_{N}$ and Th/HREE for their Group A (c.f. our high-SiO 2 group) and contrasting incompatible trace element ratios (e.g. $\mathrm{K} / \mathrm{Nb}, \mathrm{Zr} / \mathrm{Nb}$ and $\mathrm{Ce} / \mathrm{Pb}$ ). The low-SiO 2 group lavas show strong negative $\mathrm{K}$ anomalies that are increasingly subdued in the high- $\mathrm{SiO}_{2}$ group lavas, which show positive $\mathrm{Sr}$ anomalies and are in turn less prominent in the low- $\mathrm{SiO}_{2}$ group. These observations are also consistent with Hoernle et al. (2006) and Timm et al. (2009 and 2010) who also divided their data from New Zealand intraplate volcanic centres and fields into 'low$\mathrm{SiO}_{2}$ ' and 'high-SiO${ }_{2}$ ' groups, showing similar differing major and trace element geochemical compositions to the AVF low- and high- $\mathrm{SiO}_{2}$ groups. 
Table 6.1. Selected geochemical data for AVF centres, * denotes data from lavas previously analysed by McGee et al., 2013. 'i, ii, iii etc' denotes duplicate analyses from the same sample but different digestion. Full data can be found in Appendix $C$.

\begin{tabular}{|c|c|c|c|c|c|c|c|c|c|c|}
\hline Centre & Sample & $\begin{array}{c}{ }^{187} \mathrm{Os} /{ }^{188} \mathrm{Os} \\
\text { ( } \pm 2 \text { бerror) }\end{array}$ & $\begin{array}{c}\text { Os } \\
\text { (ppt) }\end{array}$ & $\begin{array}{c}\mathrm{Re} \\
\text { (ppt) }\end{array}$ & $\begin{array}{c}\mathrm{SiO}_{2} \\
\text { (wt\%) }\end{array}$ & $\begin{array}{c}\text { MgO } \\
\text { (wt\%) }\end{array}$ & $\begin{array}{c}\mathrm{Ni} \\
(\mathrm{ppm})\end{array}$ & $\begin{array}{c}{ }^{206} \mathrm{~Pb} /{ }^{204} \mathrm{~Pb} \\
\text { ( } \pm 2 \text { бerror) }\end{array}$ & $\begin{array}{c}{ }^{207} \mathrm{~Pb} /{ }^{204} \mathrm{~Pb} \\
\text { ( } \pm \text { 2бerror) }\end{array}$ & $\begin{array}{c}{ }^{208} \mathrm{~Pb} /{ }^{204} \mathrm{~Pb} \\
( \pm 2 \text { oerror) }\end{array}$ \\
\hline \multirow[t]{5}{*}{ Rangitoto } & AU59308 & $0.5470 \pm 0.0013$ & 5.8 & 411.9 & $45.47^{*}$ & $11.49^{*}$ & $239^{*}$ & $19.224 \pm 0.001^{*}$ & $15.594 \pm 0.001 *$ & $38.485 \pm 0.003^{*}$ \\
\hline & AU59311 & $0.3901 \pm 0.0016$ & 10.9 & 45.2 & 48.80 & 9.75 & 147 & $19.071 \pm 0.001$ & $15.615 \pm 0.001$ & $38.801 \pm 0.003$ \\
\hline & AU59309-i & $0.4041 \pm 0.0023$ & 10.4 & 225.9 & 48.53 & 8.65 & 217 & $19.064 \pm 0.001$ & $15.612 \pm 0.001$ & $38.787 \pm 0.003$ \\
\hline & AU59309-ii & $0.2525 \pm 0.0004$ & 22.2 & & & & & & & \\
\hline & AU59309-iii & $0.123 \pm 0.065$ & 122.6 & 218.7 & & & & & & \\
\hline \multirow[t]{3}{*}{ Mt. Wellington } & AU62391 & $0.3204 \pm 0.0013$ & 9.3 & 25.9 & $43.12^{*}$ & $12.77^{*}$ & $367^{*}$ & $19.302 \pm 0.001$ & $15.587 \pm 0.001$ & $38.872 \pm 0.003$ \\
\hline & AU62411-i & $0.3166 \pm 0.0019$ & 8.6 & 411.0 & $43.30 *$ & $12.74^{*}$ & $314^{*}$ & $19.293 \pm 0.001^{*}$ & $15.582 \pm 0.001^{*}$ & $38.858 \pm 0.003^{*}$ \\
\hline & AU62411-ii & $0.3951 \pm 0.0003$ & 10.8 & & & & & & & \\
\hline \multirow[t]{5}{*}{ Purchas Hill } & AU44711 & $0.2831 \pm 0.0005$ & 23.7 & 90.5 & $39.79 *$ & $11.4^{*}$ & $312^{*}$ & $19.132 \pm 0.002$ & $15.613 \pm 0.002$ & $38.841 \pm 0.005$ \\
\hline & AU44707-i & $0.4235 \pm 0.0011$ & 9.7 & & $42.98^{*}$ & $12.26^{*}$ & $248^{*}$ & $19.383 \pm 0.002$ & $15.589 \pm 0.002$ & $38.929 \pm 0.006$ \\
\hline & AU44707-ii & $0.2994 \pm 0.0038$ & 10.8 & 187.4 & & & & & & \\
\hline & AU44707-iii & $0.2752 \pm 0.0065$ & 9.1 & 196.6 & & & & & & \\
\hline & AU44707-iv & $0.2539 \pm 0.0009$ & 8.9 & & & & & & & \\
\hline \multirow[t]{2}{*}{ Three Kings } & AU59443 & $0.2422 \pm 0.0006$ & 9.9 & 98.3 & $43.04 *$ & $11.85^{*}$ & $267^{*}$ & $19.293 \pm 0.001^{*}$ & $15.582 \pm 0.001^{*}$ & $38.855 \pm 0.002 *$ \\
\hline & AU59453 & $0.1623 \pm 0.0006$ & 27.5 & 189.3 & $43.00 *$ & $12.17^{*}$ & $286^{*}$ & $19.298 \pm 0.002^{*}$ & $15.592 \pm 0.001 *$ & $38.886 \pm 0.003^{*}$ \\
\hline \multirow[t]{6}{*}{ Wiri } & AU43943 & $0.2730 \pm 0.0025$ & 14.1 & 231.5 & $43.58^{*}$ & $11.18^{*}$ & $253^{*}$ & $19.225 \pm 0.001^{*}$ & $15.576 \pm 0.001^{*}$ & $38.791 \pm 0.002 *$ \\
\hline & AU43931-i & $0.2242 \pm 0.0020$ & 8.5 & 153.7 & $44.03 *$ & $11.00^{*}$ & $229 *$ & $19.219 \pm 0.001^{*}$ & $15.579 \pm 0.001 *$ & $38.795 \pm 0.002 *$ \\
\hline & AU43931-ii & $0.2449 \pm 0.0012$ & 8.5 & & & & & & & \\
\hline & AU43931-iii & $0.3299 \pm 0.0017$ & 14.7 & 133.8 & & & & & & \\
\hline & AU43931-iv & $0.1987 \pm 0.0007$ & 15.0 & & & & & & & \\
\hline & AU43931-v & $0.1283 \pm 0.0001$ & 194.0 & & & & & & & \\
\hline \multirow[t]{3}{*}{ Puketutu } & AU62379 & $0.2328 \pm 0.0004$ & 7.3 & 91.7 & $42.87 *$ & $12.19^{*}$ & $331^{*}$ & $19.282 \pm 0.001^{*}$ & $15.580 \pm 0.001 *$ & $38.839 \pm 0.003^{*}$ \\
\hline & AU62383-i & $0.2659 \pm 0.0011$ & 10.4 & 140.4 & $42.84^{*}$ & $12.30^{*}$ & $342^{*}$ & $19.330 \pm 0.001^{*}$ & $15.595 \pm 0.006 *$ & $38.918 \pm 0.003^{*}$ \\
\hline & AU62383-ii & $0.2122 \pm 0.0003$ & 7.3 & & & & & & & \\
\hline \multirow[t]{2}{*}{ Pupuke } & AU58657 & $0.1374 \pm 0.0008$ & 578.4 & 207.3 & $44.75^{*}$ & $13.93^{*}$ & $463^{*}$ & $19.218 \pm 0.001$ & $15.613 \pm 0.001$ & $38.924 \pm 0.005$ \\
\hline & $\mathrm{JH} 005$ & $0.1377 \pm 0.0002$ & 195.5 & 235.7 & 45.48 & 14.22 & 538 & $19.247 \pm 0.001$ & $15.615 \pm 0.001$ & $38.931 \pm 0.004$ \\
\hline
\end{tabular}




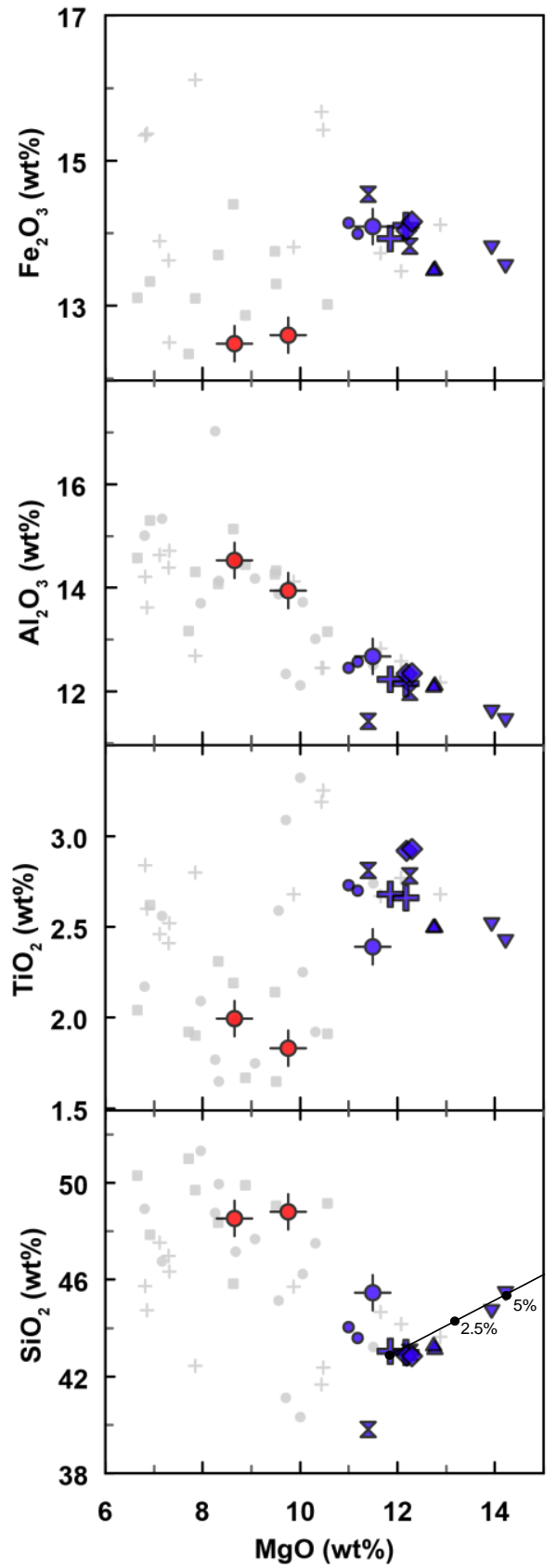

Briggs et al., 1994 Cook et al., 2005 Group A Cook et al., 2005 Group B

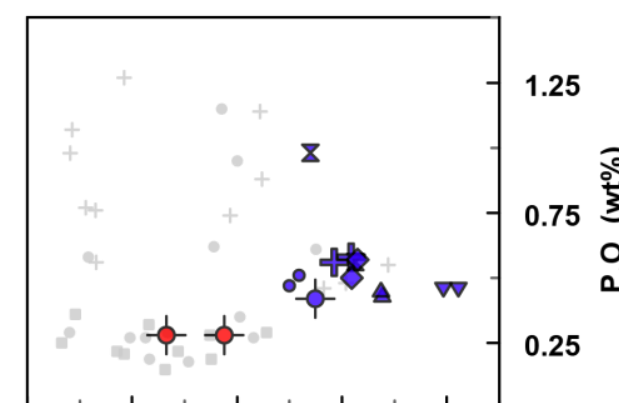

2.0
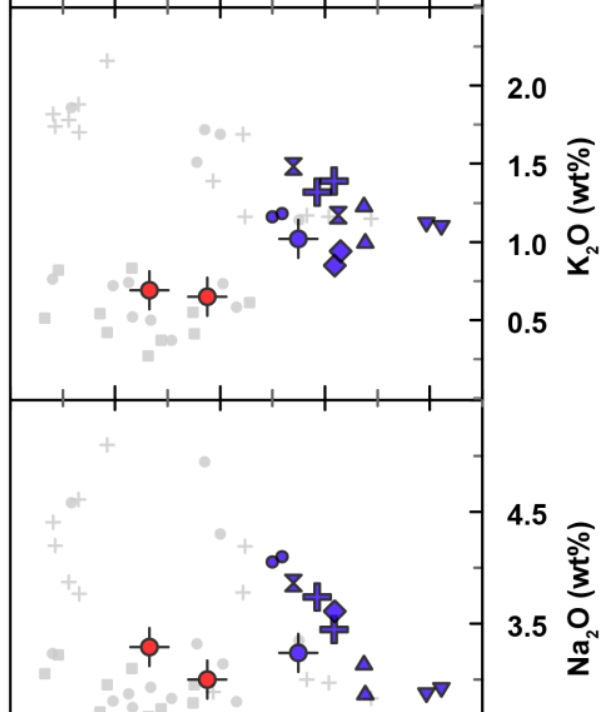

2.5

12

11 웅

10 క

10 유

Figure 6.2. Diagram panels showing major elements vs. MgO (wt.\%). Blue symbols denote group 1 and red symbols denote group 2 samples. Grey symbols represent previously published data from the South Auckland volcanic field, with squares denoting Group $A$ and crosses denoting Group $B$ as assigned by Cook et al.(2005); and spots showing data from Briggs et al. (1994), which were ungrouped. Our low-SiO $\mathrm{S}_{2}$ group (blue) generally correlates to Group B, and our high-SiO $\mathrm{Sroup}_{2}$ (red) to Group A. Also shown in the $\mathrm{SiO}_{2} \mathrm{vs.} \mathrm{MgO}$ panel is the impact of mixing olivine into the samples, showing the addition of $5 \%$ olivine (values from Deer et al., 1992) could produce the Pupuke sample signatures. 


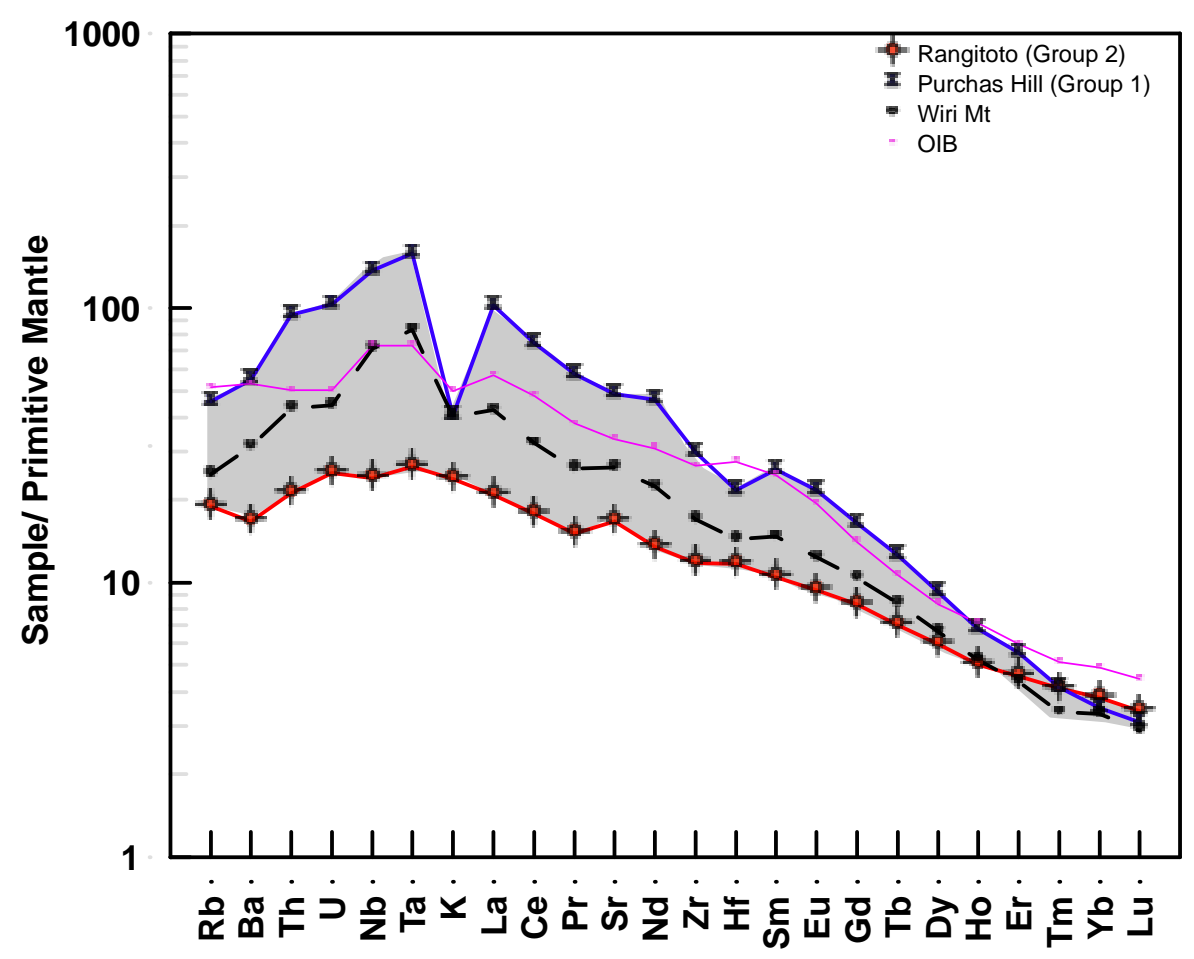

Figure 6.3. Diagram showing representative primitive mantle-normalised multi-element distribution to present the AVF trace element data range (after McGee et al., 2013). The lava end members are exemplified by Purchas Hill (Group 1; blue) and Rangitoto 2 (Group 2; red). Wiri Mt. lavas show intermediate trace element distribution in black. Grey field marks the range from the AVF field, and pink shows a typical OIB-type signature (OIB and normalisation values from McDonough and Sun, 1995).

\subsection{2. $\mathrm{Sr}-\mathrm{Nd}-\mathrm{Pb}$ isotopes}

Isotopic data for the AVF lavas are reported in Table 6.1. Seven new $\mathrm{Pb}$ isotope data have been generated supplementing previously published AVF $\mathrm{Pb}$ isotope data of McGee et al. (2013). In general the AVF lava Pb isotopic composition show limited variation $\left({ }^{206} \mathrm{~Pb} /{ }^{204} \mathrm{~Pb}=19.060-19.383,{ }^{207} \mathrm{~Pb} /{ }^{204} \mathrm{~Pb}=15.576-15.617\right.$, and $\left.{ }^{208} \mathrm{~Pb} /{ }^{204} \mathrm{~Pb}=38.787-38.931\right)$. On $\mathrm{Pb}$ isotope variation diagrams (Fig. 6.4.) the AVF data plot between the mid ocean ridge basalt (MORB), HIMU (high $\mu=$ high time integrated $\mathrm{U} / \mathrm{Pb}$ ) and enriched mantle (EM I or II) end-members (following the classification of Zindler and Hart, 1986). 


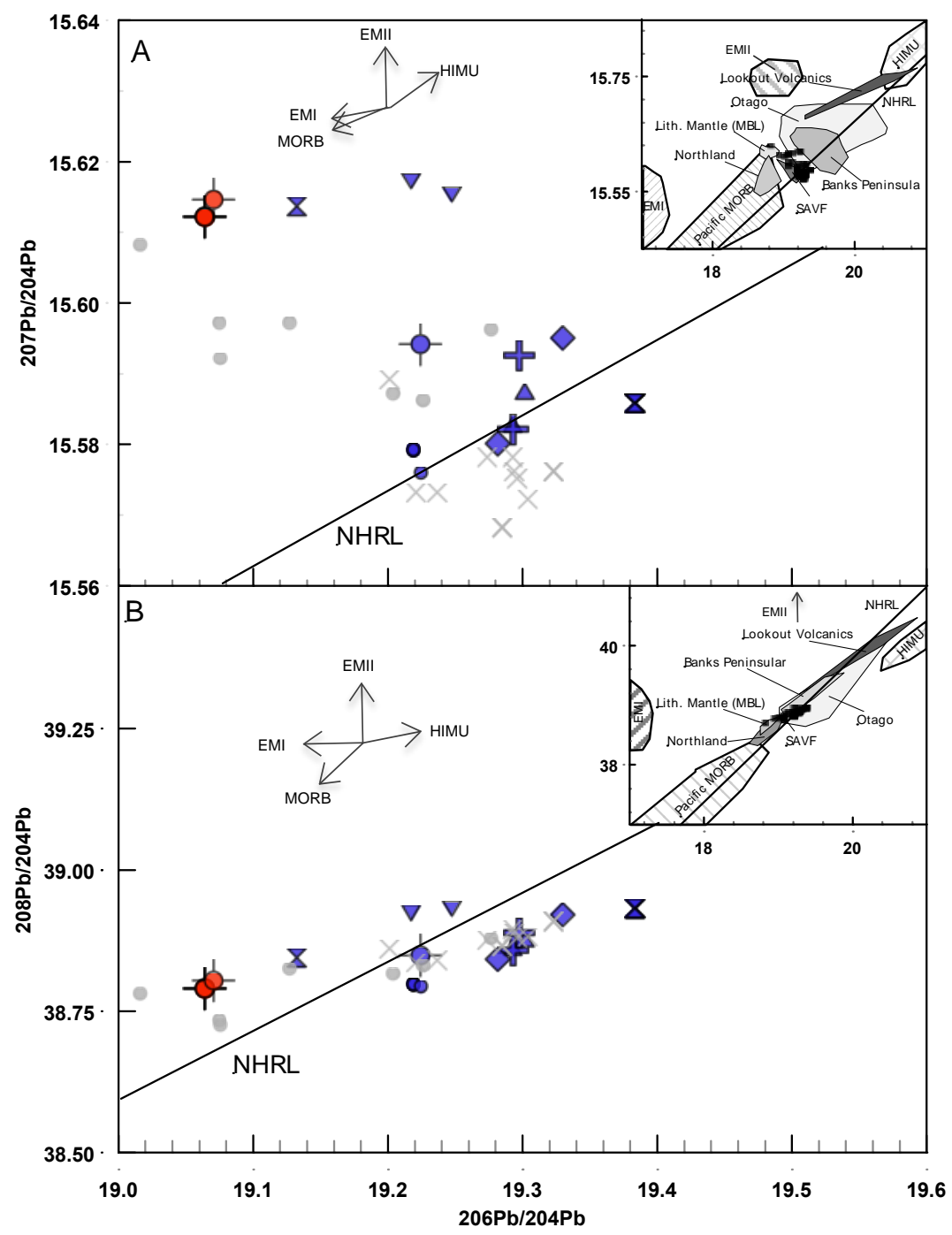

Figure 6.4. A) ${ }^{206} \mathrm{~Pb} /{ }^{204} \mathrm{~Pb}$ vs. ${ }^{207} \mathrm{~Pb} /{ }^{04} \mathrm{~Pb}$ and $\left.\mathrm{B}\right){ }^{208} \mathrm{~Pb} /{ }^{204} \mathrm{~Pb}$ vs. ${ }^{206} \mathrm{~Pb} /{ }^{204} \mathrm{~Pb}$ for all lavas from the Auckland Volcanic Field, in comparison to the Northern Hemisphere Reference Line (NHRL) from Hart (1984). On the inset plots the mantle reservoir end members are from Zindler and Hart (1986): Enriched Mantle (EMI and EMII), Pacific MORB Mantle, Lith. Mantle (MBL), and HIMU. Values for Northland from Huang et al. (2000), for Otago from Timm et al. (2010), for Banks Peninsular from Timm et al. (2009), and for Lookout Volcanics from McCoy-West et al. (2010). Also shown are values for the SAVF from Cook et al., 2005 (Group $A$ are grey spots, and group $B$ grey crosses). Symbols for the AVF data are as in Figure 6.2. again, our low-SiO 2 group (blue) generally correlates to Group $B$, and our high$\mathrm{SiO}_{2}$ group (red) to Group A from Cook et al. (2005). 
The spread in $\mathrm{Pb}$ isotope compositions observed in AVF lavas generally overlap with $\mathrm{Pb}$ isotope values from the South Auckland Volcanic Field $\left({ }^{206} \mathrm{~Pb} /{ }^{204} \mathrm{~Pb}\right.$ $=18.950-19.323 ;{ }^{207} \mathrm{~Pb} /{ }^{204} \mathrm{~Pb}=15.568-15.613$, and ${ }^{208} \mathrm{~Pb} /{ }^{204} \mathrm{~Pb}=38.723-38.906$; Cook et al., 2005; Fig. 6.4.). Purchas Hill lava AU44711 (low-SiO 2 ) show elevated ${ }^{206} \mathrm{~Pb} /{ }^{204} \mathrm{~Pb}(19.383)$ and ${ }^{208} \mathrm{~Pb} /{ }^{204} \mathrm{~Pb}(38.929)$, but ${ }^{207} \mathrm{~Pb} /{ }^{204} \mathrm{~Pb}$ similar to lavas from other AVF centres. Conversely, Rangitoto 2 (high-SiO${ }_{2}$ ) shows the lowest ${ }^{206} \mathrm{~Pb} /{ }^{204} \mathrm{~Pb}$ (e.g., 19.064), low ${ }^{208} \mathrm{~Pb} /{ }^{204} \mathrm{~Pb}$ (e.g., 38.485), coupled with some of the highest ${ }^{207} \mathrm{~Pb} /{ }^{204} \mathrm{~Pb}$ values of all AVF volcanic rocks (Fig. 6.4.).

Previously published $\mathrm{Sr}$ and $\mathrm{Nd}$ isotope data from the AVF lavas show a restricted range from ${ }^{87} \mathrm{Sr} /{ }^{86} \mathrm{Sr}=0.702710$ to 0.703125 and from ${ }^{143} \mathrm{Nd} /{ }^{144} \mathrm{Nd}=$ 0.512939 to 0.512956 (McGee et al., 2013). Although no obvious trend has been identified between $\mathrm{Sr}$ and $\mathrm{Nd}$ isotopic compositions, the AVF and SAVF high-SiO2 lavas have distinctly higher ${ }^{87} \mathrm{Sr} /{ }^{86} \mathrm{Sr}(=0.7032)$ than the lavas from the other centres at similar ${ }^{143} \mathrm{Nd} /{ }^{144} \mathrm{Nd}$ values $(=0.5129)$. Similarly there is no clear correlation observed between ${ }^{206} \mathrm{~Pb} /{ }^{204} \mathrm{~Pb}$ and ${ }^{143} \mathrm{Nd} /{ }^{144} \mathrm{Nd}$, although ${ }^{206} \mathrm{~Pb} /{ }^{204} \mathrm{~Pb}$ and ${ }^{87} \mathrm{Sr} / 86 \mathrm{Sr}$ show a broad negative trend (McGee et al., 2013; Cook et al., 2005).

The isotope data therefore support and reiterate the groups discussed for the concentration data and these groupings are also consistent with Cook et al. (2005). Their 'Group B' type (our low $\mathrm{SiO}_{2}$ ) was defined by lower ${ }^{87} \mathrm{Sr} /{ }^{86} \mathrm{Sr}$ values (= $\leq 0.7028)$ at similar ${ }^{143} \mathrm{Nd} /{ }^{144} \mathrm{Nd}$ values $(=0.51296-0.51298)$, coupled with higher ${ }^{206} \mathrm{~Pb} /{ }^{204} \mathrm{~Pb}$ values (=19.201-19.323), higher ${ }^{208} \mathrm{~Pb} /{ }^{204} \mathrm{~Pb}(=38.833-38.892)$ and lower ${ }^{207} \mathrm{~Pb} /{ }^{204} \mathrm{~Pb}$ values (15.568-15.589). In comparison to their 'Group A' type (our high$\left.\mathrm{SiO}_{2}\right)$, which has higher ${ }^{87} \mathrm{Sr} /{ }^{86} \mathrm{Sr}$ values $(=\geq 0.7029)$ and similar ${ }^{143} \mathrm{Nd} /{ }^{144} \mathrm{Nd}$ values (= 0.51294-0.51298), coupled with lower ${ }^{206} \mathrm{~Pb} /{ }^{204} \mathrm{~Pb}$ values $(=18.950-19.277)$, lower ${ }^{208} \mathrm{~Pb} /{ }^{204} \mathrm{~Pb}(=38.723-38.876)$, and higher ${ }^{207} \mathrm{~Pb} /{ }^{204} \mathrm{~Pb}$ values $(=15.586-15.613)$.

\subsubsection{Re, Os, and ${ }^{187} \mathrm{Os} /{ }^{188}$ Os}

${ }^{187} \mathrm{Os} /{ }^{188} \mathrm{Os}$ values and $\mathrm{Re}$ and $\mathrm{Os}$ concentrations are given in Table 6.1. The AVF lavas show a wide range in Os and Re concentrations (Os = 5.8-578 ppt, $\mathrm{Re}=$ 25.9-411 ppt). These concentrations fall within the range of Os contents reported from other OIB-type lavas (Os = ca.1-600ppt; Schiano et al., 2001, Re = ca.100 to 642 ppt; Hauri and Hart, 1997). The Os isotope compositions from AVF volcanic 
rocks also show a significant range from mantle values $\left({ }^{187} \mathrm{Os} /{ }^{188} \mathrm{Os}=0.1283\right.$; cf. Meisel et al., 2001) to radiogenic values $\left({ }^{187} \mathrm{Os} /{ }^{188} \mathrm{Os}=0.5470\right)$. The majority of samples $(n=19)$ have ${ }^{187} \mathrm{Os} /{ }^{188} \mathrm{Os} \geq 0.15$, higher than the range assumed for mantlederived lavas (Lassiter and Hauri, 1998; Widom et al., 1999; Rasoazanamparany et al., 2015). In general no obvious correlations between Os and Re concentrations, ${ }^{187} \mathrm{Os} /{ }^{188} \mathrm{Os}$ and $\mathrm{MgO}, \mathrm{Ni}, \mathrm{Cu}$ or $\mathrm{Zr}$ are observed. The exception is samples from Pupuke showing high $\mathrm{MgO}, \mathrm{Ni}$, and Os concentrations but low ${ }^{187} \mathrm{Os} /{ }^{188} \mathrm{Os}$ values (Fig. 6.5.).

The overall range in ${ }^{187} \mathrm{Os} /{ }^{188} \mathrm{Os}$ in the AVF lavas is larger than that observed in most OIB-like basalts (Fig.6.6.A) (Reisberg et al., 1993; Hauri and Hart, 1993; Roy-Barman and Allegre, 1995; Marcantonio et al., 1995; Lassiter and Hauri, 1998; Schiano et al., 2001; Day et al., 2010). Most AVF ${ }^{187}$ Os/188Os values however overlap with the Os isotopic composition of alkali basaltic and tholeiitic lavas from other continental intraplate volcanic fields, such as the Newer Volcanic Province, SE Australia $\left({ }^{187} \mathrm{Os} /{ }^{188} \mathrm{Os}=0.1342-0.4456\right.$; McBride et al., 2001); CEVP, Germany $\left({ }^{187} \mathrm{Os} /{ }^{188} \mathrm{Os}=0.1487-0.7526\right.$; Jung et al., 2011) and East African Rift System $\left({ }^{187} \mathrm{Os} /{ }^{188} \mathrm{Os}=0.1239-0.4366\right.$; Nelson et al., 2012) (Fig.6.6.A). Figure 6.7 shows that there is a large range in ${ }^{187} \mathrm{Os} /{ }^{188} \mathrm{Os}$ in relation to the narrow range in ${ }^{206} \mathrm{~Pb} /{ }^{204} \mathrm{~Pb}$. Lavas with more radiogenic Os isotopic composition generally contain less Os (e.g. Rangitoto sample AU59309: ${ }^{187} \mathrm{Os} /{ }^{188} \mathrm{Os}=0.5470$, Os $=5.8 \mathrm{ppt}$ ), and those with lower ${ }^{187} \mathrm{Os} /{ }^{188}$ Os contain more Os (e.g. Wiri Mt. sample AU43931: ${ }^{187} \mathrm{Os} /{ }^{188} \mathrm{Os}=0.1283$, Os $\left.=194 \mathrm{ppt}\right)$. In addition, low Os concentration lavas $(<40$ ppt) generally have more variable Os isotope signatures $(0.1623-0.5470)$, becoming less variable (0.1230-0.1374) with increasing Os contents. On an ${ }^{187} \mathrm{Os} /{ }^{188}$ Os versus 1/Os diagram the AVF samples form a broad positive trend (Fig. 6.6.B) generally plotting between crustal and mantle end member fields. Of note is that samples from Purchas Hill, Rangitoto and Three Kings form individual positive trend lines at varying gradients, whereas samples from Wiri Mt. and Mt. Wellington show no clear trends between ${ }^{187} \mathrm{Os} /{ }^{188} \mathrm{Os}$ and $1 / \mathrm{Os}$ (Fig. 6.6.B). These mixing trends converge on a similar end member with ${ }^{187} \mathrm{Os} /{ }^{188} \mathrm{Os}=0.1231 \sim 0.1283$ and Os concentration of ca. 50-200 ppt, similar to primitive upper mantle (e.g., Meisel et al., 2000), and thus are interpreted to represent the mantle end member for the AVF. 

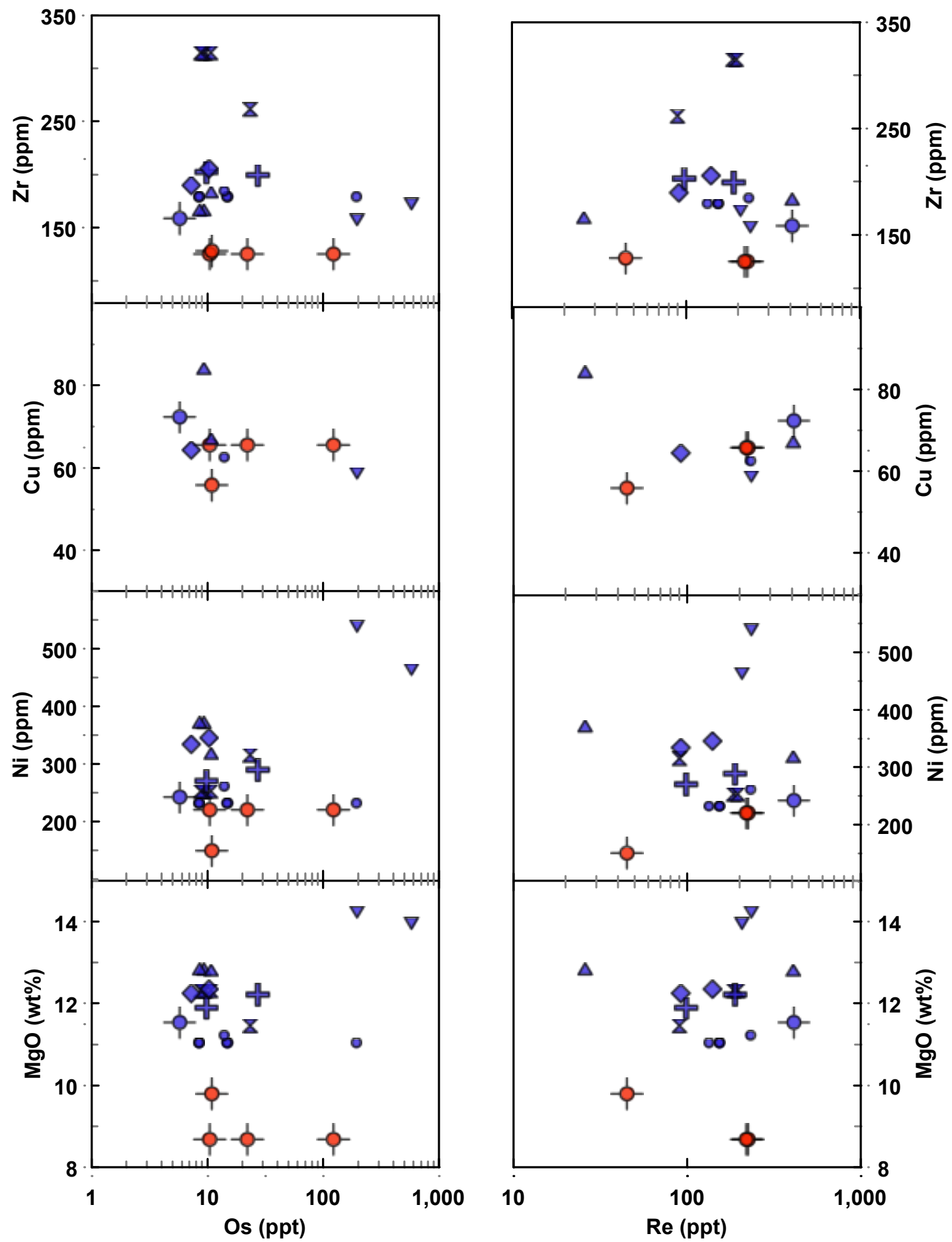

Figure 6.5. Os and Re concentrations versus $\mathrm{MgO}$ (in wt.\%), $\mathrm{Ni}, \mathrm{Cu}$ and $\mathrm{Zr}$ (all in ppm) contents. Symbols are as in Figure 6.2. 

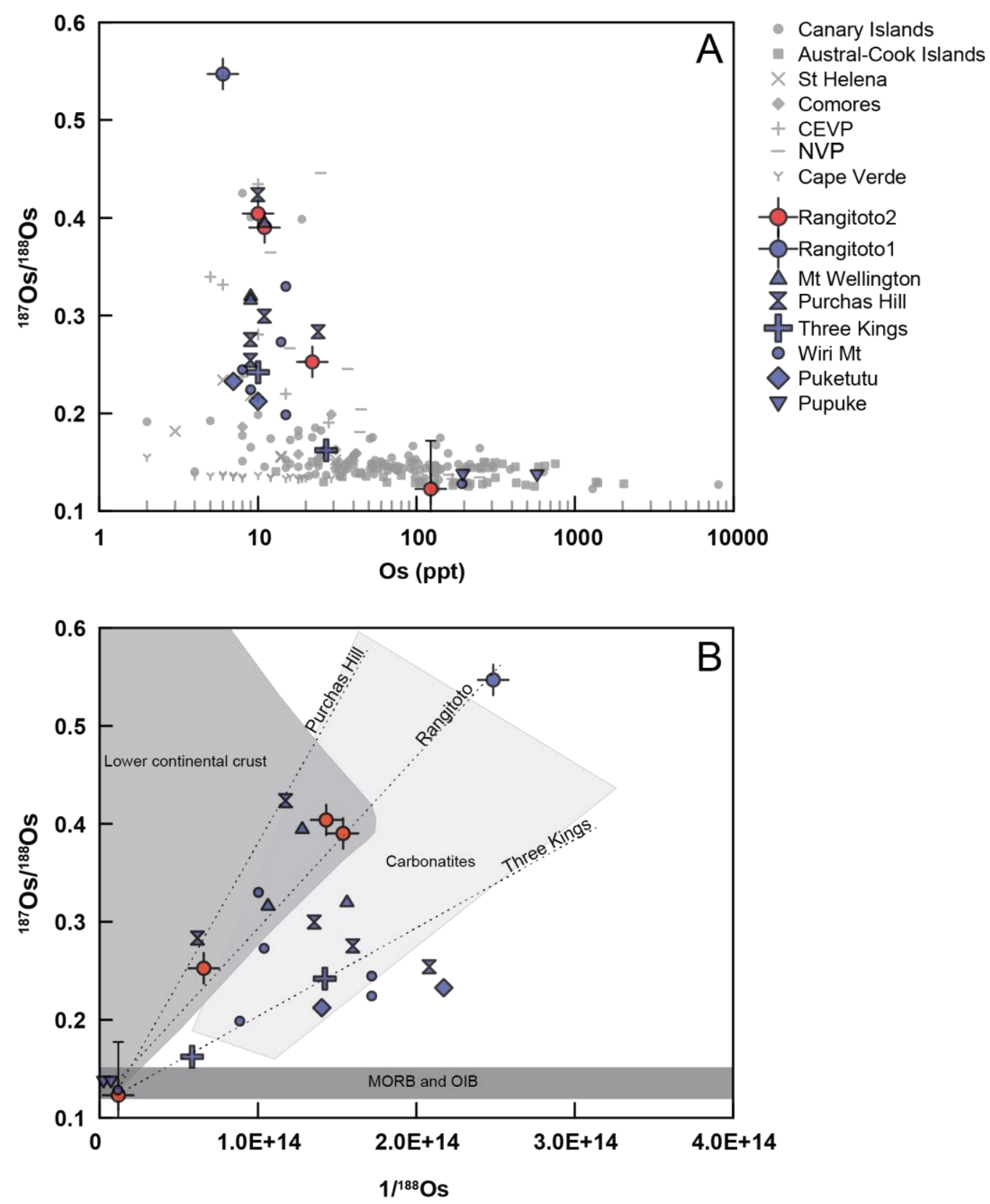

Figure 6.6. (A) ${ }^{187}$ Os $/{ }^{188}$ Os vs Os (ppt) for all samples from the AVF. Also shown in grey symbols are global OIB values for the Canary Islands (Marcantonio et al., 1995; Widom et al., 1999; Day et al., 2010); the Austral Cook Islands (Hauri and Hart, 1993; Reisberg et al., 1993); St Helena and Comores (both from Reisberg et al., 1993); Central European Volcanic Province (CEVP; Jung et al., 2011); Newer Volcanic Province, Australia (NVP; McBride et al., 2001); Cape Verde (Escrig et al., 2005). (B) ${ }^{187}$ Os $/{ }^{188}$ Os vs $1 / 188$ Os for all AVF samples, with global fields for lower continental crust (Esser and Turekian, 1994; Rudnick and Fountain, 1995; Saal et al., 1998; Rudnick and Gao, 2003), and MORB and OIB (Hauri and Hart 1993; Roy-Barman and Allegre, 1995; Schiano et al., 1997; Schiano et al., 2001; Peucker-Ehrenbring and Jahn, 2001), and Carbonatites (Escrig et al., 2005; Widom et al., 1999). Error bars are shown for Rangitoto sample AU59309, for all other analyses the errors are smaller than the symbol. 


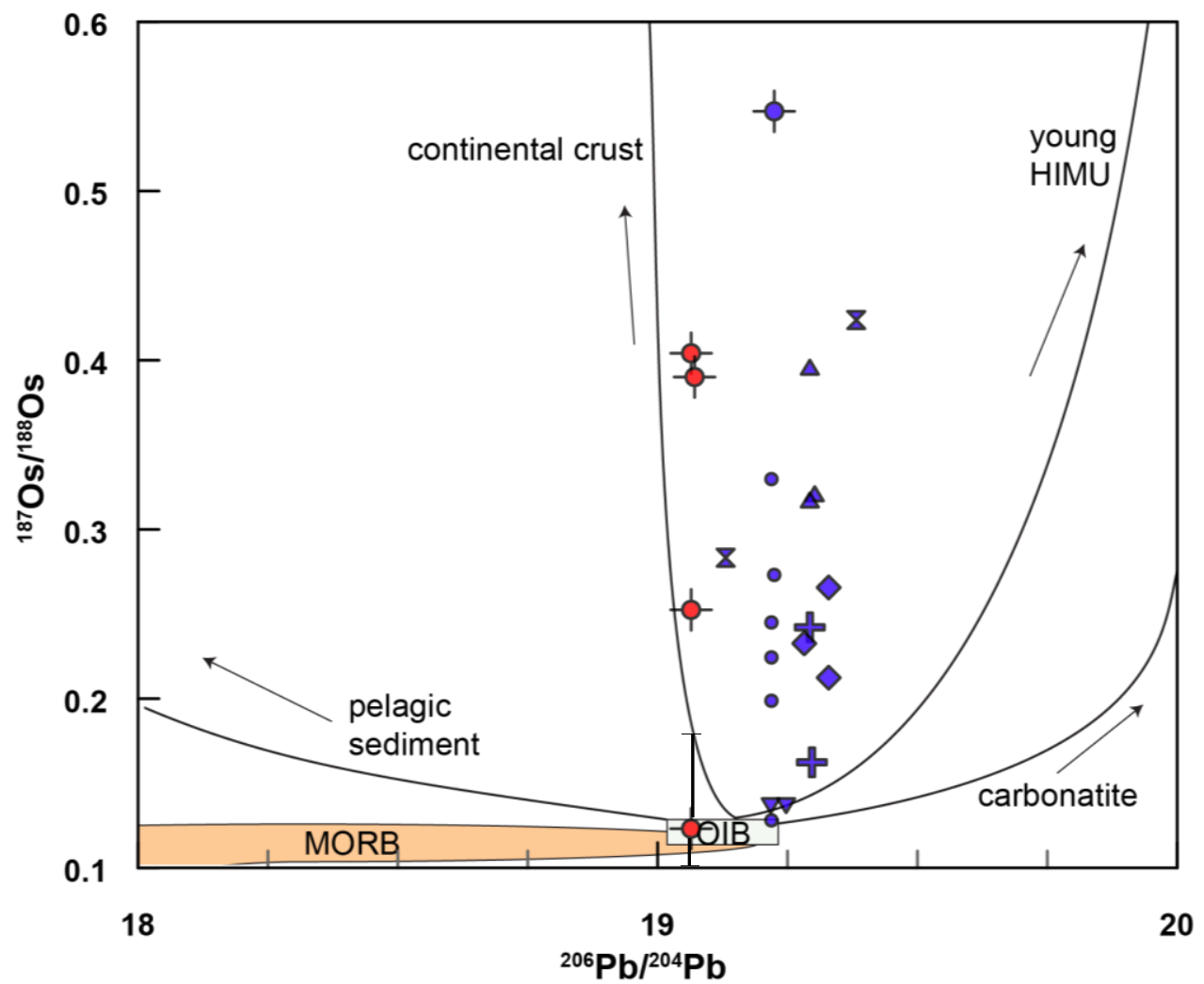

Figure 6.7. Diagram after Day (2013), to show mixing relationships for various potential contaminants in ${ }^{206} \mathrm{~Pb} /{ }^{204} \mathrm{~Pb}$ vs. ${ }^{187} \mathrm{Os} /{ }^{188}$ Os isotope space. Data values for MORB and OIB from Widom et al. (1999) and Day et al. (2010); pelagic sediments from Roy-Barman and Allegre (2005); carbonatite from Escrig et al. (2005) and Widom et al. (1999); young HIMU from Day et al. (2009); and continental crust from Saal et al. (1998) and Widom et al. (1999).

\subsection{Discussion}

\subsubsection{Mantle source heterogeneity}

Intraplate basalts with OIB-like characteristics typically contain isotope signatures from multiple sources including depleted MORB mantle (DMM), HIMU (through addition of ancient recycled oceanic crust), and enriched mantle end members (EMI, cause by terrigeneous sediment assimilation, and EMII caused by pelagic sediment assimilation; cf. Zindler and Hart 1986; outlined on Fig. 6.4.). The petrogenesis of the AVF basalts has been the subject of a number of geochemical and isotopic studies (Huang et al., 1997; Needham et al., 2011; McGee et al., 2011, 2012, 2013, 2015). In general, published Sr-, Nd-, Pb-isotope data from AVF 
samples plot intermediate between Pacific MORB and HIMU (e.g., ${ }^{206} \mathrm{~Pb} /{ }^{204} \mathrm{~Pb}=$ 19.0-19.4; Huang et al., 1997; McGee et al., 2013, Fig. 6.4.). Compared to a 'true' HIMU $\mathrm{Pb}$ isotope composition (e.g., ${ }^{206} \mathrm{~Pb} /{ }^{204} \mathrm{~Pb}>20.5$ ), which requires $\geq 0.8 \mathrm{Ga}$ to evolve from a typical MORB mantle (e.g., Thirlwall et al., 1997), the much less radiogenic $\mathrm{Pb}$ isotopic compositions in the AVF lavas were attributed to the presence of a 'young' HIMU signature by Huang et al. (1997). Similarly Cook et al. (2005) proposed that $\leq 12 \%$ melting of a garnet-bearing asthenospheric mantle containing young (<0.2 Ga) HIMU-like isotope signature can explain the geochemical composition of the SAVF low $\mathrm{SiO}_{2}$ group lavas. In addition the low $\mathrm{SiO}_{2}$ group AVF lavas contain high $\mathrm{CaO} / \mathrm{Al}_{2} \mathrm{O}_{3}, \mathrm{Na}_{2} \mathrm{O}$ and $\mathrm{K}_{2} \mathrm{O}$ at low $\mathrm{Nb} / \mathrm{U}$ and elevated $\mathrm{Ce} / \mathrm{Pb}$, $\mathrm{Nb} / \mathrm{Ce}$, and $\mathrm{U} / \mathrm{Pb}$ suggestive of the presence of carbonated garnet peridotite domains (McGee et al., 2015) hosted in MORB-like peridotitic asthenosphere (McGee et al., 2013). The geochemical and isotopic signatures of the high-SiO 2 group lavas are attributed (by McGee et al., 2013) to additional input from an EMIItype lithospheric source metasomatised by subduction-related fluids and melts into the ascending asthenospheric melt at shallower depth. Similarly, low-degree partial melting $(\leq 8 \%)$ of shallow, spinel bearing EMIl-type subduction metasomatised lithosphere has been invoked to explain the low total alkali (TAS), Nb contents, $(\mathrm{La} / \mathrm{Yb})_{\mathrm{N}}$ ratios and e.g., ${ }^{206} \mathrm{~Pb} /{ }^{204} \mathrm{~Pb}$ of the high-SiO 2 group in the SAVF (Cook et al., 2005).

Figure 6.7 shows the relationship between ${ }^{206} \mathrm{~Pb} /{ }^{204} \mathrm{~Pb}$ and ${ }^{187} \mathrm{Os} /{ }^{188} \mathrm{Os}$. Despite the large ${ }^{187} \mathrm{Os} /{ }^{188} \mathrm{Os}$ range ${ }^{206} \mathrm{~Pb} /{ }^{204} \mathrm{~Pb}$ is fairly restricted, indicating that different processes control each isotope system. As outlined above the AVF lava major and trace element, and $\mathrm{Sr}-, \mathrm{Nd}$-, and $\mathrm{Pb}$-isotope data were previously interpreted to reflect asthenospheric and lithospheric mantle sources (e.g., Huang et al., 1997; McGee et al., 2013). The high ${ }^{187} \mathrm{Os} /{ }^{188}$ Os at low Os contents however point towards the influence of a component with radiogenic Os isotopic composition and low Os content. The different behaviour of the two isotope systems questions that a heterogeneous mantle source alone is responsible for the AVF Os signatures, and this hypothesis is further investigated below in regards to other potential sources.

The interpretation of $\mathrm{Sr}$-, $\mathrm{Nd}$-, and Pb-isotope systematics of AVF lavas relies on the assumption that erupted basalts are directly representative of their mantle 
sources, as proposed by McGee et al. (2013). Nevertheless, a number of studies have noted xenolithic material (e.g., crustal schistose fragments) within tuff rings from the AVF maar craters (e.g. St Heliers, Taylors Hill, Mangere Mt; Spörli and Black, 2015), providing direct evidence for the interaction of ascending magmas with the country rock (e.g., Bryner, 1991). Because of its sensitivity to identify whether the AVF lavas have experienced crustal or lithospheric mantle contamination, we will use the $\mathrm{Re}$, Os and ${ }^{187} \mathrm{Os} /{ }^{188} \mathrm{Os}$ systematics to evaluate this conundrum.

\subsubsection{Origin of sulphides in AVF lavas}

Platinum Group Elements (PGE), including Os, are chalcophile and thus are concentrated in sulphide minerals. Although $\mathrm{Os}$ and $\mathrm{Re}$ are incompatible in olivine and clinopyroxene (e.g. Burton et al., 2002), Os is more chalcophile than $\mathrm{Re}$ and therefore highly compatible with sulphides during mantle melting (Dos $\sim 10^{4}$ between sulphides and silicate melt; Roy-Barman et al., 1998; Jamais et al., 2008). Therefore minimal sulphide fractionation can effectively remove Os from a melt. Despite the incompatibility of Os in olivine ( \pm spinel), the crystallisation of olivine can cause sulphur saturation and consequent precipitation of base metal sulphide formation (BMSs; Alard et al., 2002), thereby causing a co-variation between olivine and Os (Burton et al., 2002). In addition, olivine-hosted sulphides can form either through combined olivine and sulphide crystallisation (e.g. Bézos et al., 2005; Lorand et al., 2010; Day et al., 2010) or can be incorporated through accumulation of xenocrystic olivine during ascent (e.g. Alard et al., 2002). Sulphides formed through fractional crystallisation are either retained in residual minerals in the mantle (e.g. olivine; Lorand et al., 2010) or can segregate and form sulphides during magma transport and emplacement (e.g. Bézos et al., 2005). The PGE concentrations in the melt depends on the degree of partial melting, as only high degrees of partial melting (> $16 \%$ ) will completely remove sulphur from the mantle source, resulting in a PGE-rich melt (Day et al., 2010). Accordingly, low-degree partial melts $(\leq 6 \%)$ show lower, but more variable HSE contents due to incomplete breakdown of sulphide in the mantle source (e.g. Day et al., 2010). Conversely, $R e$ is less compatible to modestly incompatible in sulphides and thus is not preferentially incorporated into them. 
As low-degrees of partial melting have been suggested to occur beneath the AVF ( $\leq 6 \%$; McGee et al., 2011, 2012, 2013) variable Os contents are expected. Furthermore, the concentrations of $\mathrm{Os}$ and $\mathrm{Re}$ in the AVF lavas show no obvious correlation with Mg, Ni, Cu and Zr; Fig. 6.5.), suggesting that fractional crystallisation of olivine and pyroxene have had no or only a minor influence on Os and $\mathrm{Re}$ concentrations in most AVF lavas. In addition, because no significant trends between the above-mentioned elements are observed, partial melting, and silicate plus sulphide phase fractionation, cannot alone cause the Os content variability seen in the AVF lavas. Other primary phases controlling PGEs include PGE-rich alloys and possibly Cr-spinels (e.g., Day 2013). However PGEs reveal an even more complex behaviour depending on $\mathrm{fO}_{2}, f \mathrm{~S}_{2}$, temperature and pressure prevailing during mantle melting, crystal fractionation and during melt ascend and eruption. Regardless, due to low melting temperatures and low viscosities of BMSs, they are strongly soluble in basaltic melts, and can therefore be preferentially incorporated into the ascending magmas (Alard et al., 2002). It is therefore likely that ascending magma becomes contaminated with mantle or crustal sulphides if the magma passes through an appropriate source.

Assimilation of oceanic or continental crust into the mantle in subduction settings increases the radiogenic Os signature of the mantle through input of high ${ }^{187} \mathrm{Re} /{ }^{188} \mathrm{Os}$, and thus high ${ }^{187} \mathrm{Os} /{ }^{188} \mathrm{Os}$ contents (e.g., Alves et al., 1999; Borg et al., 2000; Dale et al., 2007; Suzuki et al., 2011). Furthermore at or near subduction zones, fluids derived from a subducting plate metasomatise the subcontinental lithospheric mantle and hence increase $f_{2}$ and $f \mathrm{~S}_{2}$ creating more oxidising conditions in the mantle. Mantle sulphides, stable under reduced mantle condition, then partially oxidize to sulphates (e.g., Carroll and Rutherford, 1985) releasing previously sulphide-bonded metals facilitating the movement and concentration of Os in partial melts (e.g., Jurgo, 2009; Suzuki et al., 2011). Assuming partial melts or supercritical fluids redistribute Os, both of these processes can increase the Os concentrations in the subduction metasomatised lithosphere (and melt), and can result in a more radiogenic Os isotope signature over time.

The lithosphere beneath the AVF was exposed to subduction in the Oligocene to Miocene between c. 20 and $30 \mathrm{Ma}$ (Seebeck et al., 2014). Through radioactive decay of ${ }^{187} \mathrm{Re}$ to ${ }^{187} \mathrm{Os}$ the Os isotope composition of the lithospheric mantle 
beneath the AVF would have increased in $30 \mathrm{Ma}$ to ca. ${ }^{187} \mathrm{Os} /{ }^{188} \mathrm{Os}=0.1473-0.1524$ (assuming a ${ }^{187} \mathrm{Re} /{ }^{188} \mathrm{Os}=50$ in recycled crust, Widom et al., 1999; and a mantle value of ${ }^{187} \mathrm{Os} /{ }^{188} \mathrm{Os}=0.123-0.1283$, this study). The only AVF lavas that contain values similar to the ${ }^{187} \mathrm{Os} /{ }^{188} \mathrm{Os}=0.14$ proposed to represent the lithospheric mantle are from Pupuke. Previously up to $80 \%$ contribution from the subduction metasomatised lithospheric mantle (SMLM) to the ascending asthenospheric melts has been proposed to explain the major and trace element and $\mathrm{Sr}-, \mathrm{Nd}-$ and $\mathrm{Pb}$ isotopic composition of the high $\mathrm{SiO}_{2}$ AVF lavas (McGee et al., 2013). Therefore to create the Os signature of the Pupuke samples, that accumulated olivine $\left({ }^{187} \mathrm{Os} /{ }^{188} \mathrm{Os}=0.1374-0.1377, \mathrm{Os}=196-578 \mathrm{ppt}\right)$ through addition of olivine-hosted SMLM sulphides, (assuming a $\leq 80 \%$ contribution from the SMLM and using a simple binary mixing model), the Os concentration in the SMLM would have to be $\geq 700 \mathrm{ppt}$, with ${ }^{187} \mathrm{Os} /{ }^{188} \mathrm{Os}=0.1391-0.1472$. This value is however higher than those values recorded in lithospheric mantle xenoliths from Zealandia (e.g. McCoy-West et al., 2013; Liu et al., 2015). In addition, if the lithospheric mantle is the source of Os isotopic signature and high Os contents in the Pupuke lavas it would be expected that these samples are part of the high- $\mathrm{SiO}_{2}$ group samples, contrary to what is observed.

Other than the SMLM beneath the AVF, there is at least one alternative source potentially contaminating the Pupuke samples with sulphide-bearing olivine; the ultramafic rocks (primarily serpentinised dunite and harzburgite) of the PermianTriassic Dun Mountain ophiolite belt (DMOB; e.g., Coombs et al., 1976; Sivell and McCulloch, 2000). Parts of the DMOB cross directly beneath Pupuke at shallow levels ( $\geq 1.5 \mathrm{~km}$ depth, Fig.6.1.C.) making the ultramafic rocks of the Dun Mountain ophiolite belts a likely melt contaminant.

Although there are currently no Os isotope measurements on the DMOB rocks, O'Driscoll et al. (2012) reports Os content and isotope values from the Shetland ophiolite complex, which although older (429 Ma), has similarities to the DMOB in formation (obduction at arc collision zone) and lithology (serpentinised dunite and harzburgite). ${ }^{187} \mathrm{Os} /{ }^{188} \mathrm{Os}$ isotope values reported range from 0.1204 to 0.1502 with Os concentrations ranging from 300-8000 ppt (O'Driscoll et al., 2012). Assuming mean values of ${ }^{187} \mathrm{Os} /{ }^{188} \mathrm{Os}=0.1353$ and Os $=4150 \mathrm{ppt}$ (based on the Os isotope values and contents from the Shetland ophiolite complex) simple binary 
mixing modeling (Fig. 6.8.) requires $<10 \%$ input from the Dun Mountain ultramafic rocks into our proposed ambient mantle values of ${ }^{187} \mathrm{Os} /{ }^{188} \mathrm{Os}=0.123-0.1283$ and Os $=50-200$ ppt to explain the ${ }^{187} \mathrm{Os} /{ }^{188}$ Os values and Os content observed in the Pupuke samples. However only ca. 5\% olivine accumulation is required to explain the higher $\mathrm{MgO}, \mathrm{Ni}$ and $\mathrm{Cr}$ contents of these samples. This suggests that the concentration of Os in the contaminant needs to be $\geq 6000$ ppt Os, which is within the range reported by O'Driscoll et al. (2012). Nevertheless, 5-10\% olivine accumulation can not only explain the ${ }^{187} \mathrm{Os} /{ }^{188} \mathrm{Os}$ values and Os, but also the $\mathrm{MgO}$ and $\mathrm{Ni}$ contents observed in the Pupuke samples (see mixing line on Fig. 6.2.). Contamination from the Dun Mountain ultramafic rocks cannot however explain the highly radiogenic Os isotope signatures $\left({ }^{187} \mathrm{Os} /{ }^{188} \mathrm{Os}=0.1623-0.5470\right)$ and low Os concentrations (<50 ppt) in most other AVF samples.

\subsubsection{Contamination and assimilation}

On an ${ }^{187} \mathrm{Os} /{ }^{188} \mathrm{Os}$ versus $1 /{ }^{188} \mathrm{Os}$ diagram most AVF lavas plot on a broad positive array between the OIB and continental crust, and overlap with the signature for carbonatites, indicative of a mixing end member with a high Os isotope ratio and a low Os concentration (Fig.6.6.B.).

Carbonatites have often been associated with the subcontinental lithospheric mantle sources in New Zealand (e.g., Scott et al., 2014), with a lithospheric mantle source, affected by carbonatitic metasomatism, used to explain the geochemistry of mantle xenoliths from beneath South Island, New Zealand (e.g., Scott et al., 2014; McCoy-West et al., 2015). Carbonatites typically have low Os concentrations and elevated Os isotope ratios, and therefore could represent a mantle end-member causing the highly radiogenic signature seen for the AVF lavas. The only carbonatites measured globally range in Os isotope ratios from 0.18-0.6 with Os concentrations of 4-23 ppt (Widom et al., 1999; Escrig et al., 2005). However, because of the low Os contents in carbonatites, Widom et al. (1999) highlight that carbonatitic metasomatism will have limited effect on the Os isotope composition of the mantle. In addition, if carbonatite metasomatism were responsible for the elevated Os isotope ratios and low Os concentrations, the proportion of assimilated volume would need to be minor as there is no correlation between the Os signatures and elements indicative of carbonatite metasomatism (including $\mathrm{CaO}, \mathrm{Sr}$, and $\mathrm{Nd}$; 
Cooper et al., 2015). Because the Os isotopic composition of carbonatite is $\leq 0.6$, with low Os contents, parts of the lithospheric mantle source would need to be of carbonatitic composition to be an effective contaminant. Even then, either an unrealistically high amount of assimilation into ascending melts is required to explain the elevated ${ }^{187} \mathrm{Os} /{ }^{188} \mathrm{Os}$ of $>0.25$, or direct melting of the carbonatite-domained mantle is required, which should have a notable effect on the major and trace element composition.

These results support previous conclusions by Handler et al. (1997) who also show, for wherlite and apatite-bearing peridotites, interaction with carbonatitic melt has no effect on the Os isotope composition or concentrations of Os or Re. In addition, a more recent study by McCoy-West et al. (2015) identified that metasomatism beneath Zealandia does contain a carbonatitic component, but that does not affect the PGE budget in peridotite, which is controlled by residual sulphides. Therefore an alternative end-member with high ${ }^{187} \mathrm{Os} /{ }^{188} \mathrm{Os}$ and low Os content is required to explain the radiogenic Os isotopic composition of most AVF lavas.

Crustal rocks (e.g., metasediments) typically show highly radiogenic ${ }^{187} \mathrm{Os} /{ }^{188}$ Os values (ca. 0.165-2.323; Saal et al., 1998) and low Os contents (ca. 20 to 100 ppt; Saal et al., 1998; Widom et al., 1999). Although the Sr-, Nd-, and Pbisotopic composition from the AVF lavas show no detectable evidence for crustal contamination, the highly radiogenic ${ }^{187} \mathrm{Os} /{ }^{188} \mathrm{Os}$ isotope ratios in some of the AVF lavas exceed most values reported from the lithospheric mantle and carbonatitic sources, as previously discussed. This suggests that an end-member with ${ }^{187} \mathrm{Os} /{ }^{188} \mathrm{Os}>0.6$ is required to create the radiogenic Os isotopic composition seen in the AVF samples, indicating a radiogenic crustal source.

Lavas from single centres (Rangitoto, Three Kings, Purchas Hill, Mt Wellington and Puketutu) plot mostly along individual linear mixing trends for each centre (Fig.6.6.B.). The variability observed within a single sample however, is more complex; duplicate analyses of the same sample using different digestions show variable results. This variability is attributed to the 'nugget effect' (Alves et al., 2002), which suggests variability of individual digestions is caused by sampling varying amounts of mineral-hosted sulphides or oxide micro-inclusions with either inherited 
crustal or mantle signatures from a single powdered sample. Dale et al. (2012) show that, due to preferential sampling of radiogenic source or crustal components in low degree melts, the Os isotope composition of mantle melts may not truly represent the bulk mantle Os isotope composition. The 'nugget effect' likely represents this preferential sampling of radiogenic components. Neverthless the data can be used to constrain the amount of crustal contamination in the AVF lavas.

\subsubsection{AFC modelling}

As simple binary mixing and/or fractional crystallisation cannot explain the ${ }^{187} \mathrm{Os} /{ }^{188} \mathrm{Os}$ and Os values from the AVF lavas (see Fig. 6.8.) we used the combined assimilation fractional crystallisation (AFC) model of DePaolo (1981) to quantify the amount of contamination (Fig. 6.8.). Potential contaminants have to satisfy the following criteria: 1) be a known basement lithology, and 2) have highly radiogenic Os isotope signature and low Os concentration. In addition constraining factors that the model has to satisfy includes 1) the lavas have undergone low levels of fractional crystallisation (<10\%; McGee et al., 2013; Chapter 4), and 2) mixing proportions between contaminant and melt have to be low enough to have little or no effect on trace element or $\mathrm{Sr}-\mathrm{Nd}-\mathrm{Pb}$ isotope systems.

Field studies mapping of the basement terranes and crustal xenoliths in lavas indicate, in addition to DMOB rocks, that both the Waipapa and the Murihiku terrane greywacke meta-sedimentary rock lithologies are found beneath the AVF (Fig. 6.1.B; e.g., Kermode, 1992). Although no Os isotope analysis has been undertaken on these terranes specifically, similar greywacke sediments have been studied in both Australia (Saal et al., 1998) and India (Wimpenny et al., 2007), and show that greywacke metasediments generally have highly radiogenic ${ }^{187} \mathrm{Os} /{ }^{188} \mathrm{Os}$ of 1.2832 to 5.1968 and low Os concentrations of 40-100 ppt (Wimpenny et al., 2007). AFC modelling suggests that $<1 \%$ bulk assimilation of greywacke metasediments with Os $=44.5 \mathrm{ppt}$ and ${ }^{187} \mathrm{Os} /{ }^{188} \mathrm{Os}=1.2832$ (Saal et al., 1998) into a mantle melt $\left({ }^{187} \mathrm{Os} /{ }^{188} \mathrm{Os}=0.1283\right.$; Os $=194 \mathrm{ppt}$; Wiri Mt value from this study $)$, coupled with $\leq$ $5 \%$ fractional crystallisation, can produce the range of observed radiogenic Os isotope signatures (and low Os contents) in the AVF lavas (Fig 6.8.). Such low levels of crustal assimilation has no significant effect on the traditional trace element and $\mathrm{Sr}-$, Nd-, Pb- isotope compositions. 


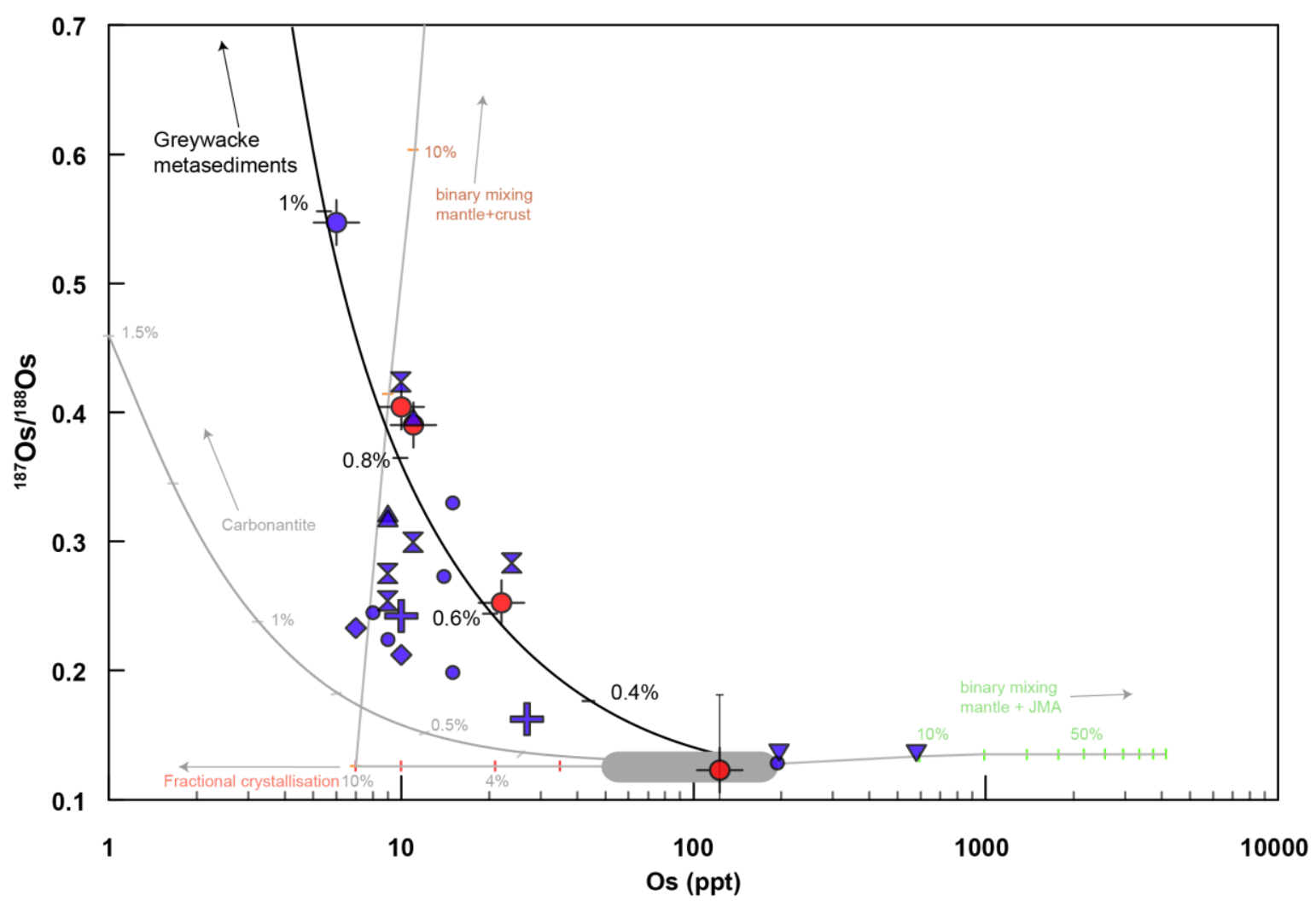

Figure 6.8. Whole rock ${ }^{187}$ Os $/{ }^{188}$ Os vs Os concentration (ppt) for OIB with proposed methods of signature formation. Sulphide assimilation is modelled (green line) using binary mixing from AVF mantle values with values measured for sulphides found in dunite within Shetland Ophiolite complex $\left({ }^{187} \mathrm{Os} /{ }^{188} \mathrm{Os}=0.1353\right.$, Os $=4150$ ppt: O'Driscoll et al., 2012). Fractional crystallisation is modelled (red text and tick marks) using the Raleigh equation for samples from 50 to $7 \mathrm{ppt}$, showing that it requires $\leq 10 \%$ fractional crystallisation to reduce the Os concentrations. Crustal assimilation is modelled (orange text and tick marks) through binary mixing of post $30 \%$ fractional crystallisation of the mantle-derived melt $\left({ }^{187} \mathrm{Os} /{ }^{188} \mathrm{Os}=\right.$ 0.128 , Os $=7 \mathrm{ppt})$ with $<10 \%$ crust, with values reflective of greywacke $\left({ }^{187} \mathrm{Os} /{ }^{188} \mathrm{Os}=\right.$ 1.283, Os = 44.5 ppt; Saal et al., 1998). Finally assimilation fractional crystallisation (AFC) is modelled (black text and tick marks) (after DePaolo, 1981) for mantle values $\left({ }^{187} \mathrm{Os} /{ }^{188} \mathrm{Os}=\right.$ 0.128 , Os = 194 ppt; this study, Wiri Mt value) with crustal values of greywacke $\left({ }^{187}\right.$ Os $/{ }^{188} \mathrm{Os}$ $=1.283$, Os = 44.5 ppt; Saal et al., 1998), $D_{\text {Os }}=20$ (Widom et al., 1999), $r$ (rate of fractional crystallisation) $=0.95$. 


\subsubsection{Implications for magma origin, generation and ascent}

Based on our new Os isotope data we demonstrate that almost all AVF lavas analysed have interacted at $\leq 30 \mathrm{~km}$ depth with continental crust beneath Auckland. Aeromagnetic surveys over the Auckland area shows that the subsurface Dun Mountain Ophiolite Belt is almost universally present beneath the AVF (Eccles et al., 2005). Despite this, only few lavas show clear indication of significant mantle olivine accumulation based on their high Os concentrations and low mantle-like Os isotope ratios. Interestingly the centres that have petrographic and geochemical evidence for mantle olivine accumulation (Wiri Mt, Pupuke and Rangitoto) are located near or on faults separating the Dun Mountain Belt from adjacent sediments within the Matai Terrane (c.f. Fig. 6.1.C; Eccles et al., 2005). These observations strongly suggest the accumulation of olivines from mantle lithologies as magma ascends along faults cutting the ultramafic rocks of the Dun Mountain Belt between $1.5 \mathrm{~km}$ and $30 \mathrm{~km}$ depth (Eccles et al., 2005).

The location of the intraplate basaltic fields on North Island, New Zealand (since 2.7 Ma) have remained static during minor arc migration during this time arguing against a direct relationship between intraplate volcanism and the subduction zone (Heming, 1980 and Smith et al., 1993). This led Heming (1980) and Smith et al. (1993) to proposed the presence of a mantle plume to cause partial mantle melting and upwelling beneath the AVF. More recently, partial melting of a geochemically depleted asthenospheric mantle source containing HIMU-type carbonated peridotite domains has been used to explain the elevated $\mathrm{Pb}$ isotopic composition in magmas derived from >80 km depth (e.g., McGee et al., 2015). These authors furthermore proposed that the asthenospheric melts variably interact with the overlying EMII-like lithosphere, metasomatised by long-lasting subduction throughout the Mesozoic, similar to the model put forward to explain intraplate volcanism on Zealandia (e.g., Timm et al., 2010). We generally concur with these models, and note the decoupling between the mantle source signatures and the Os isotope signatures. These observations demonstrate that lavas previously interpreted to represent 'purely' mantle melts must have experienced some degree of crustal contamination.

A low velocity zone, suggested to represent partial melt, has been identified by seismic tomography between 70-90 km depth beneath the Auckland region (e.g., Horspool et al., 2006). These low velocity zones are attributed to regions of partial 
melt within the mantle caused by crustal extension associated with the slab rollback (Horspool et al., 2006), resulting in upwelling of hot asthenopheric mantle and subsequent partial decompression melting. We note that the other intraplate volcanic fields (Ngatutura and Okete; Briggs et al., 1994, and the South Auckland volcanic field; Cook et al., 2005) also are spatially correlated to the position of the DMOB (Fig.6.1.C.), and suggest that these melts may also exploit the DMOB as a weakness in the crust through which low degree melts can easily ascend (Fig. 6.9.). This avenue is beyond the scope of this research, however would be a useful direction for further study.

In summary, we show that almost all AVF lavas studied show Os isotopic compositions higher than typical mantle values of $\leq 0.13$ and Os contents lower than 50 ppt, suggesting that most AVF lavas carry a crustal signature. This suggests, contrary to previous interpretation, that batches of melt beneath the AVF interacted with the continental crust, which has radiogenic ${ }^{187} \mathrm{Os} /{ }^{188} \mathrm{Os}$ and low Os contents, such as metasedimentary greywacke. Conversely, the unradiogenic Os isotopic ratios coupled with high (>150 ppt) Os concentrations of the samples from Pupuke, Wiri and Rangitoto, are attributed to contamination through olivine-bearing sulphide assimilation from the Dun Mountain Ophiolite Belt. The presence of mantle-derived sulphide hosting olivines in lavas from eruption centres located above the Dun Mountain Ophiolite Belt strongly argues for their derivation from crustal levels (Fig. 6.9.). We therefore propose that, although there is no evidence for long residence time of melts within the crust, crustal contamination does occur beneath most of the Auckland Volcanic Field and impacts the erupted products. 


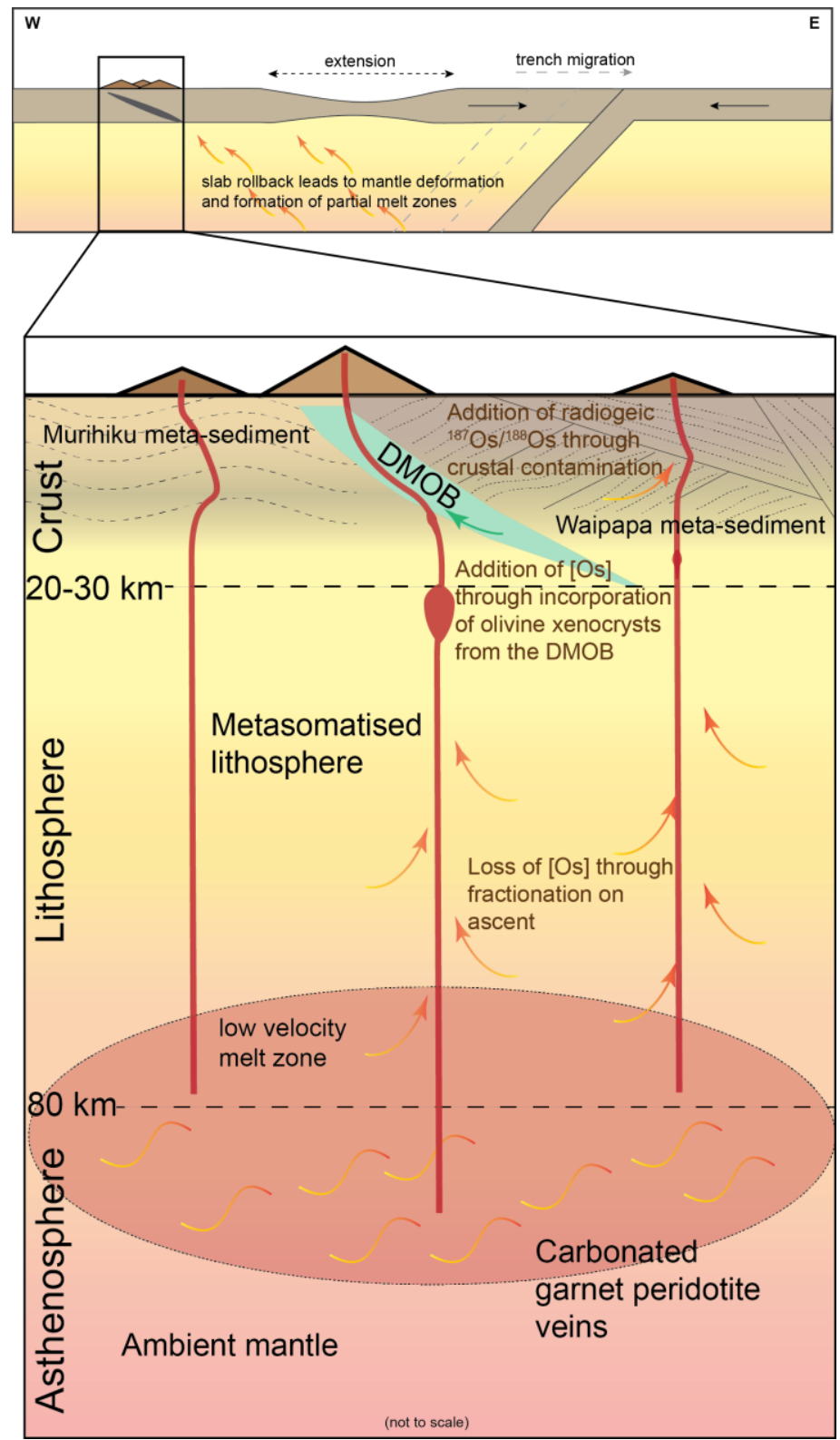

Figure 6.9. Schematic model to illustrate the proposed magma ascent for the AVF eruptions. Melts are derived from a heterogeneous source, including ambient peridotite mantle containing HIMU-like carbonated peridotite veins (McGee et al. (2015) at a depth of $>80 \mathrm{~km}$ depth, and a subduction metasomatised lithosphere at $<80 \mathrm{~km}$ depth, all of which give the ascending magma its $\mathrm{Sr}$-, $\mathrm{Nd}$-, Pb-isotopic and major and trace element signatures (McGee et al., 2013). Minimal fractionation occurs on ascent, efficiently reducing the Os concentration from mantle values, followed by preferential assimilation of olivines from the Dun Mountain Ophiolite Belt (DMOB) as xenocrystic material causing increase in Os concentration, and finally minor crustal contamination of magmas causing the radiogenic isotope signatures. A crustal depth of $20-30 \mathrm{~km}$ and the positions of the low velocity melt zone region are from tomography by Horspool et al. (2006), and upper cross section adapted from Seebeck et al. (2014). 


\subsection{Conclusions}

The Os concentrations and isotopic systematics in lavas from the AVF show no obvious correlation to the tracers of mantle sources, implying that the Os signatures are not primarily caused by source heterogeneity, but have resulted from crustal contamination. Two differing types of crustal contamination are identified. 1) Metasediments (e.g. Waipapa and Murihiku Terranes) which contain highly radiogenic Os coupled with minimal elemental Os and, 2) xenocrystic olivine hosted sulphides (from the Dun Mountain Belt) with unradiogenic mantle-like ${ }^{187} \mathrm{Os} /{ }^{188} \mathrm{Os}$ and high Os contents. Less than $1 \%$ contamination from the crust coupled with $\leq 5 \%$ fractional crystallisation, and $\leq 10 \%$ contamination from xenocrystic olivine-bearing sulphide is sufficient to produce the ${ }^{187} \mathrm{Os} /{ }^{188} \mathrm{O}$ s and high Os contents measured in the AVF lavas. The evidence for crustal contamination has important implications for magma ascent characteristics, suggesting that 1) there is interaction with the crust and, 2) that the Dun Mountain Ophiolite Belt may act as a principle pathway for the rapid ascent of these highly primitive lavas.

\section{Acknowledgements}

Financial support for this work was provided by DEVORA project. The authors would like to thank Lucy McGee for use of lava samples and some unpublished data. JLH would like to thank Elaine Smid and the University of Auckland (UoA) rock collection for sample loan, and GEOTOP at UQAM for use of analytical facilities, and Monica Handler for helpful reviews and discussion of the text. 


\section{Chapter 7}

\section{Synthesis and Conclusions}

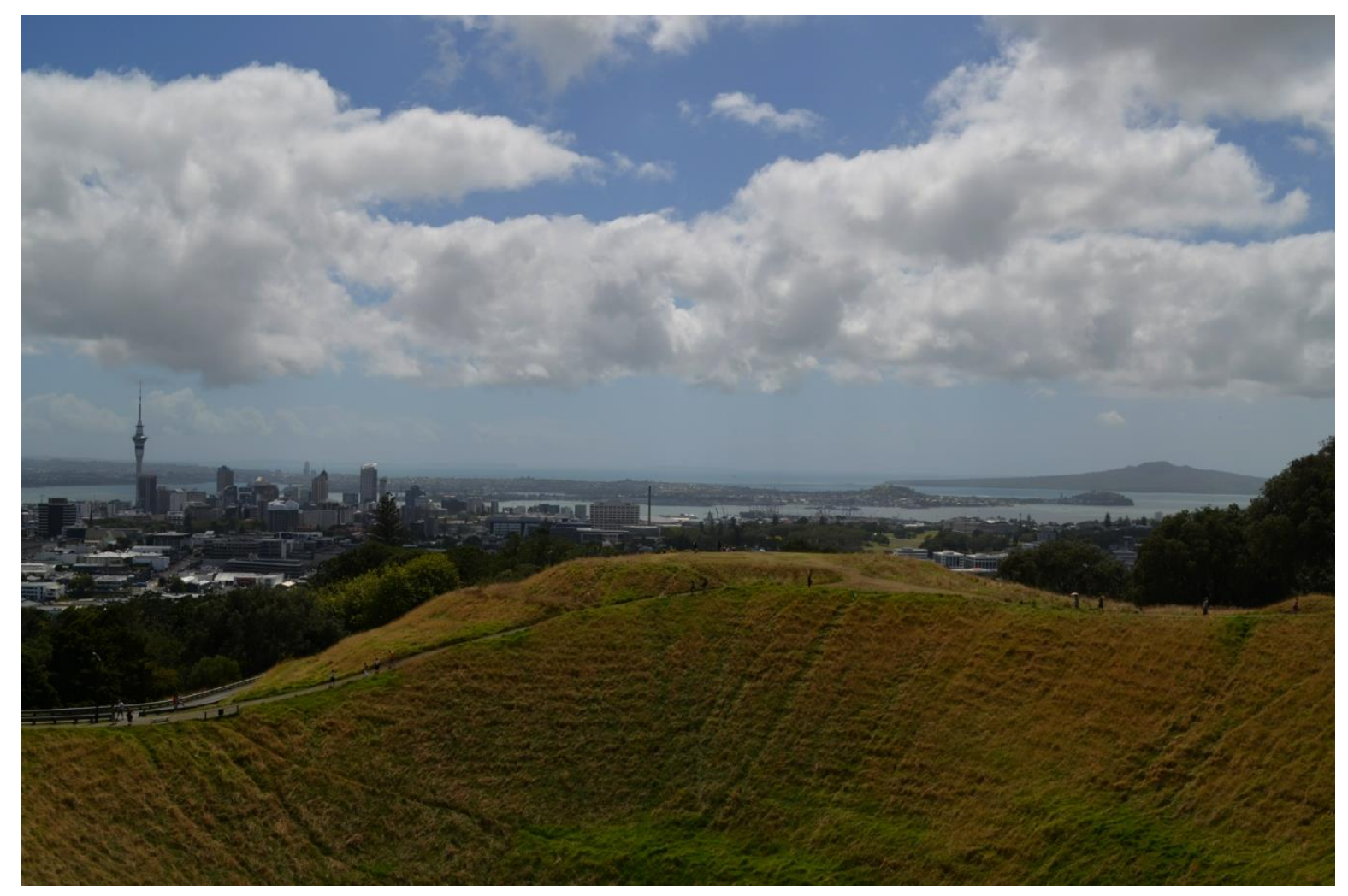

Auckland cityscape from Mt Eden crater with Mt Victoria and North Head outlined in front of Rangitoto (Image by Hopkins, J.L.). 


\subsection{Introduction}

The primary aim of this research was to improve the tephrostratigraphic framework for the Auckland Volcanic Field, New Zealand, and develop a method to link these tephra horizons to their source. A secondary aim was to use this information to constrain the spatial, temporal, and geochemical evolution of the monogenetic basaltic AVF. In this chapter I will outline the original contributions that are made by this thesis. I will revisit the research questions that were originally identified in Chapter 1 and outline how this research has tackled these questions. I will then discuss the outstanding questions that have come to light as a result of this thesis and outline potential for future research.

\subsection{Original Scientific Contributions}

Most tephrostratigraphic studies in New Zealand have focused on the active eruptive centres of Taupo Volcanic Zone (e.g., Howorth, 1975; Froggatt, 1982; Froggatt and Lowe, 1990; Dunbar and Kyle, 1992; Alloway et al., 2004; Shane et al., 2006 Allan et al., 2008; Danisik et al., 2012) or Taranaki Volcano (e.g., Alloway et al., 1994; Alloway et al., 1995; Shane, 2005; Turner et al., 2009; Turner et al., 2011). This is due to their shorter repose period and larger eruptions posing a greater volcanic hazard to New Zealand. Relatively few studies have therefore focused primarily on the basaltic eruptions from the Auckland Volcanic Field (AVF) (e.g., Molloy et al., 2009; Needham et al., 2011; Shane and Zawalna-Geer, 2011; Shane et al., 2013).

This study (Chapter 3) has, for the first time, used X-ray and magnetic susceptibility techniques combined with visual observations to pinpoint basaltic tephra horizons in the Orakei Basin and Onepoto cores. Using this new approach, I have found 1) previously un- or misidentified horizons, 2) provided new insight into the characteristics of the basaltic tephra deposits within the cores, and 3) outlined how re-worked and primary horizons can be reliably identified. I coupled these results with the first extensive trace element analysis obtained on the basaltic tephra shards for the AVF (Chapter 3), to allow new insights into the use of trace elements to create more distinct geochemical fingerprints for specific deposits. The combination of these new methods allowed me to establish a more reliable 
tephrostratigraphic framework for the AVF, and to better assess tephra dispersal and eruption frequency (Chapter 3). This study furthermore has global implications by outlining the benefits of using trace element signatures of tephra shards to further define and fingerprint specific tephra deposits, a concept which is only beginning to be exploited.

In Chapter 4 I present new major and trace element whole rock data for previously un- or under- sampled centres of the AVF. I also collate for the first time all reliable data from previous studies, both published (e.g., McGee et al., 2013), unpublished (particularly that collected and curated by I.E.M. Smith), and MSc project data (e.g., Hookway, 2000). In doing this I bring the total number of centres with both major and trace element geochemical data from 22 to 46 out of the 53 proposed centres.

In Chapter 5, the newly constructed tephrostratigraphic framework is combined with the newly collated whole rock database, and a new suite of ${ }^{40} \mathrm{Ar} /{ }^{39} \mathrm{Ar}$ age determinations (Leonard et al., in prep. Appendix D), to develop a method for the correlation of basaltic tephra horizons to their source centres. Although it is standard protocol to attempt to correlate distal tephra to source, this is most commonly facilitated through well-characterised proximal tephra deposits. The newly developed method allows the correlation of basaltic tephra to whole rock compositions, something that has not previously been attempted. Although the investigation relies predominantly on the trace element signatures of both the tephra and the whole rock, for the AVF this study found that geochemistry alone couldn't reliably fingerprint 53 centres individually. The study therefore shows that the use of multiple lines of evidence is required to correlate the tephra horizons to their source centre. In using this approach, I have conducted and reported the first study to not only correlate tephra horizons to their source centre by correlating tephra with whole rock chemistry, but also to correlate the distal basaltic AVF tephra deposits to their source. The tephra dispersal from individual centres can be mapped and used in future hazard and risk forecasting. For the AVF this process has produced the first relative and absolute eruptive history for 45 of 53 AVF centres for the last ca. $200 \mathrm{ka}$. As a result of this, I also, for the first time, show evidence for coupled eruptions in space and time, a potential cyclicity to the eruption characteristics (geochemistry and scale), and evidence for melt volume loss on ascent. 
Finally, in Chapter 6, I use the Re/Os isotope system coupled with trace element geochemistry to provide the first geochemical evidence for crustal contamination of the ascending magma batches for a number of the AVF centres. The contamination is linked to both the sedimentary country rock (meta-greywackes of the Murihiku and Waipapa terranes), and also the rocks of the Dun Mountain ophiolite belt through which the magma ascended. This is the first time geochemical evidence for crustal contamination has been noted, and has potential implications for magma ascent that has previously not been identified.

\subsection{Research Questions}

\subsubsection{Can a more detailed basaltic tephra stratigraphy for the AVF be produced for the maar deposits using newly developing analysis methods?}

\subsubsection{X-ray and Magnetic Susceptibility}

The use of X-ray and magnetic susceptibility analysis techniques are shown to be exceptionally powerful and accurate tools to identify the location and assessing the characteristics of basaltic tephra deposits within lacustrine maar sediment cores. X-ray imagery identifies basaltic tephra shards due to the high abundance of heavy X-ray absorbing elements (e.g., FeO) contained within the shards, and therefore in comparison to the lacustrine sediments, the parts of the core that contain basaltic shards appear very bright on the imagery. The abundance of Fe-rich magnetic minerals within the basaltic tephra also results in large peaks in magnetic susceptibility where tephra shards are located. Therefore, a positive indication from both these analyses allows even the thinnest $(1-2 \mathrm{~mm})$ basaltic horizons, which may have had ambiguous identification based on visual observations previously, to be accurately identified within the cores. These techniques reveal details about the density of shards, the shard size, and shape, coupled with the characteristics of the horizon itself, which includes the bedding type, structure and any deformation. This method allows initial identification through non-invasive techniques of primary and reworked horizons or section of horizons. 


\subsubsection{Tephra Geochemistry}

Prior to this study, trace element analysis of the basaltic tephra shards within the AVF had not been undertaken. The trace element analyses provided the ability to more accurately constrain and fingerprint the geochemical signature of the tephra horizons and thus to correlate horizons less ambiguously. Selected trace element concentrations, and trace element ratios, were proven to produce a more distinctive geochemical signature for a specific horizon compared to major element compositions of the same centres/lavas, facilitating better identification and designation of specific horizons. The trace elements and trace element ratios, in comparison to the corresponding major element signatures, proved to 1) constrain a highly variable signature, 2) constrain a bimodal signature and, 3) split overlapping signatures for two horizons, thereby allowing more precise correlations to be made. This study therefore has produced a highly detailed tephrostratigraphy for the AVF maar cores through the combined use of new, non-invasive, observational techniques, coupled with detailed geochemical analysis.

\subsubsection{Can individual horizons be linked to their source centre?}

\subsubsection{Tephra-derived glass to whole rock correlations}

This study has demonstrated that tephra horizons can be linked to their source centre based on the correlation between medial-distal tephra deposits and proximal lava-scoria deposits. The correlation between tephra-derived glass samples and whole rock-derived glass samples was shown to be the simplest way of correlating, with a number of major elements successful at providing comparable geochemical signatures (e.g., MgO vs. full major element suite plus trace elements $\mathrm{Rb}, \mathrm{Zr}, \mathrm{Cs}, \mathrm{Ni}, \mathrm{Cr}, \mathrm{Y}, \mathrm{Er}$, and $\mathrm{SiO}_{2}$ vs. $\mathrm{Al}_{2} \mathrm{O}_{3}, \mathrm{Na}_{2} \mathrm{O}, \mathrm{K}_{2} \mathrm{O}$ and; $\mathrm{CaO}$ vs. $\mathrm{Al}_{2} \mathrm{O}_{3}, \mathrm{Na}{ }_{2} \mathrm{O}$ ). However in many cases glassy lava samples were (and are often) not available, therefore a more complex correlation method was developed. For the AVF the incompatible trace elements and their ratios (specifically $\mathrm{La} / \mathrm{Yb}, \mathrm{Gd} / \mathrm{Yb}, \mathrm{Zr} / \mathrm{Yb}$, $\mathrm{Nd} / \mathrm{Yb}, \mathrm{Nb} / \mathrm{Yb}$, and $\mathrm{Ce} / \mathrm{Yb}$ ) are show to be 1) the most variable element or ratios across the AVF eruption products, 2) the most distinctive for individual eruptions, 3) the least affected by partial melting and fractional crystallisation and therefore, 4) the most comparable in values between bulk whole rock and tephra-derived glass. This 
method proved successful in correlating the tephra deposits to source centre, however, in some cases geochemistry could not be a defining factor in the correlation, and therefore for these cases additional criteria had to be used.

\subsubsection{Additional Criteria}

A multifaceted approach to correlation is required to not only 1) strengthen correlations highlighted by the geochemistry but also 2) resolve any ambiguities remaining from the geochemical signatures alone. For this study I combined age and location (of both tephra and centre) and scale of eruption and calculated tephra volume, with geochemistry. The combination of these criteria allows the confidence of a correlation to be given a scale, where correlations gain a higher confidence by satisfying a higher number of criteria. Of the twenty-eight tephra horizons identified, twenty have a correlation confidence rating of 2 or 1 , meaning they satisfy three or more of the four criteria used.

Therefore in conclusion, it is possible to correlate tephra deposits to source centre. However, a detailed understanding of the geochemistry of the centres involved and the potential defining geochemical signatures is required and, where geochemistry is not enough to distinguish between centres, other criteria need to be included to allow refinement of the source correlation.

\subsubsection{What is the spatial, temporal and geochemical evolution of the AVF?}

\subsubsection{Temporal Evolution}

By combining the tephra correlations with Ar-Ar and ${ }^{14} \mathrm{C}$ ages (Leonard et al., in prep. Appendix D), and morphostratigraphic constraints, 45 of 53 of the AVF centres are put into a relative age order, with absolute age estimates also presented. This age order allows the assessment of the temporal evolution of the field. The results suggest that in general the repose periods for eruptions increased from inception of the field to ca. $21.5 \mathrm{ka}$, and have now decreased to the eruption of Rangitoto, with a ca. 10 ka hiatus between Mt Wellington and Rangitoto 1. The repose periods are however, highly variable from $<0.1 \mathrm{ka}$ to $13 \mathrm{ka}$ (with two outliers at 17 and $27 \mathrm{ka}$ ), with fourteen of the centres with repose periods $<0.5 \mathrm{ka}$, and nine with repose periods $>10 \mathrm{ka}$. Therefore, based on these results it is possible to 
suggest that the next eruption from the AVF will most likely occur in $<13$ ka yrs. after Rangitoto's latest eruption, but most likely to be at the less frequent limit of this, if the deceleration of repose periods is correctly inferred.

\subsubsection{Spatial Evolution}

In general there are no overarching trends to the spatial evolution of the AVF eruptions, although there are some patterns in terms of grouping of centres. The term 'aligned' is used to describe when more than 2 centres are found in geographical alignment but without any age relationships, and the term 'coupled' is used when 2 centres are found in close proximity in both space and time. Aligned centres are attributed to the magma exploiting pre-existing weaknesses (faults or fractures) within the crust. In contrast the appearance of coupled centres is attributed to the dual ascent styles that are found within the AVF (e.g., McGee et al., 2011; McGee et al., 2015). As a result of these observations the ability to predict where the next eruption from the AVF will occur is limited. However it is considered more likely that an eruption will occur along a pre-existing fault line (e.g., Kereszturi et al., 2014) and, if dual magma batches are ascending, separated by a time gap, the secondary eruption may not necessarily occur through the primary conduit.

\subsubsection{Geochemical Evolution}

The geochemistry of the products of the field are show to represent the variable mixing from multiple magma sources at various depths within the mantle (e.g., McGee et al., 2013; McGee et al., 2015). These geochemical signatures, and thus source proportions, generally correlate to the size of the subsequent eruption. Small centres are shown to often have higher $(\mathrm{La} / \mathrm{Yb})_{N}$ ratios coupled with lower $\mathrm{SiO}_{2}$ concentrations, and the converse true for the larger centres. When these geochemical signatures for each centre are plotted in relative age order, there is possibly an apparent cyclic nature to the eruption sizes and thus geochemistries for the AVF products. This cyclicity suggests that throughout the history of the AVF the mantle source has remained constant, but variably tapped, to produce the signatures seen in the AVF products. 


\subsubsection{What can the eruptive products of the AVF tell us about the pre-eruptive processes which act on the upwelling magma?}

Evidence for a loss of magma volume is highlighted by the eruption of lavas that have the geochemical signatures of much larger melt body. This loss of magma volume is attributed to fractional crystallisation of the ascending melt, and/or retention of melt within the crust. Evidence of crustal interaction is further supported by the Os isotope systematics, which show the influence of both metasedimentary terranes (Waipapa and Murihiku) and the Dun Mountain ophiolite belt (DMOB) can be found within the AVF eruptive products. The metasedimentary terranes have a modelled input of $<1 \%$, but due to their highly radiogenic Os isotope ratios, this minor amount of contamination has a major effect on the AVF lavas Os signatures, increasing the ${ }^{187} \mathrm{Os} /{ }^{188} \mathrm{Os}$ ratios from mantle values (ca. 0.1230 ) to more extreme values (e.g., ca. 0.2-0.5). Previous isotope studies have therefore not identified this contamination, as the proportions are too small to have an impact on the less sensitive isotopic systems (e.g. $\mathrm{Pb}-\mathrm{Sr}-\mathrm{Nd}$ ). The contamination from the DMOB has a different signature leading to elevated Os concentrations (e.g., from mantle values of ca. 50 ppt to values of ca. 400 ppt seen in the Pupuke samples) but little change in Os isotope values). This is attributed to contamination of $\leq 10 \%$ xenocrystic olivine supporting findings from Sporli and Black (2015). As both these signatures are observed within single centres, it is proposed that the ascending magma interacts with both the metasedimentary terranes, and the DMOB. With the DMOB tentatively proposed as a principle pathway to facilitate rapid ascent of these primitive lavas through the crust. 


\subsection{Further Research}

\subsubsection{Application of newly developed methods on other cores}

The multi-method analyses of the cores from the AVF have proved to accurately and efficiently identify basaltic tephra within the cores. In terms of a local application, the AVF cores that were not assessed using these methods (Panmure Basin and Pukaki) would benefit from this analysis. The Pukaki core would particularly benefit from this due to the currently ambiguous analysis and correlation of multiple cores, and basaltic tephra horizons from within this maar (Chapter 1; Sandiford et al., 2001; Shane, 2005; Zawalna-Geer, 2012). All of the basaltic tephra deposits within the Pukaki core currently only have limited major element analysis. Therefore, by re-sampling the tephra horizons within this core, trace-element analysis could be undertaken on the glass shards, allowing centre correlations of a higher confidence rating to be produced (Chapter 5). This core also extends back further than the current research outlines (Shane, 2005), and therefore new horizons could be (and almost certainly would be) found below the Rotoehu rhyolitic marker horizon. The Pukaki core is of specific importance as it is the only core that likely records more of the eruptions from the south of the field. Therefore the information gathered from re-analysing this core would strengthen some of the previous correlations and add new details about eruptions in the southern AVF.

From a global perspective, the X-ray and magnetic susceptibility method is transferrable to marine, peat and ice cores, and is a valuable way to quickly and noninvasively identify regions of interest (with regards to tephra horizons) in the cores. If the matrix sediment is less dense (for X-ray) and contains less magnetic minerals than the tephra, the horizons will be easily identified by this method. Similarly these methods will be useful in identifying if units appear to be reworked or disturbed in any way.

The use of trace elements, outlined within Chapter 3, as a more geochemically unique fingerprint for tephra horizons is also highly transferrable. Where previous studies have highlighted major element concentrations that are indistinguishable between tephra horizons (e.g., Davies et al., 2014) this methodology can be applied to provide a more individual signature for the deposits, and potentially resolve any geochemical ambiguities in correlations. 


\subsubsection{Age refinement of tephra horizons and thus eruptive centres}

Currently the ages of the tephra horizons, especially those below the Rotoehu marker horizon are poorly constrained. In Chapter 3 I outline the ambiguities that arise in sedimentation rate calculations that cause major discrepancies between, and within, the cores. I recalculate these sedimentation rate ages in Chapter 5 using the new data gained from this study, however these are only calculated, rather than definitive ages. It would therefore be of use to investigate the ability to further refine the ages of the tephra horizons. This would be exceptionally important in the case of the Rotoehu tephra, the age of which remains controversial, and thus the basaltic horizons, which pre-date this deposit, are also poorly constrained. In addition, if the basaltic horizons themselves could be better dated (potentially through statistical modelling) for those horizons with a high confidence rating, a better constraint could potentially be applied to the eruption from an individual centre itself.

\subsubsection{A further application of tephra horizon correlation}

Analysis and comparison of volatile contents (e.g., $\mathrm{H}_{2} \mathrm{O}, \mathrm{CO}_{2}$, sulphur) within olivine hosted melt inclusions (Mls) between tephra (horizons with a confidence level 1) and the correlated centre's whole rock compositions, will allow the amount of degassing associated with the individual eruptions to be evaluated. Following on from this, if the correlation between centre size (Kereszturi et al., 2013) and geochemistry (McGee et al., 2015) holds true for centre size and degassing (volatile difference), the total degassing from the field could be calculated. This process has previously been used to assess if there is a link between amount of degassing and the eruption style (Cervantes and Wallace, 2003), which could also be applied to the AVF volcanoes, as the tephra horizons correlated (with level 1 confidence) come from a range of eruption types. The ability to constrain the effects of degassing on the eruption style could important information for forecasts of the characteristics of future eruptions. 


\subsubsection{Centre and field geochemical evolution}

Chapters 5 and 6 outlined results of the geochemical evolution of the AVF. There are a number of outstanding questions that need to be addressed in order to further knowledge of the mantle processes for the field. McGee et al. $(2011,2012)$ detailed the evolution throughout individual eruptions assessing the eruptions of both Rangitoto and Motukorea. The results for these centres suggest that individual eruptions evolve geochemically through time as a result of a shallowing magma source. However, this evolution has only been measured in these two systems and, to determine whether these two centres are unusual or represent 'the norm', a number of other centres should be assessed. This pattern of geochemical evolution is also noted for some of the 'coupled centres' (Chapter 5), with the older centre showing the initial deeper mantle signature and the younger centre showing the shallower mantle signature. In contrast, Smith et al. (2008) suggested a geochemical variation throughout a single eruption (Crater Hill) was consistent with fractionation on ascent from a single source, thereby providing an element of controversy that could be tested. Further investigation of these relationships could hold important information about magma ascent processes and the mantle sources.

Similarities between the geochemistry of the AVF and the South AVF (SAVF) are also noted (Chapter 6) and the ability to assess the geochemical evolution of the SAVF (and potentially the older Ngatutura and Alexandra fields) could allow more details about the evolution of the AVF to be highlighted. These data would allow further investigation of the mantle source (are they the same or different?), whether there are variations across the fields in the degrees of partial melting, and also for the geochemical evolution of the fields (are they the same or different? Is this 'within field' evolution consistent?).

The key overarching aim for all these aspects of further research is to provide more details about the AVF, thus increasing our ability to accurately forecast the characteristics and mechanisms of a future eruption. Auckland city, the people, and the infrastructure are at risk from a future eruption, and therefore accurate and realistic information is required to build effective disaster management strategies. 
References 
Affleck, D.K., Cassidy, J., Locke, C.A., 2001. Te Pou Hawaiki volcano and pre-volcanic topography in central Auckland: volcanology and hydrogeological implications. New Zealand Journal of Geology and Geophysics 44, 313-321.

Agustín-Flores, J., Németh,K., Cronin, S.J., Lindsay, J.M., Kereszturi, G., Brand, B.D., Smith, I.E.M., 2014. Phreatomagmatic eruptions through unconsolidated coastal plain sequences, Maungataketake, Auckland Volcanic Field (New Zealand). Journal of Volcanology and Geothermal Research 276, 46-63.

Alard, O., Griffin, W.L., Pearson, N.J., Lorand, J-P., O’Reilly, S.Y., 2002. New insights into the Re-Os systematics of sub-continental lithospheric mantle from in situ analysis of sulphides. Earth and Planetary Science Letters 203, 651-663.

Albarède, F., 1995. Introduction to Geochemical Modeling. Cambridge University Press, Cambridge, UK.

Allan, A.S.R., Baker, J.A., Carter, L.,Wysoczanksi, R.J., 2008. Reconstructing the Quaternary evolution of the world's most active silicic volcanic system: insights from an $\sim 1.65$ Ma deep ocean tephra record sourced from the Taupo Volcanic Zone, New Zealand. Quaternary Science Reviews 27, 2341-2360.

Allen, S.R., Smith I.E.M., 1994. Eruption styles and volcanic hazard in the Auckland Volcanic Field, New Zealand. Geoscience Reports of Shizuoka University 20, 5-14.

Alloway, B.V., Lowe, D.J., Chan, R.P.K., Eden, D.N., Froggatt, P.C., 1994. Stratigraphy and chronology of the Stent tephra, a c.a. 4000 year old distal silicic tephra from Taupo Volcanic Centre, New Zealand. New Zealand Journal of Geology and Geophysics 37, 37-47.

Alloway, D., Neall, V.E., Vucetich, C.G., 1995. Late Quaternary (post 28,000 year BP) tephrostratigraphy of the northeast and central Taranaki, New Zealand. Journal of the Royal Society of New Zealand 25, 385-458.

Alloway, B.V., Westgate, J.A., Pilans, B.J., Pearce. N.J.G., Newnham, R.M., Byrami, M.L., Aarburg, S.E., 2004. Stratigraphy, age and correlation of middle Pleistocene silicic tephra in the Auckland region, New Zealand: a prolific distal record of Taupo Volcanic Zone volcanism. New Zealand Journal of Geology and Geophysics 47, 447-479.

Alves, S., Schiano, P., Campas, F., Allegre, C.J., 2002. Osmium isotope binary mixing arrays in arc volcanism. Earth and Planetary Science Letters 198, 355-369. 
Baker, J., Peate, D., Waight. T., Meyzen, C., 2004. Pb isotopic analysis of standards and samples using a ${ }^{207} \mathrm{~Pb}-{ }^{204} \mathrm{~Pb}$ double spike and thallium to correct for mass bias with a double-focusing MC-ICP-MS. Chemical Geology 211, 275-303.

Bartrum. J.A., 1928. Lava slickenslides at Auckland. The New Zealand Journal of Science and Technology 10, 23-25.

Bebbington, M.S., 2013. Assessing probabilistic forecasts of volcanic eruption onsets. Bulletin of Volcanology 252, 14-28.

Bebbington, M.S., Cronin, S.J., 2011. Spatio-temporal hazard estimation in the Auckland Volcanic Field, New Zealand, with a new event-order model. Bulletin of Volcanology 73, 5572.

Beckett , W., 2000. Occupational respiratory disease. New England Journal of Medicine 342, 406-413.

Beier, C., Mata, J., Stöckhert, F., Mattielli, N., Brandl, P., Madureira, P., Genske, F., Martins, S., Madeira, J., and Haase. K., 2013. Geochemical evidence for melting of carbonated peridotite on Santa Maria Island, Azores. Contributions to Mineralogy and Petrology 165, 832-841.

Beierle, B., Bond, J., 2002. Density-induced settling of tephra through organic lake sediments. Journal of Paleolimnology 28, 433-440.

Berghuijs, J.F., Mattson H.B., 2013. Magma ascent, fragmentation and depositional characteristics of "dry" maar volcanoes: similarities with vent-facies kimberlite deposits. Journal of Volcanology and Geothermal Research 252, 53-72.

Bertrand, S., Daga, R., Bedert, R., Fontijn, K., 2014. Deposition of the 2011-2012 Cordón Caulle tephra (Chile, $40^{\circ} \mathrm{S}$ ) in lake sediments: implications for tephrochronology and volcanology. Journal of Geophysical Research: Earth Surface 119, 2555-2573.

Bézos, A., Lorand, J-P., Humler, E., and Gros, M., 2005. Platinum-group element systematic in Mid-Ocean Ridge basaltic glasses from the Pacific, Atlantic and Indian Oceans.

Geochimica et Cosmochimica Acta 69, 2613-2627.

Birck, J-L., Roy-Barman, M., Capmas, F., 1997. Re-Os isotopic measurements at the femtomole level in natural samples. Geostandards Newsletter 21, 19-27. 
Blondes, M.S., Reiners, P,W., Ducea, M.N., Singer, B.S., Chesley, J., 2008. Temporalcompositional trends over short and long tmie scales in basalts of Big Pine Volcanic Field, California. Earth and Planetary Science Letters 269, 140-154.

Bohrson, W., Davidson, J., Wolff, J.A., 1997. Rethinking the chemical heterogeneity of the mantle. EOS Transactions, American Geophysical Union 78, 257-262.

Borg, L.E., Brandon, D.A., Clynne M.A., Walker, R.J., 2000. Re-Os isotopic systematics of primitive lavas from Lassen region of the Cascade arc, California. Earth and Planetary Science Letters 177, 301-317.

Bourne, A.J., Davies, S.M., Abbott, P.M., Rasmussen, S.O., Steffensen, J.P., Svensson, A., 2013. Revisiting the Faroe Marine Ash Zone III in two Greenland ice cores: implications for marine-ice correlations. Journal of Quaternary Science 28, 641-646.

Boygle, J., 1999. Variability of tephra in lake and catchment sediments, Sínavatn, Iceland. Global and Planetary Change 21, 129-149.

Bradshaw, T.K., Smith, E.I., 1994. Polygenetic Quaternary volcanism at Crater Flat, Nevada. Journal of Volcanology and Geothermal Research 63, 165-182.

Brand, B.D., Gravely, D.M., Clarke, A.B., Lindsay, J.M., Bloomberg, S.H., Agustín-Flores, J., Németh, K., 2014. A combined field and numerical approach to understanding dilute pyroclastic density current dynamics and hazard potential: Auckland Volcanic Field, New Zealand. Journal of Volcanology and Geothermal Research 276, 215-232.

Brendryen, J., Haflidason, H., Sejrup, H.P., 2010. Norwegian Sea tephrostratigraphy of marine isotope stages 4 and 5: prospects and problems for tephrochronology in the North Atlantic region. Quaternary Science Reviews 29, 847-864.

Brenna, M., Cronin, S.J., 2015. Mantle heterogeneity controls on small-volume basaltic volcanism. Forum comment on McGee et al., 2015, Geology doi 10.1130/G37023C.1.

Brenna, M., Cronin, S.J., Smith, I., Sohn, Y., Németh, K., 2010. Mechanisms driving polymagmatic activity at a monogenetic volcano, Udo, Jeju Island, Korea. Contributions to Mineralogy and Petrology 160, 931-950.

Brenna, M., Cronin, S.J., Németh, K., Smith, I.E.M., Sohn, Y.K., 2011. The influence of magma plumbing complexity on monogenetic eruptions, Jeju Island, Korea. Terra Nova 23, 70-75. 
Briggs, R.M., Okada, T., Itaya, T., Shibuya, H., Smith, I.E.M., 1994. K-Ar ages, paleomagnetism, and geochemistry of the South Auckland volcanic field, North Island, New Zealand. New Zealand Journal of Geology and Geophysics 37, 143-153.

Bryant, E., 2005. Natural Hazards, Cambridge University Press, New York, USA. pp. 1-13. Bryner, V., 1991. Motukorea: the evolution of an eruption centre in the Auckland Volcanic Field. MSc thesis, University of Auckland, New Zealand.

Burton, K, W., Gannoun, A., Birck, J.L., Allègre, C.J., Schiano, P., Clocchiatti, R., Alard, O., 2002. The compatibility of rhenium and osmium in natural olivine and their behavior during mantle melting and basalt genesis. Earth and Planetary Science Letters 198, 63-76.

Carroll, M.R., Rutherford, M.J., 1985. Sulphide and sulphate saturation in hydrous silicate melts. Journal of Geophysical Research 90, 601-612.

Cassata, W.S., Singer, B.S., Cassidy, J., 2008. Laschamp and Mono Lake geomagnetic excursions recorded in New Zealand. Earth and Planetary Science Letters 268, 76-88.

Cervantes, P., Wallace, P., 2003. Magma degassing and basaltic eruption styles: a case study of $\sim 2000$ year BP Xitle volcano in central Mexico. Journal of Volcanology and Geothermal Research 120, 249-270.

Chesley, J.T., Ruiz, J., Righter, K., Ferrari, L., Gómez-Tuena, A., 2002. Source contamination versus assimilation: an example from the Trans-Mexican Volcanic Arc. Earth and Planetary Science Letters 195, 211-221.

Condit, C.D., Connor, C.B., 1996. Recurrence rates of volcanism in basaltic volcanic fields: An example from the Springerville volcanic field, Arizona. Geological Society of America Bulletin 108, 1225-1241.

Connor, C.B., 1990. Cinder cone clustering in the Trans-Mexican Volcanic Belt: implications for structural and petrologic models. Journal of Geophysical Research 95 (B12) 1939519405.

Connor, C.B., Conway, F.M., 2000. Basaltic volcanic fields, in Sigurdsson, H. et al., ed., Encyclopedia of Volcanoes, San Diego, Academic Press pp331-343.

Conway, F.M., Connor, C.B., Hill, B.E., Condit, C.D., Mullaney, K., Hall, C.M., 1998. Recurrence rates of basaltic volcanism in SP cluster, San Francisco volcanic field, Arizona. Geology 26, 655-658. 
Cook, C., Briggs, R.M., Smith, I.E.M., Maas, R., 2005. Petrology and geochemistry of the intraplate basalts in the South Auckland Volcanic Field, New Zealand: evidence for two coeval magma suites from distinct sources. Journal of Petrology 46, 473-503.

Coombs, D.S., Landis, C.A., Norris, R.J., Sinton, J.M., Borns, D.J., Craw, D., 1976. Dun Mountain ophiolite belt, New Zealand, its tectonic setting, constitution, and origin, with special reference to the southern portion. American Journal of Science 276, 561-603.

Cooper, A.F., Collins, A.K., Palin, J.M., Spratt, J., 2015. Mineralogical evolution and REE mobility during crystallisation of ancylite-bearing ferrocarbonatite, Haast River, New Zealand. Lithos 216-217, 324-337.

Creaser, R.A., Papanastassiou, D.A., Wasserburg, G.J., 1991. Negative thermal ion mass spectrometry of osmium, rhenium and iridium. Geochimica et Cosmochimica Acta 50, 397401.

Dale, C.W., Gannoun, A., Burton, K.W., Argles, T.W., Parkinson, I.J., 2007. Rheniumosmium isotope and elemental behavior during subduction of oceanic crust and the implications for mantle recycling. Earth and Planetary Science Letters 253, 211-225.

Dale, C.W., Macpherson, C.G., Pearson, D.G., Hammond, S.J., Arculus, R.J., 2012. Interelement fractionation of highly siderophile elements in the Tonga Arc due to flux melting of a depleted source. Geochimica et Cosmochimica Acta 89, 202-225.

Danišík, M., Shane, P., Schmitt, A.K., Hogg, A., Santos, G.M., Storm, S., Evans, N.J., Fifield, L.K., Lindsay, J.M., 2012. Re-anchoring the late Pleistocene tephrochronology of New Zealand based on concordant radiocarbon ages and combined ${ }^{238} \mathrm{U} /{ }^{230} \mathrm{Th}$ disequilibrium and $(\mathrm{U}-\mathrm{Th}) / \mathrm{He}$ zircon ages. Earth and Planetary Science Letters 349-350, 240-250.

Davies, S.M., Abbott, P.M., Meara, R.H., Pearce, N.J.G., Austin, W.E.N., Chapman, M.R., Svensson, A., Bigler, M., Rasmussen, T.L., Rasmussen, S.O., Farmer, E.J., 2014. A North Atlantic tephrostratigraphical framework for 130-60 ka b2k: new tephra discoveries, marinebased correlations, and future challenges. Quaternary Science Reviews 106, 101-121.

Day, J.M.D., 2013. Hotspot volcanism and highly siderophile elements. Chemical Geology 341, 50-74.

Day, J.M.D., Pearson, D.G., Macpherson, C.G., Lowry, D., Carracedo, J.C., 2009. Pyroxenite-rich mantle formed by recycled oceanic lithosphere: Oxygen-osmium isotope evidence from Canary Island lavas. Geology 37, 555-558. 
Day, J.M.D., Pearson, D.G., Macpherson, C.G., Lowry, D., Carracedo, J.C., 2010. Evidence for distinct portions of subducted oceanic crust and lithosphere in HIMU-type mantle beneath El Hierro and La Palma, Canary Islands. Geochimica et Cosmochimica Acta 74, 6565-6589.

Deer, W.A., Howie, R.A., Zussman, J., 1992. An introduction to the rock forming minerals. Wiley, New York.

de Klerk, P., Janke, W., Kühm, P., Theuerkauf, M., 2008. Environmental impact of the Laacher See eruption at a large distance from the volcano: integrated palaeoecological studies from Vorpommern (NE Germany). Palaeogeography, Palaeoclimatology, Palaeoecology 270, 196-214.

Delcamp, A., van Wyk de Vries, B., Stéphane, P., Kervyn, M., 2014. Endogenous and exogenous growth of the monogenetic Lemptégy volcano, Chaîne des Puys, France. Geosphere 10, 998-1019.

Demidjuk, Z., Turner, S., Sandiford, M., George, R., Foden, J., Etheridge, M., 2007. U-series isotope and geodynamic constraints on mantle melting processes beneath the New Volcanic Province in South Australia. Earth and Planetary Science Letters 261, 517-533.

DePaolo, D.J., 1981. Trace element and isotopic effects of combined wallrock assimilation and fractional crystallization. Earth and Planetary Science Letters 53, 189-202.

Dirksen, O., van den Bogaard, C., Danhara, T., Diekmann, B., 2011. Tephrochronological investigation at Dvuh-yurtochnoe lake area, Kamchatka: Numerous landslides and lake tsunami, and their environmental impacts. Quaternary International 246, 298-311.

Dohrenwend, J.C., Wells, S.G., Turrin, B.D., 1986. Degradation of Quaternary cinder cones in the Cima volcanic field, Mojave Desert, California. Geological Society of America Bulletin 97, 421-427.

Dunbar, N.W., Kyle, P.R., 1992. Volatile contents of obsidian clasts in tephra from the Taupo Volcanic Zone, New Zealand: Implications to eruptive processes. Journal of Volcanology and Geothermal Research 49, 127-145.

Eade, J., 2009. Petrology and correlation of lava flows from the central part of the Auckland Volcanic Field. MSc thesis, University of Auckland, New Zealand.

Eccles, J.D., Cassidy, J., Locke, C.A., Spörli, K.B., 2005. Aeromagnetic imaging of the Dun Mountain Ophiolite Belt in northern New Zealand: insight into the fine structure of a major SW Pacific terrane suture. Journal of the Geological Society, London 162, 723-735. 
Engwell, S.L., Sparks, R.S.J., Carey, S., 2014. Physical characteristics of tephra layers in the deep-sea realm: the Campanian Ignimbrite eruption. Geological Society of London Special Publication 398, 47-64.

Erlund, E.J., Cashman, K.V., Wallace, P.J., Poili, L., Rosi, M., Johnson, E., Delgado Granados, H., 2010. Compositional evolution of magma from Parícutin Volcano, Mexico: the tephra record. Journal of Volcanology and Geothermal Research 197, 167-187.

Escrig, S., Doucelance, R., Moreira, M., Allegre, J.C., 2005. Os isotope systematics in Fogo Island: evidence for lower continental crust fragments under the Cape Verde Southern Islands. Chemical Geology 219, 93-113.

Esser, B.K., Turekian, K.K., 1994. The osmium isotopic composition of the continental crust. Geochimica et Cosmochimica Acta 57, 3093-3104.

Fergusson, G., Rafter, T.A., 1959. New Zealand C14 age measurements - 4. New Zealand Journal of Geology and Geophysics 2, 208-241.

Francis, P., Oppenheimer, C., 2004. Volcanoes. Oxford, Oxford University Press pp521. Franklin, J.T., 1999. Geology of the Orakei Basin area. MSc thesis, University of Auckland, New Zealand.

Froggatt, P.C., 1982. Review of methods of estimating rhyolitic tephra volumes applications to the Taupo Volcanic Zone, New Zealand. Journal of Volcanology and Geothermal Research 14, 301-318.

Froggatt, P.C., Lowe, D.J., 1990. A review of late Quaternary silicic and some other tephra formations from New Zealand - their stratigraphy, nomenclature, distribution, volume, and age. New Zealand Journal of Geology and Geophysics 33, 89-109.

Gerbode, C., Dasgupta, R., 2010. Carbonate-fluxed melting of MORB-like pyroxenite at 2.9 GPa and genesis of HIMU ocean island basalts. Journal of Petrology 51, 2067-2088.

Govindaraju, K., 1994. Compilation of working values and sample description for 383 geostandards. Geostandards Newsletter 18 (special issue).

Gramlich, J.W., Murphy, T.J., Garner, E.L., Shields, W.R., 1973. Absolute isotopic abundance ratio and atomic weight of a reference sample of rhenium. Journal of Research of the National Bureau of Standards 77A, 691-698. 
Green, J.D., Lowe, D.J., 1985. Stratigraphy and developments of c.a. 17,000 year old Lake Maratoto, North Island, New Zealand, with some inferences about post glacial climatic change. New Zealand Journal of Geology and Geophysics 28, 675-699.

Green, R.M., Bebbington, M.S., Cronin, S.J., Jones, G., 2014. Automated statistical matching of multiple tephra records exemplified using five long maar sequences younger than 75ka, Auckland, New Zealand. Quaternary Research 82, 405-419.

Guilbaud, M.-N., Siebe, C., Layer, P., Salinas, S., 2012. Reconstruction of the volcanic history of the Tacámbaro-Puruarán area (Michoacán, México) reveals high frequency of Holocene monogenetic eruptions. Bulletin of Volcanology 74, 1187-1211.

Gutmann, J.T., 2007. Geologic Studies in the Pnacate Volcanic Field. Journal of the Southwest 49, 189-243.

Haase, K.M., Devey, C.W., 1996. Geochemistry of labas from the Ahu and Tupa volcanic fields, Easter Hotspot, southeast Pacific: implications for intraplate magma genesis near a spreading axis. Earth and Planetary Science Letters 137, 129-143.

Handler, M.R., Bennett, V.C., Esat, T.M., 1997. The persistence of off-cratonic lithospheric mantle: Os isotopic systematics of variably metasomatised southeast Australian xenoliths. Earth and Planetary Science Letters 151, 61-75.

Hart, S.R., 1984. A large-scale isotope anomaly in the Southern Hemisphere mantle. Nature 309, 753-757.

Hasebe, N., Fukutani, A., Sudo, M., Tagami, T., 2001. Transition of eruptive styles in an arcarc collision zone: K-Ar dating of Quaternary monogenetic and polygenetic volcanoes in the Higashi-Izu region, Izu peninsula, Japan. Bulletin of Volcanology 63, 377-386.

Hasenaka, T., Carmichael, I.S.E., 1987. The cinder cones of Michoacan-Guanajuao, Central Mexico: Petrology and chemistry. Journal of Petrology 28, 241-269.

Hatherton, T., Sibson, R.H., 1970. Junction Magnetic Anomaly north of Waikato River. New Zealand Journal of Geology and Geophysics 13, 655-662.

Hauri, E.H., Hart, S.R., 1993. Re-Os isotope systematics of HIMU and EMII oceanic island basalts from the South Pacific Ocean. Earth and Planetary Science Letters 114, 353-371.

Hauri, E.H., Hart, S.R., 1997. Rhenium abundance and systematics in oceanic basalts. Chemical Geology 139, 185-205. 
Hayward, B.W., Morley, M.S., Sabaa, A.T., Grenfell, H.R., Daymond-King, R., Molloy, C., Shane, P.A., Augustinus, P.A., 2008. Fossil record of the post-glacial marine breaching of Auckland's volcanic maar craters. Records of the Auckland Museum 45, 73-99.

Hayward, B.W., Murdoch, G., Maitland, G., 2011. Volcanoes of Auckland, The Essential Guide. Auckland University Press, Auckland, New Zealand.

Heming, R.F., 1980. Patterns of Quaternary basaltic volcanism in the northern North Island, New Zealand. New Zealand Journal of Geology and Geophysics 23, 335-344.

Heming, R.F., Barnet, P.R., 1986. The petrology and petrochemistry of the Auckland volcanic field. In: Smith, I.E.M., (Ed), Late Cenozoic Volcanism in New Zealand. Royal Society of New Zealand Bulletin 23, 64-75.

Herzberg, C., Asimow, P.D., Arndt, N., Niu, Y., Lesher, C.M., Fitton, J.G., Cheadle, M.J., and Saunders, A.D., 2007. Temperatures in ambient mantle and plumes: Constraints from basalts, picrites, and komatiites. Geochemistry, Geophysics, Geosystems 8, doi: 10.1029/2006GC0001390.

Hill, B.E., Connor, C.B., Jarzemba, M.S., La Femina, P.C., Navarro, M., Strauch, W., 1998. 1995 eruptions of Cerro Negro volcano, Nicaragua, and risk assessment for future eruptions. Geological Society of America Bulletin 110, 1231-1241.

Hoernle, K., White, J.D.L., van den Bogaard, P., Hauff, F., Coombs, D.S., Werner, A.F., Timm, C., Garbe-Schönberg, D., Reay, A., Cooper, A.F., 2006. Cenozoic intraplate volcanism on New Zealand: upwelling induced by lithospheric removal. Earth and Planetary Science Letters 248, 350-367.

Hookway, M., 2000. The geochemistry of Rangitoto. MSc thesis, University of Auckland, New Zealand.

Horspool, N.A., Savage, M.K., Bannister, S., 2006. Implications for intraplate volcanism and back arc deformation in northwestern New Zealand, from joint inversion of receiver functions and surface waves. Geophysical Journal International 166, 1466-1483.

Horwell, C.J., Baxter, P.J., 2006. The respiratory health hazards of volcanic ash: a review for volcanic risk mitigation. Bulletin of Volcanology 69, 1-24.

Horwell, C.J., Fenglio, I., Ragnarsdottir, K.V., Sparks, R.S.J., Fubini, B., 2003. Surface reactivity of volcanic ash from the eruption of Soufrière Hills volcano, Monserrat, with implications for health hazards. Environmental Research 93, 202-215. 
Houghton, B.F., Wilson, C.J.N., Rosenberg, M.D., Smith, I.E.M., Parker, R.J., 1996. Mixed deposits of complex magmatic and phreatomagmatic volcanism: an example from Crater Hill, Auckland, New Zealand. Bulletin of Volcanology 58, 59-66.

Houghton, B.F., Wilson, C.J.N., Smith, I.E.M., 1999. Shallow-seated controls on styles of explosive basaltic volcanism: a case study from New Zealand. Journal of Volcanology and Geothermal Research 91, 97-120.

Houghton, B.F., Bonadonna, C., Gregg, C.E., Johnston, D.M., Cousins, W.J., Cole, J.W., Del Carlo, P., 2006. Proximal tephra hazards: recent eruption studies applied to volcanic risk in the Auckland Volcanic Field, New Zealand. Journal of Volcanology and Geothermal Research 155, 138-149.

Hoverd, J.L., Shane, P.A., Smith, I.E.M., Smith, V.C., Wilson, C.J.N., 2005. Towards an improved understanding of local and distal volcanic stratigraphy in Auckland: stratigraphy of a long core from Glover Park (St Helier's Volcano) in Auckland. Institute of Geological \& Nuclear Sciences Science Report 2005/31, pp45.

Howorth, R., 1975. New formations of late Pleistocene tephras from the Okataina Volcanic Centre, New Zealand. New Zealand Journal of Geology and Geophysics 18, 683-712.

Huang, Y., Hawkesworth, C., van Calsteren, P., Smith, I., Black, P., 1997. Melt generation models for the Auckland volcanic field, New Zealand: constraints from U-Th isotopes. Earth and Planetary Science Letters 149, 67-84.

Huang, Y., Hawkesworth, C., Smith, I., van Calsteren, P., Black, P., 2000. Geochemistry of late Cenozoic basaltic volcanism in Northland and Coromandel, New Zealand: implications for mantle enrichment processes. Chemical Geology 164, 219-238.

Hwang, S.K., Jin, X., Ahn, U.S., 2005. Volcanic forms and eruption processes of Laiheishan and Huoshaoshan in the Wudalianchi volcanics, NE China. Journal of Petrological Society Korea 14, 251-263.

Jamais, M., Lassiter, J.C., Brügmann, G., 2008. PGE and Os-isotopic variations in lavas from Kohala Volcano, Hawaii: constraints on PGE behaviour and melt/crust interaction. Chemical Geology 250, 16-28.

Jochum, K.P., and Nehring, 2006. GeoRem preferred values. http://georem.mpchmainz.gwdg.de/sample_query_pref.asp. 
Jochum, K.P., Willbold, M., Raczek, I., Stoll, B., Herwig, K., 2005. Chemical characteristics of the USGS reference glasses GSA-1G, GSC-1G, GSE-1G, BCR-2G, BHVO-2G, and BIR$1 G$ using EMPA, ID-TIMS, ID-ICP-MS, and LA-ICP-MS. Geostandards and Geoanalytical Research 29, 285-302.

Johnson, E.R., Wallace, P.J., Cashman, K.V., Granados, H.D., Kent, A.J.R., 2008. Magmatic volatile contents in degassing-induced crystallisation at Volcan Jorullo, Mexico: implications for melt evolution and the plumbing systems of monogenetic volcanoes. Earth and Planetary Science Letters 269, 478-487.

Johnson, E.R., Wallace, P.J., Cashman, K.V., Granados, H.D., 2010. Degassing of volatiles $\left(\mathrm{H}_{2} \mathrm{O}, \mathrm{CO}_{2}, \mathrm{~S}, \mathrm{Cl}\right)$ during ascent, crystallisation, and eruption of mafic monogenetic volcanoes in central Mexico. Journal of Volcanology and Geothermal Research 197, 225238.

Johnson, P.J., Valentine, G.A., Cortés, J.A., Tadini, A., 2014. Basaltic tephra from monogenetic Marcath Volcano, centre Nevada. Journal of Volcanology and Geothermal Research 281, 27-33.

Jones, J., 2007. The amphibolite xenoliths of St Heliers. MSc thesis, University of Auckland, New Zealand.

Jung, S., Pfänder, J.A., Brauns, M., Maas, R., 2011. Crustal contamination and mantle source characteristics in continental intra-plate volcanic rocks: $\mathrm{Pb}, \mathrm{Hf}$ and $\mathrm{Os}$ isotopes from central European volcanic province basalts. Geochimica et Cosmochimica Acta 75, 26642683.

Jugo, P.J., 2009. Sulfur content at sulfide saturation in oxidized magmas. Geology 37, 415418

Kamber, B.S., Collerson, K.D., 2000. Zr/Nb systematics of ocean island basalts reassessed the case for binary mixing. Journal of Petrology 41, 1007-1021.

Kear, D., 2004. Reassessment of Neogene tectonism and volcanism in North Island, New Zealand. New Zealand Journal of Geology and Geophysics 47, 361-374.

Kenny, J., Lindsay, J., Howe, T., 2011. Large scale faulting in the Auckland Region, DEVORA project. Institute of Earth Science and Engineering technical report 1-2011.04.

Kereszturi, G., Németh, K., Cronin, S.J., Agustin-Flores, J., Smith, I.E.M., Lindsay, J., 2013. A model for calculating eruptive volumes for monogenetic volcanoes - Implications for the 
Quaternary Auckland Volcanic Field, New Zealand. Journal of Volcanology and Geothermal Research 266, 16-33.

Kereszturi, G., Németh, K., Cronin, S.J., Procter, J., Augustin-Flores, J., 2014. Influences on the variability of eruption sequences and style transitions in the Auckland Volcanic Field, New Zealand. Journal of Volcanology and Geothermal Research 286, 101-115.

Kermode, L.O., 1975. Urban geology of Mt Eden borough. New Zealand Geological Survey, unpublished report G17.

Kermode, L.O., 1992. Geology of the Auckland urban area. Scale 1:50,000. Institute of Geological and Nuclear Sciences geological, map 2. IGNS, Lower Hutt.

Kermonde, L.O., Smith I.E.M., Moore, C.L., Stewart, R.B., Ashcroft, J., Nowell, S.B., Hayward, B.W., 1992. Inventory of quaternary volcanoes and volcanic features of Northland, South Auckland and Taranaki. Geological Society of New Zealand Miscellaneous Publications 61, p100.

Kimbrough, D.L., Mattinson, J.M., Coombs, D.S., Landis, C.A., Johnston, M.R., 1992. Uranium-lead ages from the Dun Mountain ophiolite belt and Brook Street Terrane, South Island, New Zealand. Geological Society of America Bulletin 104, 429-443.

Kraus, S., Kurbatov, A., Yates, M., 2013. Geochemical signatures of tephras from Quaternary Antarctic Peninsula volcanoes. Andean Geology 40, 1-40

Kuntz, M.A., Champion, D.E., Spiker, E.C., Lefebre, R.H., 1986. Contrasting magma types and steady-state, volume-predictable, basaltic volcanism along the Great Rift, Idaho. Geological Society of America Bulletin 97, 597-594.

Lassiter, J.C., Hauri, E.H., 1998. Osmium-isotope variations in Hawaiian lavas: evidence for recycled oceanic lithosphere in the Hawaiian plume. Earth and Planetary Science Letters 164, 483-496.

Lassiter, J.C., Luhr, J.F., 2001. Osmium abundance and isotope variations in mafic Mexican volcanic rocks: Evidence for crustal contamination and constraints on the geochemical behaviour of osmium during partial melting and fractional crystallisation. Geochemistry, Geophysics, Geosystems 2, paper number 2000GC000116.

Le Corvec, N., Bebbington, M.S., Lindsay, J.M., McGee, L.E., 2013a. Age, distance and geochemical evolution within a monogenetic volcanic field: Analysing patterns in the 
Auckland Volcanic Field eruption sequence. Geochemistry, Geophysics, Geosystems 14, 3648-3665.

Le Corvec, N., Spörli, K.B., Rowland, J., Lindsay, J., 2013b. Spatial distribution and alignments of volcanic centres: Clues to the formation of monogenetic volcanic fields. EarthScience Reviews 124, 96-114.

LeMaitre, R.W., 2002. Igneous Rocks: Classification and Glossary of Terms. $2^{\text {nd }}$ Edition, Cambridge University Press, pp236.

Leonard, G.S., Calvert, A.T., Wilson, C.J.N., Smid, E., Lindsay, J., Champion, D., Hopkins, J.L., in prep. High precision ${ }^{40} \mathrm{Ar}-{ }^{39} \mathrm{Ar}$ dating of late Quaternary basalts: the complex accelerating eruption rate of Auckland Volcanic Field, New Zealand.

Lindsay, J.M., Leonard, G.S., Smid, E.R., Hayward, B.W., 2011. Ages of Auckland Volcanic Field: a review of existing data. New Zealand Journal of Geology and Geophysics 54, 379401.

Liu, J., Scott, J.M., Martin, C.E., Pearson, D.G., 2015. The longevity of Archean mantle residues in the convecting upper mantle and their role in young continent formation. Earth and Planetary Science Letters 424, 109-118.

Lorand, J-P., Alard, O, Luguet, A., 2010. Platinum-group element micronuggets and refertilisation process in Lherz orogenic peridotite (northeastern Pyrenees, France). Earth and Planetary Science Letters 289, 298-310.

Lowe, D.J., 1988a. Stratigraphy, age, composition and correlation of late Quaternary tephras interbedded with organic sediments in Waikato lakes, North Island, New Zealand. New Zealand Journal of Geology and Geophysics 31, 125-165.

Lowe, D.J., 1988b. Late Quaternary volcanism in New Zealand: towards an integrated record using distal airfall tephras in lakes and bogs. Journal of Quaternary Science 3, 111120.

Lowe, D.J., 2011. Tephrochronology and its application: a review. Quaternary Geochronology 6, 107-153.

Lowe, D.J., Newnham, R. M., 2004. Role of tephra in dating Polynesian settlement and impact, New Zealand. Past Global Changes News 12, 5-7.

Lowe, D.J., Palmer, D.J., 2005. Andisols of New Zealand and Australia. Journal of Integrated Field Science 2, 39-65. 
Lowe, J.J., Rasmussen, S.O., Björck, S., Hoek, W.Z., Steffensen, J.P., Walker, M.J.C., Yu, Z.C., 2008. Synchronisation of palaeoenvironmental events in the North Atlantic region during the Last Termination: a revised protocol recommended by the INTIMATE group. Quaternary Science Reviews 27, 6-17.

Lowe, D.J., Blaauw, M., Hogg, A.G., Newham, R.M., 2013. Ages of 24 widespread tephras erupted since 30,000 years ago in New Zealand, with re-evaluation of the timing and palaeoclimatic implications of the Lateglacial cool episode recorded in the Kaipo bog. Quaternary Science Reviews 74, 170-194.

Luguent, A., Nowell, G.N., Pearson, D.G., 2008. ${ }^{184} \mathrm{Os} /{ }^{188} \mathrm{Os}$ and ${ }^{186} \mathrm{Os} /{ }^{188} \mathrm{Os}$ measurements by negative thermal ionisation mass spectrometry (N-TIMS): effects of interfering elements and mass fractionation corrections on data accuracy and precision. Chemical Geology 248, 342-362.

Magill, C.R., McAneney, K.J., Smith, I.E.M., 2005. Probabilistic assessment of vent locations for the next Auckland Volcanic Field event. Mathematical Geology 37, 227-242.

Manville, V., Wilson, C.J.N., 2004. Vertical density currents: a review of their potential role in the deposition and interpretation of deep-sea ash layers. Journal of the Geological Society London 161, 947-958.

Marcantonio, F., Zindler, A., Elliott, T., Staudigel, H., 1995. Os isotope systematics of La Palma, Canary Islands; evidence for recycled crust in the mantle source of HIMU ocean islands. Earth and Planetary Science Letters 133, 397-410.

McBride, J.S., Lambert, D.D., Nicholls, I.A., Price, R.C., 2001. Osmium isotopic evidence for crust-mantle interaction in the genesis of continental intraplate basalts from the Newer Volcanics Province, Southeastern Australia. Journal of Petrology 42, 1197-1218.

McCoy-West, A.J., Baker, J.A., Faure, K., Wysoczanski, R., 2010. Petrogenesis and origins of Mid-Cretaceous continental intraplate volcanism in Marlborough, New Zealand:

Implications for the long-lived HIMU magmatic mega-province of the SW Pacific. Journal of Petrology 51, 2003-2045.

McCoy-West, A.J., Bennett, V.C., Puchtel, I.S., Walker, R., 2013. Extreme persistence of cratonic lithosphere in the southwest Pacific: Paleoproterozoic Os isotopic signatures in Zealandia. Geology 41, 231-234.

McCoy-West, A.J., Bennett, V.C., O'Neill, H St. C., Hermann, J., Puchtel, I.S., 2015. The interplay between melting, refertilisation and carbonatite metasomatism in off-cratonic 
lithospheric mantle under Zealandia: an integrated major, trace and platinum group element study. Journal of Petrology 56, 563-604.

McDonough, W.F., Sun, S.-s., 1995. The composition of the Earth. Chemical Geology 120, 223-253.

McGee, L.E., 2012. Melting processes in small basaltic systems: the Auckland Volcanic Field, New Zealand. Ph.D. thesis, University of Auckland, New Zealand.

McGee, L.E., Beier, C., Smith, I.E.M., Turner, S., 2011. Dynamics of melting beneath a small-scale basaltic system: a U-Th-Ra study for Rangitoto volcano, Auckland Volcanic Field, New Zealand. Contributions to Mineralogy and Petrology 162, 547-563.

McGee, L.E., Millet, M.-A., Smith, I.E.M., Németh, K., Lindsay, J.M., 2012. The inception and progression of melting in a monogenetic eruption: Motukorea Volcano, the Auckland Volcanic Field, New Zealand. Lithos 156, 360-374.

McGee, L.E, Smith, I.E.M., Millet, M.-A., Handley, H., Lindsay, J., 2013. Asthenospheric control of melting processes in a monogenetic basaltic system: a case study of the Auckland Volcanic Field, New Zealand. Journal of Petrology 54, 2125-2153.

McGee, L.E., Millet, M.-A., Beier, C., Smith, I.E.M., Lindsay, J.M., 2015. Mantle heterogeneity controls small-volume basaltic eruption characteristics. Geology 43, 551-554.

McKenzie, D., O’Nions, R.K., 1991. Partial melt distributions from inversion of rare earth element concentrations. Journal of Petrology 32, 1021-1091.

Meisel, T., Walker, R.J., Irving, A.J., Lorand, J-P., 2000. Osmium isotopic compositions of mantle xenoliths: A global perspective. Geochimica et Cosmochimica Acta 65, 1311-1323.

Meisel, T., Reisberg, L., Moser, J., Carignan, J., Melcher, F., Brugmann, G., 2003. Re-Os systematics of UB-N, a serpentinized peridotite reference material. Chemical Geology 201, 161-179.

Miller, C.A., 1996. Geophysical and geochemical characteristics of the Auckland Volcanic Field. MSc thesis, University of Auckland, New Zealand.

Miller, T.P., Casadevall, T.J., 2000. Volcanic ash hazards to aviation, in Sigurdsson, H. et al., ed., Encyclopedia of Volcanoes, San Diego, Academic Press pp331-343. 
Mochizuki, N., Tsunakawa, H., Shibuya, H., Tagami, T., Ozawa, A., Cassidy, J., Smith, I.E.M., 2004. K-Ar ages of the Auckland geomagnetic excursions. Earth, Planets and Space $56,283-288$.

Molloy, C.M., 2008. Tephrostratigraphy of the Auckland maar craters. MSc thesis, University of Auckland, New Zealand.

Molloy, C.M., Shane, P., Augustinus, P., 2009. Eruption recurrence rates in a basaltic volcanic field based on tephra layers in maar sediments: implications for the hazards in the Auckland volcanic field. Geological Society of America Bulletin 121, 1666-1677.

Moufti, M.R., Moghazi, A.M., Ali, K.A., 2012. Geochemistry and Sr-Nd-Pb isotopic composition of the Harrat Al-Madinah volcanic field, Saudi Arabia. Gondwana Research 21, 670-689.

Needham, A., 2009. The eruptive history of Rangitoto volcano, Auckland Volcanic Field, New Zealand. MSc thesis, University of Auckland, New Zealand.

Needham, A.J., Lindsay, J.M., Smith, I.E.M., Augustinus, P., Shane, P.A., 2011. Sequential eruption of alkaline and subalkaline magmas from a small monogenetic volcano in the Auckland Volcanic Field, New Zealand. Journal of Volcanology and Geothermal Research 201, 126-142.

Nelson, W.R., Furman, T., van Keken, P.E., Shirey, S.B., Hanan, B.B., 2012. Os-Hf istopic insight into mantle plume dynamics beneath the East African Rift System. Chemical Geology 320-321, 66-79.

Németh, K., 2010. Monogenetic volcanic fields, origin, sedimentary record, and relationship with polygenetic volcanism. In Canon-Tapia, E., Szakacz, A., (Ed.), What is a Volcano? Geological Society of America Special Papers 470, 43-66.

Németh, K., White, J.D.L., Reay, A., Martin, U., 2003. Compositional variation during monogenetic volcano growth and its implications for magma supply to continental volcanic fields. Journal of the Geological Society, London 160, 523-530.

Németh, K., Cronin, S., Smith, I.M., Agustin-Flores, J., 2012. Amplified hazard of small volume monogenetic eruptions due to environmental controls, Orakei Basin, Auckland, Volcanic Field, New Zealand. Bulletin of Volcanology 74, 2121-2137

Newnham, R.M., Lowe, D.J., 1999. Testing the synchroneity of pollen signals using tephrostratigraphy. Global and Planetary Change 21, 113-128. 
Newnham, R.M., Lowe, D.J., Alloway, B.V., 1999. Volcanic hazards in Auckland, New Zealand: a preliminary assessment of the threat posed by central North Island silicic volcanism based on the Quaternary tephrostratigraphical record. Geological Society London, Special Publications 161, 27-45.

Newnham, R.M., Lowe, D.J., Giles, T.M., Alloway, B.V., 2007. Vegetation and climate of Auckland, New Zealand, since ca. 32000 cal. yr ago: support for an extended LGM. Journal of Quaternary Science 22, 517-534.

New Zealand Transport Agency, 2011. Submission report in support of application for variation under conditions. ACCC-Ash-Cloud.

Nicholls, I.A., Joyce, E.B., 1989, Newer Volcanics, in Johnson, R.W., ed., Intraplate volcanism in Eastern Australia and New Zealand: Cambridge University Press, Cambridge, pp. 137-140.

O’Driscoll, B., Day, J.M.D., Walker, R.J., Daly, S., McDonough, W.F., Piccoli, P.M., 2012. Chemical heterogeneity in the upper mantle recorded by peridotites and chromitites from the Shetland Ophiolite Complex, Scotland. Earth and Planetary Science Letters 333-334, 226237.

Óladóttir, B.A., Sigmarsson, O., Larsen, G., Devidal, J-L., 2011. Provenance of basaltic tephra from Vatnajökull subglacial volcanoes, Iceland, as determined by major- and traceelement analyses. The Holocene 21, 1037-1048.

Óladóttir, B.A., Larsen, G., Sigmarsson, O., 2012. Deciphering eruption history and magmatic processes from tephra in Iceland. Jökull 62, 21-38.

Ort, M.H., Elson, M.D., Anderson, K.C., Duffield, W.A., Hooten, J.A., Champion, D.E., Waring, G., 2008. Effects of scoria-cone eruptions upon nearby human communities. Geological Society of America Bulletin 120, 476-486.

Ortega-Gutiérrez, F., Gómez-Tuena, A., Elías-Herrera, M., Solari, L.A., Reyes-Salas, M., Marcías-Romo, C., 2014. Petrology and geochemistry of the Valle de Santiago lower crust xenoliths: Young tectonothermal processes beneath the central Trans-Mexican volcanic belt. Lithosphere 6, 335-360.

Oxford Economics, 2010. The economic impacts of air travel restrictions due to volcanic ash. Report for Airbus. Oxford, Oxford Economics. 
Paton, C., Hellstrom, J., Paul, B., Woodhead, J., Hergt, J., 2011. Iolite, freeware for the visualisation and processing of mass spectrometric data. Journal of Analytical Atomic Spectrometry 26, 2508-2518.

Payne, R.J., Gehrels, M.J., 2010. The formation of tephra layers in peatlands: an experimental approach. Catena 81, 12-23.

Pearce, N.J.G., Westgate, J.A., Perkins, W.T., Preece, S.J., 2004. The applications of ICPMS methods to tephrochronological problems. Applied Geochemistry 19, 289-322.

Pearce, N.J.G., Denton, J.S., Perkins, W.T., Westgate, J.A., Alloway, B.V., 2007. Correlation and characteristation of individual glass shards from tephra deposits using trace element laser ablation ICP-MS analyses: current status and future potential. Journal of Quaternary Science 22, 721-736.

Pearce, N.J.G., Alloway, B.V., Westgate, J.A., 2008. Mid-Pleistocene silicic tephra beds in the Auckland region, New Zealand: their correlation and origins based on the trace element analyses of single glass shards. Quaternary International 178, 16-43.

Pertermann, M., Hirschmann, M.M., 2003. Partial melting experiments on MORB-like pyroxenite between 2 and $3 \mathrm{GPa}$ : Constraints on the presence of pyroxenite in basalt source regions from solidus location and melting rate. Journal of Geophysical Research - Solid Earth 108 (B2), 12-29.

Peucker-Ehrenbrink, B., and Jahn, B., 2001. Rhenium-osmium isotope systematics and platinum group element concentrations: loess and the upper continental crust. Geochemistry, Geophysics, Geosystems 2, doi:10.1029/2001GC000172.

Pickrill, R.A., Nelson, C.S., Stoffers, P., Craig, G.G.P., 1991. Influence of late Holocene pyroclastic eruptions on the sedimentary geochemistry of Lake Rotoiti, North Island, New Zealand. Journal of Paleolimnology 6, 173-192.

Pyle, D.M., 1989. The thickness, volume and grain size of tephra fall deposits. Bulletin of Volcanology 51, 1-15.

Ramsey, M.H., Potts, P.J., Webb, P.C., Watkins, P., Watson, J.S., Coles, B.J., 1995. An objective assessment of analytical method precision: comparison of ICP-AES and XRF for the analysis of silicate rocks. Chemical Geology 124, 1-19.

Rasoazanamparany, C., Widom, E., Valentin, G.A., Smith, E.I., Cortés, J.A., Juentz, D., Johnsen, R., 2015. Origin of chemical and isotopic heterogeneity in a mafic, monogenetic 
volcanic field: A case study of the Lunar Crater Volcanic Field, Nevada. Chemical Geology 397, 76-93.

Reisberg, L., Zindler, A., Marcantonio, F., White, W., Wyman, D., Weaver, B., 1993. Os isotope systematics in ocean island basalts. Earth and Planetary Science Letters 120, 149167.

Robinson, J.A., Wood, B.J., 1998. The depth of the spinel to garnet transition at the peridotite solidus. Earth and Planetary Science Letters 164, 277-284.

Roy-Barman, M., Allègre, C.J., 1995. ${ }^{187} \mathrm{Os} /{ }^{186} \mathrm{Os}$ in oceanic island basalts; Tracing oceanic crust recycling in the mantle. Earth and Planetary Science Letters 129, 145-161.

Roy-Barman, M., Wasserburg, G.J., Papanastassiou, D.A., Chaussidon, M., 1998. Osmium isotope concentrations and Re-Os concentrations in sulphide globules from basaltic glasses. Earth and Planetary Science Letters 154, 331-347.

Rudnick, R.L., Fountain, D.M., 1995. Nature and composition of the continental crust - a lower crustal perspective. Reviews of Geophysics 33, 267-309.

Rudnick, R.L., Gao, S., 2003. Composition of the continental crust. Treatise on Geochemistry 3, 1-64.

Rymer, H., 2000. Volcanic Hazards. In Sigurdsson, H. et al., (Ed), Encyclopedia of Volcanoes, San Diego, Academic Press, pp. 895-896.

Saal, A.E., Rudnick, R.L., Ravizza, G.E., Hart, S.R., 1998. Re-Os isotope evidence for the composition, formation and age of the lower continental crust. Nature 393, 58-61

Sandiford, A., Alloway, B., Shane, P., 2001. A 28,000-6600 cal yr record of local and distal volcanism preserved in a paleolake, Auckland, New Zealand. New Zealand Journal of Geology and Geophysics 44, 323-336.

Schiano, P., Birck, J.-L., Allègre, C.J., 1997. Osmium-strontium-neodymium-lead isotopic covariations in mid-ocean ridge basalt glasses and the heterogeneity of the upper mantle. Earth and Planetary Science Letters 150, 363-379.

Schiano, P., Burton, K.W., Dupre,B., Birck, J.-L., Guille, G., Allegre, C.J., 2001. Correlated Os-Pb-Nd-Sr isotopes in the Austral-Cook chain basalts: the nature of mantle components in plume sources. Earth and Planetary Science Letters 186, 527-537. 
Scott, J.M., Hodgkinson, A., Palin, J.M., Waight, T.E., Van der Meer, Q.H.A., Cooper, A.F., 2014. Ancient melt depletion overprinted by young carbonatitic metasomatism in the New Zealand lithospheric mantle. Contributions to Mineralogy and Petrology 167, 963.

Searle, E.J., 1959a. Schistose rocks from St Heliers Bay, Auckland. New Zealand Journal of Geology and Geophysics 2, 368-379.

Searle, E.J., 1959b. The volcanoes of Ihumatao and Mangere, Auckland. New Zealand Journal of Geology and Geophysics 2, 870-888.

Searle, E.J., 1961a. The age of the Auckland volcanoes. New Zealand Geographer 17, $52-$ 63.

Searle, E.J., 1961b. The petrology of the Auckland basalts. New Zealand Journal of Geology and Geophysics 4, 165-204.

Searle, E.J., 1964. City of volcanoes: A geology of Auckland. Auckland, Pauls Book Arcade.

Searle, E.J., 1965. Auckland volcanic district. In Thompson, B.N., and Kermode, K.O., (Eds), New Zealand volcanology: Northland, Coromandel, Auckland. New Zealand, Department of Scientific and Industrial Research Information Series 49, 90-103.

Seebeck, H., Nicol, A., Giba, M., Pettinga, J., Walsh, J., 2014. Geometry of the subducting Pacific plate since $20 \mathrm{Ma}$, Hikurangi margin, New Zealand. Journal of the Geological Society, London 171, 131-143.

Shane, P., 2000. Tephrochronology: a New Zealand case study. Earth-Science Reviews 49, 223-259.

Shane, P., 2005. Towards a comprehensive distal andesitic tephrostratigraphic framework for New Zealand based on eruptions from Egmont Volcano. Journal of Quaternary Science $20,45-57$.

Shane, P., Smith, I.E.M., 2000. Geochemical fingerprinting of basaltic tephra deposits in the Auckland Volcanic Field. New Zealand Journal of Geology and Geophysics 43, 569-577.

Shane, P., Hoverd, J., 2002. Distal record of multi-sourced tephra in Onepoto Basin, Auckland, New Zealand: implications for volcanic chronology, frequency and hazards. Bulletin of Volcanology 64, 441-454. 
Shane, P., Sandiford, A., 2003. Paleovegetation of marine isotope stages 4 and 3 in Northern New Zealand and the age of the widespread Rotoehu tephra. Quaternary Research 59, 420-429.

Shane, P., Zawalna-Geer, A., 2011. Correlation of basaltic tephra from the Mt. Wellington volcano: implications for the penultimate eruption from the Auckland Volcanic Field. Quaternary International 246, 374-381.

Shane, P.A., Black, T.M., Eggins, S.M., Westgate, J.A., 1998. Late Miocene marine tephra beds: recorders of rhyolitic volcanism in North Island, New Zealand. New Zealand Journal of Geology and Geophysics 41, 165-178.

Shane, P., Sikes, E.L., Guilderson, T.P., 2006. Tephra beds in deep-sea cores off northern New Zealand: implications for the history of Taupo Volcanic Zone, Mayor Island and White Island volcanoes. Journal of Volcanology and Geothermal Research 154, 276-290.

Shane, P., Gehrels, M., Zawalna-Geer, A., Augustinus, P., Lindsay, J., Chaillou, I., 2013. Longevity of a small shield volcano revealed by crypto-tephra studies (Rangitoto volcano, New Zealand): Change in eruptive behaviour of a basaltic field. Journal of Volcanology and Geothermal Research 257, 174-183.

Shapley, M.D., Finney, B.P., 2015. Lake morphometry controls the remobilization and long term geochemical imprint of distal tephra deposition. Journal of Paleolimnology 53, 309-320.

Shaw, C.S.J., 2004. The temporal evolution of three magmatic systems in the West Eifel volcanic field, Germany. Journal of Volcanology and Geothermal Research 131, 213-240.

Sivell, W.J., McCulloch, M.T., 2000. Reassessment of the origin of the Dun Mountain ophiolite, New Zealand: Nd-isotopic and geochemical evolution of magma suites. New Zealand Journal of Geology and Geophysics 43, 133-146.

Smith, I.E.M., Okada, T., Itaya, T., Black, P.M., 1993. Age relationships and tectonic implications of late Cenozoic basaltic volcanism in Northland, New Zealand. New Zealand Journal of Geology and Geophysics 36, 385-393.

Smith, I.E.M., Blake, S., Wilson, C.J.N., Houghton, B.F., 2008. Deep-seated fractionation during the rise of a small-volume basalt magma batch: Crater Hill, Auckland, New Zealand. Contributions to Mineralogy and Petrology 155, 511-527. 
Smith, I.E.M., McGee, L.E., Lindsay, J.M., 2009. Review of the petrology of the Auckland Volcanic Field. Institute of Earth Science and Engineering technical report, University of Auckland, Auckland 1-2009.03

Sorrentino, L., Stilwell, J.D., Mays, C., 2014. A model of tephra dispersal from an early Palaeogene shallow submarine Surtseyan-style eruption(s), the Red Bluff Tuff Formation, Chatham Island, New Zealand. Sedimentary Geology 300, 86-102.

Spargo, S.R.W., 2007. The Pupuke volcanic centre: polygenetic magmas in a monogenetic field. MSc thesis, University of Auckland, New Zealand.

Spörli, K.B., Black, P.M., 2013. Catalogue of crustal xenoliths from the St Heliers Volcanoes, Auckland Volcanic Field, New Zealand. Institute of Earth Science and Engineering technical report, University of Auckland, Auckland 1-2013.01.

Spörli, K.B., Black, P.M., Lindsay, J.M., 2015. Excavation of buried Dun Mountain-Maitai terrane ophiolite by volcanoes of the Auckland Volcanic field, New Zealand. New Zealand Journal of Geology and Geophysics doi:10.1080/00288306.2015.1035285.

Striewski, B., Shulmeister, J., Augustinus, P.C., Soderholm, J., 2013. Late Holocene climate variability from Lake Pupuke maar, Auckland, New Zealand. Quaternary Science Reviews $77,46-54$.

Strong, M., Wolff, J., 2003. Compositional variations within scoria cones. Geology 31, $143-$ 146.

Sun, S.-S., McDonough, W.F., 1989. Chemical and isotopic systematics of oceanic basalts: implications for mantle composition and processes. In Saunders, A.D., and Norry, M.J., (Eds.), Magmatism in the Ocean Basins. Geological Society, London, Special Publications 42, 313-345.

Suzuki, K., Senda, R., Shimizu, K., 2011. Osmium behaviour in a subduction system elucidated from chromian spinel in Bonin Island beach sands. Geology 39, 999-1002.

Tanaka, K.L., Shoemaker, E.M., Ulrich, G.E., Wolfe, E.W., 1986. Migration of volcanism in the San Francisco volcanic field, Arizona. Geological Society of America Bulletin 97, 129141.

Thirlwall, M.F., 1997. Pb isotopic and elemental evidence for OIB derivation from young HIMU mantle. Chemical Geology 139, 51-74. 
Thompson, M., Potts, P.J., Kane, J.S., Webb, P., Watson, J.S., 2000. GeoPT4 International proficiency test for analytical geochemistry laboratories. Geostandards Newsletter 24, E1-37.

Timm, C., Hoernle, K., van den Bogaard, P., Bindeman, I., Weaver, S., 2009. Geochemical evolution of intraplate volcanism at Banks Peninsular, New Zealand: interaction between asthenospheric and lithospheric melts. Journal of Petrology 50, 989-1023.

Timm, C., Hoernle, K., Werner, R., Hauff, F., van de Bogaard, P., White, J., Mortimer, N., Garbe-Schönberg, D., 2010. Temporal and geochemical evolution of the Cenozoic intraplate volcanism of Zealandia. Earth-Science Reviews 98, 38-64.

Tomsen, E., Lindsay, J.M., Gahegan, M., Wilson, T.M., Blake, D.M., 2014. Evacuation planning in the Auckland Volcanic Field, New Zealand: a spatio-temporal approach for emergency management and transportation network decisions. Journal of Applied Volcanology 6, 1-22.

Turner, M.B., Bebbington, M.S., Cronin, S.J., Stewart, R.B., 2009. Merging eruption data sets: building an integrated Holocene eruptive record for Mt Taranaki, New Zealand. Bulletin of Volcanology 71, 903-918.

Turner, M.B., Cronin, S.J., Bebbington, M.S., Smith, I.E.M., Stewart, R.B., 2011. Relating magma composition to eruption variability at andesitic volcanoes: A case study from Mount Taranaki, New Zealand. Geological Society of America Bulletin, 123, 2005-2015.

Valentine, G.A., Gregg, T.K.P., 2008. Continental basaltic volcanoes - processes and problems. Journal of Volcanology and Geothermal Research 177, 857-873.

Valentine, G.A., Hirano, N., 2010. Mechanisms of low-flux intraplate volcanic fields - Basin and Range (North America) and northwest Pacific Ocean. Geology 38, 55-58.

Valentine, G.A., Keating, G.N., 2007. Eruptive styles and inferences about plumbing systems at Hidden Cone and Little Black Peak scoria cone volcanoes (Nevada, USA). Bulletin of Volcanology 70, 105-113.

Valentine, G.A., Krogh, K.E.C., 2006. Emplacement of shallow dikes and sills beneath a small basaltic volcanic center - the role of pre-existing structure (Paiute Ridge, southern Nevada, USA. Earth and Planetary Science Letters 246, 217-230.

Valentine, G.A., Krier, D., Perry, F.V., Heiken, G., 2005. Scoria cone construction mechanisms, Lathrop Wells volcano, southern Nevada, USA. Geology 33, 629-632. 
Valentine, G.A., Krier, D., Perry, F.V., Heiken, G., 2008 Eruptive and geomorphic processes at the Lathrop Wells scoria cone volcano. Journal of Volcanology and Geothermal Research $161,57-80$.

Vandergoes, M.J., Hogg, A.G., Lowe, D.J., Newnham, R.M., Denton, G.H., Southon, J., Barrell, D.J.A., Wilson, C.J.N., McGlone, M.S., Allan, A.S.R., Almond, P.C., Petchey, F., Dabell, K., Dieffenbacher-Krall, A.C., Blaauw, M., 2013. A revised age for the Kawakawa/Oruanui tephra, a key marker for the last glacial maximum in New Zealand. Quaternary Science Reviews 74, 195-201.

van Otterloo, J., Cas, R.A.F., 2013. Reconstructing the eruption magnitude and enery budgets for the pre-historic eruption of the monogenetic $\sim 5$ ka Mt. Gambier Volcanic Complex, south-eastern Australia. Bulletin of Volcanology 75, 769.

von Veh, M. W., Németh, K., 2009. An assessment of the alignments of vents based on geostatistical analysis in the Auckland Volcanic Field, New Zealand. Géomorphologie 3, 175-186.

Vogel, D.C., Keays, R.R., 1997. The petrogenesis and platinum-group element geochemistry of the Newer Volcanic Province, Victoria, Australia. Chemical Geology 136, 181-204.

Walker, G.P.L., 2000. Basaltic volcanoes and volcanic systems, in Sigurdsson, H. et al., ed., Encyclopaedia of Volcanoes, San Diego, Academic Press, pp283-289.

Walczyk, T., Hebeda, E.H., and Heumann, K.G., 1991. Osmium isotope ratio measurements by negative thermal ionisation mass spectrometry (NTI-MS). Improvement in precision and enhancement in emissions by introducing oxygen and freons into the ion source. Fresenius' Journal of Analytical Chemistry 344, 537-541.

Westgate, J.A., Gorton, M.P., 1981. Correlation techniques in tephra studies. In Self, S., Sparks, R.S.J., Editors, Tephra studies. Dordrecht, D. Reidel, 73-94.

Westgate, J.A., Perkins, W.T., Fuge, R., Pearce, N.J.G., Wintle, A.G., 1994. Trace element analysis of volcanic glass shards by laser ablation inductively coupled mass spectrometry: application to Quaternary tephrochronological studies. Applied Geochemistry 9, 323-335.

Widom, E., Hoernle, K.A., Shirey, S.B., Schmincke, H.-U., 1999. Os Isotope Systematics in the Canary Islands and Madeira: lithospheric contamination and mantle plume signatures. Journal of Petrology 40, 279-296. 
Wilson, C.J.N., Rhoades, D.A., Lanphere, M.O., Calvert, A.T., Houghton, B.F., Weaver, S.D., Cole, J.W., 2007. A multi-approach radiometric age estimate for the Rotoiti and Earthquake flat eruptions, New Zealand, with implications for the MIS 4/3 boundary. Quaternary Science Reviews 26, 1861-1870.

Wilson, G., Wilson, T.M., Deligne, N.I., Cole, J.W., 2014. Volcanic hazard impacts to critical infrastructure: A review. Journal of Volcanology and Geothermal Research 286, 148-182.

Wimpenny, J., Gannoun, A., Burton, K.W., Widdowson, M., James, R.H., Gíslason S.R., 2007. Rhenium and osmium isotope and elemental behaviour accompanying laterite formation in the Deccan region of India. Earth and Planetary Science Letters 261, 239-258.

Winter, J.D., 2010. Principles of igneous and metamorphic petrology. $2^{\text {nd }}$ ed. Pearson Prentice Hall, New Jersey.

Zawalna-Geer, A., 2012. Towards a tephra framework for the Auckland Maar lake sediments and the potential of applying cryptotephra techniques. Phd Thesis, University of Auckland, New Zealand.

Zindler, A., Hart, S., 1986. Chemical Geodynamics. Annual Review of Earth and Planetary Sciences 14, 493-571.

Zou, H., Fan, Q., Yao, Y., 2008. U-Th systematics of dispersed young volcanoes in NE China: Asthenosphere upwelling cause by piling up and upward thickening of stagnant Pacific slab. Chemical Geology 255, 134-142. 